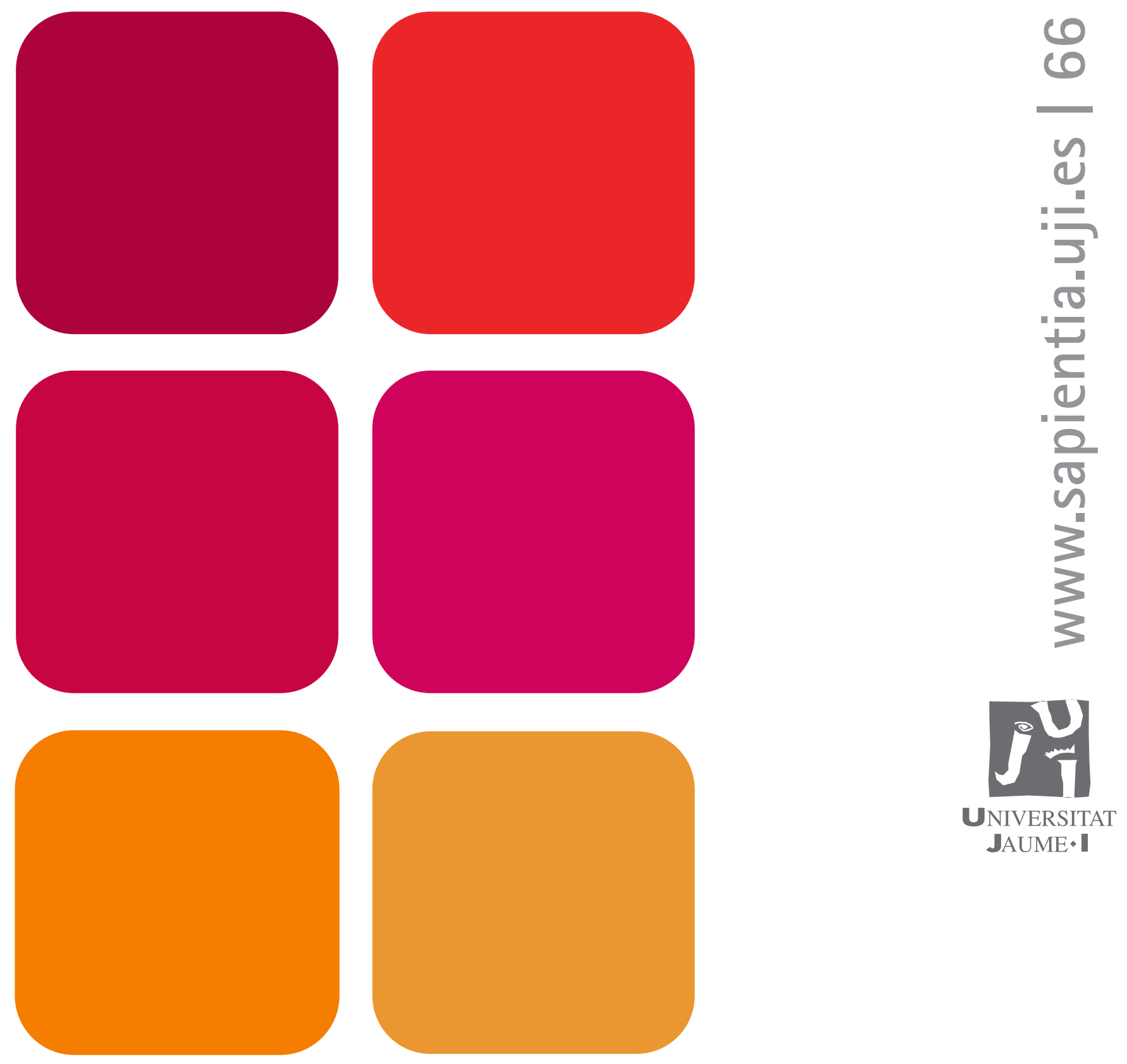

\title{
Introducción a la contabilidad
}




\section{Introducción a la contabilidad}

José Alcarria Jaime

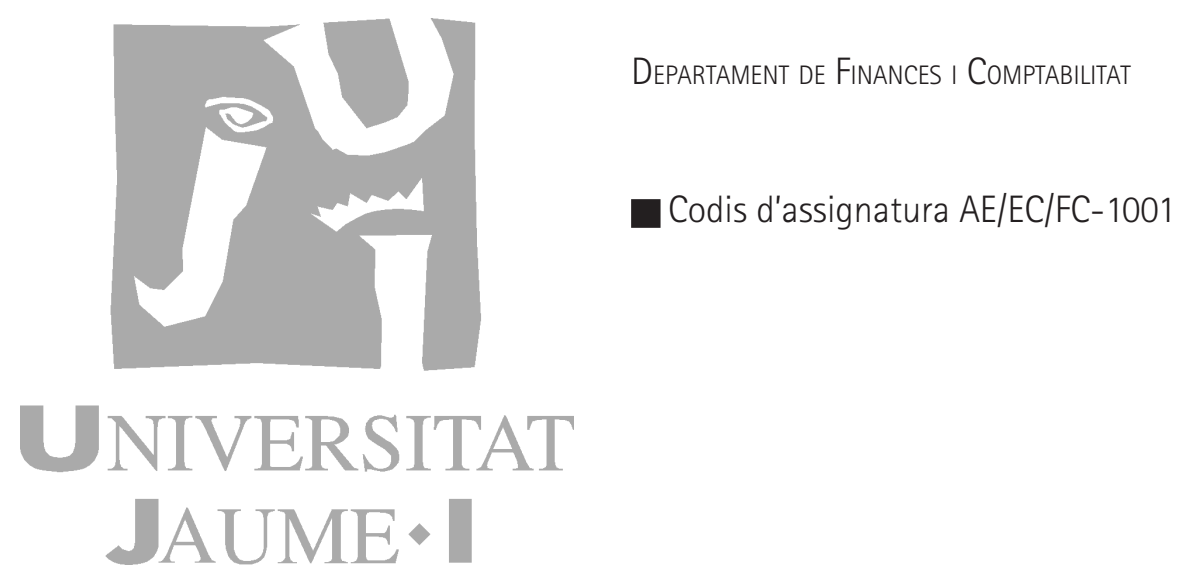


Edita: Publicacions de la Universitat Jaume I. Servei de Comunicació i Publicacions Campus del Riu Sec. Edifici Rectorat i Serveis Centrals. 12071 Castelló de la Plana http://www.tenda.uji.es e-mail: publicacions@uji.es

Col-lecció Sapientia, 66

www.sapientia.uji.es

Primera edició, 2012

ISBN: 978-84-695-3672-8

17 Publicacions de la Universitat Jaume I és una editorial membre de l'UNE, cosa que en garanteix la difusió de les obres en els àmbits nacional i inter-

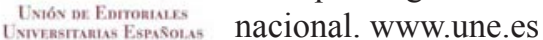

\section{(c) (i) (9)(2)}

Aquest text està subjecte a una llicència Reconeixement-NoComercial-CompartirIgual de Creative Commons, que permet copiar, distribuir i comunicar públicament l'obra sempre que especifique l'autor i el nom de la publicació i sense objectius comercials, i també permet crear obres derivades, sempre que siguen distribuïdes amb aquesta mateixa llicència.

http://creativecommons.org/licenses/by-nc-sa/2.5/es/deed.ca 


\section{ÍNDICE}

INTRODUCCIÓN $\ldots \ldots \ldots \ldots \ldots \ldots \ldots \ldots \ldots \ldots \ldots \ldots \ldots \ldots \ldots \ldots \ldots \ldots \ldots$

Tema 1. La contabilidad como sistema de información ........... 8

1.1. Actividad económica y la necesidad de información ........... 9

1.2. Concepto y áreas de la contabilidad . . . . . . . . . . . . . 12

1.3. Usuarios de la información contable . . . . . . . . . . . . . . 17

1.4. Objetivos y requisitos de la información contable .......... 21

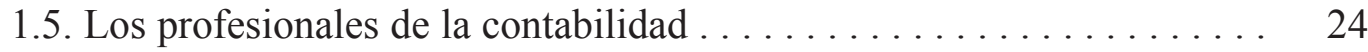

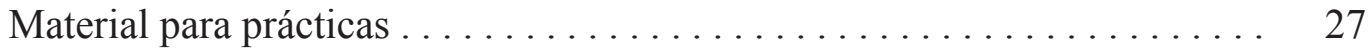

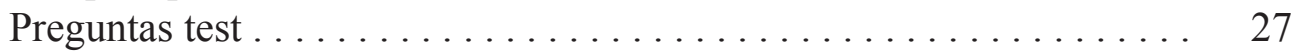

Cuestiones teóricas ............................. 29

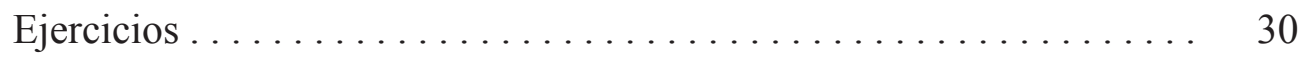

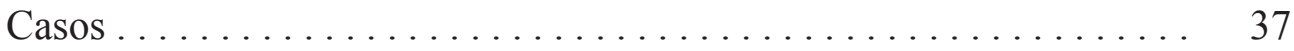

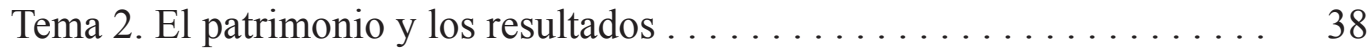

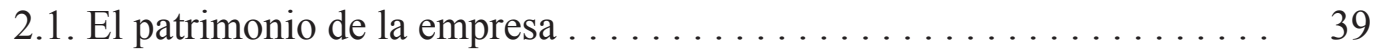

2.2. Las masas patrimoniales, activo, pasivo y patrimonio neto . . . . . . 41

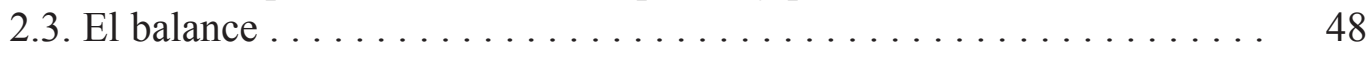

2.4. Cambios en el patrimonio neto: ingresos y gastos . . . . . . . 51

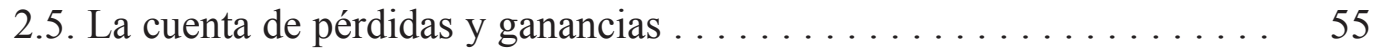

2.6. La ecuación contable y las transacciones empresariales . . . . . . . 58

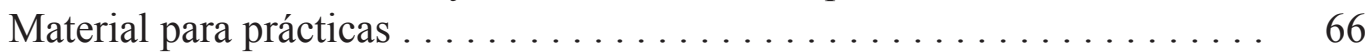

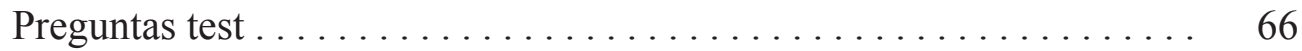

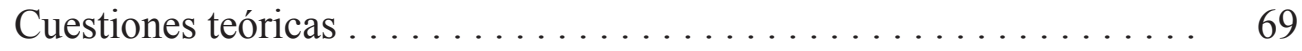

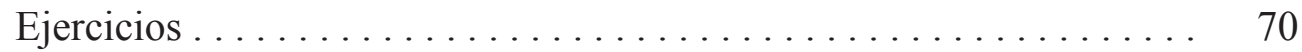

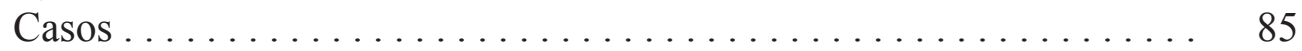

Tema 3. El metodo contable y la partida doble . . . . . . . . . . . 90

3.1. Principio de dualidad y el método de la partida doble . . . . . . . . . . 91

3.2. Las cuentas, estructura y reglas de registro . . . . . . . . . . . 91

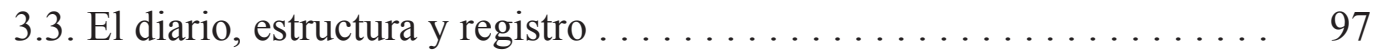

3.4. El cuadro de cuentas . . . . . . . . . . . . . . . . . . . 98

3.5. Ejemplo de registro en las cuentas y en el diario . . . . . . . . . . . . 104

3.6. El balance de comprobación de sumas y saldos . . . . . . . . . . . . 109

3.7. Proceso contable y secuencia de registro . . . . . . . . . . . . . 114

3.8. Formatos reales de cuentas de mayor y diario . . . . . . . . . . . 117

Material para prácticas . . . . . . . . . . . . . . . . . . . . . . . . . . . 119

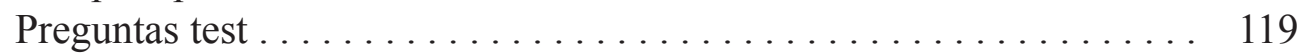


Cuestiones teóricas . . . . . . . . . . . . . . . . . . . . . 121

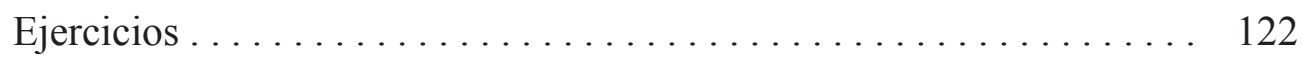

Tema 4. El registro contable de transacciones . . . . . . . . . . . . . . . . . . 149

4.1. Introducción . . . . . . . . . . . . . . . . . . . . . . . . . . . . 150

4.2. El impuesto sobre el valor añadido . . . . . . . . . . . . . . 150

4.3. Operaciones comerciales: existencias, compras y ventas . . . . . . . 155

4.4. Otros gastos e ingresos de explotación . . . . . . . . . . . . . . 163

4.5. Inversiones (I): inmovilizado intangible, material e inversiones inmobiliarias. . . . . . . . . . . . . . . . . . . . . . . . . . . . . 167

4.6. Inversiones (II): inversiones financieras . . . . . . . . . . . . . . 170

4.7. Financiación (I): financiación ajena . . . . . . . . . . . . . . . 174

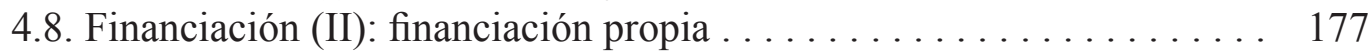

Material para prácticas . . . . . . . . . . . . . . . . . . . . 179

Preguntas test .................................. 179

Cuestiones teóricas . . . . . . . . . . . . . . . . . . . . . . . . . . . 182

Ejercicios ................................ 183

Casos ......................................... 204

Tema 5. El ciclo contable . . . . . . . . . . . . . . . . . . . . . 205

5.1. Concepto de período y ciclo contable . . . . . . . . . . . . . 206

5.2. Apertura de la contabilidad ....................... 207

5.3. Fase de registro de transacciones durante el ejercicio . . . . . . . . 208

5.4. Los ajustes de fin de período . . . . . . . . . . . . . . . . . 210

5.5. Balance de comprobación. Liquidación y cierre contable . . . . . . . 222

5.6. Elaboración de cuentas anuales . . . . . . . . . . . . . . . . . . . 227

Material para prácticas . . . . . . . . . . . . . . . . . . . . . . . . . . . . . 229

Preguntas test . . . . . . . . . . . . . . . . . . . . . . 229

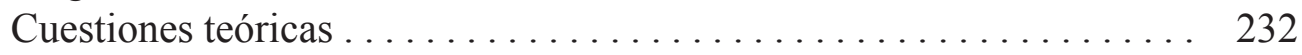

Ejercicios .................................. 233

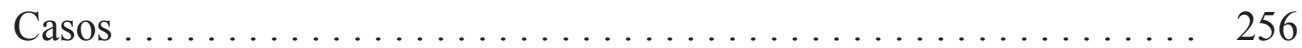

Tema 6. Análisis e interpretación de la información contable . . . . . . . . . 257

6.1. Análisis del balance: situación patrimonial y financiera . . . . . . . . 258

6.2. Análisis de cuenta de pérdidas y ganancias: resultados y rentabilidad ............................. 263

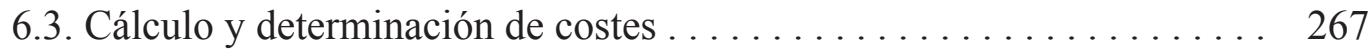

6.4. Informes internos de costes . . . . . . . . . . . . . . . . . 275

Material para prácticas . . . . . . . . . . . . . . . . . . 279

Preguntas test ................................ 279

Cuestiones teóricas . . . . . . . . . . . . . . . . . . . . . . 281

Ejercicios ................................. 282

Casos . . . . . . . . . . . . . . . . . . . . . . . . . . . . . . . . 297

Tema 7. Normalización contable . . . . . . . . . . . . . . . . . . . . . 298

7.1. Comparabilidad de la información contable . . . . . . . . . . . . . 299

7.2. Normativa contable española . . . . . . . . . . . . . . . . 301 
7.3. Estructura y contenido del Plan General de Contabilidad . . . . . . . . 303

7.4. El marco conceptual de la contabilidad en el PGC . . . . . . . . . . 305

7.5. Las otras partes del Plan General de Contabilidad . . . . . . . . . . . 318

7.6. Obligaciones mercantiles en materia contable . . . . . . . . . . . 324

Material para prácticas . . . . . . . . . . . . . . . . . . . . . 327

Preguntas test ........................... 327

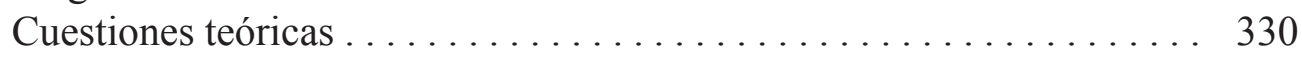

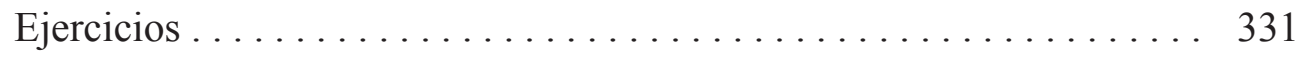

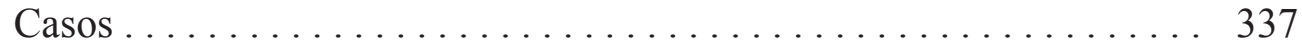

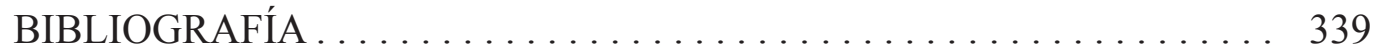




\section{Introducción}

El objetivo de este texto es proporcionar el material teórico y práctico para el seguimiento de la asignatura de «Introducción a la Contabilidad» de los grados en Finanzas y Contabilidad, Administración de Empresas y Economía de la Universitat Jaume I de Castellón.

Se trata de una asignatura de formación básica que se cursa en primer semestre del primer curso en dichos grados y está dirigida a alumnos sin conocimientos previos sobre esta materia. Los objetivos generales de la misma son: (1) introducir los conceptos básicos utilizados en contabilidad de empresas privadas; (2) conocer los informes contables más usuales, tanto de carácter externo como interno; y (3) conocer algunas herramientas básicas de análisis de dichos informes contables.

En esta asignatura se estudia la contabilidad de entidades privadas, fundamentalmente sociedades anónimas y limitadas y empresarios individuales. Se tratan aspectos generales de su contabilidad con independencia de la naturaleza de sus actividades o de otros factores que pudieran suponer diferencias específicas. No obstante, muchos de los conceptos aquí tratados tienen su aplicación también en el resto de entidades.

Aunque el objetivo principal del texto es apoyar la docencia de dicha asignatura, tanto para alumno como para profesor, puede ser igualmente útil para otro tipo de usuarios.

El enfoque del mismo es eminentemente didáctico y práctico poniendo énfasis en proporcionar continuos ejemplos e ilustraciones de los temas tratados y complementando el material con abundantes ejercicios y problemas.

El contenido se ha dividido en siete temas:

- En los temas 1 a 5 se introduce la contabilidad financiera resaltando sus objetivos, se explican conceptos contables básicos, se muestra el procedimiento e instrumentos de registro contable y finalmente se presenta la estructura y contenido básicos de los informes periódicos que toda empresa está obligada a elaborar y presentar.

- En el tema 6 se introducen conceptos básicos para el análisis de la información contable externa así como sobre el procedimiento de cálculo de costes y la elaboración e interpretación de informes internos sobre los mismos.

- En el tema 7 se presenta, de forma resumida, el marco normativo contable básico que rige la elaboración y presentación de información contable por parte de las empresas y entidades públicas españolas a sus usuarios externos.

En el desarrollo de cada tema, además de la exposición de contenidos, se proporcionan ilustraciones y ejemplos para apoyar las explicaciones que se presentan. 
Cada tema se complementa con material para prácticas que incluye preguntas test, cuestiones teóricas, ejercicios de diversa complejidad y casos para resolver bien individualmente o bien por grupos de alumnos. Este material puede utilizarse tanto para su resolución en clase, docencia presencial, como para la asignación de trabajos a realizar individualmente o por grupos para su presentación y corrección por parte del profesor.

Debido al carácter básico de esta asignatura, en los distintos temas no se recomiendan lecturas específicas. Para ampliar el contenido de cada tema, puede consultarse la bibliografía que figura en la guía didáctica oficial de la asignatura $\mathrm{y}$, en su caso, la normativa contable aplicable. 


\section{TEMA 1}

\section{La contabilidad como sistema de información}

INTRODUCCIÓN

En este tema se presenta la contabilidad como sistema de información, resaltando su utilidad para la toma de decisiones de sus usuarios. Se diferencia entre distintas áreas de la contabilidad y se señalan los objetivos y requisitos de la información contable.

CONTENIDO

1.1. Actividad económica y la necesidad de información

1.2. Concepto y áreas de la contabilidad

1.3. Los usuarios de la información contable

1.4. Objetivos y requisitos de la información contable

1.5. Los profesionales de la contabilidad 


\subsection{Actividad económica y la necesidad de información}

La sociedad actual, en todos sus ámbitos, se caracteriza por ser una sociedad de la información. Como parte de este entorno, la actividad económica, y los distintos participantes de la misma, precisan de gran cantidad de datos de naturaleza económica y de otro tipo.

La información económica es vital para la sociedad en la que vivimos. Toda entidad privada, desde una pequeña empresa a una multinacional, necesita procesar información y elaborar informes para tomar decisiones de naturaleza económica. También las entidades públicas precisan de información de carácter económico en el desarrollo de las actividades que tienen encomendadas.

La información económica que precisan estas entidades es de muy diverso tipo, y en particular sobre el valor de sus bienes y sus deudas, así como la cuantía de sus ingresos y sus gastos.

Prácticamente todas las personas trabajan con conceptos e información económica o contable en su vida diaria. Cuando una persona calcula los gastos que ha tenido o va a tener cada mes, al objeto de saber si con su sueldo puede o no ahorrar para el viaje de vacaciones o cambiar de coche, está utilizando y razonando en términos económico-contables.

Constantemente se oyen y se usan conceptos económicos o contables. Diariamente en los periódicos, televisión y radio las noticias económicas hacen referencia a términos como presupuestos, déficit, gastos, ingresos, beneficios, pérdidas, activos y pasivos, etc., tanto para referirse a las actividades del sector privado (empresas) como las actividades del sector público (ayuntamientos y otros entes).

\section{Ercros}

ELPAIS.com - Economía - 27-02-2009

Ercros contabiliza una depreciación del valor de sus activos de 198 millones.

El grupo químico presenta unas pérdidas de 203,39 millones en 2008.

El grupo químico Ercros ahondó su travesía por los números rojos en 2008 al verse obligada a contabilizar una pérdida por deterioro de sus activos por importe de 198,29 millones de euros. Así, la compañía ha presentado hoy unas pérdidas de 203,39 millones, frente a los 32,76 millones perdidos en 2007.

La compañía ha enfatizado que el resultado operativo bruto aumentó de un año al otro (de 27,86 a 43,59 millones).

El consejo de administración de la química ha dado luz verde a una reducción de capital (de 362 a 161 millones) para «dar mayor flexibilidad a la cotización y reflejar el valor real de la empresa». 
ELPAIS.com - Economía - 18-02-2010

Las cajas ganan 3.480 millones, la cifra más baja en 10 años.

En uno de los años más difíciles que recuerda el sector, las 45 entidades de ahorro ganaron $4.426,2$ millones, un $34 \%$ menos que en 2008 . Se destaca que las cajas han logrado esos beneficios tras dotar unas provisiones por 12.067 millones (entre los 9.751 millones por deterioro de activos financieros y los 2.316 por la pérdida de valor de inmuebles).

Ilustración 1.1. Noticias en prensa

\section{Informes contables y toma de decisiones}

La actividad económica exige disponer de informes económico-financieros para la toma de decisiones. La contabilidad proporciona parte de los informes que esta actividad requiere. Por ejemplo, los sistemas de contabilidad en las empresas sirven para elaborar tres tipos de informes:

1. Informes internos de rutina para los gerentes: ayuda a la toma de decisiones que se presentan con cierta regularidad. Estos informes sirven para el control operacional de la organización.

\begin{tabular}{|l|}
\hline Ejemplo 1.1. Informe rutinario de derechos de cobro contra clientes \\
EL CORTE INGLÉs puede elaborar un informe semanal con un resumen de \\
los importes que le adeudan los clientes por pagos con la tarjeta de El \\
Corte Inglés, en el cual incluye las fechas de cobro previstas y destaca \\
aquellos clientes que no han pagado todavía pese a haber vencido el \\
crédito. De esta forma, cada lunes, el gerente dispone de información \\
sobre la cuantía total que se adeuda, la parte que se espera cobrar di- \\
cha semana y los clientes a los que hay que reclamar el pago ya que \\
la fecha ha expirado.
\end{tabular}

2. Informes internos no rutinarios para los gerentes: ayuda a la toma de decisiones que se realizan con carácter irregular en la organización o no tienen precedente. Estos informes pueden servir, por ejemplo, para el control estratégico de la organización.

\begin{tabular}{|l|} 
Ejemplo 1.2. Informe no rutinario \\
La central estadounidense de ForD se plantea la reestructuración de \\
sus actividades en un determinado país. Para ello requiere un informe \\
sobre las inversiones, ingresos y gastos de cada una de las actividades \\
que desarrolla su filial en dicho país, con particular atención a aspec- \\
tos como productividad y rentabilidad.
\end{tabular}


3. Informes externos para inversionistas, autoridades y demás grupos interesados: proporciona información sobre la posición financiera, operaciones y actividades relacionadas de la organización.

\begin{tabular}{|c|c|}
\hline DOHO DOMINGUEZ & $\begin{array}{l}\text { Ejemplo 1.3. Informe externo para los accionistas } \\
\text { La empresa ADOLFO DOMÍNGUEZ elabora y presenta todos los años, entre } \\
\text { otros informes, un informe denominado «Cuenta de pérdidas y ga- } \\
\text { nancias» en el que se muestran los ingresos obtenidos por venta de } \\
\text { productos y los gastos incurridos para ello. Este informe muestra los } \\
\text { beneficios obtenidos en el desarrollo de su actividad, mostrando la } \\
\text { rentabilidad del negocio. }\end{array}$ \\
\hline
\end{tabular}

Las personas, empresas e instituciones usan la información contable para la toma de decisiones con relación a su patrimonio y sus actividades. Existen tres tipos de decisiones básicas, que de una forma u otra realizan todas las unidades económicas (algunas de las decisiones que se indican pueden requerir otro tipo de información además de la información económica y contable):

1. Decisiones de financiación. Se trata de decisiones relacionadas con la obtención de fondos por parte de terceros. Los informes contables deben proporcionar la información necesaria para contestar a preguntas tales como: ¿debo pedir prestado o no?, ¿qué importe solicitar?, ¿a qué entidad financiera?, ¿qué modalidad de deuda es más adecuada?, ¿tengo capacidad para endeudarme?, ¿podré pagar los intereses correspondientes y devolver el importe principal solicitado?, etc.

2. Decisiones de inversión. Se trata de decisiones relacionadas con la inversión de los recursos financieros disponibles. Los informes contables deben proporcionar la información necesaria para contestar a preguntas tales como: ¿es conveniente sustituir la maquinaria actual por otra más eficiente?, ¿debo ampliar el negocio adquiriendo más locales o fábricas?, ¿si tengo fondos disponibles en qué empresa debo invertir?, ¿qué empresa es más rentable?, ¿qué empresa está menos endeudada y es más solvente?, ¿qué empresa genera más beneficios?, etc.

3. Decisiones operativas. Se trata de decisiones relacionadas con la gestión diaria de los negocios y las actividades. Los informes contables deben proporcionar la información necesaria para contestar a preguntas tales como: ¿qué actividades de las que realiza mi empresa debo potenciar?, ¿y cuáles debo cancelar?, ¿qué clientes son más rentables?, ¿debo contratar más personal?, ¿con qué bancos es mejor operar?, etc. 


\subsection{Concepto y áreas de la contabilidad}

\section{¿Qué es la contabilidad?}

La contabilidad es un sistema de información, y como tal está encargada del registro, la elaboración y la comunicación de información, fundamentalmente de naturaleza económico-financiera, respecto a una entidad que requieren sus usuarios para la adopción racional de decisiones en el ámbito de las actividades económicas.

\section{Áreas de la contabilidad}

Las áreas de estudio de la contabilidad pueden clasificarse según diversos criterios:

(1) Según el nivel de agregación a la que se refiere la información:

- Macrocontabilidad: De agregados económicos: producto interior bruto (PIB), balanza de pagos, renta nacional etc., referidos a cualquier ámbito territorial (mundial, Unión Europea, España, Comunidad Valenciana, etc.) o sector económico (textil, automóvil, construcción, financiero, seguros, etc.).

- Microcontabilidad: De empresas, administraciones y otras entidades consideradas de forma individual.

(2) Según el ámbito de circulación económica objeto de estudio:

- Contabilidad externa, general o financiera. Centrada en las actividades y relaciones de la entidad contable con su entorno: deudores y acreedores, compras y otros gastos, ventas y otros ingresos, pagos y cobros, etc. Su objetivo es informar sobre la riqueza o patrimonio de la entidad y de sus variaciones.

- Contabilidad interna, analítica o de costes. Centrada en el proceso de transformación económica interna: consumos y costes de transformación de materias primas en productos, consumos y costes por actividades, etc. Su objetivo es estudiar los sistemas y procedimientos de determinación de los costes de productos, actividades y servicios.

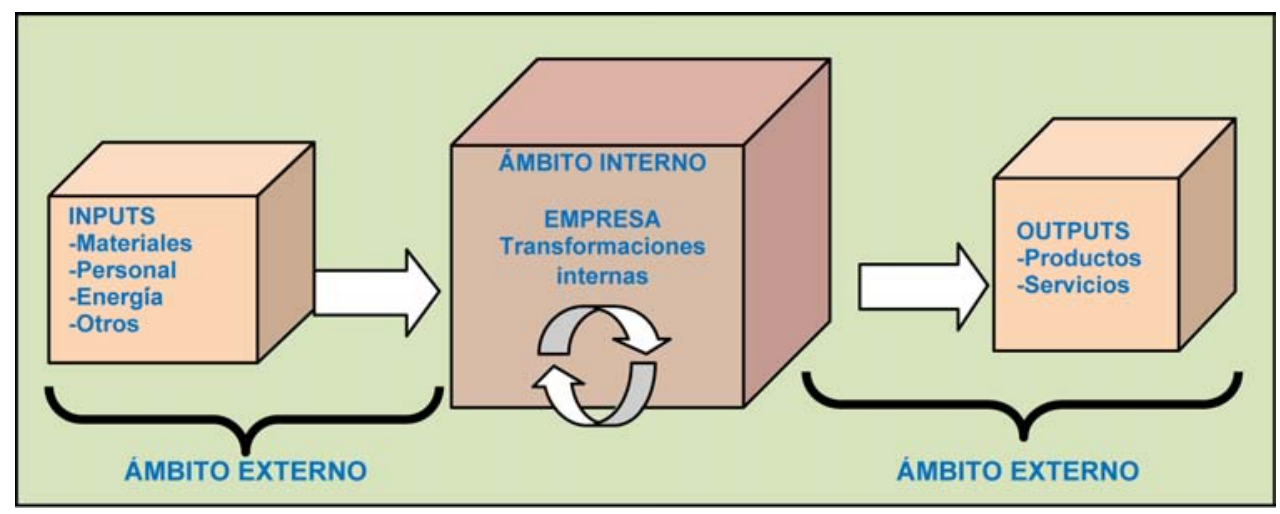

Ilustración 1.2. Ámbitos de circulación económica en una entidad 
(3) Según el tipo de entidad a la que se refiere la información:

- Contabilidad privada. Referida a la contabilidad de las entidades mercantiles (sociedades anónimas, de responsabilidad limitada, etc.) o empresarios individuales.

- Contabilidad pública. Referida a la contabilidad de entidades del sector público (ayuntamientos, diputaciones, comunidades autónomas, etc.).

- Contabilidad de entidades no lucrativas. Referida a este tipo de entidades: asociaciones, organizaciones no gubernamentales (ONG), etc.

Las distintas entidades tienen, además de necesidades informativas diferentes, requerimientos normativos específicos.

\begin{tabular}{|c|c|c|c|}
\hline & $\begin{array}{l}\text { EMPRESARIO } \\
\text { INDIVIDUAL }\end{array}$ & $\begin{array}{l}\text { SOCIEDAD } \\
\text { ANÓNIMA } \\
\text { (S.A.) }\end{array}$ & $\begin{array}{l}\text { SOCIEDAD } \\
\text { LIMITADA } \\
\text { (S.L.) }\end{array}$ \\
\hline DESCRIPCIÓN & $\begin{array}{l}\text { Persona Física que en } \\
\text { nombre propio ejerce } \\
\text { su actividad. }\end{array}$ & Sociedad mercantil. & Sociedad mercantil. \\
\hline $\begin{array}{l}\text { DENOMINACIÓN } \\
\text { DE LA PROPIEDAD }\end{array}$ & Propietario & Accionista & Socio \\
\hline $\begin{array}{l}\text { APORTACIÓN } \\
\text { DE LOS } \\
\text { PROPIETARIOS }\end{array}$ & Capital & $\begin{array}{l}\text { Capital social, dividido } \\
\text { en acciones general- } \\
\text { mente del mismo valor } \\
\text { y mismos derechos. }\end{array}$ & $\begin{array}{l}\text { Capital social, di- } \\
\text { vidido en participa- } \\
\text { ciones. }\end{array}$ \\
\hline $\begin{array}{l}\text { PERSONALIDAD } \\
\text { JURÍDICA }\end{array}$ & $\begin{array}{l}\text { La del titular del } \\
\text { negocio. }\end{array}$ & Propia & Propia \\
\hline $\begin{array}{l}\text { APORTACIÓN } \\
\text { SOCIAL }\end{array}$ & $\begin{array}{l}\text { Capital y trabajo por } \\
\text { el titular. Desembolso } \\
\text { inicial sin mínimo. }\end{array}$ & $\begin{array}{l}\text { Capital social mínimo } \\
60.000 € \text { y desembol- } \\
\text { so } 25 \% \text { inicial mínimo. }\end{array}$ & $\begin{array}{l}\text { Capital social } \\
\text { mínimo } 3.000 € \\
\text { desembolsados } \\
\text { totalmente. }\end{array}$ \\
\hline $\begin{array}{l}\text { NORMATIVA } \\
\text { LEGAL }\end{array}$ & $\begin{array}{l}\text { Código de comercio, } \\
\text { con sus modificaciones } \\
\text { posteriores. }\end{array}$ & $\begin{array}{l}\text { Texto Refundido de } \\
\text { la Ley de Sociedades } \\
\text { Anónimas. 1564/1989, } \\
\text { de } 22 \text { diciembre, y } \\
\text { modificaciones poste- } \\
\text { riores. }\end{array}$ & $\begin{array}{l}\text { Ley } 2 / 1995 \text { de } \\
\text { Sociedades de } \\
\text { Responsabilidad } \\
\text { Limitada de } 23 \text { de } \\
\text { marzo, y modifica- } \\
\text { ciones posteriores. }\end{array}$ \\
\hline $\begin{array}{l}\text { NÚMERO } \\
\text { DE SOCIOS }\end{array}$ & Siempre 1. & $\begin{array}{l}\text { Mínimo } 1 \\
\text { (unipersonal). }\end{array}$ & $\begin{array}{l}\text { Mínimo } 1 \\
\text { (unipersonal). }\end{array}$ \\
\hline
\end{tabular}




\begin{tabular}{||l|l|l|l||}
\hline & $\begin{array}{l}\text { Control del negocio } \\
\text { por el titular. }\end{array}$ & $\begin{array}{l}\text { Proporcional al } \\
\text { número de acciones } \\
\text { poseídas: } \\
\text { Derechos económicos } \\
\text { (dividendos y valor } \\
\text { DE LOS SOCIOS }\end{array}$ & $\begin{array}{l}\text { Similar a las S.A. } \\
\text { Participan en } \\
\text { proporción a su } \\
\text { aportación en la } \\
\text { gesticos (voto en Jun- } \\
\text { ta Accionistas); } \\
\text { derecho de suscripción } \\
\text { preferente de nuevas } \\
\text { acciones. }\end{array}$ \\
\hline RESPONSABILIDAD & $\begin{array}{l}\text { Ilimitada y personal y } \\
\text { con todos sus bienes. }\end{array}$ & $\begin{array}{l}\text { Limitada al capital } \\
\text { aportado (mayor en la } \\
\text { unipersonal). }\end{array}$ & $\begin{array}{l}\text { Limitada al capital. } \\
\text { Compleja en la } \\
\text { unipersonal. }\end{array}$ \\
\hline ÓRGANO RECTOR & No hay. & $\begin{array}{l}\text {-Junta Accionistas. } \\
\text {-Consejo Administra- } \\
\text { ción o Administrador. }\end{array}$ & $\begin{array}{l}\text {-Junta General. } \\
\text {-Consejo Adminis- } \\
\text { tración o Adminis- } \\
\text { trador. }\end{array}$ \\
\hline
\end{tabular}

(4) Según el objeto de estudio:

- Análisis contable. Estudio de las técnicas de análisis e interpretación de información contable o financiera.

- Contabilidad y control de gestión. Estudio centrado en la generación de información y el control de carácter interno útil para la gestión operativa y estratégica de los negocios.

- Auditoría contable. Es la revisión de la información contable de una entidad por parte de expertos contables independientes al objeto de verificar el cumplimiento de los principios y normas contables.

- Contabilidad presupuestaria. Estudio de los procesos de elaboración de presupuestos y control presupuestario.

- Valoración de empresas. Estudio de los métodos, técnicas y procedimientos para la valoración de empresas.

- Consolidación de estados financieros. Estudio de los métodos y procedimientos para la agregación de información contable de entidades que pertenecen a grupos de empresas.

- Contabilidad internacional. Estudio de las normativas y prácticas contables en el ámbito internacional.

- Contabilidades sectoriales. Estudio de las particularidades contables de sectores específicos: bancario, seguros, constructoras, energía, etc. 


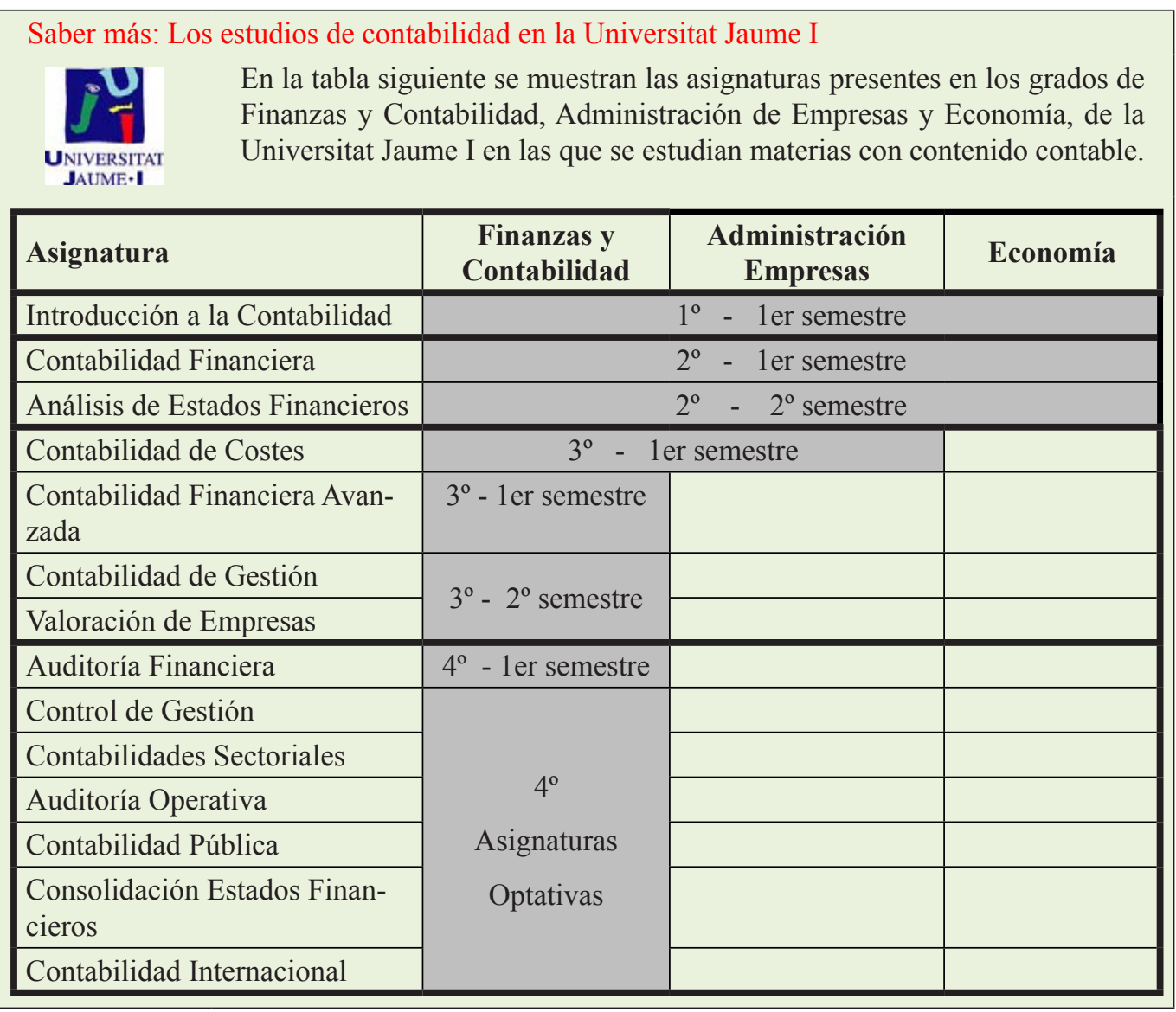

\section{Entidades contables}

Una entidad contable es un negocio u organización o parte de un negocio u organización que desde el punto de vista contable debe tratarse como una unidad separada.

Cada entidad contable registra, elabora y presenta su propia información económica y contable.

\section{Ejemplo 1.4. El patrimonio empresarial de un empresario autónomo}

Si una persona física es empresario autónomo, deberán separarse los bienes, deudas y otros elementos patrimoniales afectos a la actividad empresarial, y considerarse como una entidad contable separada, del resto de bienes, deudas y elementos patrimoniales que a título personal pueda tener dicho empresario. El empresario necesita información económica referida únicamente a la entidad contable separada que constituye su negocio sin incluir en los mismos el resto de bienes y deudas personales.

\section{Ejemplo 1.5. Una filial de una multinacional como entidad contable}

Las empresas multinacionales suelen organizarse mediante filiales en distintos países cada una de las cuales tiene su propia personalidad jurídica aunque su capital pertenezca totalmente a la empresa matriz. Así, FORD tiene diversas filiales a lo largo del mundo como por ejemplo FORD ESPAÑA SA. Esta última sociedad, FORD ESPAÑA SA, es una entidad contable separada que prepara informes económicos propios e individuales, y sin incluir información de otras filiales de FORD o de la matriz. 


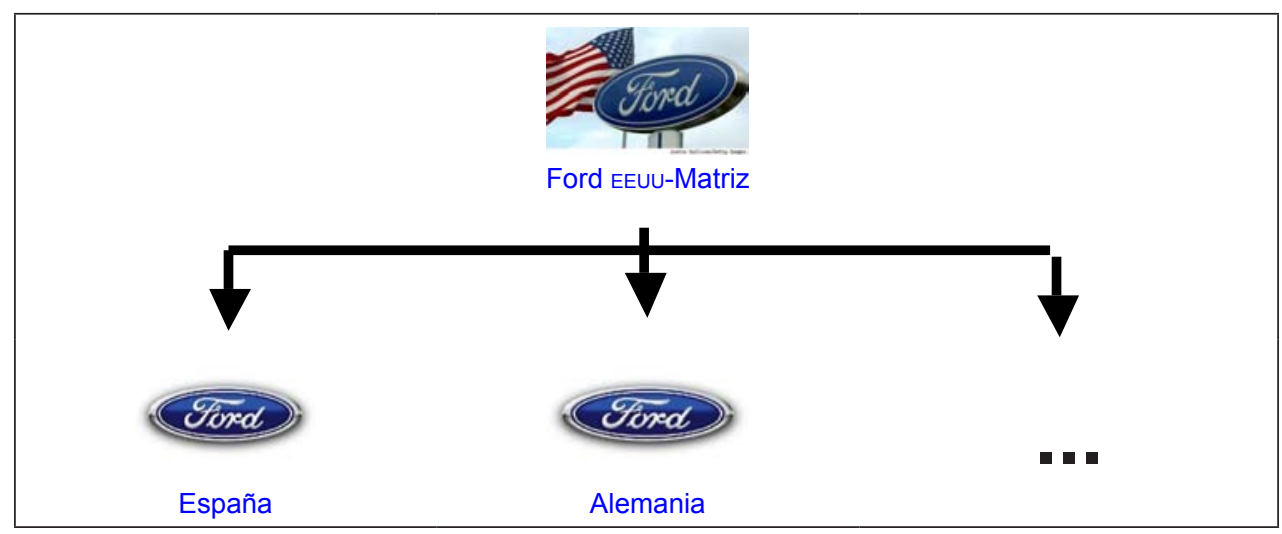

Ilustración 1.3. Multinacional: matriz y filiales

Cada entidad contable tiene sus propias necesidades de información contable y está sujeta a diferentes requerimientos legales respecto a la misma. Las diferencias existentes en la información contable de distintas entidades derivan, o pueden derivar, de varias circunstancias:

- de si es una entidad de derecho privado o de derecho público;

- siendo de derecho privado, de su forma jurídica: empresario individual, sociedad anónima, sociedad limitada, cooperativa, asociación, etc.;

- de la naturaleza de su actividad: construcción, industrial, financiera, servicios, etc.;

- de otros factores: si son entidades que cotizan en Bolsa o no, si forman parte de un grupo de empresas, etc.

\section{El sistema contable en una entidad individual}

Cada día todas las empresas, y otras entidades privadas o públicas, realizan gran cantidad de operaciones: compras, ventas, cobros, pagos, etc., que precisan un sistema capaz de analizar, valorar, registrar y clasificar esas transacciones para posteriormente elaborar documentos o informes que sinteticen toda la información útil para la toma de decisiones.

Un sistema contable consiste en el conjunto de métodos, procedimientos y recursos materiales y humanos que una entidad utiliza para llevar a cabo el registro de sus actividades económicas y para poder elaborar información, detallada o sintetizada, de manera que sea útil a aquellos que tienen que tomar decisiones.

Así, en todo sistema de información contable se precisará tanto de elementos humanos, los profesionales de la contabilidad y personal administrativo, como de elementos materiales tales como las instalaciones y el equipo utilizados (despachos, ordenadores, impresoras, etc.). También se precisarán documentos físicos justificativos de las operaciones (facturas, recibos, extractos bancarios, etc.) y disponer de métodos y procedimientos para su captación, análisis, registro y archivo. 
Finalmente hay que señalar que la normativa mercantil contiene una gran cantidad de disposiciones en materia contable las cuales, junto al conocimiento propio de la profesión, son necesarias para el adecuado funcionamiento del sistema contable.

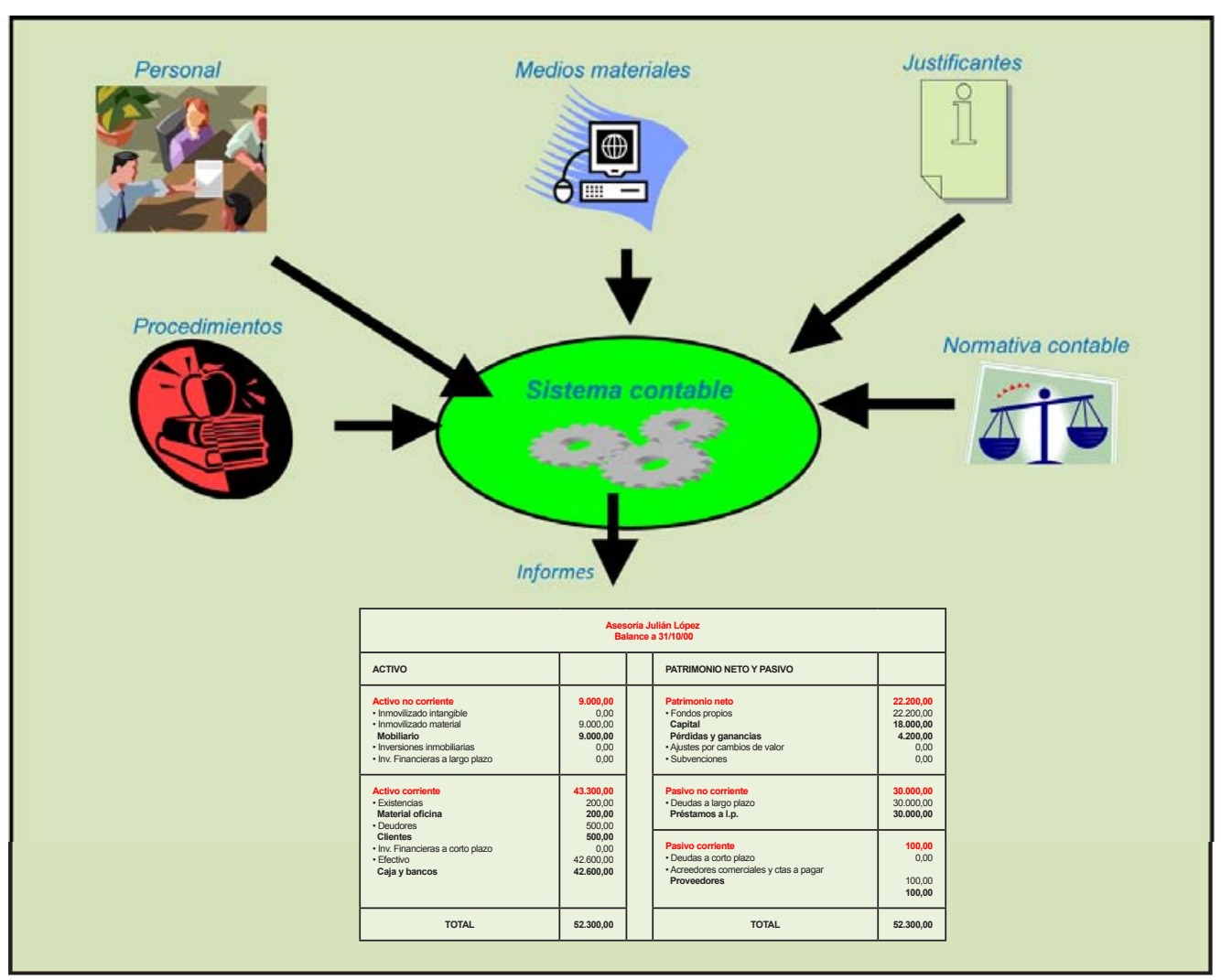

Ilustración 1.4. El sistema contable

El aprendizaje del registro de las transacciones más habituales de una empresa, que suele denominarse teneduría de libros, requiere pocas semanas o meses, sin embargo, para ser un profesional de la contabilidad se necesita un período mayor de estudio, dedicación y experiencia.

La contabilidad no se encarga solo del mantenimiento de los registros contables, también supone el diseño de sistemas contables eficientes, el análisis de las transacciones previo al registro y la elaboración e interpretación de informes contables, tanto sobre información histórica como previsional.

\subsection{Usuarios de la información contable}

El objetivo general de la contabilidad de proporcionar información útil para la toma de decisiones se materializa en satisfacer las necesidades de determinados usuarios, que son los que en última instancia determinan dichos objetivos a conseguir y requisitos concretos que cabe exigir a la información a su disposición.

El concepto de usuario de la contabilidad abarca tanto a los usuarios actuales, que son los que en un determinado momento precisan y utilizan la información que se 
les proporciona, como a los usuarios potenciales, es decir, a todos aquellos que en un futuro podrían necesitarla aunque en esos momentos no sea de su interés.

Estos usuarios de la contabilidad pueden clasificarse en externos e internos.

\section{Usuarios externos}

Los usuarios externos son aquellos (personas, empresas u otros) a los que la información contable les viene dada, no participan ni directa ni indirectamente en la elaboración de la misma y toman decisiones de carácter externo a la empresa tanto de inversión como de financiación. Normalmente no disponen de más información que la que la empresa está obligada a proporcionar por ley, o voluntariamente quiera darles.

\begin{tabular}{|c|c|}
\hline Tipo de usuario & Intereses o necesidades informativas \\
\hline Accionistas o propietarios & $\begin{array}{l}\text { El interés básico de los propietarios es determinar la generación } \\
\text { de beneficios de la empresa y su rentabilidad. Desde el punto de } \\
\text { vista de los accionistas, esta información es imprescindible para } \\
\text { determinar la conveniencia de invertir en unas sociedades en lugar } \\
\text { de en otras. En este sentido la información debe ayudarles a deter- } \\
\text { minar no solo el rendimiento pasado, sino también la capacidad } \\
\text { de generar rendimientos futuros. }\end{array}$ \\
\hline Acreedores & $\begin{array}{l}\text { El interés esencial de los acreedores de una empresa es conocer } \\
\text { el endeudamiento y la solvencia de la misma. Es decir, precisan } \\
\text { información para evaluar la razonabilidad de que van a recuperar } \\
\text { los fondos prestados. También la generación de beneficios de la } \\
\text { empresa puede ser un dato relevante debido a que condiciona su } \\
\text { capacidad para satisfacer los intereses de sus deudas. }\end{array}$ \\
\hline Hacienda Pública & $\begin{array}{l}\text { El interés básico de la Hacienda Pública es recaudatorio o fis- } \\
\text { cal. Precisa de información sobre los beneficios que obtienen la } \\
\text { empresa al objeto de determinar los impuestos que deben recaer } \\
\text { sobre la misma. }\end{array}$ \\
\hline Otras entidades públicas & $\begin{array}{l}\text { Otras entidades públicas, como por ejemplo la Comisión Nacional } \\
\text { del Mercado de Valores, precisan de información contable especí- } \\
\text { fica respecto a las empresas que cotizan en bolsa. }\end{array}$ \\
\hline $\begin{array}{l}\text { Otros: empleados, sindi- } \\
\text { catos, clientes, agencias } \\
\text { de rating, fiscales, jueces, } \\
\text { analistas financieros, etc. }\end{array}$ & $\begin{array}{l}\text { Los empleados y sindicatos suelen tener en cuenta la información } \\
\text { contable de las empresas relativa a generación de beneficios en los } \\
\text { procesos de negociación colectiva. } \\
\text { Los clientes pueden evaluar a las empresas donde compran al } \\
\text { objeto de determinar la conveniencia de seguir comprando (por } \\
\text { ejemplo, para evitar problemas de garantías futuras). } \\
\text { Otros usuarios tienen diversos objetivos: análisis de rentabilidad, } \\
\text { de solvencia, cumplimiento de normativa contable, etc. }\end{array}$ \\
\hline
\end{tabular}

Ilustración 1.5. Tipos de usuarios externos de una empresa e intereses de los mismos

En la mayoría de los países la información a proporcionar a los usuarios externos viene recogida en normas legales, de naturaleza mercantil y de cumplimiento obligatorio, que indican el detalle de la misma y la periodicidad de su presentación. 


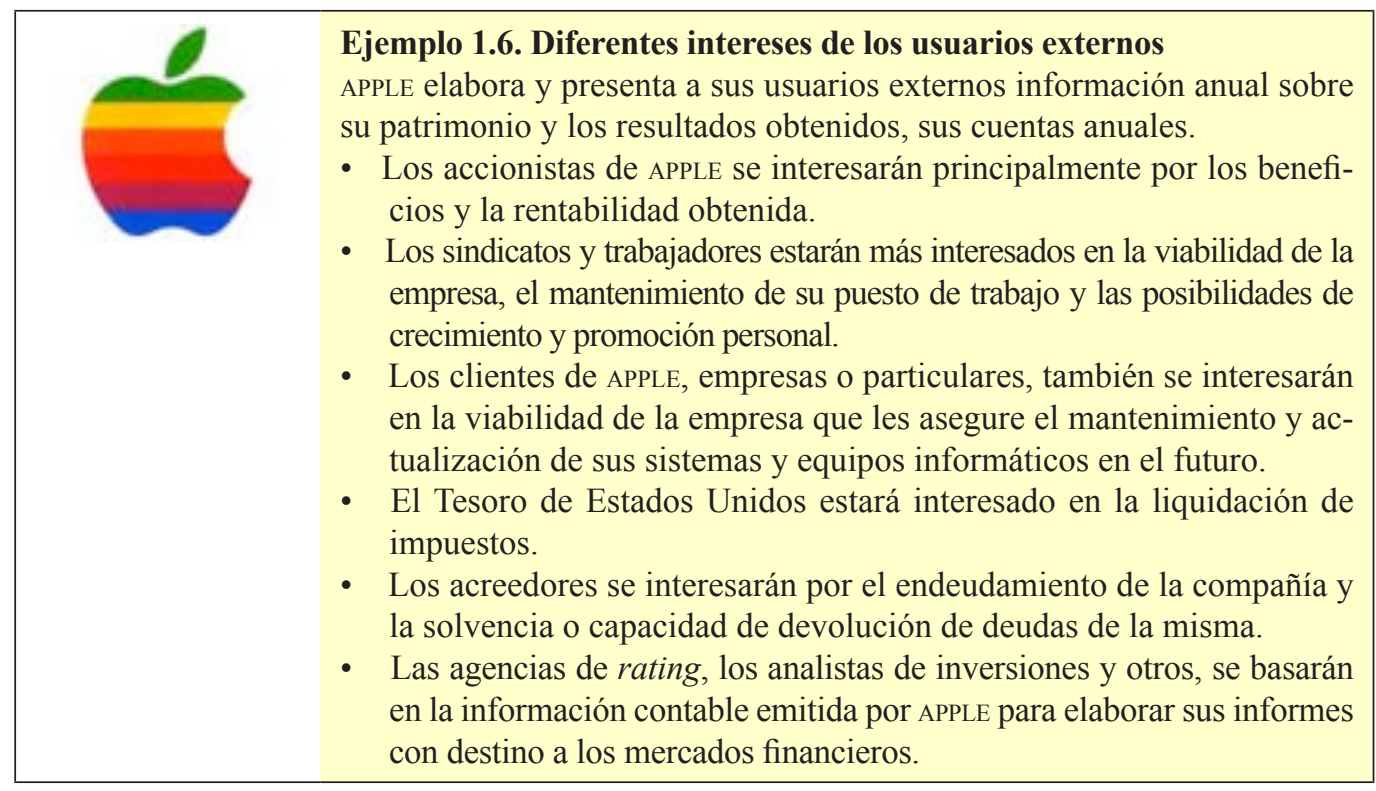

\section{Usuarios internos}

Los usuarios internos son todas aquellas personas que, situados en distintos niveles jerárquicos de la empresa, participan en mayor o menor medida en la elaboración de la información contable y la utilizan en decisiones de carácter interno a la misma para la gestión de sus áreas de responsabilidad.

\begin{tabular}{|l|l|}
\hline \multicolumn{1}{|c|}{ Tipo de usuario } & \multicolumn{1}{c|}{ Intereses o necesidades informativas } \\
\hline $\begin{array}{l}\text { Consejo de Administración } \\
\text { o Dirección General }\end{array}$ & $\begin{array}{l}\text { Los directivos de alto nivel precisan de informes contables gene- } \\
\text { rales al objeto de decidir cuestiones de tipo estratégico: fijación de } \\
\text { objetivos a largo plazo, políticas generales de compra y venta, po- } \\
\text { líticas y decisiones de inversión y de financiación, de expansión de } \\
\text { la empresa, líneas de negocio. }\end{array}$ \\
\hline Jefes de Departamento & $\begin{array}{l}\text { Los directivos de menor nivel precisan de informes detallados so- } \\
\text { bre las parcelas de responsabilidad que cada uno de ellos tenga. } \\
\text { Así la información contable que precisa el director comercial será } \\
\text { distinta de la que necesite el director de recursos humanos u otros } \\
\text { directivos. El uso de esta información será para decisiones de tipo } \\
\text { operativo, gestión diaria de la empresa o al menos en el corto } \\
\text { plazo. } \\
\text { Cuanto menor sea el nivel del directivo, la información necesaria } \\
\text { será más detallada y precisa. Por ejemplo, el responsable comer- } \\
\text { cial de Extremo Oriente en una empresa exportadora precisará de } \\
\text { información detallada y periódica sobre cada uno de los clientes } \\
\text { de su zona }\end{array}$ \\
\hline $\begin{array}{l}\text { Directivos y mandos } \\
\text { intermedios }\end{array}$
\end{tabular}

Ilustración 1.6. Tipos de usuarios internos de una empresa e intereses de los mismos

Estos usuarios suelen disponer de toda la información que requieren, en el marco de su nivel jerárquico, sus responsabilidades y sus necesidades, con el detalle que deseen y con la periodicidad que estimen oportuna. 


\section{Diferencias entre la información contable según los usuarios}

Los usuarios externos toman sus decisiones sobre la base de la información que proporcionan las empresas, debiendo confiar en ella. Por ello, la información que se proporciona a los usuarios externos está sujeta a una regulación externa a la empresa (del Estado, de organizaciones profesionales, etc.). En España esta información está regulada por la normativa mercantil, entre cuyas normas la de mayor detalle y aplicación práctica es el Plan General de Contabilidad (PGC).

La información contable externa se presenta en unos formatos y con una estructura definida en las disposiciones legales, que se conocen en España como cuentas anuales. El nivel de detalle de esta información es escaso dado que presenta datos agregados y referidos a la totalidad de la empresa.

La regulación contable persigue alcanzar dos objetivos:

- que los informes contables de las empresas sean fiables al basarse en principios y criterios de general aceptación y aplicados por todas ellas.

- que la información proporcionada por una empresa a lo largo del tiempo sea comparable y también que sea comparable la información proporcionada por distintas empresas.

Por otro lado, los informes contables para usuarios internos no están, ni pueden estar, regulados legalmente, por lo que no están sujetos a principios y criterios contables externos. La dirección de la empresa podrá seleccionar múltiples criterios que dependerán de sus necesidades informativas, incluso podrá aplicar criterios distintos para informes que tengan distinto objetivo. Es decir, la regulación de la contabilidad interna también es interna (los propios elaboradores y destinatarios de la información fijan sus reglas), con el objetivo de que los informes sean útiles para la toma de decisiones en el ámbito de la gestión de la empresa.

Por tanto, la información a que tienen acceso los usuarios externos es, lógicamente, mucho menor que la que está al alcance de los usuarios internos. Los usuarios internos, en la medida que deben tomar decisiones en el ámbito de la gestión económico-financiera de la empresa, precisan de mayor cantidad y periodicidad de información.

Por otra parte, la información que se presenta a los usuarios externos se refiere a hechos pasados, mientras que los usuarios internos suelen elaborar tanto información histórica como previsional al objeto de tomar sus decisiones oportunamente. 


\begin{tabular}{|c|c|c|}
\hline & USUARIOS EXTERNOS & USUARIOS INTERNOS \\
\hline Informes & Cuentas anuales. & Informes internos. \\
\hline Tipo de información & Histórica. & Histórica y previsional. \\
\hline $\begin{array}{c}\text { Normas de elaboración } \\
\text { Principios y criterios } \\
\text { contables }\end{array}$ & $\begin{array}{c}\text { Normativa mercantil, entre la } \\
\text { que destaca el } \\
\text { Plan General Contabilidad. }\end{array}$ & $\begin{array}{c}\text { La dirección marca sus propias } \\
\text { normas. }\end{array}$ \\
\hline $\begin{array}{c}\text { Periodicidad } \\
\text { contable. }\end{array}$ & Generalmente anual. \\
Nivel de agregación & $\begin{array}{c}\text { Información agregada de toda } \\
\text { la empresa. }\end{array}$ & $\begin{array}{c}\text { Nivel de desagregación o detalle } \\
\text { deseado. }\end{array}$ \\
\hline
\end{tabular}

Ilustración 1.7. Características de la información contable a disposición de sus usuarios

Ejemplo 1.7. Información sobre mercancías disponible para un usuario ex-
terno y uno interno
- En los informes contables de CARREFOUR destinados a los usuarios externos úni-
camente figura la cuantía total de mercancías que tiene la empresa en almacén
a la fecha del informe, así como otros datos agregados tales como la cifra de
ventas y el coste global de las mercancías vendidas en un año. También se
informa sobre los criterios generales utilizados para su valoración.
- Por su parte, los usuarios internos de cARREFour, como el responsable de al-
macén, el director comercial y otros, disponen de informes detallados sobre
la cantidad y valor de cada tipo de mercancía y de cada producto individual
presente en almacén. Además, conocen las ventas y el coste de lo vendido a
nivel de productos, líneas de productos, mercados geográficos, tipo de clien-
te al que se ha vendido y cualquier otra información que estime necesaria
para la gestión.

\subsection{Objetivos y requisitos de la información contable}

En los apartados anteriores se ha comentado la utilidad de la información contable para sus usuarios en el ámbito de las decisiones económicas. También se han destacado las diferencias entre la información a disposición de los usuarios externos e internos.

Dada la importancia que para los usuarios externos tiene disponer de la información necesaria y suficiente, en términos de contenido y calidad para la toma de decisiones, la normativa mercantil establece los objetivos y requisitos que dicha información contable debe cumplir.

La regulación de estos aspectos es necesaria puesto que, como se ha comentado, los usuarios externos solo disponen de información contable sobre las entidades que estas proporcionan, de forma voluntaria o bien de acuerdo a las disposiciones legales. 


\section{Objetivos de la información contable para los usuarios externos}

Los informes financieros o estados contables que las empresas privadas presentan en España a los usuarios externos de forma obligatoria se denominan cuentas anuales. El objetivo de estas se señala en la normativa, Plan General de Contabilidad de la siguiente forma:

Las cuentas anuales deben redactarse con claridad, de forma que la información suministrada sea comprensible y útil para los usuarios al tomar sus decisiones económicas, debiendo mostrar la imagen fiel del patrimonio, de la situación financiera y de los resultados de la empresa, de conformidad con las disposiciones legales (PGC, Primera Parte, 1ํㅡㄹ Cuentas Anuales. Imagen fiel).

Las cuentas anuales están formadas por los siguientes estados contables:

- Balance.

- Cuenta de pérdidas y ganancias (Cuenta de PyG).

- Estado de cambios en el patrimonio neto (ECPN).

- Estado de flujos de efectivo (EFE).

- Memoria.

En este texto introductorio de contabilidad se estudiarán de forma básica los dos primeros informes: balance y cuenta de pérdidas y ganancias.

En entidades públicas o en entidades sin ánimo de lucro, junto con los objetivos anteriores, se enfatizan otros aspectos como son el control de la legalidad, la eficacia y eficiencia en la prestación de servicios públicos, etc.

\section{Requisitos de la información contable incluida en la cuentas anuales}

Para poder cumplir el objetivo de utilidad para sus usuarios se requiere que la información contable incluida en las cuentas anuales sea relevante y fiable.

- La información es relevante cuando es útil para la toma de decisiones económicas, es decir, cuando ayuda a evaluar sucesos pasados, presentes o futuros, o bien a confirmar o corregir evaluaciones realizadas anteriormente. En particular, para cumplir con este requisito, las cuentas anuales deben mostrar adecuadamente los riesgos a los que se enfrenta la empresa.

La relevancia exige que la información sea oportuna (presentada cuando se precisa), que tenga valor predictivo y capacidad de retroalimentación (feedback).

- La información es fiable cuando está libre de errores materiales y es neutral, es decir, está libre de sesgos, y los usuarios pueden confiar en que refleja la imagen fiel de lo que pretende representar. 
Una cualidad derivada de la fiabilidad es la integridad, que se alcanza cuando la información financiera contiene, de forma completa, todos los datos que pueden influir en la toma de decisiones, sin ninguna omisión de información significativa.

\section{La fiabilidad exige que la información sea verificable}

Adicionalmente, la información financiera debe cumplir con las cualidades de comparabilidad y claridad.

- La comparabilidad, que debe extenderse tanto a las cuentas anuales de una empresa en el tiempo como a las de diferentes empresas en el mismo momento y para el mismo período de tiempo, debe permitir contrastar la situación y rentabilidad de las empresas, e implica un tratamiento similar para las transacciones y demás sucesos económicos que se producen en circunstancias parecidas.

- Por su parte, la claridad implica que, sobre la base de un razonable conocimiento de las actividades económicas, la contabilidad y las finanzas empresariales, los usuarios de las cuentas anuales, mediante un examen diligente de la información suministrada, puedan formarse juicios que les faciliten la toma de decisiones.

Finalmente, como en el resto de actividades económicas, debe tenerse en cuenta que el beneficio, en términos de información, que proporciona el sistema contable sea superior al coste de elaboración de dicha información (restricción coste $<$ beneficio).

\section{martinsa}

\section{EUROPA PRESS. Lunes 27/10/2008}

MADRID.- Martinsa-Fadesa ha encargado a las firmas TecniTasa, Tirsa y Valmasa que le elaboren un informe de tasación de sus bienes inmobiliarios, según ha informado la inmobiliaria, que se encuentra en situación de concurso de acreedores.

El último informe de valoración de la compañía, que preside Fernando Martín, realizado por CB Richard Ellis en junio sobre el cierre de 2007, indica que los bienes de la compañía presentan un valor de 10.804,50 millones de euros. De su lado, el valor contable de los bienes de Martinsa-Fadesa a 31 de diciembre de 2007 era de 8.700 millones de euros.

En la noticia anterior se observa que el valor contable al que aparecen a 31 de diciembre de 2007 los bienes inmobiliarios de Martinsa, pese que es un valor fiable y conocido (es el valor de adquisición que consta en las escrituras públicas de de compra-venta) no es relevante en la situación de concurso de acreedores. En este caso, el valor relevante es el valor de tasación que trata de aproximarse a un valor razonable de mercado. Dado que el valor de mercado puede variar con el tiempo se precisan tasaciones periódicas de los bienes. Pese a que el valor de tasación no es totalmente fiable, puesto que depende de criterios de los tasadores, proporciona un valor aproximado que es más relevante. 


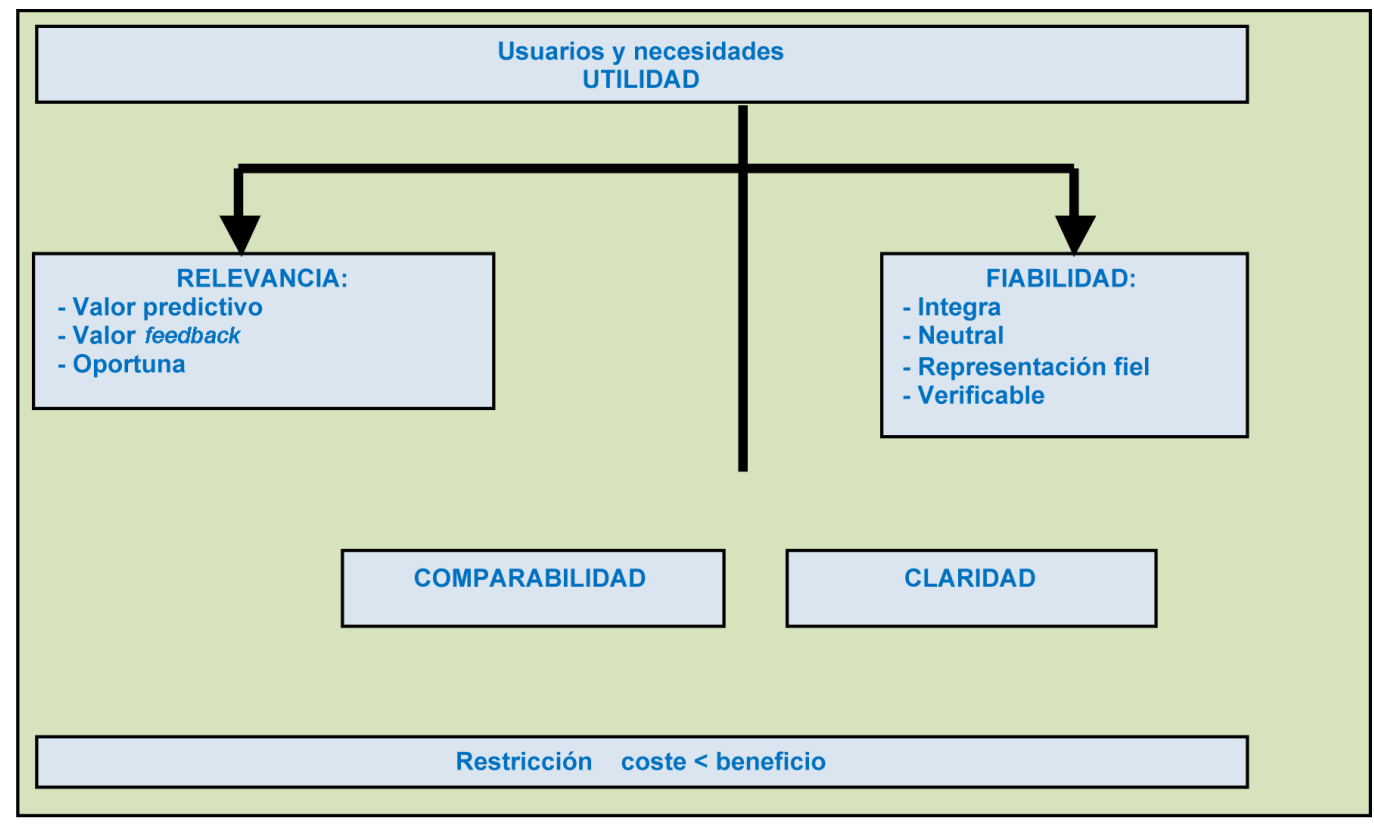

Ilustración 1.9. Requisitos de la información contable

\subsection{Los profesionales de la contabilidad}

Tener conocimientos sólidos sobre contabilidad, y para algunas actividades un título acreditativo de los mismos, permite el desempeño de multitud de actividades profesionales, entre las que puede destacarse las que se exponen en los párrafos siguientes.

1. Gestión contable en la empresa privada. Todas las empresas, con independencia de su forma jurídica, tamaño o actividad, están obligadas por la normativa mercantil a llevar contabilidad y elaborar informes contables.

- En muchas pequeñas empresas la persona encargada de la gestión administrativa suele ser la encargada de mantener los registros contables de las operaciones que se realizan.

- En grandes empresas suele haber todo un departamento de contabilidad, que aunque independiente, forma parte del departamento administrativo-financiero. Dentro del departamento de contabilidad, hay personal dedicado al control y registro de compras y gastos, de ventas e ingresos, de tesorería, otros encargados de la auditoría interna, de realización de presupuestos, del control de costes, de análisis de la información, etc. El responsable último del área contable es el director financiero, que forma parte del equipo directivo de la empresa.

2. Asesoría o consultoría contable y fiscal. Muchos graduados actúan independientemente o dentro de empresas especializadas, prestando asesoramiento o consultoría a empresas a cambio de honorarios. La actividad de estas asesorías 
es muy diversa, desde la simple recomendación al cliente ante un problema de decisión, a la gestión de todos los registros contables y elaboración y presentación de toda la información que el cliente pueda precisar para su propio uso o para cumplir la legislación mercantil y fiscal en materia de información financiera obligatoria.

3. Auditoría de cuentas. Una fuente de actividad importante son las empresas de auditoría o auditores independientes, cuya misión es verificar la información contable presentada por las empresas a los usuarios externos. Esta actividad requiere de una habilitación oficial que expide el Ministerio de Economía tras acreditar una formación teórica y práctica en contabilidad y auditoría de cuentas y la superación de unas pruebas de aptitud. Los auditores deben estar inscritos en el Registro de Economistas Auditores (REA, véase más adelante las organizaciones profesionales).

4. Gestión contable en el sector público, tanto de empresas públicas como de administraciones (central y autonómica, diputaciones, ayuntamientos). Los conocimientos de contabilidad permiten desempeñar funciones similares a las que se realizan en el sector privado. Las empresas públicas se rigen por las mismas normas que las empresas privadas y por su parte, las distintas administraciones requieren de importantes departamentos de contabilidad para la gestión de sus presupuestos y la elaboración de información patrimonial.

5. Gestión contable de entidades no lucrativas (asociaciones, fundaciones, oNG, etc.). Las necesidades y requerimientos informativos en materia contable de estas entidades no difieren significativamente de los de la empresa privada, incorporando algunos elementos de gestión presupuestaria.

6. Otras profesiones. Finalmente debe señalarse que se requieren conocimientos de contabilidad para otras muchas actividades profesionales. Los conceptos contables son usados en multitud de campos y se precisa su conocimiento por parte de:

- En el sector financiero: analistas de inversiones, empresas de calificación, entidades financieras.

- En el sector jurídico: abogados y jueces, dado que en los tribunales se juzgan multitud de actividades económicas.

- En el sector de técnica o tecnología: ingenieros y arquitectos que junto con las cuestiones técnicas añaden aspectos económicos como factores a considerar para la elección entre alternativas.

- Sector político: dado que la gestión de los recursos públicos precisa de estudios tanto sobre los ingresos como sobre los costes de las políticas públicas.

- etc. 


\section{Organizaciones profesionales}

Los profesionales de la contabilidad se agrupan en diversas organizaciones y asociaciones entre las que, en España, destacan:

- AECA (Asociación Española de Contabilidad y Administración de Empresas). Es una institución profesional emisora de principios y normas de contabilidad generalmente aceptados y de pronunciamientos y estudios sobre buenas prácticas en gestión empresarial. Los socios de AECA representan el amplio conjunto profesional, empresarial, académico, e investigador en el ámbito contable y de gestión empresarial en España y también en el extranjero; así como la práctica totalidad e instituciones, asociaciones, corporaciones profesionales, organizaciones de la Administración y un gran número de empresas industriales, comerciales y de servicios, especialmente financieros, de auditoría y consultoría. Referencias: www.aeca.es.

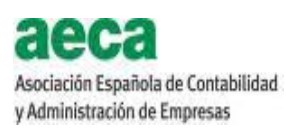

- REA (Registro de Economistas Auditores). Es una organización profesional, que representa a todos los auditores de España, está al servicio de la actividad de la auditoría y que vela por su prestigio dentro de la sociedad y ser garantía de calidad en el ejercicio de la misma. Todos los profesionales habilitados oficialmente para realizar auditorías están inscritos en el REA. Referencias: www.rea.es.

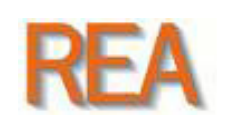

- Colegios Oficiales de Economistas. Son corporaciones de derecho público (hay uno por comunidad autónoma), representativas de la profesión de economista, cuyos fines esenciales son la ordenación del ejercicio de la profesión, la representación exclusiva de la misma y la defensa de los intereses profesionales de sus colegiados. Referencias: Colegio Oficial de Economistas de Valencia: www.coev.com.

\section{C(s)EV}

- ICJCE (Instituto de Censores Jurados de Cuentas de España). Es la principal corporación de auditores y representante de la auditoría española en las instituciones profesionales internacionales. Está al servicio de los auditores de cuentas para mantener la calidad profesional y el cumplimiento de las normas deontológicas, al tiempo que defiende y tutela a los destinatarios de la auditoría a través de los controles técnicos de calidad de los informes que emiten sus miembros. Referencias: www.icjce.es. 


\section{Material para prácticas}

\section{Preguntas test}

1. Según el Plan General de Contabilidad el objetivo de la contabilidad es:

a) Proporcionar información comprensible y útil para los usuarios mostrando la imagen fiel del patrimonio de la situación financiera y de los resultados de la empresa.

b) Diseñar un conjunto de métodos, procedimientos y recursos materiales y humanos para el registro de sus actividades económicas.

c) El mantenimiento de registro contables de acuerdo a los criterios de oportunidad, comparabilidad y fiabilidad.

d) La elaboración de informes rutinarios y no rutinarios para gerentes y otros usuarios.

2. Las cuentas anuales son:

a) El balance y la cuenta de pérdidas y ganancias, el estado de flujos de efectivo, el informe de gestión y la memoria.

b) El balance, la cuenta de pérdidas y ganancias, el estado de flujos de efectivo, el Estado de cambios en el patrimonio neto y la memoria.

c) El balance, la cuenta de pérdidas y ganancias, el estado de cambios en el patrimonio neto y el informe de gestión.

d) El balance, la cuenta de pérdidas y ganancias, el estado de flujos de efectivo y el informe de gestión.

3. Son usuarios externos de la contabilidad:

a) Los empleados que trabajan en la empresa o los clientes de la empresa.

b) Los administradores de la empresa.

c) Los encargados de la gestión de la empresa.

d) Todos los anteriores.

4. Son usuarios internos de la contabilidad:

a) Los empleados que trabajan en la empresa.

b) Las administraciones públicas.

c) Los prestamistas de la empresa.

d) Ninguno de los anteriores.

5. En relación a la información contable y sus usuarios:

a) La información disponible para los usuarios externos es básicamente previsional.

b) La información disponible para los usuarios internos se denomina cuentas anuales.

c) La dirección fija las normas de elaboración de los informes internos.

d) La dirección fija las normas de elaboración de los informes internos y externos. 
6. Son requisitos de la información contable:

a) Relevancia y relatividad.

b) Relevancia, fiabilidad y existencia de sesgo.

c) Relevancia y fiabilidad.

d) Comparabilidad y coste.

7. La información contable es comparable cuando:

a) Está elaborada basándose en unos principios y normas de general aceptación.

b) Los resultados y el balance de distintas empresas ofrecen cifras aproximadas.

c) Los usuarios que la estudian persiguen los mismos fines.

d) Los estados contables de una empresa en dos ejercicios sucesivos presentas datos parecidos.

8. La información es fiable si:

a) Está soportada por documentos físicos justificativos.

b) No tiene errores materiales, es neutral, integra y verificable.

c) Tiene capacidad predictiva, es comparable y clara.

d) Es relevante y su coste de obtención es inferior al beneficio que proporciona.

\section{SOLUCIONES AL TEST:}

\begin{tabular}{|l|l|l|l|l|}
\hline 1. & 2. & 3. & 4. & 5. \\
\hline 6. & 7. & 8. & & \\
\hline
\end{tabular}




\section{Cuestiones teóricas}

1. Indique los tres tipos de informes que elabora la contabilidad para la toma de decisiones indicando sus usuarios.

2. La información contable ayuda a tres tipos de decisiones fundamentales, ¿cuáles son?

3. Defina la contabilidad.

4. Defina el concepto de entidad contable.

5. Según el ámbito de circulación económica que estudia, ¿cómo se clasifica la contabilidad?

6. ¿De qué elementos consta el sistema contable y cuál es su objetivo?

7. ¿Qué dos grandes grupos de usuarios de la información contable hay y qué les diferencia?

8. ¿Qué tipo de usuarios son los propietarios? Distinga sus necesidades informativas de las de los acreedores.

9. ¿Cuáles son las necesidades informativas de los usuarios internos?

10. Indique tres tipos de forma jurídica de empresa y citar dos diferencias entre ellas.

11. Señale un ejemplo de decisión de financiación a tomar por un usuario interno. Indique la información que al usuario le gustaría conocer.

12. Señale un ejemplo de decisión de inversión a tomar por un usuario externo. Indique la información que al usuario le gustaría conocer.

13. Señale tres diferencias entre la información contable a disposición de los usuarios externos e internos

14. ¿Está sujeta la contabilidad financiera a normas legales de elaboración? ¿Por qué?

15. ¿Está sujeta la contabilidad de gestión a normas legales de elaboración? ¿Por qué?

16. ¿Cuál es el objetivo de la información contable contenida en las cuentas anuales?

17. Indique los requisitos de la información contable.

18. ¿Qué significa que la información contable debe ser fiable?

19. ¿Qué significa que la información contable debe ser relevante?

20. Indique en que campos principales desarrollan los contables su actividad profesional

21. ¿Cuáles son las principales organizaciones en las que se enmarcan los profesionales contables? 


\section{Ejercicios}

Ejercicio 1. Información económico-contable para un inversor

Suponga que dispone de recursos económicos y se le presenta la posibilidad de invertir en dos empresas, General Motors y Ford. Indique qué información, económica-contable, le gustaría disponer de las mismas al objeto de poder tomar una decisión.

Ejercicio 2. Información económico-contable para un prestamista

Suponga que es una entidad financiera (banco) y recibe una solicitud para un préstamo de la empresa TOLDOS MARTÍNEZ SL. Indique qué información económica-contable le gustaría disponer de la misma al objeto de poder tomar una decisión.

\section{Ejercicio 3. Información económico-contable para un directivo}

Suponga que es directivo de la empresa Volkswagen, la cual tiene empresas filiales (fábricas) en distintos países del mundo. Los accionistas de Volkswagen desean obtener la mayor rentabilidad posible de su inversión. El sector del automóvil es muy competitivo y la empresa siente una gran presión por parte de empresas coreanas y japonesas que ha hecho descender dicha rentabilidad. Piense en qué información sobre dichas filiales, de naturaleza económico-contable, debería utilizar al objeto de poder tomar decisiones relativas al cierre de fábricas, y/o la ampliación de fabricas, en los distintos países.

Ejercicio 4. Información para un directivo distinta de la económico-contable En relación al ejercicio 3 anterior, piense en qué otras consideraciones (no económico-contables) habría que tener en cuenta para tomar las decisiones. 
Ejercicio 5. Fiabilidad y relevancia de la información contable

Reflexione si los valores de cotización bursátil serían útiles como criterio de valoración contable de las inversiones en acciones, teniendo en cuenta la volatilidad habitualmente existente en los mercados financieros. Ponga en relación esta cuestión con los requisitos de fiabilidad y relevancia.

\section{Ejercicio 6. Fiabilidad y relevancia de la información contable}

Reflexione sobre si para un inversor el valor de compra de un local comercial como criterio de valoración contable sería útil para la toma decisiones, teniendo en cuenta que dicho local se adquirió hace diez años. Ponga en relación esta cuestión con los requisitos de fiabilidad y relevancia.

\section{Ejercicio 7. Información comparable y restricción coste-beneficio}

Muchas empresas de tamaño reducido estiman que los requerimientos informativos contables son excesivos o muy complejos. En su opinión, hasta qué punto la comparabilidad de la información exigiría que todas las empresas, con independencia de su tamaño, tengan que cumplir las mismas normas contables.

\section{Ejercicio 8. Claridad de la información contable}

Reflexione sobre si el hecho de que pocas personas sean capaces de interpretar correctamente la información contable empresarial entra en contradicción con el requisito de que dicha información deba ser clara. 


\section{Ejercicio 9. Información contable y usuarios}

Utilice las noticias mostradas a continuación e identifique para cada una de ellas qué tipo de información contable han requerido los distintos usuarios y a qué conclusiones han llegado.

\section{A) USUARIO: LA PROPIA EMPRESA}

\begin{tabular}{|l|l|}
\hline B & $\begin{array}{l}\text { Cinco Días 23-07-2010 } \\
\text { Sabadell busca más oportunidades para crecer al confiar en su resistencia } \\
\text { Parece que la publicación de hoy de los test de estrés no inquieta a Banco Sabadell, que } \\
\text { presentó ayer sus resultados semestrales. Ganó } 233,6 \text { millones de euros, el } 29,6 \% \text { menos } \\
\text { que un año antes, tras destinar } 339 \text { millones de plusvalías a provisiones cautelares. Pese al } \\
\text { recorte del resultado, estar embarcado en una opa para adquirir Banco Guipuzcoano y haber } \\
\text { fracasado su oferta por Cajasur, el grupo busca otras oportunidades en España y EEUU. }\end{array}$ \\
\hline
\end{tabular}

\begin{tabular}{|l|l|}
\hline Información requerida: & \\
\hline Objetivo: & \\
\hline Conclusiones: & \\
\hline
\end{tabular}

\section{B) USUARIO: AGENCIAS DE CALIFICACIÓN (RATING)}

Cinco Días - Madrid - 23/07/2010
Fitch baja el rating de Caja Madrid por sus datos de mora
La agencia de calificación crediticia Fitch recortó ayer el rating a largo plazo de Caja Ma-
drid hasta A desde A+, y lo situó en perspectiva negativa, debido a la presión que soporta
la entidad por la caída de ingresos y el deterioro de su calidad crediticia.

\section{C) USUARIO: ANALISTAS DEL SECTOR}

\section{Expansion 25-01-2009, por Marc Menchén. Barcelona} ¿Puede el Barça alcanzar unos ingresos de $\mathbf{1 . 0 0 0}$ millones?

Los expertos señalan que alcanzar una cifra de negocio de 1.000 millones, como aseguran Alfons Godall y Sandro Rosell, es muy complicado a medio plazo. Las vías de financiación del club tienen poco margen de crecimiento. 


\section{$\underline{\text { Palcos }}$}

Si en el ejercicio 2002-2003 el club ingresó 37,3 millones por la explotación del Camp Nou, la temporada anterior facturó 93,7 millones de euros por esta razón. Calzada señala que este espectacular aumento de la facturación, de un $151,21 \%$, se debe a que el club redujo el «excesivo» número de invitaciones, aumentó las modalidades de abono e hizo lo propio con los palcos VIP.

Gay apuesta por imitar a equipos como el Arsenal londinense o el Bayern de Munich, que han enfocado sus nuevos estadios más al sector empresarial y de servicios. En España, el Real Madrid, que ingresó 118 millones por este concepto la temporada pasada, es quien más ha trabajado en esta dirección.

El club podría rentabilizar aún más sus vallas publicitarias y los acuerdos adquiridos con patrocinadores como el operador de telecomunicaciones árabe Etisalat o la aerolínea Turkish Airlines. Estos contratos han permitido al Barça pasar de facturar 25,3 millones a 117,4 millones de euros en siete años, un 364\% más.

\begin{tabular}{|l|l|}
\hline Información requerida: & \\
\hline Objetivo: & \\
\hline Conclusiones: & \\
\hline
\end{tabular}

\section{D) USUARIO: POLICÍA Y ADMINISTRACIÓN DE JUSTICIA}

Según el listado de acreedores, al que hoy ha tenido acceso Efe, 22 entidades financieras acreedoras de Martinsa-Fadesa han logrado que se les reconozca una deuda mayor con la inmobiliaria, que en total debe 6.905 millones a todos los acreedores.

La mayor entidad acreedora de Martinsa-Fadesa, Caja Madrid, se benefició con un incremento de su deuda del 3,2\%, hasta 1.015,5 millones de euros, mientras que la segunda mayor acreedora, La Caixa, logró una mejora del 9,1\%, hasta 746,9 millones de euros.

Las entidades financieras acreedoras de Martinsa son fundamentales para sacar adelante el nuevo convenio de acreedores presentado ante el Juzgado de lo Mercantil número 1 de A Coruña para que la inmobiliaria supere el concurso voluntario de acreedores, previsiblemente a principios de 2011.

\begin{tabular}{|l|l|}
\hline Información requerida: & \\
\hline Objetivo: & \\
\hline Conclusiones: & \\
\hline
\end{tabular}

\section{E) USUARIO: POLICÍA Y ADMINISTRACIÓN DE JUSTICIA}

\begin{tabular}{|l}
\hline $\begin{array}{l}\text { Cinco Días, 17 Oct. } 2008 \\
\text { Microsoft Fast Search \& Transfer, acusada de fraude contable en Noruega }\end{array}$ \\
$\begin{array}{l}\text { La división de delitos económicos de la policía noruega, registró las oficinas de la com- } \\
\text { pañía Fast, propiedad de Microsoft, en busca de pruebas que sustenten los cargos por } \\
\text { contabilidad fraudulenta. }\end{array}$ \\
$\begin{array}{l}\text { Fast Search \& Transfer, la segunda compañía mundial en aplicaciones de búsqueda para empresas, fue } \\
\text { adquirida por Microsoft en febrero por 1.200 millones de dólares. }\end{array}$ \\
$\begin{array}{l}\text { Los cargos se relacionan con las cuentas desde antes de la entrada de la compañía de software. Microsoft } \\
\text { y Fast explicaron «no estar en condiciones de hacer declaraciones» aunque dijeron estar cooperando ple- } \\
\text { namente con la policía. }\end{array}$
\end{tabular}




\begin{tabular}{|l|l|}
\hline Información requerida: & \\
\hline Objetivo: & \\
\hline Conclusiones: & \\
\hline
\end{tabular}

\section{F) USUARIO: ANALISTAS DE INVERSIONES}

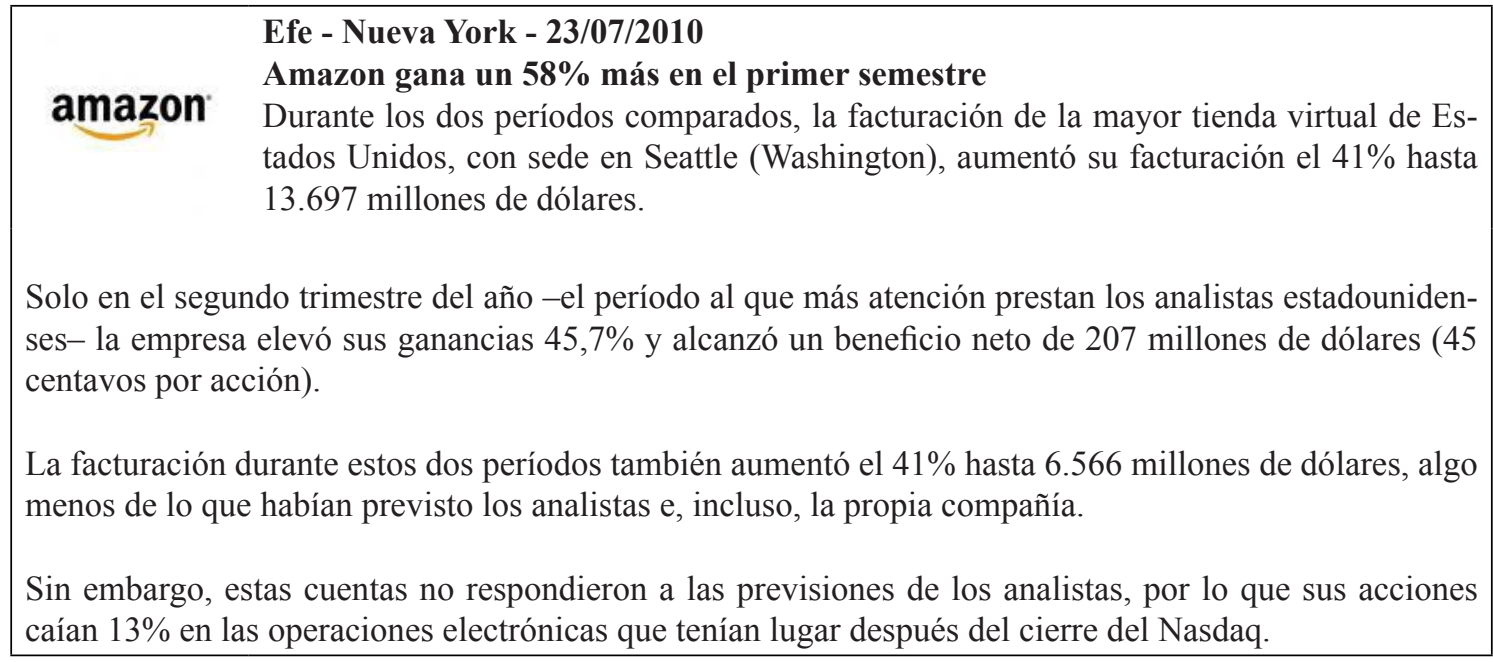

\begin{tabular}{|l|l|}
\hline Información requerida: & \\
\hline Objetivo: & \\
\hline Conclusiones: & \\
\hline
\end{tabular}

\section{G) USUARIO: ANALISTAS DE INVERSIONES}

Cinco Días, Fabrizio Simula - Madrid - 23/07/2010
Antena 3 se apunta a la tendencia alcista. Goldman Sachs eleva la recomendación
de neutral a comprar
Las empresas televisivas españolas llevan una buena racha en Bolsa. Antena 3 se apuntó
ayer una subida del $4,51 \%$, una de las mayores del parqué madrileño, y cerró en 5,79
euros. Aun así, el valor ha perdido un $25,58 \%$ en lo que va de año, sobre todo por las
fuertes bajadas de abril y mayo.




\begin{tabular}{|l|l|}
\hline Información requerida: & \\
\hline Objetivo: & \\
\hline Conclusiones: & \\
\hline
\end{tabular}

\section{H)USUARIO: ORGANISMOS PÚBLICOS (BANCO DE ESPAÑA, CNMV, HACIENDA)}

\begin{tabular}{|l|}
\hline $\begin{array}{l}\text { EI País, 31/03/2009 } \\
\text { Los administradores del Banco de España estudian las cuentas de Caja Castilla La } \\
\text { Mancha } \\
\text { Los tres administradores nombrados por el Banco de España (Jorge Diaz Cerdá, Carlos } \\
\text { Miguel Hervás y Raúl Hernández) comunicaron ayer el cese a todos los consejeros y co- } \\
\text { menzaron a analizar la situación con el director general y su adjunto. }\end{array}$ \\
$\begin{array}{l}\text { El Banco de España tiene muchos datos sobre cCM porque, además del control rutinario, realizó un infor- } \\
\text { me de inspección para su fusión. Además, la consultora Pricewaterhouse-Coopers sigue ultimando el es- } \\
\text { tudio encargado por Unicaja, que cifra en } 3.000 \text { millones las necesidades de recursos de cCM. Esta partida } \\
\text { se desglosa en la falta de liquidez y de capital para cubrir pérdidas latentes. cCM ya ha agotado el recurso } \\
\text { permitido a la liquidez del Banco de España, ya que pidió } 900 \text { millones. }\end{array}$ \\
\hline
\end{tabular}

\begin{tabular}{|l|l|}
\hline Información requerida: & \\
\hline Objetivo: & \\
\hline Conclusiones: & \\
\hline
\end{tabular}

\section{I) USUARIO: ORGANISMOS PÚBLICOS (HACIENDA)}

Efe, 29/07/2008
La juez nombra a dos inspectores de Hacienda para analizar las cuentas del Betis
Mientras no se para de hablar de la posible venta del paquete accionarial de Manuel Ruiz
de Lopera, la juez que instruye la denuncia de la Fiscalía contra el máximo mandatario
del Real Betis por un presunto delito societario en la gestión del club, ha nombrado a dos
inspectores de Hacienda para analizar las cuentas, en lugar de la empresa auditora que
inicialmente había pedido a la Junta.

La Fiscalía imputó a Lopera un delito societario por «descapitalizar» el Betis «en beneficio propio o de terceros».

El juzgado de instrucción 6 solicitó a la Consejería de Justicia nombrar una empresa privada de auditoría para analizar la «situación económica, financiera y patrimonial» del Betis. Ahora, la juez considera suficiente el trabajo de los inspectores de Hacienda.

El fiscal dice que conforme a los últimos estados de cuentas aprobados en los ejercicios económicos 200405 y 2005-06, el Betis «tiene pérdidas de más de 11 millones de euros.

\begin{tabular}{|l|l|}
\hline Información requerida: & \\
\hline Objetivo: & \\
\hline Conclusiones: & \\
\hline
\end{tabular}




\section{J) USUARIO DE LA INFORMACIÓN CONTABLE: POTENCIALES INVERSORES}

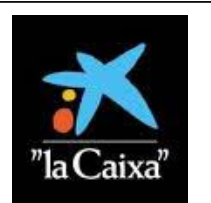

Expansión 05/07/2010

La Caixa, ACs y CvC estudian una OPA sobre Abertis por 12.000 millones.

La CNMv ha suspendido la cotización de Abertis cuando sus acciones se disparaban un $12,16 \%$, hasta 13,555 euros. Sus dos principales accionistas, ACs y La Caixa, y CVC, preparan una oferta para alcanzar el $100 \%$ de su capital.

Desde ACS y Criteria han confirmado la posible OPA al reconocer que mantienen «conversaciones» con el fondo de capital riesgo CVC, «para explorar su entrada en el accionariado de Abertis»

Según fuentes financieras, la operación se realizaría mediante la formulación de una OPA valorada en unos 12.000 millones de euros, una cantidad que se elevaría a 25.000 millones si se incluye la deuda de la compañía. En el momento de la suspensión, la capitalización bursátil de Abertis ascendía a 10.017,66 millones de euros.

No obstante, ACS ha señalado que no puede determinarse «la valoración de Abertis al indicado efecto ni, por tanto, los rangos de valor empresa que se mencionan en las noticias» sobre la posible OPA.

La Caixa, ACS y CVC financiarían la operación mediante préstamos y, tras alcanzar el 100\% de Abertis, reestructurarían el capital del grupo. Según ha podido saber Expansión.com, apuntan que el banco italiano Mediobanca, asesor de la operación, ya ha comenzado a trabajar en la concesión de un préstamo por 8.000 millones de euros.

Florentino Pérez lleva más de un año buscando comprador para la participación que ACs tiene en Abertis. La concesionaria gala Vinci es una de las compañías que han mostrado su interés.

Con los beneficios obtenidos de esta desinversión, Florentino Pérez reforzaría su presencia en el capital de Iberdrola, donde tiene una participación del 12\%. El presidente de ACs quiere aumentar su porcentaje hasta el $20 \%$

De momento Iberdrola ha frenado las pretensiones de Florentino Pérez de hacerse con un sillón en el consejo de Iberdrola. El presidente de la eléctrica, Ignacio Sánchez Galán, ha mostrado sus reticencias desde el principio argumentando, entre otras cosas, que ACS es un competidor directo en el negocio eléctrico y en el de infraestructuras.

\begin{tabular}{|l|l|}
\hline Información requerida: & \\
\hline Objetivo: & \\
\hline Conclusiones: & \\
\hline
\end{tabular}




\section{Casos}

Caso 1. Busque en la prensa económica (Expansión, Cinco Días, El economista u otros), o en las páginas de economía de periódicos generalistas cinco noticias con información contable de empresas. Indique qué usuarios han hecho uso de la información contable y qué utilidad puede tener para ellos.

Caso 2. Busque en las páginas de anuncios de la prensa económica o de periódicos generalistas anuncios de ofertas de empleo en las que se precisen conocimientos de contabilidad (las ediciones dominicales suelen tener suplementos dedicados a la empresa en los que aparecen en mayor cantidad). Relacione los conocimientos solicitados por las empresas con las asignaturas de contabilidad presentes en los planes de estudio de grado. 


\section{TEMA 2}

\section{El patrimonio \\ y los resultados}

\section{INTRODUCCIÓN}

En este tema se define el patrimonio y se estudian los elementos que lo integran. Se define la ecuación fundamental del patrimonio que constituye la base de la representación contable y se utiliza ésta para analizar transacciones empresariales y las variaciones en el patrimonio. Finalmente se mostrarán algunos de los informes contables que integran las cuentas anuales.

\section{CONTENIDO}

2.1. El patrimonio de la empresa

2.2. Las masas patrimoniales, activo, pasivo y patrimonio neto

2.3. El balance

2.4. Cambios en el patrimonio neto: ingresos y gastos

2.5. La cuenta de pérdidas y ganancias

2.6. La ecuación contable y las transacciones empresariales 


\subsection{El patrimonio de la empresa}

El concepto de patrimonio tiene dos acepciones: una económica y otra contable.

- Concepto contable: Es la diferencia entre los bienes y derechos de una entidad y sus deudas u obligaciones. El patrimonio, por lo tanto, sería estrictamente la diferencia de valor entre dichos elementos, el «patrimonio neto».

Este concepto está relacionado con la teoría del propietario. A este lo que le interesa es conocer el valor y variaciones del patrimonio de una propiedad suya, que es la propia empresa, y por lo tanto la diferencia entre el valor de los bienes y derechos y las obligaciones que recaen sobre la misma. Podríamos decir que se considera que los bienes y derechos son del propietario y las deudas también son del mismo, la diferencia entre ambas es el patrimonio neto de la empresa y del propietario.

Según esta concepción el patrimonio sería el área más oscura de la ilustración siguiente.

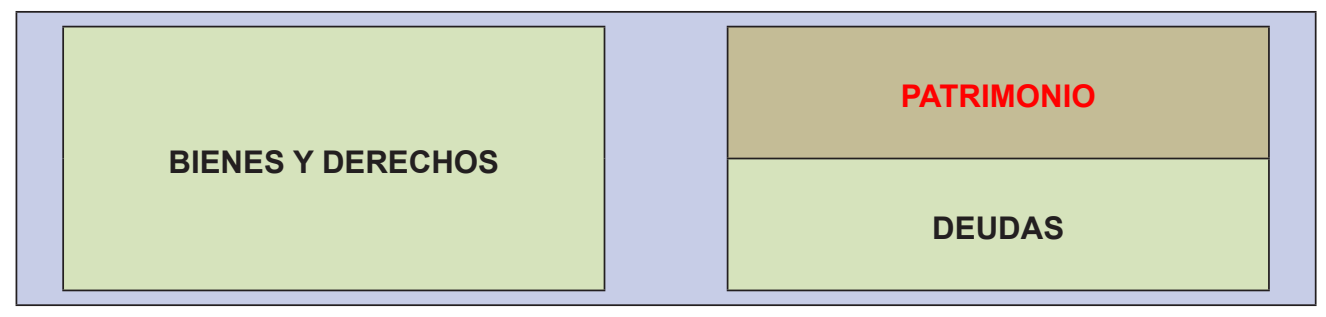

Ilustración 2.1. Concepto contable de patrimonio

- Concepto económico: Conjunto de bienes y derechos frente a los que se encuentran unas fuentes de financiación o recursos financieros. El patrimonio es el conjunto de todos estos elementos.

Este concepto está relacionado con la teoría de la entidad según la cual una empresa es algo independiente de sus propietarios. Los propietarios junto a los acreedores aportan fondos, recursos financieros, a la empresa que son invertidos en los bienes o derechos.

Estos bienes o derechos son propiedad de la empresa, la cual ha obtenido su financiación de dos fuentes: propias (propietarios) y ajenas (terceros acreedores). Como unidad independiente, el patrimonio de la empresa se ve como el conjunto de bienes y derechos y el conjunto de fuentes de financiación.

Las fuentes de financiación ajenas constituyen las deudas de la empresa, mientras que las fuentes de financiación propias también reciben la denominación de «patrimonio neto», que es la diferencia entre el valor de los bienes y derechos y las deudas de la empresa. 
Según esta concepción el patrimonio podría representarse de la siguiente forma:

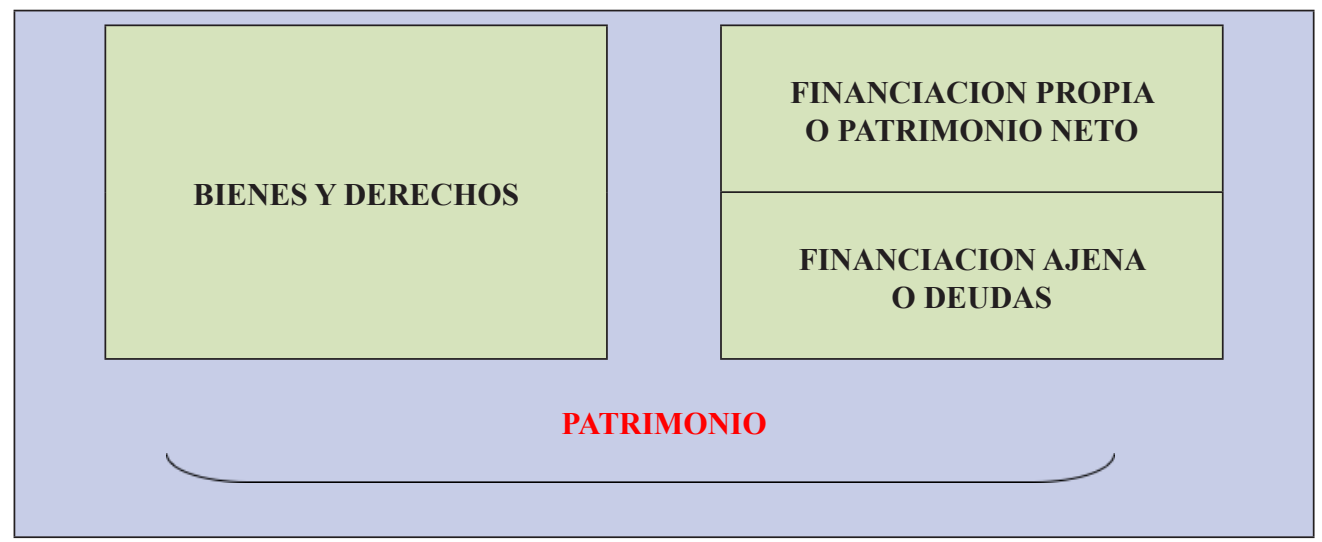

Ilustración 2.2. Concepto económico de patrimonio

En definitiva, según la teoría de la entidad, el patrimonio de una empresa está formado por:

- Un conjunto de bienes y derechos, que se denominan contablemente activos, que representan las inversiones realizadas por la empresa en el desarrollo de su actividad, cuya posesión ha sido posible debido a la disposición de unos recursos financieros.

- Unos recursos financieros con los que ha adquirido los bienes. Entre ellos se distinguen aquellos que representan obligaciones o deudas, denominados contablemente pasivos, y aquellos que representan el interés de los propietarios en la empresa y que en principio no deben reintegrarse, denominados contablemente patrimonio neto. Este patrimonio neto coincidiría con el concepto contable, más restrictivo, de patrimonio.

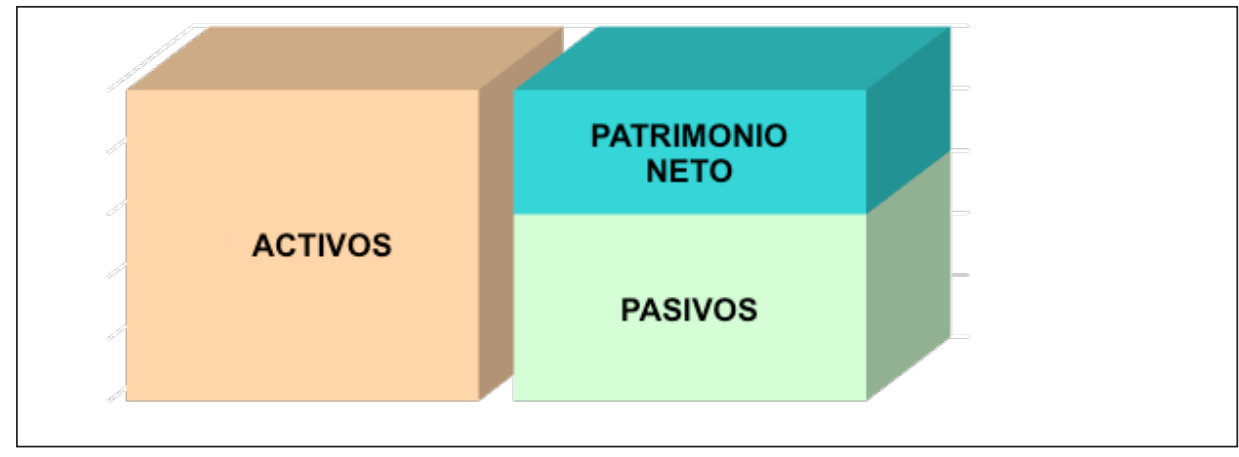

Ilustración 2.3. El patrimonio de una entidad contable

Por tanto, una empresa obtiene los recursos necesarios para invertir en activos de dos fuentes fundamentales, bien de sus propietarios, bien de sus acreedores. Así:

- Los propietarios aportan fondos a la empresa de dos formas: bien directamente entregando dinero efectivo o bienes que constituyen activos, o bien 
indirectamente permitiendo que la empresa retenga los beneficios que obtiene de su actividad o los incrementos netos en el valor de sus activos, en lugar de reclamarlos para su uso como propietario de los mismos. El conjunto de estos fondos constituye el patrimonio neto.

- Determinados acreedores prestan o entregan fondos (dinero efectivo) u otros activos (otros bienes) a la empresa, por lo que la empresa deberá reintegrar en un futuro el importe o valor de los mismos. Mientras no sean reintegrados los fondos prestados o satisfechas las deudas generadas por la entrega de los bienes, el valor de los mismos constituirán pasivos.

En la siguiente ilustración se incluyen algunas denominaciones frecuentemente utilizadas para referirse al patrimonio económico de una entidad contable.

\begin{tabular}{|c|c|c|}
\hline \multicolumn{2}{|c|}{ La dimensión económico-financiera del patrimonio } \\
\hline Activo & $=$ & Pasivo + Patrimonio neto \\
\hline Bienes y derechos & $=$ & Deudas + Patrimonio neto \\
\hline Estructura económica & $=$ & Estructura financiera \\
\hline Inversiones & $=$ & Fuentes de financiación \\
\hline Aplicación de fondos o recursos & $=$ & Origen de fondos o recursos \\
\hline
\end{tabular}

Ilustración 2.4. El patrimonio de una entidad contable

\subsection{Las masas patrimoniales, activo, pasivo y patrimonio neto}

En el patrimonio de una unidad económica se pueden identificar tres tipos de elementos patrimoniales: activos, pasivos y elementos de patrimonio neto.

\section{Activos}

El activo o los activos son el conjunto de bienes, derechos y otros recursos controlados económicamente por la empresa con los que esta desarrolla su actividad económica. Los activos provienen de transacciones o acontecimientos pasados y pueden ser propiedad de la empresa o simplemente ser controlados por la misma. Además se requiere que tengan la capacidad de producir futuros beneficios. 

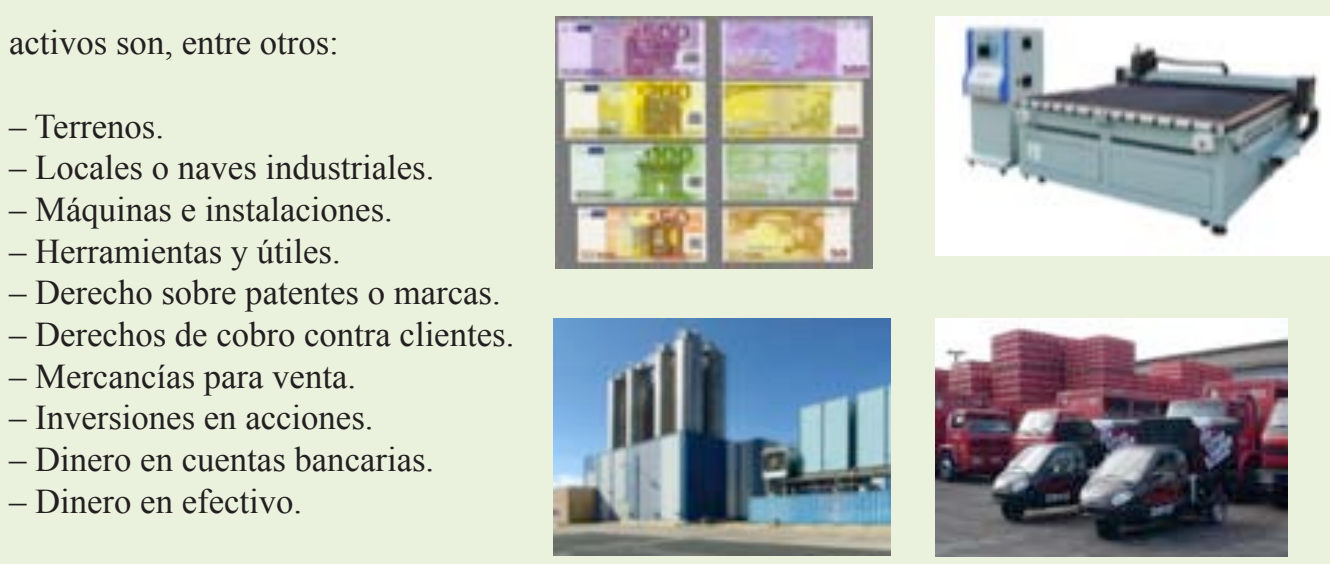

Ilustración 2.5. Ejemplos de activos empresariales

De esta definición se deduce que los activos deben provenir de acontecimientos pasados, luego no se considerarán activos aquellos bienes o derechos que puedan pasar a ser propiedad de la empresa o ser controlados por la misma como consecuencia de sucesos futuros por más probable que sea su realización.

\section{Ejemplo 2.1. Los activos provienen de acontecimientos pasados}

Un terreno adquirido el 1 de abril de 2000 por la empresa CONSTRUCTORA SA es un activo de la misma puesto que proviene de un hecho pasado, la compra.

Sin embargo, si la empresa tiene firmado un contrato para la compra futura de un terreno, dicho terreno no es un activo de empresa puesto que, aunque será muy probable la compra, esta todavía no se ha realizado y constituye un suceso futuro (sin perjuicio de que el contrato en sí pueda ser un activo como derecho a favor de la empresa que es).

No es necesaria la propiedad del elemento, sino que es suficiente el control sobre el mismo, ya que en ambos casos (propiedad o control) la entidad se garantiza la recepción de futuros beneficios. Así, el simple control o derecho de uso de un bien podría dar lugar a un activo, ya que de él se derivaría un futuro beneficio en los mismos términos que el anterior.

Ejemplo 2.2. Son activos bienes o derechos controlados aunque no sean propiedad de la empresa La empresa APPLE ha pagado $1.000 .000 €$ al objeto de poder utilizar durante 10 años una patente propiedad de ADOBE en sus productos informáticos.

En este caso el propietario de la patente sigue siendo ADOBE, pero APPLE tiene el derecho al uso de la misma durante un período de tiempo por lo que puede reconocer la misma como un activo y por el importe pagado.

Por otra parte, la capacidad de producir futuros beneficios, no implica que estos sean seguros o perfectamente identificables.

\footnotetext{
Ejemplo 2.3. El beneficio futuro derivado de un activo no tiene por qué ser seguro ni identificable ni determinado en el tiempo

La empresa CONSTRUCTORA SA cree que podrá obtener beneficios futuros del terreno adquirido el 1 de abril de 2000, bien por su venta, bien al construir sobre él una promoción y vender las viviendas, bien por alquiler, etc. No obstante, no existe la certeza absoluta del beneficio por cuanto los precios de los terrenos podrían descender, y en el caso de generar beneficios tampoco ciertamente se sabe cuándo se producirán ni en qué cuantía.
} 


\section{Clasificación de activos}

En la siguiente ilustración se muestra un listado comentado de los activos más comunes, indicando su denominación más usual en contabilidad y su clasificación en masas patrimoniales (agrupaciones) de acuerdo al tiempo de permanencia en el patrimonio de la empresa y a su naturaleza.

\begin{tabular}{|c|c|}
\hline \multicolumn{2}{|c|}{$\begin{array}{l}\text { ACTIVOS NO CORRIENTES } \\
\text { - Elementos destinados a servir de forma duradera en las actividades de la empresa. Se incluyen las inver- } \\
\text { siones financieras con vencimiento superior a un año. } \\
\text { - En general, todos los activos no considerados corrientes. }\end{array}$} \\
\hline TIPO Y CONCEPTO & EJEMPLOS DE ACTIVOS \\
\hline $\begin{array}{l}\text { Inmovilizado intangible } \\
\text { Derechos susceptibles de valoración }\end{array}$ & $\begin{array}{l}\text { Concesiones. Concesiones administrativas. } \\
\text { Propiedad industrial. Derechos sobre una patente, marca, } \\
\text { nombre comercial. } \\
\text { Aplicaciones informáticas (software). }\end{array}$ \\
\hline $\begin{array}{l}\text { Inmovilizado material } \\
\text { Elementos tangibles, muebles o inmuebles }\end{array}$ & $\begin{array}{l}\text { Terrenos (usados en la actividad). } \\
\text { Construcciones (usados en la actividad). } \\
\text { Maquinaria } \\
\text { Instalaciones } \\
\text { Mobiliario } \\
\text { Equipos para procesos de información } \\
\text { Elementos de transporte }\end{array}$ \\
\hline $\begin{array}{l}\text { Inversiones Inmobiliarias } \\
\text { Inversiones inmobiliarias }\end{array}$ & $\begin{array}{l}\text { Inversiones en terrenos (no usados en la actividad de ex- } \\
\text { plotación). } \\
\text { Inversiones en construcciones (no usados en la actividad } \\
\text { de explotación). }\end{array}$ \\
\hline $\begin{array}{l}\text { Inversiones financieras a largo plazo } \\
\text { Inversiones a largo plazo, con vencimiento } \\
\text { superior a un año, cualesquiera que sea su } \\
\text { forma de instrumentación. }\end{array}$ & $\begin{array}{l}\text { Instrumentos de patrimonio. Acciones: títulos-valores re- } \\
\text { presentativos del capital de otra entidad. } \\
\text { Valores de deuda a largo plazo. Bonos, obligaciones, le- } \\
\text { tras del tesoro. } \\
\text { Créditos a largo plazo. Derechos de cobro por dinero pres- } \\
\text { tado a terceros. }\end{array}$ \\
\hline \multicolumn{2}{|c|}{$\begin{array}{l}\text { ACTIVOS CORRIENTES } \\
\text { - Activos que se espera vender o consumir en el ciclo normal de la explotación (en general menos de un año). } \\
\text { - Activos financieros con vencimiento inferior al año incluido el efectivo y otros medios líquidos equivalentes. }\end{array}$} \\
\hline TIPO Y CONCEPTO & EJEMPLOS DE ACTIVOS \\
\hline $\begin{array}{l}\text { Existencias } \\
\text { Activos para ser vendidos en el curso normal } \\
\text { de la explotación, consumidos en el proceso } \\
\text { de producción, o en la prestación de servicios. }\end{array}$ & $\begin{array}{l}\text { Mercaderías comerciales (para venta sin transformación). } \\
\text { Otros aprovisionamientos (combustibles, repuestos, ma- } \\
\text { terial de oficina, etc.). }\end{array}$ \\
\hline $\begin{array}{l}\text { Deudores comerciales y otras cuentas a } \\
\text { cobrar } \\
\text { Créditos (derechos de cobro) contra terceros } \\
\text { por operaciones comerciales. }\end{array}$ & $\begin{array}{l}\text { Clientes. Créditos con compradores de existencias así } \\
\text { como usuarios de los servicios prestados por la empresa } \\
\text { cuando estas sean actividades principales. } \\
\text { Deudores. Créditos con compradores de servicios que no } \\
\text { tenga la condición estricta de clientes. } \\
\text { Hacienda Pública deudora (por devolución de impuestos). }\end{array}$ \\
\hline $\begin{array}{l}\text { Inversiones financieras a corto plazo } \\
\text { Inversiones a corto plazo, con vencimiento } \\
\text { inferior a un año, cualesquiera que sea su for- } \\
\text { ma de instrumentación. }\end{array}$ & $\begin{array}{l}\text { Instrumentos de patrimonio. Acciones: títulos-valores re- } \\
\text { presentativos del capital de otra entidad. } \\
\text { Valores de deuda a corto plazo. Bonos, obligaciones, le- } \\
\text { tras del tesoro. } \\
\text { Créditos a corto plazo. Derechos de cobro por dinero pres- } \\
\text { tado a terceros. } \\
\text { Intereses a cobrar a corto plazo. Derechos de cobro por } \\
\text { intereses de inversiones financieras. }\end{array}$ \\
\hline $\begin{array}{l}\text { Efectivo } \\
\text { Dinero efectivo en caja o cuentas bancarias o } \\
\text { medios equivalentes }\end{array}$ & $\begin{array}{l}\text { Caja } \\
\text { Bancos, cuentas corrientes. }\end{array}$ \\
\hline
\end{tabular}

Ilustración 2.6. Clasificación de activos 


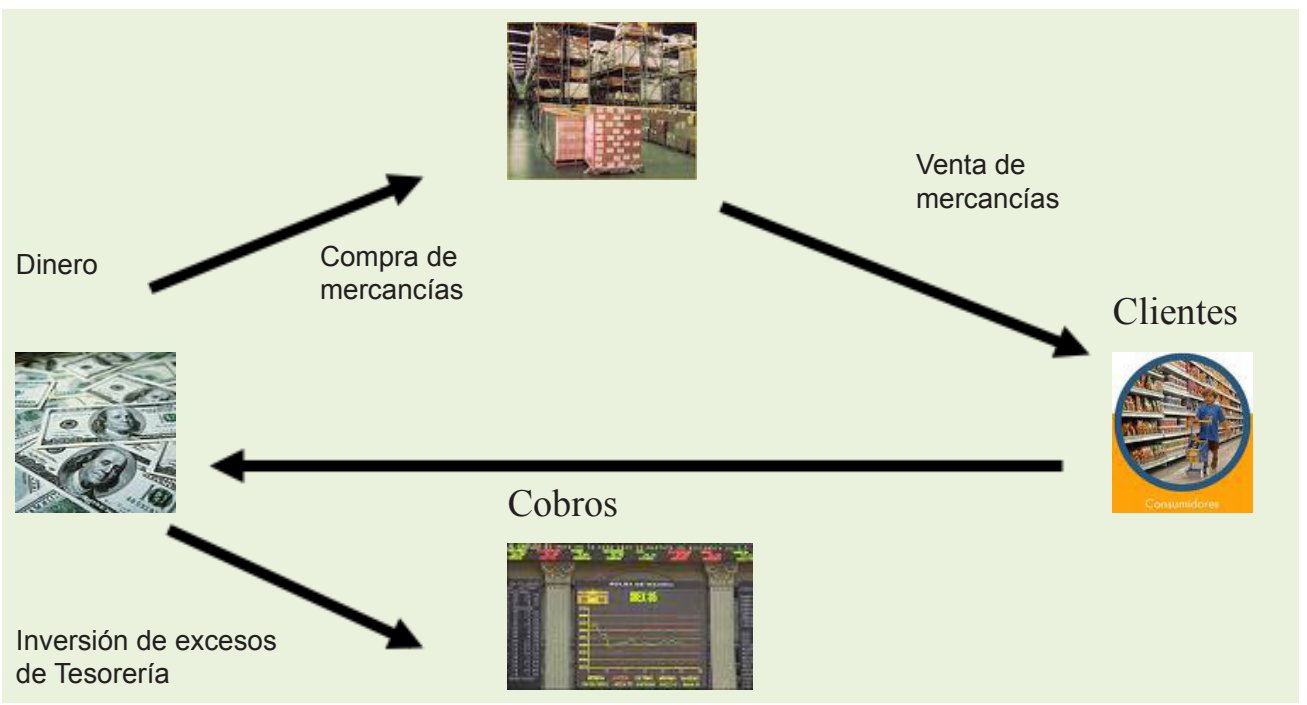

Ilustración 2.7. Clasificación de activos. La circulación del activo corriente

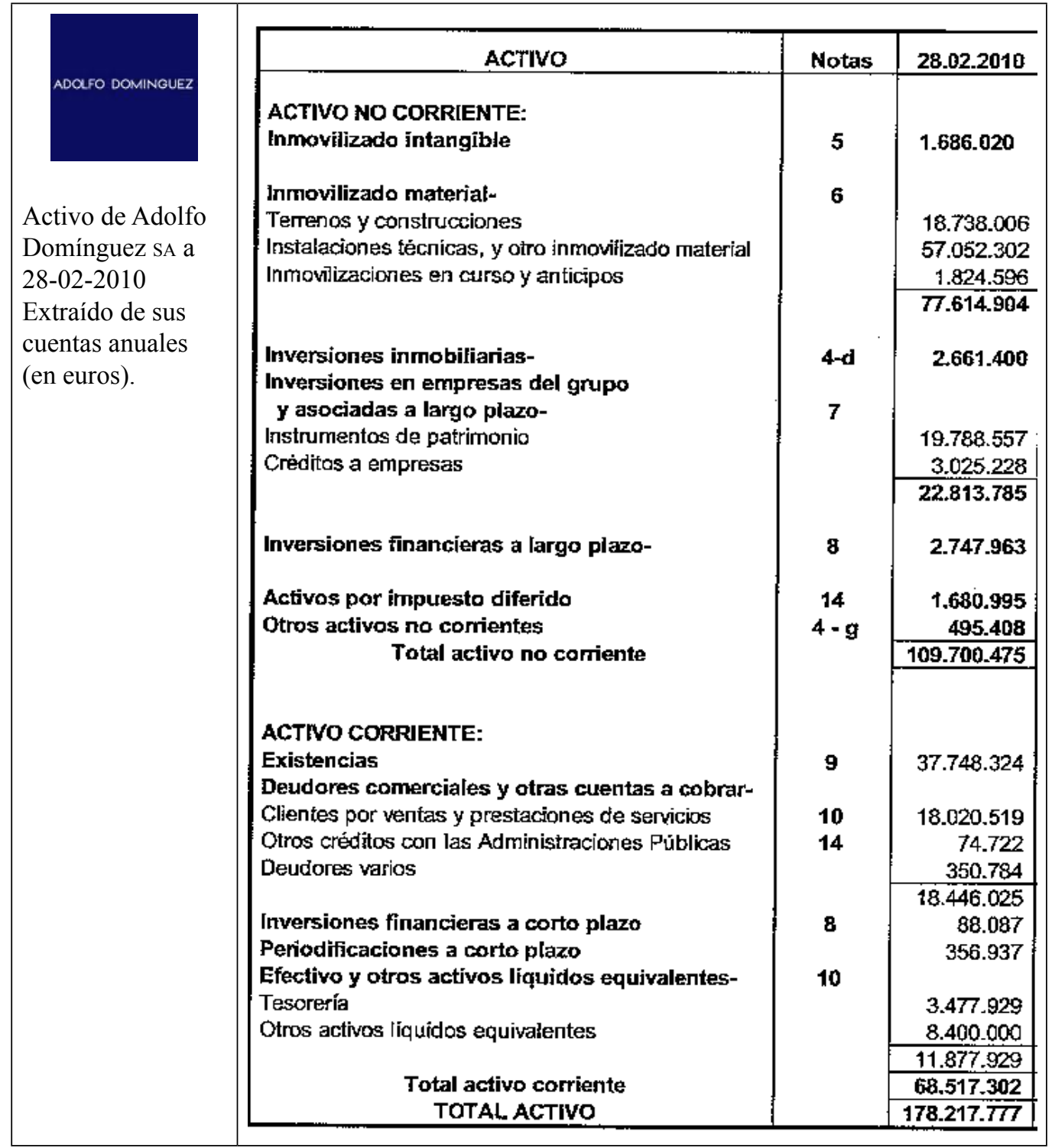

Ilustración 2.8. Activo de Adolfo Domínguez a 28-02-2010 


\section{Pasivos}

El pasivo o los pasivos son obligaciones actuales, deudas, en que la empresa incurre en el ejercicio de su actividad. Estas derivan de cualquier transacción o hecho pasado que genere una segura o posible deuda que en un futuro puedan originar la entrega de activos para su cancelación. Habitualmente las deudas provienen de adquisiciones de bienes y servicios, aunque pueden tener otros orígenes.

\section{Ejemplo 2.4. Los pasivos provienen de hechos pasados}

Cuando la empresa CONSTRUCTORA SA contrata a un empleado no surge ningún pasivo, por cuanto en dicha fecha el trabajador no ha prestado aún ningún servicio y no existe ninguna obligación de pago al mismo. Las futuras obligaciones de pago de salario no constituyen pasivo alguno porque los servicios del empleado son hechos futuros.

No obstante, conforme pasa el tiempo y el trabajador desarrolla su actividad para la empresa se genera una obligación, un pasivo. Este pasivo deriva de hechos pasados, el trabajo que ha realizado el empleado.

Pasivos son, entre otros:

- Préstamos bancarios.

- Deudas con proveedores de mercancías.

- Deudas por suministros (agua, electricidad, etc.).

- Deudas con Hacienda por impuestos.

- Deudas con la Seguridad Social.

- Deudas con los trabajadores.

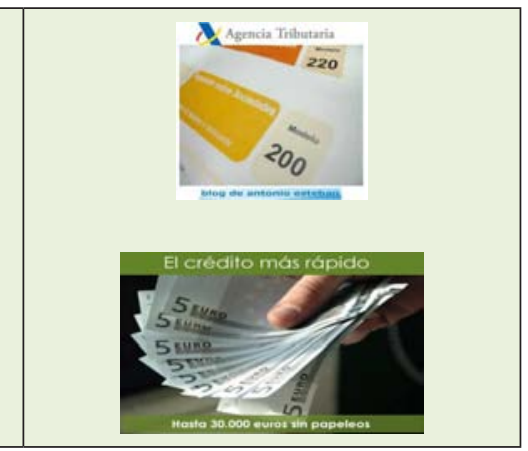

Ilustración 2.9. Ejemplo de pasivos empresariales

\section{Ejemplo 2.5. Cancelación de pasivos}

Cuando la empresa CONSTRUCTORA SA adquirió el terreno el 1 de abril de 2000 el precio de compra pactado fue de $50.000 € \mathrm{y}$ las condiciones de pago fueron: $20.000 €$ en efectivo en el momento de la compra y $30.000 €$ a pagar en el plazo de seis meses. Esta obligación de pago de $30.000 €$ que asume la empresa el 1 de abril de 2001 constituye un pasivo para la misma, que solo desaparecerá cuando haga efectivo el pago (entregue activos) a la fecha de vencimiento del mismo.

También son pasivos aquellas deudas de la empresa claramente identificadas en su naturaleza pero que están indeterminadas en cuanto a su importe o fecha de cancelación, siempre que sea probable que a su vencimiento deban entregarse activos.

\section{Ejemplo 2.6. Pasivos indeterminados en importe y fecha de ocurrencia}

En el convenio colectivo de la empresa CONSTRUCTORA SA (el convenio rige las relaciones empresa-trabajadores y fija los derechos y obligaciones de unos y otra) figura la obligación de la empresa de pagar una pensión de jubilación a sus empleados cuando esta se produzca. En este caso la empresa sabe que tendrá dicha obligación, pero no sabe cuándo se producirá ni el importe de la pensión que estará obligada a satisfacer. No obstante, dicha obligación constituye un pasivo y su importe tendrá que ser estimado por la empresa con la información que tenga disponible. 


\section{Clasificación de pasivos}

En la siguiente ilustración se muestra un listado comentado de los pasivos más comunes, indicando la denominación más usual en contabilidad y su clasificación en masas patrimoniales (agrupaciones) de acuerdo al tiempo de permanencia en el patrimonio de la empresa y a su naturaleza.

\section{PASIVOS NO CORRIENTES}

- Todos los pasivos no considerados corrientes.

- Obligaciones de la empresa con vencimiento o extinción superior a un año.

\begin{tabular}{|l|l|}
\hline \multicolumn{1}{|c|}{ TIPO Y CONCEPTO } & \multicolumn{1}{c|}{ EJEMPLOS DE PASIVOS } \\
\hline $\begin{array}{l}\text { Deudas a largo plazo } \\
\begin{array}{l}\text { Deudas u obligaciones con vencimiento } \\
\text { superior a un año. }\end{array}\end{array}$ & $\begin{array}{l}\text { Deudas con entidades de crédito. Préstamos a largo plazo. } \\
\text { Deudas a largo plazo. Otras deudas a largo plazo. } \\
\text { Proveedores de inmovilizado a largo plazo }\end{array}$ \\
\hline
\end{tabular}

\section{PASIVOS CORRIENTES}

- Pasivos que se espera liquidar (pagar) en el ciclo normal de la explotación (si no es identificable en menos de un año).

- Obligaciones con vencimiento o extinción en menos de un año.

\begin{tabular}{|l|l|}
\hline \multicolumn{1}{|c|}{ TIPO Y CONCEPTO } & \multicolumn{1}{c|}{ EJEMPLOS DE PASIVOS } \\
\hline $\begin{array}{l}\text { Deudas a corto plazo } \\
\text { Deudas u obligaciones con vencimiento } \\
\text { inferior a un año. }\end{array}$ & $\begin{array}{l}\text { Deudas con entidades de crédito. Préstamos a corto plazo. } \\
\text { Deudas a corto plazo. Otras deudas a corto plazo. } \\
\text { Proveedores de inmovilizado a corto plazo } \\
\text { Intereses a pagar a corto plazo. Deudas por intereses. }\end{array}$ \\
\hline $\begin{array}{l}\text { Acreedores comerciales y otras cuentas } \\
\text { a pagar } \\
\begin{array}{l}\text { Débitos (obligaciones de pago) a favor de } \\
\text { terceros por operaciones comerciales. }\end{array}\end{array}$ & $\begin{array}{l}\text { Proveedores. Deudas con suministradores de existencias. } \\
\text { Acreedores varios. Deudas con suministradores de servicios } \\
\text { que no tenga la condición estricta de proveedores. } \\
\text { Remuneraciones pendientes de pago. Deudas con el personal } \\
\text { por sueldos y otros conceptos. } \\
\text { Hacienda Pública Acreedora. Deudas por impuestos, tasas, etc.). } \\
\text { Seguridad Social Acreedora. Deudas por cuotas sociales a } \\
\text { cargo de la empresa. }\end{array}$ \\
\hline
\end{tabular}

Ilustración 2.10. Clasificación de pasivos

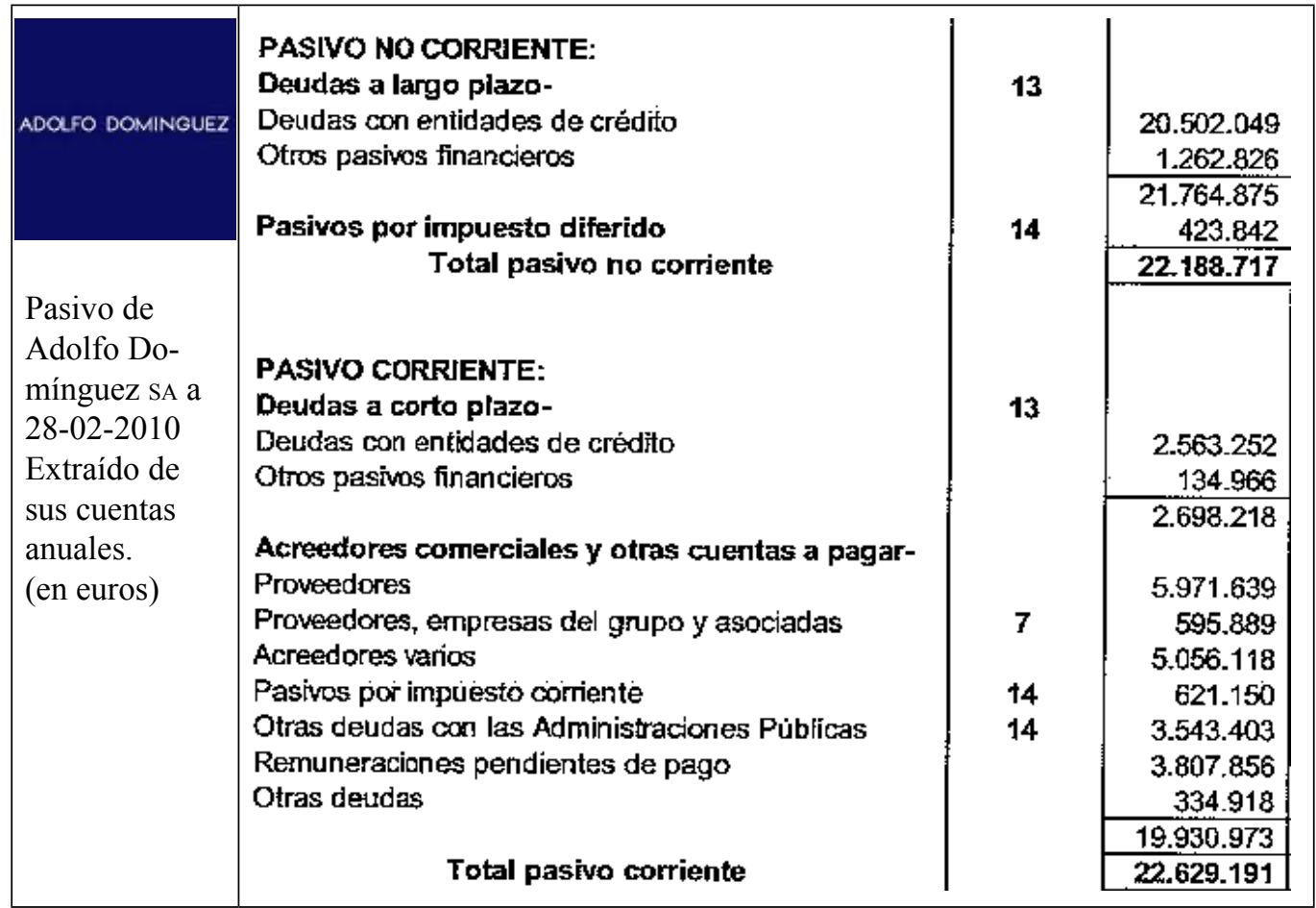

Ilustración 2.11. Pasivo de Adolfo Domínguez a 28-02-2010 


\section{Patrimonio neto}

El patrimonio neto es la parte residual de los activos de la empresa una vez deducidos sus pasivos, es decir, es la diferencia entre el valor de sus activos y sus pasivos. Incluye las aportaciones realizadas por los propietarios en el momento de creación de la empresa o momentos posteriores así como los resultados acumulados y otras variaciones que le afecten.

\section{Ejemplo 2.7. El patrimonio neto como parte residual de activos y pasivos}

La empresa CONSTRUCTORA SA ha procedido el 15 de junio de 2000 a valorar contablemente todos sus activos y el importe resultante es de $100.000 €$.

Asimismo ha procedido a valorar sus pasivos, ascendían en ese momento sus deudas a $60.000 €$. En consecuencia, el patrimonio neto contable de la empresa es de $100.000-60.000=40.000 €$. Este es el valor contable del interés de los propietarios de la empresa.

Además determinó que esos $40.000 €$ tienen su origen en:

- las aportaciones iniciales de los propietarios por importe de $10.000 €$ hace tres años, y

- los beneficios que ha obtenido la empresa en dichos tres años por importe de $30.000 €$.

\section{Elementos de patrimonio neto}

En la siguiente ilustración se muestra un listado comentado de los elementos más comunes del patrimonio neto, indicando la denominación usual en contabilidad y su clasificación en masas patrimoniales (agrupaciones) de acuerdo a su naturaleza.

\section{FONDOS PROPIOS}

- Aportaciones de socios, beneficios de la empresa retenidos o pendientes de distribución y otras partidas.

\begin{tabular}{|c|c|}
\hline TIPO Y CONCEPTO & ELEMENTOS DE PATRIMONIO NETO \\
\hline $\begin{array}{l}\text { Capital } \\
\text { Aportaciones de los socios en la creación de } \\
\text { la empresa o posteriormente. }\end{array}$ & $\begin{array}{l}\text { Capital social. Para SA y SL. } \\
\text { Capital. Para empresarios individuales. }\end{array}$ \\
\hline $\begin{array}{l}\text { Reservas } \\
\text { Beneficios de años anteriores retenidos por la } \\
\text { empresa (no distribuidos a los propietarios). }\end{array}$ & $\begin{array}{l}\text { Reservas legales. Beneficios retenidos por obli- } \\
\text { gación legal. } \\
\text { Reservas voluntarias. Beneficios retenidos vo- } \\
\text { luntariamente. }\end{array}$ \\
\hline $\begin{array}{l}\text { Resultados } \\
\text { Beneficios del período a que se refiere el in- } \\
\text { forme y de los que no se ha acordado su dis- } \\
\text { tribución. }\end{array}$ & Pérdidas y ganancias. \\
\hline \multicolumn{2}{|c|}{$\begin{array}{l}\text { SUBVENCIONES Y DONACIONES } \\
\text { - Fondos obtenidos por estos conceptos que no hay que reintegrar. }\end{array}$} \\
\hline TIPO Y CONCEPTO & $\begin{array}{l}\text { EJEMPLOS DE ELEMENTOS } \\
\text { DE PATRIMONIO NETO }\end{array}$ \\
\hline $\begin{array}{l}\text { Subvenciones } \\
\text { Subvenciones no reintegrables. }\end{array}$ & $\begin{array}{l}\text { Subvenciones de capital. Obtenidas para la fi- } \\
\text { nanciación de inversiones. }\end{array}$ \\
\hline
\end{tabular}

Ilustración 2.12. Elementos del patrimonio neto más comunes 


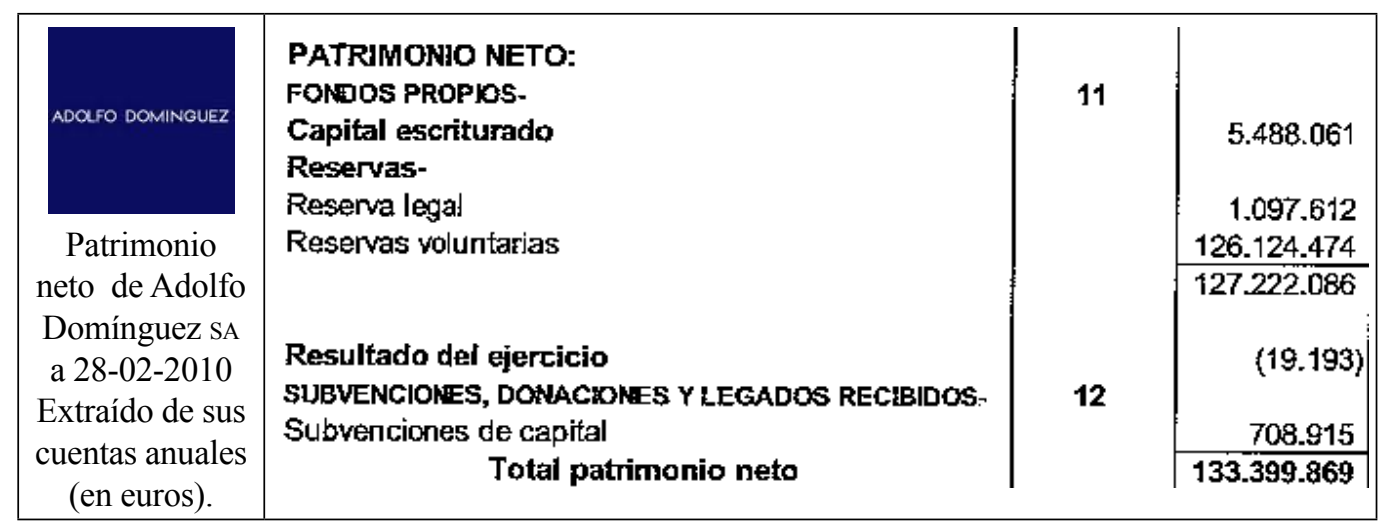

De esta información se deduce que a dicha fecha, 28-02-2010:

- Las aportaciones de los socios han ascendido a 5.488.061 € (capital).

- Desde su creación ha retenido beneficios por importe de 127.222.086 (reservas).

- El último año ha obtenido unas pérdidas de 19.193 (resultado).

- Ha obtenido subvenciones por importe de 708.915 (subvenciones).

Ilustración 2.13. Patrimonio neto de Adolfo Domínguez a 28-02-2010

\subsection{El balance}

Al informe contable que muestra el patrimonio de una empresa se denomina $b a$ lance, uno de los informes que forma parte de las cuentas anuales.

El balance, también denominado balance de situación, representa la situación patrimonial y financiera de una entidad en un momento determinado. El balance muestra los activos de una unidad económica y los pasivos que recaen sobre la misma, mostrando por diferencia entre ellos, el valor de su patrimonio neto.

Todo balance es como una fotografía de la situación patrimonial de una unidad económica en un momento dado, por lo que siempre deberá mostrarse a la fecha a la que dicho balance se refiere.

Los balances se presentan mostrando los activos, pasivos y patrimonio neto adecuadamente clasificados y ordenados en masas patrimoniales y con el desglose y detalle oportunos, de acuerdo a los formatos oficiales incluidos en la normativa contable. En España, las empresas que presentan las cuentas anuales de conformidad con el PGC presentan balances en los que los activos se ordenan de menor a mayor liquidez y los pasivos de menor a mayor exigibilidad. 


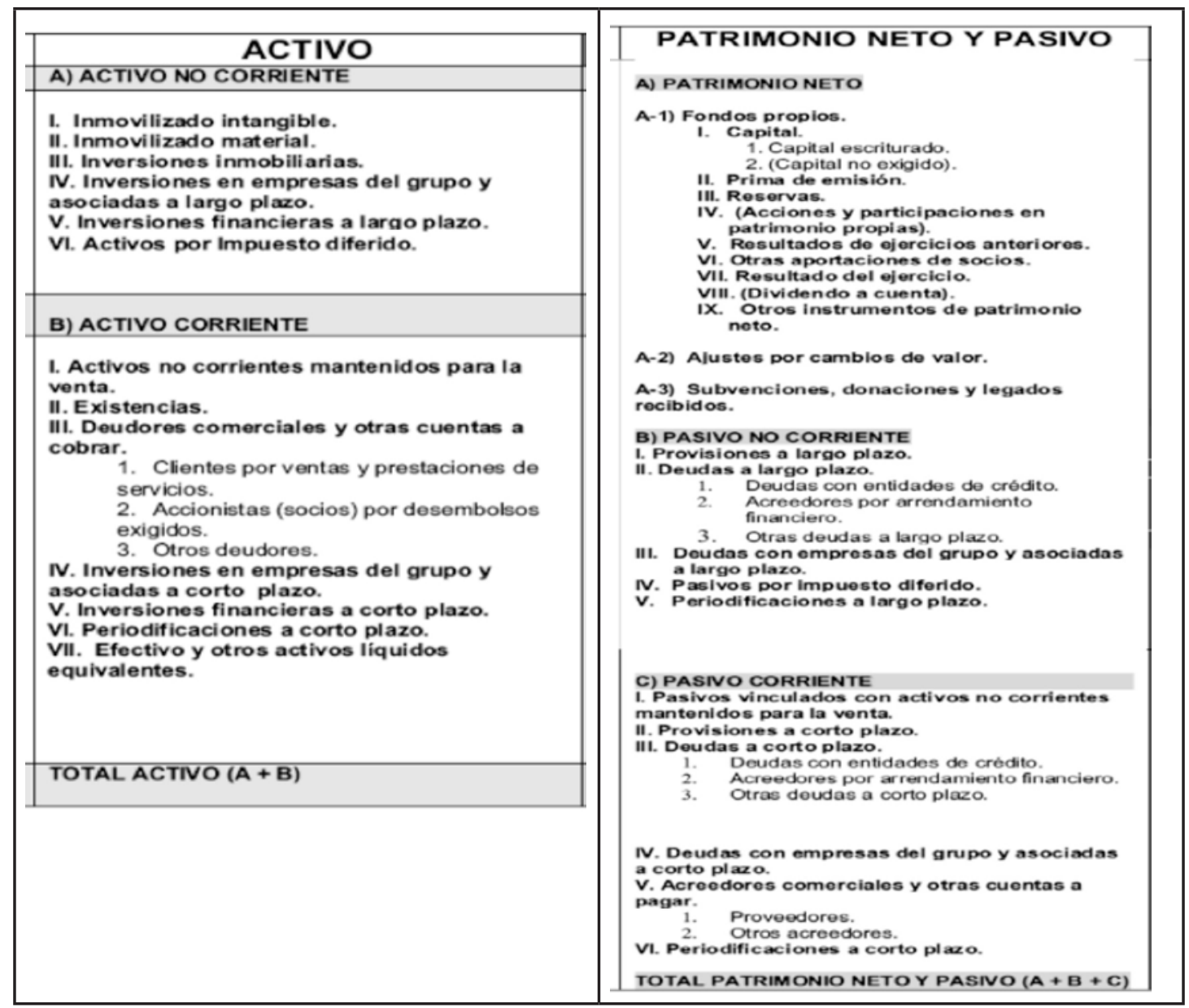

Ilustración 2.14. Formato oficial de balance abreviado recogido en el PGG

\section{Formato de balance utilizado en este texto}

En la siguiente ilustración se muestra la estructura del balance en el que se muestran las agrupaciones patrimoniales que se utilizarán a lo largo de este texto.

\begin{tabular}{|c|c|}
\hline \multicolumn{2}{|c|}{$\begin{array}{c}\text { EMPRESA X } \\
\text { Balance a 31-12-00 }\end{array}$} \\
\hline ACTIVO & PATRIMONIO NETO Y PASIV \\
\hline $\begin{array}{l}\text { A) ACTIVO NO CORRIENTE } \\
\text { I. Inmovilizado intangible. } \\
\text { II. Inmovilizado material. } \\
\text { III. Inversiones inmobiliarias. } \\
\text { V. Inversiones financieras a largo } \\
\text { plazo. }\end{array}$ & $\begin{array}{l}\text { A) PATRIMONIO NETO } \\
\text { A.1) Fondos propios } \\
\text { I. Capital. } \\
\text { III. Reservas. } \\
\text { VII. Pérdidas y ganancias. } \\
\text { A.3) Subvenciones }\end{array}$ \\
\hline $\begin{array}{l}\text { B) ACTIVO CORRIENTE } \\
\text { II. Existencias. }\end{array}$ & $\begin{array}{l}\text { B) PASIVO NO CORRIENTE } \\
\text { II. Deudas a largo plazo. }\end{array}$ \\
\hline $\begin{array}{l}\text { III. Deudores comerciales y cuentas } \\
\text { a cobrar. } \\
\text { V. Inversiones financieras a corto plazo. } \\
\text { VI. Periodificaciones a corto plazo. } \\
\text { VII. Efectivo. }\end{array}$ & $\begin{array}{l}\text { C) PASIVO CORRIENTE } \\
\text { III. Deudas a corto plazo. } \\
\text { V. Acreedores comerciales y cuentas } \\
\text { a pagar. } \\
\text { VI. Periodificaciones a corto plazo. }\end{array}$ \\
\hline TOTAL ACTIVO (A+B) & $\begin{array}{c}\text { TOTAL PATRIMONIO NETO } \\
\text { Y PASIVO }(\mathrm{A}+\mathrm{B}+\mathrm{C})\end{array}$ \\
\hline
\end{tabular}

Ilustración 2.15. Balance (se omiten algunas partidas del formato abreviado oficial del PGC) 


\section{Partidas del balance}

- ACTIVO. A.I), A.II), A.III) y B.II) Inmovilizado, inversiones inmobiliarias y existencias. Figurarán en los epígrafes correspondientes según su naturaleza.

- ACTIVO. B.III) Deudores comerciales y cuentas a cobrar. Créditos comerciales contra clientes y otros deudores (ver tema 4).

- ACTIVO. A.V) y B.V) Inversiones financieras a largo y corto plazo. Figurarán las inversiones en instrumentos de patrimonio (acciones y participaciones), valores representativos de deuda (obligaciones, bonos, etc.) y los créditos no comerciales: préstamos concedidos, aplazamientos de cobro de ventas de inmovilizado y otros figurarán según su vencimiento (ver tema 4).

- ACTIVO. A) y B). En los epígrafes correspondientes a los activos se situarán, si existen, y con signo negativo las amortizaciones acumuladas y deterioros de los mismos (ver tema 5).

- ACTIVO. B.VI) y PASIVO. C.VI) Periodificaciones a corto plazo de activo y pasivo. Figurarán respectivamente los gastos o ingresos contabilizados que corresponden a ejercicios futuros (ver tema 5).

- PATrimonio Neto. A.1.VII) Pérdidas y ganancias. El resultado del ejercicio se situará en los fondos propios con signo positivo (beneficio) o signo negativo (pérdida). Véase el apartado siguiente en este tema.

- PATRIMONiO NeTO. A.3) Subvenciones. En el epígrafe de subvenciones figuran principalmente aquellas de capital, destinadas a la financiación de activos fijos.

- PASIVO. B.II) y C.III) Deudas a corto y largo plazo. Deudas no comerciales, negociadas con terceros: préstamos obtenidos, aplazamientos de pago por compra de inmovilizado y otras deudas (ver tema 4).

- PASIVO. C.V) Acreedores comerciales y otras cuentas a pagar. Deudas con proveedores, acreedores por prestación de servicios, con empleados, con administraciones públicas por impuestos, con la Seguridad Social, etc. (ver tema 4).

En las ilustraciones $2.8,2.10$ y 2.13 se ha mostrado el activo, pasivo y patrimonio neto de Adolfo Domínguez a 28-02-2010, cuyo conjunto daría lugar al balance de dicha empresa, que se muestra a continuación. 
Balance (normal) de Adolfo Domínguez SA a 28-02-2010 extraído de sus cuentas anuales (en euros)

\begin{tabular}{|c|c|c|c|c|c|}
\hline ACTIVO & Notas & 28.02 .2010 & PATREMONIO NETO Y PASNO & Notas & 28.02 .2010 \\
\hline 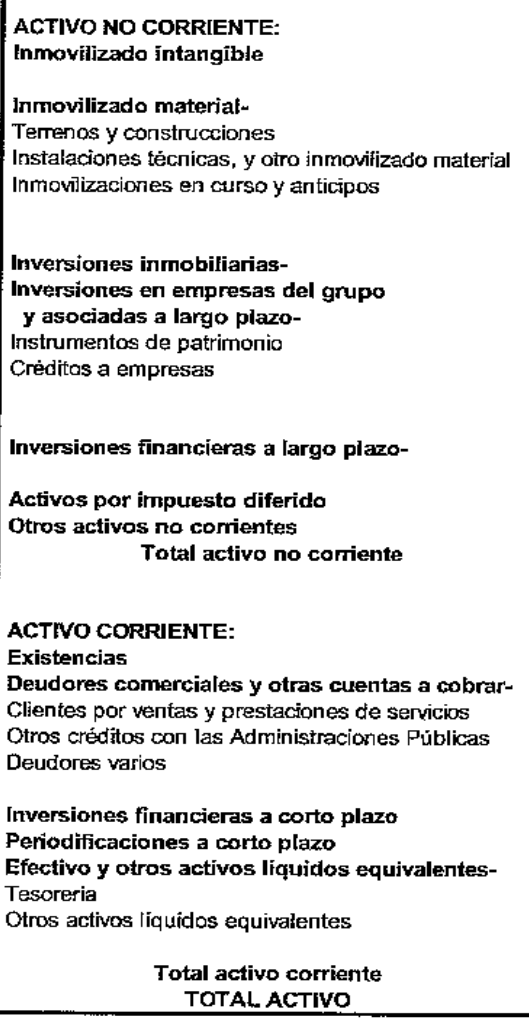 & $\begin{array}{c}8 \\
14 \\
4-g\end{array}$ & \begin{tabular}{|r|}
18.738 .006 \\
57.052 .302 \\
1.824 .596 \\
77.614 .904 \\
\\
2.661 .400 \\
\\
19.788 .557 \\
3.025 .228 \\
22.813 .785 \\
\\
2.747 .963 \\
\\
1.680 .995 \\
495.408 \\
109.700 .475 \\
\end{tabular} & 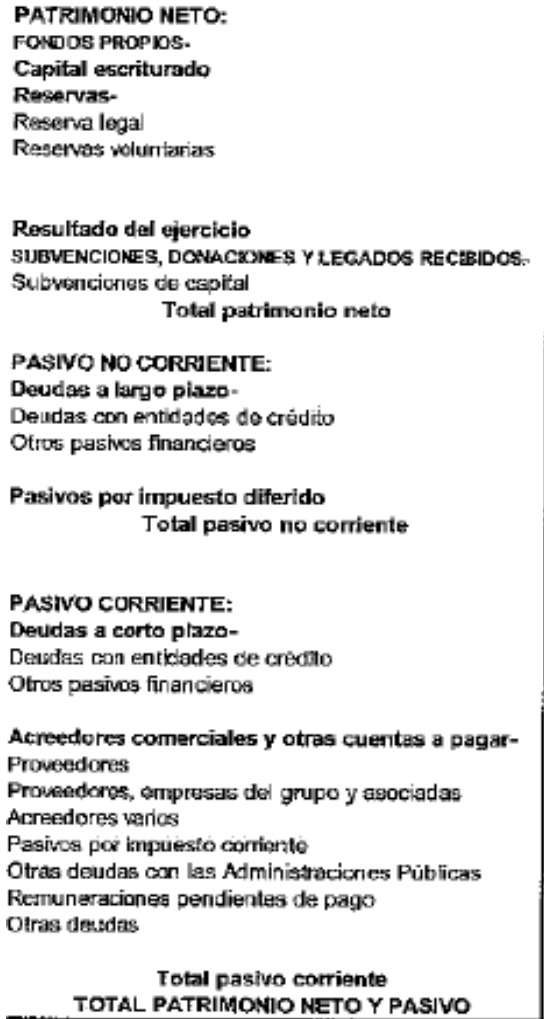 & $\begin{array}{c}7 \\
14 \\
14\end{array}$ & \begin{tabular}{|r|}
2.563 .252 \\
134.966 \\
2.698 .218 \\
\\
5.971 .639 \\
595.899 \\
5.056 .118 \\
621.150 \\
3.543 .403 \\
3.807 .856 \\
334.918 \\
19.936 .973 \\
22.629 .191 \\
178.217 .777 \\
\end{tabular} \\
\hline
\end{tabular}

Ilustración 2.16. Balance de Adolfo Domínguez a 28-02-2010

\subsection{Cambios en el patrimonio neto: ingresos y gastos}

Los cambios en el patrimonio neto de una entidad contable pueden deberse a tres motivos: (1) operaciones con los propietarios de la misma, (2) ingresos y (3) gastos.

\section{Operaciones con los propietarios de la entidad}

El patrimonio neto de una entidad puede aumentar por la aportación de recursos por parte de los propietarios, bien en forma de dinero o en forma de bienes, y puede disminuir por la retirada de recursos por parte de los mismos.

Ejemplo 2.8. Aportación de recursos de propietarios

Los propietarios de la empresa CONSTRUCTORA SA, al objeto de que la empresa pueda acometer nuevas inversiones deciden aportar a la misma, en concepto de capital social $300.000 €$. De este importe se aportan en efectivo $200.000 €$ y el resto, $100.000 €$, mediante la entrega de un terreno por dicho valor. 
Ejemplo 2.9. Retirada de recursos de propietarios

Debido a las elevadas ganancias obtenidas en períodos anteriores por la empresa CONSTRUCTORA SA, los propietarios deciden retirar $100.000 €$ de la misma. Para ello reparten en forma de dividendos parte de las reservas de la empresa.

\section{Ingresos}

Los ingresos son incrementos del patrimonio neto, distintos de las aportaciones de fondos a la entidad por parte de los propietarios, como consecuencia de las actividades económicas de venta de bienes o prestación de servicios o como consecuencia de las variaciones en el valor de activos y pasivos.

En todo caso, los ingresos se materializan en incrementos en el valor los activos o disminución en el valor de sus pasivos (o combinaciones de los dos).

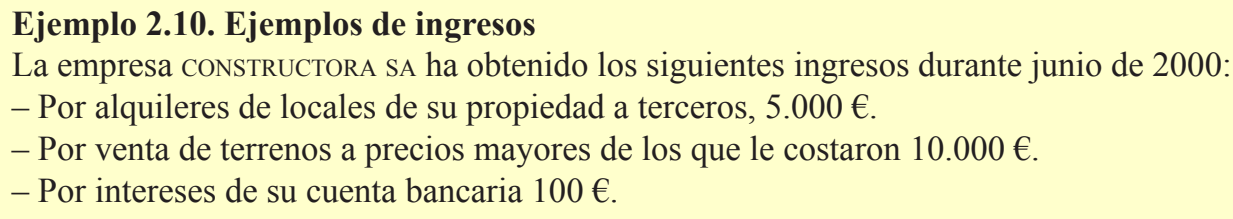

\section{Clasificación de ingresos}

En la siguiente ilustración se muestra un listado comentado de los ingresos más comunes, indicando la denominación usual utilizada en contabilidad y clasificándolos de acuerdo a su naturaleza.

\begin{tabular}{|l|l|}
\hline $\begin{array}{l}\text { DE EXPLOTACIÓN } \\
\text { Relacionados con las actividades habi- } \\
\text { tuales de la empresa y de sus activos y } \\
\text { pasivos no financieros. }\end{array}$ & $\begin{array}{l}\text { Ventas de mercaderías } \\
\text { Prestación de servicios } \\
\text { Otros ingresos de explotación: por comisiones, por } \\
\text { arrendamientos, subvenciones de explotación, etc. } \\
\text { Beneficios por venta de activos no corrientes: por } \\
\text { ventas de inmovilizado, etc. }\end{array}$ \\
\hline $\begin{array}{l}\text { FINANCIEROS } \\
\text { Provienen de activos, pasivos y opera- } \\
\text { ciones financieras. }\end{array}$ & $\begin{array}{l}\text { Ingresos de participaciones en capital: dividendos } \\
\text { de acciones. } \\
\text { Ingresos de créditos: intereses a favor de créditos. } \\
\text { Beneficios por venta de instrumentos financieros: } \\
\text { de acciones o valores de renta fija. }\end{array}$ \\
\hline
\end{tabular}

Ilustración 2.17. Clasificación de ingresos

\section{Gastos}

Los gastos son disminuciones del patrimonio neto, distintas de las distribuciones de fondos de la entidad a los propietarios, como consecuencia de la actividad económica de adquisición de bienes y servicios, o como consecuencia de las variaciones en el valor de activos y pasivos. 
Los gastos se materializan en la entrega de activos o la asunción de pasivos (o combinaciones de los dos).

\section{Ejemplo 2.11. Ejemplos de gastos}

La empresa CONSTRUCTORA SA ha incurrido en los siguientes gastos durante junio de 2000:

- Por compras de material de oficina, $100 €$.

- Por sueldos y salarios de su personal, $4.000 €$.

- Por consumo de electricidad y agua, $300 €$.

- Por intereses de un préstamo, $200 €$.

- Por robos producidos de maquinaria en una obra en construcción, $2.000 €$.

\section{Clasificación de gastos}

En la siguiente ilustración se muestran un listado comentado de los gastos más comunes, indicando la denominación usual utilizada en contabilidad y clasificándolos de acuerdo a su naturaleza.

\begin{tabular}{|c|c|c|}
\hline \multirow{5}{*}{$\begin{array}{l}\text { DE EXPLOTACIÓN } \\
\text { Relacionados con las } \\
\text { actividades habituales } \\
\text { de la empresa y de sus } \\
\text { activos y pasivos no } \\
\text { financieros. }\end{array}$} & Aprovisionamientos & $\begin{array}{l}\text { Compras de mercaderías. } \\
\text { Compras de otros aprovisionamientos. }\end{array}$ \\
\hline & Gastos de personal & $\begin{array}{l}\text { Sueldos y salarios. } \\
\text { Seguridad social a cargo de empresa. }\end{array}$ \\
\hline & $\begin{array}{l}\text { Otros gastos de } \\
\text { explotación }\end{array}$ & $\begin{array}{l}\text { Arrendamientos y cánones } \\
\text { Reparación y conservación } \\
\text { Servicios de profesionales independientes: } \\
\text { honorarios de abogados, asesores y otros } \\
\text { Primas de seguros } \\
\text { Servicios bancarios } \\
\text { Publicidad, propaganda y relaciones públicas } \\
\text { Suministros: (agua, electricidad, gas, etc. } \\
\text { Otros servicios exteriores: teléfono y otros. } \\
\text { Tributos (impto. sobre bienes inmuebles, etc.). }\end{array}$ \\
\hline & Amortizaciones & $\begin{array}{l}\text { Amortización del inmovilizado. Deprecia- } \\
\text { ción sistemática del inmovilizado por uso o } \\
\text { paso del tiempo. }\end{array}$ \\
\hline & $\begin{array}{l}\text { Deterioro y pérdi- } \\
\text { das por venta de ac- } \\
\text { tivos no corrientes }\end{array}$ & $\begin{array}{l}\text { Pérdidas por venta de activos no corrientes: } \\
\text { de inmovilizado. } \\
\text { Deterioro de valor de activos no corrientes }\end{array}$ \\
\hline $\begin{array}{l}\text { FINANCIEROS } \\
\text { Provenientes de acti- } \\
\text { vos, pasivos y opera- } \\
\text { ciones financieras }\end{array}$ & & $\begin{array}{l}\text { Intereses de deudas: préstamos y otros. } \\
\text { Pérdidas por venta de instrumentos finan- } \\
\text { cieros: de instrumentos de patrimonio o valo- } \\
\text { res de deuda. } \\
\text { Deterioro de valor de instrumentos finan- } \\
\text { cieros (instrumentos patrimonio, valores deu- } \\
\text { da, créditos). }\end{array}$ \\
\hline \multicolumn{2}{|c|}{ IMPUESTO SOBRE BENEFICIOS } & Impuesto sobre beneficios. \\
\hline
\end{tabular}

Ilustración 2.18. Clasificación de gastos 


\section{Resumen de las variaciones en el patrimonio neto}

Tal y como se ha explicado en los apartados anteriores, el patrimonio neto se incrementa si:

a) Los propietarios realizan aportaciones adicionales a la actividad. En este caso el incremento en el neto de la entidad es el resultado de transferir a la misma cualquier elemento susceptible de incrementar el valor del mismo (activos) o de la cancelación de deudas (pasivos) de la misma.

b) Durante un período los ingresos son superiores a los gastos, es decir, se generan beneficios.

Y el neto patrimonial disminuye si:

a) Se distribuye o reparte entre los propietarios. En este caso, la disminución en el neto puede ser a consecuencia de la entrega o transferencia de activos a los propietarios o a la asunción de deudas de los propietarios por parte de la entidad/empresa.

b) Durante un ejercicio los gastos son superiores a los ingresos, es decir, se incurre en pérdidas.

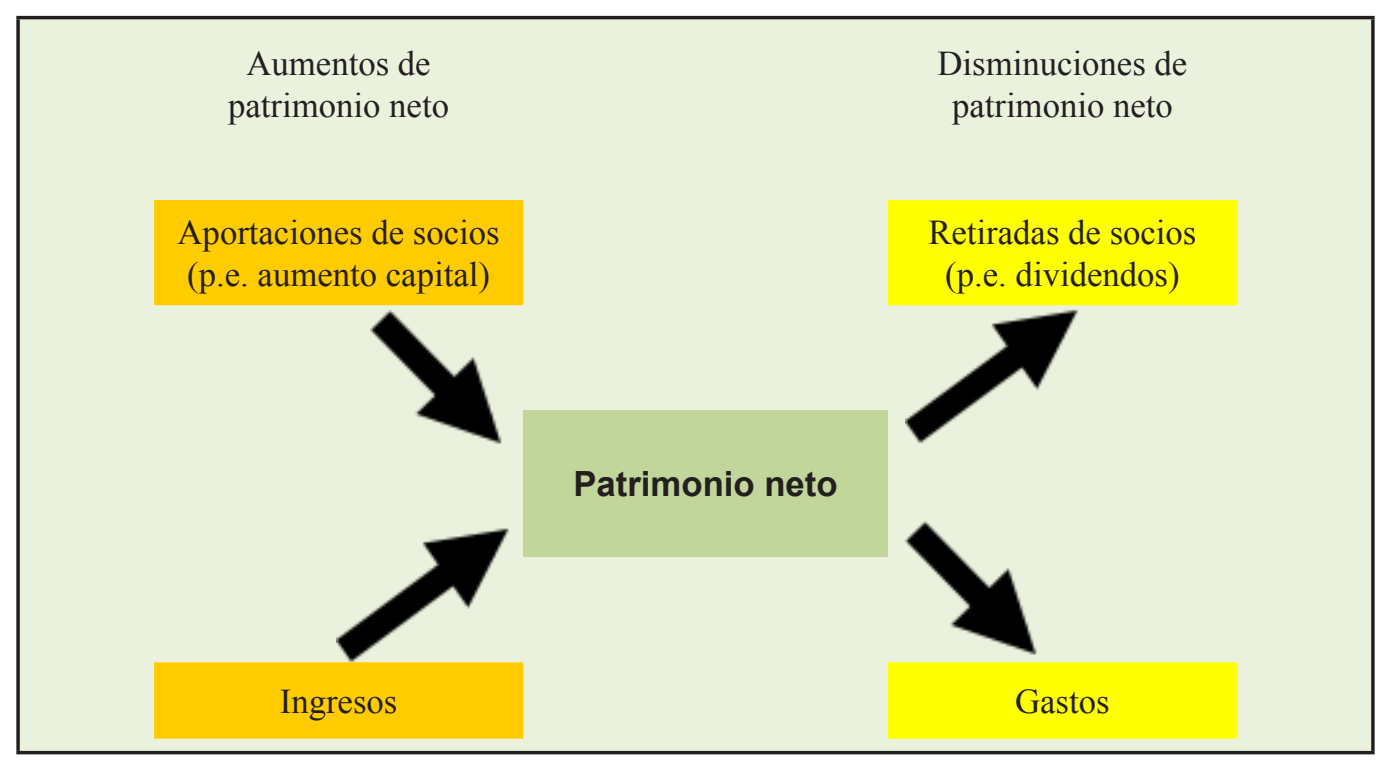

Ilustración 2.19. Aumentos y disminuciones del patrimonio neto 


\subsection{La Cuenta de pérdidas y ganancias}

El resultado de un período es la diferencia entre ingresos obtenidos y los gastos en el mismo, que puede resultar en beneficios o pérdidas. La información sobre ingresos, gastos y resultados de una empresa se muestra en un informe denominado cuenta de pérdidas y ganancias y que forma parte de las cuentas anuales.

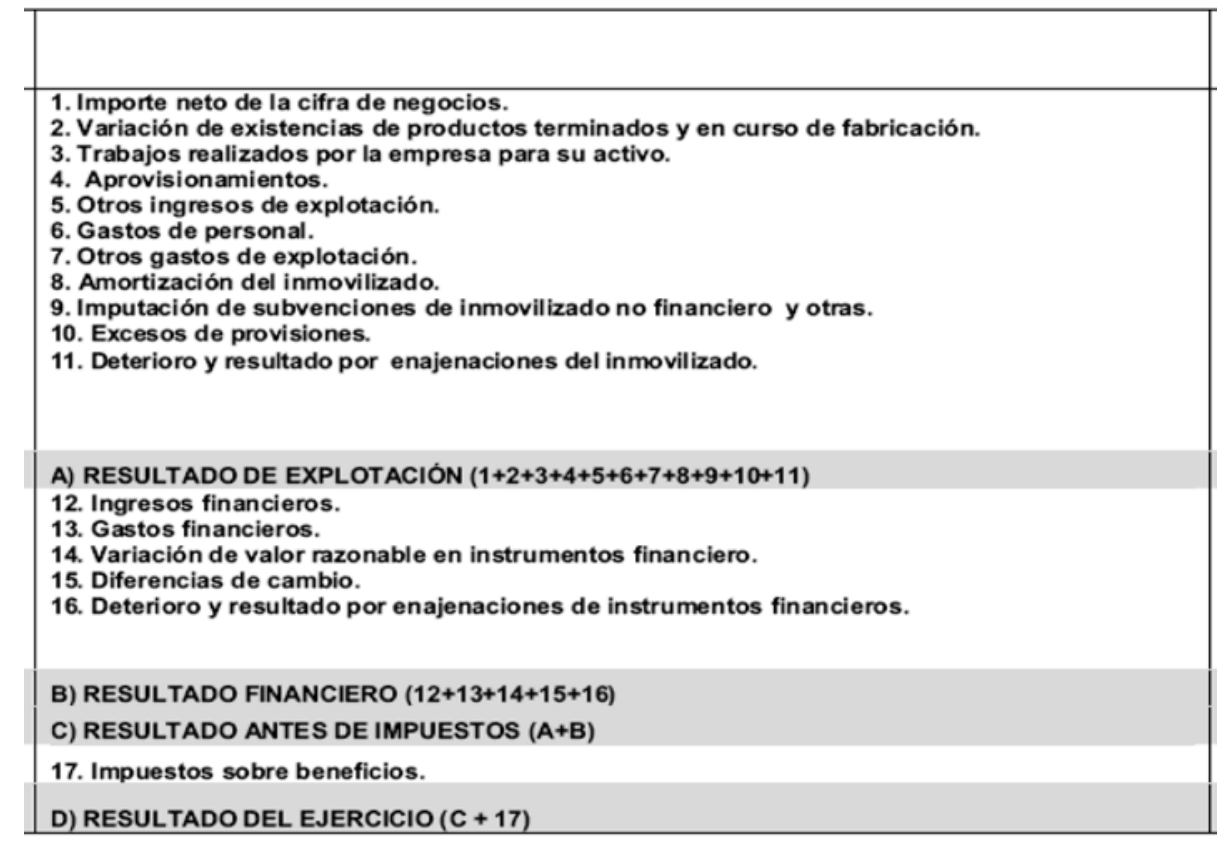

Ilustración 2.20. Formato oficial de cuenta de pérdidas y ganancias abreviada del PGC

La cuenta de pérdidas y ganancias muestra los ingresos obtenidos por una unidad económica y los gastos necesarios realizados para la obtención de aquellos durante un período de tiempo determinado, resultando por diferencia el resultado neto del ejercicio.

Si los ingresos superan a los gastos el resultado, será positivo (beneficios) y si los ingresos son inferiores a los gastos el resultado, es negativo (pérdidas).

La cuenta de pérdidas se presenta mostrando los ingresos y los gastos, con signo positivo o negativo, adecuadamente clasificados y ordenados y con el desglose y detalle oportunos, de acuerdo a los formatos oficiales incluidos en la normativa contable.

En la cuenta de pérdidas y ganancias se calcula, además del resultado del período, los siguientes resultados parciales:

- Resultado de explotación: ingresos de explotación - gastos de explotación.

- Resultado financiero: ingresos financieros - gastos financieros.

- Resultado antes de impuestos: suma de los dos anteriores.

- Resultado del ejercicio: resultado antes de impuestos - impuesto sobre beneficios. 
Ejemplo 2.12. Cálculo de los resultados de una empresa

La empresa CONSTRUCTORA SA presenta la siguiente información sobre sus ingresos y gastos del año 2000:

Ingresos de explotación $=100.000,00$

Gastos de explotación menos impuesto sobre beneficios $=80.000,00$

Ingresos financieros $=3.000,00$

Gastos financieros $=8.000,00$

Impuesto sobre beneficios $=4.000,00$

Resultado de explotación $=100.000,00-80.000,00=20.000,00$

Resultado financiero $=3.000 .00-8.000,00=-5.000,00$

Resultado antes de impuestos $=20.000,00-5.000,00=15.000,00$

Resultado del ejercicio $=15.000,00-4.000,00=11.000,00$

\section{Formato de cuenta de pérdidas y ganancias utilizado en este texto}

En la siguiente ilustración se muestra la estructura de la cuenta de pérdidas y ganancias que se utilizará a lo largo de este texto.

\begin{tabular}{|c|c|}
\hline $\begin{array}{l}\text { EMPRESA } X \\
\text { cuenta de pérdidas y ganancias del período 01-01-00 a 31-12 }\end{array}$ & \\
\hline $\begin{array}{l}\text { 1. Importe de la cifra de negocios. } \\
\text { 4. Aprovisionamientos (consumo mercancías). } \\
\text { 5. Otros ingresos de explotación. } \\
\text { 6. Gastos de personal. } \\
\text { 7. Otros gastos de explotación. } \\
\text { 8. Amortizaciones del inmovilizado. } \\
\text { 11. Deterioro y resultado por enajenaciones de inmovilizado. }\end{array}$ & \\
\hline A.1) RESULTADO DE EXPLOTACIÓN $=(1)+(4)+(5)+(6)+(7)+(8)+(11)$ & \\
\hline $\begin{array}{l}\text { 12. Ingresos financieros. } \\
\text { 13. Gastos financieros. } \\
\text { 16. Deterioro y resultado por enajenaciones de instrumentos financieros. }\end{array}$ & \\
\hline A.2) RESULTADO FINANCIERO $=(12)+(13)+(16)$ & \\
\hline A.3) RESULTADO ANTES DE IMPUESTOS = (A.1)+(A.2) & \\
\hline 17. Impuesto sobre beneficios. & \\
\hline A.4) RESULTADO DEL EJERCICIO = (A.3)+(17) & \\
\hline
\end{tabular}

Ilustración 2.21. Cuenta de pérdidas y ganancias (se omiten algunas de las partidas del modelo abreviado oficial)

Partidas de la Cuenta de Pérdidas y ganancias

1. Importe de la cifra de negocios. Ingresos por ventas y prestación de servicios que constituyen la actividad principal de la empresa.

4. Aprovisionamientos. Consumos de mercancías y otros aprovisionamientos, que figuran como existencias, en que la empresa incurre para el desarrollo de su actividad principal (ver tema 4). Incluye los deterioros de existencias (ver tema 5). 
5. Otros ingresos de explotación. Ingresos accesorios tales como arrendamientos, comisiones, subvenciones de explotación y otros (ver tema 4).

6. Gastos de personal. Gastos relacionados con el personal tales como sueldos y salarios, seguridad social a cargo de la empresa y otros gastos sociales.

7. Otros gastos de explotación. Otros gastos de explotación como arrendamientos, servicios profesionales, servicios bancarios, publicidad, transportes, suministros (electricidad, agua, gas, etc.) y otros. Incluye deterioros de créditos comerciales (ver temas 4 y 5 ).

8. Amortizaciones del inmovilizado. Amortizaciones del inmovilizado intangible, material e inversiones inmobiliarias (ver tema 5).

11. Deterioro y resultado por enajenaciones de inmovilizado. Pérdidas de valor de inmovilizado (intangible, material e inversiones inmobiliarias) y resultados positivos y negativos por venta de los mismos (ver temas 4 y 5 ).

12. Ingresos financieros. Ingresos de naturaleza financiera como intereses de cuentas bancarias o créditos, dividendos por inversiones en acciones y otros.

13. Gastos financieros. Gastos de naturaleza financiera como intereses de deudas y préstamos.

16. Deterioro y resultados por enajenaciones de instrumentos financieros. Pérdidas de valor de activos financieros y resultados positivos y negativos por venta de los mismos (ver temas 4 y 5 ).

17. Impuesto sobre beneficios. Impuesto sobre los beneficios de las sociedades (ver tema 5).

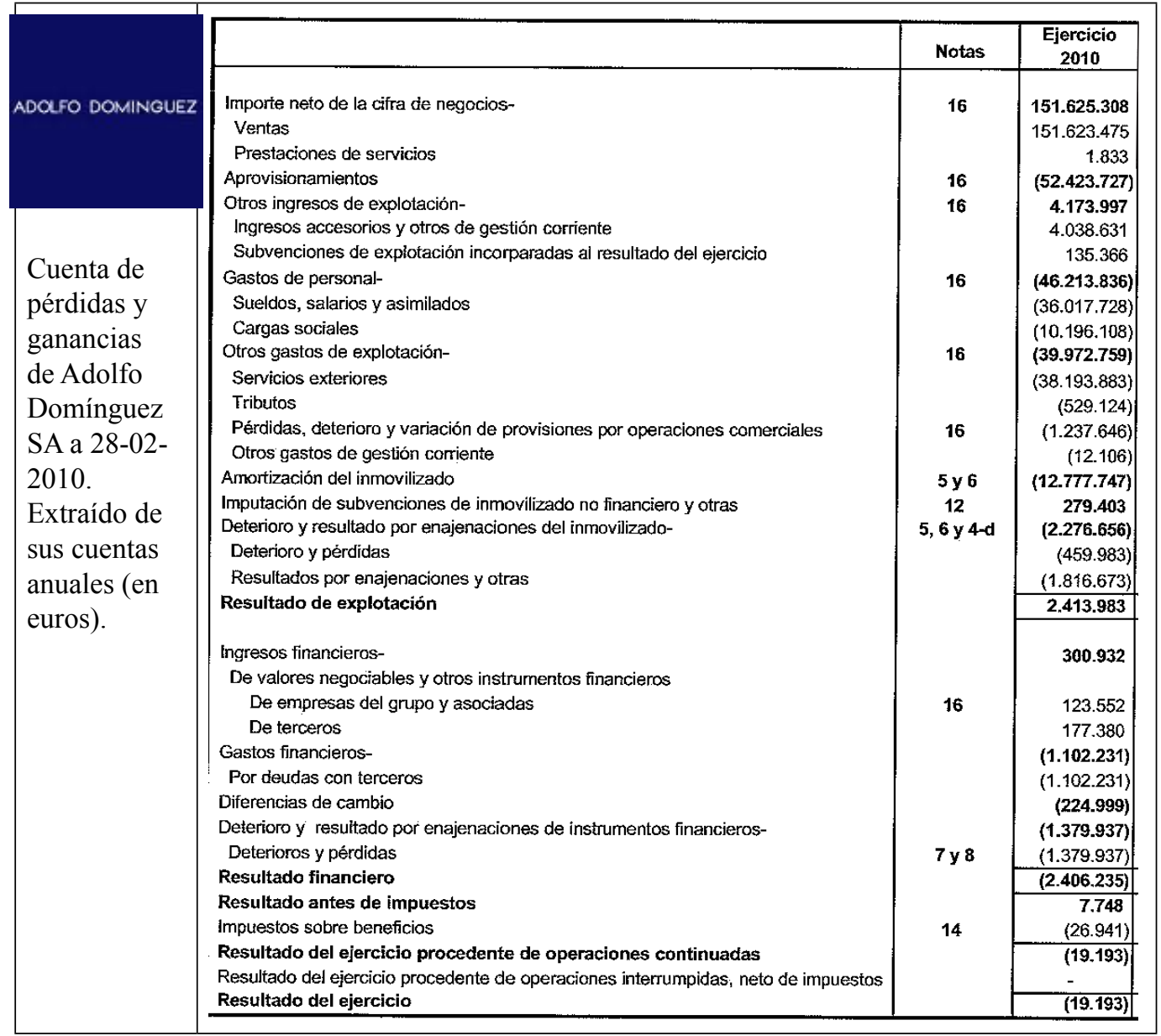

Ilustración 2.22. Cuenta de pérdidas y ganancias (normal) de Adolfo Domínguez de 2010 


\subsection{La ecuación contable y las transacciones empresariales}

\section{Ecuación fundamental del patrimonio}

Como se ha visto, el patrimonio neto se define como la diferencia entre el valor de los activos y los pasivos de una entidad.

$$
\begin{gathered}
N=A-P \\
\text { PATRIMONIO NETO }=\text { ACTIVOS }- \text { PASIVOS }
\end{gathered}
$$

De dicha definición se deduce que en toda entidad contable se cumple que la suma del valor de sus bienes y derechos (activos) es igual a la suma del valor de los pasivos y del patrimonio neto. Se trata de una identidad que se cumple en todo momento y que representa el equilibrio que se da en todo patrimonio.

A la expresión matemática que recoge esta identidad contable se le conoce como «ecuación fundamental del patrimonio».

$$
\begin{gathered}
A=P+N \\
\text { ACTIVOS }=\text { PASIVOS }+ \text { PATRIMONIO NETO }
\end{gathered}
$$

El patrimonio de cualquier unidad económica sufre continuas variaciones al tiempo que realiza las actividades propias de su negocio. Estas variaciones deben respetar la ecuación fundamental del patrimonio, como se verá a continuación:

Dada una situación inicial: $\quad \mathrm{A}_{0}=\mathrm{P}_{0}+\mathrm{N}_{0} \quad$ (Activo $=$ Pasivo + Patrimonio Neto $)$

En un período 1:

- Se producirán aumentos de algunos activos $\left(\Delta \mathrm{A}_{1}\right)$ y disminuciones en otros acti$\operatorname{vos}\left(\nabla A_{1}\right)$.

- Se producirán aumentos de algunos pasivos $\left(\Delta \mathrm{P}_{1}\right)$ y disminuciones en otros pasi$\operatorname{vos}\left(\nabla P_{1}\right)$.

- Se producirán aumentos de patrimonio neto $\left(\Delta \mathrm{N}_{1}\right)$ y disminuciones en patrimonio neto $\left(\nabla \mathrm{N}_{1}\right)$.

Dado que la ecuación fundamental debe respetarse, al final de dicho período:

$$
\mathrm{A}_{0}+\Delta \mathrm{A}_{1}+\nabla \mathrm{A}_{1}=\mathrm{P}_{0}+\Delta \mathrm{P}_{1}+\nabla \mathrm{P}_{1}+\mathrm{N}_{0}+\Delta \mathrm{N}_{1}+\nabla \mathrm{N}_{1}
$$

Los aumentos y disminuciones de patrimonio neto pueden clasificarse en:

- Aportaciones de propietarios $\left(\mathrm{A}_{1}\right)$ y retiradas de propietarios $\left(\mathrm{R}_{1}\right)$,

- e ingresos $\left(\mathrm{I}_{1}\right)$ y gastos $\left(\mathrm{G}_{1}\right)$, siendo: 
Entonces:

$$
\mathrm{A}_{0}+\Delta \mathrm{A}_{1}+\nabla \mathrm{A}_{1}=\mathrm{P}_{0}+\mathrm{DP}_{1}+\nabla \mathrm{P}_{1}+\mathrm{N}_{0}+\left(\mathrm{A}_{1}-\mathrm{R}_{1}\right)+\left(\mathrm{I}_{1}-\mathrm{G}_{1}\right)
$$

Por lo que la ecuación fundamental del patrimonio extendida para el final del período 1 podría expresarse:

$$
\mathrm{A}_{1}=\mathrm{P}_{1}+\mathrm{N}_{0}+\text { Operaciones con propietarios }+ \text { Resultados }=\mathrm{P}_{1}+\mathrm{N}_{1}
$$

\section{Ecuación contable y variaciones patrimoniales}

Las variaciones que sufren los patrimoniales empresariales reciben el nombre de «hechos contables».

Un hecho contable puede definirse como: «cualquier acontecimiento que influye o puede influir cuantitativa o cualitativamente de forma significativa en el patrimonio de una entidad y que puede ser captado y registrado contablemente».

En la ilustración siguiente se muestran los distintos tipos de hechos contables que

\begin{tabular}{|c|c|c|c|}
\hline \multirow{9}{*}{ 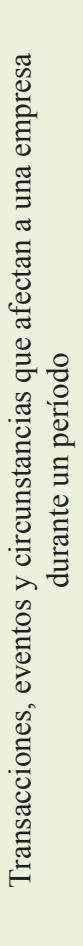 } & \multirow{5}{*}{$\begin{array}{l}\text { Cambios en activos, } \\
\text { pasivos y elementos } \\
\text { de patrimonio neto } \\
\text { que } \\
\text { NO suponen } \\
\text { variaciones en la } \\
\text { cuantía del patrimonio } \\
\text { neto }\end{array}$} & Cambio de activos por activos. & $\begin{array}{l}\text { Compra de un coche con pago al } \\
\text { contado. }\end{array}$ \\
\hline & & Cambio de pasivos por pasivos. & $\begin{array}{l}\text { Negociación de préstamo convirtién- } \\
\text { dolo de corto a largo plazo. }\end{array}$ \\
\hline & & $\begin{array}{l}\text { Compra de activos asumiendo } \\
\text { pasivos. }\end{array}$ & $\begin{array}{l}\text { Compra de un coche con pago } \\
\text { aplazado. }\end{array}$ \\
\hline & & $\begin{array}{l}\text { Cancelación de pasivos entre- } \\
\text { gando activos. }\end{array}$ & $\begin{array}{l}\text { Devolución de un préstamo con } \\
\text { dinero. }\end{array}$ \\
\hline & & $\begin{array}{l}\text { Cambios o compensaciones entre } \\
\text { elementos de patrimonio neto. }\end{array}$ & $\begin{array}{l}\text { Compensación de pérdidas del ejerci- } \\
\text { cio con reservas de años anteriores. }\end{array}$ \\
\hline & \multirow{4}{*}{$\begin{array}{l}\text { Cambios en activos y } \\
\text { pasivos que } \\
\text { SÍ suponen } \\
\text { variaciones en la } \\
\text { cuantía del patrimonio } \\
\text { neto }\end{array}$} & Ingresos. & $\begin{array}{l}\text { - Venta de mercaderías. } \\
\text { - Alquiler de un local arrendado. } \\
\text { - Venta de un activo con beneficio. }\end{array}$ \\
\hline & & Gastos. & $\begin{array}{l}\text { - Consumo de mercaderías. } \\
\text {-Gastos de publicidad. } \\
\text { - Venta de un activo con pérdidas. }\end{array}$ \\
\hline & & \multirow{2}{*}{$\begin{array}{l}\text { Cambios en el patrimonio neto } \\
\text { derivados de transferencias entre } \\
\text { la empresa y sus propietarios. }\end{array}$} & $\begin{array}{l}\text { Aportación de capital de los propie- } \\
\text { tarios. }\end{array}$ \\
\hline & & & $\begin{array}{l}\text { Distribución de dividendos entre } \\
\text { propietarios. }\end{array}$ \\
\hline
\end{tabular}
pueden afectar a una empresa durante un período.

Ilustración 2.23. Tipología de hechos contables

Sea cual sea el tipo, origen o causa de un cambio en activos, pasivos y patrimonio neto debe respetarse la igualdad establecida la ecuación fundamental del patrimonio. 
Para observar el cumplimiento de la ecuación fundamental a continuación se va a utilizar la misma para analizar diversas transacciones u operaciones empresariales.

Para ello se utilizará el ejemplo que se describe a continuación.

\begin{tabular}{|c|c|c|c|}
\hline \multicolumn{4}{|c|}{ Ejemplo 2.13. Transacciones empresariales } \\
\hline \multicolumn{4}{|c|}{ Patrimonio de Asesoría Julián López a 01/01/00 } \\
\hline \multicolumn{2}{|c|}{ ACTIVO } & \multicolumn{2}{|c|}{ PATRIMONIO NETO Y PASIVO } \\
\hline $\begin{array}{l}\text { ACTIVO NO CORRIENTE } \\
\text { Local comercial } \\
\text { Mobiliario }\end{array}$ & $\begin{array}{r}\mathbf{4 0 . 0 0 0 , 0 0} \\
39.000,00 \\
1.000,00\end{array}$ & $\begin{array}{l}\text { PATRIMONIO NETO } \\
\text { Capital } \\
\text { Pérdidas y ganancias }\end{array}$ & $\begin{array}{r}\mathbf{2 0 . 0 0 0 , 0 0} \\
20.000,00 \\
0,00\end{array}$ \\
\hline $\begin{array}{l}\text { ACTIVO CORRIENTE } \\
\text { Material oficina }\end{array}$ & $\begin{array}{r}\mathbf{2 0 . 0 0 0 , 0 0} \\
500,00\end{array}$ & $\begin{array}{l}\text { PASIVO NO CORRIENTE } \\
\text { Préstamos a largo plazo }\end{array}$ & $\begin{array}{l}\mathbf{3 0 . 0 0 0 , 0 0} \\
30.000,00\end{array}$ \\
\hline $\begin{array}{l}\text { Clientes } \\
\text { Caja y bancos }\end{array}$ & $\begin{array}{r}5.000,00 \\
14.500,00\end{array}$ & $\begin{array}{l}\text { PASIVO CORRIENTE } \\
\text { Proveedores }\end{array}$ & $\begin{array}{l}\mathbf{1 0 . 0 0 0 , 0 0} \\
10.000,00\end{array}$ \\
\hline TOTAL ACTIVO & $60.000,00$ & $\begin{array}{l}\text { TOTAL PATRIMONIO NETO Y } \\
\text { PASIVO }\end{array}$ & $60.000,00$ \\
\hline
\end{tabular}

Transacción 1. Alquiler de un vehículo y contrato de personal (1 de enero de 00). Julián alquila un vehículo para desarrollar su actividad por el que pagará cada final de mes $300 €$. Asimismo contrata a un empleado al que pagará $1.500 €$ al mes.

Transacción 2. Compra de mobiliario al contado ( 2 de enero de 00). Julián compra mobiliario diverso para amueblar el despacho por importe de $10.000 €$ pagándolo con un cheque bancario.

Transacción 3. Compra de material de oficina a crédito (3 de enero de 00$)$. Julián compra material diverso de oficina por importe de $200 €$. Acuerda con la papelería pagar el importe por mitades el 31 de enero y el 20 de noviembre próximos.

Transacción 4. Factura a un cliente al contado (5 de enero de 00). Factura a un cliente por un servicio de asesoramiento $5.000 €$, los cuales cobra en efectivo.

Transacción 5. Factura a un cliente a crédito (10 enero de 00). Factura a un cliente por un servicio de asesoramiento $1.000 €$. Acuerda con el cliente que cobrará $500 €$ en 15 días y el resto en 30 días.

Transacción 6. Retira dinero para uso personal ( 22 enero de 00). Al objeto de atender ciertos gastos personales Julián retira $2.000 €$ de la cuenta corriente.

Transacción 7. Cobro de un cliente ( 25 de enero de 00). Tal y como se acordó con el cliente de la transacción 5 , Julián cobra $500 €$ del mismo en efectivo.

Transacción 8. Venta de mobiliario en efectivo ( 28 de enero de 00 ). Al objeto de tener más espacio decide vender parte del mobiliario que adquirió en la transacción 2. Así, vende una mesa por $1.000 €$, que es el importe que le costó cobrando el importe en efectivo.

Transacción 9. Obtención de un préstamo (30 de enero de 00). Al objeto de disponer de fondos para adquirir un despacho para su negocio en el próximo mes, solicita un préstamo por $10.000 €$ a devolver en 3 años que le es concedido. El importe se deposita en su cuenta bancaria.

Transacción 10. Pago del recibo de alquiler del vehículo (31 enero de 00). A final de mes paga en efectivo el recibo de alquiler por $300 €$.

Transacción 11. Pago a proveedores (31 de enero de 00). Tal y como se acordó, Julián paga $100 €$ con un cheque bancario al proveedor de la transacción 3.

Transacción 12. Pago al empleado (31 de enero de 00). A finales de mes elabora la nómina del empleado, de $1.500 €$, que paga mediante transferencia bancaria.

A continuación se analizan las transacciones anteriores determinando su efecto sobre la ecuación fundamental del patrimonio: 


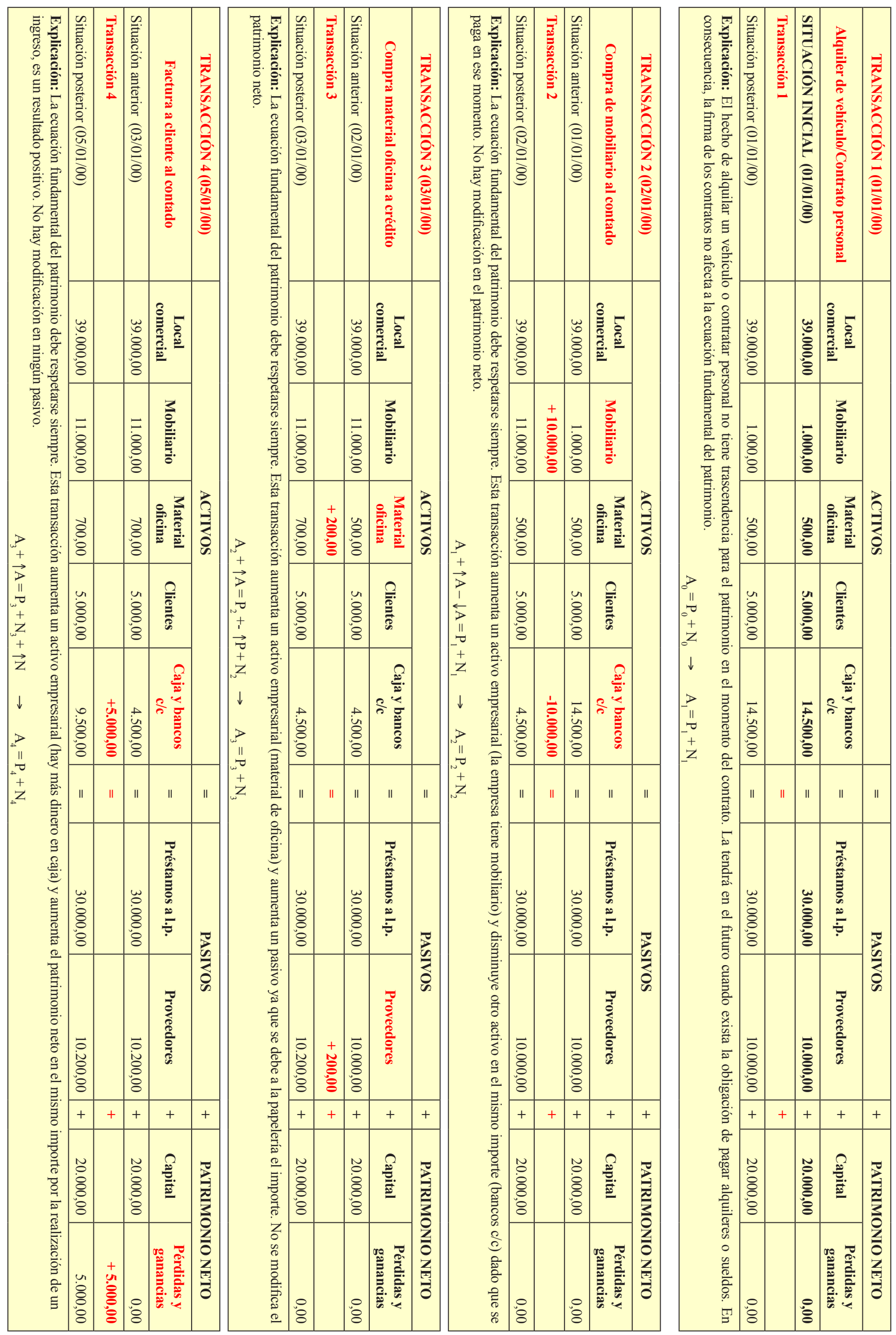




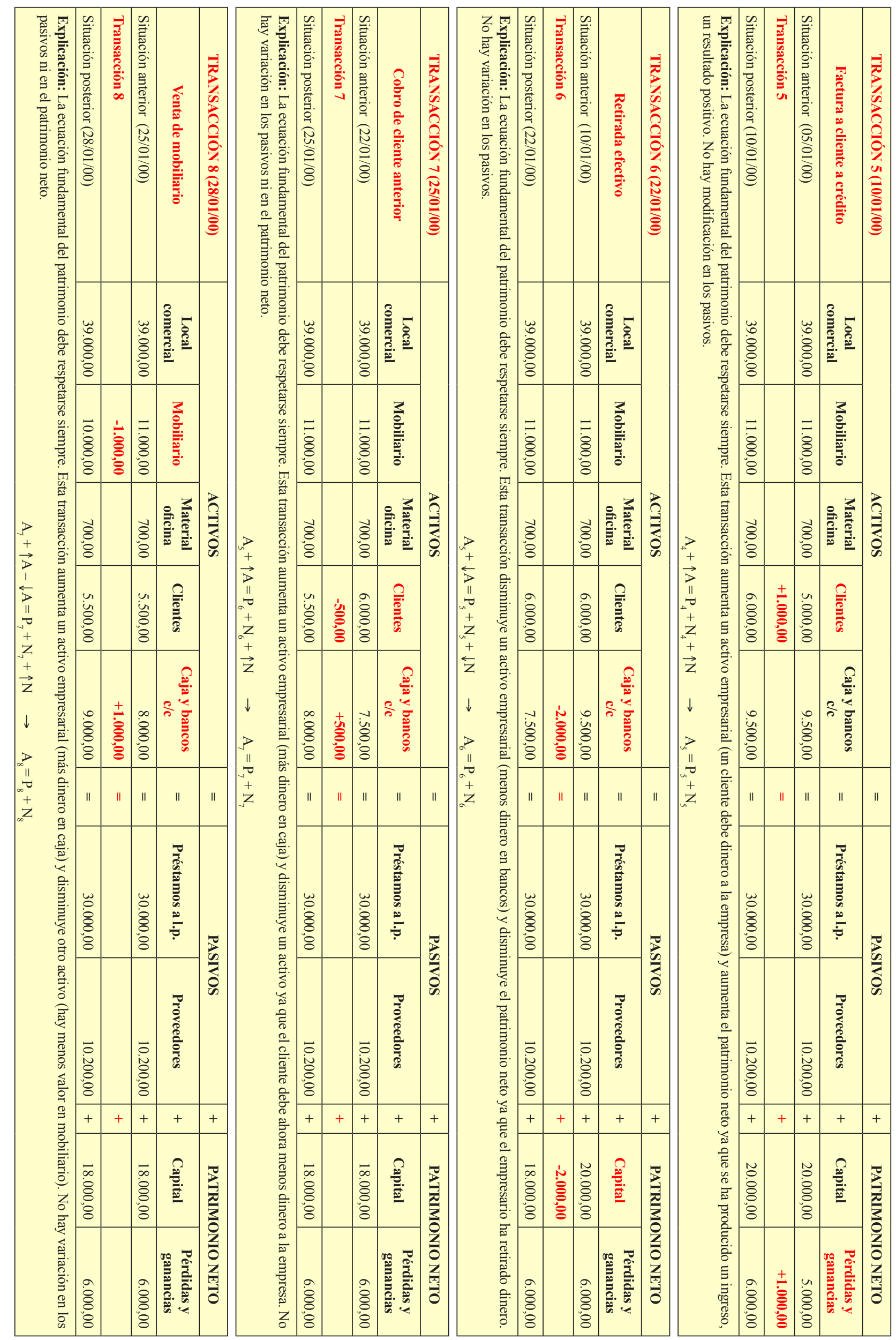




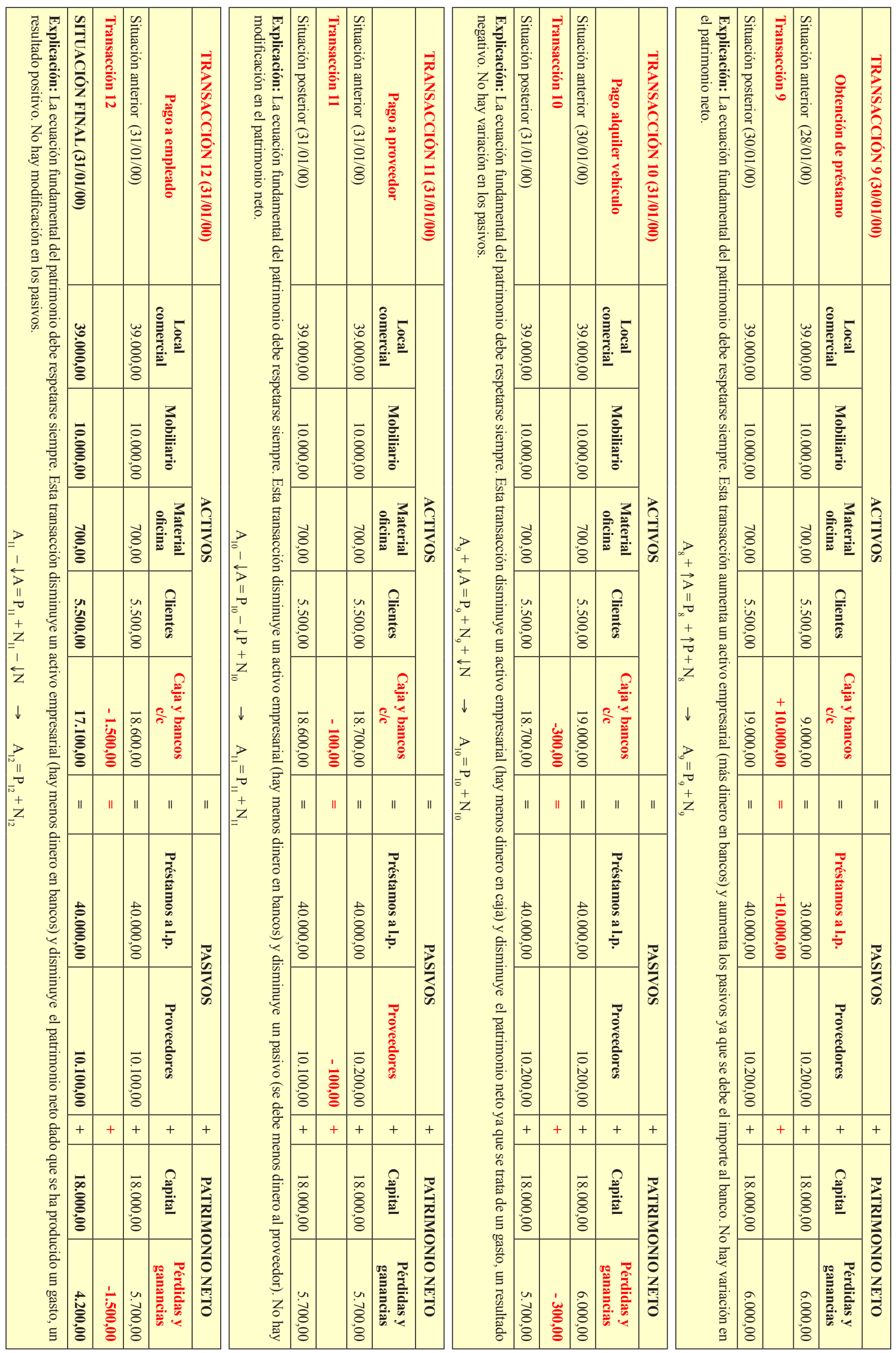




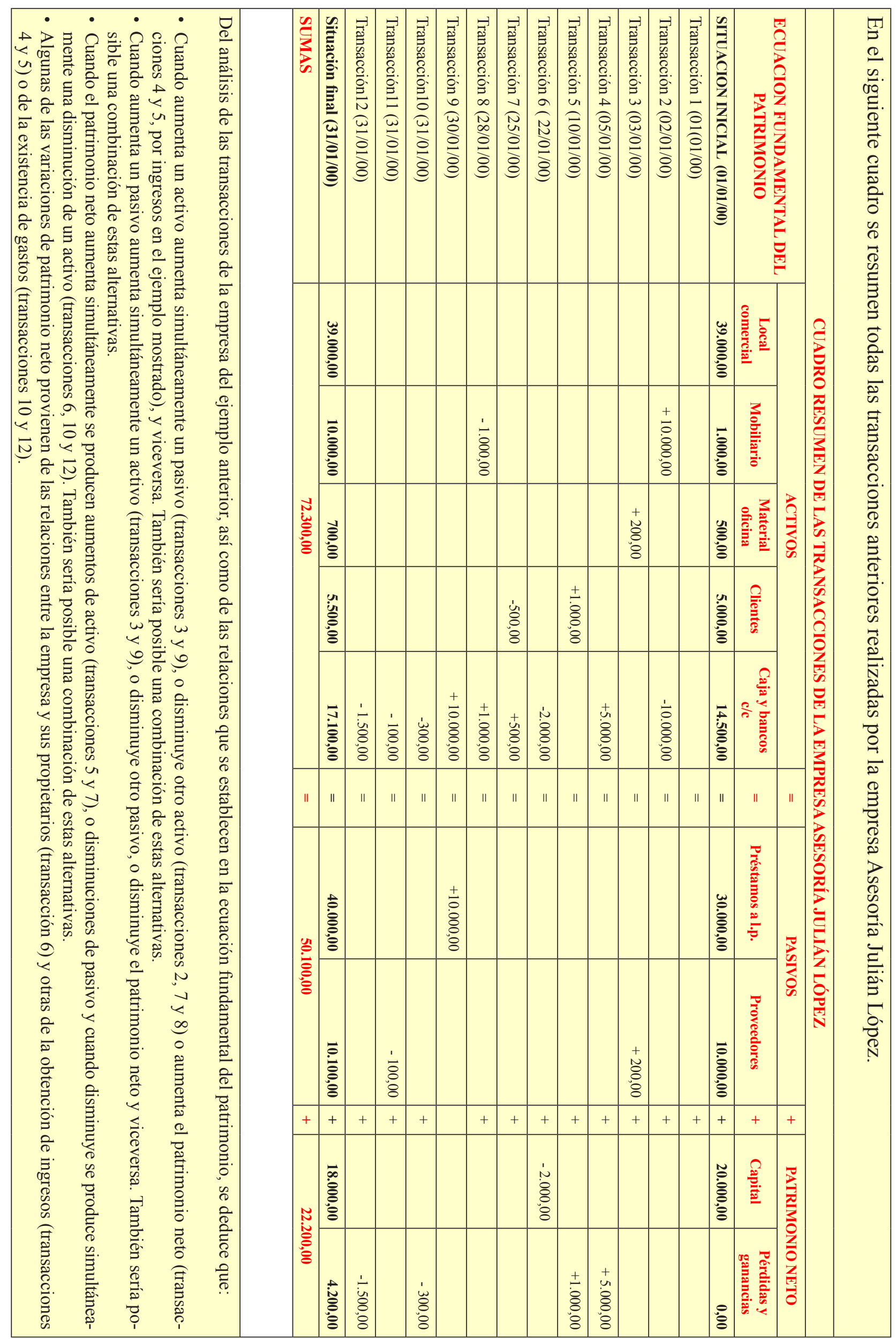

CC José Alcarria Jaime - ISBN: 978-84-695-3672-8 


\section{El balance de Asesoría Julián López}

A continuación se muestra el balance final, a 31 de diciembre de 2000, para el caso del ejemplo, la empresa de Asesoría Julián López.

\begin{tabular}{|c|c|c|c|}
\hline \multicolumn{4}{|l|}{ Ejemplo 2.14. Balance } \\
\hline \multicolumn{4}{|c|}{$\begin{array}{c}\text { Asesoría Julián López } \\
\text { Balance a 31/10/00 }\end{array}$} \\
\hline \multicolumn{2}{|l|}{ ACTIVO } & \multicolumn{2}{|c|}{ PATRIMONIO NETO Y PASIVO } \\
\hline A) ACTIVO NO CORRIENTE & $49.000,00$ & A) PATRIMONIO NETO & $22.200,00$ \\
\hline I. Inmovilizado intangible & 0,00 & A.1) Fondos propios & $22.200,00$ \\
\hline II. Inmovilizado material & $49.000,00$ & I. Capital & $18.000,00$ \\
\hline Local Comercial & $39.000,00$ & III. Reservas & $\mathbf{0 , 0 0}$ \\
\hline Mobiliario & $10.000,00$ & VII. Pérdidas y ganancias & $4.200,00$ \\
\hline III. Inversiones inmobiliarias & $\mathbf{0 , 0 0}$ & A.3) Subvenciones & 0,00 \\
\hline V. Inversiones financieras a largo plazo & $\mathbf{0 , 0 0}$ & & \\
\hline B) ACTIVO CORRIENTE & $23.300,00$ & B) PASIVO NO CORRIENTE & $40.000,00$ \\
\hline II. Existencias & 700,00 & II. Deudas a largo plazo & $40.000,00$ \\
\hline Material oficina & 700,00 & Préstamos a largo plazo & $40.000,00$ \\
\hline III. Deudores comerciales y cuentas a & $5.500,00$ & C) PASIVO CORRIENTE & $10.100,00$ \\
\hline cobrar & $5.500,00$ & III. Deudas a corto plazo & $\mathbf{0 , 0 0}$ \\
\hline Clientes & $\mathbf{0 , 0 0}$ & V. Acreedores comerciales y & \\
\hline V. Inversiones financieras a corto plazo & 0,00 & cuentas a pagar & $10.100,00$ \\
\hline VI. Periodificaciones a corto plazo & $17.100,00$ & Proveedores & $10.100,00$ \\
\hline VII. Efectivo & $17.100,00$ & VI. Periodificaciones a corto plazo & $\mathbf{0 , 0 0}$ \\
\hline Caja y bancos & & & \\
\hline TOTAL ACTIVO (A+B) & $72.300,00$ & $\begin{array}{c}\text { TOTAL PATRIMONIO NETO } \\
\text { Y PASIVO }(\mathbf{A}+\mathbf{B}+\mathbf{C})\end{array}$ & $72.300,00$ \\
\hline
\end{tabular}

Obsérvese que el resultado del período, $4.200 €$ (beneficios) se ha incluido en el balance en una rúbrica específica de los fondos propios dentro del patrimonio neto denominada pérdidas y ganancias. Este resultado se obtiene de la cuenta de pérdidas y ganancias que se muestra a continuación.

\section{La cuenta de pérdidas y ganancias de Asesoría Julián López}

A continuación se muestra la cuenta de pérdidas y ganancias a 31 de diciembre de 2000 para el caso de la empresa de Asesoría Julián López.

\begin{tabular}{|c|c|}
\hline \multicolumn{2}{|c|}{$\begin{array}{l}\text { Asesoría Julián López } \\
\text { Cuenta de pérdidas y ganancias del período 01/10/00 a 31/10/00 }\end{array}$} \\
\hline 1. Importe de la cifra de negocios (transacciones 4 y 5 ) & $+6.000,00$ \\
\hline Prestación de servicios & $-6.000,00$ \\
\hline 4. Aprovisionamientos (consumo mercancías) & $-0,00$ \\
\hline 5. Otros ingresos de explotación & $+\mathbf{0 , 0 0}$ \\
\hline 6. Gastos de personal (transacción 12) & $-1.500,00$ \\
\hline Sueldos y Salarios & $-1.500,00$ \\
\hline 7. Otros gastos de explotación (transacción 10) & $-\mathbf{3 0 0 , 0 0}$ \\
\hline Arrendamientos & $-300,00$ \\
\hline 8. Amortizaciones del inmovilizado & $-\mathbf{0 , 0 0}$ \\
\hline 11. Deterioro y resultado por enajenaciones de inmovilizado & $+/-0,00$ \\
\hline A.1) RESULTADO DE EXPLOTACIÓN $=(1)+(4)+(5)+(6)+(7)+(8)+(11)$ & $+4.200,00$ \\
\hline 12. Ingresos financieros & $+0,00$ \\
\hline 13. Gastos financieros & $-0,00$ \\
\hline 16. Deterioro y resultado por enajenaciones de instrumentos financieros & $+/-0,00$ \\
\hline A.2) RESULTADO FINANCIERO $=(12)+(13)+(16)$ & $+4.200,00$ \\
\hline A.3) RESULTADO ANTES DE IMPUESTOS = (A.1)+(A.2) & $+4.200,00$ \\
\hline 17. Impuesto sobre beneficios & $-0,00$ \\
\hline A.4) RESULTADO DEL EJERCICIO $=(\mathrm{A} .3)+(17)$ & $+4.200,00$ \\
\hline
\end{tabular}




\section{Material para prácticas}

\section{Preguntas test}

1. Los activos son:

a) El conjunto de bienes, derechos y otros recursos presentes y futuros con los que la empresa desarrollará su actividad.

b) Para reconocer un activo es necesario acreditar su propiedad.

c) Bienes y derechos, provenientes de acontecimientos pasados controlados económicamente por la empresa y con capacidad de producir futuros beneficios.

d) Bienes y derechos adquiridos por la empresa en el período a que se refiera el balance.

2. El patrimonio de la empresa se puede representar matemáticamente como:
a) $\mathrm{A}=\mathrm{P}-\mathrm{N}$
b) $\mathrm{P}=\mathrm{A}-\mathrm{N}$
c) $\mathrm{N}=\mathrm{A}+\mathrm{P}$
d) Ninguna de las anteriores.

3. De los siguientes elementos, indique cuál forma parte del patrimonio neto:

a) Derechos frente a terceros por préstamos obtenidos pendientes de pago.

b) Derechos frente a terceros por préstamos concedidos pendientes de cobro.

c) Aportación del empresario a la empresa sin ánimo de solicitar o exigir la devolución.

d) Ninguna de las anteriores.

4. Señale cuál de las siguientes afirmaciones es correcta:

a) El activo comprende las fuentes de financiación de la empresa.

b) El inmovilizado material está formado por bienes intangibles.

c) Las reservas forman parte de los fondos propios.

d) El pasivo comprende las inversiones realizadas por la empresa con los fondos obtenidos.

5. Sea una empresa en la que:
Terrenos $=10$
Construcciones $=100$
Existencias $=50$
Maquinaria $=25$
Acreedores $=35$
Deudores $=15$
Capital $=100$
Clientes $=10$
Proveedores $=35$ Deudas a $\mathrm{c} /=40$

Su activo corriente es: $\quad$ a) 75 b) 110 c) 145 d) Ninguna de las anteriores.

6. El patrimonio de una empresa está formado por los siguientes elementos:

- Maquinaria 30 - Mobiliario 15 - Existencias 20 - Caja 10

- Proveedores 15 -Clientes 5 -Capital 50 -Deudas 1.p. 15
$\mathrm{Su}$ activo corriente es:
a) 20
b) 35
c) 45
d) 80 
7. Señale cuál de los siguientes elementos patrimoniales pertenece al activo corriente:
a) Mobiliario de oficina.
b) Clientes.
c) Aportaciones de los propietarios.
d) Proveedores.

8. ¿Cuál de las cuentas siguientes constituye financiación a largo plazo de la empresa?:
a) Inversiones financieras temporales.
b) Créditos a largo plazo.
c) Deudas a largo plazo.
d) Inversiones financieras permanentes.

9. ¿Cuál de los siguientes conceptos constituyen una fuente de financiación propia?
a) La parte de los beneficios repartida a los socios.
b) La parte de los beneficios retenida por la empresa.
c) Cantidades reintegrables (a devolver) aportadas por terceras personas.
d) Deudas a largo plazo con proveedores de inmovilizado.

10. Las reservas:

a) Es el dinero efectivo que las empresas mantienen a su disposición para cualquier contingencia o problema imprevisible.

b) Obligan a pagar dividendos.

c) Se originan por la retención de beneficios y aportaciones de propietarios.

d) Junto con el resto de fuentes de financiación forman parte de los recursos con los que se financia el activo de una empresa.

11. El hecho de que una empresa adquiera un terreno:
a) Supone un gasto.
b) Es una inversión que no modifica la cuantía del patrimonio neto.
c) Es una ganancia que aumenta el beneficio.
d) Alterará la cuantía del neto patrimonial.

12. Señale cuál de las siguientes afirmaciones es correcta:
a) El activo comprende las fuentes de financiación de la empresa.
b) El inmovilizado material está formado por bienes intangibles.
c) Las reservas forman parte de los fondos propios.
d) El pasivo comprende las inversiones realizadas por la empresa con los fon- dos obtenidos.

13. De los elementos patrimoniales que se relacionan a continuación, señale cuál de ellos constituye una inversión permanente de la empresa:
a) Clientes.
b) Reservas voluntarias.
c) Participaciones en capital a largo plazo.
d) Proveedores. 
14. De los elementos patrimoniales que se señalan a continuación, señale cuál pertenece al «pasivo corriente»:

a) Deudas a largo plazo con entidades de crédito.

b) Existencias de mercaderías.

c) Proveedores.

d) Deudores diversos.

15. Señale cuál de las cuentas siguientes representa una fuente de financiación a largo plazo para la empresa.
a) Proveedores.
b) Créditos a corto plazo.
c) Deudas a largo plazo.
d) Inversiones financieras temporales.

16. Indique cuál de las siguientes expresiones no es correcta:
a) El inmovilizado material está formado por bienes tangibles.
b) Las reservas forman parte de los fondos propios.
c) El activo representa la estructura financiera de la empresa.
d) El inmovilizado incluye elementos para el uso en la actividad.

\section{SOLUCIONES AL TEST:}

\begin{tabular}{|l|l|l|l|l|}
\hline 1. & 2. & 3. & 4. & 5. \\
\hline 6. & 7. & 8. & 9. & 10. \\
\hline 11. & 12. & 13. & 14. & 15. \\
\hline 16. & & & & \\
\hline
\end{tabular}




\section{Cuestiones teóricas}

1. Concepto de patrimonio según la teoría de la entidad.

2. Concepto de patrimonio según la teoría del propietario.

3. ¿Qué es la estructura económica de una empresa?

4. ¿Qué es la estructura financiera de la empresa?

5. Definir qué es un activo y citar tres ejemplos.

6. Definir qué es un pasivo y citar tres ejemplos.

7. Definir el patrimonio neto.

8. ¿Qué significa que un bien o derecho constituye un activo solo si proviene de un hecho pasado?

9. ¿Puede ser un activo un bien del cual no se conoce el beneficio futuro que va a proporcionar a la empresa?

10. ¿Cómo se cancela generalmente un pasivo?

11. ¿Puede reconocerse como pasivo una deuda indeterminada en cuanto a su importe?

12. Diferenciar entre activo corriente y no corriente. Cite un ejemplo de cada.

13. Señale las masas patrimoniales en que se clasifica el activo no corriente

14. Diferenciar entre pasivo corriente y no corriente. Cite un ejemplo de cada.

15. Señale las masas patrimoniales en que se divide el patrimonio neto.

16. ¿Qué tipo de elemento es un préstamo obtenido de una entidad financiera, y en qué agrupación puede clasificarse? ¿De qué depende dicha clasificación?

17. Defina ingresos y cite tres ejemplos.

18. Defina gastos y cite tres ejemplos.

19. Señale las agrupaciones más importantes de gastos según su naturaleza.

20. Indique los tres tipos de variaciones que dan lugar a cambios en el patrimonio neto.

21. ¿Cuál es la expresión de la ecuación fundamental del patrimonio?

22. ¿Cuáles son las fuentes de financiación de la empresa y cuál es su origen?

23. Definir hecho contable.

24. Cite dos transacciones concretas que den lugar a un incremento en el patrimonio neto.

25. Cite dos transacciones concretas que den lugar a una disminución en el patrimonio neto.

26. Exprese la ecuación fundamental del patrimonio para el final de un período desagregando el patrimonio neto para tener en cuenta todas sus variaciones.

27. Explique qué es el balance, su estructura básica y sobre qué informa.

28. Explique qué es la cuenta de pérdidas y ganancias, su estructura básica y sobre qué informa.

29. ¿Qué relación existe entre el balance y la cuenta de pérdidas y ganancias? 


\section{Ejercicios}

Ejercicio 1. Identificación y clasificación de elementos del patrimonio Clasifique los siguientes elementos del patrimonio según su naturaleza y siguiendo el ejemplo incluido en el punto $a$ ). Utilice la clasificación y las denominaciones incluidas en el apartado 2 de este tema.

\begin{tabular}{|l|l|l|}
\hline a) Derecho de cobro contra cliente. & Activo corriente & Deudores comerciales \\
\hline b) Obligación de pago por compra de productos. & & \\
\hline c) Derecho a la explotación de una concesión administrativa. & & \\
\hline d) Mobiliario de la empresa. & & \\
\hline e) Inversión en bonos del Tesoro a 3 años. & & \\
\hline$f$ ) Inversión en letras del Tesoro a 1 año. & & \\
\hline$g)$ Local comercial para exposición. & & \\
\hline h) Deudas con la Tesorería de la Seguridad Social. & & \\
\hline i) Deudas con un banco por un préstamo a 3 años. & & \\
\hline$j)$ Deudas con terceros por préstamos a 1 año. & & \\
\hline k) Beneficios de un año anterior no repartidos. & & \\
\hline l) Importe de las aportaciones iniciales de los propietarios. & & \\
\hline$m)$ Maquinaria para la transformación de productos. & & \\
\hline n) Dinero efectivo en cuentas bancarias. & & \\
\hline$o)$ Inversión temporal en acciones de otra empresa. & & \\
\hline$p)$ Deudas con los trabajadores por la nómina. & & \\
\hline
\end{tabular}

\section{Ejercicio 2. Identificación y clasificación de elementos del patrimonio}

Clasifique los siguientes elementos de los estados financieros según su naturaleza y siguiendo el ejemplo incluido en el punto $a$ ). Utilice la clasificación y denominaciones incluidas en el apartado 3 de este tema.

\begin{tabular}{|l|l|l|}
\hline a) Sueldos y salarios del mes. & \multicolumn{1}{|c|}{ Gastos } & De explotación \\
\hline b) Ventas de mercaderías. & & \\
\hline c) Publicidad, propaganda y relaciones públicas. & & \\
\hline d) Gastos por intereses de deudas. & & \\
\hline e) Tributos. & & \\
\hline f) Ingresos por intereses de créditos. & & \\
\hline g) Prestación de servicios. & & \\
\hline h) Amortizaciones del inmovilizado material. & & \\
\hline i) Arrendamientos. & & \\
\hline j) Compras de mercaderías. & & \\
\hline k) Ingresos de participaciones de capital. & & \\
\hline
\end{tabular}


Ejercicio 3. Transacciones que dan lugar a variaciones patrimoniales Para los siguientes tipos de variaciones patrimoniales, indique alguna transacción que dé lugar a las mismas:

\begin{tabular}{|l|l|}
\hline \multicolumn{1}{|c|}{ Variación patrimonial } & Transacción \\
\hline a) Aumento de un activo y disminución de otro. & \\
\hline b) Aumento de un activo y aumento de un pasivo. & \\
\hline $\begin{array}{l}\text { c) Disminución de un activo y disminución de un } \\
\text { pasivo. }\end{array}$ & \\
\hline d) Aumento de activo y aumento de patrimonio neto. & \\
\hline $\begin{array}{l}\text { e) Disminución de activo y disminución de patrimonio } \\
\text { neto. }\end{array}$ & \\
\hline $\begin{array}{l}\text { f) Aumento de activo, disminución de activo y } \\
\text { aumento de un pasivo. }\end{array}$ & \\
\hline $\begin{array}{l}\text { g) Aumento de una obligación y disminución de } \\
\text { patrimonio neto. }\end{array}$ & \\
\hline $\begin{array}{l}\text { h) Aumento de un activo, disminución de un activo } \\
\text { y aumento de patrimonio neto. }\end{array}$ & \\
\hline
\end{tabular}

\section{Ejercicio 4. Ecuación fundamental del patrimonio}

Sobre la base de la ecuación fundamental del patrimonio, calcule los interrogantes siguientes:

\begin{tabular}{|l|c|c|c|}
\hline & Activos & Pasivos & Patrimonio neto \\
\hline Empresa A & $¿ ?$ & 4.000 & 30.000 \\
\hline Empresa B & 86.000 & $i ?$ & 20.000 \\
\hline Empresa C & 150.000 & 110.000 & ¿? \\
\hline & Activos & Pasivos & Patrimonio neto \\
\hline Empresa A & & 4.000 & 30.000 \\
\hline Empresa B & 86.000 & & 20.000 \\
\hline Empresa C & 150.000 & 110.000 & \\
\hline
\end{tabular}

\section{Ejercicio 5. Ecuación fundamental del patrimonio extendida}

Sobre la base de la ecuación fundamental del patrimonio extendida en su aplicación al patrimonio al final de un período, calcule los interrogantes siguientes (se supondrá que todas las variaciones en el patrimonio neto derivan de ingresos y gastos imputados a resultados):

\begin{tabular}{|l|c|c|c|c|c|c|}
\hline & $\begin{array}{c}\text { Activos } \\
\text { fin } \\
\text { período }\end{array}$ & $\begin{array}{c}\text { Pasivos a fin } \\
\text { de período }\end{array}$ & $\begin{array}{c}\text { Patrimonio neto } \\
\text { inicial }\end{array}$ & $\begin{array}{c}\text { Ingresos } \\
\text { del } \\
\text { período }\end{array}$ & $\begin{array}{c}\text { Gastos } \\
\text { del } \\
\text { período }\end{array}$ & $\begin{array}{c}\text { Resultado } \\
\text { del } \\
\text { período }\end{array}$ \\
\hline Empresa A & $¿ ?$ & 15.000 & 20.000 & 10.000 & 6.000 & $i ?$ \\
\hline Empresa B & 55.000 & $i ?$ & 20.000 & $i ?$ & 20.000 & 20.000 \\
\hline Empresa C & 100.000 & 80.000 & $i ?$ & $i ?$ & 5.000 & 2.000 \\
\hline
\end{tabular}




\begin{tabular}{|l|c|c|c|c|c|c|}
\hline & $\begin{array}{c}\text { Activos } \\
\text { fin } \\
\text { período }\end{array}$ & $\begin{array}{c}\text { Pasivos a fin } \\
\text { de período }\end{array}$ & $\begin{array}{c}\text { Patrimonio neto } \\
\text { inicial }\end{array}$ & $\begin{array}{c}\text { Ingresos } \\
\text { del } \\
\text { período }\end{array}$ & $\begin{array}{c}\text { Gastos } \\
\text { del } \\
\text { período }\end{array}$ & $\begin{array}{c}\text { Resultado } \\
\text { del } \\
\text { período }\end{array}$ \\
\hline Empresa A & & 15.000 & 20.000 & 10.000 & 6.000 & \\
\hline Empresa B & 55.000 & & 20.000 & & 20.000 & 20.000 \\
\hline Empresa C & 100.000 & 80.000 & & & 5.000 & 2.000 \\
\hline
\end{tabular}

Ejercicio 6. Efecto de transacciones sobre los elementos del patrimonio

Suponga que un empresario individual realiza las transacciones que se indican a continuación. Señalar los elementos del patrimonio (activos, pasivos y patrimonio neto) que se verían afectados por las mismas y en qué sentido (aumento o disminución).

\begin{tabular}{|l|l|}
\hline \multicolumn{1}{|c|}{ Transacción } & Variaciones patrimoniales \\
\hline $\begin{array}{l}\text { a) Compra una máquina pagando el importe al } \\
\text { contado. }\end{array}$ & \\
\hline $\begin{array}{l}\text { b) Compra una máquina mitad al contado y } \\
\text { mitad a crédito. }\end{array}$ & \\
\hline $\begin{array}{l}\text { c) Vende un mueble por su valor de coste, se } \\
\text { cobra al contado. }\end{array}$ & \\
\hline $\begin{array}{l}\text { d) Vende una máquina por un valor inferior al de } \\
\text { coste, el importe se cobra al contado. }\end{array}$ & \\
\hline $\begin{array}{l}\text { e) Vende un mueble por un valor superior al de } \\
\text { coste, se cobrará a los tres meses. }\end{array}$ & \\
\hline
\end{tabular}

\section{Ejercicio 7. Efecto de transacciones sobre los elementos del patrimonio}

Suponga que un empresario individual realiza las transacciones que se indican a continuación. Señalar los elementos del patrimonio (activos, pasivos y patrimonio neto) que se verían afectados por las mismas y en qué sentido (aumento o disminución).

\begin{tabular}{|l|l|}
\hline \multicolumn{1}{|c|}{ Transacción } & Variaciones patrimoniales \\
\hline $\begin{array}{l}\text { a) Aporta al negocio un local comercial para uso } \\
\text { de la actividad. }\end{array}$ & \\
\hline $\begin{array}{l}\text { b) Negocia con un cliente la venta de productos. } \\
\text { Se acuerda que el cliente volverá la semana } \\
\text { siguiente a formalizar su compra. }\end{array}$ & \\
\hline c) Cobra el importe que debía un cliente. & \\
\hline $\begin{array}{l}\text { d) Recibe un extracto de su cuenta bancaria } \\
\text { comunicando que se ha pagado la factura del } \\
\text { teléfono. }\end{array}$ & \\
\hline $\begin{array}{l}\text { e) Registra una deuda con Hacienda en concepto } \\
\text { de impuestos. }\end{array}$ & \\
\hline $\begin{array}{l}\text { f) Adquiere un coche con el dinero recibido de } \\
\text { una herencia. }\end{array}$ & \\
\hline
\end{tabular}


Ejercicio 8. Efecto de transacciones sobre los elementos del patrimonio Suponga que un empresario individual realiza las transacciones que se indican a continuación. Señalar los elementos del patrimonio (activos, pasivos y patrimonio neto) que se verían afectados por las mismas y en qué sentido (aumento o disminución).

\begin{tabular}{|c|c|}
\hline \multicolumn{1}{|c|}{ Transacción } & Variaciones patrimoniales \\
\hline $\begin{array}{l}\text { a) Finaliza el mes y tiene derecho a cobrar el importe } \\
\text { de un local que ha arrendado. Se espera a cobrar el } \\
\text { importe en el plazo de quince días. }\end{array}$ & \\
\hline $\begin{array}{l}\text { b) Recibe una comunicación de Hacienda indicándole } \\
\text { que se ha reformado la ley del impuesto sobre benefi- } \\
\text { cios empresariales y que el próximo año va a subir el } \\
\text { porcentaje de impuestos que tendrá que pagar sobre } \\
\text { los beneficios que obtenga. }\end{array}$ & \\
\hline $\begin{array}{l}\text { c) Retira de la cuenta bancaria de la empresa un importe } \\
\text { en efectivo para su uso personal. }\end{array}$ & \\
\hline $\begin{array}{l}\text { d) Pierde una máquina por incendio de la fábrica. } \\
\text { f) Paga en efectivo a los trabajadores la nómina del mes. }\end{array}$ & \\
\hline $\begin{array}{l}\text { g) Recibe la factura correspondiente al suministro de } \\
\text { agua del mes, la cual queda pendiente de pago. }\end{array}$ & \\
\hline
\end{tabular}

\section{Ejercicio 9. Variaciones en el patrimonio neto, ingresos y gastos}

Distinga de entre las transacciones de los ejercicios 6, 7 y 8 anteriores que modifican el patrimonio neto, aquellas que suponen ingresos y gastos 


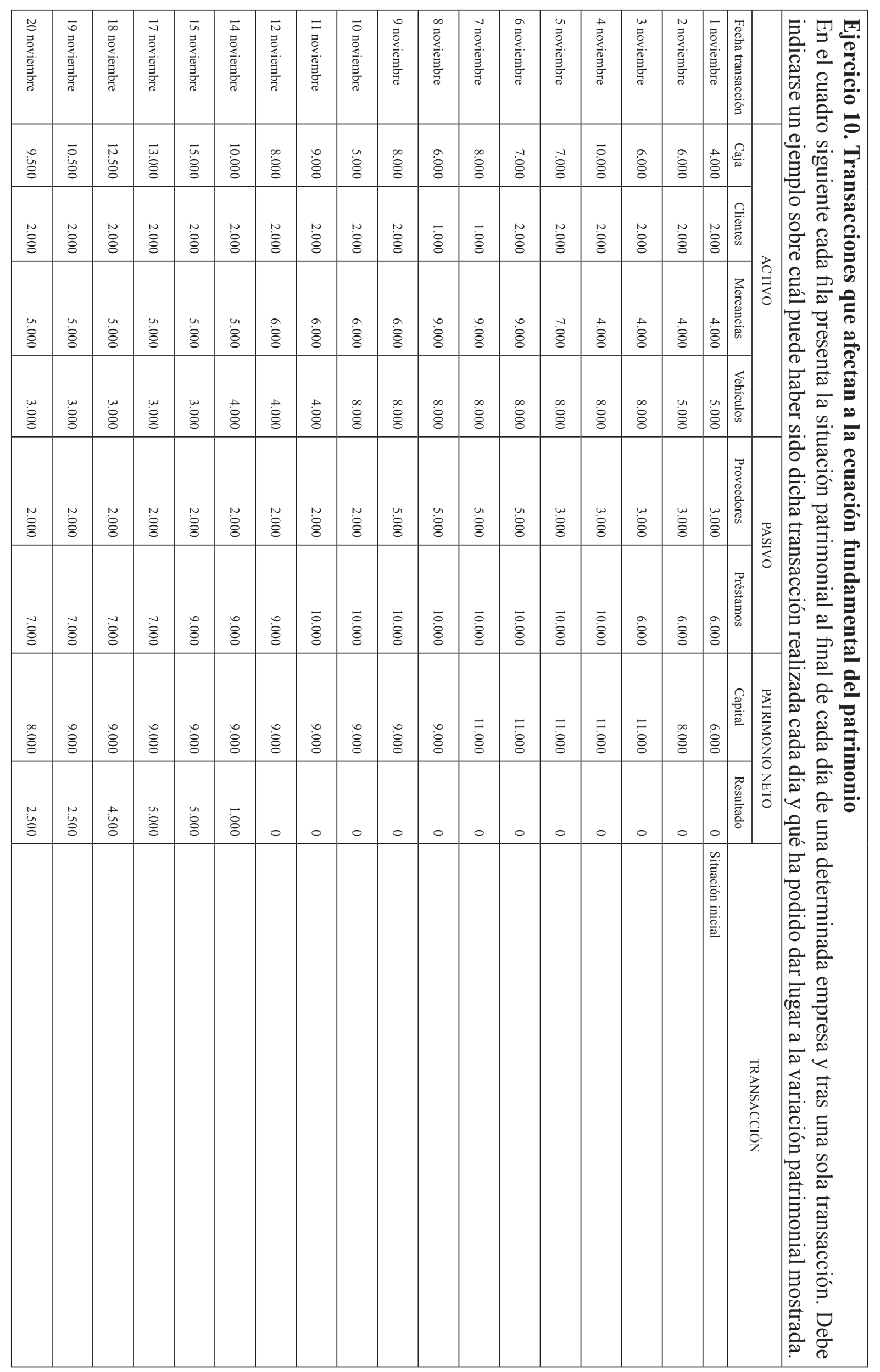




\section{Ejercicio 11. Elaboración de un balance}

Con los elementos que se muestran a continuación elabore y presente el balance de la empresa SUMINISTROS ELÉCTRICOS DE CASTELLÓN SA referido al 31 de diciembre de 2000. Los elementos del balance deben denominarse y clasificarse según como se ha visto en el tema.

\begin{tabular}{|l|r|}
\hline \multicolumn{1}{|c|}{ Elemento patrimonial } & \multicolumn{1}{c|}{ Importe } \\
\hline Productos para vender. & 3.000 \\
\hline Derechos de cobro contra clientes. & 2.000 \\
\hline Efectivo en caja. & 500 \\
\hline Deudas con suministradores de materiales (vencimiento un mes). & 3.400 \\
\hline Préstamos bancarios a devolver en 3 años. & 10.000 \\
\hline Máquinas para la transformación. & 8.000 \\
\hline Nave industrial. & 11.000 \\
\hline Mobiliario del departamento administrativo y comercial. & 1.000 \\
\hline Inversión a largo plazo en acciones. & 1.500 \\
\hline Deudas con Hacienda a pagar en 2 meses. & 2.500 \\
\hline Aportaciones iniciales de los socios. & 12.000 \\
\hline Inversión a corto plazo en acciones. & 900 \\
\hline
\end{tabular}

\begin{tabular}{|l|l|l|l|}
\hline \multicolumn{1}{|c|}{ SUMINISTROS ELÉCTRICOS DE CASTELLÓN S.A. } \\
Balance a 31/12/00
\end{tabular}


Ejercicio 12. Elaboración de un balance

Con los elementos que se muestran a continuación elabore y presente un balance de la empresa PANIFICADORA LITORAL SA referido a 31 de diciembre de 2000. Los elementos del balance deben denominarse y clasificarse según se ha visto en el tema.

\begin{tabular}{|l|r|}
\hline \multicolumn{1}{|c|}{ Elemento patrimonial } & Importe \\
\hline Materias primas para transformación. & 200.000 \\
\hline Deudas con los trabajadores por la nómina (ya vencidas). & 90.000 \\
\hline Productos terminados y listos para venta. & 500.000 \\
\hline Derechos de cobro contra clientes. & 300.000 \\
\hline Deudas con la Seguridad Social a pagar en un mes. & 50.000 \\
\hline Subvenciones de capital. & 200.000 \\
\hline Efectivo en cuentas corrientes bancarias. & 150.000 \\
\hline Efectivo en caja. & 10.000 \\
\hline Derecho a utilización en exclusiva de una patente industrial. & 500.000 \\
\hline $\begin{array}{l}\text { Deudas con suministradores de materiales (vencimiento dos } \\
\text { meses). }\end{array}$ & 700.000 \\
\hline Préstamos bancarios a devolver en 4 años. & 500.000 \\
\hline Máquinas para la transformación. & 500.000 \\
\hline Nave industrial. & 1.250 .000 \\
\hline Mobiliario del departamento administrativo y comercial. & 1.000 .000 \\
\hline Inversión a largo plazo en acciones. & 1.500 .000 \\
\hline Crédito concedido a largo plazo a un trabajador. & 500.000 \\
\hline Derechos de cobro contra otros deudores. & 200.000 \\
\hline Aportaciones iniciales de los socios. & 100.000 \\
\hline Beneficios retenidos de otros años. & 50.000 \\
\hline Beneficios del año a que se refiere el balance. & 250.000 \\
\hline Deudas con el suministrador de electricidad (a pagar en un mes). & 50.000 \\
\hline Inversión a corto plazo en acciones. & 10.000 \\
\hline Préstamos bancarios a devolver en 9 meses. & . \\
\hline & \\
\hline
\end{tabular}




\begin{tabular}{|l|l|l|l|}
\hline \multicolumn{3}{|c|}{ ACTIVISTROS ELÉCTRICOS DE CASTELLÓN S.A. } \\
Balance a 31/12/00
\end{tabular}

\section{Ejercicio 13. Elaboración de la cuenta de pérdidas y ganancias}

Con los ingresos y gastos que se recogen a continuación presente una cuenta de pérdidas y ganancias de la empresa MUEBLES LA PLANA SA referidos al período 1 de enero de 2000 a 31 de diciembre de 2000. Los elementos de la cuenta de pérdidas y ganancias deben denominarse y clasificarse según como se ha visto en el tema.

\begin{tabular}{|l|r|}
\hline \multicolumn{1}{|c|}{ Elemento } & Importe \\
\hline Ingresos por venta de productos. & 2.300 .000 \\
\hline Impuesto sobre sociedades. & 110.000 \\
\hline Coste de compra de productos vendidos. & 1.000 .000 \\
\hline Dividendos cobrados de una inversión en acciones. & 40.000 \\
\hline Sueldos y salarios del personal. & 500.000 \\
\hline Intereses pagados por préstamos obtenidos. & 120.000 \\
\hline Seguridad social del personal a cargo de la empresa. & 100.000 \\
\hline Gastos por suministro eléctrico. & 50.000 \\
\hline Desgaste sufrido por el local comercial y mobiliario de exposición. & 200.000 \\
\hline Ingresos por arrendamientos de parte del local comercial. & 100.000 \\
\hline
\end{tabular}




\begin{tabular}{|l|r|}
\hline Beneficios por la venta de un vehículo del inmovilizado. & 90.000 \\
\hline Pérdidas por venta de una máquina de producción. & 50.000 \\
\hline Alquileres pagados correspondientes al almacén. & 40.000 \\
\hline Tributos a favor del Ayuntamiento. & 10.000 \\
\hline Intereses a su favor de cuentas corrientes bancarias. & 20.000 \\
\hline
\end{tabular}

\begin{tabular}{|l|l|}
\hline \multicolumn{2}{|c|}{ Cuenta de pérdidas y ganancias del período 01/01/00 a 31/12/00 } \\
\hline 1. Importe de la cifra de negocios. & \\
4. Aprovisionamientos (consumo mercancías). & \\
5. Otros ingresos de explotación. & \\
6. Gastos de personal. & \\
7. Otros gastos de explotación. & \\
8. Amortizaciones del inmovilizado. & \\
11. Deterioro y resultado por enajenaciones de inmovilizado. & \\
\hline A.1) RESULTADO DE EXPLOTACIÓN $=(1)+(4)+(5)+(6)+(7)+(8)+(11)$ & \\
\hline 12. Ingresos financieros. & \\
\hline 13. Gastos financieros. & \\
16. Deterioro y resultado por enajenaciones de instrumentos financieros. & \\
\hline A.2) RESULTADO FINANCIERO $=(12)+(13)+(14)+(16)$ & \\
\hline A.3) RESULTADO ANTES DE IMPUESTOS $=($ A.1 $)+($ A.2 $)$ & \\
\hline 17. Impuesto sobre beneficios. & \\
\hline A.4) RESULTADO DEL EJERCICIO $=($ A.3 $)+(17)$ & \\
\hline
\end{tabular}


Ejercicio 14. Efecto de transacciones sobre la ecuación fundamental del patrimonio

Utilizando la ecuación fundamental del patrimonio muestre las repercusiones que sobre el patrimonio de una empresa individual de nueva creación denominada TASACIONES ESPAÑOLAS SA (TAES), tienen las siguientes transacciones realizadas en marzo de 2000.

a) El 1 de marzo se crea la empresa, aportando los socios un total de 10.000,00€ en efectivo.

b) El 3 de marzo, se compra en efectivo material de oficina por valor de 1.000,00 $€$.

c) El 5 de marzo, se compra a crédito material de oficina por valor de 500,00€.

d) El 10 de marzo, se compra un local comercial por valor de 10.000,00 €. De estas se pagan en efectivo $1.000 € \mathrm{y}$ el resto se pagará dentro de 6 meses.

e) El 11 de marzo, se devuelve al proveedor del punto $b$ ) materiales de coste 100,00€ al detectarse un defecto en los mismos, el proveedor devuelve el dinero.

f) El 12 de marzo, se devuelve al proveedor del punto $c$ ) materiales de oficina de coste $50,00 €$ por no corresponder con el pedido realizado, el proveedor sustituye y entrega el material correcto.

$g$ ) El 15 de marzo, el proveedor del punto $b$ ) anuncia una subida en el precio de sus productos de oficina para el próximo trimestre.

h) El 15 de marzo se obtiene un préstamo a largo plazo por 3.000,00 €.

i) El 16 de marzo, se cobran servicios de tasación a varios clientes por 5.000,00€.

j) El 17 de marzo, se facturan servicios de tasación (a crédito) a varios clientes por $20.000,00 €$.

k) El 18 de marzo, uno de los clientes, que en este momento no debe nada a la empresa, comunica por carta que a partir de ese momento dejará de requerir los servicios de la empresa puesto que ha encontrado otra más ventajosa.

l) El 18 de marzo se compra mobiliario al contado por importe de 1.000,00 €.

m) El 19 de marzo, los socios retiran de la empresa 100,00 € para cubrir sus necesidades personales.

n) El 20 de marzo, las previsiones económicas del gobierno hacen prever un descenso muy importante en los ingresos futuros de la empresa.

$o$ ) El 25 de marzo, se vende la mitad del local comercial adquirido en el punto $d$ ) por $12.000,00 €$, importe que se cobra al en efectivo.

p) El 26 de marzo, se compra material de oficina por $600,00 €$, una tercera parte en efectivo y el resto a crédito.

q) El 26 de marzo se pagan 3.000,00 € a los proveedores de inmovilizado del punto $d$ ).

r) El 27 de marzo se ha pagado en efectivo gastos por suministro eléctrico y teléfono por importe de $300,00 €$.

s) Durante marzo se ha consumido material de oficina por importe de 800,00€

t) A final de mes se paga en efectivo la nómina de personal que asciende a 4.000,00€ y además los gastos de seguridad social a cargo de la empresa por importe de $500,00 €$. 


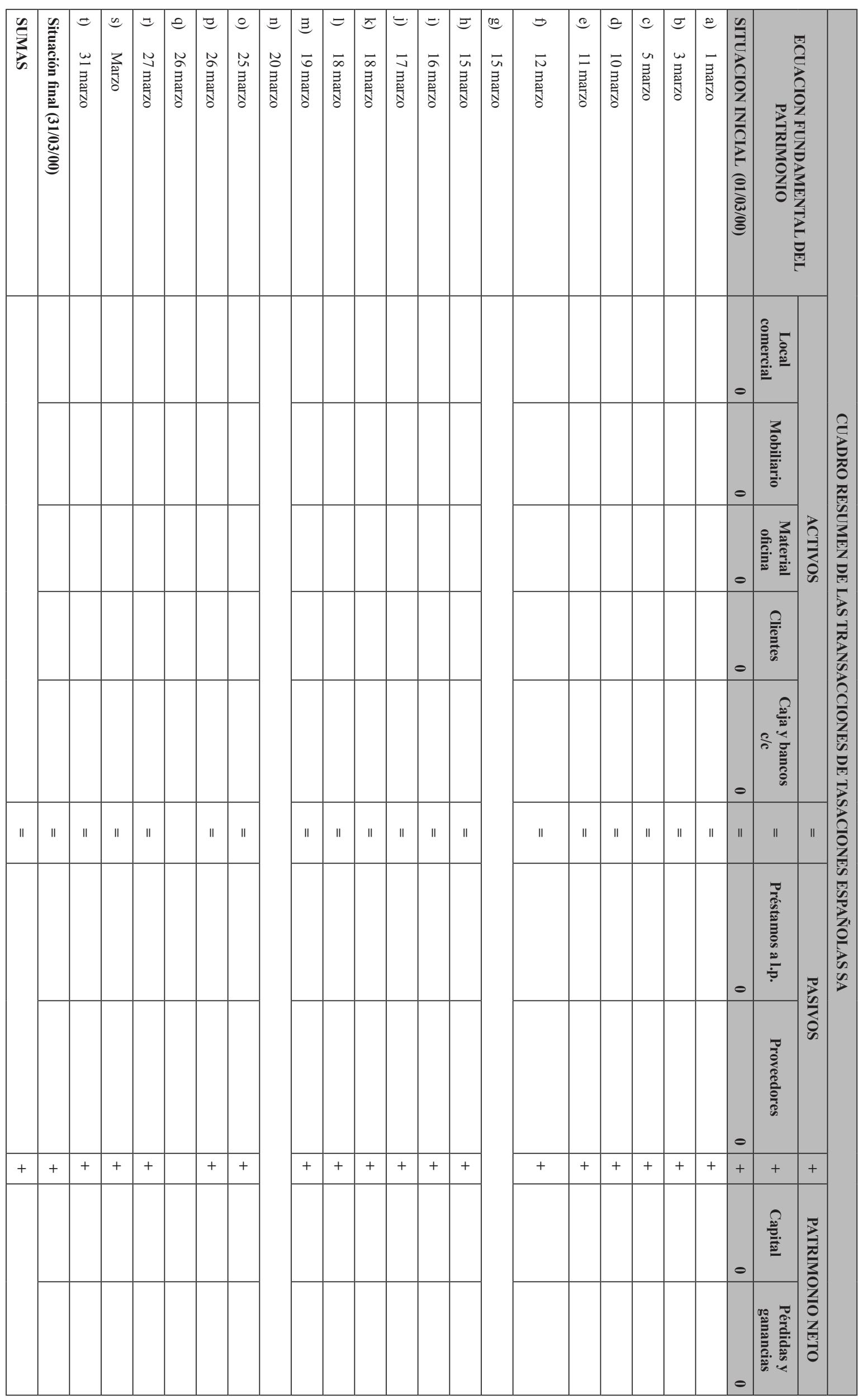


Ejercicio 15. Elaboración de cuentas anuales

Con los datos del ejercicio anterior elabore y presente el balance y la cuenta de pérdidas y ganancias de la empresa TAES referidas a 31 de marzo de 2000.

\begin{tabular}{|l|l|l|l|}
\hline \multicolumn{1}{|c|}{ TASACIONES ESPANOLAS S.A. } \\
Balance a 31/03/00
\end{tabular}

\begin{tabular}{|l|l|}
\hline \multicolumn{1}{|c|}{ TASACIONES ESPAÑOLAS S.A. } \\
\multicolumn{1}{|c|}{ Cuenta de pérdidas y ganancias del período 01/03/00 a 31/03/00 } \\
\hline 1. Importe de la cifra de negocios & \\
4. Aprovisionamientos & \\
5. Otros ingresos de explotación & \\
6. Gastos de personal & \\
7. Otros gastos de explotación & \\
8. Amortizaciones del inmovilizado & \\
11. Deterioro y resultado por enajenaciones de inmovilizado & \\
\hline A.1) RESULTADO DE EXPLOTACIÓN $=(1)+(4)+(5)+(6)+(7)+(8)+(11)$ & \\
\hline $\begin{array}{l}\text { 12. Ingresos financieros } \\
\text { 13. Gastos financieros } \\
\text { 16. Deterioro y resultado por enajenaciones de instrumentos financieros }\end{array}$ & \\
\hline A.2) RESULTADO FINANCIERO $=(12)+(13)+(14)+(16)$ & \\
\hline A.3) RESULTADO ANTES DE IMPUESTOS $=($ A.1 $)+($ A.2 $)$ & \\
\hline 17. Impuesto sobre beneficios & \\
\hline A.4) RESULTADO DEL EJERCICIO $=($ A.3 $)+(17)$ & \\
\hline
\end{tabular}

Ejercicio 16. Efecto de transacciones sobre la ecuación fundamental del patrimonio

Utilizando la ecuación fundamental del patrimonio, analice y represente las repercusiones que tienen determinadas transacciones del mes de enero sobre el patrimonio la empresa ESPECTÁCULOS UNIVERSALES SA (ESUNSA), que se dedica a la prestación 
de servicios de espectáculo (organización de fiestas, bailes, conciertos, etc.) con su propio personal. La empresa presenta el siguiente balance a 1 de enero de 2000 previo a la realización de las transacciones que se indican.

\begin{tabular}{|c|c|c|c|}
\hline \multicolumn{4}{|c|}{$\begin{array}{c}\text { EUNSA SA } \\
\text { Balance a } 1 \text { de enero de } 2000\end{array}$} \\
\hline \multicolumn{2}{|c|}{ ACTIVO } & \multicolumn{2}{|c|}{ PASIVO Y PATRIMONIO NETO } \\
\hline $\begin{array}{l}\text { Local comercial } \\
\text { Mobiliario } \\
\text { Vehículos } \\
\text { Clientes } \\
\text { Bancos c/c } \\
\text { Caja }\end{array}$ & $\begin{array}{r}100.000 \\
50.000 \\
30.000 \\
20.000 \\
10.000 \\
5.000\end{array}$ & $\begin{array}{l}\text { PATRIMONIO NETO } \\
\text { Capital } \\
\text { PASIVOS } \\
\text { Préstamos a largo plazo } \\
\text { Préstamos a corto plazo } \\
\text { Hacienda Pública Acreedora } \\
\text { Proveedores }\end{array}$ & $\begin{array}{r}\mathbf{1 5 0 . 0 0 0} \\
150.000 \\
\\
\mathbf{6 5 . 0 0 0} \\
40.000 \\
10.000 \\
5.000 \\
10.000\end{array}$ \\
\hline TOTAL ACTIVO & 215.000 & $\begin{array}{l}\text { TOTAL PATRIMONIO } \\
\text { NETO Y PASIVO }\end{array}$ & 215.000 \\
\hline
\end{tabular}

Las transacciones que ocurren durante enero son:

a) El 4 de enero cobra en efectivo de los clientes un importe de $3.000 €$.

b) El 7 de enero paga a sus proveedores $6.000 €$ a través de una transferencia bancaria.

c) El 11 de enero solicita un nuevo préstamo a largo plazo por $40.000 €$ que se ingresan en la cuenta corriente bancaria.

d) El 14 de enero adquiere un mueble para la oficina por $1.000 €$ pagando el importe en efectivo.

e) El 15 de enero organiza unos espectáculos para un cliente y factura por la gestión $15.000 €$. De dicha cantidad se cobra en efectivo la mitad y el resto se cobrará a los 3 meses.

f) El 16 de enero ingresa en la cuenta corriente bancaria $5.000 €$ del efectivo disponible.

g) El 17 de enero devuelve en su totalidad el préstamo a corto plazo, se carga la totalidad del importe en la cuenta corriente bancaria.

h) El 18 de enero adquiere un nuevo vehículo por importe de $20.000 €$. El pago del mismo se producirá a los 60 días.

i) El 20 de enero paga en efectivo la mitad de la deuda a la Hacienda Pública.

j) El 21 de enero vende un vehículo por $25.000 €$, su coste es de $10.000 €$. Del importe se cobra en efectivo $12.000 €$ y el resto queda pendiente de cobro.

k) El 25 de enero se recibe una factura por una campaña de publicidad realizada a inicios de enero por $2.000 €$, que queda pendiente de pago.

l) La nómina de los trabajadores del mes asciende a $6.000 €$ y se pagan al en efectivo a final del mes.

m) Los gastos de seguridad social a cargo de la empresa del mes ascienden a $2.000 €$ y quedan pendientes de pago a final de mes.

n) A final de mes se cargan en la cuenta corriente los intereses de los préstamos que ascienden a $300 €$.

o) La cuenta corriente bancaria genera unos intereses a favor de $20 €$, importe que se abona en cuenta el 31 de enero.

p) A final de mes se realiza un recuento físico del mobiliario y se detecta que fal$\tan 10$ sillas valoradas en $300 €$. 


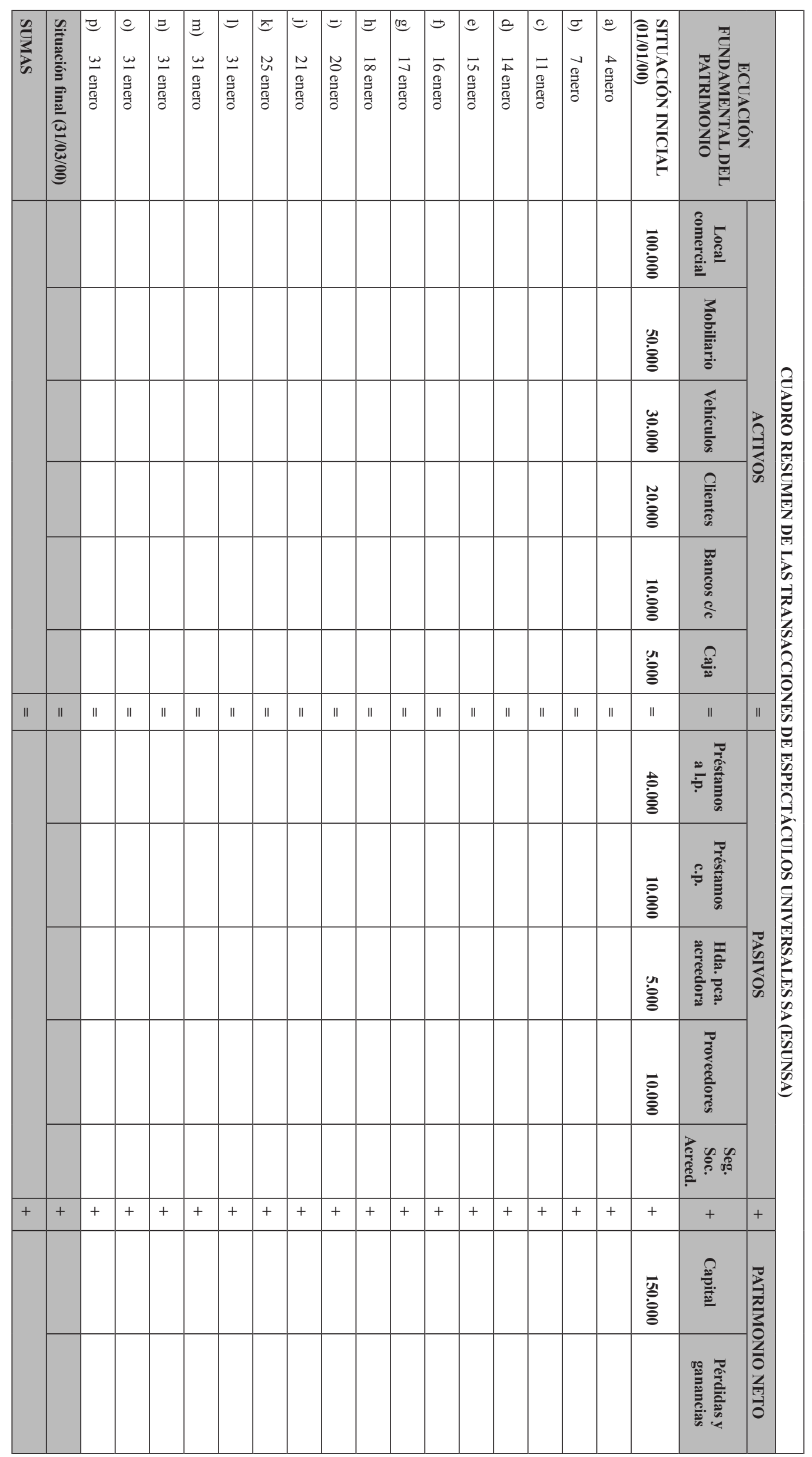




\section{Ejercicio 17. Cuentas anuales}

Con los datos del ejercicio anterior elabore y presente el balance y la cuenta de pérdidas y ganancias de la empresa a 1 de enero de 2000 .

\begin{tabular}{|c|c|}
\hline \multicolumn{2}{|c|}{$\begin{array}{c}\text { ESPECTÁCULOS UNIVERSALES S.A. } \\
\text { Balance a 31/01/00 }\end{array}$} \\
\hline ACTIVO & PATRIMONIO NETO Y PASIV \\
\hline $\begin{array}{l}\text { A) ACTIVO NO CORRIENTE } \\
\text { I. Inmovilizado intangible } \\
\text { II. Inmovilizado material } \\
\text { III. Inversiones inmobiliarias } \\
\text { V. Inversiones financieras a largo plazo }\end{array}$ & $\begin{array}{l}\text { A) PATRIMONIO NETO } \\
\text { A.1) Fondos propios } \\
\text { I. Capital } \\
\text { III. Reservas } \\
\text { VII. Pérdidas y ganancias } \\
\text { A.3) Subvenciones }\end{array}$ \\
\hline \multirow{3}{*}{$\begin{array}{l}\text { B) ACTIVO CORRIENTE } \\
\text { II. Existencias } \\
\text { III. Deudores comerciales y cuentas a } \\
\text { cobrar } \\
\text { V. Inversiones financieras a corto plazo } \\
\text { VI. Periodificaciones a corto plazo } \\
\text { VII. Efectivo }\end{array}$} & $\begin{array}{l}\text { B) PASIVO NO CORRIENTE } \\
\text { II. Deudas a largo plazo }\end{array}$ \\
\hline & $\begin{array}{l}\text { C) PASIVO CORRIENTE } \\
\text { III. Deudas a corto plazo } \\
\text { V. Acreedores comerciales y cuentas a } \\
\text { pagar }\end{array}$ \\
\hline & VI. Periodificaciones a corto plazo \\
\hline TOTAL ACTIVO $(\mathrm{A}+\mathrm{B})$ & $\begin{array}{c}\text { TOTAL PATRIMONIO NETO Y } \\
\text { PASIVO }(\mathrm{A}+\mathrm{B}+\mathrm{C})\end{array}$ \\
\hline
\end{tabular}

\begin{tabular}{|l|l|}
\hline \multicolumn{2}{|c|}{ ESPECTÁCULOS UNIVERSALES SA } \\
\multicolumn{1}{|c|}{ Cuenta de pérdidas y ganancias del período 01/01/00 a 31/01/00 } \\
\hline $\begin{array}{l}\text { 1. Importe de la cifra de negocios } \\
\text { 4. Aprovisionamientos } \\
\text { 5. Otros ingresos de explotación } \\
\text { 6. Gastos de personal }\end{array}$ \\
$\begin{array}{l}\text { 7. Otros gastos de explotación } \\
\text { 8. Amortizaciones del inmovilizado } \\
\text { 11. Deterioro y resultado por enajenaciones de inmovilizado }\end{array}$ \\
\hline A.1) RESULTADO DE EXPLOTACIÓN $=(1)+(4)+(5)+(6)+(7)+(8)+(11)$ \\
\hline 12. Ingresos financieros & \\
13. Gastos financieros & \\
16. Deterioro y resultado por enajenaciones de instrumentos financieros & \\
\hline A.2) RESULTADO FINANCIERO $=(12)+(13)+(14)+(16)$ & \\
\hline A.3) RESULTADO ANTES DE IMPUESTOS $=($ A.1 $)+($ A.2 $)$ & \\
\hline 17. Impuesto sobre beneficios & \\
\hline A.4) RESULTADO DEL EJERCICIO $=($ A.3 $)+(17)$ & \\
\hline
\end{tabular}




\section{Casos}

Caso 1. Análisis de cuentas

A continuación se muestra el balance y la cuenta de pérdidas y ganancias de INDITEX correspondiente al ejercicio 2009 .

\begin{tabular}{|c|c|c|c|}
\hline $\begin{array}{l}\text { INDUSTRIA DE I } \\
\text { Balances } \\
31 \text { de enero } \\
\text { (Expresados }\end{array}$ & $\begin{array}{l}\text { SENOO TEX } \\
\text { e Situación } \\
\text { e } 2010 \text { y } 20 \\
\text { miles de eu }\end{array}$ & S.A. & \multirow[b]{2}{*}{2008} \\
\hline Active & Nota & 2009 & \\
\hline Inmovilizado intangible & Nota 5 & 10.656 & 9.591 \\
\hline Patentes, licencias, marcas y similares & & 3.923 & 4.260 \\
\hline Aplicaciones informáticas & & 4.863 & 4.249 \\
\hline Anticipos & & 1.870 & 1.033 \\
\hline Otro inmovilizado intangible & & - & 49 \\
\hline Inmovilizado material & Nota 6 & 103.586 & 110.303 \\
\hline Terrenos y construcciones & & 31.669 & 31.599 \\
\hline $\begin{array}{l}\text { Instalaciones técnicas, maquinaria, utillaje, mobiliario y } \\
\text { otro inmovilizado material }\end{array}$ & & 61.148 & 48.881 \\
\hline Inmovilizado en curso y anticipos & & 10.769 & 29.823 \\
\hline Inversiones inmobiliarias & Nota 7 & 299.319 & 299.922 \\
\hline Terrenos & & 43.558 & 34.828 \\
\hline Construcciones & & 255.761 & 206.676 \\
\hline Inversiones en adaptación y anticipos & & - & 58.418 \\
\hline Inversiones en empresas del grupo y asociadas a largo plazo & & 2.086.491 & 1.892 .886 \\
\hline Instrumentos de patrimonio & Nota 10 & 1.954 .264 & 1.735 .833 \\
\hline Créditos a empresas & Nota 12 & 132.227 & 157.053 \\
\hline Inversiones financieras a largo plazo & Nota 12 & 12.144 & 16.159 \\
\hline Instrumentos de patrimonio & & 11.516 & 15.521 \\
\hline Otros activos financieros & & 628 & 638 \\
\hline Activos por impuesto diferido & Nota 21 & 1.693 & 1.153 \\
\hline Total activos no corrientes & & 2.513 .889 & 2.330 .014 \\
\hline Existencias & Nota 14 & 270.809 & 337.005 \\
\hline Comerciales & & 247.631 & 303.380 \\
\hline Materias primas y otros aprovisionamientos & & 23.178 & 33.625 \\
\hline Deudores comerciales y otras cuentas a cobrar & & 402.025 & 482.892 \\
\hline Clientes por ventas y prestaciones de servicios corto plazo & & 49.387 & 39.899 \\
\hline Clientes, empresas del grupo y asociadas corto plazo & & 309.430 & 376.618 \\
\hline Deudores varios & & 11.673 & 46.472 \\
\hline Personal & & 246 & 328 \\
\hline Activos por impuestos corrientes & & - & 1.763 \\
\hline Otros créditos con las Administraciones Públicas & & 31.289 & 17.812 \\
\hline Inversiones en empresas del grupo y asociadas a corto plazo & Nota 12 & 580.426 & 598.851 \\
\hline Crtditos a empresas & & 580.392 & 590.965 \\
\hline Otros activos financieros & & 34 & 7.886 \\
\hline Inversiones financieras a corto plazo & Nota 12 & 58 & 53 \\
\hline Créditos a empresas & & 44 & 44 \\
\hline Otros activos financieros & & 14 & 9 \\
\hline Periodificaciones a corto plazo & & - & 1 \\
\hline Efectivo y otros activos líquidos equivalentes & Nota 15 & 59.474 & 127.486 \\
\hline Tesoreria & & 48.649 & 41.859 \\
\hline Otros activos líquidos equivalentes & & 10.825 & 85.627 \\
\hline Total activos corrientes & & 1.312 .792 & 1.546 .288 \\
\hline Total activo & & 3.826 .681 & 3.876 .302 \\
\hline
\end{tabular}




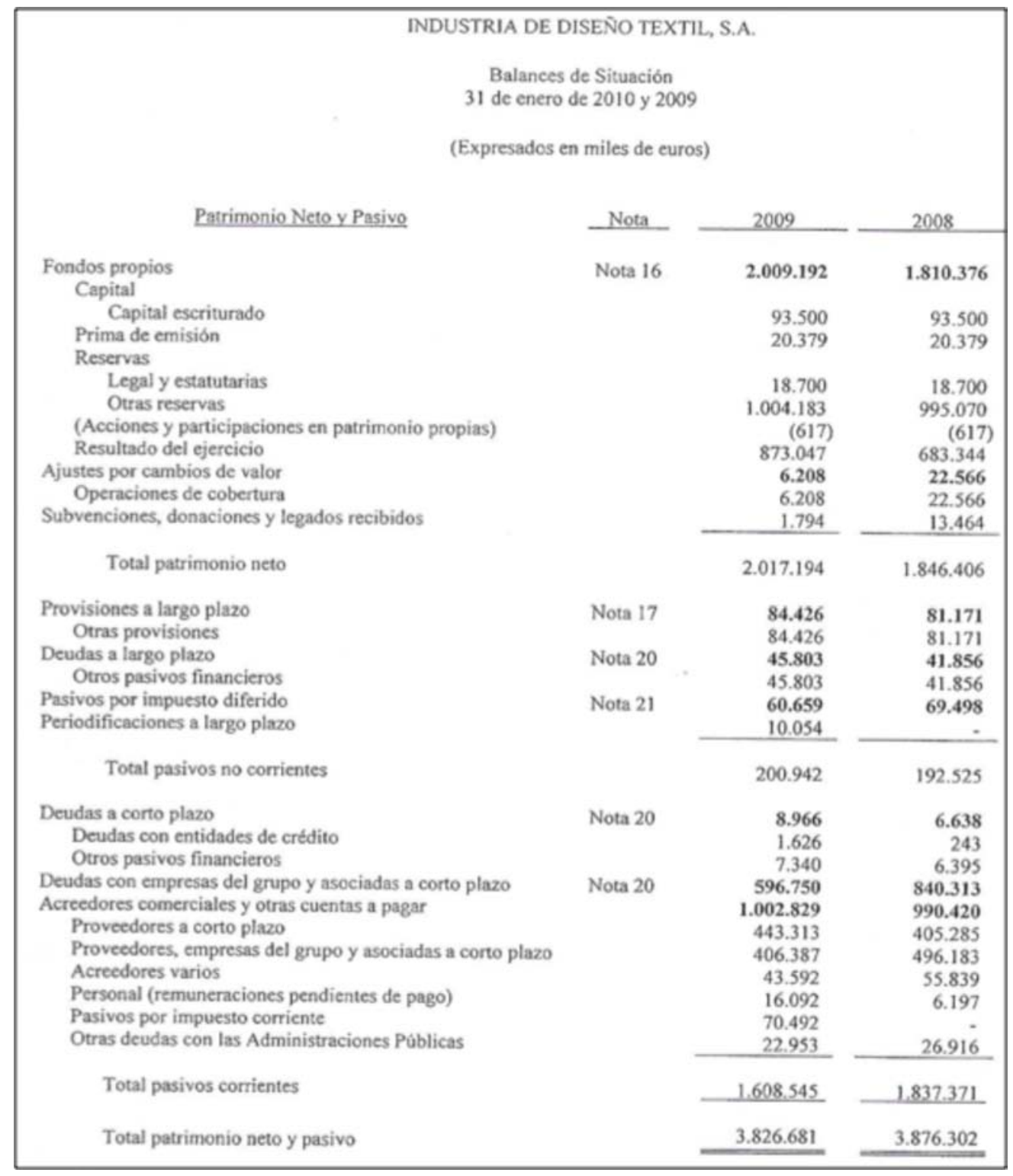




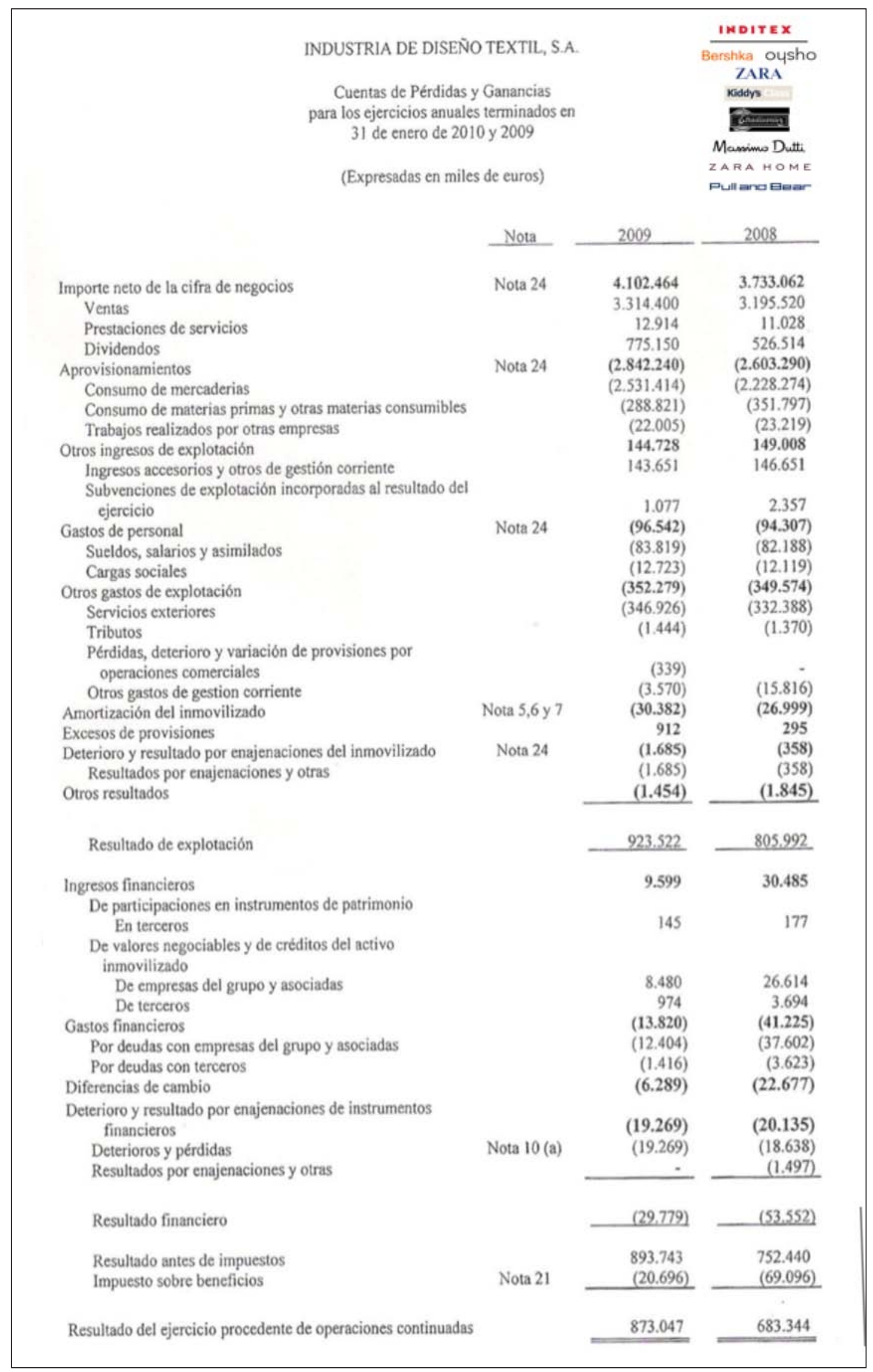


1. Observe el balance y:

- Determine el valor total de su activo, pasivo y patrimonio neto y expresarlo en forma de la ecuación fundamental del patrimonio para los dos años cuyos datos se muestran.

- Determine la variación habida en el valor total de su activo, pasivo y patrimonio neto entre dichos dos años.

- Compare el valor total de los pasivos (corrientes y no corrientes) con el valor total de los activos y comente dicha proporción para los dos años mostrados.

- Compare el importe de efectivo con el pasivo corriente para los dos años y comente los resultados.

2. Observe la cuenta de pérdidas y ganancias y:

- Determine el valor total de sus ingresos y gastos en los dos años cuyos datos se muestran.

- Compare el resultado del ejercicio con los ingresos totales y determine el porcentaje de beneficio sobre ventas para los dos años.

- Compare el resultado del ejercicio con el valor total del activo para los dos años y determine el porcentaje de rentabilidad sobre el activo

- Compare el resultado del ejercicio con el patrimonio neto y determine el porcentaje de rentabilidad sobre el patrimonio neto.

\section{Caso 2. Análisis de cuentas}

Resuelva las cuestiones indicadas en el Caso 1 con las cuentas anuales de una empresa de su elección de entre las IBEX-35 de Bolsa de Madrid de un sector no financiero. La información puede obtenerse en las página web de la Comisión

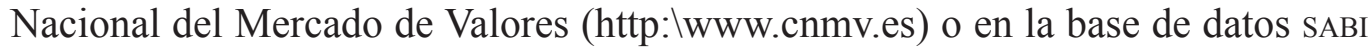
disponible en la biblioteca de la UJI.

\section{Caso 3. Cuentas previsionales}

Suponga que la Universidad ha cedido al Consejo de Estudiantes un local en el Ágora para destinarlo al ocio de estudiantes bajo la gestión del mismo. Suponga que es un representante de los alumnos en el Consejo de Estudiantes de la uJ y que ha sido encargado por el mismo de la gestión de dichas actividades. Suponga que el Consejo de Estudiantes va a organizar dicha actividad como empresa y con el objetivo de ganar dinero, que servirá para financiar posteriormente otras actividades del Consejo. Trabajo a realizar:

1. Identifique al menos tres actividades concretas (venta de bienes, prestación de servicios, actividades lúdicas, culturales, etc.) que podría realizar dicha empresa.

2. Identifique y valore las inversiones en activos necesarios para el desarrollo de dichas actividades. Como se ha dicho el local es cedido por la UJ y sin coste. Suponga que todas las inversiones deben pagarse en efectivo 
3. Identifique y valore al menos dos posibles fuentes de financiación para cubrir el valor total de dichas inversiones iniciales. Suponga que se percibe en efectivo dicho importe.

4. Identifique y valore al menos cinco transacciones de ingresos y cinco de gastos que probablemente ocurrirán durante el primer año, suponga que todo se cobra y paga en efectivo menos el último ingreso y el último gasto del año, que quedan pendientes de cobro/pago hasta el año siguiente.

5. Prepare una cuenta de pérdidas y ganancias previsional para el primer año.

6. Prepare un balance previsional para el final del primer año. 


\section{TEMA 3}

\section{El método contable y la partida doble}

INTRODUCCIÓN

Partiendo del principio de dualidad y el método de la partida doble, en este tema se estudian los instrumentos materiales de registro de la contabilidad, las cuentas y el diario, así como las reglas de registro en dichos instrumentos. Finalmente se mostrará la estructura y contenido del balance de comprobación de sumas y saldos.

\section{CONTENIDO}

3.1 Principio de dualidad y el método de la partida doble

3.2 Las cuentas, estructura y reglas de registro

3.3 El diario, estructura y registro

3.4 El cuadro de cuentas

3.5 Ejemplo de registro en las cuentas y en el diario

3.6 El balance de comprobación de sumas y saldos

3.7 Proceso contable y secuencia de registro

3.8 Formatos reales de cuentas de mayor y diario 


\subsection{Principio de dualidad y el método de la partida doble}

Tal y como se ha podido comprobar en el tema anterior, en cualquier hecho contable siempre hay, al menos, dos elementos de las cuentas anuales afectados. Además, la variación en estos elementos es tal que la ecuación fundamental del patrimonio se respeta siempre.

$$
\begin{gathered}
A_{0}=P_{0}+N_{0} \\
A_{0}+\uparrow A+\downarrow A=P_{0}+\uparrow P+\downarrow P+N_{0}+\uparrow N+\downarrow N \\
A_{1}=P_{1}+N_{1}
\end{gathered}
$$

Este hecho es consecuencia de la propia definición del patrimonio neto, como diferencia entre los activos y pasivos de una unidad económica. A este hecho se le conoce como «principio de dualidad» y constituye una de las bases fundamentales del procedimiento de registro contable denominado «método de la partida doble».

Los fundamentos del método de la partida doble pueden resumirse en:

\section{Método de la partida doble}

1. La ecuación fundamental del patrimonio expresa una identidad contable que debe cumplirse en todo momento.

2. En cualquier hecho contable hay al menos dos elementos de la ecuación afectados (sufren algún tipo de variación), con lo que exige al menos el registro de dos anotaciones para recoger la variación de cada uno de ellos.

3. Las variaciones de los elementos que resultan afectados contrarrestan entre si sus efectos sobre la ecuación fundamental del patrimonio de forma que esta sigue cumpliéndose tras el hecho contable.

Este método se instrumenta actualmente mediante la utilización de equipos informáticos, aunque antes de la aparición de estos el registro de los hechos contables se producía manualmente. Con independencia de la instrumentación manual o informática del proceso físico de registro, la teoría contable a aplicar para el análisis de cualquier transacción es siempre la misma.

\subsection{Las cuentas, estructura y reglas de registro}

Una cuenta es un instrumento de representación de los elementos patrimoniales. En una cuenta se refleja el valor inicial, los aumentos y disminuciones y valor final de un elemento: 
- Cada elemento de activo, pasivo y patrimonio neto se representa mediante una cuenta específica, que tendrá una denominación adecuada que identifique el elemento al cual representa.

Por ejemplo: (1) la cuenta de activo que representa los derechos de cobro frente a clientes se denomina «Clientes (A)»; (2) la cuenta de pasivo que representa las obligaciones de pago de la empresa a sus proveedores por las compras se denomina «Proveedores (P)»; y (3) la cuenta de patrimonio neto que representa las aportaciones de los socios se denomina «Capital $(\mathrm{N}) »$.

- Cada ingreso y gasto se representa también por una cuenta, que tendrá una denominación adecuada que haga referencia al concepto de ingreso o gasto que representa.

Por ejemplo: (1) la cuenta que representa los ingresos obtenidos por prestar servicios a terceros se denomina «Prestación de servicios (I)» y la cuenta que representa el gasto por sueldos del personal se denomina «Sueldos y salarios $(\mathrm{G}) »$.

- Al libro encuadernado, u otro soporte físico o virtual, en el que se recoge el conjunto de todas las cuentas individuales de activos, pasivos, patrimonio neto, ingresos y gastos se denomina «libro mayor».

En la siguiente ilustración se muestra la representación sintética de una cuenta, mostrando su estructura y los términos utilizados en relación a la utilización de la misma para el registro de transacciones empresariales.

\begin{tabular}{|c|c|}
\hline \multicolumn{2}{|c|}{ CUENTA DE: Denominación del elemento } \\
\hline DEBE (D) : Parte izquierda & HABER $($ H) : Parte derecha \\
\hline Anotar al Debe: & Anotar al Haber: \\
\hline CARGAR - adeudar - cargo & ABONAR - acreditar - abono \\
\hline$\sum D=$ Suma del debe o suma deudora & $\sum H=$ Suma del haber o suma acreedora \\
\hline \multicolumn{2}{|c|}{$\begin{array}{l}\text { Saldo = Suma deudora - Suma acreedora } \\
\text { SALDO ACREEDOR }\left(\sum \mathrm{D}<\sum H\right) \text { o SALDO DEUDOR }\left(\sum \mathrm{D}>\sum \mathrm{H}\right)\end{array}$} \\
\hline \multicolumn{2}{|c|}{$\begin{array}{l}\text { Conceptos y términos utilizados en relación con las cuentas: } \\
\text { ABRIR: Crear una cuenta que anteriormente no existía. Utilizarla por primera vez. } \\
\text { SALDAR: Anotar el importe que sea necesario y en el lado que sea necesario (Debe o Haber) de } \\
\text { forma que el saldo de la cuenta tras la anotación sea cero. } \\
\text { CERRAR: Inutilizar una cuenta para impedir su posterior uso. Para cerrar una cuenta previamente } \\
\text { hay que saldarla. }\end{array}$} \\
\hline $\begin{array}{l}\text { Aunque es frecuente que a efectos didác } \\
\text { únicamente el importe de la transacción } \\
\text { el número de transacción (ver diario), la }\end{array}$ & $\begin{array}{l}\text { Debe o Haber de las cuentas se anote } \\
\text { rse en cuenta que conviene anotar también } \\
\text { a breve explicación de la misma. }\end{array}$ \\
\hline
\end{tabular}

Ilustración 3.1. Representación sintética de una cuenta y términos utilizados en el registro 


\section{Reglas de registro de cuentas de activos, pasivos y patrimonio neto}

Las reglas generales para el registro del valor inicial, aumentos y disminuciones de activos, pasivos y patrimonio neto, y que reciben el nombre de «convenio general del cargo y el abono» son las que muestran la siguiente ilustración.

\begin{tabular}{|c|c|c|c|c|c|c|c|}
\hline \multicolumn{7}{|c|}{ Ecuación Fundamental del Patrimonio } \\
\hline ACTIVOS & $=$ & \multicolumn{2}{|c|}{ PASIVOS } & + & \multicolumn{2}{c|}{ PATRIMONIO NETO } \\
\hline Aumento & Disminución & & Disminución & Aumento & & Disminución & Aumento \\
& & & & & & - & + \\
\hline
\end{tabular}

Ilustración 3.2. Convenio general del cargo y el abono

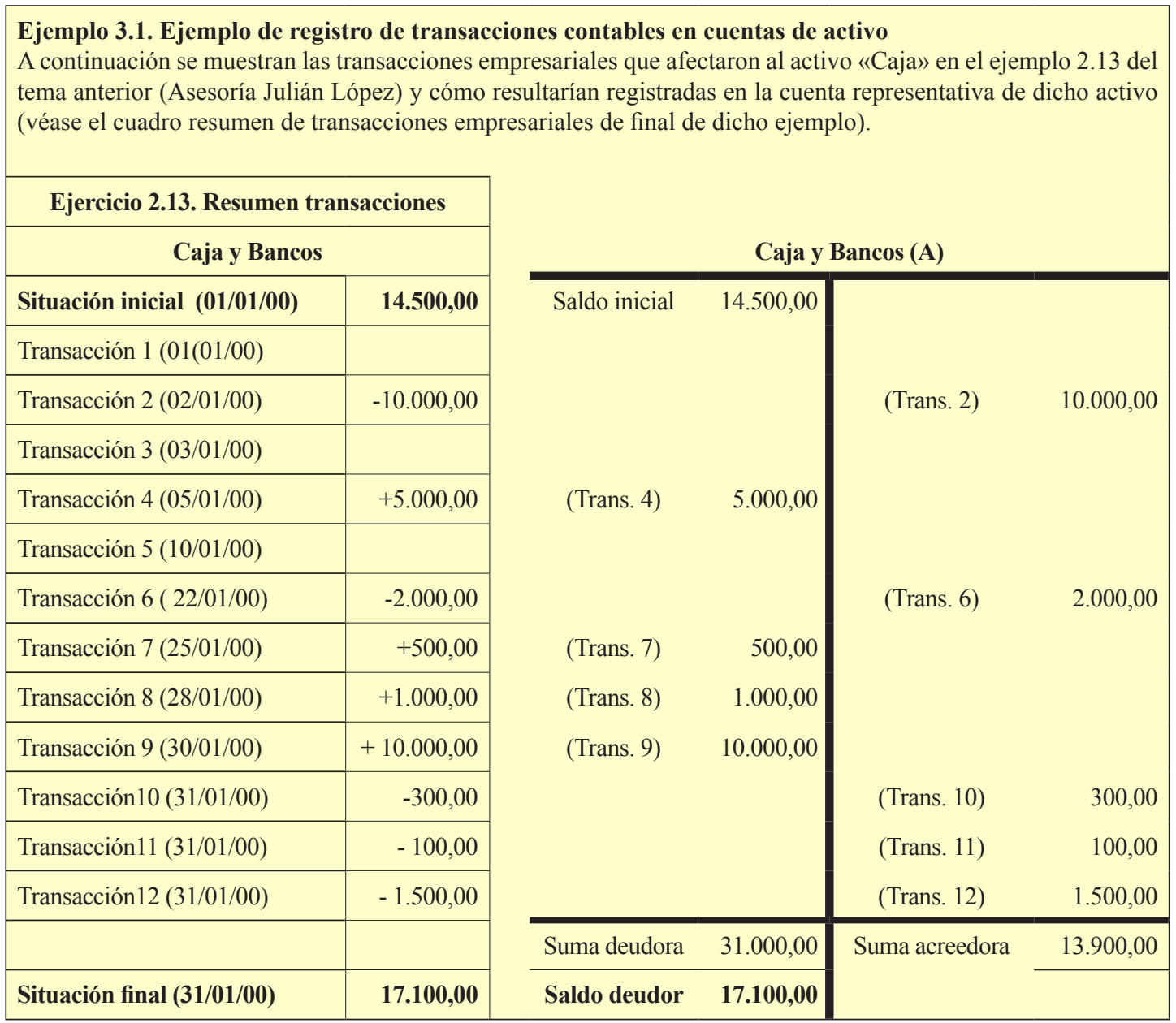




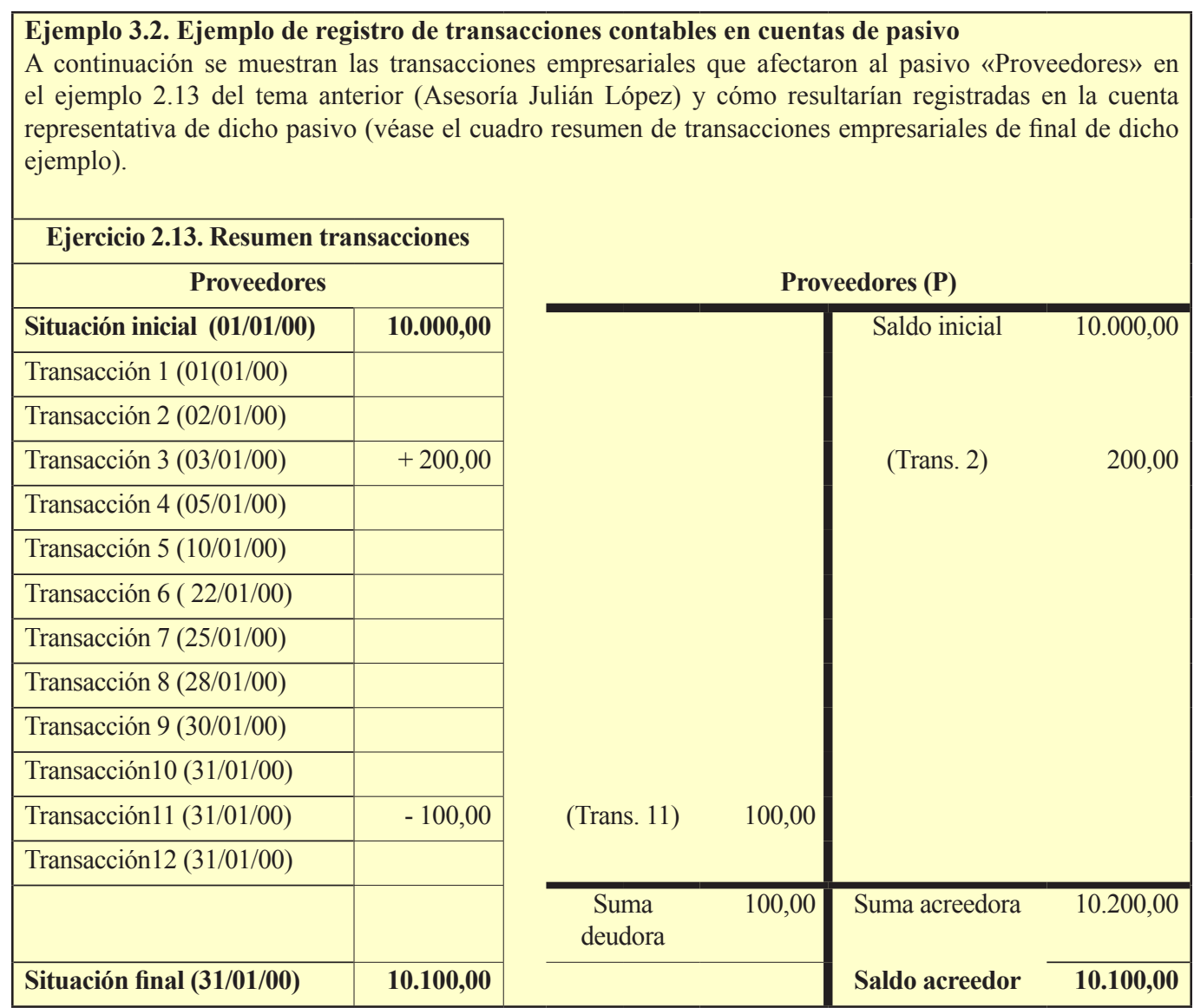

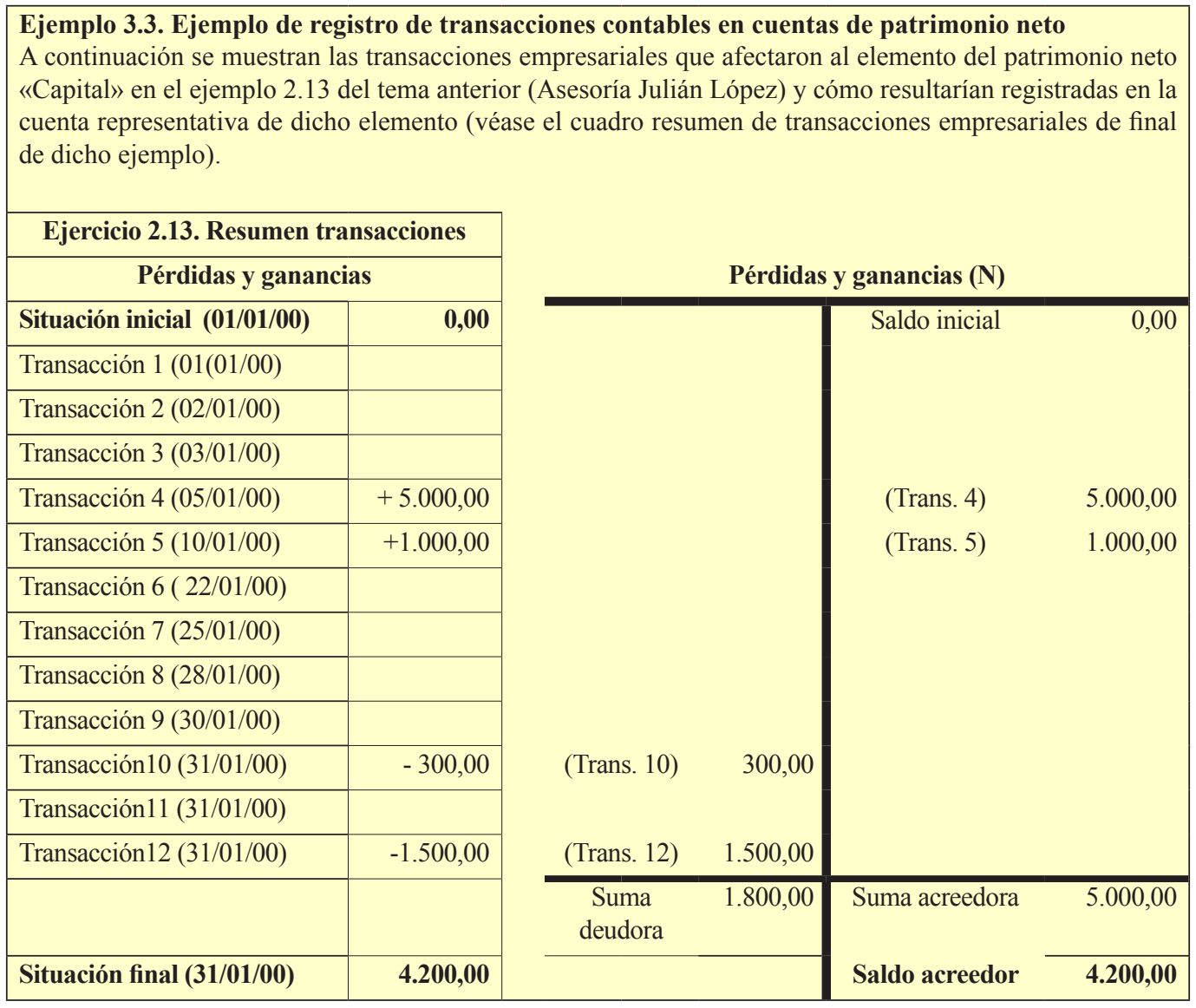




\section{Reglas de registro de cuentas de ingresos y gastos}

Dado que los ingresos suponen aumentos del patrimonio neto y los gastos disminuciones del mismo, las reglas de registro para las cuentas de ingresos y gastos derivan de la regla de registro para las cuentas de patrimonio neto. Las cuentas de ingresos y gastos pueden considerarse un «desglose» de la cuenta de pérdidas y ganancias $(\mathrm{N})$ que representa el resultado del ejercicio y que es una partida de patrimonio neto.

Los gastos suponen disminuciones de patrimonio neto, que se registrarían en el Debe de las cuentas de patrimonio neto, luego en las cuentas de gastos la anotación, se hará al Debe.

Los ingresos suponen aumentos de patrimonio neto, que se registrarían en el Haber de las cuentas de Patrimonio neto, luego en las cuentas de ingresos la anotación, se hará al Haber.

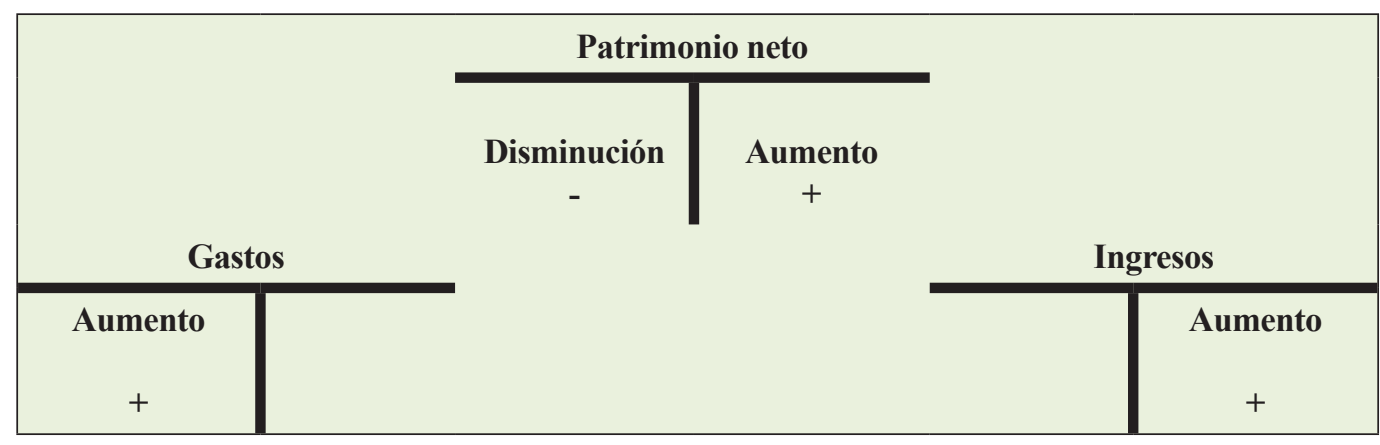

Ilustración 3.3. Reglas de registro de cuentas de ingresos y gastos 
Ejemplo 3.4. Ejemplo de registro de transacciones contables en cuentas de ingresos y gastos

A continuación se muestra el desglose de la cuenta «Pérdidas y ganancias» mostrada en el ejemplo 3.3 anterior

en las cuentas de ingresos y gastos. Las transacciones registradas eran:

- Transacción 4. Factura de venta. Ingresos por prestación de servicios.

- Transacción 5. Factura de venta. Ingresos por prestación de servicios.

- Transacción 10. Alquiler del vehículo. Gastos por arrendamientos.

- $\quad$ Transacción 12. Sueldos de empleados. Gastos por sueldos y salarios.

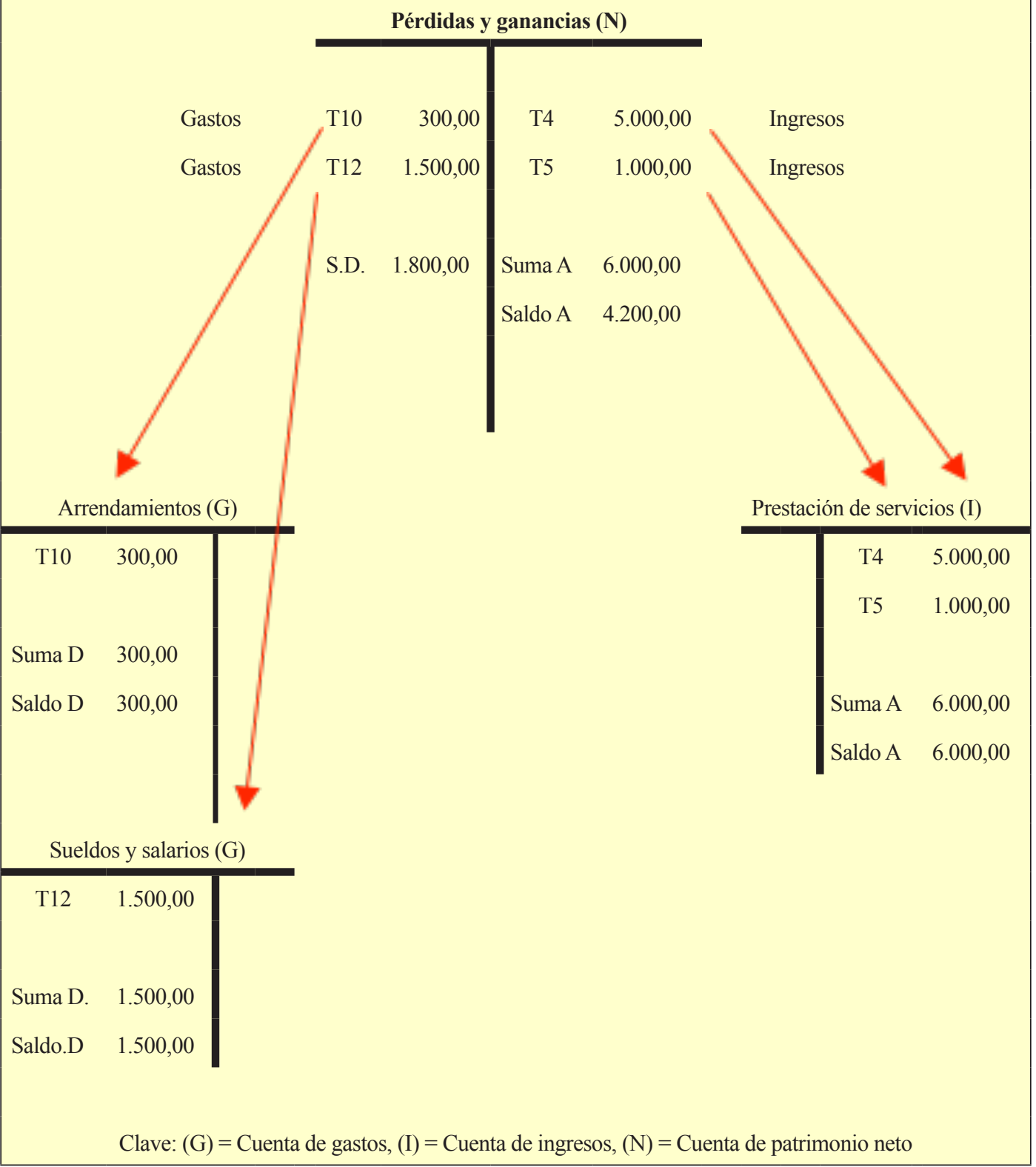




\subsection{El diario, estructura y registro}

El diario es un instrumento de representación que recoge cronológicamente todas las transacciones o eventos que afectan al patrimonio empresarial.

Cada anotación en el diario, denominada «asiento», muestra toda la información acerca de una transacción concreta y explica la misma.

Los asientos del diario están ordenados por fecha y numerados. Al libro encuadernado, u otro soporte físico o virtual, en el que se recogen todos los asientos se denomina «libro diario».

En la siguiente ilustración se muestra la representación sintética del diario, mostrando su estructura y los términos utilizados en relación al uso del mismo para el registro de transacciones empresariales.

\begin{tabular}{|c|c|c|c|c|}
\hline $\begin{array}{l}\mathrm{N}^{0} \text { de } \\
\text { asiento }\end{array}$ & Fecha & $\begin{array}{c}\text { Cuentas } \\
\mathbf{y} \\
\text { Explicación de la transacción }\end{array}$ & Debe (D) & Haber (H) \\
\hline 1 & $00 / 00 / 00$ & $\begin{array}{l}\text { Cuenta(s) que deben cargarse } \\
\text { Cuenta(s) que deben abonarse } \\
\text { Explicación del hecho contable }\end{array}$ & $\mathrm{X}$ & X \\
\hline 2 & $00 / 00 / 00$ & $\begin{array}{l}\text { Cuenta(s) que deben cargarse } \\
\text { Cuenta(s) que deben abonarse } \\
\text { Explicación del hecho contable }\end{array}$ & $\mathrm{X}$ & X \\
\hline$\cdots$ & $\ldots$ & $\ldots$ & $\ldots$ & $\ldots$ \\
\hline $\begin{array}{l}\text { Sumas de } \\
\text { un período }\end{array}$ & & $\begin{array}{l}\text { Suma Deudora } \\
\text { Suma Acreedora }\end{array}$ & $\sum \mathrm{D}$ & $\sum \mathrm{A}$ \\
\hline
\end{tabular}

Ilustración 3.4. Representación sintética del Diario y términos utilizados en registro

En un asiento de diario podrán aparecer tantas cuentas con anotación al debe y tantas cuentas con anotación al haber como precise el registro de la transacción.

Tal y como se observa en la ilustración anterior, el registro en el diario no precisa de reglas especiales. En cada transacción concreta bastará con conocer las cuentas afectadas y su variación aplicando las reglas de registro (convenio general del cargo y el abono) a las mismas para saber si la anotación procede hacerla al debe o al haber. 


\subsection{El cuadro de cuentas}

Las cuentas vienen identificadas, además de con un nombre alusivo al elemento patrimonial representado, con un código numérico.

Dicho código tiene la finalidad de facilitar la identificación de la cuenta, mejorar la eficiencia en la gestión, sobre todo con medios informáticos, y realizar clasificaciones y ordenaciones de cuentas según la naturaleza de los elementos patrimoniales que representan.

Al listado de cuentas, con códigos y denominaciones, que utiliza una empresa se denomina «cuadro de cuentas», y todas las empresas disponen de uno.

A continuación se muestra un cuadro de cuentas de referencia y que es un extracto del incluido en el Plan General de Contabilidad. Este cuadro de cuentas es de aplicación voluntaria para las empresas, pero es ampliamente utilizado. Este cuadro de cuentas clasifica y codifica las mismas en grupos, subgrupos y cuentas hasta el nivel de 3 o a lo sumo 4 dígitos o niveles.

\section{Extracto de grupos y subgrupos del cuadro de cuentas del PGC}

\begin{tabular}{|c|c|}
\hline \multicolumn{2}{|c|}{ GRUPO 1: FINANCIACIÓN BÁSICA: PATRIMONIO NETO Y PASIVO NO CORRIENTE } \\
\hline 10. CAPITAL & \multirow{4}{*}{$\begin{array}{l}\text { PATRIMONIO NETO: Fondos aportados por propieta- } \\
\text { rios, beneficios retenidos y resultados del ejercicio. }\end{array}$} \\
\hline 11. RESERVAS & \\
\hline 12. RESULTADOS PENDIENTES DE APLICACIÓN & \\
\hline 13. SUBVENCIONES, DONACIONES & \\
\hline $\begin{array}{l}\text { 17. DEUDAS A L.P. POR PRÉSTAMOS RECIBIDOS } \\
\text { Y OTROS }\end{array}$ & $\begin{array}{l}\text { PASIVO NO CORRIENTE: Deudas a largo plazo por } \\
\text { préstamos (ver tema 4). }\end{array}$ \\
\hline \multicolumn{2}{|l|}{ GRUPO 2: INMOVILIZADO: ACTIVO NO CORRIENTE } \\
\hline 20. INMOVILIZACIONES INTANGIBLES & \multirow{3}{*}{ Inversiones en este tipo de bienes (ver tema 4). } \\
\hline 21. INMOVILIZACIONES MATERIALES & \\
\hline 22. INVERSIONES INMOBILIARIAS & \\
\hline $\begin{array}{l}\text { 25. OTRAS INVERSIONES FINANCIERAS A LARGO } \\
\text { PLAZO }\end{array}$ & Inversiones y créditos financieros (ver tema 4). \\
\hline $\begin{array}{l}\text { 28. AMORTIZACIÓN ACUMULADA DEL INMOVI- } \\
\text { LIZADO }\end{array}$ & \multirow{2}{*}{$\begin{array}{l}\text { Depreciaciones acumuladas y deterioros de valor de } \\
\text { estos activos (ver tema 5). }\end{array}$} \\
\hline 29. DETERIORO DE VALOR DEL INMOVILIZADO & \\
\hline \multicolumn{2}{|l|}{ GRUPO 3: EXISTENCIAS: ACTIVO CORRIENTE } \\
\hline 30. COMERCIALES & \multirow{2}{*}{ Inversiones en este tipo de bienes para su venta o uso. } \\
\hline 32. OTROS APROVISIONAMIENTOS & \\
\hline 39. DETERIORO DE VALOR DE LAS EXISTENCIAS & Deterioros de valor de existencias (ver tema 5). \\
\hline
\end{tabular}




\begin{tabular}{|c|c|}
\hline \multicolumn{2}{|c|}{ GRUPO 4: ACREEDORES Y DEUDORES POR OP. COMERCIALES: ACTIVO Y PASIVO CORRIENTE } \\
\hline 40. PROVEEDORES & \multirow{2}{*}{ Deudas comerciales. } \\
\hline 41. ACREEDORES VARIOS & \\
\hline 43. CLIENTES & \multirow{2}{*}{ Créditos comerciales. } \\
\hline 44. DEUDORES VARIOS & \\
\hline 46. PERSONAL & Deudas y créditos con el personal (ver tema 4). \\
\hline 47. ADMINISTRACIONES PÚBLICAS & Deudas y créditos con las Administraciones Públicas. \\
\hline 48. AJUSTES POR PERIODIFICACION & Ajustes de fin de año en partidas comerciales (ver tema 5). \\
\hline $\begin{array}{l}\text { 49. DETERIORO DE VALOR DE CRÉDITOS } \\
\text { COMERCIALES }\end{array}$ & Deterioros de valor de créditos comerciales (ver tema 5). \\
\hline \multicolumn{2}{|c|}{ GRUPO 5: CUENTAS FINANCIERAS: ACTIVO Y PASIVO CORRIENTE } \\
\hline $\begin{array}{l}\text { 52. DEUDAS A C.P. POR PRÉSTAMOS RECIBIDOS } \\
\text { Y OTROS }\end{array}$ & Deudas financieras (ver tema 4). \\
\hline $\begin{array}{l}\text { 54. OTRAS INVERSIONES FINANCIERAS } \\
\text { TEMPORALES }\end{array}$ & Inversiones y créditos financieros (ver tema 4). \\
\hline 57. TESORERÍA & Dinero efectivo, cuentas bancarias y similares. \\
\hline 58. AJUSTES POR PERIODIFICACION & Ajustes de fin de año en cuentas financieras (ver tema 5). \\
\hline $\begin{array}{l}\text { 59. DETERIORO DEL VALOR DE INSTRUMENTOS } \\
\text { FINANCIEROS }\end{array}$ & Deterioros de valor de activos financieros (ver tema 5). \\
\hline \multicolumn{2}{|l|}{ GRUPO 6: COMPRAS Y GASTOS } \\
\hline 60. COMPRAS & \multirow{5}{*}{ Gastos de explotación según su naturaleza. } \\
\hline 61. VARIACIÓN DE EXISTENCIAS & \\
\hline 62. SERVICIOS EXTERIORES & \\
\hline 63. TRIBUTOS & \\
\hline 64. GASTOS DE PERSONAL & \\
\hline 66. GASTOS FINANCIEROS & Gastos financieros. \\
\hline $\begin{array}{l}\text { 67. PÉRDIDAS PROCEDENTES DE ACTIVOS NO } \\
\text { CORRIENTES Y GTOS. EXCEPCIONALES }\end{array}$ & Pérdidas por venta de inmovilizado y otros (ver tema 4). \\
\hline 68. DOTACIONES PARA AMORTIZACIONES & \multirow{2}{*}{$\begin{array}{l}\text { Gastos del ejercicio por depreciaciones del inmoviliza- } \\
\text { do y por deterioros de valor de activos (ver tema 5). }\end{array}$} \\
\hline 69. PÉRDIDAS POR DETERIODO & \\
\hline \multicolumn{2}{|l|}{ GRUPO 7: VENTAS E INGRESOS } \\
\hline 70. VENTAS DE MERCADERÍAS, SERVICIOS & \multirow{3}{*}{ Ingresos de explotación según su naturaleza. } \\
\hline 74. SUBVENCIONES & \\
\hline 75. OTROS INGRESOS DE GESTIÓN & \\
\hline 76. INGRESOS FINANCIEROS & Ingresos financieros. \\
\hline $\begin{array}{l}\text { 77. BENEFICIOS PROCEDENTES DE ACTIVOS NO } \\
\text { CORRIENTES E INGRESOS EXCEPCIONALES }\end{array}$ & Beneficios por venta de inmovilizado y otros (ver tema 4). \\
\hline $\begin{array}{l}\text { 79. EXCESOS Y APLICACIONES DE PERDIDAS } \\
\text { POR DETERIORO }\end{array}$ & $\begin{array}{l}\text { Ingresos por recuperación de valor de deterioros de acti- } \\
\text { vos (ver tema 5). }\end{array}$ \\
\hline
\end{tabular}




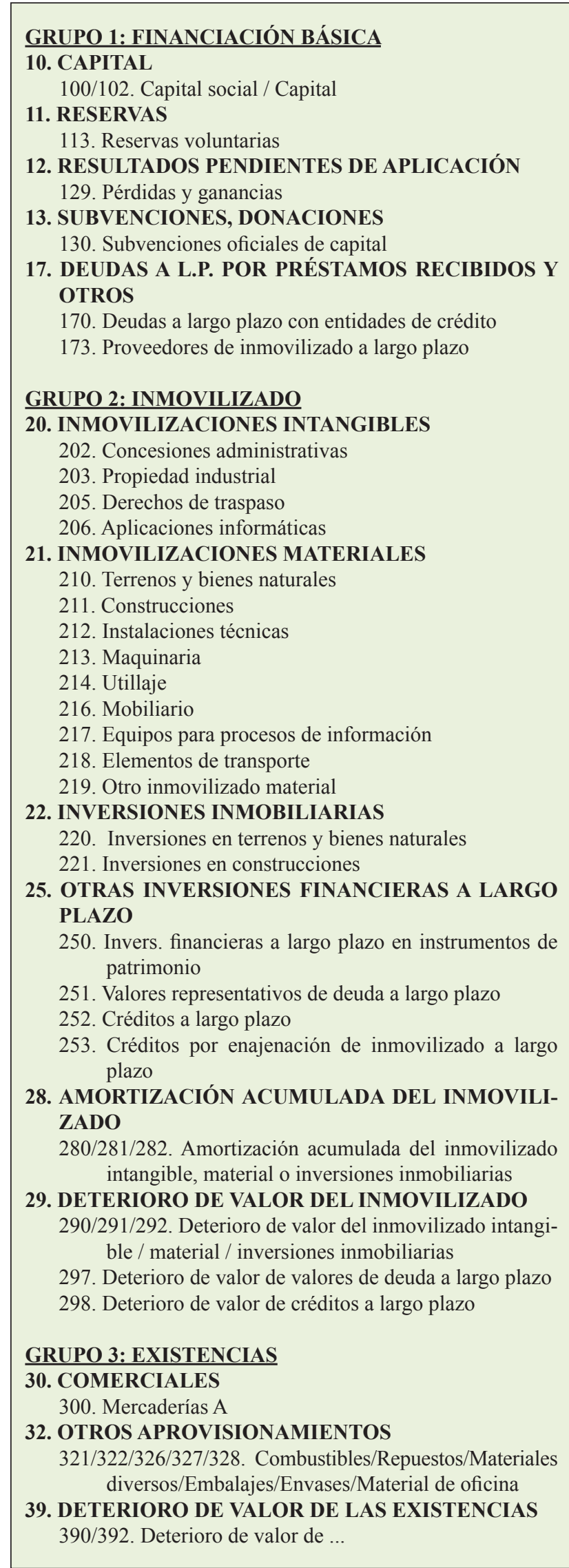

GRUPO 4: ACREEDORES Y DEUDORES POR OP. COMERCIALES

40. PROVEEDORES

400. Proveedores

41. ACREEDORES VARIOS

410. Acreedores por prestaciones de servicios

43. CLIENTES

430. Clientes

44. DEUDORES VARIOS

440. Deudores

46. PERSONAL

460. Anticipos de remuneraciones

465. Remuneraciones pendientes de pago

47. ADMINISTRACIONES PÚBLICAS

470. Hacienda Pública, deudora por diversos conceptos 472. H.P. IVA soportado

475. Hacienda Pública, acreedora por conceptos fiscales

476. Organismos de la Seguridad Social, acreedores

477. H.P. IVA repercutido

48. AJUSTES POR PERIODIFICACIÓN

480. Gastos anticipados

485. Ingresos anticipados

49. DETERIORO DE VALOR DE CRÉDITOS COMERCIALES

490. Deterioro de valor de créditos por operaciones comerciales

\section{GRUPO 5: CUENTAS FINANCIERAS}

\section{DEUDAS A C.P. POR PRÉSTAMOS RECIBIDOS Y} OTROS

520. Deudas a corto plazo con entidades de crédito

523. Proveedores de inmovilizado a corto plazo

527. Intereses a corto plazo de deudas con entidades de crédito

54. OTRAS INVERSIONES FINANCIERAS TEMPORALES

540. Invers. financieras temporales en instrumentos de patrimonio

541. Valores representativos de deuda a corto plazo

542. Créditos a corto plazo

543. Créditos por enajenación de inmovilizado a corto plazo

545. Dividendo activo a cobrar

546. Intereses a corto plazo de valores representativos de deuda

547. Intereses a corto plazo de créditos

58. DEPÓSITOS Y FIANZAS ... Y AJUSTES POR PERIODIFICACIÓN

567. Intereses pagados por anticipado

568. Intereses cobrados por anticipado

57. TESORERÍA

570. Caja, euros

572. Bancos e instituciones de crédito c/c vista, euros

59. DETERIORO DEL VALOR DE INSTRUMENTOS FINANCIEROS

597. Deterioro de valor de valores representativos de deuda c. $p$.

598. Deterioro de valor de créditos a corto plazo 


\section{GRUPO 6: COMPRAS Y GASTOS \\ 60. COMPRAS \\ 600/601/602. Compras de mercaderías/de materias primas / de otros aprovisionamientos \\ 606. Descuentos sobre ventas por pronto pago \\ 607. Trabajos realizados por otras empresas \\ 608. Devolución de compras y op. similares \\ 609. Rappels en compras \\ 61. VARIACIÓN DE EXISTENCIAS}

610/611/612. Variación de existencias de mercaderías / de materias primas / de otros aprovisionamientos

62. SERVICIOS EXTERIORES

621. Arrendamientos y cánones

622. Reparaciones y conservación

623. Servicios de profesionales independientes

624. Transportes

625. Primas de seguros

626. Servicios bancarios y similares

627. Publicidad, propaganda y relaciones públicas

628. Suministros

629. Otros servicios

63. TRIBUTOS

630. Impuesto sobre beneficios

631. Otros tributos

64. GASTOS DE PERSONAL

640. Sueldos y salarios

642. Seguridad Social a cargo de la empresa

66. GASTOS FINANCIEROS

662. Intereses de deudas

666. Pérdidas en participaciones y val. representativos de deuda

667. Pérdidas de créditos

669. Otros gastos financieros

67. PÉRDIDAS PROCEDENTES DE ACTIVOS NO CORRIENTES Y GTOS. EXCEPCIONALES

670/671/672. Pérdidas procedentes del inmovilizado intangible / material / inversiones inmobiliarias

678. Gastos excepcionales

68. DOTACIONES PARA AMORTIZACIONES

680/681/682. Amortización del inmovilizado intangible / material / inversiones inmobiliarias

69. PÉRDIDAS POR DETERIODO

690/691/692. Pérdidas por deterioro del inmovilizado intangible / material / inversiones inmobiliarias
693. Pérdidas por deterioro de existencias

694. Pérdidas por deterioro de créditos comerciales

696/698. Pérdidas por deterioro de participaciones y valores representativos de deuda a largo plazo / a corto plazo

697/699. Pérdidas por deterioro de créditos a largo plazo / corto plazo

\section{GRUPO 7: VENTAS E INGRESOS}

70. VENTAS DE MERCADERÍAS, SERVICIOS

700. Ventas de mercaderías

705. Prestaciones de servicios

706. Descuentos sobre ventas por pronto pago

708. Devolución de ventas y op. similares

709. Rappels en ventas

74. SUBVENCIONES

740. Subvenciones donaciones o legados a la explotación

75. OTROS INGRESOS DE GESTIÓN

752. Ingresos por arrendamientos

759. Ingresos por servicios diversos

76. INGRESOS FINANCIEROS

760. Ingresos de participaciones en instrumentos de patrimonio

761. Ingresos de valores representativos de deuda

762. Ingresos de créditos

766. Beneficios en participaciones y val. represen. de deuda

769. Otros ingresos financieros

77. BENEFICIOS PROCEDENTES DE ACTIVOS NO CORRIENTES E INGRESOS EXCEPCIONALES

$770 / 771 / 772$. Beneficios procedentes del inmovilizado intangible / material inversiones inmobiliarias

778. Ingresos excepcionales

79. EXCESOS Y APLICACIONES DE PÉRDIDAS POR DETERIORO

790/791/792. Reversión del deterioro del inmovilizado intangible / material / inversiones inmobiliarias

793. Reversión del deterioro de existencias

794. Reversión del deterioro de créditos comerciales

796/798. Reversión del deterioro de participaciones y valores representativos de deuda largo plazo / corto plazo

797/799. Reversión del deterioro de créditos a largo plazo / corto plazo 
En un cuadro de cuentas las cuentas figuran con un desglose de tres o cuatro dígitos (véase página anterior). ¿Cuál es el nivel de desglose en cuentas que utilizan las empresas? El que estiman necesario. Habitualmente una pequeña empresa le suelen bastar con cuentas de $6,7 \mathrm{u} 8$ dígitos.

La contabilización de transacciones real no se hace en la cuenta «430. Clientes», sino en una cuenta concreta de un cliente, que podría ser la «430.0023. José López Ruiz».

En ocasiones, dependiendo de la aplicación informática usada, una vez elegido un nivel de desglose, todas las cuentas deben ser utilizadas a ese nivel. Así, las anotaciones no suelen registrarse en la cuenta «(570). Caja» sino en la cuenta «570.0000. Caja».

Evidentemente los medios informáticos actuales permiten obtener fácilmente información sobre cuentas con el nivel de agregación que se desee, por lo que las cuentas con menor número de dígitos sirven de resumen informativo de la información contenida en las cuentas más detalladas.

El sistema de codificación de cuentas por niveles (número de dígitos) permite realizar agrupaciones que pueden proporcionar información de interés. Así la cuenta «430.0 Clientes, euros» podría desglosarse según el área geográfica de procedencia del cliente (país, comunidad autónoma, provincia, etc.). Por ejemplo, con un desglose en 10 dígitos:

\subsection{Clientes de Barcelona 4300.08.0000 José López López}

430.012 Clientes de Castellón

...

430.046 Clientes de Valencia

$\cdots$

Lógicamente las posibilidades de uso de los códigos, a efectos de ordenación o clasificación, son ilimitadas.

\section{Saber más: Cuentas generales, cuentas de detalle y libros-registro auxiliares}

Habitualmente, las empresas disponen de una cuenta detallada para cada elemento patrimonial que desean controlar, utilizando cuentas de 7 o más dígitos. Esto es necesario porque, por ejemplo, las empresas necesitan una cuenta para cada proveedor en la que registran las operaciones con el mismo. Así, cada empresa tiene tantas cuentas de proveedores como proveedores tenga (decenas, centenas, miles o más). Esto mismo es aplicable al resto de cuentas: clientes, cuentas bancarias, etc.

De esta forma, las anotaciones contables se realizan en cuentas con el nivel mayor de detalle, de 7 o más dígitos, mostrando las variaciones patrimoniales de cada elemento concreto.

Por tanto, el saldo de la cuenta de mayor «400 Proveedores» no es más que la suma de los saldos de las cuentas de detalle: «4000001 Proveedor 1», «4000002 Proveedor 2», etc.

\begin{tabular}{|c|c|c|}
\hline $\begin{array}{c}\text { Cuentas de detalle donde se registran } \\
\text { transacciones }\end{array}$ & $\begin{array}{c}\text { Cuentas generales por agregación } \\
\text { de las de detalle }\end{array}$ \\
\hline
\end{tabular}

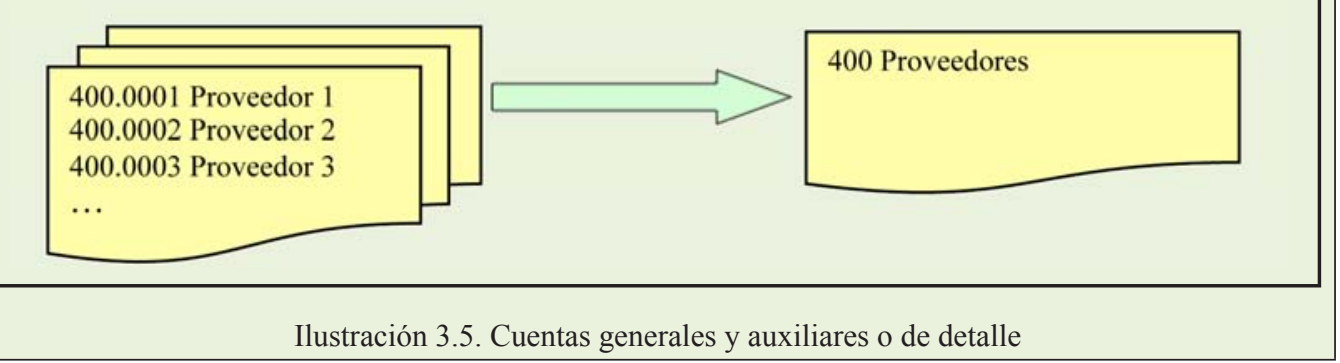


No obstante, en muchas ocasiones las empresas no utilizan cuentas contables de detalle sino que se realizan anotaciones en el diario y en el mayor en cuentas generales (de menos dígitos) sin que se disponga de cuentas contables detalladas para cada elemento patrimonial.

Esto es posible siempre y cuando la información específica y detallada se encuentre en libros registro auxiliares y suele hacerse cuando el número de elementos patrimoniales es muy elevado. Por ejemplo, una empresa comercial que tenga un inventario de mercancías con 50.000 referencias de artículos distintas optará por controlar estas mediante libros registro auxiliares (o un programa informático de facturación y almacén) sin utilizar 50.000 cuentas contables de detalle, una para cada producto.

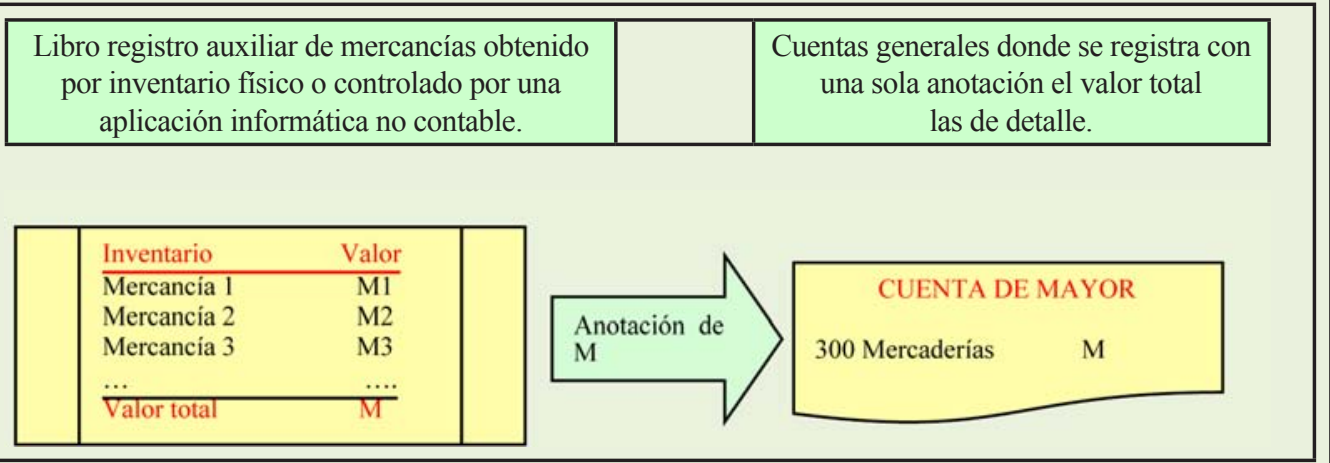

Ilustración 3.6. Cuentas y libros auxiliares

Por otra parte, las anotaciones en el Diario no tienen porque hacerse una a una para cada transacción realizada, sino que las transacciones de igual naturaleza pueden agregarse en un solo asiento conjunto para un período de tiempo, según el Código de Comercio máximo un mes. Para ello es necesario contar también con libros registro auxiliares que contengan la información específica y detallada de las transacciones.

Un ejemplo bastante usual lo constituye la anotación conjunta de las ventas en efectivo de un período (una semana o un mes). Para ello es necesario disponer de un libro registro de ventas o «diario de ventas» donde se anotan todas y cada una de ellas (incluso válido será un listado de tickets de máquinas registradoras) y periódicamente se realiza un asiento por el importe total de las ventas del período.

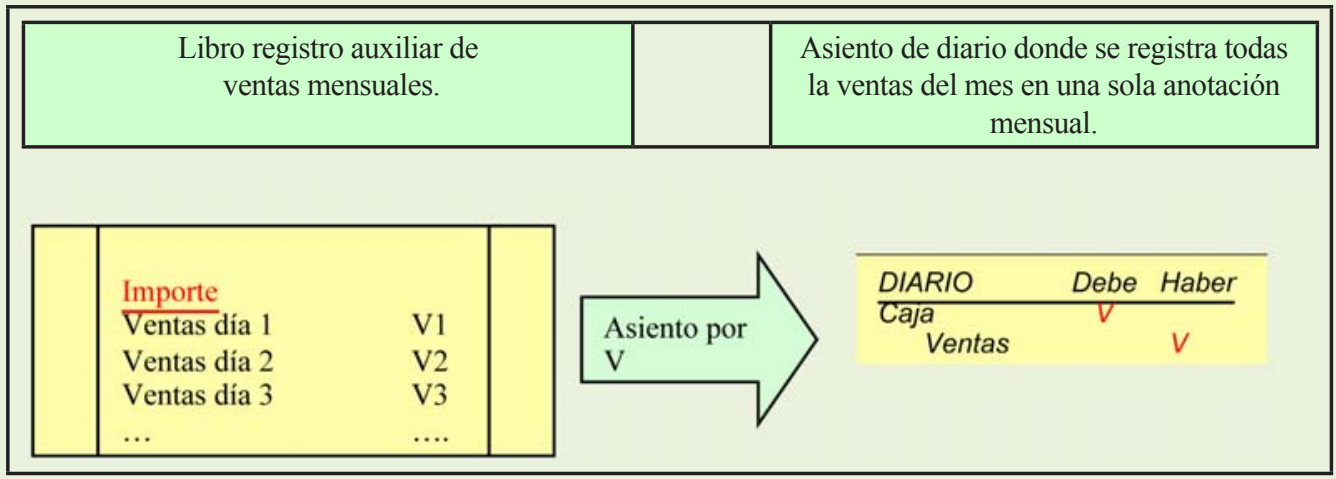

Ilustración 3.7. Asiento global en diario y libros auxiliares

También son frecuentes libros auxiliares de caja, de compras, de inventario de mercancías, de inventario de inmovilizado y otros. 


\subsection{Ejemplo de registro en las cuentas y en el diario}

En este apartado se va a proceder a realizar las anotaciones en las cuentas y en el diario de las operaciones correspondientes al ejemplo 2.13 del tema anterior, Asesoría Julián López, y de acuerdo a lo indicado en los apartados 2 y 3 de este tema.

Para ello se analizará cada transacción identificando los elementos afectados y si son activos, pasivos, patrimonio neto, ingresos o gastos, se señalará la clase de variación que sufren (aumento o disminución) y se aplicará la regla de registro correspondiente.

Obsérvese la relación existente entre las anotaciones en el diario y en las cuentas (libro mayor).

\section{Ejemplo 3.5. Registro de transacciones contables en cuentas y diario (del Ejemplo 2.13 del tema anterior) \\ En las anotaciones en las cuentas el número entre paréntesis hace referencia al número de asiento y no al número de la transacción.}

Transacción 1 (01/01/00): Alquiler de vehículo y contrato de personal

No procede puesto que no afecta a ningún elemento patrimonial

Transacción 2 (02/01/00): Compra mobiliario al contado

\begin{tabular}{|l|c|c|c|c|}
\hline Elementos afectados & Tipo de elemento & Aumento o disminución & Regla registro & Importe \\
\hline Caja y Bancos & Activo & Disminución & Haber & $10.000,00$ \\
\hline Mobiliario & Activo & Aumento & Debe & $10.000,00$ \\
\hline
\end{tabular}

\begin{tabular}{|c|c|c|c|}
\hline & 57x. Caja y & $n \cos (\mathrm{A})$ & 216. Mobili \\
\hline \multirow[t]{2}{*}{ Anotación en cuentas } & $14.500,00(0)$ & $10.000,00(1)$ & $\begin{array}{r}1.000,00(0) \\
10.000,00(1)\end{array}$ \\
\hline & & & \\
\hline
\end{tabular}

\begin{tabular}{|l|c|c|c|c|c|}
\hline & Asiento & Fecha & Cuentas & Debe & Haber \\
\hline $\begin{array}{l}\text { Anotación en } \\
\text { diario }\end{array}$ & 1 & $02 / 01 / 00$ & $\begin{array}{c}216 . \text { Mobiliario (A) } \\
\text { 57x. Caja y Bancos } \\
\text { (A) }\end{array}$ & $10.000,00$ & \\
& & & $10.000,00$ \\
\hline
\end{tabular}

Transacción 3 (03/01/00): Compra material oficina a crédito

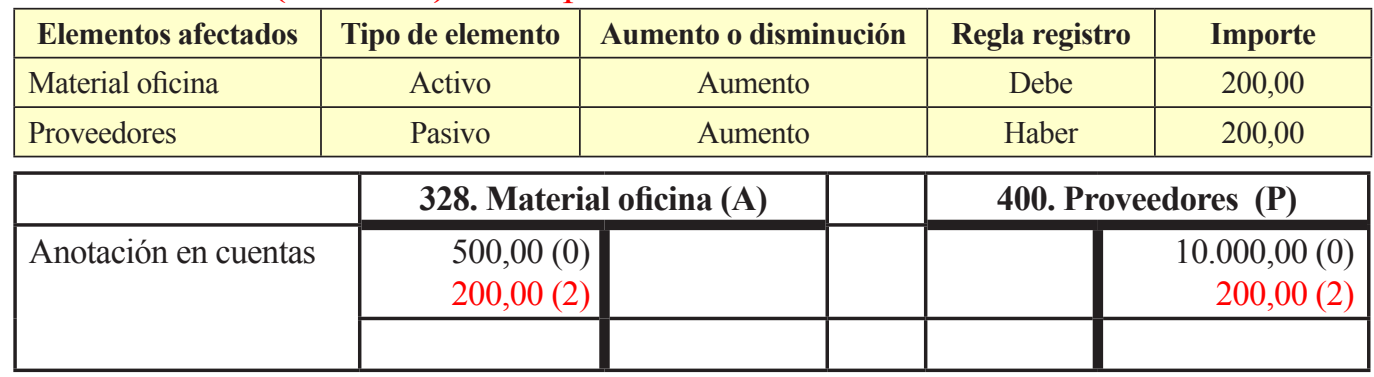




\begin{tabular}{|l|c|c|c|c|c|}
\hline & Asiento & Fecha & Cuentas & Debe & Haber \\
\hline $\begin{array}{l}\text { Anotación en } \\
\text { diario }\end{array}$ & 2 & $03 / 01 / 00$ & $\begin{array}{c}\text { 328. Material oficina (A) } \\
\text { 400. Proveedores (P) }\end{array}$ & 200,00 & 200,00 \\
\hline
\end{tabular}

Transacción 4 (05/01/00): Factura a cliente al contado

\begin{tabular}{|l|c|c|c|c|}
\hline Elementos afectados & Tipo de elemento & Aumento o disminución & Regla registro & Importe \\
\hline Prestación servicios & Ingresos & Aumento & Haber & $5.000,00$ \\
\hline Caja y Bancos & Activo & Aumento & Debe & $5.000,00$ \\
\hline
\end{tabular}

\begin{tabular}{|c|c|c|c|}
\hline & 57x. Caja y & $\operatorname{ancos}(\mathrm{A})$ & 705. Prestación servicios (I) \\
\hline \multirow[t]{2}{*}{ Anotación en cuentas } & $\begin{array}{r}14.500,00(0) \\
5.000,00(3)\end{array}$ & $10.000,00(1)$ & $\begin{array}{r}0,00(0) \\
5.000,00(3)\end{array}$ \\
\hline & & & \\
\hline
\end{tabular}

\begin{tabular}{|l|c|c|c|c|c|}
\hline & Asiento & Fecha & Cuentas & Debe & Haber \\
\hline $\begin{array}{l}\text { Anotación en } \\
\text { diario }\end{array}$ & 3 & $05 / 01 / 00$ & $\begin{array}{c}57 x \text {. Caja y Bancos (A) } \\
\text { 705. Prestación servicios } \\
(\mathrm{I})\end{array}$ & $5.000,00$ & \\
\hline
\end{tabular}

Transacción 5 (10/01/00): Factura a cliente a crédito

\begin{tabular}{|l|c|c|c|c|}
\hline Elementos afectados & Tipo de elemento & Aumento o disminución & Regla registro & Importe \\
\hline Clientes & Activo & Aumento & Debe & $1.000,00$ \\
\hline Prestación servicios & Ingresos & Aumento & Haber & $1.000,00$ \\
\hline
\end{tabular}

\begin{tabular}{|c|c|c|}
\hline & 430. Clientes (A) & 705. Prestación servicios (I) \\
\hline \multirow[t]{2}{*}{ Anotación en cuentas } & $\begin{array}{l}5.000,00(0) \\
1.000,00(4)\end{array}$ & $\begin{array}{r}0,00(0) \\
5.000,00(3)\end{array}$ \\
\hline & & $1.000,00(4)$ \\
\hline
\end{tabular}

\begin{tabular}{|l|c|c|c|c|c|}
\hline & Asiento & Fecha & Cuentas & Debe & Haber \\
\hline $\begin{array}{l}\text { Anotación en } \\
\text { diario }\end{array}$ & 4 & $10 / 01 / 00$ & $\begin{array}{c}430 . \text { Clientes (A) } \\
705 . \text { Prestación Servicios } \\
\text { (I) }\end{array}$ & $1.000,00$ & \\
& & & $1.000,00$ \\
\hline
\end{tabular}

Transacción 6 (22/01/00): Retirada de fondos del propietario por cheque

\begin{tabular}{|l|c|c|c|c|}
\hline Elementos afectados & Tipo de elemento & Aumento o disminución & Regla registro & Importe \\
\hline Caja y Bancos & Activo & Disminución & Haber & $2.000,00$ \\
\hline Capital & Neto & Disminución & Debe & $2.000,00$ \\
\hline
\end{tabular}

\begin{tabular}{|l|r|r|r|r|r|}
\hline & \multicolumn{2}{|c|}{ 100. Capital (N) } & & \multicolumn{2}{|c|}{ 57x. Caja y bancos (A) } \\
\hline Anotación en cuentas & $2.000,00(5)$ & $20.000,00(0)$ & & $14.500,00(0)$ & $10.000,00(1)$ \\
& & & & $5.000,00(3)$ & $2.000,00(5)$ \\
\cline { 2 - 6 } & & & & & \\
\hline
\end{tabular}

\begin{tabular}{|l|c|c|c|c|c|}
\hline & Asiento & Fecha & Cuentas & Debe & Haber \\
\hline $\begin{array}{l}\text { Anotación en } \\
\text { diario }\end{array}$ & 5 & $22 / 01 / 00$ & $\begin{array}{c}\text { 100. Capital (N) } \\
57 x . \text { Caja y Bancos } \\
(\mathrm{A})\end{array}$ & $2.000,00$ & \\
\hline
\end{tabular}


Transacción 7 (25/01/00): Cobro de cliente en efectivo

\begin{tabular}{|l|c|c|c|c|}
\hline Elementos afectados & Tipo de elemento & Aumento o disminución & Regla registro & Importe \\
\hline Clientes & Activo & Disminución & Haber & 500,00 \\
\hline Caja y Bancos & Activo & Aumento & Debe & 500,00 \\
\hline
\end{tabular}

\begin{tabular}{|l|r|r|r|r|r|}
\hline & \multicolumn{2}{|c|}{$\mathbf{5 7 x}$. Caja y bancos (A) } & & \multicolumn{2}{|c|}{ 430. Clientes (A) } \\
\hline Anotación en cuentas & $14.500,00(0)$ & $10.000,00(1)$ & & $5.000,00(0)$ & $500,00(6)$ \\
& $5.000,00(3)$ & $2.000,00(5)$ & & $1.000,00(4)$ & \\
\cline { 2 - 6 } & $500,00(6)$ & & & & \\
\hline
\end{tabular}

\begin{tabular}{|l|c|c|c|c|c|}
\hline & Asiento & Fecha & Cuentas & Debe & Haber \\
\hline $\begin{array}{l}\text { Anotación en } \\
\text { diario }\end{array}$ & 6 & $25 / 01 / 00$ & $\begin{array}{c}57 x \text {. Caja y Bancos (A) } \\
430 . \text { Clientes (A) }\end{array}$ & 500,00 & 500,00 \\
\hline
\end{tabular}

Transacción 8 (28/01/00): Venta de mobiliario en efectivo

\begin{tabular}{|l|c|c|c|c|}
\hline Elementos afectados & Tipo de elemento & Aumento o disminución & Regla registro & Importe \\
\hline Caja y Bancos & Activo & Aumento & Debe & $1.000,00$ \\
\hline Mobiliario & Activo & Disminución & Haber & $1.000,00$ \\
\hline
\end{tabular}

\begin{tabular}{|c|c|c|c|c|}
\hline & \multicolumn{2}{|c|}{ 57x. Caja y bancos (A) } & \multicolumn{2}{|c|}{ 216. Mobiliario (A) } \\
\hline \multirow[t]{3}{*}{ Anotación en cuentas } & $\begin{array}{r}14.500,00(0) \\
5.000,00(3)\end{array}$ & $\begin{array}{r}10.000,00(1) \\
2.000,00(5)\end{array}$ & $10.000,00(0)$ & $1.000,00(7)$ \\
\hline & $500,00(6)$ & & & \\
\hline & $1.000,00(7)$ & & & \\
\hline
\end{tabular}

\begin{tabular}{|l|c|c|c|c|c|}
\hline & Asiento & Fecha & Cuentas & Debe & Haber \\
\hline $\begin{array}{l}\text { Anotación en } \\
\text { diario }\end{array}$ & 7 & $28 / 01 / 00$ & $\begin{array}{c}57 x . \text { Caja y Bancos (A) } \\
216 . \text { Mobiliario (A) }\end{array}$ & $1.000,00$ & \\
\hline
\end{tabular}

Transacción 9 (30/01/00): Obtención de préstamo

\begin{tabular}{|l|c|c|c|c|}
\hline Elementos afectados & Tipo de elemento & Aumento o disminución & Regla registro & Importe \\
\hline Caja y Bancos & Activo & Aumento & Debe & $10.000,00$ \\
\hline Préstamos largo p. & Pasivos & Aumento & Haber & $10.000,00$ \\
\hline
\end{tabular}

\begin{tabular}{|c|c|c|c|}
\hline & \multicolumn{2}{|c|}{ 57x. Caja y bancos (A) } & 170. Préstamos l.p. (P) \\
\hline \multirow[t]{4}{*}{ Anotación en cuentas } & $\begin{array}{r}14.500,00(0) \\
5.000,00(3)\end{array}$ & $\begin{array}{r}10.000,00(1) \\
2.000,00(5)\end{array}$ & $\begin{array}{l}30.000,00(0) \\
10.000,00(8)\end{array}$ \\
\hline & $500,00(6)$ & & \\
\hline & $1.000,00(7)$ & & \\
\hline & $10.000,00(8)$ & & \\
\hline
\end{tabular}

\begin{tabular}{|l|c|c|c|c|c|}
\hline & Asiento & Fecha & Cuentas & Debe & Haber \\
\hline $\begin{array}{l}\text { Anotación en } \\
\text { diario }\end{array}$ & 8 & $30 / 01 / 00$ & $\begin{array}{c}57 x \text {. Caja y Bancos (A) } \\
\text { 170. Préstamos 1.p. (P) }\end{array}$ & $10.000,00$ & $10.000,00$ \\
\hline
\end{tabular}


Transacción 10 (31/01/00): Pago alquiler vehículo

\begin{tabular}{|l|c|c|c|c|}
\hline Elementos afectados & Tipo de elemento & Aumento o disminución & Regla registro & Importe \\
\hline Arrendamientos & Gastos & Aumento & Debe & 300,00 \\
\hline Caja y Bancos & Activo & Disminución & Haber & 300,00 \\
\hline
\end{tabular}

\begin{tabular}{|l|r|r|r|r|r|}
\hline & 621. Arrendamientos (G) & & \multicolumn{3}{|c|}{ 57x. Caja y bancos (A) } \\
\hline \multirow{2}{*}{ Anotación en cuentas } & $0,00(0)$ & & $14.500,00(0)$ & $10.000,00(1)$ \\
& $300,00(9)$ & & & $5.000,00(3)$ & $2.000,00(5)$ \\
\cline { 2 - 6 } & & & & $500,00(6)$ & $300,00(9)$ \\
\hline & & & & $1.000,00(7)$ & \\
\hline & & & & $10.000,00(8)$ & \\
\hline
\end{tabular}

\begin{tabular}{|l|c|c|c|c|c|}
\hline & Asiento & Fecha & Cuentas & Debe & Haber \\
\hline $\begin{array}{l}\text { Anotación en } \\
\text { diario }\end{array}$ & 9 & $31 / 01 / 00$ & $\begin{array}{c}\text { 621. Arrendamientos }(\mathrm{G}) \\
\text { 57x. Caja y Bancos } \\
\text { (A) }\end{array}$ & 300,00 & \\
& & & & 300,00 \\
\hline
\end{tabular}

Transacción 11 (31/01/00): Pago a proveedor

\begin{tabular}{|l|c|c|c|c|}
\hline Elementos afectados & Tipo de elemento & Aumento o disminución & Regla registro & Importe \\
\hline Proveedores & Pasivo & Disminución & Debe & 100,00 \\
\hline Caja y Bancos & Activo & Disminución & Haber & 100,00 \\
\hline
\end{tabular}

\begin{tabular}{|r|r|r|r|r|r|}
\hline & \multicolumn{2}{|c|}{ 400. Proveedores (P) } & & \multicolumn{2}{|c|}{$\mathbf{5 7 x .}$ Caja y bancos (A) } \\
\hline \multirow{3}{*}{ Anotación en cuentas } & $100,00(10)$ & $10.000,00(0)$ & & $14.500,00(0)$ & $10.000,00(1)$ \\
& & $200,00(2)$ & & $5.000,00(3)$ & $2.000,00(5)$ \\
\cline { 2 - 6 } & & & & $500,00(6)$ & $300,00(9)$ \\
\hline & & & & $1.000,00(7)$ & $100,00(10)$ \\
\hline & & & & $10.000,00(8)$ & \\
\hline
\end{tabular}

\begin{tabular}{|l|c|c|c|c|c|}
\hline & Asiento & Fecha & Cuentas & Debe & Haber \\
\hline $\begin{array}{l}\text { Anotación en } \\
\text { diario }\end{array}$ & 10 & $31 / 01 / 00$ & $\begin{array}{c}400 . \text { Proveedores (P) } \\
57 x . \text { Caja y Bancos } \\
\text { (A) }\end{array}$ & 100,00 & 100,00 \\
\hline
\end{tabular}

Transacción 12 (31/01/00): Pago sueldo a empleados

\begin{tabular}{|l|c|c|c|c|}
\hline Elementos afectados & Tipo de elemento & Aumento o disminución & Regla registro & Importe \\
\hline Sueldos y Salarios & Gastos & Aumento & Debe & $1.500,00$ \\
\hline Caja y Bancos & Activo & Disminución & Haber & $1,500,00$ \\
\hline
\end{tabular}

\begin{tabular}{|c|c|c|c|}
\hline & 640. Sueldos y & y ba & $\cos \mathrm{c} / \mathrm{c}(\mathrm{A})$ \\
\hline \multirow[t]{4}{*}{ Anotación en cuentas } & $\begin{array}{r}0,00(0) \\
1.500,00(11) \\
\end{array}$ & & $\begin{array}{r}10.000,00(1) \\
2.000,00(5)\end{array}$ \\
\hline & & & $300,00(9)$ \\
\hline & & & $100,00(10)$ \\
\hline & & & $1.500,00(11)$ \\
\hline
\end{tabular}

\begin{tabular}{|l|c|c|c|c|c|}
\hline & Asiento & Fecha & Cuentas & Debe & Haber \\
\hline $\begin{array}{l}\text { Anotación en } \\
\text { diario }\end{array}$ & 11 & $31 / 01 / 00$ & $\begin{array}{c}\text { 640. Sueldos y Salarios (G) } \\
\text { 57x. Caja y Bancos } \\
\text { (A) }\end{array}$ & $1.500,00$ & $1.500,00$ \\
\hline
\end{tabular}


Es frecuente que a efectos didácticos las operaciones de compra o venta de bienes y/o de prestación de servicios al contado se registren directamente contra las cuentas de efectivo (570. Caja o 572. Bancos c/c), tal y como se ve, por ejemplo, en las transacciones 2 y 4 del ejemplo visto con anterioridad.

Transacción 2 (02/01/00): Compra mobiliario al contado por 10.000,00

\begin{tabular}{|l|c|c|c|c|c|}
\hline & Asiento & Fecha & Cuentas & Debe & Haber \\
\hline $\begin{array}{l}\text { Anotación en } \\
\text { diario }\end{array}$ & 1 & $02 / 01 / 00$ & $\begin{array}{c}\text { 216. Mobiliario (A) } \\
\text { 57x. Caja y Bancos } \\
(\mathrm{A})\end{array}$ & $10.000,00$ & \\
& & & $10.000,00$ \\
\hline
\end{tabular}

Transacción 4 (05/01/00): Factura a cliente al contado por 5.000,00

\begin{tabular}{|l|c|c|c|c|c|}
\hline & Asiento & Fecha & Cuentas & Debe & Haber \\
\hline $\begin{array}{l}\text { Anotación en } \\
\text { diario }\end{array}$ & 3 & $05 / 01 / 00$ & $\begin{array}{c}57 x \text {. Caja y Bancos (A) } \\
705 . \text { Prestación Servicios } \\
\text { (I) }\end{array}$ & $5.000,00$ & \\
\hline
\end{tabular}

Sin embargo, el registro real en las empresas de las operaciones de contado suele realizarse contabilizando primero el crédito (derecho de cobro) o débito (obligación de pago) en cuentas de deudores o acreedores para inmediatamente registrar la cancelación de esos importes contra las cuentas de efectivo. De esta forma, las transacciones anteriores se contabilizarían:

Transacción 2 (02/01/00): Compra mobiliario al contado por 10.000,00

\begin{tabular}{|l|c|c|c|c|c|}
\hline & Asiento & Fecha & Cuentas & Debe & Haber \\
\hline $\begin{array}{l}\text { Anotación } \\
\text { en diario }\end{array}$ & 1 & $02 / 01 / 00$ & $\begin{array}{l}\text { 216. Mobiliario (A) } \\
\text { 523. Proveedores de } \\
\text { inmovilizado c.p. (P) }\end{array}$ & $10.000,00$ & $10.000,00$ \\
\hline & & & & & \\
\hline & $02 / 01 / 00$ & $\begin{array}{l}\text { 523. Proveedores de inmovilizado } \\
\text { c.p. (P) 57x. Caja y Bancos (A) }\end{array}$ & $10.000,00$ & $10.000,00$ \\
\hline
\end{tabular}

Transacción 4 (05/01/00): Factura a cliente al contado por 5.000,00

\begin{tabular}{|l|c|c|c|c|c|}
\hline & Asiento & Fecha & Cuentas & Debe & Haber \\
\hline $\begin{array}{l}\text { Anotación } \\
\text { en diario }\end{array}$ & 3 & $05 / 01 / 00$ & $\begin{array}{c}430 . \text { Clientes (A) } \\
705 . \text { Prestación Servicios } \\
\text { (I) }\end{array}$ & $5.000,00$ & $5.000,00$ \\
\hline & & & & & \\
\hline & & $05 / 01 / 00$ & $\begin{array}{c}57 x . \text { Caja y Bancos (A) } \\
430 . \text { Clientes (A) }\end{array}$ & $5.000,00$ & $5.000,00$ \\
\hline
\end{tabular}

El efecto sobre el patrimonio de la empresa de contabilizar estas operaciones de esta forma es idéntico al anterior, pero así queda siempre constancia en las cuentas de los deudores y acreedores de todas las operaciones realizadas con ellos, pudiéndose hacer un seguimiento adecuado y completo. Además, esta información es posteriormente útil a efectos de declaraciones fiscales. 


\subsection{El balance de comprobación de sumas y saldos}

El balance de comprobación de sumas y saldos es un instrumento que sirve de resumen de las sumas deudoras y acreedoras y de los saldos deudores y acreedores de las cuentas utilizadas durante un período determinado. Asimismo suele contener las sumas y saldos acumulados de períodos anteriores.

Para poder elaborarlo es necesario sumar todas las anotaciones realizadas durante el período deseado, calculando las sumas y saldos deudores y acreedores de todas las cuentas utilizadas.

Dependiendo del objetivo pretendido, un balance de comprobación de sumas y saldos puede referirse a la totalidad de las cuentas utilizadas o a una parte de ellas. Por ejemplo, podría elaborarse un balance de comprobación que incluyese solamente las cuentas de clientes, al objeto de realizar un análisis de este conjunto particular de activos.

El Balance de Comprobación de sumas y saldos de un período, por ejemplo el segundo trimestre de un año, 01/04/00 a 30/06/00, contendría:

- El saldo deudor y acreedor de las cuentas al inicio del trimestre, 01/04/00.

- Las sumas deudoras y acreedoras de las cuentas tras las operaciones registradas durante el segundo trimestre $(01 / 04 / 00$ a 30/06/00).

- El saldo deudor o acreedor de las cuentas tras las operaciones registradas durante el segundo trimestre (01/04/00 a 30/06/00).

- Las sumas deudoras y acreedoras acumuladas de las cuentas tras las operaciones registradas desde inicios de año (01/01/00 a 30/06/00).

- El saldo deudor y acreedor de las cuentas tras las operaciones registradas desde inicios de año (01/01/00 a 30/06/00).

\begin{tabular}{|c|c|c|c|c|c|c|c|}
\hline & $\begin{array}{c}\text { Inicial } \\
\text { 01/04/00 }\end{array}$ & \multicolumn{3}{|c|}{$\begin{array}{c}\text { Del período } \\
\text { 01-04-00 a 30-06-00 }\end{array}$} & \multicolumn{3}{c|}{$\begin{array}{c}\text { Acumulado } \\
\text { 01-01-00 a 30-06-00 }\end{array}$} \\
\hline CUENTA & $\begin{array}{c}\text { Saldo deudor } \\
\text { (acreedor) }\end{array}$ & $\begin{array}{c}\text { Suma } \\
\text { deudora }\end{array}$ & $\begin{array}{c}\text { Suma } \\
\text { acreedora }\end{array}$ & $\begin{array}{c}\text { Saldo deudor } \\
\text { (acreedor) }\end{array}$ & $\begin{array}{c}\text { Suma } \\
\text { deudora }\end{array}$ & $\begin{array}{c}\text { Suma } \\
\text { acreedora }\end{array}$ & $\begin{array}{c}\text { Saldo deudor } \\
\text { (acreedor) }\end{array}$ \\
\hline$\ldots$ & & & & & & & \\
\hline & & & & & & & \\
\hline TOTALES & $(1)$ & $(2)$ & $(3)$ & (4) & (5) & (6) & (7) \\
\hline
\end{tabular}

Nota: Con este formato los saldos deudores se muestran con signo positivo y los saldos acreedores entre paréntesis o con signo negativo.

Ilustración 3.5. La información de un balance de comprobación de sumas y saldos

No debe confundirse el balance de comprobación de sumas y saldos con el balance (cuenta anual) en el que solo aparecen cuentas de activo, pasivo y patrimonio neto. 
En el balance como informe contable anual no aparecen cuentas de ingresos y gastos sino su resumen, es decir, el resultado en la cuenta de patrimonio neto denominada «Cuenta de pérdidas y ganancias». Además, en el balance las cuentas están ordenadas y clasificadas por masas patrimoniales, mientras que en balance de comprobación se ordenan por códigos (generalmente) o denominaciones. Por otra parte, el balance se refiere a una fecha concreta y el balance de comprobación de sumas y saldos a un período (para las sumas) y a la fecha final de dicho período (para los saldos).

Para diferenciarlos, en ocasiones al balance se le denomina también «balance de situación».

\section{Características del balance de comprobación}

En un balance de comprobación que incluya todas las cuentas se cumplen las siguientes relaciones (véase ilustración anterior):

- En un período: Total sumas deudoras (2) = Total sumas acreedoras (3).

- En un período: Total saldos deudores = Total saldos acreedores, por lo que la suma $(1)=0$.

- En el acumulado: Total sumas deudoras (5) = Total sumas acreedoras (6).

- En el acumulado: Total saldos deudores = Total saldos acreedores, por lo que la suma $(7)=0$.

Además, las sumas deudoras y acreedoras del período (o acumuladas) deben coincidir con las sumas de los importes anotados al debe y haber, respectivamente, del diario en el período correspondiente (o acumuladas).

\section{Ejemplo de balance de comprobación}

A continuación va a presentarse un balance de comprobación de sumas y saldos correspondiente a la empresa Asesoría Julián López utilizada en este tema para ilustrar el proceso de registro.

En primer lugar, se muestra el mayor (conjunto de todas las cuentas utilizadas) de dicha empresa tras haber registrado las operaciones del mes de enero. Posteriormente se calculan las sumas y saldos deudores y acreedores y finalmente la ilustración siguiente recoge el formato de balance de comprobación de sumas y saldos del período $01 / 01 / 00$ a 31/01/00. 


\begin{tabular}{|c|c|c|c|}
\hline \multicolumn{4}{|c|}{ Ejemplo 3.6. Balance de comprobación de sumas y saldos } \\
\hline \multicolumn{4}{|c|}{ MAYOR DE LA ASESORÍA JULIÁN LÓPEZ, DE 01/01/00 A 31/01/00 } \\
\hline \multicolumn{2}{|c|}{ 211. Construcciones (A) } & \multicolumn{2}{|c|}{ 216. Mobiliario (A) } \\
\hline $39.000,00(0)$ & & $10.000,00(0)$ & $1.000,00(7)$ \\
\hline Suma D. $39.000,00$ & Suma A. 0,00 & Suma D. $10.000,00$ & Suma A. $1.000,00$ \\
\hline Saldo D. $39.000,00$ & & Saldo D. $9.000,00$ & \\
\hline \multicolumn{2}{|c|}{ 328. Material de Oficina (A) } & \multicolumn{2}{|c|}{ 430. Clientes (A) } \\
\hline $\begin{array}{l}500,00(0) \\
200,00(2)\end{array}$ & & $\begin{array}{l}5.000,00(0) \\
1.000,00(4)\end{array}$ & $500,00(6)$ \\
\hline Suma D. 700,00 & Suma A. 0,00 & Suma D. $6.000,00$ & Suma A. 500,00 \\
\hline Saldo D. 700,00 & & Saldo D. 5.500,00 & \\
\hline \multicolumn{2}{|c|}{ 57x. Caja y bancos (A) } & \multicolumn{2}{|c|}{ 170. Préstamos l.p. (P) } \\
\hline $\begin{array}{r}14.500,00(0) \\
5.000,00(3)\end{array}$ & $\begin{array}{r}10.000,00(1) \\
2.000,00(5)\end{array}$ & & $\begin{array}{l}30.000,00(0) \\
10.000,00(8)\end{array}$ \\
\hline $500,00(6)$ & $300,00(9)$ & & \\
\hline $1.000,00(7)$ & $100,00(10)$ & & \\
\hline $10.000,00(8)$ & $1.500,00(11)$ & & \\
\hline Suma D. $31.000,00$ & $\begin{array}{r}\text { Suma A. } \\
13.900,00\end{array}$ & Suma D. 0,00 & Suma A. $40.000,00$ \\
\hline \multicolumn{2}{|l|}{ Saldo D. $17.100,00$} & & Saldo A. $40.000,00$ \\
\hline \multicolumn{2}{|c|}{ 400. Proveedores $(\mathrm{P})$} & \multicolumn{2}{|c|}{ 100. Capital (N) } \\
\hline $100,00(10)$ & $\begin{array}{r}10.000,00(0) \\
200,00(2)\end{array}$ & $2.000,00(5)$ & $20.000,00(0)$ \\
\hline \multirow[t]{2}{*}{ Suma D. 100,00} & $\begin{array}{r}\text { Suma A. } \\
10.200,00 \\
\end{array}$ & Suma D. $2.000,00$ & Suma A. $20.000,00$ \\
\hline & $\begin{array}{r}\text { Saldo A. } \\
10.100,00\end{array}$ & & Saldo A. $18.000,00$ \\
\hline \multicolumn{2}{|c|}{ 705. Prestación de servicios (I) } & \multicolumn{2}{|c|}{ 621. Arrendamientos (G) } \\
\hline & $\begin{array}{r}0,00(0) \\
5.000,00(3) \\
\end{array}$ & $\begin{array}{r}0,00(0) \\
300,00(9) \\
\end{array}$ & \\
\hline & $1.000,00(4)$ & & \\
\hline \multirow[t]{2}{*}{ Suma D. 0,00 } & Suma A. $6.000,00$ & Suma D. 300,00 & Suma A. 0,00 \\
\hline & Saldo A. $6.000,00$ & Saldo D. 300,00 & \\
\hline \multicolumn{4}{|c|}{ 640. Sueldos y salarios (G) } \\
\hline \multicolumn{4}{|l|}{$0,00(0)$} \\
\hline \multicolumn{4}{|l|}{$1.500,00(11)$} \\
\hline Suma D. $1.500,00$ & Suma A. 0,00 & & \\
\hline Saldo D. $1.500,00$ & & & \\
\hline
\end{tabular}




\begin{tabular}{|c|c|c|c|c|c|c|c|}
\hline \multirow[b]{3}{*}{ CUENTA } & \multicolumn{5}{|c|}{$\begin{array}{c}\text { Asesoría Julián López } \\
\text { Balance de comprobación de sumas y saldos } \\
\text { Período } 01 / 01 / 00 \text { a } 31 / 01 / 00\end{array}$} & & \\
\hline & \multirow{2}{*}{$\begin{array}{c}\begin{array}{c}\text { Inicial } \\
01 / 01 / 00\end{array} \\
\begin{array}{c}\text { Saldo } \\
\text { deudor } \\
\text { (acreedor) }\end{array}\end{array}$} & \multicolumn{3}{|c|}{$\begin{array}{c}\text { Del período } \\
\text { (operaciones del mes) }\end{array}$} & \multicolumn{3}{|c|}{ Acumulado hasta 31/01/00 } \\
\hline & & $\begin{array}{c}\text { Suma } \\
\text { deudora }\end{array}$ & $\begin{array}{c}\text { Suma } \\
\text { acreedora }\end{array}$ & $\begin{array}{c}\text { Saldo } \\
\text { deudor } \\
\text { (acreedor) }\end{array}$ & $\begin{array}{c}\text { Suma } \\
\text { deudora }\end{array}$ & $\begin{array}{c}\text { Suma } \\
\text { acreedora }\end{array}$ & $\begin{array}{c}\text { Saldo } \\
\text { deudor } \\
\text { (acreedor) }\end{array}$ \\
\hline 100. Capital (A) & $(20.000,00)$ & $2.000,00$ & & $2.000,00$ & $2.000,00$ & $20.000,00$ & $(18.000,00)$ \\
\hline 170. Préstamos 1.p. (P) & $(30.000,00)$ & & $10.000,00$ & $(10.000,00)$ & & $40.000,00$ & $(40.000,00)$ \\
\hline 211. Construcciones (A) & $39.000,00$ & & & & $39.000,00$ & & $39.000,00$ \\
\hline 216. Mobiliario (A) & $1.000,00$ & $10.000,00$ & $1.000,00$ & $9.000,00$ & $11.000,00$ & $1.000,00$ & $10.000,00$ \\
\hline 328. Material oficina (A) & 500,00 & 200,00 & & 200,00 & 700,00 & & 700,00 \\
\hline 400. Proveedores (A) & $(10.000,00)$ & 100,00 & 200,00 & $(100,00)$ & 100,00 & $10.200,00$ & $(10.100,00)$ \\
\hline 430. Clientes (A) & $5.000,00$ & $1.000,00$ & 500,00 & 500,00 & $6.000,00$ & 500,00 & $5.500,00$ \\
\hline 57x. Caja y Bancos (A) & $14.500,00$ & $16.500,00$ & $13.900,00$ & $2.600,00$ & $31.000,00$ & $13.900,00$ & $17.100,00$ \\
\hline 621. Arrendamientos (G) & 0,00 & 300,00 & & 200,00 & 300,00 & & 300,00 \\
\hline 640. Sueldos y Salarios (G) & 0,00 & $1.500,00$ & & $1.500,00$ & $1.500,00$ & & $1.500,00$ \\
\hline 705. Prestación servicios (I) & 0,00 & & $6.000,00$ & $(6.000,00)$ & & $6.000,00$ & $(6.000,00)$ \\
\hline TOTALES & 0,00 & $29.600,00$ & $6.000,00$ & 0,00 & $89.600,00$ & $6.000,00$ & 0,00 \\
\hline
\end{tabular}

\section{Utilidad del balance de comprobación}

La utilidad general del balance de comprobación es servir de resumen informativo de las cuentas y permitir, en ocasiones, detectar errores.

La detección de errores numéricos de cuadre (diferencias en las sumas o saldos deudores y acreedores) era muy importante cuando la contabilidad era llevada manualmente. En la actualidad el uso de sistemas informáticos elimina esta posibilidad de error.

No obstante, los errores que provocan asientos conceptualmente incorrectos pueden no ser detectados dado que, según el método de la partida doble, los importes anotados al debe y haber deben ser siempre iguales. 
Ejemplo 3.7. Error de registro de transacción pero con balance cuadrado

Supóngase que el siguiente asiento es el correcto (corresponde a una venta de mobiliario al contado):

\begin{tabular}{|c|c|c|c|c|}
\hline Asiento & Fecha & Cuentas & Debe & Haber \\
\hline 9 & $28 / 10 / 00$ & $\begin{array}{c}57 x . \text { Caja y bancos (A) } \\
216 . \text { Mobiliario (A) }\end{array}$ & 500,00 & 500,00 \\
\hline
\end{tabular}

Y que, sin embargo, se contabiliza el siguiente (que sería una compra de mobiliario al contado):

\begin{tabular}{|c|c|c|c|c|}
\hline Asiento & Fecha & Cuentas & Debe & Haber \\
\hline 9 & $28 / 10 / 00$ & $\begin{array}{c}\text { 216. Mobiliario (A) } \\
\text { 57x. Caja y bancos } \\
\text { (A) }\end{array}$ & 500,00 & 500,00 \\
\hline
\end{tabular}

Este error puede detectarse si la persona que lleva la contabilidad percibe que los saldos no son correctos. Por ejemplo, si se apercibe que el saldo de la cuenta de «mobiliario» es anormalmente alto (la compra realmente contabilizada aumenta el saldo cuando en realidad debería disminuir por la venta) y el saldo de la cuenta de «caja y bancos» anormalmente bajo. También puede comprobarse al conciliar el saldo de caja y bancos por arqueo.

Finalmente, el balance de comprobación de sumas y saldos puede servir de base para la elaboración de la cuenta de pérdidas y ganancias (tomando los saldos de las cuentas de ingresos y gastos) y del balance (tomando los saldos de las cuentas de activos, pasivos y elementos de patrimonio neto más una cuenta, denominada pérdidas y ganancias, para recoger el resultado del ejercicio). 


\subsection{Proceso contable y secuencia de registro}

El proceso contable puede sintetizarse en los pasos que se muestran en la siguiente ilustración:
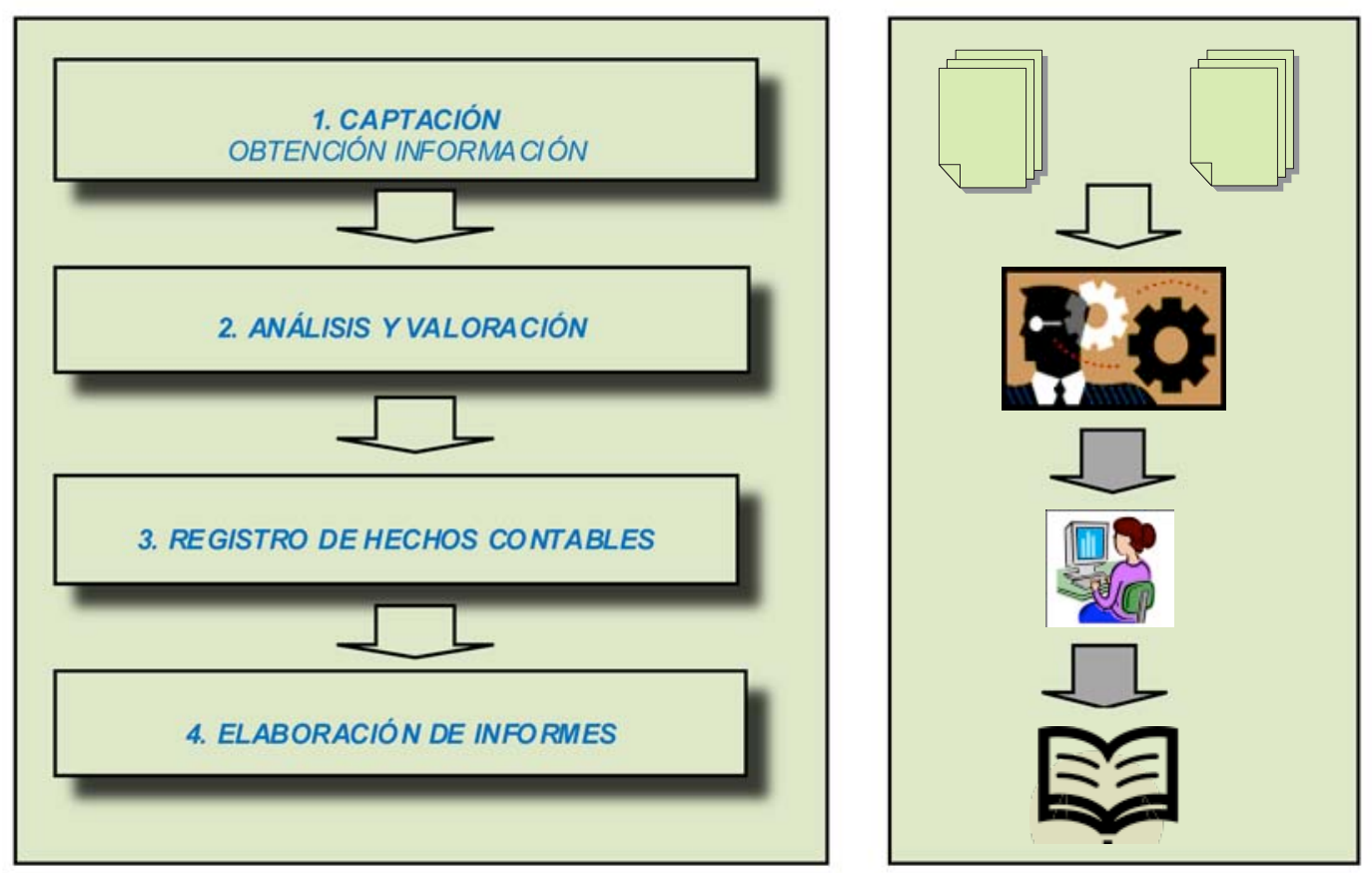

Ilustración 3.6. El proceso contable

1. Captación de hechos contables. La captación se realiza a través de documentación soporte de acontecimientos producidos o actividades realizadas (tickets, recibos, facturas, nóminas, extractos bancarios, informes, etc.).

El sistema contable debe establecerse de forma que se tenga la seguridad de que se captan todos los hechos contables, que no existen acontecimientos que puedan escapar a la detección del sistema, puesto que ello producirá una deficiencia en la información tratada y elaborada.

Ejemplo 3.8. Documento de entrega de residuos como justificación de hecho
contable
RECIPLASA es una empresa cuya actividad consiste en el reciclaje de residuos urbanos,
entre otros de la ciudad de Castellón. El día 14 de junio de 2000 recibió un camión
de residuos y, tras el pesaje correspondiente, emitió un documento de recepción que
ponía de manifiesto que se habían descargado 20 t de residuos.
Dicho documento pone de manifiesto un hecho contable, la recepción de residuos, que constituye la
justificación de los servicios de reciclaje realizados para el Ayuntamiento de Castellón.

2. Análisis y valoración de hechos contables. Consiste en el análisis de los hechos contables y la valoración de lo ocurrido teniendo en cuenta sus repercusiones sobre la unidad económica. Se trata de una fase crítica del proceso en la cual se 
requieren los conocimientos técnicos específicos que se exigen en la profesión contable.

Estas dos primeras fases son particularmente importantes y, en muchos casos, complejas. La labor principal del contable incidirá inicialmente en la fase de diseño de los sistemas de captación de datos y con posterioridad en la valoración de hechos contables conforme estos se vayan produciendo.

Ejemplo 3.9. Análisis y valoración de hecho contable
RECIPLASA, a la vista de los documentos de recepción de residuos concluye que
procede reconocer un ingreso por una prestación de servicios al tiempo que debe
registrar un crédito contra el Ayuntamiento de Castellón. La valoración de dichos
servicios se atiene al contrato firmado con el Ayuntamiento y que determina una
tasa o precio por tonelada a tratar, y que resulta ser de $30 € /$ t. En consecuencia, el
valor total del servicio es de $600 €$.

3. Registro de hechos contables. Consistente en la anotación de los hechos contables en los instrumentos de registro adecuados.

La fase de registro de hechos contables suele ser mecánica y repetitiva, una vez se ha analizado correctamente el hecho producido. A esta fase también se le denomina «teneduría de libros» y es la que, erróneamente, suele identificar más a la profesión contable.

Ejemplo 3.10. Registro
RECIPLASA registrará el 14 de junio de 00 en el Diario y en el Mayor el hecho
RECIPLASA
de Castellón, y abonará la cuenta de ingresos por prestación de servicios. Ambas
anotaciones serán por $600 €$.

4. Elaboración de información de síntesis. Consiste en la acumulación de la información registrada y la elaboración de informes de síntesis útiles para la toma de decisiones.

Muchos informes se elaboran de forma rutinaria y están actualmente completamente mecanizados (las aplicaciones informáticas de contabilidad incluyen los diseños con su estructura y contenido y se emiten de forma automática), otros por el contrario precisan de una elaboración previa.

Ejemplo 3.11. Informe contable de síntesis
RECIPLASA elabora al final del mes de junio un informe resumen de los servicios
de reciclaje prestados a los distintos municipios de la provincia de Castellón
en dicho mes. En dicho informe se pone de manifiesto las toneladas tratadas
procedentes de cada municipio, los importes facturados y las fechas de cobro
previstas.
Además se incluye información sobre la evolución histórica de dichos servicios
(meses anteriores), con lo cual pretende estimar las necesidades futuras del servi-
cio y planificar las inversiones y necesidades de personal futuras.




\section{Secuencia del registro contable}

El procedimiento de registro físico en las empresas se realiza con el orden que se muestra en la siguiente ilustración:

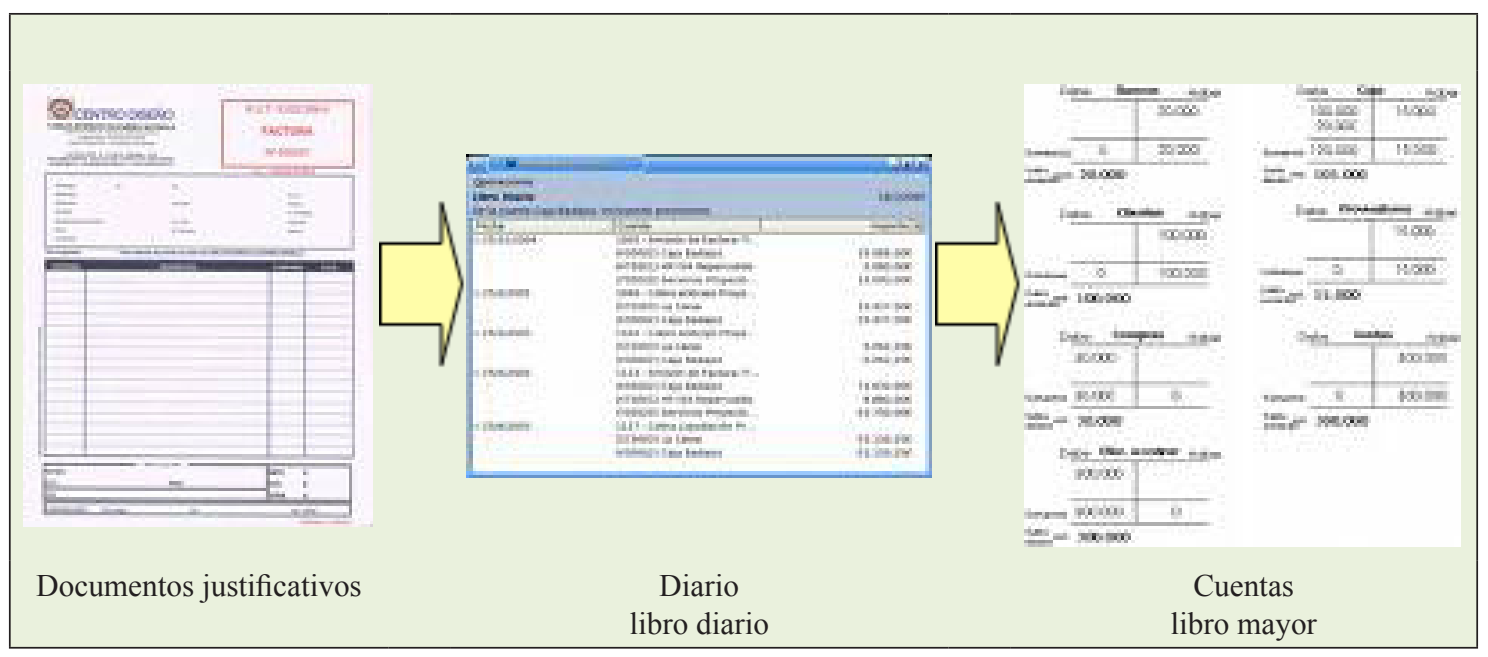

Ilustración 3.7 Secuencia del proceso de registro

Tal y como muestra la ilustración anterior la secuencia en el proceso de registro contable es la siguiente:

1. Captación y análisis de los documentos justificativos de la transacción. Se determinan los elementos patrimoniales afectados, su variación y dónde procede anotar dicha variación.

2. Registro de la transacción en asientos del Diario. Este registro en las pequeñas empresas se realiza frecuentemente de forma manual, aunque las posibilidades de automatización son elevadas.

Así, si los documentos los emite la propia empresa en muchas ocasiones el registro en diario se realiza de forma automática. Por ejemplo, cuando una empresa emite una factura a un cliente utilizando para ello una aplicación informática de facturación y control de almacenes, si este está enlazado con una aplicación informática de contabilidad puede realizar automáticamente los asientos que corresponden a la venta.

3. Traspaso de los asientos a las cuentas. Una vez terminado y validado un asiento, la aplicación informática de contabilidad traslada el mismo a las cuentas afectadas. Este traslado se realiza de forma automática sobre la base de las cuentas utilizadas. 


\subsection{Formatos reales de cuentas de mayor y diario}

A continuación se muestran ejemplos de lo que podrían ser formatos reales de diario y cuenta de mayor y que presentan algunas diferencias respecto al formato utilizado a efectos didácticos en los libros de texto y en este material. asimismo se muestran las relaciones existentes entre las anotaciones en el diario y las de la cuenta de mayor.

Muestra de diario con un formato real

\section{DIARIO}

\begin{tabular}{crrlll} 
ASIENTO & FECHA & CUENTA & \multicolumn{1}{c}{ DESCRIPCIÓN } & DEBE & HABER \\
\hline & & & & & \\
3 & $7 / 10$ & $\mathbf{5 7 2 0 0 0 1}$ & Obtención préstamo BANCAJA 454 & $\mathbf{2 6 . 0 0 0}$ & \\
3 & $7 / 10$ & 1700000 & Obtención préstamo BANCAJA 454 & & 26.000 \\
& & & & & \\
4 & $10 / 10$ & 2270000 & Compra ordenador IBM Fra. 34/01 & 25.000 & \\
$\mathbf{4}$ & $\mathbf{1 0} / \mathbf{1 0}$ & $\mathbf{5 7 2 0 0 0 1}$ & Compra ordenador IBм Fra. 34/01 & & $\mathbf{1 0 . 0 0 0}$ \\
4 & $10 / 10$ & 4010000 & Compra ordenador IBM Fra. 34/01 & 15.000
\end{tabular}

Obsérvese que en este formato no aparece la denominación de la cuenta, información que viene sustituida por el código de la misma y que tendrá su equivalencia en el cuadro de cuentas de la empresa.

En este caso la cuenta 572001 utilizada en ambos asientos es una cuenta corriente bancaria concreta que es la que se muestra en la siguiente ilustración.

Muestra de cuenta con un formato real

\section{CUENTA}

CÓDIGO: 572001

FECHA ASIENTO CONTRA-
CUENTA: BANCAJA CTA 3333-22

DESCRIPCIÓN DEBE HABER SALDO

$69.000 \quad 69.000$

$\begin{array}{clllllr}1 / 10 & 1 & 1020000 & \text { Creación empresa } & 69.000 & 69.000 \\ 5 / 10 & 2 & 2210000 & \text { Compra Local. Escritura 345/01 } & 60.000 & 9.000 \\ \mathbf{7 / 1 0} & \mathbf{3} & \mathbf{1 7 0 0 0 0 0} & \text { Obtención préstamo BANCAJA 454 } & \mathbf{2 6 . 0 0 0} & & \mathbf{3 5 . 0 0 0} \\ \mathbf{1 0 / 1 0} & \mathbf{4} & \mathbf{2 2 7 0 0 0 0} & \text { Compra ordenador IBM Fra. 34/01 } & & \mathbf{1 0 . 0 0 0} & \mathbf{2 5 . 0 0 0}\end{array}$

$\begin{array}{lll}\cdots & \cdots & \cdots\end{array}$

Obsérvese que en este formato cada anotación en la cuenta hace referencia al número de asiento que la generó y a la cuenta contrapartida de dicho asiento. Además cada vez que se realiza una anotación en la cuenta se muestra el saldo resultante en la última columna. 


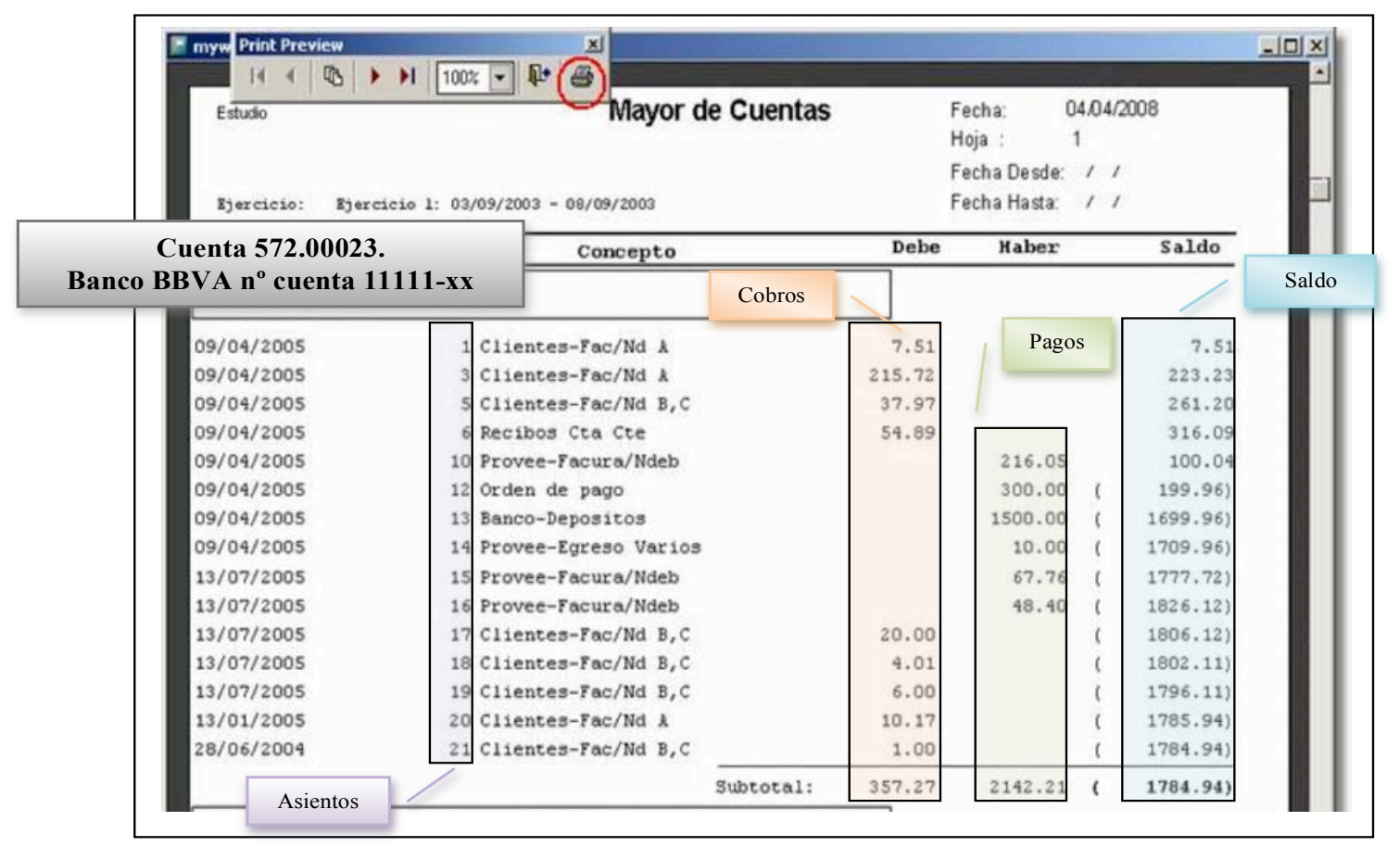

Ilustración 3.8. Cuenta de mayor

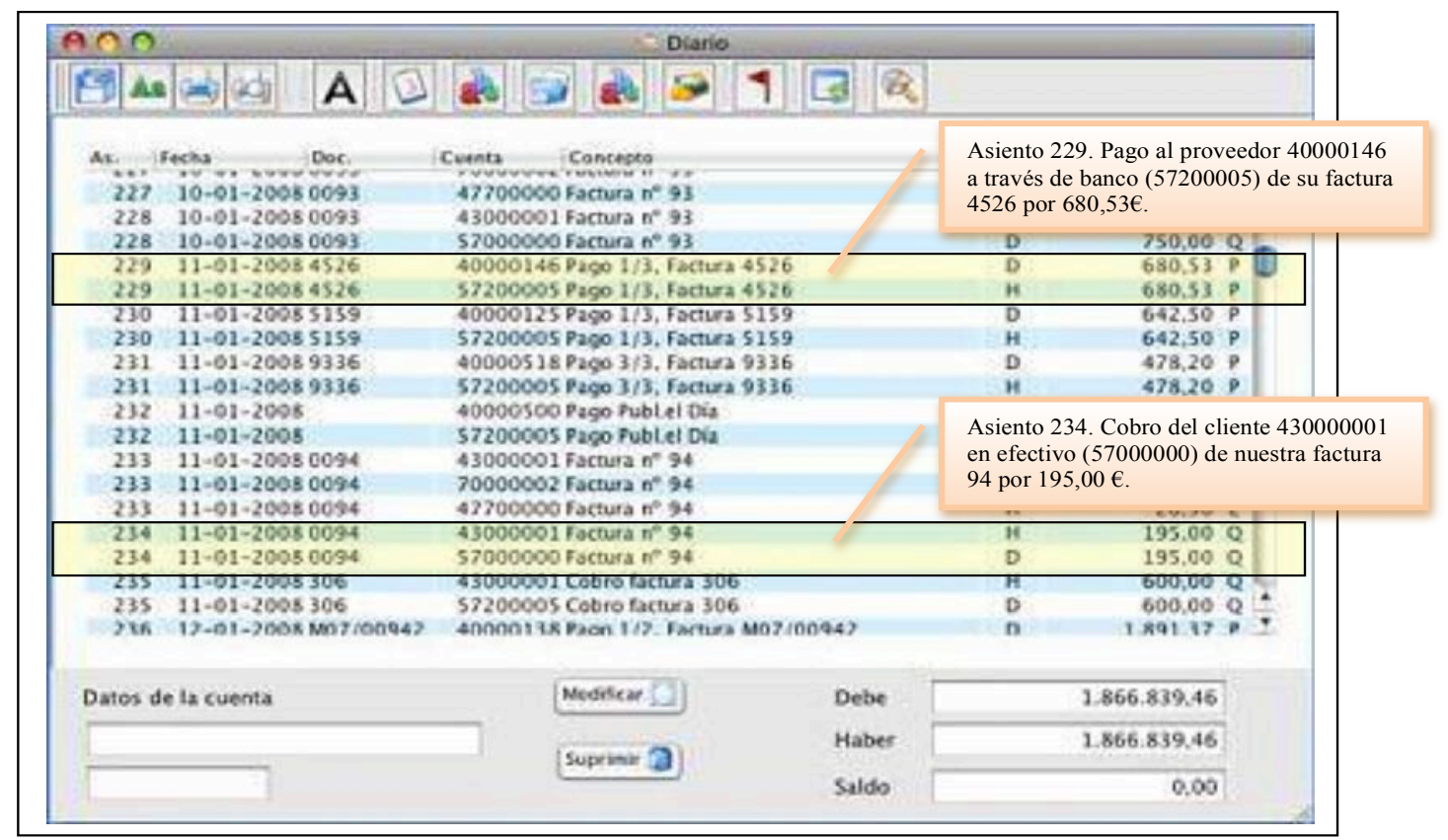

Ilustración 3.9. Diario 


\section{Material para prácticas}

\section{Preguntas test}

1. El método de la partida doble supone que:

a) Toda anotación debe ser doble: en el libro diario y en el libro mayor.

b) El importe que se adeude a determinados elementos patrimoniales debe abonarse a otros.

c) En todo hecho contable, la cantidad que se adeuda a un elemento patrimonial, deberá serle abonada de nuevo, al efecto de respetar la ecuación fundamental del patrimonio.

d) Las sumas deudoras del diario deben coincidir con los saldos deudores del mayor.

2. El libro diario recoge:

a) La suma de todas las anotaciones realizadas en el debe de una cuenta.

b) La situación de las cuentas referentes a cada elemento patrimonial.

c) Las anotaciones de los hechos contables por orden cronológico.

d) Ninguna de las anteriores.

3. Si una empresa presta dinero a alguno de sus empleados, se produce:

a) Un aumento de pasivo y un gasto.

b) Un aumento de activo y un ingreso.

c) Un aumento de pasivo y una disminución de activo.

d) Un aumento de activo y una disminución de otro activo.

4. ¿Por qué se registran los hechos contables en el libro diario?

a) Para asegurar que todas las operaciones se anotan en el libro mayor.

b) Para verificar la igualdad entre cargos y abonos.

c) Para facilitar su análisis por partida doble.

d) Para disponer de un registro cronológico de todas las operaciones.

5. Según el convenio del cargo y el abono:

a) Las cuentas de activo siempre tendrán saldo acreedor.

b) Las cuentas de pasivo solo se abonan.

c) Las cuentas de activo funcionan al revés que las de pasivo y neto.

d) Las cuentas de neto y activo funcionan al revés que las de pasivo.

6. La obtención de un préstamo a largo plazo bancario aumenta:

a) El activo corriente y el pasivo no corriente.

b) Solo el activo corriente.

c) Solo el pasivo no corriente.

d) El activo no corriente y el pasivo corriente. 
7. ¿Qué se recoge en el Haber de una cuenta de gastos?
a) El aumento del gasto.
b) Una disminución de patrimonio neto.
c) Los gastos incurridos.
d) Ninguna de las anteriores.

8. El balance de comprobación es la síntesis:

a) De las cuentas que se han comprobado y de las cuentas que no se han comprobado.

b) De las cuentas que están saldadas.

c) De las sumas y los saldos de las cuentas en un momento determinado.

d) De la situación patrimonial de la empresa.

9. Se dice que se abona una cuenta cuando:
a) Se hace una anotación en el debe de la cuenta.
b) Se hace una anotación en el haber de la cuenta.
c) Se calculan las sumas deudoras.
d) Se calculan las sumas acreedoras.

10. El hecho de abonar una cuenta implica:

a) Realizar un apunte que aumente su saldo.

b) Realizar un apunte en el haber de esa cuenta.

c) Prepararla para su cancelación o cierre.

d) Incrementar su saldo si se trata de una cuenta de activo.

11. El proceso contable tiene las siguientes fases:
a) Captación de información, registro y elaboración de informes.
b) Captación de información, análisis, registro y elaboración de informes.
c) Registro, comprobación de sumas y saldos y cuentas anuales.
d) Registro, diario, mayor y elaboración de informes.

12. Si se anota al debe una cuenta de pasivo significa que:
a) Aumentan las deudas de la empresa.
b) Aumentan los gastos de la empresa.
c) Disminuyen las deudas de la empresa.
d) Disminuyen los gastos de la empresa.

\section{SOLUCIONES AL TEST:}

\begin{tabular}{|l|l|l|l|l|}
\hline 1. & 2. & 3. & 4. & 5. \\
\hline 6. & 7. & 8. & 9. & 10. \\
\hline 11. & 12. & & & \\
\hline
\end{tabular}




\section{Cuestiones teóricas}

1. Cite los fundamentos del método de la partida doble.

2. Defina qué es una cuenta y muestre su estructura sintética.

3. ¿Qué es el debe de una cuenta? ¿Y el haber?

4. ¿Qué significa cargar o adeudar una cuenta? ¿Y abonar o acreditar?

5. ¿Qué significa saldar una cuenta?

6. Indique las reglas de cargo y abono de las cuentas de activo, pasivo y patrimonio neto.

7. Indique y justifique las reglas de cargo y abono de las cuentas de ingresos y gastos.

8. ¿Cómo se calculan las sumas deudoras y acreedoras así como los saldos deudores y acreedores de una cuenta?

9. ¿Puede tener una cuenta simultáneamente una suma deudora y una suma acreedora? ¿Y un saldo deudor y un saldo acreedor? Justifique la respuesta.

10. Comente la afirmación: «Si una cuenta tiene saldo deudor significa que la empresa debe dinero»».

11. Comente la afirmación: «En general, las cuentas representativas de activos presentarán saldos deudores».

12. Comente la afirmación: «En general, las cuentas representativas de patrimonio neto presentarán saldos acreedores».

13. ¿Qué es el cuadro de cuentas de una empresa?

14. ¿Por qué es útil que las cuentas, aparte de tener una denominación, estén codificadas?

15. ¿Qué es el diario?

16. ¿Qué es un asiento y qué anotaciones se realizan en el mismo?

17. ¿Es cierto que en un asiento solo pueden aparecer registradas dos cuentas, una al debe y otra al haber?

18. ¿Qué se entiende por libros auxiliares de contabilidad? ¿Cuál es su utilidad?

19. ¿Qué es el balance de comprobación de sumas y saldos?

20. Indique las diferencias entre el balance de comprobación de sumas y saldos y el balance (cuenta anual).

21. Comente la afirmación: «El balance de comprobación de sumas y saldos permite la detección de todos los errores contables».

22. Comente la afirmación: «Un balance de sumas y saldos cuadrado implica que la contabilidad está libre de errores».

23. ¿Es cierto que la suma de los saldos deudores (o acreedores) del balance de comprobación de sumas y saldos coincide con la suma del debe (o haber) del diario?

24. Cite las utilidades del balance de comprobación de sumas y saldos.

25. Indique las fases del proceso contable.

26. En qué consiste la fase de valoración dentro del proceso contable.

27. Distinga entre contabilidad y teneduría de libros.

28. Explique la secuencia real registro contable en las empresas. 


\section{Ejercicios}

\section{Ejercicio 1. Codificación y denominación de cuentas}

A continuación se presentan diversos activos, pasivos y elementos de patrimonio neto para los que hay que identificar la cuenta del cuadro de cuentas del PGC (código y denominación con tres dígitos) que debería utilizarse, siguiendo para ello el ejemplo propuesto.

\begin{tabular}{|c|c|}
\hline Elemento (activo, pasivo o patrimonio neto) & Cuenta del PGC \\
\hline Créditos contra compradores de mercancías vendidas. & 430. Clientes \\
\hline \multicolumn{2}{|l|}{$\begin{array}{l}\text { Deudas a corto plazo por préstamos con entidades } \\
\text { financieras. }\end{array}$} \\
\hline \multicolumn{2}{|l|}{$\begin{array}{l}\text { Resultados retenidos voluntariamente de beneficios } \\
\text { anteriores. }\end{array}$} \\
\hline \multicolumn{2}{|l|}{ Créditos contra Hacienda por devolución de impuestos. } \\
\hline \multicolumn{2}{|l|}{ Dinero depositado en cuentas bancarias. } \\
\hline \multicolumn{2}{|l|}{$\begin{array}{l}\text { Deudas a largo plazo por préstamos con entidades } \\
\text { financieras. }\end{array}$} \\
\hline \multicolumn{2}{|l|}{ Maquinaria para la fabricación de productos. } \\
\hline \multicolumn{2}{|l|}{$\begin{array}{l}\text { Deudas con la Seguridad Social por las cotizaciones de } \\
\text { trabajadores. }\end{array}$} \\
\hline \multicolumn{2}{|l|}{ Derecho a la utilización en exclusiva de una patente. } \\
\hline \multicolumn{2}{|l|}{$\begin{array}{l}\text { Inversiones a largo plazo en acciones con objetivo de } \\
\text { rentabilidad. }\end{array}$} \\
\hline \multicolumn{2}{|l|}{ Existencias comerciales de la empresa. } \\
\hline \multicolumn{2}{|l|}{ Deudas con el suministrador de electricidad } \\
\hline \multicolumn{2}{|l|}{$\begin{array}{l}\text { Aportaciones iniciales de los socios en la constitución } \\
\text { de la sociedad. }\end{array}$} \\
\hline \multicolumn{2}{|l|}{ Deudas con suministradores de mercancías. } \\
\hline \multicolumn{2}{|l|}{$\begin{array}{l}\text { Créditos contra terceros por servicios accesorios pres- } \\
\text { tados. }\end{array}$} \\
\hline \multicolumn{2}{|l|}{ Deudas con Hacienda por el Impuesto de Sociedades. } \\
\hline \multicolumn{2}{|l|}{$\begin{array}{l}\text { Créditos con terceros por préstamos concedidos a corto } \\
\text { plazo. }\end{array}$} \\
\hline \multicolumn{2}{|l|}{ Locales comerciales propiedad de la empresa. } \\
\hline \multicolumn{2}{|l|}{ Inversiones en acciones a corto plazo. } \\
\hline \multicolumn{2}{|l|}{$\begin{array}{l}\text { Créditos contra terceros a largo plazo por préstamos } \\
\text { concedidos. }\end{array}$} \\
\hline Dinero efectivo en la caja de la empresa. & \\
\hline
\end{tabular}

\section{Ejercicio 2. Codificación y denominación de cuentas}

A continuación se presentan diversos gastos e ingresos para los que hay que identificar la cuenta del cuadro de cuentas del PGC (código y denominación a nivel de tres dígitos) que debería utilizarse, siguiendo para ello el ejemplo propuesto.

\begin{tabular}{|l|l|}
\hline \multicolumn{1}{|c|}{ GASTO O INGRESO } & \multicolumn{1}{c|}{ CUENTA DEL PGC } \\
\hline Compras de mercaderías. & 600. Compras de mercaderías \\
\hline $\begin{array}{l}\text { Ingresos por intereses de préstamos concedidos a largo } \\
\text { plazo. }\end{array}$ & \\
\hline
\end{tabular}




\begin{tabular}{|l|l|}
\hline Gastos por seguridad social a cargo de la empresa. & \\
\hline Compras de materiales auxiliares para la producción. & \\
\hline $\begin{array}{l}\text { Ingresos por intereses de préstamos concedidos a corto } \\
\text { plazo. }\end{array}$ & \\
\hline Variación de existencias de mercaderías. & \\
\hline Gastos por intereses de préstamos obtenidos a corto plazo. & \\
\hline Gastos por servicios de profesionales independientes. & \\
\hline Ventas de mercancías comerciales. & \\
\hline Gastos por primas de seguros. & \\
\hline Beneficios por operaciones con el inmovilizado intangible. & \\
\hline Tributos municipales. & \\
\hline Ingresos por prestación de servicios. & \\
\hline Sueldos de los trabajadores de la empresa. & \\
\hline $\begin{array}{l}\text { Gastos por intereses de préstamos obtenidos a largo } \\
\text { plazo. }\end{array}$ & \\
\hline Pérdidas por operaciones con el inmovilizado material. & \\
\hline Gasto por la amortización anual de los muebles. & \\
\hline Gastos por arrendamiento de inmuebles. & \\
\hline $\begin{array}{l}\text { Aumento del valor de cotización de acciones a valor } \\
\text { razonable. }\end{array}$ & \\
\hline Subvenciones obtenidas para la explotación. & \\
\hline
\end{tabular}

Los ejercicios 3 a 20 muestran diversas transacciones. Se pide que se registren las mismas en el diario y las cuentas que proceda (para cada asiento se abrirán cuentas nuevas aunque sean transacciones de la misma empresa). Indique el código de la cuenta según el cuadro de cuentas el PGC y si la cuenta es de activo (a), pasivo (p), patrimonio neto (n), ingresos (i) o gastos (g).

\section{Ejercicio 3. Emisión de factura por prestación de servicios}

El día 5 de abril de 2000 la ASESORÍA LÓPEZ SL factura a un cliente 500,00 € por prestación de servicios.

\begin{tabular}{|c|c|c|c|c|}
\hline Asto & Fecha & Cuentas & Debe & Haber \\
\hline & & & & \\
& & & & \\
\hline
\end{tabular}
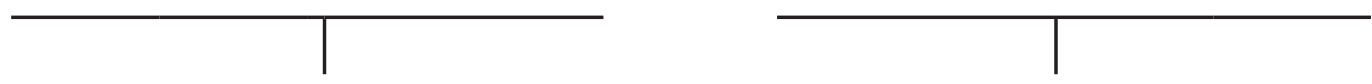

\section{Ejercicio 4. Registro de cobro de un cliente}

EL CORTE INGLÉS cobra, el 3 de febrero de 2000, en efectivo 600,00 € de un cliente.

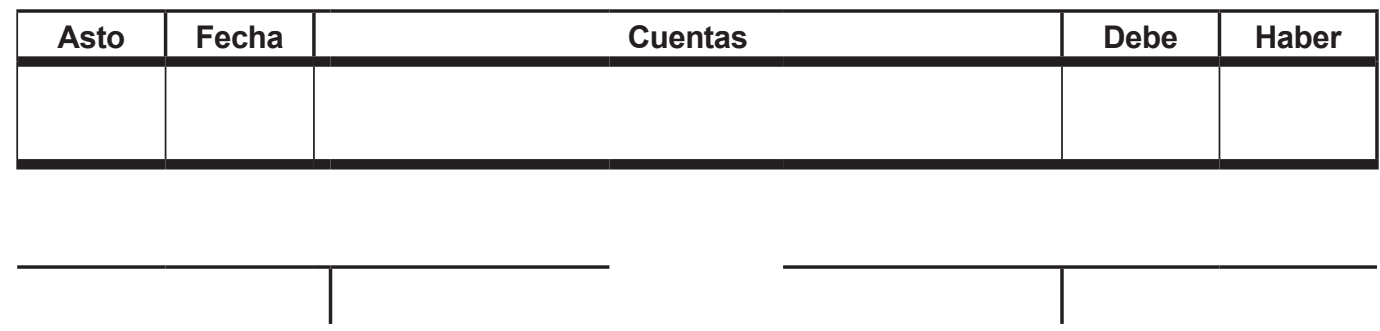


Ejercicio 5. Recepción de factura de compra de material de oficina

EL CORTE INGLÉS SA compra, el 8 de agosto de 2000, material diverso de papelería por $1.000,00 €$. El proveedor permite el aplazamiento del pago hasta septiembre.

\begin{tabular}{|c|c|c|c|c|}
\hline Asto & Fecha & Cuentas & Debe & Haber \\
\hline & & & & \\
& & & & \\
\hline
\end{tabular}
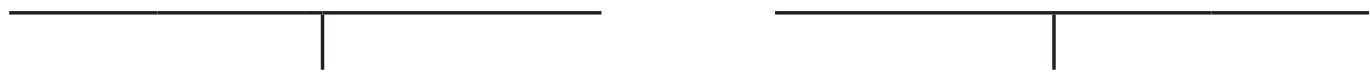

Ejercicio 6. Registro de pago a proveedor

CARREFOUR SA entrega el 4 de mayo de 2000 un cheque bancario por 2.000,00 $€$ a un proveedor con el fin de cancelar una deuda contraída por una pasada compra.

\begin{tabular}{|c|c|c|c|c|}
\hline Asto & Fecha & Cuentas & Debe & Haber \\
\hline & & & & \\
\hline
\end{tabular}
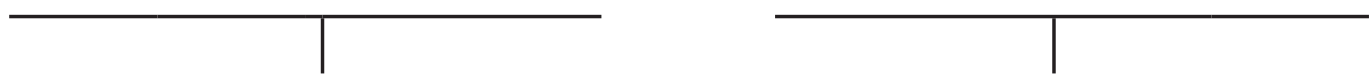

Ejercicio 7. Registro de compra de un inmovilizado en efectivo

EL CORTE INGLÉS SA compra, el 7 de agosto de 2000, un vehículo para reparto pagando en efectivo un valor de $15.000,00 €$.

\begin{tabular}{|l|l|l|l|l|}
\hline Asto & Fecha & Cuentas & Debe & Haber \\
\hline & & & & \\
\hline & & & \\
\hline & & &
\end{tabular}

Ejercicio 8. Registro de comunicación de tributos

COMIDAS ASTURIANAS SA recibe a 23 de agosto por correo el recibo del impuesto sobre bienes inmuebles (IBI) del ayuntamiento de Castellón y cuyo importe asciende $950 €$. El plazo de pago es de 3 meses.

\begin{tabular}{|c|c|c|c|c|}
\hline Asto & Fecha & Cuentas & Debe & Haber \\
\hline & & & & \\
& & & & \\
\hline
\end{tabular}


Ejercicio 9. Pago de tributos

COMIDAS ASTURIANAS SA paga el 23 de noviembre, el recibo del IBI señalado en el ejercicio anterior a través de transferencia bancaria de su cuenta en el Banco Bilbao Vizcaya Argentaria (BBVA).

\begin{tabular}{|c|c|c|c|c|}
\hline Asto & Fecha & Cuentas & Debe & Haber \\
\hline & & & & \\
\hline
\end{tabular}
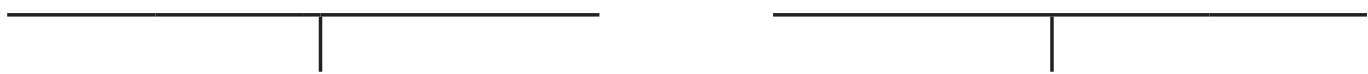

\section{Ejercicio 10. Registro de reintegro bancario}

El 13 de julio de 2000, el tesorero de NÁUTICA EL MAR SL retira 250,00 € de la cuenta corriente que mantiene la empresa en BANCAJA para atender diversas necesidades de tesorería.

\begin{tabular}{|c|c|c|c|c|}
\hline Asto & Fecha & Cuentas & Debe & Haber \\
\hline & & & & \\
& & & & \\
\hline
\end{tabular}
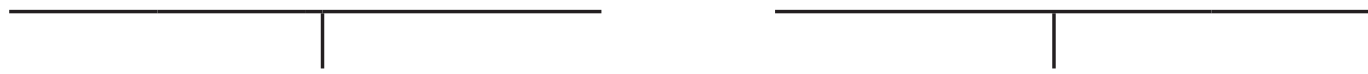

\section{Ejercicio 11. Registro de ingreso bancario}

El 16 de julio de 2000, el tesorero de NÁUTICA EL MAR SL ingresa 5.000,00 € que tenía en la caja de la empresa en la cuenta corriente que mantiene en el Banco de Santander-Central-Hispano (BSCH).

\begin{tabular}{|c|c|c|c|c|}
\hline Asto & Fecha & Cuentas & Debe & Haber \\
\hline & & & & \\
\hline
\end{tabular}
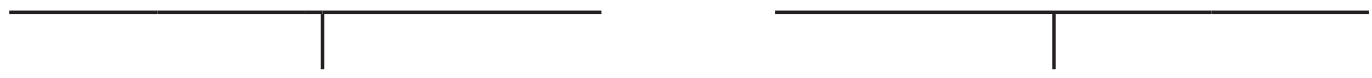

\section{Ejercicio 12. Registro de gasto por electricidad pagado}

La empresa MCDONALDS recibe el 2 de marzo un extracto bancario del BSCH en el que se le comunica el cargo en su cuenta bancaria del recibo de la electricidad del mes de febrero y que asciende a $120,00 €$. El propio extracto bancario sirve como justificante de la transacción.

\begin{tabular}{|c|c|c|c|c|}
\hline Asto & Fecha & Cuentas & Debe & Haber \\
\hline & & & & \\
& & & & \\
\hline
\end{tabular}
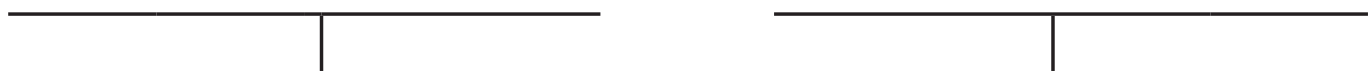


\section{Ejercicio 13. Registro de factura de gas no pagada}

La empresa MCDONALDS recibe el 3 de marzo de 2000 por correo la factura de Repsol Gas en concepto del gas consumido durante febrero y que asciende a 750,00€. La factura se pagará a la semana siguiente.

\begin{tabular}{|c|c|c|c|c|}
\hline Asto & Fecha & Cuentas & Debe & Haber \\
\hline & & & & \\
\hline
\end{tabular}
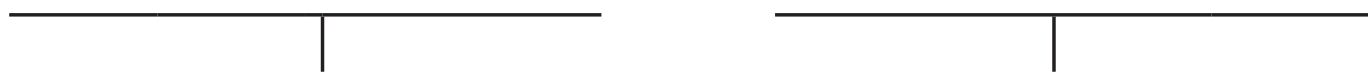

Ejercicio 14. Registro de pago de factura de gas

La empresa MCDONALDS recibe, el 10 de marzo de 2000, un extracto bancario del BBVA en el que se comunica que se ha pagado la factura de gas del ejercicio anterior ya que estaba contabilizada.

\begin{tabular}{|c|c|c|c|c|}
\hline Asto & Fecha & Cuentas & Debe & Haber \\
\hline & & & & \\
& & & & \\
\hline
\end{tabular}
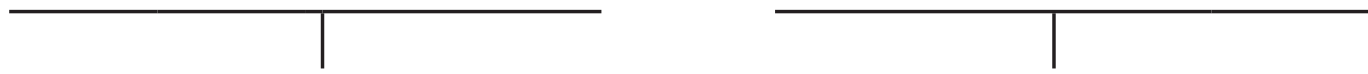

Ejercicio 15. Registro de obtención de préstamo

VIAJES ORIENTALES SA obtiene un préstamo del BBVA, el 1 de junio de 2000, por valor de 100.000,00 € que se ingresa en la cuenta abierta en dicha entidad. Este préstamo es a largo plazo.

\begin{tabular}{|c|c|c|c|c|}
\hline Asto & Fecha & Cuentas & Debe & Haber \\
\hline & & & & \\
\hline
\end{tabular}
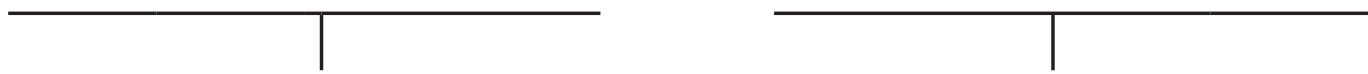

\section{Ejercicio 16. Registro de pago de intereses}

Según comunicación del BBVA el 2 de julio de 2000, los intereses correspondientes al mes de junio del préstamo de la empresa VIAJES ORIENTALES SA del ejercicio anterior ascienden $250,00 €$. Este importe se ha cargado en la cuenta corriente de la empresa.

\begin{tabular}{|c|c|c|c|c|}
\hline Asto & Fecha & Cuentas & Debe & Haber \\
\hline & & & & \\
& & & & \\
\hline
\end{tabular}
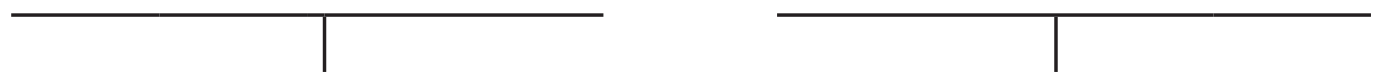
Ejercicio 17. Registro de reintegro de préstamo

El 3 de julio VIAJES ORIENTALES SA devuelve 20.000,00 € del préstamo del ejercicio 15 anterior.

\begin{tabular}{|c|c|c|c|c|}
\hline Asto & Fecha & Cuentas & Debe & Haber \\
\hline & & & & \\
& & & & \\
\hline
\end{tabular}
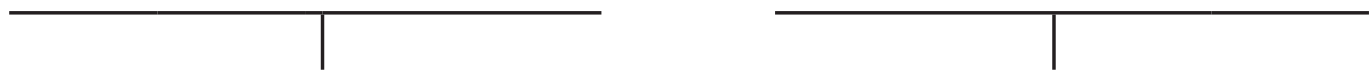

Ejercicio 18. Registro de gastos de profesionales

COPIGRAF SA recibe el 2 de noviembre de 2000 una factura de su asesoría fiscal por importe de 180,00 € por los servicios prestados durante ese mes. No figura en la factura la fecha de pago.

\begin{tabular}{|c|c|c|c|c|}
\hline Asto & Fecha & Cuentas & Debe & Haber \\
\hline & & & & \\
\hline
\end{tabular}
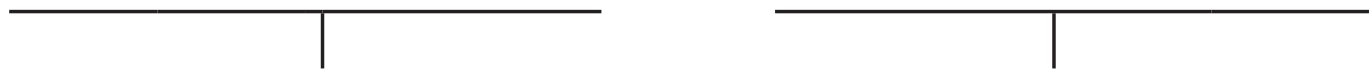

Ejercicio 19. Registro de nómina de empleados

Finalizado el mes de enero de 2000 COPIGRAF SA contabiliza los sueldos de los empleados y que ascienden a $10.000,00 €$. El importe se pagará a los pocos días.

\begin{tabular}{|c|c|c|c|c|}
\hline Asto & Fecha & Cuentas & Debe & Haber \\
\hline & & & & \\
& & & & \\
\hline
\end{tabular}
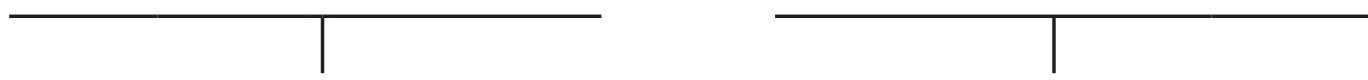

\section{Ejercicio 20. Registro de pago de nómina}

COPIGRAF SA paga, el 3 de febrero de 2000 los sueldos anteriores a sus empleados a través de transferencia bancaria.

\begin{tabular}{|c|c|c|c|c|}
\hline Asto & Fecha & Cuentas & Debe & Haber \\
\hline & & & & \\
& & & & \\
\hline
\end{tabular}


Los ejercicios 21 a 31 muestran asientos del diario de la empresa LIMPIEZA INDUSTRIAL SA (no correlativos). Para cada uno de ellos deberá explicarse, con el detalle que sea posible, la transacción que figura contabilizada.

Ejercicio 21. Identificar la transacción

\begin{tabular}{|c|c|c|c|c|}
\hline Asiento & Fecha & Cuentas & Debe & Haber \\
\hline 123 & $01 / 09 / 00$ & 662. Intereses de deudas (G) & 600,00 & \\
& & 572. Bancos c/c (A) & & \\
& & Préstamo 41-23 BANCAJA & & \\
\hline & & & & \\
& & & & \\
\hline
\end{tabular}

Ejercicio 22. Identificar la transacción

\begin{tabular}{|c|c|c|c|r|}
\hline Asiento & Fecha & Cuentas & Debe & Haber \\
\hline 74 & $05 / 07 / 00$ & 631. Tributos (G) & $1.000,00$ & \\
& & 570. Caja (A) & & \\
& & Impto. Vehículos año 2000 Ford Transit & & \\
\hline \multicolumn{3}{|l}{} \\
\end{tabular}

Ejercicio 23. Identificar la transacción

\begin{tabular}{|c|c|c|c|c|}
\hline Asiento & Fecha & Cuentas & Debe & Haber \\
\hline 110 & $30 / 08 / 00$ & 621. Arrendamientos (G) & 400,00 & \\
& & 570. Caja (A) & & \\
& & Fra.21 Calle Alcover, 21 & \\
\hline \multicolumn{5}{|r|}{} \\
\hline
\end{tabular}

Ejercicio 24. Identificar la transacción

\begin{tabular}{|c|c|c|c|c|}
\hline Asiento & Fecha & Cuentas & Debe & Haber \\
\hline 23 & $14 / 06 / 00$ & $\begin{array}{c}570 . \text { Caja (A) } \\
\text { 705. Prestación de servicios (I) }\end{array}$ & $10.000,00$ & \\
& & Fra.231 a El Sol Naciente SA & & \\
\hline & & & \\
\hline \multicolumn{4}{|r|}{} \\
\hline
\end{tabular}


Ejercicio 25. Identificar la transacción

\begin{tabular}{|c|c|c|c|c|}
\hline Asiento & Fecha & Cuentas & Debe & Haber \\
\hline 41 & $01 / 07 / 00$ & $\begin{array}{c}430 . \text { Clientes (A) } \\
\text { 705. Prestación de servicios (I) }\end{array}$ & $2.000,00$ & \\
& & Fra. 242 a Frutería El Manzano & & \\
\hline & & & \\
\hline
\end{tabular}

Ejercicio 26. Identificar la transacción

\begin{tabular}{|c|c|c|c|c|}
\hline Asiento & Fecha & Cuentas & Debe & Haber \\
\hline 111 & $31 / 08 / 00$ & 628. Suministros (G) & 130,00 & \\
& & 570. Caja (A) & & 130,00 \\
& & Iberdrola, fra. 2233/00 & & \\
\hline \multicolumn{2}{|r|}{} \\
\hline
\end{tabular}

Ejercicio 27. Identificar la transacción

\begin{tabular}{|c|c|c|c|r|}
\hline Asiento & Fecha & Cuentas & Debe & Haber \\
\hline 150 & $02 / 10 / 00$ & $\begin{array}{c}\text { 627. Publicidad, propaganda y rp (G) } \\
\text { 572. Bancos c/c (A) }\end{array}$ & 550,00 & \\
& & Vallas Ernesto SL. Fra.12/00 & & \\
& & & \\
\hline \multicolumn{5}{|r|}{} \\
\hline
\end{tabular}

Ejercicio 28. Identificar la transacción

\begin{tabular}{|c|c|c|c|c|}
\hline Asiento & Fecha & Cuentas & Debe & Haber \\
\hline 62 & $31 / 07 / 00$ & $\begin{array}{c}\text { 640. Sueldos y salarios (G) } \\
\text { 465. Remuneraciones ptes. pago (P) }\end{array}$ & $4.000,00$ & \\
& & Nómina de julio & & \\
& & \multicolumn{2}{l}{} \\
\hline \multicolumn{4}{|r}{} \\
\hline
\end{tabular}

Ejercicio 29. Identificar la transacción

\begin{tabular}{|c|c|c|c|c|}
\hline Asiento & Fecha & Cuentas & Debe & Haber \\
\hline 164 & $03 / 10 / 00$ & 520. Préstamos a c.p. (P) & $1.500,00$ & \\
& & 572. Bancos c/c (A) & & $1.500,00$ \\
& & BANCAJA, préstamo 99-32/00 & \\
\hline \multicolumn{5}{|r|}{} \\
\hline
\end{tabular}


Ejercicio 30. Identificar la transacción

\begin{tabular}{|c|c|c|c|c|}
\hline Asiento & Fecha & Cuentas & Debe & Haber \\
\hline 21 & $06 / 06 / 00$ & 572 . Bancos c/c (A) & 500,00 & \\
& & 705. Prestación de servicios (I) & & \\
& & Fra.223 a Roberto Ruiz & \\
\hline \multicolumn{4}{|r|}{} \\
\hline
\end{tabular}

Ejercicio 31. Identificar la transacción

\begin{tabular}{|c|c|c|c|c|}
\hline Asiento & Fecha & Cuentas & Debe & Haber \\
\hline 51 & $30 / 06 / 00$ & 640. Sueldos y salarios (G) & $21.000,00$ & \\
& & 572. Bancos c/c (A) & & $21.000,00$ \\
& & Nómina de junio & & \\
\hline \multicolumn{5}{|r}{} \\
\end{tabular}

\section{Ejercicio 32. Identificación de transacciones}

Dada la siguiente cuenta de mayor identificar las operaciones registradas en la misma.

\begin{tabular}{|l|r|l|r|r|}
\hline \multicolumn{7}{|c|}{ CUENTA 572.00045. Bancaja cuenta corriente no 667788-XX } \\
\hline Fecha & Asiento & \multicolumn{1}{|c|}{ Concepto } & Debe & Haber \\
\hline $01 / 01 / 00$ & & \\
Saldo inicial \\
\hline $05 / 02 / 00$ & 43 & Fra. 12/00 Juan (430.00033) & 550,00 & $1.000,00$ \\
\hline $02 / 03 / 00$ & 68 & Recibo 31/00 Iberdrola (410.00056) & & 160,00 \\
\hline $15 / 03 / 00$ & 112 & Reintegro 33/00 & & 200,00 \\
\hline $16 / 04 / 00$ & 134 & Fra. 32/00 Luis (430.00011) & 120,00 & \\
\hline
\end{tabular}

\begin{tabular}{|c|r|r|}
\hline \multicolumn{3}{|c|}{ CUENTA 572.00045. Bancaja cuenta corriente $\mathbf{n}^{\mathbf{0}}$ 667788-XX } \\
\hline Fecha & Asiento & \\
\hline $01 / 01 / 00$ & 1 & \\
\hline $05 / 02 / 00$ & 43 & \\
& & \\
\hline $02 / 03 / 00$ & 68 & \\
\hline $15 / 03 / 00$ & 112 & \\
\hline $16 / 04 / 00$ & 134 & \\
& & \\
\hline
\end{tabular}




\section{Ejercicio 33. Balance de comprobación de sumas y saldos}

Se muestran las cuentas de Mayor de la librería EL PAPIRO SA correspondientes al período 1 de enero de 00 a 31 de marzo de 2000. Calcule las sumas y saldos de las mismas y elabore un balance de comprobación de sumas y saldos del período.

\begin{tabular}{|c|c|c|c|c|c|}
\hline \multicolumn{2}{|c|}{ 100. Capital (N) } & \multicolumn{2}{|c|}{ 113. Reservas volunt. (N) } & \multicolumn{2}{|c|}{ 170. Préstamos I.p. (P) } \\
\hline \multicolumn{2}{|c|}{ 210. Terrenos (A) } & \multicolumn{2}{|c|}{ 211. Construcciones (A) } & \multicolumn{2}{|c|}{ 216. Mobiliario (A) } \\
\hline \multicolumn{2}{|c|}{ 218. Elementos transporte (A) } & \multicolumn{2}{|c|}{ 252. Créditos I.p. (A) } & \multicolumn{2}{|c|}{ 300. Mercaderías (A) } \\
\hline $15.000,00$ & $1.000,00$ & $4.000,00$ & 1.000 .00 & $2.000,00$ & \\
\hline \multicolumn{2}{|c|}{ 400. Proveedores (P) } & \multicolumn{2}{|c|}{ 410. Acreedores diversos (P) } & \multicolumn{2}{|c|}{ 430. Clientes (A) } \\
\hline 1.000 .00 & $40.000,00$ & 200,00 & $6.000,00$ & $\begin{array}{r}8.000,00 \\
20.000,00\end{array}$ & $15.000,00$ \\
\hline \multicolumn{2}{|c|}{ 440. Deudores (A) } & \multicolumn{2}{|c|}{ 465. Remune. Ptes. pago (P) } & \multicolumn{2}{|c|}{ 520. Préstamos c.p. (P) } \\
\hline \multirow[t]{2}{*}{$2.000,00$} & 1.500 .00 & $2.000,00$ & $2.000,00$ & $5.000,00$ & $13.000,00$ \\
\hline & & & & & $15.000,00$ \\
\hline \multicolumn{2}{|c|}{ 527. Intereses a pagar c.p. (P) } & \multicolumn{2}{|c|}{ 540. Acciones c.p. (A) } & \multicolumn{2}{|c|}{ 542. Créditos c.p. (A) } \\
\hline 300,00 & $1.100,00$ & $\begin{array}{r}3.000,00 \\
500,00\end{array}$ & $1.000,00$ & $8.000,00$ & 2.000 .00 \\
\hline \multicolumn{2}{|c|}{ 570. Caja (A) } & \multicolumn{2}{|c|}{ 572. Bancos c/c (A) } & \multicolumn{2}{|c|}{ 600.Compras mercaderías (G) } \\
\hline $1.500,00$ & $4.000,00$ & $23.500,00$ & $20.000,00$ & $2.000,00$ & \\
\hline $11.000,00$ & $3.000,00$ & $16.100,00$ & 600,00 & $1.900,00$ & \\
\hline 200,00 & $2.000,00$ & $11.500,00$ & $1.000,00$ & & \\
\hline \multicolumn{2}{|c|}{ 624. Transportes (G) } & \multicolumn{2}{|c|}{ 625. Primas de seguros (G) } & \multicolumn{2}{|c|}{ 628.Suministros (G) } \\
\hline \multirow[t]{2}{*}{$3.000,00$} & & $3.500,00$ & & $4.500,00$ & \\
\hline & & $1.200,00$ & & & \\
\hline \multicolumn{2}{|c|}{ 640.Sueldos y salarios (G) } & \multicolumn{2}{|c|}{ 642. Seg.Social c/empresa (G) } & \multicolumn{2}{|c|}{ 662. Intereses deudas (G) } \\
\hline $80.000,00$ & & $6.000,00$ & & 800,00 & \\
\hline $8.000,00$ & & & & 300,00 & \\
\hline \multicolumn{2}{|c|}{ 700. Venta de mercaderías (I) } & \multicolumn{2}{|c|}{ 762.Ingresos de créditos (I) } & \multicolumn{2}{|c|}{ 771. B Vta Inmóvil. (I) } \\
\hline & $100.000,00$ & & 200,00 & & $5.000,00$ \\
\hline & $1.000,00$ & & 150,00 & & 450,00 \\
\hline & $21.000,00$ & & & & \\
\hline & $2.000,00$ & & & & \\
\hline
\end{tabular}




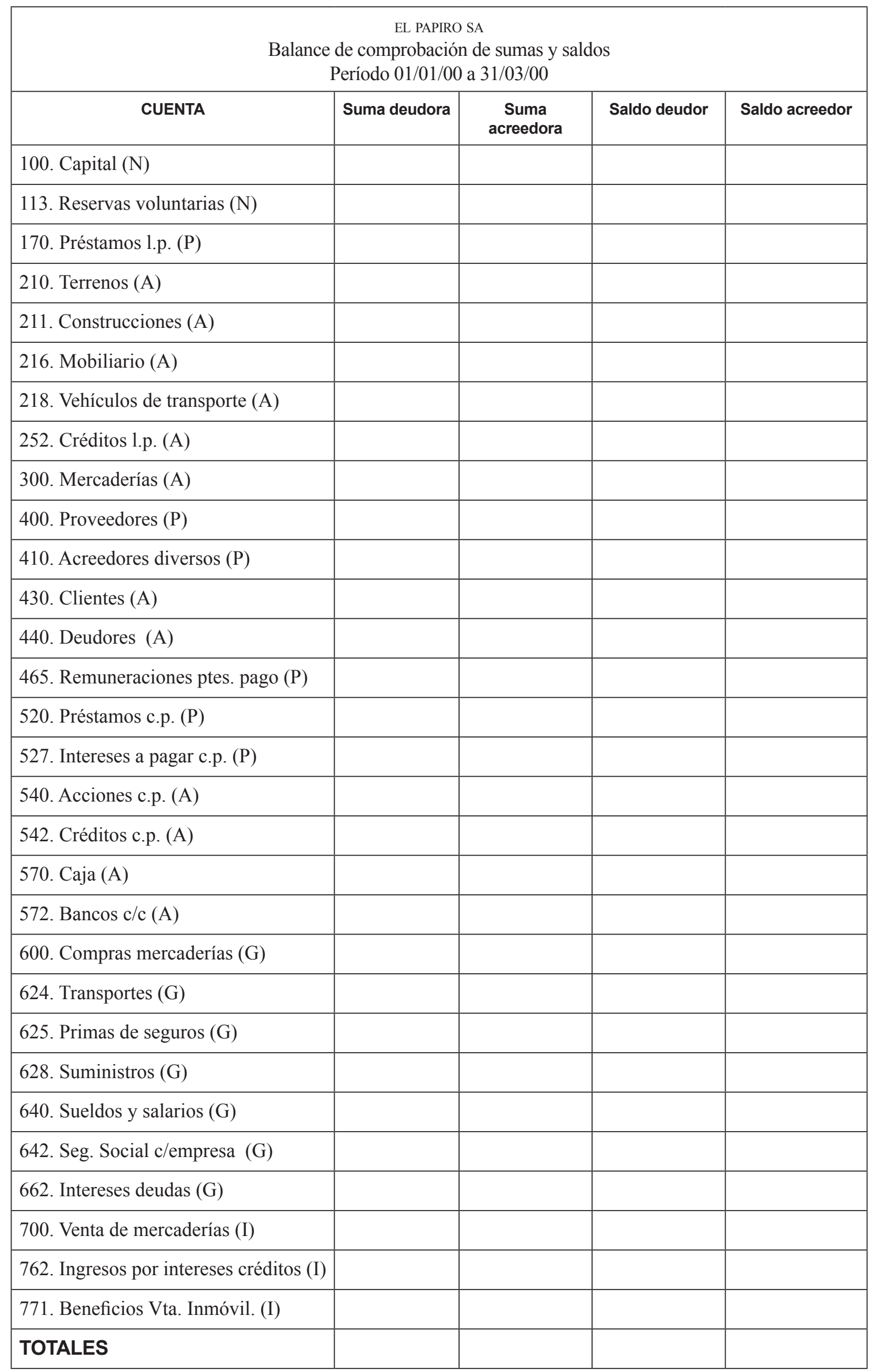


Ejercicio 34. Registro de transacciones

1. Registre en el diario transacciones del ejercicio 14 del tema 2.

2. Abra las cuentas de mayor que proceda y traspase a las cuentas los asientos contabilizados.

3. Elabore un balance de comprobación de sumas y saldos final.

\section{DIARIO TASACIONES INMOBILIARIAS SA}

\begin{tabular}{|l|l|l|l|}
\hline a) 1 marzo 00 & & & \\
\hline b) 3 marzo 00 & & & \\
\hline c) 5 marzo 00 & & & \\
\hline d) 10 marzo 00 & & & \\
\hline e) 11 marzo 00 & & & \\
\hline f) 12 marzo 00 & & & \\
\hline g) 15 marzo 00 & & & \\
\hline h) 15 marzo 00 & & & \\
\hline i) 16 marzo 00 & & & \\
\hline j) 17 marzo 00 & & & \\
\hline k) 18 marzo 00 & & & \\
\hline l) 18 marzo 00 & & & \\
\hline m) 19 marzo 00 & & & \\
\hline n) 20 marzo 00 & & & \\
\hline o) 25 marzo 00 & & & \\
\hline p) 26 marzo 00 & & & \\
\hline q) 26 marzo 00 & & & \\
\hline r) 27 marzo 00 & & & \\
\hline s) 31 marzo 00 & & & \\
\hline t) 31 marzo 00 & & & \\
\hline
\end{tabular}




\section{MAYOR TASACIONES INMOBILIARIAS SA}
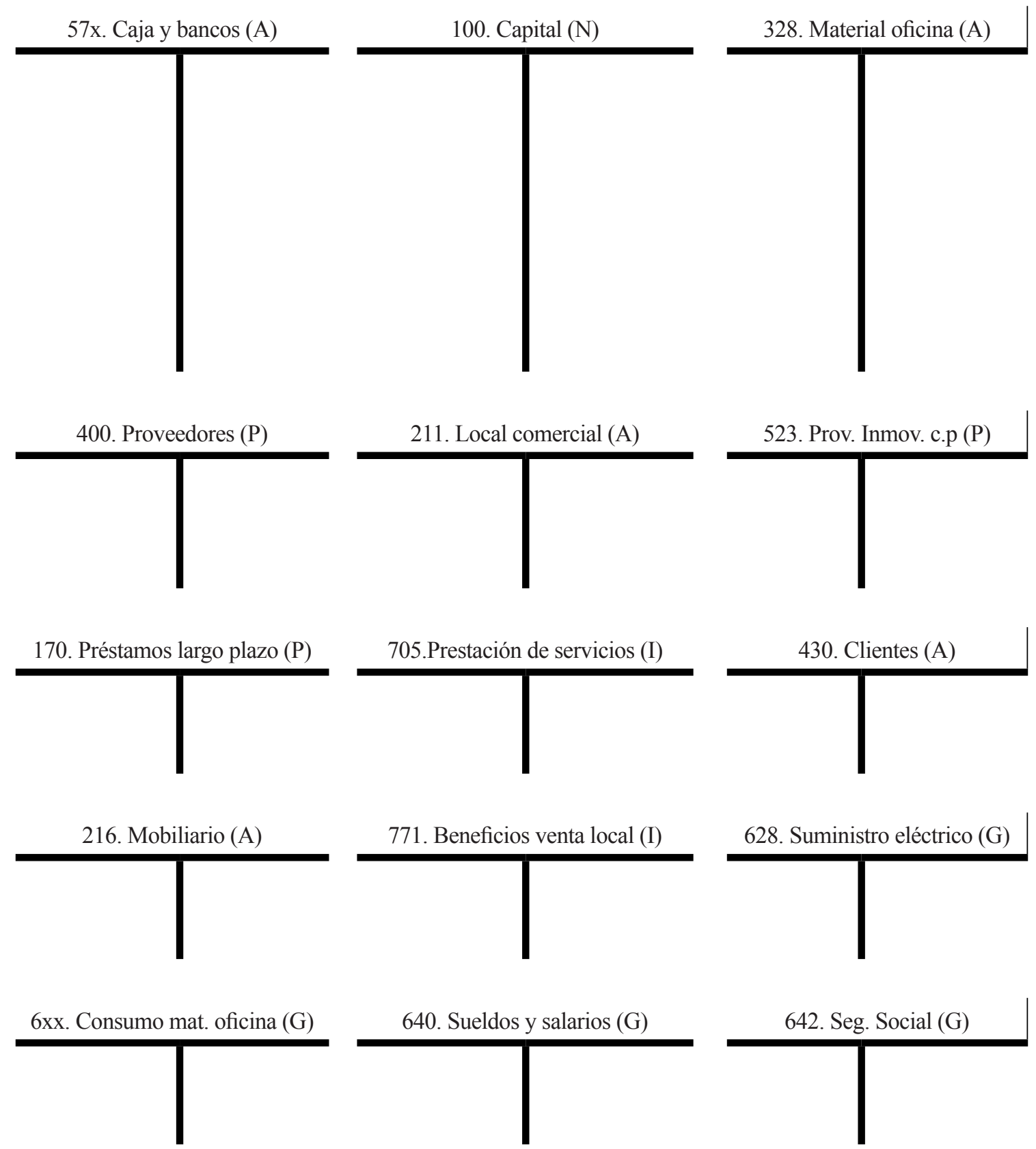


\section{BALANCE DE COMPROBACIÓN DE SUMAS Y SALDOS}

\begin{tabular}{|l|l|l|l|l|}
\hline \multicolumn{5}{|c|}{$\begin{array}{c}\text { TASACIONES INMOBILIARIAS SA } \\
\text { Balance de comprobación de sumas y saldos } \\
\text { Período 01/03/00 a 31/03/00 }\end{array}$} \\
\hline \multicolumn{1}{|c|}{ CUENTA } & Suma deudora & Suma acreedora & Saldo deudor & Saldo acreedor \\
\hline 100. Capital (N) & & & & \\
\hline 170. Préstamos a largo plazo (P) & & & & \\
\hline 211. Local comercial (A) & & & & \\
\hline 226. Mobiliario (A) & & & & \\
\hline 302. Material de oficina (A) & & & & \\
\hline 400. Proveedores (P) & & & & \\
\hline 430. Clientes (A) & & & & \\
\hline 523. Proveed. inmov. cp. (P) & & & & \\
\hline 57x. Caja y bancos (A) & & & & \\
\hline 600. Consumo material oficina (G) & & & & \\
\hline 628. Suministro eléctrico (G) & & & & \\
\hline 640. Sueldos y salarios (G) & & & & \\
\hline 642. Seguridad Social (G) & & & & \\
\hline 705. Prestación de servicios (I) & & & & \\
\hline 771. Beneficios venta local (I) & & & & \\
\hline TOTALES & & & & \\
\hline
\end{tabular}


Ejercicio 35. Registro de transacciones

Tomando como base el ejercicio 16 del tema 2:

1. Abra las cuentas de la empresa anotando donde proceda el saldo inicial, a 1 de enero de 2000, de las mismas

2. Registre en el diario transacciones realizadas en enero de 2000.

3. Traspase a las cuentas los asientos contabilizados.

4. Elabore un balance de comprobación de sumas y saldos final.

\section{DIARIO EUNSA}

\begin{tabular}{|l|l|l|l|}
\hline a) 4 enero 00 & & & \\
\hline b) 7 enero 00 & & & \\
\hline c) 11 enero 00 & & & \\
\hline d) 14 enero 00 & & & \\
\hline e) 15 enero 00 & & & \\
\hline f) 16 enero 00 & & & \\
\hline g) 17 enero 00 & & & \\
\hline h) 18 enero 00 & & & \\
\hline i) 20 enero 00 & & & \\
\hline j) 21 enero 00 & & & \\
\hline k) 25 enero 00 & & & \\
\hline l) 31 enero 00 & & & \\
\hline m) 31 enero 00 & & & \\
\hline n) 31 enero 00 & & & \\
\hline o) 31 enero 00 & & & \\
\hline p) 31 enero 00 & & & \\
\hline
\end{tabular}




\section{MAYOR EUNSA}
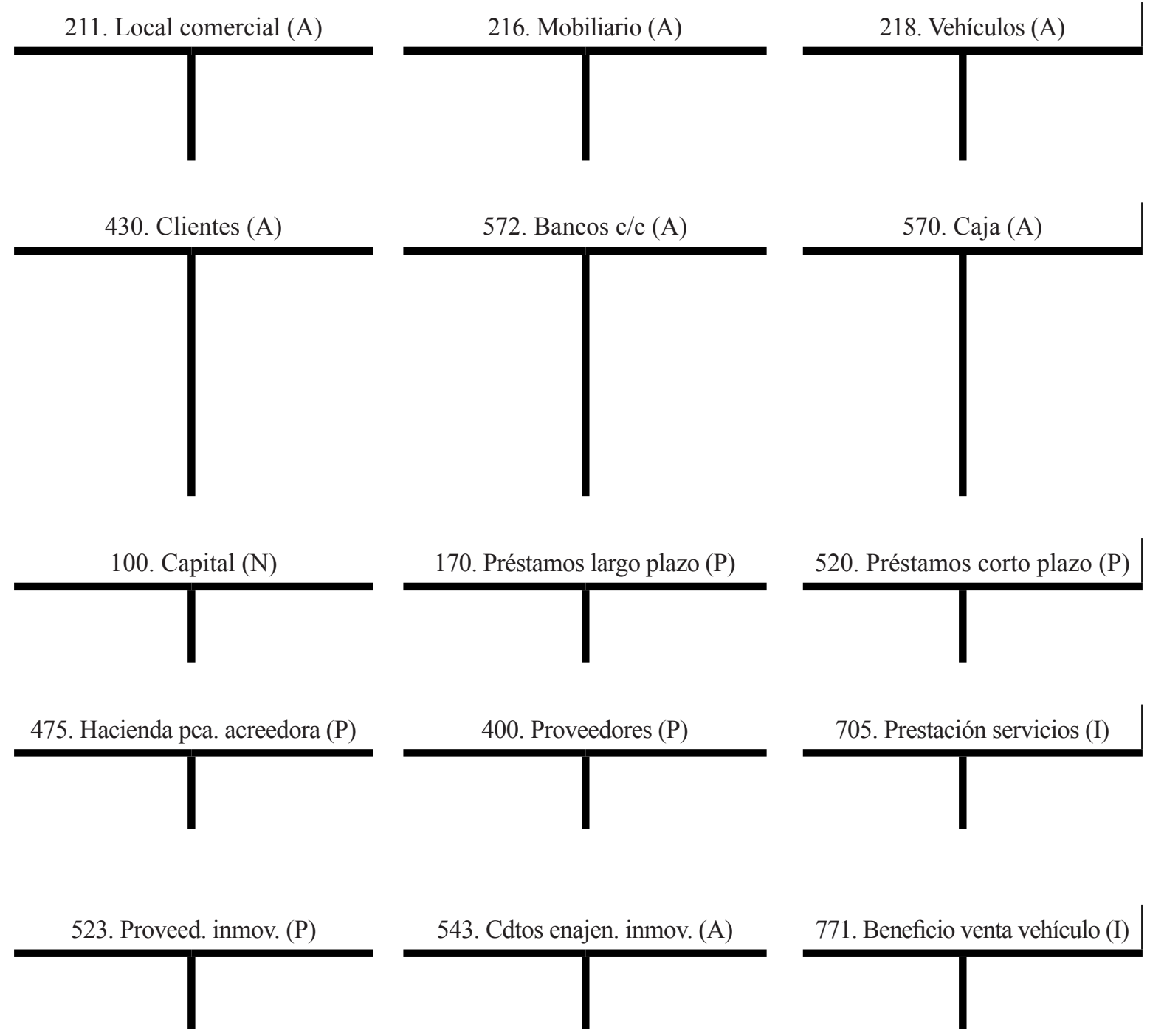

771. Beneficio venta vehículo (I)
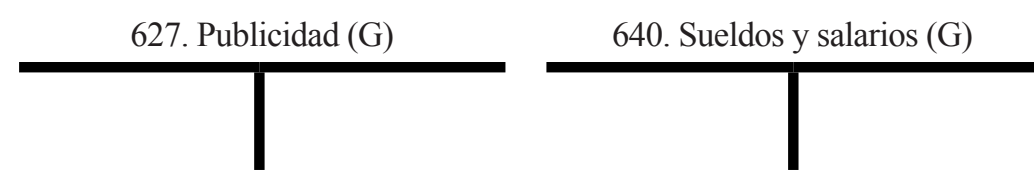

642. Seguridad social $(\mathrm{G})$

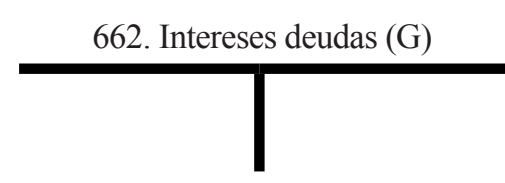

769. Ingresos financieros (I)

671. Pérdidas mobiliario $(\mathrm{G})$
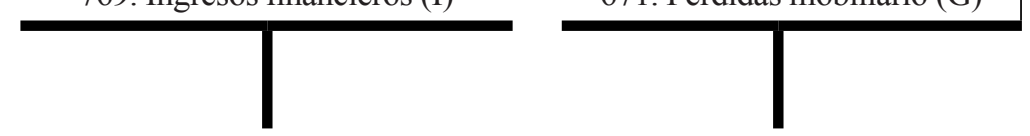

410. Acred. prest .serv. (P)

476. Org. seg. soc. acreed. (P)
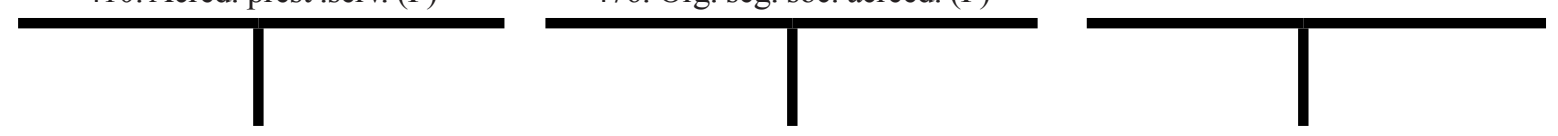


\section{BALANCE DE COMPROBACIÓN DE SUMAS Y SALDOS}

\begin{tabular}{|l|l|l|l|l|}
\hline \multicolumn{5}{|c|}{$\begin{array}{r}\text { ESPECTÁCULOS UNIVERSALES SA (EUNSA) } \\
\text { Balance de comprobación de sumas y saldos } \\
\text { Período 01/01/00 a 31/01/00 }\end{array}$} \\
\hline \multicolumn{1}{|c|}{ CUENTA } & Suma deudora & Suma acreedora & Saldo deudor & Saldo acreedor \\
\hline 100. Capital (N) & & & & \\
\hline 170. Préstamos a largo plazo (P) & & & & \\
\hline 211. Local comercial (A) & & & & \\
\hline 216. Mobiliario (A) & & & & \\
\hline 218. Vehículos (A) & & & & \\
\hline 400. Proveedores (P) & & & & \\
\hline 410. Acree. prest servicios (P) & & & & \\
\hline 430. Clientes (A) & & & & \\
\hline 440. Deudores (A) & & & & \\
\hline 475. Hacienda pca. Acreedora (P) & & & & \\
\hline 476. Org. seg. soc. acreed. (P) & & & & \\
\hline 520. Préstamos a corto plazo (P) & & & & \\
\hline 523. Proveed. inmovil. c.p. (P) & & & & \\
\hline 570. Caja (A) & & & & \\
\hline 572. Bancos c/c (A) & & & & \\
\hline 627. Publicidad (G) & & & & \\
\hline 640. Sueldos y salarios (G) & & & & \\
\hline 642. Seguridad social (G) & & & & \\
\hline 662. Intereses deudas (G) & & & & \\
\hline 671. Pérdidas mobiliario (G) & & & & \\
\hline 705. Prestación servicios (I) & & & & \\
\hline 769. Ingresos financieros (I) & & & & \\
\hline 771. Beneficio venta vehículo (I) & & & & \\
\hline TOTALES & & & & \\
\hline
\end{tabular}

\section{Ejercicio 36. Registro de transacciones}

La empresa ASISTENCIA JURÍDICA EMPRESARIAL SA, de nueva creación, realiza las siguientes transacciones durante el año 2000:

a) Se crea el 1 de octubre del año 2000. Los socios aportan 100.000,00€, que se depositan en una cuenta bancaria en el Banco de Santander a nombre de la empresa.

b) Compra de un local comercial, el 5 de octubre de 2000, con pago con cheque. El coste es de 70.000,00€.

c) Obtiene un préstamo bancario a largo plazo el 7 de octubre de 2000, de 50.000 $€$, que se ingresa en la cuenta abierta por la empresa. 
d) Compra mobiliario y ordenador, el 10 de octubre de 2000, por valor de 20.000,00 $€$ y $5.000,00 €$ respectivamente. Se paga parte al contado mediante transferencia de $10.000 €$ y parte a crédito (se pagará: $3.000,00 €$ el 26 de octubre y 12.000,00 $€ 10$ de enero del año siguiente).

e) Paga, el 26 de octubre, de 3.000,00 € con cheque a los acreedores del punto $d$ ) según lo pactado.

f) Compra de material de oficina, el 15 de noviembre de 2000, por 4.000,00€ con pago aplazado a 90 días.

g) Factura a clientes por servicios 35.000,00 €, el 17 de noviembre de 2000, importe que cobra mediante cheque bancario.

h) Paga por cuenta corriente, el 12 de diciembre de 2000, el recibo de electricidad de los meses de octubre y noviembre por 700,00€.

i) Paga a través de cuenta corriente, el 15 de diciembre de 2000, una campaña publicitaria por importe de $20.000,00 €$.

j) Paga a través de la cuenta corriente, el 16 de diciembre de 2000, el alquiler del local que asciende a $3.000,00 €$.

k) Factura, el 20 de diciembre, servicios a clientes por $30.000,00 €$. Concede un aplazamiento de cobro de 60 días.

l) En diciembre contrata a un administrativo, ascendiendo su sueldo a 1.500,00 $€$, que paga mediante transferencia bancaria. Los costes de seguridad social del mes ascienden a $800,00 €$, cantidad que no se pagará hasta el mes de enero.

Se pide que:

1. Analice y registre en el diario las transacciones anteriores.

2. Abra las cuentas de mayor que proceda y traspase las operaciones anteriores.

3. Elabore el balance de comprobación de sumas y saldos tras todas las operaciones.

\section{DIARIO ASISTENCIA JURÍDICA}

\begin{tabular}{|l|l|l|l|}
\hline a) 1 octubre 00 & & & \\
\hline b) 5 octubre 00 & & & \\
\hline c) 7 octubre 00 & & & \\
\hline d) 10 octubre 00 & & & \\
\hline e) 26 octubre 00 & & & \\
\hline f) 15 noviembre 00 & & & \\
\hline g) 17 noviembre 00 & & & \\
\hline h) 12 diciembre 00 & & & \\
\hline i) 15 diciembre 00 & & & \\
\hline j) 16 diciembre 00 & & & \\
\hline k) 20 diciembre 00 & & & \\
\hline l) 31 diciembre 00 & & & \\
\hline
\end{tabular}




\section{MAYOR ASISTENCIA JURÍDICA}

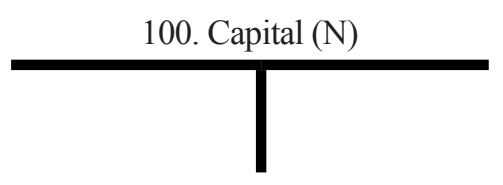

216. Mobiliario (A)
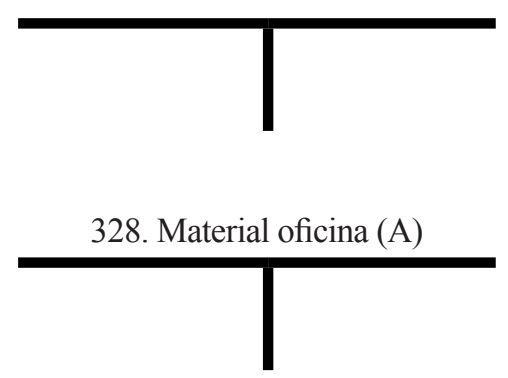

628. Suministro eléctrico $(\mathrm{G})$

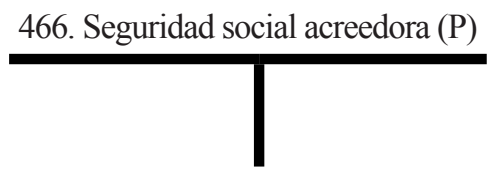

705. Prestación servicios (I)
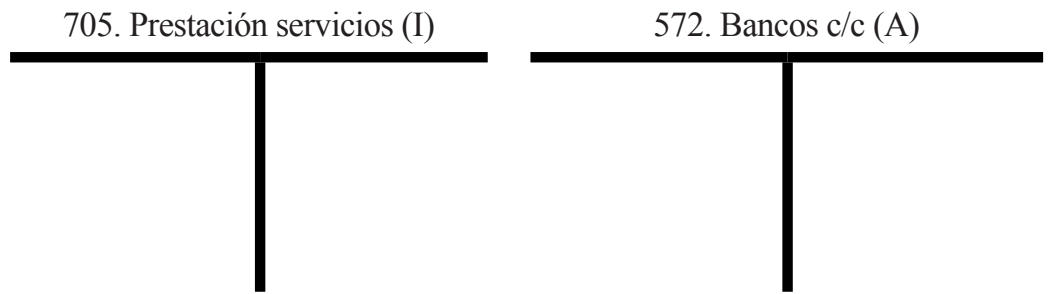
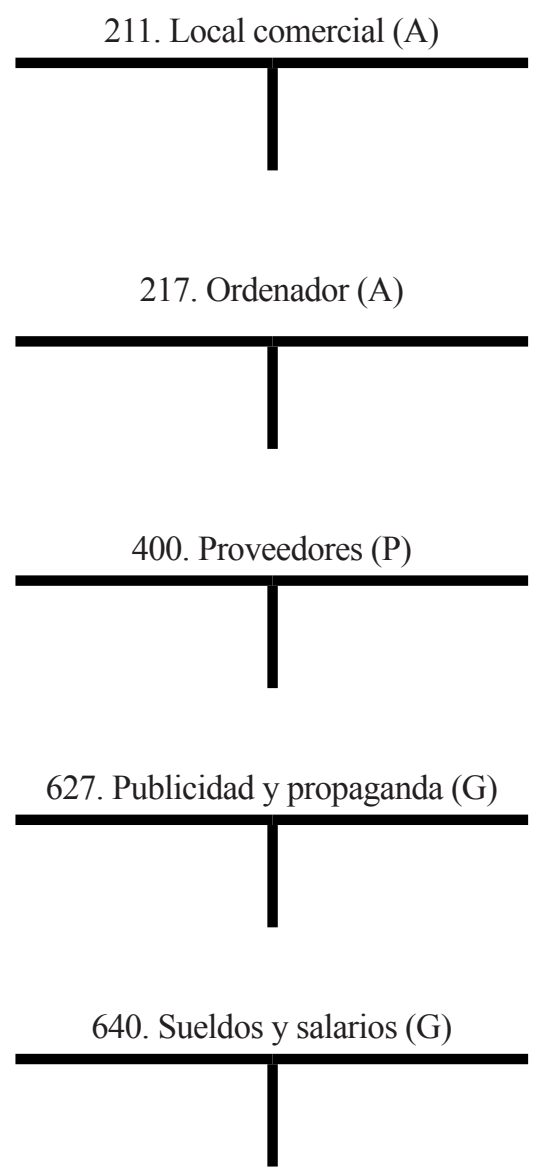

217. Ordenador (A)

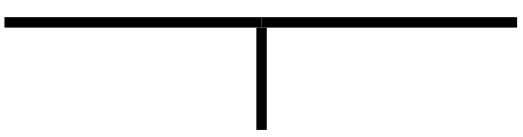

627. Publicidad y propaganda $(\mathrm{G})$

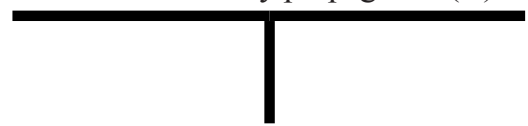

640. Sueldos y salarios $(G)$

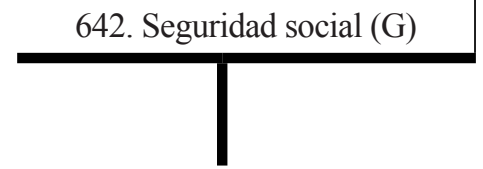

170. Préstamos largo plazo (P)

523. Proveed. Inmovilizado c.p. (P)
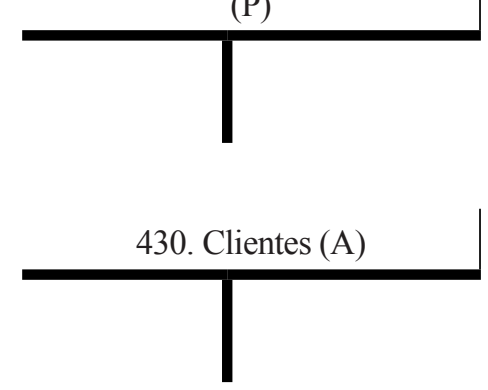

621. Arrendamientos (G)

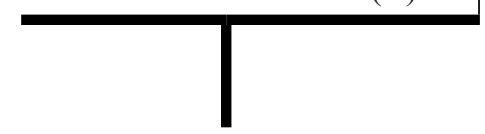

572. Bancos c/c (A) 
3. BALANCE DE COMPROBACIÓN DE SUMAS Y SALDOS

\begin{tabular}{|l|l|l|l|l|}
\hline \multicolumn{5}{|c|}{$\begin{array}{c}\text { ASISTENCIA JURÍDICA EMPRESARIAL SA } \\
\text { Balance de comprobación de sumas y saldos } \\
\text { Período 01/10/00 a 31/12/00 }\end{array}$} \\
\hline \multicolumn{1}{|c|}{ CUENTA } & Suma deudora & Suma acreedora & Saldo deudor & Saldo acreedor \\
\hline 100. Capital (N) & & & & \\
\hline 170. Préstamos a largo plazo (P) & & & & \\
\hline 211. Local comercial (A) & & & & \\
\hline 216. Mobiliario (A) & & & & \\
\hline 217. Ordenador (A) & & & & \\
\hline 302. Material oficina (A) & & & & \\
\hline 400. Proveedores (P) & & & & \\
\hline 430. Clientes (A) & & & & \\
\hline 476. Seguridad social acreedora (P) & & & & \\
\hline 523. Proveed. inmovilizado (P) & & & & \\
\hline 572. Bancos c/c (A) & & & & \\
\hline 621. Arrendamientos (G) & & & & \\
\hline 627. Publicidad y propaganda (G) & & & & \\
\hline 628. Suministro eléctrico (G) & & & & \\
\hline 640. Sueldos y salarios (G) & & & & \\
\hline 642. Seguridad social (G) & & & & \\
\hline 705. Prestación servicios (I) & & & & \\
\hline TOTALES & & & & \\
\hline
\end{tabular}


Ejercicio 37. Elaboración de cuentas anuales

A partir del balance de sumas y saldos final obtenido en el punto 3 del ejercicio anterior, elabore:

1. La cuenta de pérdidas y ganancias del período de 1 de octubre al 31 de diciembre del año 2000.

2. El balance a 31 de diciembre de 2000 .

\begin{tabular}{|l|l|}
\hline \multicolumn{1}{|c|}{ CSISTENCIA JURÍDICA EMPRESARIAL SA } \\
\hline \multicolumn{1}{|c|}{ Cuenta de pérdidas y ganancias del período 01/10/00 a 31/12/00 } \\
$\begin{array}{l}\text { 1. Importe de la cifra de negocios } \\
\text { 4. Aprovisionamientos } \\
\text { 5. Otros ingresos de explotación } \\
\text { 6. Gastos de personal } \\
\text { 7. Otros gastos de explotación }\end{array}$ \\
$\begin{array}{l}\text { 8. Amortizaciones del inmovilizado } \\
\text { 11. Deterioro y resultado por enajenaciones de inmovilizado }\end{array}$ \\
\hline A.1) RESULTADO DE EXPLOTACIÓN $=(1)+(4)+(5)+(6)+(7)+(8)+(11)$ \\
\hline $\begin{array}{l}\text { 12. Ingresos financieros } \\
\text { 13. Gastos financieros } \\
\text { 16. Deterioro y resultado por enajenaciones de instrumentos financieros }\end{array}$ \\
\hline A.2) RESULTADO FINANCIERO $=(12)+(13)+(14)+(16)$ & \\
\hline A.3) RESULTADO ANTES DE IMPUESTOS $=($ A.1 $)+($ A.2 $)$ & \\
\hline 17. Impuesto sobre beneficios & \\
\hline A.4) RESULTADO DEL EJERCICIO $=($ A.3 $)+(17)$ & \\
\hline
\end{tabular}

\begin{tabular}{|c|c|}
\hline \multicolumn{2}{|c|}{$\begin{array}{l}\text { ASISTENCIA JURÍDICA EMPRESARIAL SA } \\
\text { Balance a 31/12/00 }\end{array}$} \\
\hline ACTIVO & PATRIMONIO NETO Y PASIVO \\
\hline $\begin{array}{l}\text { A) ACTIVO NO CORRIENTE } \\
\text { I. Inmovilizado intangible } \\
\text { II. Inmovilizado material } \\
\text { III. Inversiones inmobiliarias } \\
\text { V. Inversiones financieras a largo plazo }\end{array}$ & $\begin{array}{l}\text { A) PATRIMONIO NETO } \\
\text { A.1) Fondos propios } \\
\text { I. Capital } \\
\text { III. Reservas } \\
\text { VII. Pérdidas y ganancias } \\
\text { A.3) Subvenciones }\end{array}$ \\
\hline $\begin{array}{l}\text { B) ACTIVO CORRIENTE } \\
\text { II. Existencias }\end{array}$ & $\begin{array}{l}\text { B) PASIVO NO CORRIENTE } \\
\text { II. Deudas a largo plazo }\end{array}$ \\
\hline $\begin{array}{l}\text { III. Deudores comerciales y ctas cobrar } \\
\text { V. Inversiones financieras a corto plazo } \\
\text { VI. Periodificaciones a corto plazo } \\
\text { VII. Efectivo }\end{array}$ & $\begin{array}{l}\text { C) PASIVO CORRIENTE } \\
\text { III. Deudas a corto plazo } \\
\quad \text { Proveedores inmovilizado } \\
\text { V. Acreedores comerciales y ctas. a pagar } \\
\\
\text { VI. Periodificaciones a corto plazo }\end{array}$ \\
\hline TOTAL ACTIVO (A+B) & $\begin{array}{l}\text { TOTAL PATRIMONIO NETO Y } \\
\text { PASIVO }(A+B+C)\end{array}$ \\
\hline
\end{tabular}




\section{Ejercicio 38. Registro de transacciones}

La empresa MECANIZADOS INDUSTRIALES SL presenta el siguiente balance de comprobación de sumas y saldos de 1 de enero a 30 de noviembre del 2000 (datos en euros):

\begin{tabular}{|c|c|c|c|c|}
\hline CUENTA & Suma deudora & Suma acreedora & Saldo deudor & Saldo acreedor \\
\hline 100. Capital Social (N) & 0 & 20.000 & 0 & 20.000 \\
\hline 170. Deudas a largo plazo (P) & 10.000 & 40.000 & 0 & 30.000 \\
\hline 211. Construcciones (A) & 35.000 & 5.000 & 30.000 & 0 \\
\hline 213. Maquinaria (A) & 16.000 & 1.000 & 15.000 & 0 \\
\hline 250. Inversiones en acciones 1.p. (A) & 25.000 & 22.000 & 3.000 & 0 \\
\hline 300. Mercaderías (A) & 1.000 & 200 & 800 & 0 \\
\hline 400. Proveedores $(\mathrm{P})$ & 15.000 & 21.000 & 0 & 6.000 \\
\hline 430. Clientes (A) & 15.000 & 4.350 & 10.650 & 0 \\
\hline 440. Deudores (A) & 4.000 & 2.000 & 2.000 & 0 \\
\hline 475. Hacienda acreedora $(\mathrm{P})$ & 1.000 & 9.000 & 0 & 8.000 \\
\hline 520. Préstamos a 1.p. (P) & 0 & 10.000 & 0 & 10.000 \\
\hline 570. Caja $€(A)$ & 6.000 & 1.000 & 5.000 & 0 \\
\hline 572. Bancos c/c (A) & 20.000 & 19.500 & 500 & 0 \\
\hline 600. Compra de mercaderías (G) & 37.000 & 0 & 37.000 & 0 \\
\hline 623. Servicios profes. indeptes $(\mathrm{G})$ & 1.500 & 0 & 1.500 & 0 \\
\hline 625. Primas de seguros $(G)$ & 300 & 0 & 300 & 0 \\
\hline 628. Suministros $(\mathrm{G})$ & 400 & 0 & 400 & 0 \\
\hline 640. Sueldos y salarios $(G)$ & 11.000 & 0 & 11.000 & 0 \\
\hline 642 Seguridad social (G) & 4.000 & 0 & 4.000 & 0 \\
\hline 662. Intereses de deudas $(\mathrm{G})$ & 3.000 & 0 & 3.000 & 0 \\
\hline 700. Ventas de Mercaderías (I) & 0 & 49.000 & 0 & 49.000 \\
\hline 752.Ingresos por arrendamientos (I) & 0 & 1.150 & 0 & 1.150 \\
\hline TOTALES & 205.200 & 205.200 & 134.150 & 134.150 \\
\hline
\end{tabular}

Durante el mes de diciembre realiza las siguientes operaciones (datos en euros):

a) Cobra el día 4 a través del banco 75,00 $€$, correspondientes un local arrendado.

b) El día 6 vende acciones que costaron $500,00 €$ por $600,00 €$ cobrándose a través del banco.

c) El día 10 paga intereses de sus préstamos bancarios por importe de 500,00€

d) El día 11 cobra a través del banco un total de 1.500,00 € de sus clientes.

e) El día 15 paga mediante transferencia bancaria a sus proveedores un total de $400,00 €$. 
f) El día 18 compra un mueble para la oficina que le cuesta $300,00 €$, lo paga en efectivo.

g) El día 28 recibe la factura de agua de diciembre que asciende a 100,00 €, importe que queda pendiente de pago.

h) El día 29 recibe el recibo de electricidad por 350,00€ que queda pendiente de pago.

i) El día 30 paga la nómina del mes de diciembre, mediante transferencia bancaria, y que asciende a 1.000,00 brutos.

j) A 30 de diciembre, la Seguridad Social a cargo de la empresa es de 400,00 € y queda pendiente de pago.

Se pide que:

1. Abra las cuentas de la empresa anotando donde proceda las sumas (no los saldos) representativas de la situación a 1 de diciembre de 2000.

2. Analice y registre las transacciones de diciembre en el diario.

3. Traspase a las cuentas los asientos anteriores.

4. Elabore el balance de comprobación de sumas y saldos a 31 de diciembre de 2000.

\section{DIARIO MECANIZADOS INDUSTRIALES SL}

\begin{tabular}{|l|l|l|l|}
\hline a) 4 diciembre 00 & & & \\
\hline b) 6 diciembre 00 & & & \\
\hline c) 10 diciembre 00 & & & \\
\hline d) 11 diciembre 00 & & & \\
\hline e) 15 diciembre 00 & & & \\
\hline f) 18 diciembre 00 & & & \\
\hline g) 28 diciembre 00 & & & \\
\hline h) 29 diciembre 00 & & & \\
\hline i) 30 diciembre 00 & & & \\
\hline
\end{tabular}




\section{MAYOR MECANIZADOS INDUSTRIALES SL}
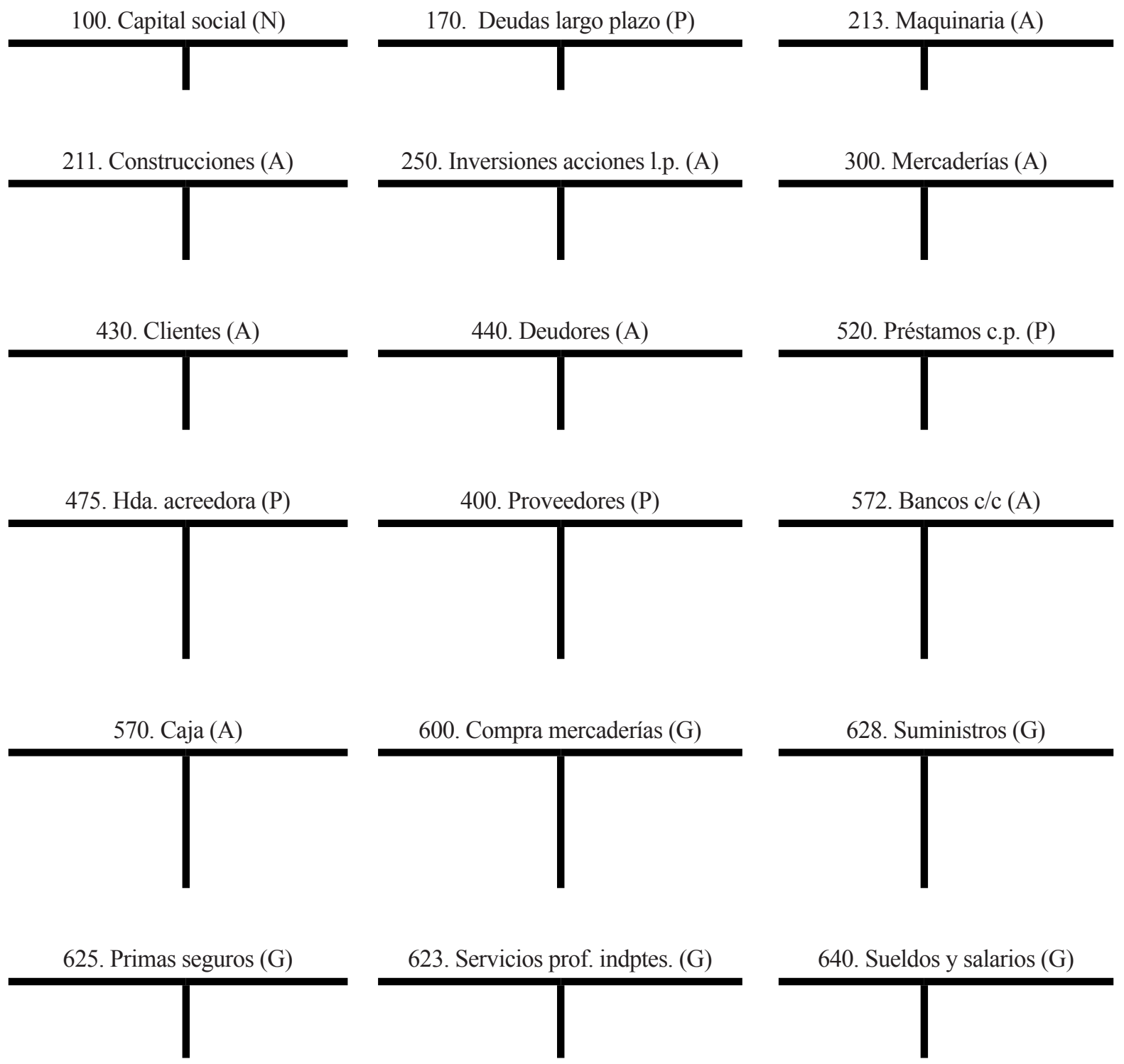

640. Sueldos y salarios (G)
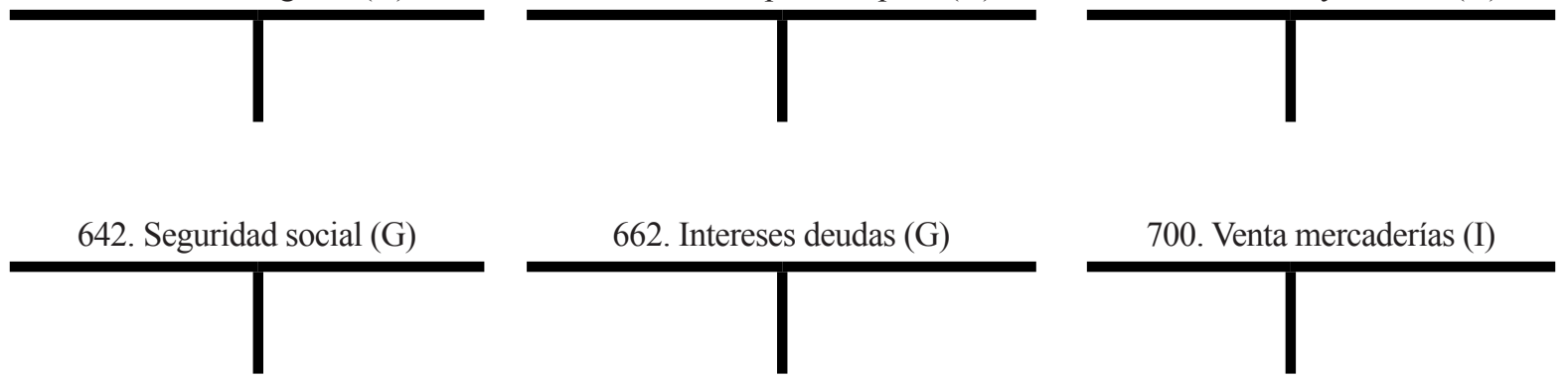

700. Venta mercaderías (I)

752. Ingresos por arrendamientos (I)

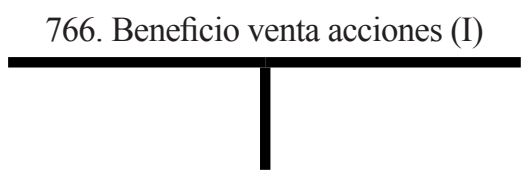

216. Mobiliario (A)

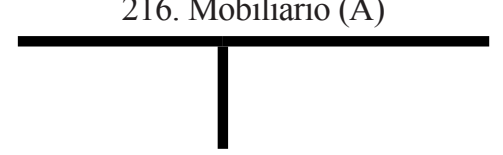

410. Acreedores (P)

476. Seg. social acreedora (P)
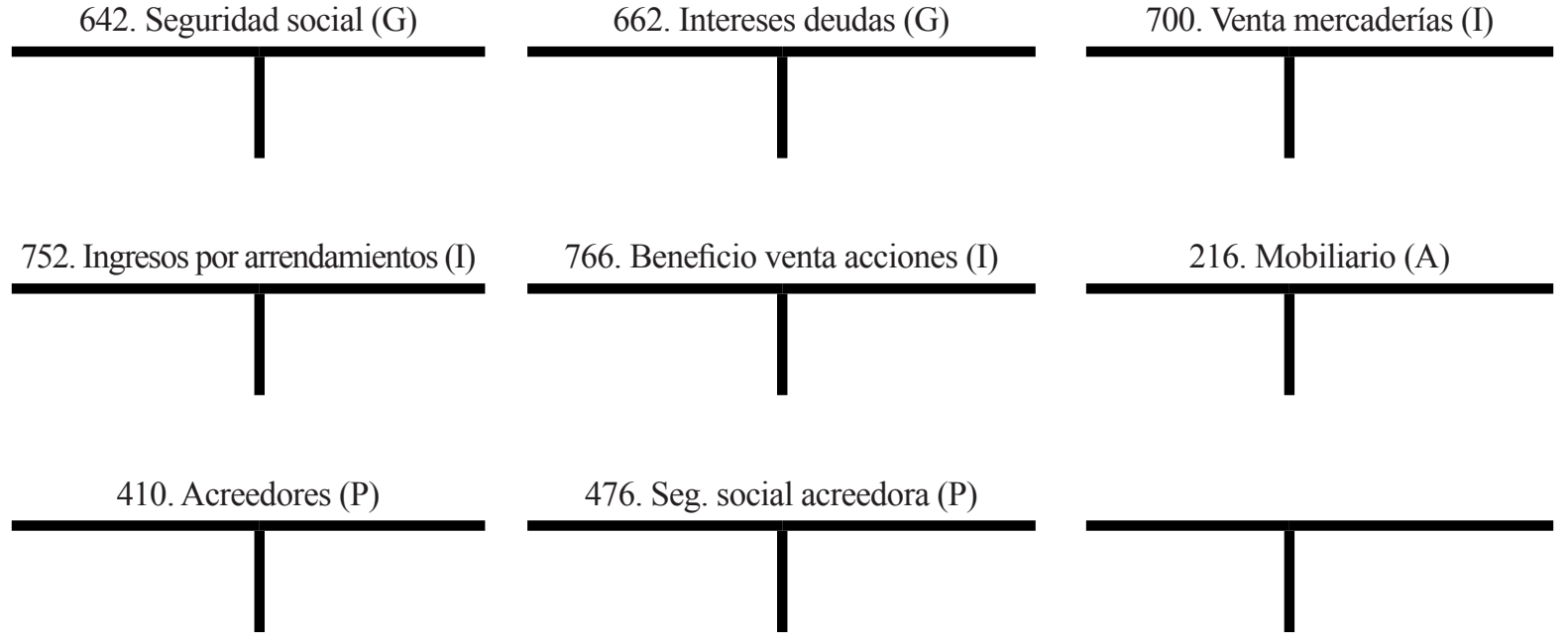


\section{BALANCE DE COMPROBACIÓN DE SUMAS Y SALDOS}

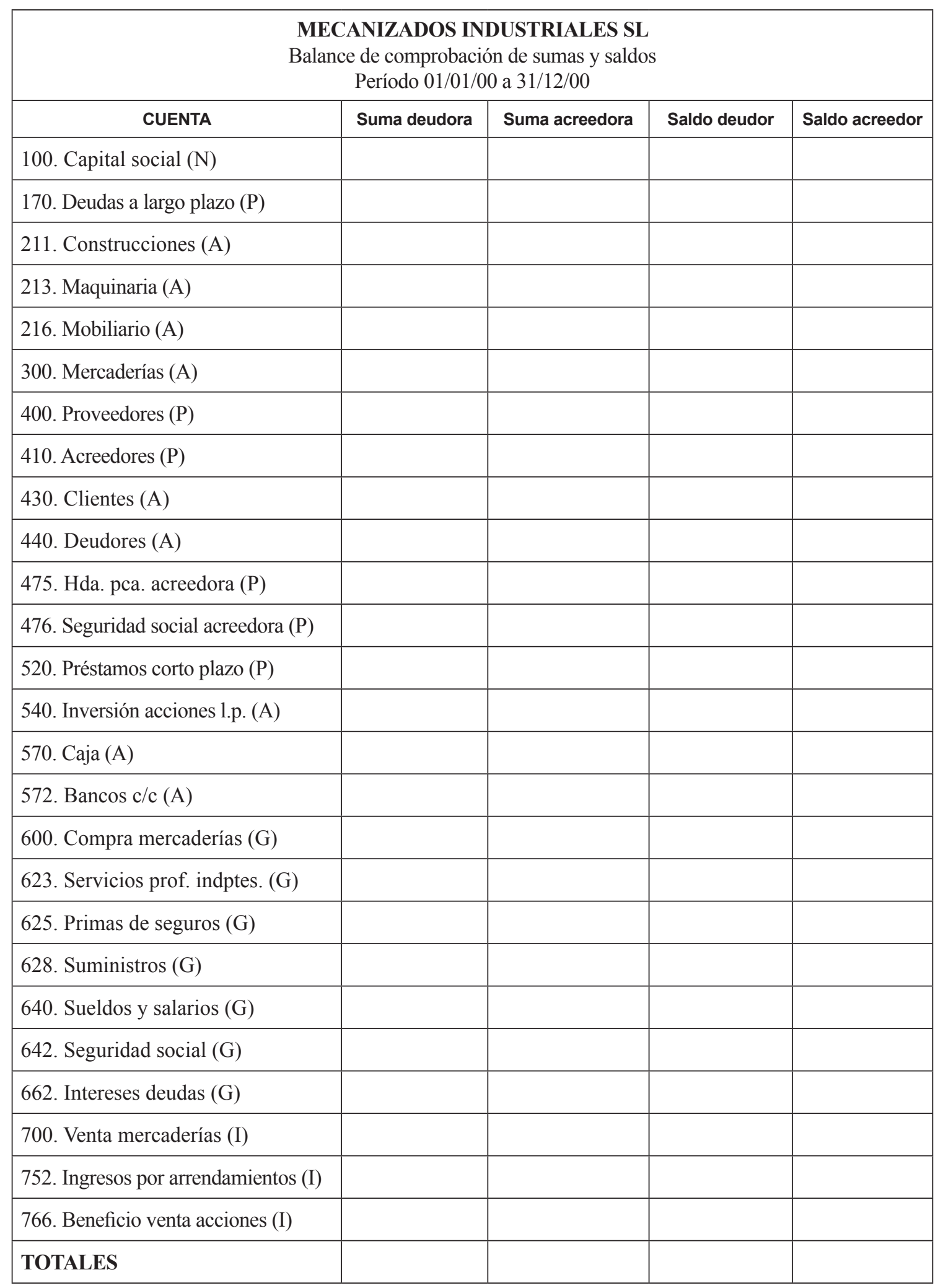


Ejercicio 39. Elaboración de cuentas anuales

A partir del balance de sumas y saldos final obtenido en el punto 4 del ejercicio anterior, elabore:

1. La cuenta de pérdidas y ganancias del período de 1 de octubre al 31 de diciembre del año 2000.

2. El balance a 31 de diciembre de 2000 .

\section{MECANIZADOS INDUSTRIALES SL}

Cuenta de pérdidas y ganancias del período 01/01/00 a 31/12/00

1. Importe de la cifra de negocios

4. Aprovisionamientos

5. Otros ingresos de explotación

6. Gastos de personal

7. Otros gastos de explotación

8. Amortizaciones del inmovilizado

11. Deterioro y resultado por enajenaciones de inmovilizado

A.1) RESULTADO DE EXPLOTACIÓN $=(1)+(4)+(5)+(6)+(7)+(8)+(11)$

12. Ingresos financieros

13. Gastos financieros

16. Deterioro y resultado por enajenaciones de instrumentos financieros

A.2) RESULTADO FINANCIERO $=(12)+(13)+(14)+(16)$

A.3) RESULTADO ANTES DE IMPUESTOS = (A.1)+(A.2)

17. Impuesto sobre beneficios

A.4) RESULTADO DEL EJERCICIO $=($ A.3 $)+(17)$ 


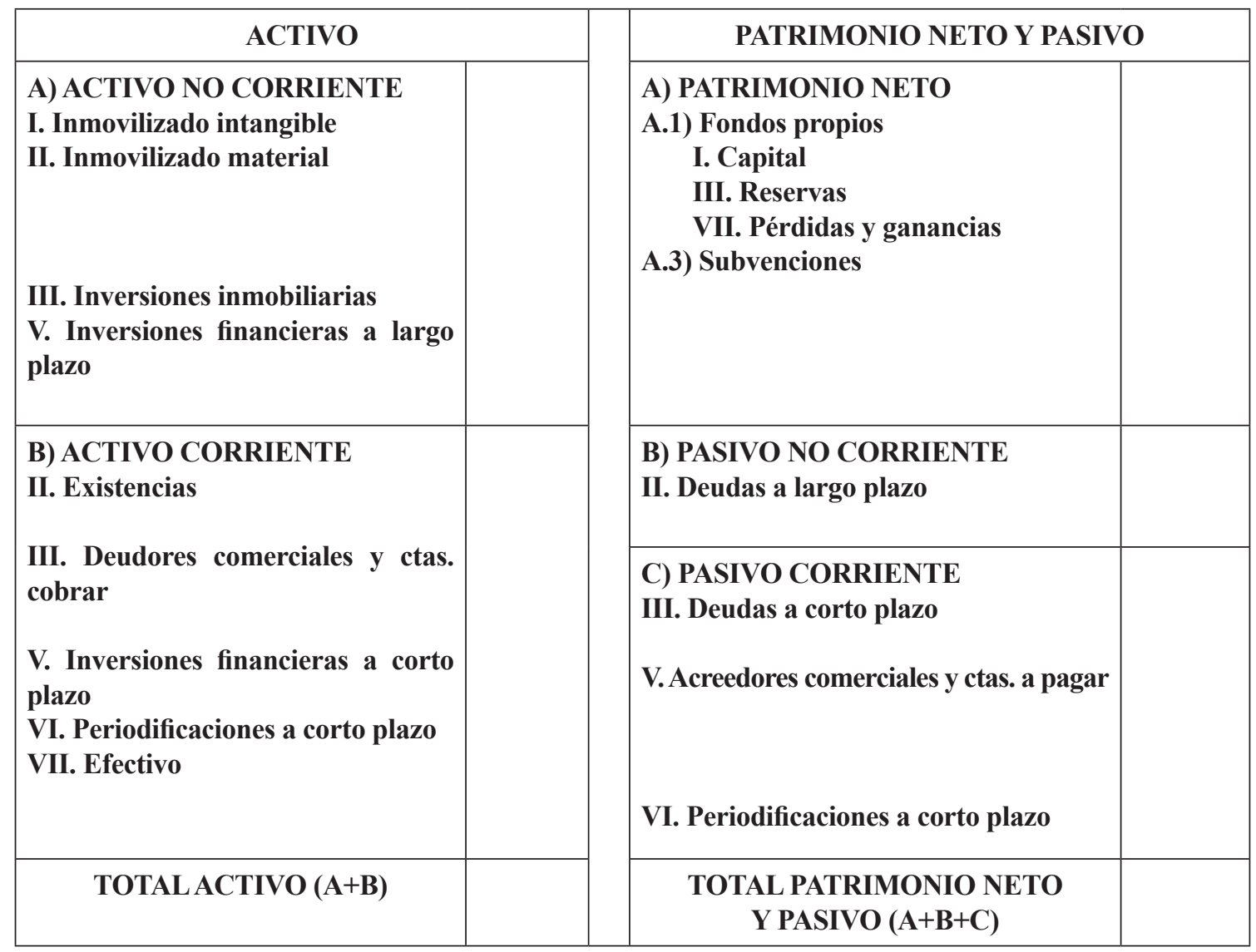




\section{TEMA 4}

\section{El registro contable de transacciones}

\section{INTRODUCCIÓN}

En este tema se muestra el procedimiento de registro contable básico de distintas transacciones empresariales, clasificando estas según su naturaleza. Así se distinguen transacciones de tipo comercial, compras y ventas, de otro tipo de ingresos y gastos. Asimismo se introduce la problemática del registro de operaciones de inversión y financiación.

\section{CONTENIDO}

4.1. Introducción

4.2. El impuesto sobre el valor añadido

4.3. Operaciones comerciales: existencias, compras y ventas

4.4. Otros gastos e ingresos de explotación

4.5. Inversiones (I): inmovilizado intangible, material e inversiones inmobiliarias

4.6. Inversiones (II): inversiones financieras

4.7. Financiación (I): financiación ajena

4.8. Financiación (II): financiación propia 


\subsection{Introducción}

El objetivo de este tema es presentar de forma sencilla los aspectos esenciales de operaciones más usuales que realizan la generalidad de empresas. Tras introducir la contabilización del impuesto sobre el valor añadido se muestran distintas transacciones habituales clasificadas en: (1) operaciones comerciales, (2) otros ingresos y gastos de explotación, (3) operaciones de inversión y (4) operaciones de financiación ajena y propia.

\subsection{El impuesto sobre el valor añadido}

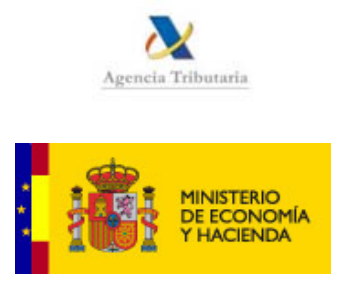

El Impuesto sobre el Valor Añadido (IVA) es un impuesto indirecto que grava la adquisición de bienes y prestación de servicios nacionales o intracomunitarios (entre países de la Unión Europea) y también las importaciones.

En general, cuando las empresas adquieren bienes y servicios soportan un IVA y cuando venden productos o prestan servicios repercuten un IVA. El tipo impositivo general es del $18 \%$ sobre la base imponible del impuesto, aunque existen otros tipos impositivos (reducido del 8\% y superreducido del $4 \%$ ) para determinadas transacciones.

Las empresas deben comparar periódicamente, mensual o trimestralmente, el IVA repercutido con el soportado, constituyendo la diferencia (liquidación) un débito a favor de la Hacienda Pública (si durante el período se ha repercutido más IVA que el que ha soportado) o un crédito contra la misma (si durante el período se ha soportado más IVA que el repercutido).

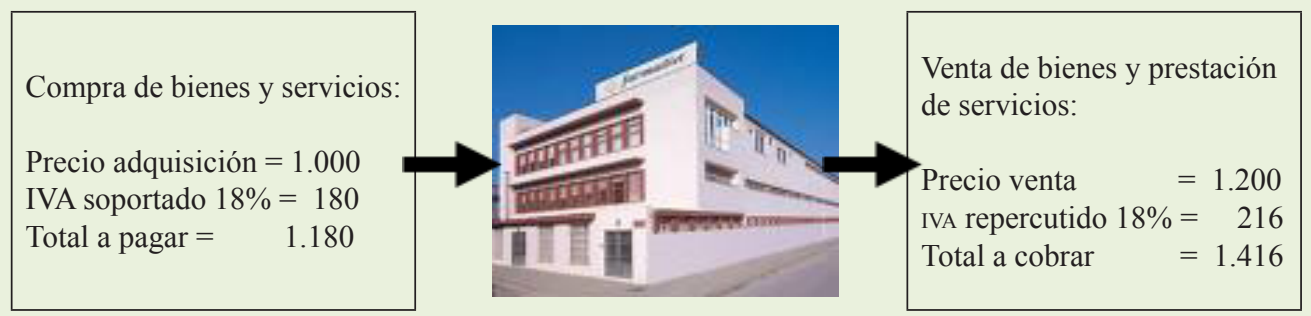

Liquidación del período $=$ IVA repercutido - IVA soportado $=216-180=36 €$. Constituye un débito a favor de la Hacienda Pública que la empresa deberá pagar en los plazos establecidos.

Ilustración 4.1. El impuesto sobre el valor añadido (IVA) 


\section{Conceptos básicos del IVA}

A) Operaciones sujetas al impuesto. En ellas se devenga un IVA.

1. En las entregas de bienes y prestaciones de servicios el vendedor repercutirá un IVA que será soportado por el comprador.

2. En las adquisiciones intracomunitarias de bienes, el comprador soporta y repercute simultáneamente el IVA (debe realizarse una autofactura). El vendedor ni soporta ni repercute el IVA.

3. En las importaciones de bienes, el importador soporta el IVA en aduana.

4. Los anticipos a cuenta de futuras operaciones sujetas, también están sujetos a IVA. El que reciba anticipo repercutirá el IVA que será soportado por el que lo entrega.

B) Operaciones no sujetas al impuesto o exentas del mismo. En ellas el vendedor no repercute IVA y, por tanto, el comprador no soporta IVA. Por ejemplo, los «cobros y pagos en dinero» y las prestaciones derivadas del «trabajo dependiente», exportaciones de bienes y servicios, actividades u operaciones de interés público (sanitarias), financieras (préstamos, intereses) y otras (loterías).

C) A efectos de las liquidaciones periódicas, el IVA soportado podrá ser para el comprador deducible o no deducible:

- Si es deducible: el comprador puede restarlo del IVA repercutido al objeto de determinar el débito o crédito con la Hacienda Pública.

- Si no es deducible: el comprador no podrá restarlo del IVA repercutido al objeto de determinar el débito o crédito con la Hacienda Pública.

Para una empresa que soporte y repercuta IVA en el régimen general, el IVA es un impuesto neutral ya que si durante un período se cobra (repercute) más IVA del que se paga (soporta), la diferencia a favor debe ingresarse en Hacienda y en caso contrario la diferencia entre el IVA pagado y cobrado se exigirá a la Hacienda Pública.

No obstante, en aplicación de la normativa del impuesto, puede ocurrir que el IVA soportado en determinadas transacciones no sea deducible. Esto supone que en las liquidaciones periódicas no pueda restarse del IVA repercutido para calcular el importe a ingresar o devolver de la Hacienda Pública.

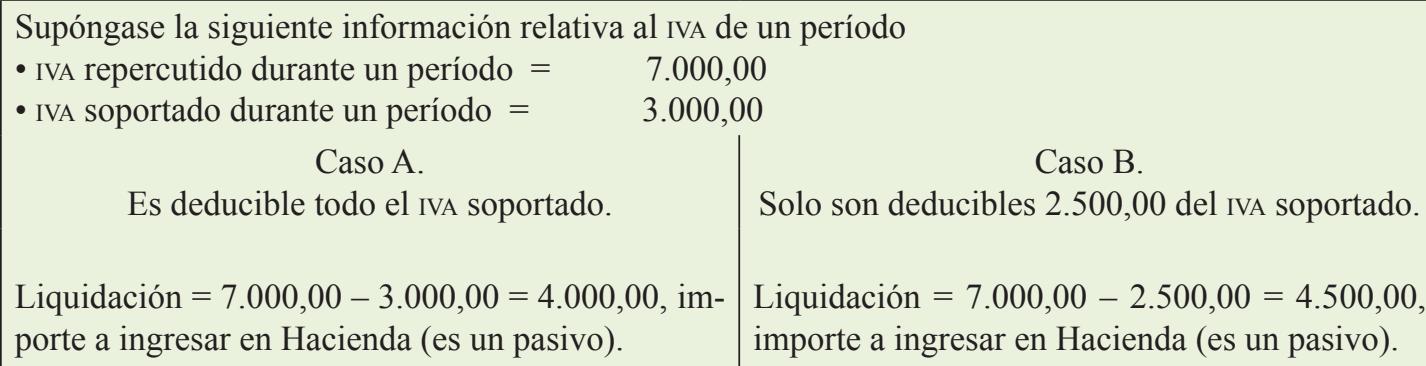

Caso B. Solo son deducibles $2.500,00$ del IVA soportado. Liquidación $=7.000,00-2.500,00=4.500,00$ importe a ingresar en Hacienda (es un pasivo). 


\section{Repercusión contable del IVA (Norma de valoración 12a)}

Las empresas actúan de intermediarios en el sistema recaudatorio del IVA, que al final recae sobre los usuarios finales de bienes y servicios y, en general, no constituye ni un gasto ni un ingreso para las mismas. La excepción la constituye el IVA soportado en caso de que no sea deducible, que deberá considerarse como un mayor precio de adquisición del bien o servicio adquirido.

Así, cuando una empresa soporte IVA, y este sea deducible deberá registrar el importe soportado en una cuenta especial que muestre que se trata de una cuantía que le adeuda la Hacienda Pública (será una cuenta de activo) y al contrario, cuando una empresa repercuta IVA deberá registrar el importe repercutido en una cuenta especial que muestre que se trata de una cuantía que deberá ingresar en la Hacienda Pública (será una cuenta de pasivo).

Las principales cuentas previstas por el PGC para el registro del IVA muestran en la siguiente ilustración.

Para el registro de operaciones

472. Hacienda Pública, IVA soportado 477. Hacienda Pública, IVA repercutido

\section{Para las liquidaciones periódicas}

470. Hacienda pública, deudora 4700. H.P. deudora por IVA

475 Hacienda Pública, acreedora 4750 H.P. acreedora por IVA

Ilustración 4.3. Cuentas relacionadas con el IVA

\section{Ejemplo 4.1. IVA repercutido en una prestación de servicios}

La empresa ABOGADOS ASOCIADOS SL factura, el 4 de abril de 2000, 1.000,00 $€$ a la empresa COMPONENTES TÉRMICOS SA por servicios prestados. La operación está sujeta a un IVA del $18 \%$, de carácter deducible.

La contabilización para ABOGADOS ASOCIADOS SL sería:

\begin{tabular}{|c|c|c|c|c|}
\hline X & $04 / 04 / 00$ & $\begin{array}{l}\text { (430) Clientes (A) } \\
\text { (705) Prestación de servicios (I) } \\
\text { (477) H.P. IVA repercutido (P) }\end{array}$ & $1.180,00$ & $\begin{array}{r}1.000,00 \\
180.00\end{array}$ \\
\hline \multicolumn{5}{|c|}{ a contabilización para COMPONENTES TÉRMICOS SA sería: } \\
\hline $\mathrm{X}$ & $04 / 04 / 00$ & $\begin{array}{l}\text { (623) Servicios de profesionales indptes (G) } \\
\text { (472) H.P. IVA soportado (A) } \\
\text { (410) Acreed. prestac. servicios (P) }\end{array}$ & $\begin{array}{r}1.000,00 \\
180.00\end{array}$ & $1.180,00$ \\
\hline
\end{tabular}

Ejemplo 4.2. IVA soportado no deducible en una adquisición de servicios Supóngase que con los datos del ejemplo 4.1 anterior, el IVA soportado por la empresa COMPONENTES TÉRMICOS SL no fuese de carácter deducible.

La contabilización para ABOGADOS ASOCIADOS SL sería la misma.

La contabilización para COMPONENTES TÉRMICOS SA sería:

\begin{tabular}{|c|r|r|r|r|}
\hline$X$ & $04 / 04 / 00$ & $\begin{array}{r}(623) \text { Servicios de profesionales indptes (G) } \\
(410) \text { Acreed. prest. servicios (P) }\end{array}$ & $1.180,00$ & $1.180,00$ \\
\hline
\end{tabular}




\section{Ejemplo 4.3. Prestaciones de servicios no sujetas a IvA}

El Hospital La Plana factura, el 5 de junio de 2000, 600,00 € a la empresa METALIZADOS ARAGÓN SA en concepto de servicios médicos especiales realizados al personal de dicha empresa.

Esta operación no está sujeta a IVA.

El Hospital La Plana contabilizaría:

\begin{tabular}{|c|c|c|c|c|}
\hline$X$ & $05 / 06 / 00$ & $\begin{array}{l}\text { (430) Clientes (A) } \\
\text { (705) Prestación de servicios (I) }\end{array}$ & 600,00 & 600,00 \\
\hline \multicolumn{5}{|c|}{ METALIZADOS ARAGÓN SA contabilizaría: } \\
\hline$X$ & $05 / 06 / 00$ & $\begin{array}{l}\text { (649) Otros gastos sociales (G) } \\
\text { (410) Acreed. prest. servicios (P) }\end{array}$ & 600,00 & 600,00 \\
\hline
\end{tabular}

\section{Ejemplo 4.4. Operación intracomunitaria}

TRAVEL SERVICES INC., empresa radicada en Gran Bretaña, factura, el 5 de junio de 2000, $1.500,00 €$ a la empresa TILES EXPORT SA empresa radicada en Castellón, en concepto de servicios profesionales prestados. Esta operación intracomunitaria está sujeta al 16\% de IVA. El importe se satisface en efectivo.

TRAVEL SERVICES INC., el vendedor de servicios, contabilizaría:

\begin{tabular}{|c|c|c|c|c|}
\hline $\mathrm{X}$ & $05 / 06 / 00$ & $\begin{array}{l}\text { (430) Clientes (A) } \\
\text { (705) Prestación de servicios(I) }\end{array}$ & $1.500,00$ & $1.500,00$ \\
\hline \multicolumn{5}{|c|}{ TILES EXPORT SA, el comprador de servicios, contabilizaría: } \\
\hline $\mathrm{X}$ & $05 / 06 / 00$ & $\begin{array}{l}\text { (623) Servicios profesionales indptes. (G) } \\
\text { (472) H.P. IVA soportado (A) } \\
\text { (410) Acreed. prest. servicios (P) } \\
\text { (477) H.P. IvA repercutido (P) }\end{array}$ & $\begin{array}{l}1.500,00 \\
270,00\end{array}$ & $\begin{array}{l}1.500,00 \\
270,00\end{array}$ \\
\hline
\end{tabular}

\section{La liquidación periódica del IVA}

Periódicamente (en general cada trimestre, y las empresas grandes y otras cada mes) se compara el IVA repercutido con el soportado, y la diferencia constituye un débito con la Hacienda Pública que se registra en la cuenta «(4750). Hacienda Pública, Acreedor por IVA» o un crédito contra la misma que se registra en la cuenta «(4700). Hacienda Pública, deudor por IVA». Cuando en un período (trimestre o mes) la liquidación es a favor de la empresa, el importe se puede compensar con las liquidaciones a pagar de períodos siguientes. En la última liquidación, final de año, se puede solicitar la devolución del importe (algunas empresas, p.e. exportadoras, pueden solicitar la devolución en cada liquidación mensual). 


\section{Ejemplo 4.5. La liquidación periódica del IVA}

La empresa ELECTROSOL SA ha presentado los siguientes saldos en sus cuentas de IVA durante el año 2000:

\begin{tabular}{ll|lc}
\hline $\begin{array}{l}\text { Primer trimestre: } \\
\text { (472) H.P. IVA soportado }\end{array}$ & $3.000,00$ & Segundo trimestre: & \\
(477) H.P. IVA repercutido & $5.100,00$ & (472) H.P. IVA soportado & $2.800,00$ \\
& (477) H.P. IVA repercutido & $1.300,00$ \\
\hline Tercer trimestre: & & Cuarto trimestre: & \\
(472) H.P. IVA soportado & $6.400,00$ & (472) H.P. IVA soportado & $2.200,00$ \\
(477) H.P. IVA repercutido & $9.600,00$ & (477) H.P. IVA repercutido & $3.500,00$ \\
\hline
\end{tabular}

Por la liquidación del primer trimestre y pago si procede:

\begin{tabular}{|l|l|l|l|l|}
\hline$X$ & $20 / 04 / 00$ & $\begin{array}{l}\text { (477) H.P. IVA repercutido (P) } \\
(472) \text { H.P. IVA soportado (A) } \\
(4750) \text { H.P. acreedora por IVA (P) }\end{array}$ & $5.100,00$ & $\begin{array}{l}3.000,00 \\
2.100,00\end{array}$ \\
\hline$X$ & $20 / 04 / 00$ & $\begin{array}{l}\text { (4750) H.P. acreedora por IVA (P) } \\
\text { (572) Bancos c/c (A) }\end{array}$ & $2.100,00$ & $2.100,00$ \\
\hline
\end{tabular}

Por la liquidación del segundo trimestre y pago si procede:

\begin{tabular}{|c|c|c|c|c|}
\hline $\mathrm{X}$ & $20 / 07 / 00$ & $\begin{array}{l}\text { (477) H.P. IVA repercutido (P) } \\
\text { (4700) H.P. deudora por IVA (A) } \\
\text { (472) H.P. IVA soportado (A) }\end{array}$ & $\begin{array}{l}1.300,00 \\
1.500,00\end{array}$ & $2.800,00$ \\
\hline \multicolumn{5}{|c|}{ Por la liquidación del tercer trimestre y pago si procede: } \\
\hline $\mathrm{X}$ & $20 / 10 / 00$ & $\begin{array}{l}\text { (477) H.P. IVA repercutido (P) } \\
\text { (472) H.P. IVA soportado (A) } \\
\text { (4700) H.P. deudora por IVA (A) } \\
\text { (4750) H.P. acreedora por IVA (P) }\end{array}$ & $9.600,00$ & $\begin{array}{l}6.400,00 \\
1.500,00 \\
1.700,00\end{array}$ \\
\hline$X$ & $20 / 10 / 00$ & $\begin{array}{l}\text { (4750) H.P. acreedora por IVA (P) } \\
\text { (572) Bancos c/c (A) }\end{array}$ & $1.700,00$ & $1.700,00$ \\
\hline \multicolumn{5}{|c|}{ Por la liquidación del cuarto trimestre y pago si procede: } \\
\hline $\mathrm{X}$ & $20 / 01 / 01$ & $\begin{array}{l}\text { (477) H.P. IVA repercutido (P) } \\
\text { (472) H.P. IVA soportado (A) } \\
\text { (4750) H.P. acreedora por IVA (P) }\end{array}$ & $3.500,00$ & $\begin{array}{l}2.200,00 \\
1.300,00\end{array}$ \\
\hline $\mathrm{X}$ & $20 / 01 / 01$ & $\begin{array}{l}\text { (4750) H.P. acreedora por IVA (P) } \\
(572) \text { Bancos c/c (A) }\end{array}$ & $1.300,00$ & $1.300,00$ \\
\hline
\end{tabular}




\subsection{Operaciones comerciales: existencias, compras y ventas}

Las empresas pueden clasificarse básicamente en tres grupos según el tipo de actividad que realizan:

- Empresas comerciales. Su actividad fundamental es la compra de mercancías para su venta sin transformación. Ejemplos serían: CARREFOUR, EL CORTE INGLÉs, MERCADONA, etc.

- Empresas industriales. Su actividad consiste en la compra de materias primas y su transformación en productos terminados para su venta. Ejemplos serían: FORD SA, DANONE, CEMENTOS PORTLAND, etc.

- Empresas de servicios. Su actividad consiste en la prestación de servicios: escuelas, hospitales, asesorías y consultorías, etc.

\section{Ejemplo 4.6. Existencias}

El concepto de existencias depende de la actividad de la empresa, del bien de que se trate y del uso del mismo. Así por ejemplo, un concesionario de vehículos RENAULT tendrá vehículos en su exposición para la venta y que se clasificarán como existencias pero también dispondrá de vehículos de taller o para desplazamientos de los empleados que serán calificados como inmovilizado material (elementos de transporte).

En este apartado se estudiarán los aspectos básicos de contabilización de las existencias en empresas comerciales. En la tabla siguiente se recogen las cuentas incluidas en el PGC relativas a las mismas.

\begin{tabular}{|l|l|l|}
\hline \multicolumn{1}{|c|}{ Proveedores y compras } & \multicolumn{1}{|c|}{$\begin{array}{c}\text { Cuentas de existencias } \\
\text { y variaciones }\end{array}$} & \multicolumn{1}{c|}{ Clientes y ventas } \\
\hline 40. PROVEEDORES & $\begin{array}{l}\text { 30. COMERCIALES } \\
\text { 300. Mercaderías A } \\
\text { 32. OTROS APROVISIONAMIENTOS } \\
\text { 321. Combustibles } \\
\text { 322. Repuestos } \\
\text { 325. Materiales diversos } \\
\text { 328. Material de oficina }\end{array}$ & $\begin{array}{l}\text { 43. CLIENTES } \\
\text { 430. Clientes }\end{array}$ \\
$\begin{array}{l}\text { 60. COMPRAS } \\
\text { 600. Compras de mercaderías } \\
\text { 602. Compras otros aprovisio- } \\
\text { namientos }\end{array}$ & $\begin{array}{l}\text { 61. VARIACIÓN DE EXISTENCIAS } \\
\text { 610. Variación de existencias de merca- } \\
\text { 612. Variación de existencias de otros } \\
\text { aprovisionamientos }\end{array}$ & $\begin{array}{l}\text { 70. VENTAS DE MERCADE- } \\
\text { RIAS, SERVICIOS } \\
\text { 700. Ventas de mercaderías } \\
\text { 705. Prestaciones de servicios }\end{array}$ \\
\hline $\begin{array}{l}\text { NOTA: La cuenta «705. Prestaciones de servicios» recoge los ingresos por este concepto de em- } \\
\text { presas del sector servicios. Su contrapartida son cuentas de efectivo (57x) o bien cuentas de clientes } \\
\text { (430). }\end{array}$
\end{tabular}

Ilustración 4.4. Cuentas relacionadas con las operaciones comerciales 


\section{La valoración de las entradas de mercaderías (compras)}

Las existencias adquiridas al exterior se valoran por el precio de adquisición:

- Es el precio de factura más todos los gastos adicionales que se produzcan hasta que los bienes se encuentren en almacén (transportes, aranceles de aduanas, seguros y otros). Los descuentos, rebajas y otras partidas similares se deducirán del precio de adquisición.

- El importe de los impuestos indirectos que las graven solo se incluirá en dicho valor cuando no sea recuperable, o deducible, de la Hacienda Pública.

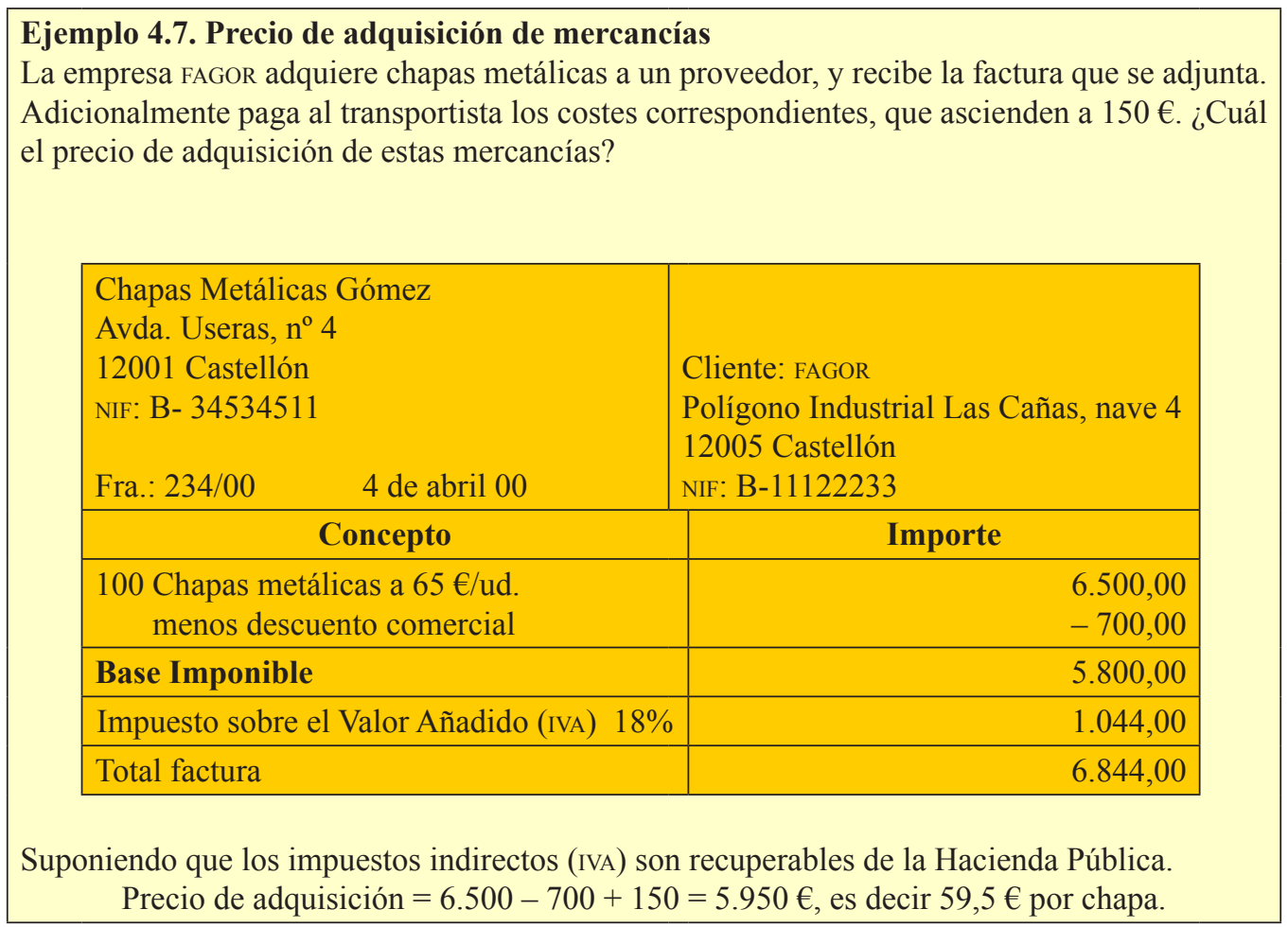

\section{La valoración de salidas de mercaderías (coste de las ventas)}

Las existencias de que una empresa dispone o compra durante un período pueden al final del mismo:

- Haber sido vendidas: su coste recibe el nombre de «coste de las mercancías vendidas», «coste de aprovisionamientos» $\mathrm{o}$ «coste de ventas».

- Estar en almacén pendientes de venta: su coste constituye el valor de las existencias finales en almacén.

Por ello uno de los problemas que plantea la gestión contable de almacenes es valorar las salidas de mercancías. 
El criterio general indica que las mercancías vendidas deben ser valoradas de acuerdo a su precio de adquisición. Esto podrá realizarse si las distintas unidades físicas de los bienes son identificadas y se controlan por separado y se conoce el coste concreto de cada unidad física, por lo que cuando se venda alguna unidad podrá darse de baja por dicho coste. Obviamente, también se conocerá exactamente el coste de las mercancías que todavía quedan el almacén.

No obstante, en caso de bienes cuyas unidades físicas no son identificadas por separado, y en el caso de que se hayan producido compras o entradas a distintos precios, no es posible conocer el coste concreto de cada una de ellas. Esto suele ocurrir en bienes de escaso valor (lo que no justifica un seguimiento individualizado) o que no sean identificables por separado.

En este caso, cuando se producen ventas, y dado que no se conoce el coste específico de cada unidad física concreta vendida, es necesario aplicar algún criterio valorativo que permita asignar un coste a las salidas. Solo de esta forma se conocerá también el coste de las existencias que quedan en almacén. Los criterios valorativos aplicables se explican en cursos más avanzados de contabilidad.

Un concesionario de vehículos mantendrá un registro o control individualizado de los vehículos en almacén disponibles para la venta, conociendo en todo momento el precio de adquisición concreto de cada uno de ellos.

No obstante, también tendrá garrafas de 2,5 litros de aceite de motor SAE-40, que pueden haber sido adquiridas en momentos distintos y a distintos precios. Lo habitual es que, aun conociendo los costes incurridos en cada compra de garrafas, no se conozca el coste de una garrafa concreta (de una unidad física que se escoja).

\section{Ilustración 4.5. Control individualizado de unidades físicas en almacén}

En todo caso, la única forma de comprobar realmente el valor de las existencias en almacén al final de un período consiste en realizar un inventario (recuento) físico valorado. Una vez realizado este, puede determinarse el coste de las mercancías vendidas aplicando la siguiente expresión:

Coste de existencias vendidas $=\mathrm{Ei}+\mathrm{C}-\mathrm{Ef}=$

$=$ Valor de existencias iniciales + Compras - Valor de existencias finales

\section{El registro contable de las compras y las ventas comerciales}

De acuerdo a lo indicado en el tema 3 anterior las operaciones de compra y de venta de mercancías, como cualquier otro activo, se contabilizarían como muestra el siguiente ejemplo. 


\begin{tabular}{|c|c|c|}
\hline $\begin{array}{l}\text { Ejemplo 4.8. Registro de compra-ventas } \\
\text { La empresa FAGOR adquiere mercancías a c } \\
\text { tricos a } 100 € \text { } € \text { ud.) y posteriormente vende } \\
\text { ( } 6 \text { motores) IVA aplicable } 18 \% \text {. }\end{array}$ & $\begin{array}{l}000,00 €(1 \\
\text { cías a créd }\end{array}$ & $\begin{array}{l}\text { ores eléc- } \\
900,00 €\end{array}$ \\
\hline Por la compra: & & \\
\hline $\begin{array}{l}\text { 300. Mercancías (A) } \\
\text { 472. H.P. IVA soportado (A) } \\
\text { 400. Proveedores (P) }\end{array}$ & $\begin{array}{r}1.000,00 \\
180,00\end{array}$ & $1.180,00$ \\
\hline Por la venta: & & \\
\hline $\begin{array}{l}\text { 430. Clientes (A) } \\
\text { 300. Mercancías (A) (6 uds. x100 €/ud.) } \\
\text { 7xx. Beneficio en ventas (I) } \\
\text { 477. H.P. IVA repercutido (P) }\end{array}$ & $1.062,00$ & $\begin{array}{l}600,00 \\
300,00 \\
162,00\end{array}$ \\
\hline
\end{tabular}

Este procedimiento de contabilización recibe el nombre de «procedimiento de cuenta única administrativa» o «permanencia de inventario por cuenta única administrativa» y se caracteriza por registrar contablemente las entradas y salidas de mercancías, por su coste, en la propia cuenta de mercancías, que quedan registradas en cada venta el beneficio obtenido o margen comercial en una cuenta separada de ingresos.

Este es el procedimiento seguido con carácter general para cualquier activo que es objeto de compra y venta.

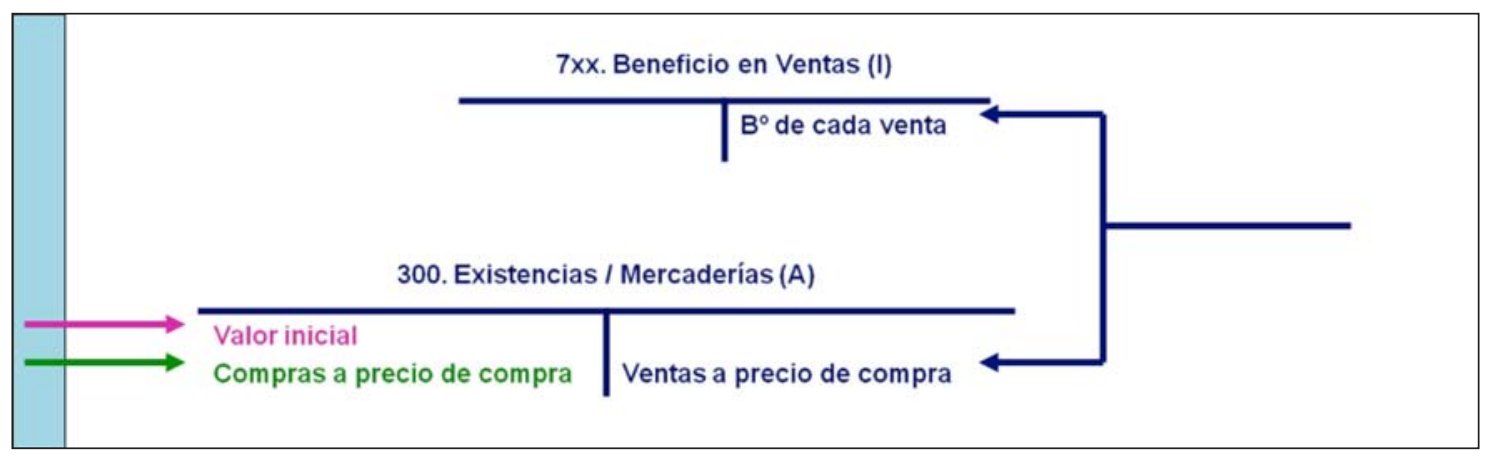

Ilustración 4.6. Movimiento de cuentas en el procedimiento de cuenta única administrativa

Este procedimiento:

- Mantiene la cuenta de mercaderías ajustada al valor de las mercancías existente en cada momento.

- Precisa conocer y registrar el coste de los productos que se compran y se venden, por lo que precisa de un sistema de control de inventarios permanente (reflejado en la cuenta de existencias).

- Calcula un resultado para cada venta que se registra en una cuenta específica de ingresos o beneficios. 


\section{Un procedimiento alternativo de registro de compras y ventas comerciales}

Dado que las empresas comerciales realizan continuamente compras y ventas de innumerables productos, el procedimiento de ajustar contablemente las cuentas de mercaderías en cada compra y cada venta y de registrar para cada producto vendido el margen de beneficio obtenido es poco operativo.

Por ello, lo habitual es que las empresas realicen el control de almacenes, entradas y salidas y valoración de existencias, mediante aplicaciones informáticas de gestión de almacenes, arbitrando un procedimiento más operativo para el registro contable de estas operaciones.

El procedimiento contable usualmente seguido, y es el que se recoge en el Plan General de Contabilidad, se denomina «procedimiento de desdoblamiento incompleto» y consiste en registrar las compras y las ventas en cuentas específicas de gastos e ingresos respectivamente, sin determinar el margen comercial en cada operación de venta.

Las operaciones anteriormente comentadas se registrarían como muestra el siguiente ejemplo.

\begin{tabular}{|l|l|l|}
$\begin{array}{l}\text { Ejemplo 4.9. Registro de compra-venta de mercaderías por desdoblamiento incompleto } \\
\text { La contabilización de las operaciones del ejemplo } 4.8 \text { por desdoblamiento incompleto sería: }\end{array}$ \\
\hline Por la compra & $\begin{array}{l}\text { 1.000,00 } \\
180,00\end{array}$ & \\
\hline $\begin{array}{l}\text { 600. Compra de mercancías (G) } \\
\text { 472. H.P. IVA soportado (A) } \\
\text { 400. Proveedores (P) }\end{array}$ & $1.062,00$ & $1.180,00$ \\
\hline Por la venta & & 900,00 \\
\hline 430. Clientes (A) & & 162,00 \\
700. Venta de Mercancías (I) & & \\
477. H.P. IvA repercutido (P)
\end{tabular}

Este procedimiento es conceptualmente incorrecto puesto que:

- La compra de mercancías no constituye un gasto, sino un intercambio de un activo por otro activo y en consecuencia una inversión que no disminuye el valor del patrimonio neto de la empresa.

- La venta de mercancías no constituye un ingreso por su importe total, sino solo por el margen obtenido que es lo que aumenta el valor del patrimonio neto de la empresa.

- En la cuenta de mercancías no se registra el movimiento de estas, por lo que no representa el valor de las existencias en cada momento. 
Por ello, este procedimiento exige con cierta periodicidad, y siempre que haya que elaborar un balance o una cuenta de pérdidas y ganancias, que se realice un ajuste o regularización de existencias para:

- Adecuar las cuentas de mercancías al valor de estas al final de un período.

- Determinar correctamente el margen comercial obtenido en el período.

Los asientos de regularización de existencias tienen habitualmente el esquema que muestra la siguiente ilustración.

Para saldar la cuenta de mercancías, por el valor inicial de estas:

(610) Variación de existencias $(\mathrm{G})$

(300) Mercaderías (A)

Valor inicial Valor inicial

Para adecuar el saldo de la cuenta de mercancías al valor final de estas:

(300) Mercaderías (A)

(610) Variación de existencias $(G)$

Valor final Valor final

Nota: podría realizarse un solo asiento de regularización por la variación neta de existencias, cargando o abonando las cuentas según proceda. Véase ejemplo 4.6.

Ilustración 4.7. Asientos tipo de regularización de existencias

El saldo de la cuenta «610.Variación de existencias» puede ser deudor o acreedor:

- Un saldo acreedor significa una variación de existencias positiva (más existencias finales que iniciales $=$ el coste de lo vendido es inferior al coste de lo comprado) equivale a un ingreso, ya que restará del valor de las compras para calcular el coste de ventas y en consecuencia aumenta el resultado comercial.

- Un saldo deudor significa una variación de existencias negativa (menos existencias finales que iniciales $=$ el coste de lo vendido es superior al coste de lo comprado) equivale a un gasto, ya que se sumará al valor de las compras para calcular el coste de ventas y en consecuencia disminuye el resultado comercial.

\section{Ejemplo 4.10. Regularización de existencias \\ La regularización de existencias para el ejemplo 4.9 sería:}

Para saldar la cuenta de mercancías, por el valor inicial de estas (en este ejemplo, inicialmente no hay existencias):

\begin{tabular}{|l|l|l|}
$\begin{array}{l}\text { (610) Variación de existencias (G) } \\
\text { (300) Mercaderías (A) }\end{array}$ & 0,00 & 0,00 \\
\hline
\end{tabular}

Para adecuar el saldo de la cuenta de mercancías al valor final de estas $(4$ x $100=400)$ :

\begin{tabular}{|l|l} 
(300) Mercaderías (A) & 400,00
\end{tabular}

(610) Variación de existencias $(G)$

400,00 
600. Compras de mercaderías (G)

Compras a precio de compra

300. Existencias (A)

Valor inicial

Valor final



Ilustración 4.8. Movimiento de cuentas en el procedimiento de desdoblamiento incompleto

Este procedimiento es mucho más operativo en el día a día de las empresas y por ello es el más utilizado. Por otra parte, proporciona de forma directa en las cuentas dos magnitudes importantes para la gestión empresarial: la cifra total de compras y la cifra total de ventas (en el procedimiento de cuenta única administrativa estas magnitudes pueden calcularse mediante el análisis de entradas y salidas de mercancías y el margen comercial).

\section{El margen comercial}

Con este procedimiento el margen comercial puede calcularse de la siguiente forma:

$$
\begin{array}{c|l}
\text { MARGEN } & =\text { Ventas }- \text { Coste de las mercancías vendidas } \\
\text { COMERCIAL } & =\text { Ventas }-\left(\mathrm{E}_{\mathrm{i}}+\text { Compras }-\mathrm{E}_{\mathrm{f}}\right)=\text { Ventas }- \text { Compras }+\left(\mathrm{E}_{\mathrm{f}}-\mathrm{E}_{\mathrm{i}}\right) \\
& =\text { Ventas }- \text { Compras }+ \text { Variación de existencias }
\end{array}
$$

Donde: $\quad \mathrm{E}_{\mathrm{i}}$ es el valor de las mercancías al inicio de un período. $\mathrm{E}_{\mathrm{f}}$ es el valor de las mercancías al final del período.

Para poder determinar el margen comercial se precisa conocer el valor de las existencias al final del período por lo que se realiza, cuando haya que elaborar cuentas anuales y en todo caso a fin de ejercicio, un inventario físico valorado del almacén, es decir, un recuento y posterior valoración de las mercancías existentes en ese momento. 


\section{Ejemplo 4.11. Cálculo del margen comercial}

Las cuentas de una empresa muestran que:

- El valor de las ventas es $=4$ unidades $\times 1.250,00 € /$ ud. $=5.000,00$

- El valor de las compras es $=5$ unidades $\mathrm{x} 1.000,00 € / \mathrm{ud} .=5.000,00$

- El resultado comercial no es $=$ ventas - compras $=5.000,00-5.000,00=0,00$

De los datos anteriores se deduce que por cada unidad vendida se genera un beneficio de 250,00 euros ya que su coste es $1.000,00$ y se vende a $1.250,00$. Por tanto el resultado comercial es $=4$ $\mathrm{x}(1.250,00-1.000,00)=1.000,00$.

Así, la forma correcta de calcular el resultado comercial sería:

- Importe de las ventas $=5.000,00$

- Coste de ventas $=$ uds. vendidas $\mathrm{x}$ coste adquisición $=4$ uds. $\times 1.000 € / \mathrm{ud} .=4.000, \mathrm{O}$ bien $=$ compras - variación existencias $=5.000,00-1.000,00=4.000,00$

- Resultado comercial $=$ ventas - coste de ventas $=5.000,00-4.000,00=1.000,00$

\section{Ejemplo 4.12. Operaciones de compraventa con desdoblamiento incompleto}

Comercial teXtiles sa tiene a inicios de abril en su almacén mercancías por valor de 5.000,00€. Durante dicho mes compra mercancías por valor de $6.000,00$ (a precio adquisición) y vende mercancías por importe de 15.000,00 (a precio de venta). Todas las operaciones se realizan a crédito. El valor de las mercancías en almacén al final del mes es de 4.000,00 (a precio de adquisición). Contabilice las compras y las ventas así como la regularización de mercancías a final de mes según el procedimiento de desdoblamiento incompleto y determine el margen comercial. Las operaciones están sujetas a un IVA del 18\%.

La cuenta de mercaderías figura con un saldo inicial de 5.000,00 (deudor).

Por la compra en efectivo de mercancías de valor $6.000,00 €$.

600. Compra de mercancías (G)

472. H.P. IVA soportado (A)

400. Proveedores $(\mathrm{P})$

$6.000,00$

$1.080,00$

$7.080,00$

Por la venta en efectivo de las anteriores por $15.000,00 €$.

430. Clientes (A)

700. Venta de mercancías (I)

477. H.P. IVA repercutido (P)

$15.000,00$

$2.700,00$

Por la regularización de mercancías a fin de mes $=\mathrm{E}_{\mathrm{f}}-\mathrm{E}_{\mathrm{i}}=4.000,00-5.000,00=-1.000,00 €$ (se realiza un solo asiento por la variación neta)

610. Variación de existencias $(\mathrm{G})$

300. Mercaderías (A)

$1.000,00$

$1.000,00$

Al final del período, la cuenta de mercaderías figurará con un saldo de 5.000,00 - 1.000,00 = 4.000,00 (deudor)

El margen comercial será:

- 700. Ventas de mercancías (I) $\quad 15.000,00$

-600. Compras de mercancías (G) $\quad-6.000,00$

- $\underline{610 .}$ Variación de existencias $(\mathrm{G}) \quad-1.000,00$

Margen comercial $\quad 8.000,00$ 


\subsection{Otros gastos e ingresos de explotación}

Todas las empresas suelen incurrir en una serie de gastos de forma habitual y periódica que les permiten mantener su actividad comercial, o de otro tipo. Asimismo es frecuente que incurran en otros gastos $u$ obtengan otros ingresos accesorios a su gestión habitual.

Las cuentas relativas a otros gastos e ingresos de gestión que se utilizarán en este apartado se muestran en la ilustración siguiente.

\begin{tabular}{|l|c|}
\hline \multicolumn{1}{|c|}{ Gastos e Ingresos } & Cuentas acreedoras y deudoras \\
\hline 62. SERVICIOS EXTERIORES & 41. ACREEDORES VARIOS \\
621. Arrendamientos y cánones & 410. Acreedores por prestaciones de \\
622. Reparaciones y conservación & servicios \\
623. Servicios de profesionales independientes & 46. PERSONAL \\
624. Transportes & 460. Anticipos de remuneraciones \\
625. Primas de seguros & 465. Remuneraciones pendientes de pago \\
626. Servicios bancarios y similares & 47. ADMINISTRACIONES PÚBLICAS \\
627. Publicidad, propaganda y relaciones & 475. Hacienda Pública, acreedora por \\
públicas & conceptos fiscales \\
628. Suministros & 4751. H.P. acreedora por retenciones \\
629. Otros servicios & practicadas \\
63. TRIBUTOS & 476. Organismos de la Seguridad Social, \\
631. Otros tributos & acreedores \\
64. GASTOS DE PERSONAL & \\
640. Sueldos y salarios & \\
642. Seguridad Social a cargo de la empresa & \\
74. SUBVENCIONES & 44. DEUDORES VARIOS \\
740. Subvenciones a la explotación & 440. Deudores \\
75. OTROS INGRESOS DE GESTIÓN & 47. ADMINISTRACIONES PÚBLICAS \\
752. Ingresos por arrendamientos & 470. Hacienda Pública, deudora por diver- \\
759. Ingresos por servicios diversos & sos conceptos \\
\hline
\end{tabular}

Ilustración 4.9. Cuentas de otros gastos e ingresos de gestión

\section{El registro de gastos de personal}

Las operaciones más frecuentes relacionadas con el personal corresponden al devengo y pago de las nóminas mensuales así como de los gastos por Seguridad Social que conllevan. Esto genera débitos con los empleados por sueldos y Seguridad Social pendientes de pago y créditos contra los mismos por anticipos de nóminas (todas estas operaciones no están sujetas a IVA).

Los documentos principales relacionados con los gastos de personal son las nóminas y el formulario TC1 que se presenta ante la Seguridad Social.

- La nómina recoge el sueldo bruto del trabajador y las deducciones que se le practican en concepto de retenciones por IRPF y por Seguridad Social que posteriormente la empresa tendrá que ingresar en las Administraciones Públicas. 
- El documento TC1 sirve para calcular el importe a ingresar a la Tesorería General de la Seguridad Social, importe este que incluye la cuota del trabajador (la deducida de su sueldo) y la cuota patronal denominada «Seguridad Social a cargo de la empresa».

\begin{tabular}{|c|c|c|c|}
\hline \multicolumn{4}{|c|}{ Gastos para la empresa } \\
\hline \multicolumn{3}{|c|}{ NÓMINA } & \multirow{3}{*}{$\begin{array}{l}\text { Seguridad Social } \\
\text { a cargo de la } \\
\text { empresa (642) }\end{array}$} \\
\hline \multicolumn{3}{|c|}{ Sueldo bruto (640) } & \\
\hline Sueldo neto & Deducción por IRPF & $\begin{array}{c}\text { Deducción por Segu- } \\
\text { ridad Social a cargo } \\
\text { del trabajador }\end{array}$ & \\
\hline & Acreedores de la & mpresa & \\
\hline $\begin{array}{c}\text { (465) Remuneracio- } \\
\text { nes pendientes de } \\
\text { pago }\end{array}$ & $\begin{array}{l}\text { (4751) H. P. Acreedora por } \\
\text { retenciones practicadas }\end{array}$ & $\begin{array}{r}\text { (476) Organismos de } 1 \\
\text { Acreedore } \\
\text { FORMULA }\end{array}$ & $\begin{array}{l}\text { Seguridad Social } \\
\text { (OSSA) } \\
\text { IO тс1 }\end{array}$ \\
\hline
\end{tabular}

Ilustración 4.10. Composición de la nómina, gastos y acreedores

Como se ha comentado, las retenciones a los trabajadores por IRPF se ingresan normalmente por trimestres. Por el contrario, la deducción por Seguridad Social a cargo del trabajador, junto con el importe a pagar por seguridad social a cargo de la empresa, se ingresan al final del mes siguiente al de su devengo.

\begin{tabular}{|c|c|}
\hline $\begin{array}{l}\text { Nómina del mes de: abril } 2000 \\
\text { Trabajador: Juan López López }\end{array}$ & $\begin{array}{l}\text { DNI: } 18.888 .888 \text { A } \\
\text { No }^{0} S: 12034855555555\end{array}$ \\
\hline $\begin{array}{l}\text { (A) Devengos: } \\
\text { - Sueldo Base } \\
\text { - Plus antigüedad } \\
\text { - Complemento transporte } \\
\text { - Complemento horas extras } \\
\text { (B) Descuentos: } \\
\text { - Seguridad Social a cargo trabajador } \\
\text { - Retención por IRPF }(22 \%)\end{array}$ & $\begin{array}{l}\text { 2.700,00 } \\
2.000,00 \\
200,00 \\
150.00 \\
350,00 \\
\\
\\
110,00 \\
594,00\end{array}$ \\
\hline (C) Total importe neto (A) - (B) & $1.996,00$ \\
\hline
\end{tabular}

Ilustración 4.11. Muestra de nómina

Puede verse un ejemplo de documento TC1 en los ejercicios de este tema. 


\section{Ejemplo 4.13. Gastos de personal}

La empresa ELECTROSOL SA ha realizado las siguientes operaciones en el 2000 relativas al personal de la empresa. Todos los pagos se han realizado a través de la cuenta corriente bancaria:

a) A principios del mes de febrero concede un anticipo de $3.000 €$ a un trabajador sobre su nómina del mes.

b) Al final del mes se paga la nómina de los trabajadores de la empresa que asciende a $20.000 €$ brutos. De este importe se deducen $1.000 €$ de Seguridad Social a cargo de los trabajadores, $2.000 €$ por retención de IRPF y el anticipo anteriormente concedido. La Seguridad Social a cargo de la empresa asciende a $5.000 €$. La deuda con la Seguridad Social y Hacienda queda pendiente de pago.

c) A finales del mes siguiente, marzo, se paga a la Seguridad Social el importe adeudado por los gastos sociales de febrero.

d) Finalizado el primer trimestre se ingresa en Hacienda en importe de las retenciones por IRPF de los tres meses que ascienden a $7.000 €(1.500 €$ enero, $2.000 €$ en febrero y $3.500 €$ en marzo).

Por la concesión del anticipo:

\begin{tabular}{|c|r|c|r|r|}
\hline $\mathrm{X}$ & $01 / 02 / 00$ & $\begin{array}{c}\text { (460) Anticipos de remuneraciones (A) } \\
(572) \operatorname{Bancos} \mathrm{c} / \mathrm{c}(\mathrm{A})\end{array}$ & $3.000,00$ & $3.000,00$ \\
\hline
\end{tabular}

Por el devengo de la nómina de febrero:

\begin{tabular}{|c|c|c|c|c|}
\hline $\mathrm{X}$ & $28 / 02 / 00$ & $\begin{array}{l}\text { (640) Sueldos y salarios (G) } \\
\text { (460) Anticipos de remuneraciones } \\
\text { (A) } \\
\text { (465) Remuneraciones ptes. pago } \\
\text { (P) } \\
(476) \text { Org. Seg. Social acreedores } \\
\text { (P) } \\
\text { (4751) H. P. acreed. retenciones } \\
\text { prac. (P) }\end{array}$ & $20.000,00$ & $\begin{array}{r}3.000,00 \\
14.000,00 \\
1.000,00 \\
2.000,00\end{array}$ \\
\hline $\mathrm{X}$ & $28 / 02 / 00$ & $\begin{array}{l}\text { (465) Remuneraciones ptes. pago (P) } \\
\text { (572) Bancos c/c (A) }\end{array}$ & $14.000,00$ & $14.000,00$ \\
\hline $\mathrm{X}$ & $28 / 02 / 00$ & $\begin{array}{l}\text { (642) Seguridad social c/empresa }(G) \\
\text { (476) Org. seg. social acreedores }\end{array}$ & $5.000,00$ & $5.000,00$ \\
\hline
\end{tabular}

Por el pago a Seguridad Social un mes más tarde:

\begin{tabular}{|c|c|c|c|c|}
\hline $\mathrm{X}$ & $30 / 03 / 00$ & $\begin{array}{c}\text { (476) Org. seg. social acreedores (P) } \\
\text { (572) Bancos c/c (A) }\end{array}$ & $6.000,00$ & $6.000,00$ \\
\hline \multicolumn{5}{|l|}{ Por el pago de las retenciones a Hacienda del trimestre: } \\
\hline X & $20 / 04 / 00$ & $\begin{array}{c}\text { (4751) H. P. acreed. retenciones prac. (P) } \\
\text { (572) Bancos c/c (A) }\end{array}$ & $7.000,00$ & $7.000,00$ \\
\hline
\end{tabular}




\section{El registro de otros gastos de explotación}

El asiento tipo para el registro de los gastos es el que se muestra en la ilustración siguiente. Asimismo se muestran algunos ejemplos prácticos de aplicación.

$\begin{array}{lr}(62 / 63 / 64) \text { Cuenta de gasto } & \mathrm{X} \\ \text { (472) H.P. IVA soportado (si procede) } & \mathrm{X} \\ (570 / 572) \text { Efectivo (Caja o Bancos c/c) } & \mathrm{X} \\ (41 / 46 / 47) \text { Cuentas de pasivos } & \mathrm{X}\end{array}$

Ilustración 4.13. Asiento tipo de gastos

\section{Ejemplo 4.14. Gastos por servicios exteriores}

TEXTILES SL ha recibido una factura, el 4 de abril de 2000, por una reparación que realizó en un vehículo de su propiedad. El importe de la factura es de $240,00 €$ y se pagará a los 30 días, IVA aplicable $18 \%$.

Se registraría el 04/04/00:

622. Reparaciones y conservación $(\mathrm{G})$

472. H.P. IVA soportado (A)

410. Acreedores varios $(\mathrm{P})$

\section{Ejemplo 4.15. Gastos por tributos}

TEXTILES SL recibe una comunicación del Ayuntamiento en la que se informa la apertura del plazo $(01 / 07 / 10)$ para el pago del recibo del IBI (impuesto sobre bienes inmuebles) correspondiente al local comercial de su propiedad del año 2000. El importe es de 350,00 €. Los tributos no están sujetos a IVA.

Se registraría el 01/07/00:

631. Tributos $(\mathrm{G})$

475. Hacienda Pública acreedora (P)

350,00

\section{El registro de ingresos}

El asiento tipo para el registro de ingresos es el que se muestra en la ilustración siguiente. Asimismo se muestran algunos ejemplos prácticos de aplicación.

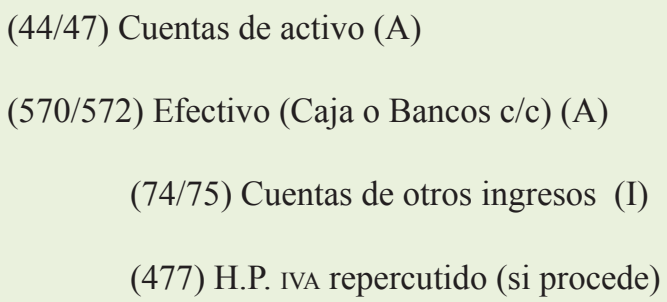




\section{Ejemplo 4.16. Ingresos por arrendamientos}

TEXTILES SL es propietaria de un terreno que tiene arrendado a un tercero. A 31 de marzo de 2000 factura a su inquilino el alquiler del mes por importe de $600,00 €$, IVA aplicable $18 \%$.

Se registraría a 31/03/00:

440. Deudores diversos (A)

752. Ingresos por arrendamientos (I)

477. H. P. IVA repercutido (P)

600,00

108,00

Ejemplo 4.17. Subvenciones de explotación
MINERÍA DEL CANTÁBRICO SA recibe mensualmente del Estado una subvención a la explotación de una
mina que tiene en Asturias, de 5,00 € por t de carbón extraída. En el mes de junio ha extraído $7.000 \mathrm{t}$
por lo que registra el derecho al cobro de dicha subvención. Este ingreso no está sujeto a IVA.
Se registraría a 30/06/00 $(5 \times 7.000)$ :
$\begin{aligned} & \text { 470. Hacienda Pública deudora (A) } \\ & 740 \text {. Subvenciones a la explotación (I) }\end{aligned}$

\subsection{Inversiones (I): inmovilizado intangible, material e inversiones inmobiliarias}

Con menor frecuencia que las operaciones vistas en los apartados anteriores las empresas realizan inversiones de diverso tipo. Una operación de inversión supone la adquisición y/o reconocimiento de un activo.

Algunas inversiones son necesarias para dotarse de la infraestructura necesaria para realizar las actividades de explotación, son a largo plazo y proporcionan rendimientos por su uso (locales comerciales, mobiliario, maquinaria, etc.) y otras inversiones, a largo o a corto plazo, tienen como fin obtener una rentabilidad por otros medios distintos al uso para la actividad, bien por su alquiler a terceros, o porque proporcionan rendimientos periódicos (intereses) o por su venta posterior a mayor precio.

En este apartado se estudiarán las inversiones en inmovilizado intangible, material e inversiones inmobiliarias y en el siguiente las inversiones financieras. En la siguiente ilustración se muestran las cuentas que se utilizan en el primer caso.

\begin{tabular}{|c|c|c|}
\hline $\begin{array}{l}\text { 20. INMOVILIZACIONES } \\
\text { INTANGIBLES }\end{array}$ & $\begin{array}{l}\text { 21. INMOVILIZACIONES } \\
\text { MATERIALES }\end{array}$ & $\begin{array}{l}\text { 22. INVERSIONES } \\
\text { INMOBILIARIAS }\end{array}$ \\
\hline $\begin{array}{c}\text { 202. Concesiones admi- } \\
\text { nistrativas }\end{array}$ & 210. Terrenos y bienes naturales & 220. Inversiones en \\
211. Construcciones & terrenos y bienes \\
203. Propiedad industrial & 212. Instalaciones técnicas & naturales \\
205. Derechos de traspaso & 213. Maquinaria & construcciones \\
206. Aplicaciones in- & 214. Utillaje & \\
formáticas & 215. Otras instalaciones & \\
& 216. Mobiliario & \\
& 217. Equipos para procesos de & \\
& información & \\
& 218. Elementos de transporte & \\
& 219. Otro inmovilizado material & \\
\hline
\end{tabular}

Ilustración 4.15. Cuentas de inversiones 
Las ganancias o pérdidas por la venta se registrarán en las cuentas que se muestran en la ilustración siguiente.

\begin{tabular}{|c|c|}
\hline \multicolumn{1}{|c|}{ Pérdidas } & Ganancias \\
\hline 67. PÉRDIDAS PROCEDENTES DE & 77. BENEFICIOS PROCEDENTES DE \\
ACTIVOS NO CORRIENTES Y GTOS. & ACTIVOS NO CORRIENTES E INGRE- \\
EXCEPCIONALES & SOS EXCEPCIONALES \\
670/671/672. Pérdidas procedentes del & $770 / 771 / 772$. Beneficios procedentes del \\
inmovilizado intangible, material o & inmovilizado intangible, material, o \\
inversiones inmobiliarias & inversiones inmobiliarias. \\
\hline
\end{tabular}

Ilustración 4.16. Cuentas de gastos e ingresos por venta de inmovilizado y activos no corrientes

\section{Adquisición de inmovilizado e inversiones inmobiliarias}

El criterio general de valoración de las inversiones en inmovilizado o inversiones inmobiliarias es el precio de adquisición que incluye, al igual que en las existencias, todos los costes necesarios hasta que el elemento está en condiciones de funcionamiento, excluyendo todo tipo de descuentos y los impuestos repercutibles.

Las adquisiciones pueden hacerse con pago en efectivo o bien quedar pendiente de pago, el esquema de los asientos contables se muestra en la siguiente ilustración.

\begin{tabular}{|c|c|}
$\begin{array}{l}(20 / 21 / 22) \text { Elemento patrimonial en que se invierte (A) } \\
(472) \text { H.P. IVA soportado (si procede) }\end{array}$ & $\mathrm{X}$ \\
$(570 / 572)$ Efectivo (Caja o Bancos c/c)(A) & $\mathrm{X}$ \\
$(173 / 523)$ Proveedores de inmovilizado a largo/ corto plazo (P) & $\mathrm{X}$ \\
$($ ver apartado siguiente) & \\
\hline
\end{tabular}

Ilustración 4.17. Asiento tipo de compra de inmovilizado e inversiones inmobiliarias

Ejemplo 4.18. Inversión en inmovilizado
TEXTILES SL ha adquirido el 5 de febrero de 2000 para su planta de producción de pantalones una
máquina de coste $10.000,00 €$. La puesta en funcionamiento de la máquina supone un coste de
500,00 €, este importe se considera mayor precio de adquisición de la máquina. Se paga el 50\%
en efectivo y el resto se pagará a los tres meses, IVA aplicable $18 \%$.
Se registraría el 05/02/00:
\begin{tabular}{l|r|r|} 
213. Maquinaria (A) & $10.500,00$ & \\
472. H. P. IVA soportado (A) & & $6.890,00$ \\
572. Bancos c/c (A) & & $6.195,00$ \\
\hline 523. Proveedores de inmovilizado a corto plazo (P)
\end{tabular}




\section{Venta de inmovilizado e inversiones inmobiliarias}

La venta de un inmovilizado o inversión inmobiliaria supone registrar la baja en la cuenta correspondiente (y la baja de todas las cuentas existentes relacionadas con ese activo) y el reconocimiento de una ganancia o pérdida por la venta. Asimismo el cobro puede realizarse en efectivo o bien quedar aplazado.

El asiento tipo para registrar una venta se muestra en la siguiente ilustración.

\begin{tabular}{|c|c|c|}
\hline (57x) Efectivo (Caja o Bancos c/c) (A) & $\mathrm{X}$ & \\
\hline $\begin{array}{l}\text { (253/543) Créditos por enajenación de inmovilizado a largo/corto } \\
\text { plazo (A) }\end{array}$ & $\mathrm{X}$ & $X$ \\
\hline \multicolumn{3}{|l|}{$(20 / 21 / 22)$ Elemento patrimonial que se vende (A) } \\
\hline \multicolumn{3}{|l|}{ (477) H.P. IVA repercutido } \\
\hline \multicolumn{3}{|l|}{ y, según proceda } \\
\hline \multicolumn{3}{|l|}{$67 x$. Pérdidas procedentes de activos no corrientes $(G)$} \\
\hline \multicolumn{3}{|l|}{$\mathrm{o}$} \\
\hline 77x. Beneficios procedentes de activos no corrientes (I) & & \\
\hline
\end{tabular}

Ilustración 4.18. Asiento tipo de venta de inmovilizado e inversiones inmobiliarias

\begin{tabular}{|l|}
\hline Ejemplo 4.19. Venta de inmovilizado \\
El 1 de marzo de 2000 la empresa TEXTILES SL vende mobiliario diverso de una de sus oficinas \\
que dejará de utilizar por importe de 5.000,00 €. Dicho mobiliario está registrado contablemente \\
por un valor de 7.200,00 €. El importe se cobrará en 60 días. IVA aplicable $18 \%$. \\
Se registraría el 01/03/00: \\
\begin{tabular}{l|r|r|}
\hline 543. Créditos a corto plazo por enaj. de inmovilizado (A) & $5.900,00$ & \\
671. Pérdidas procedentes del inmovilizado material (G) & $2.200,00$ & $7.200,00$ \\
216. Mobiliario (A) & & 900,00 \\
477. H. P. IVA repercutido (P) & & \\
\end{tabular}
\end{tabular}




\title{
4.6. Inversiones (II): inversiones financieras
}

\author{
Las inversiones financieras pueden realizarse en:
}

- Instrumentos de patrimonio: adquiriendo acciones o participaciones de empresas y adquiriendo la condición de propietario o socio de las mismas.

- Valores de deuda: adquiriendo obligaciones, bonos, etc. de empresas o entes públicos y adquiriendo la condición de acreedor de las mismas.

- Créditos o préstamos concedidos, los cuales se originan por la entrega directa de efectivo (concediendo un préstamo) o bien permitiendo el aplazamiento en el cobro de una venta de un activo (ver ejemplo 19 anterior).

Saber más: Instrumentos de patrimonio y valores representativos de deuda

Instrumentos de patrimonio: El capital de una empresa se divide en partes iguales denominadas generalmente acciones o participaciones sociales, cada título tiene un valor nominal que representa un parte de dicho capital. Las empresas para obtener financiación pueden emitir cuando lo precisen nuevo capital dividido en acciones o participaciones. El adquirente de instrumentos de patrimonio, que adquiere la condición de propietario de la empresa, posee derechos políticos (de voto en las juntas de accionistas) y económicos (a la recepción de dividendos, a un valor liquidativo de la sociedad).

Valores representativos de deuda: Algunas empresas para obtener financiación emiten deuda dividida en partes iguales denominadas obligaciones, bonos o letras. Cada título de deuda tiene un valor nominal sobre el que se calculan las obligaciones del emisor y los derechos del adquirente, el cual tiene la condición de acreedor de la empresa. Cada título de deuda proporciona un rendimiento generalmente periódico (tipo de interés) y da derecho a la devolución del importe prestado a la fecha de vencimiento.

Los instrumentos de patrimonio y los valores representativos de deuda:

- Son valores mobiliarios que pueden cotizar o no en las bolsas de valores. En las bolsas se realizan operaciones de compra-venta diarias fijándose cotizaciones o precios de mercado. Si no cotizan en bolsas las operaciones de compra-venta se hacen directamente entre particulares.

- Pueden adquirirse en el momento de emisión por parte de la entidad emisora como posteriormente en transacciones entre particulares o bien en las bolsas de valores si se trata de títulos cotizados.

- Pueden venderse en transacciones entre particulares al precio que estos acuerden o pueden venderse en las Bolsas de valores si se trata de títulos cotizados.

- Los valores representativos de deuda tienen fecha de vencimiento (fecha en que debe devolverse el nominal/principal) en la que se recupera el valor prestado. Los instrumentos de patrimonio no tienen fecha de vencimiento, la recuperación del valor invertido solo puede hacerse por venta, por reducción de capital de la sociedad emisora con devolución de importes o por liquidación de la sociedad y reparto del valor liquidativo).

Lista de cotizaciones de la Bolsa de Madrid

\begin{tabular}{|c|c|c|c|c|c|c|}
\hline Yalar & Sotizastonen & yar 4 & Max & Mia, & Yelumen & Hots \\
\hline Acengos & 21.92 & $-1.73+$ & 12.24 & 11.90 & 103.050 & 12154150 \\
\hline AEERTHS & 12.22 & $0,08+$ & $\$ 2.39$ & 12,11 & $570.5: 4$ & $4+12: 55: 09$ \\
\hline Accrolls & 85,60 & $-0.70+$ & 87,15 & 84,60 & 79.105 & $5: 2,56: 31$ \\
\hline ACEBANOXX & 20,51 & $-2.05+$ & 20.81 & 10,46 & 286.831 & $12,55,54$ \\
\hline$A C S$ & 22.05 & $-3.75+$ & 23.63 & 21.92 & $489.6: 6$ & $5: 12: 56: 09$ \\
\hline BALESTO & 6,67 & $-2.06+$ & 6.85 & 6.59 & 136.565 & $12: 56: 18$ \\
\hline PAMXXINTER & 6,31 & $-2,17+$ & 6.48 & 6,31 & 380.993 & $12: 56: 52$ \\
\hline nEva & 6.67 & $-1.91+$ & 6.87 & 6.65 & 14.848 .321 & 12,56150 \\
\hline DCO POPULAR & 5.07 & $-2.12+$ & 5.22 & 5.05 & 2.049 .068 & 12156156 \\
\hline ACQ SAEACEL & 4,03 & $-1.23+$ & 4.09 & 4,02 & 703.914 & $412: 55: 5:$ \\
\hline
\end{tabular}


En la siguiente ilustración se muestran las cuentas a utilizar para registrar estas inversiones.

Las operaciones con instrumentos financieros no están sujetas a IVA.

\section{OTRAS INVERSIONES FINANCIE- RAS A LARGO PLAZO}

250. Invers. financieras a 1. plazo en instrumentos de patrimonio

251. Valores representativos de deuda a largo plazo

252. Créditos a largo plazo

253. Créditos por enajenación de inmovilizado a largo plazo
54. OTRAS INVERSIONES FINANCIERAS TEMPORALES

540. Invers. financieras temporales en instrumentos de patrimonio

541. Valores representativos de deuda a corto plazo

542. Créditos a corto plazo

543. Créditos por enajenación de inmovilizado a corto plazo

Ilustración 4.19. Cuentas de inversiones financieras

Las cuentas utilizadas para registrar las ganancias o pérdidas por la venta de inversiones financieras se muestran en la ilustración siguiente.

\begin{tabular}{|c|c|}
\hline Gastos financieros y cuentas acreedoras & Ingresos financieros y cuentas deudoras \\
\hline $\begin{array}{c}\text { 66. GASTOS FINANCIEROS } \\
\text { 666. Pérdidas en participaciones y val. } \\
\text { representativos de deuda }\end{array}$ & $\begin{array}{c}\text { 76. INGRESOS FINANCIEROS } \\
\text { 766. Beneficios en participaciones y val. } \\
\text { representativos de deuda }\end{array}$ \\
\hline
\end{tabular}

Ilustración 4.20. Cuentas de gastos e ingresos por venta de inversiones financieras

\section{Adquisición de inversiones financieras}

El criterio general de valoración de las inversiones financieras es el valor razonable de la contraprestación entregada que normalmente es el precio de la transacción (con algunos ajustes en determinados casos).

Las adquisiciones pueden hacerse con pago en efectivo o bien quedar pendiente de pago, aunque para simplificar solo se mostrarán aquí las operaciones en efectivo, siendo el asiento tipo general el siguiente:

(25/54) Activo financiero en que se invierte (A)

$\mathrm{X}$

(570/572) Efectivo (Caja o Bancos c/c) (A)

Ilustración 4.21. Asiento tipo de inversión en efectivo de activos financieros 


\section{Ejemplo 4.20. Inversión en acciones}

El 3 de julio de 2000, TEXTILES SA ha adquirido 1.000 acciones de FLEXIBLES SL, empresa que no cotiza en bolsa, a un coste de $10 €$ cada una. El pago se produce en efectivo. La finalidad de la empresa es mantener la inversión durante largo tiempo.

El 03/07/00 se registraría:

250. Inversiones financieras a largo plazo en instrumentos de patrimonio $(\mathrm{A})$

572. Bancos c/c (A)

$10.000,00$

\section{Ejemplo 4.21. Concesión de un crédito}

El 8 de agosto de 2000, TEXTILES SA ha concedido un crédito de 30.000,00 a un tercero, el cual debe devolverlo en dos cuotas de $10.000,00$ que vencerán al año y a los dos años respectivamente.

El 08/08/00 se registraría:

252. Créditos a largo plazo (A)

542. Créditos a corto plazo (A) 572. Bancos c/c (A)

\begin{tabular}{|l|l|}
\hline $15.000,00$ & \\
$15.000,00$ & $30.000,00$ \\
\end{tabular}

\section{Ingresos periódicos de las inversiones financieras}

Las inversiones financieras suelen devengar ingresos para el inversor, así:

- Los instrumentos de patrimonio (acciones), devengan dividendos cuando la empresa de la que se poseen las acciones reparte beneficios entre sus accionistas.

- Los valores de deuda (obligaciones, bonos, etc.) devengan intereses por el paso del tiempo.

- Créditos o préstamos concedidos devengan intereses por el paso del tiempo.

Las cuentas utilizadas para estos ingresos se muestran en la siguiente ilustración.

\begin{tabular}{|l|l|}
\hline \multicolumn{1}{|c|}{ Cuentas deudoras } & \multicolumn{1}{c|}{ Ingresos financieros } \\
\hline 545. Dividendo activo a cobrar & 76. INGRESOS FINANCIEROS \\
546. Intereses a corto plazo de valores represen- & $\begin{array}{l}\text { 760. Ingresos de participaciones en instr. pa- } \\
\text { tativos de deuda }\end{array}$ \\
547. Intereses a corto plazo de créditos & $\begin{array}{l}\text { 761. Ingresos de valores representativos de } \\
\text { deuda }\end{array}$ \\
& 762. Ingresos de créditos \\
& 769. Otros ingresos financieros \\
\hline
\end{tabular}

Ilustración 4.22. Cuentas de ingresos financieros 


\section{Ejemplo 4.22. Reconocimiento de ingresos por dividendos}

La empresa Textiles SA tiene 500 acciones de REPSOL SA, empresa que ha acordado el 10 de mayo de 01 el reparto del beneficio del año 2000. Así, se ha anunciado el reparto de un dividendo de $4 €$ por acción.

El 10/05/01 se registraría:

545. Dividendo activo a cobrar (A)

760. Ingresos de participaciones en instrumentos de patrimonio (I)

\section{Ejemplo 4.23. Reconocimiento de ingresos por intereses}

El 30 de junio de 01 la empresa TEXTILES SL reconoce el derecho al cobro de los intereses del mes de junio de un crédito concedido de $10.000 €$ a un tipo de interés del $6 \%$ anual.

El 30/06/01 se registraría $(10.000 \times 6 \% / 12=500)$ :

547. Intereses a corto plazo de créditos (A)

762. Ingresos de créditos (I)

\section{Venta o recuperación de inversiones financieras}

La venta (de instrumentos de patrimonio o valores de deuda) o recuperación del valor al vencimiento (valores representativos de deuda o créditos) de una inversión financiera supone registrar la baja en la cuenta correspondiente (y la baja de todas las cuentas existentes relacionadas con ese activo), la entrada de efectivo y el reconocimiento, en el caso de venta, de una ganancia o pérdida por la misma. En el caso de ventas, el cobro puede realizarse en efectivo o bien quedar aplazado, aunque aquí se muestra solo el caso de cobro en efectivo.

\begin{tabular}{l}
$\begin{array}{l}\text { (57x) Efectivo (Caja o Bancos c/c) (A) } \\
(25 / 54) \text { Activo financiero que se vende o recupera (A) }\end{array}$ \\
y, según proceda \\
\hline 66x. Pérdidas de instrumentos financieros (G) \\
o \\
76x. Beneficios de instrumentos financieros (I) \\
\hline $\begin{array}{l}\text { NOTA: Si existen cuentas relacionadas con los activos enajenados deberán darse también de } \\
\text { baja, teniendo en cuenta su repercusión sobre el resultado de la operación. }\end{array}$ \\
\hline
\end{tabular}

Ilustración 4.23. Asiento tipo de venta en efectivo o recuperación de valor de activos financieros 
Ejemplo 4.24. Venta de acciones

El 3 de diciembre de 02, la empresa teXtiles SA vende las acciones del ejemplo 4.20 por $12.000,00 €$.

El 03/12/02 se registraría:

572. Bancos c/c (A)

250. Inversiones financieras a largo plazo en instrumentos de patrimonio (A)

766. Beneficios en participaciones y valores representativos de deuda (I)

$12.000,00$

$10.000,00$

$2.000,00$

Ejemplo 4.25. Cobro de parte de un crédito

Transcurrido un año, el 8 de agosto de 01, TEXTILES sL cobra la parte del crédito que concedió en el ejemplo 4.21 anterior.

El 08/08/01 se registraría:

572. Bancos c/c (A)

543. Créditos a corto plazo (A)

$15.000,00$

\subsection{Financiación (I): financiación ajena}

Las operaciones de inversión estudiadas en el apartado anterior requieren recursos financieros o fuentes de financiación. Estos recursos pueden provenir de acreedores y deben reintegrarse a su vencimiento, financiación ajena o pasivo, o bien pueden proceder de los propietarios de la empresa, financiación propia o patrimonio neto.

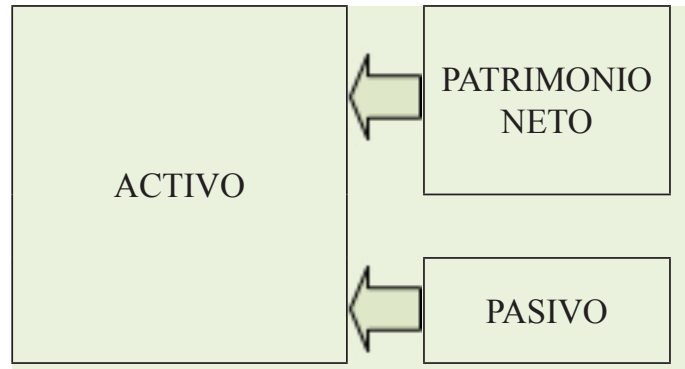

Incluye las aportaciones realizadas por los socios en la constitución de la empresa o posteriormente, así como los beneficios no repartidos.

Recursos obtenidos de terceros que deben ser reintegrados al vencimiento.

Estructura Económica Inversiones

Estructura financiera

Fuentes de financiación

Ilustración 4.24. Fuentes de financiación de la empresa

En este apartado se estudia la financiación ajena y en el siguiente, la financiación propia.

La financiación ajena se obtiene de dos formas:

- Mediante la obtención directa de efectivo, es decir, solicitando préstamos.

- Mediante el aplazamiento de pago de alguna compra realizada. En el apartado 3 se mostró cómo el aplazamiento de compras de mercancías se registra en cuentas 
específica de «proveedores». Aquí se mostrarán las cuentas de «proveedores de inmovilizado».

Las operaciones con instrumentos financieros no están sujetas a IVA.

\section{Obtención de financiación en efectivo}

Las cuentas de pasivos financieros que se utilizan para registrar la obtención de financiación ajena a reintegrar se muestran en la siguiente ilustración.

\begin{tabular}{|c|c|}
\hline \multicolumn{1}{|c|}{ A largo plazo } & A corto plazo \\
\hline 17. DEUDAS A L.P. POR PRÉSTAMOS & 52. DEUDAS A C.P. POR PRÉSTAMOS \\
RECIBIDOS Y OTROS CONCEPTOS & RECIBIDOS Y OTROS CONCEPTOS \\
170. Deudas a largo plazo con entidades & 520. Deudas a corto plazo con entidades \\
de crédito. & de crédito \\
$\begin{array}{c}\text { 173. Proveedores de inmovilizado a largo } \\
\text { plazo }\end{array}$ & $\begin{array}{l}\text { 523. Proveedores de inmovilizado a corto } \\
\text { plazo }\end{array}$ \\
\hline
\end{tabular}

Ilustración 4.25. Cuentas de pasivos financieros

La siguiente ilustración muestra un asiento tipo del caso de que la financiación obtenida constituye una entrada de efectivo en la empresa.

(570/572) Efectivo (Caja o Bancos c/c) (A)

$\mathrm{X}$

(170/520) Deudas a largo/corto plazo entidades de crédito $(\mathrm{P})$

Ilustración 4.26. Asiento tipo de obtención de financiación en efectivo

Ejemplo 4.26. Obtención de un préstamo

El 1 de septiembre de 2000, TEXTILES SA obtiene un préstamo del Banco de Santander de 50.000,00€ a devolver en cuotas iguales durante 5 años.

El 01/09/00 se registraría:

572. Bancos c/c (A)
520. Deudas a corto plazo con ent. crédito $(\mathrm{P})$

170. Deudas a largo plazo con ent. crédito $(\mathrm{P})$

\section{Débitos financieros por compra de inmovilizado}

La compra de inmovilizado con pago aplazado genera pasivos financieros, «proveedores de inmovilizado», tal y como se mostró en el ejemplo 4.17 anterior. 


\section{Gastos periódicos de los pasivos financieros}

La financiación ajena suelen devengar intereses a pagar por el paso del tiempo. Las cuentas utilizadas para reconocer los mismos se muestran en la ilustración siguiente.

\begin{tabular}{|l|c|}
\hline \multicolumn{1}{|c|}{ Gastos financieros } & \multicolumn{1}{c|}{ Cuentas acreedoras } \\
\hline $\begin{array}{l}\text { 66. GASTOS FINANCIEROS } \\
\text { 662. Intereses de deudas } \\
\text { 669. Otros gastos financieros }\end{array}$ & 52. DEUDAS A C.P. POR PRÉSTAMOS RECI- \\
& $\begin{array}{c}\text { BIDOS Y OTROS } \\
\text { 527. Intereses a corto plazo de deudas con enti- } \\
\text { dades de crédito }\end{array}$ \\
\hline
\end{tabular}

Ilustración 4.27. Cuentas de gastos financieros

(662) Intereses de deudas $(G)$

$\mathrm{X}$

(527) Intereses a corto plazo de deudas (P)

Ilustración 4.28. Asiento tipo de intereses devengados por un préstamo

\section{Ejemplo 4.27. Reconocimiento de gastos por intereses}

El 30 de septiembre de 2000 la empresa TEXTILES SA está obligada a pagar los intereses del mes del préstamo obtenido a inicios de ese mes en el ejemplo 2.26. El tipo de interés pactado fue del $6 \%$.

El 30/09/00 se registraría $(50.000 \times 6 \% / 12=250)$ :

(662) Intereses de deudas $(\mathrm{G})$

(527) Intereses a corto plazo de deudas $(\mathrm{P})$

\section{Devolución de financiación ajena}

Cuando se produzca la devolución de los capitales prestados el asiento es, lógicamente, el contrario.

$(17 \mathrm{x} / 52 \mathrm{x})$ Cuentas de pasivos financieros $(\mathrm{P})$

Ilustración 4.29. Asiento tipo de reintegro de un pasivo financiero

\section{Ejemplo 4.28. Devolución de un préstamo}

El 1 de septiembre de 01 la empresa TEXTILES SA devuelve la parte del préstamo, del ejemplo 2.26, que vence en dicha fecha.

El 01/09/01 se registraría:

520. Deudas a corto plazo con ent. crédito $(\mathrm{P})$ 572. Bancos c/c (A) 


\subsection{Financiación (II): financiación propia}

Como se indicó en el tema 2, las fuentes de financiación propia tienen tres orígenes:

- Aportaciones iniciales o posteriores de los socios: capital social o capital (para empresarios individuales).

- Beneficios retenidos por la empresa en años anteriores, reservas; o beneficios del último año pendientes de reparto, pérdida y ganancias.

- Subvenciones y donaciones obtenidas de entidades públicas o privadas, que son fondos obtenidos al cumplir determinadas condiciones y que no deben reintegrarse.

Las cuentas donde se recoge la financiación propia de una empresa se muestran en la siguiente ilustración.

\begin{tabular}{|l|l|l|}
\hline Aportaciones de socios & \multicolumn{1}{|c|}{ Beneficios retenidos y obtenidos } & \multicolumn{1}{c|}{ Subvenciones } \\
\hline 10. CAPITAL & 11. RESERVAS & 13. SUBVENCIONES, \\
100. Capital social & 113. Reservas voluntarias & DONACIONES \\
102. Capital & 12. RESULTADOS PENDIENTES & 130. Subvenciones oficia- \\
& DE APLICACIÓN & les de capital \\
& 129. Pérdidas y ganancias & \\
\hline
\end{tabular}

Ilustración 4.30. Cuentas de financiación propia

Dado el carácter básico de este texto de contabilidad no se profundizará en este tipo de fuentes de financiación, mostrándose únicamente algunos ejemplos.

\section{Aportaciones de socios}

En el siguiente ejemplo se registran las aportaciones de capital por parte de los socios de la empresa.

Ejemplo 4.29. Creación de empresa y aportación de capital
El 1 de noviembre de 2000 se crea la empresa JUGUETES MEDITERRÁNEO SL, con un capital escritu-
rado de 20.000,00 €, importe que los socios desembolsan en su totalidad en una cuenta bancaria
de la empresa.
El 01/11/00 se registraría:
$\begin{aligned} & \text { 572. Bancos c/c (A) } \\ & \text { 100. Capital social (N) }\end{aligned}$
$\begin{aligned} & \text { Las disminuciones y retiradas de capital ocasionarían el asiento contrario, disminuyendo la cifra } \\ & \text { de capital. }\end{aligned}$




\section{Distribución del resultado}

En el siguiente ejemplo se muestra una distribución de resultados de un ejercicio tras el acuerdo de la Junta de Accionistas de una empresa.

\section{Ejemplo 4.30. Distribución del resultado}

El 1 de mayo de 01 la Junta de Accionistas de la empresa juguetes MEDITERRÁneo sL decide destinar los beneficios del año 2000 , que fueron $5.000,00$ y por partes iguales a reservas voluntarias y dividendos. Un mes más tarde se pagan los dividendos.

El 01/05/01 se registraría la distribución:

\begin{tabular}{|l|r|r|}
\hline $\begin{array}{l}\text { 129. Pérdidas y ganancias (N) } \\
\text { 113. Reservas voluntarias (N) } \\
\text { 545. Dividendo activo a pagar (P) }\end{array}$ & $5.000,00$ & $2.500,00$ \\
$2.500,00$
\end{tabular}

En caso de que en 2000 se hubiesen generado pérdidas, estas podrían compensarse disminuyendo las reservas voluntarias. Se cargan las reservas con abono a la cuenta de resultados.

\section{Subvenciones de capital}

Finalmente el siguiente ejemplo muestra la obtención y cobro de una subvención de capital (como se indicó en el apartado 4.4, las subvenciones de explotación se consideran otros ingresos de explotación, ver ejemplo 4.17).

\section{Ejemplo 4.31. Subvenciones de capital}

El 1 de abril de 2000 la empresa JUGUETES MEDITERRÁNEO SL obtiene y cobra una subvención de capital de 10.000,00 para financiar la compra de nueva maquinaria.

El 01/04/00 se registraría:

\begin{tabular}{|l|r|r|}
\hline $\begin{array}{l}\text { 470. Hda. Pca. Deudora por subvenciones (A) } \\
\text { 130. Subvenciones de capital (N) }\end{array}$ & $10.000,00$ & $10.000,00$ \\
\hline $\begin{array}{l}\text { 572. Bancos c/c (A) } \\
\text { 470. Hda. Pca. Deudora por subvenciones (A) }\end{array}$ & $10.000,00$ & $10.000,00$ \\
\hline
\end{tabular}

Saber más: Subvenciones de capital y de explotación

Las subvenciones que figuran en el patrimonio neto financian generalmente inversiones de inmovilizado (construcciones, maquinaria, etc.).

- Inicialmente se consideran y registran como patrimonio neto, «cuenta 130. Subvenciones de capital», y

- van traspasándose a resultados paralela y proporcionalmente a la amortización de los inmovilizados financiados abonándose como contrapartida la «cuenta 746. Subvenciones de capital transferidas a resultados»».

Las subvenciones de explotación sirven para compensar parte de los gastos de explotación de una actividad y se consideran ingresos del ejercicio en que surge el derecho a su percepción utilizando la «cuenta 740. Subvenciones de explotación». 


\section{Material para prácticas}

\section{Preguntas test}

1. La cuenta de IVA soportado:

a) Presentará saldo deudor.

b) Presentará saldo acreedor.

c) Puede presentar saldo deudor o acreedor.

d) Es un gasto.

2. El precio de adquisición de mercaderías es:

a) El importe que se adeuda al proveedor de las mismas.

b) El precio en factura más todos los gastos hasta que los bienes se encuentren en el almacén.

c) El precio en factura más todos los gastos hasta que los bienes se encuentren en el almacén más los descuentos incluidos en la factura.

d) El precio en factura más todos los gastos hasta que los bienes se encuentren en el almacén menos los descuentos incluidos en la factura.

3. En relación al tratamiento contable de las mercaderías, señale cuál de las siguientes afirmaciones es correcta:

a) El procedimiento denominado «cuenta única administrativa» está recogido en el PGC.

b) El procedimiento denominado «desdoblamiento incompleto» para contabilizar cada venta exige conocer el coste de adquisición de las unidades vendidas.

c) El procedimiento denominado «permanencia de inventario por cuenta única administrativa» exige conocer el beneficio bruto en cada operación de venta.

d) Ninguna de las afirmaciones anteriores es correcta.

4. En el procedimiento de cuenta única administrativa (permanencia de inventario) de mercaderías:

a) El valor de las existencias finales se obtiene de forma extracontable.

b) El saldo de la cuenta de mercaderías debe coincidir con el valor de existencias en cada momento.

c) Es el recogido en el PGC.

d) Hay que calcular extracontablemente el margen comercial.

5. La cuenta de «variación de existencias de mercaderías»:

a) Tendrá siempre saldo deudor.

b) Tendrá siempre saldo acreedor.

c) Puede tener saldo deudor o acreedor.

d) Se utiliza en el procedimiento de permanencia de inventario. 
6. El procedimiento de cuenta única administrativa para las mercaderías (llamado también de permanencia en inventario), implica que:

a) Se registra el resultado después de cada operación de venta.

b) No se registra el resultado después de cada operación de venta.

c) Se registra el resultado después de cada operación de compra.

d) Se utiliza la cuenta «variación de existencias de mercaderías».

7. Si las existencias se contabilizan por el de desdoblamiento incompleto:

a) La cuenta «variación de existencias» recoge la diferencia entre el valor de coste inicial y final de las existencias.

b) La cuenta «existencias» presenta como saldo el valor estimado de las existencias en almacén en cada momento.

c) Hay que conocer el precio de coste para contabilizar cada venta.

d) La cuenta «variación de existencias» recoge la diferencia entre el valor de coste y el valor de mercado de las existencias finales.

8. ¿Cómo se denomina a los que suministran a las empresas servicios diversos?
a) Deudores.
b) Proveedores.
c) Acreedores por prestación de servicios.
d) Clientes.

9. La cuenta «(465) Remuneraciones pendientes de pago»:
a) Se liquida (salda) con el devengo de la nómina.
b) Es una cuenta de activo no corriente.
c) Se genera cuando se paga la nómina a los empleados.
d) Es un pasivo corriente.

10. Cuando una empresa vende un inmovilizado material, ello supone:
a) Reconocer el pasivo por el importe pendiente de pago al proveedor.
b) Darlo de baja junto a las cuentas con las que está relacionado y reconocer un resultado.
c) Darlo de baja y reconocer un pasivo por el importe a cobrar.
d) Reconocer el inmovilizado por su precio de venta.

11. En relación a las inversiones en instrumentos financieros:
a) No proporcionan rendimientos si no se venden.
b) Las acciones generan intereses a lo largo del tiempo.
c) Los valores representativos de deuda devengan dividendos.
d) Ninguna de las anteriores.

12. En relación a las inversiones en instrumentos financieros:

a) Cuando se venden, se obtienen beneficios o pérdidas financieras.

b) Al beneficio o pérdida obtenido por la venta de acciones deberá deducirse el importe de los dividendos ya cobrados y registrados.

c) Los créditos concedidos, si son a muy largo plazo, no devengan intereses.

d) Los valores de deuda deben mantenerse siempre hasta el vencimiento sin que sea posible su venta. 
13. En relación a la financiación ajena:

a) Los préstamos generan gastos financieros que se restan del importe de la deuda.

b) Puede surgir si la empresa acepta aplazar el cobro por la venta de un inmovilizado.

c) Las devoluciones de préstamos se abonan en las cuentas de los préstamos.

d) Las devoluciones de préstamos se cargan en las cuentas de los préstamos.

14. Se denomina capital o capital social:

a) Al importe de los fondos aportados por los propietarios a la empresa.

b) A la parte del importe de los fondos aportados por los propietarios que se mantienen en caja o cuentas bancarias.

c) A las aportaciones de los socios más las subvenciones de capital obtenidas.

d) A las aportaciones de los socios más las subvenciones de capital más las reservas.

SOLUCIONES AL TEST:

\begin{tabular}{|l|l|l|l|l|}
\hline 1. & 2. & 3. & 4. & 5. \\
\hline 6. & 7. & 8. & 9. & 10. \\
\hline 11. & 12. & 13. & 14. & \\
\hline
\end{tabular}




\section{Cuestiones teóricas}

1. ¿Qué son las operaciones sujetas al IVA? Indique algunos ejemplos.

2. ¿Qué son las operaciones no sujetas o exentas de IVA? Indique algún ejemplo.

3. Tratamiento contable del IVA soportado no deducible.

4. Tratamiento contable del IVA en operaciones intracomunitarias.

5. Tratamiento contable del IVA en importaciones y exportaciones.

6. ¿Qué recoge la cuenta de «Hda. Pública, IVA repercutido» y qué representa para la empresa: un gasto, un ingreso, un pasivo, un activo o un elemento de patrimonio neto?

7. ¿En qué consisten las liquidaciones trimestrales (o mensuales) de IVA?

8. ¿Cuáles son las cuentas principales usadas para el registro del devengo de nóminas mensuales del personal?

9. ¿Cómo se contabiliza la concesión de un anticipo sobre la nómina de un trabajador y su posterior compensación por parte de la empresa?

10. Diferencie entre la Seguridad Social a cargo del trabajador y la Seguridad Social a cargo de la empresa.

11. Diferencie entre las cuentas «Seguridad Social a cargo de la empresa» y «Organismos de la Seguridad Social acreedores».

12. ¿Qué importes forman parte del precio de adquisición de las mercancías que una empresa compra?

13. Diferencie entre inventario periódico e inventario permanente de mercancías.

14. Explique las diferencias entre el procedimiento de contabilización por cuenta única administrativa y por desdoblamiento incompleto para las mercaderías.

15. Indique los errores conceptuales del procedimiento de desdoblamiento incompleto y cómo se solucionan.

16. ¿Para qué se utiliza la cuenta de «variación de existencias», qué saldo puede tener y que significa dicho saldo?

17. Indique dos cuentas de inmovilizado intangible y que se recoge en ellas.

18. Indique tres cuentas de inmovilizado material y que se recoge en ellas.

19. ¿Cuál es el criterio general de valoración del inmovilizado intangible y el material?

20. Indique los tres tipos de inversiones financieras más habituales.

21. ¿Qué es una acción?

22. ¿Qué es un Bono del Tesoro?

23. ¿Cuál es el criterio general de valoración de las inversiones financieras?

24. Explique qué rendimientos periódicos proporciona la inversión en acciones y cómo se registran.

25. Indique qué rendimientos periódicos proporciona una inversión en Bonos del Tesoro y cómo se registran.

26. Indique las fuentes de financiación de la empresa y sus características esenciales.

27. ¿De qué dos formas una empresa incurre en una obligación o pasivo?

28. ¿Qué tipo de gastos periódicos ocasionan los pasivos financieros?

29. ¿Qué diferencia existe entre las cuentas «reservas» y «pérdidas y ganancias»?

30. ¿Qué diferencia a un préstamo de una subvención?

31. ¿Qué diferencias hay entre el tratamiento contable de las subvenciones de capital y las de explotación? 


\section{Ejercicios}

NOTAS:

- Para las operaciones con mercancías utilice el procedimiento de desdoblamiento incompleto.

- En las operaciones no financieras al contado se deberá registrar primero la cuenta deudora o acreedora correspondiente y posteriormente el cobro o pago.

\section{Ejercicio 1. Precio de adquisición de mercancías}

El 1 de abril de 2000, INFOPRÁCTICA adquiere para su posterior venta un lote de 100 usB por lo que el proveedor ha facturado un importe de 300,00 €. Los gastos de transporte y el seguro del mismo, que van a cargo de INFOPRÁCTICA, asciende a $30,00 €$. Determine el precio de adquisición de los uSB por unidad y contabilice la compra, que queda pendiente de pago, IVA aplicable $18 \%$.

Precio adquisición $=$

\begin{tabular}{|l|l|l|l|}
\hline 1 abril 00 & & & \\
\hline
\end{tabular}

\section{Ejercicio 2. Compra de mercancías a crédito}

ALCAMPO SA compra el 1 de abril de 2000 mercancías a proveedores por 10.000,00 $€$ más el IVA del 18\%. El plazo de pago pactado es 120 días.

1 abril 00

\begin{tabular}{|l|l|l|}
\hline & & \\
\hline
\end{tabular}

Ejercicio 3. Compra de mercancías en efectivo

CARREFOUR SA compra el 2 de mayo de 2000 mercancías a proveedores y paga en efectivo 5.000,00 más el IVA del 18\%.

\begin{tabular}{|l|l|l|l|}
\hline 2 mayo 00 & & & \\
\hline 2 mayo 00 & & & \\
& & & \\
\hline
\end{tabular}

Ejercicio 4. Compra de mercancías parcialmente a crédito

CARREFOUR SA compra el 8 de abril de 2000 mercancías a sus proveedores por un importe de 6.000,00 €. Se paga la mitad por transferencia bancaria y mitad queda pendiente de pago hasta el mes siguiente, IVA aplicable $18 \%$.

\begin{tabular}{|l|l|l|l|}
\hline 8 abril 00 & & & \\
\hline 8 abril 00 & & & \\
\hline
\end{tabular}


Ejercicio 5. Venta de mercaderías a crédito

DULCES SA vende, el 3 de marzo de 2000, mercancías a crédito por un importe de $3.000,00 €$ más el IVA del 18\%.

\begin{tabular}{|l|l|l|l|}
\hline 3 marzo 00 & & & \\
\hline
\end{tabular}

\section{Ejercicio 6. Venta de mercancías en efectivo}

LUIS GARCíA SA vende, el 1 de febrero de 2000, mercancías al contado por valor de $400,00 €$ más el IVA del 18\%, importe que cobra en efectivo.

\begin{tabular}{|l|l|l|l|}
\hline 1 febrero 00 & & & \\
\hline 1 febrero 00 & & & \\
\hline
\end{tabular}

\section{Ejercicio 7. Venta de mercaderías parcialmente a crédito}

PRIM MOTORS SL vende, el 14 de mayo de 2000, un vehículo por un importe de $15.000,00 €$ más el IVA del 18\%. La mitad se cobra a través de un cheque bancario y la otra mitad queda pendiente de cobro sin fecha.

\begin{tabular}{|l|l|l|l|}
\hline 14 mayo 00 & & & \\
\hline 14 mayo 00 & & & \\
& & & \\
\hline
\end{tabular}

Ejercicio 8. Contabilización de facturas

Dada la siguiente factura:

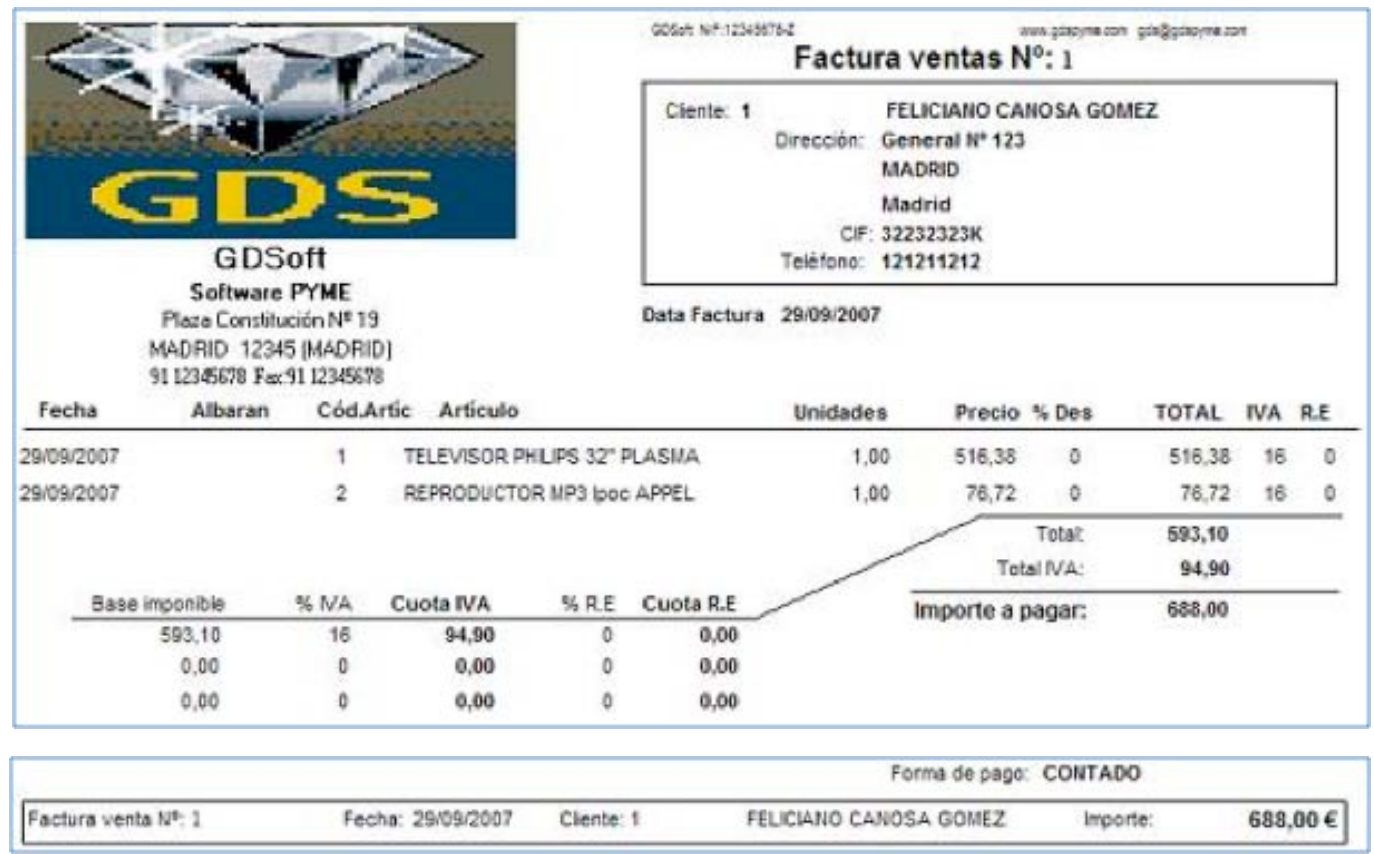


a) Contabilice la venta de GDS.

b) Contabilice la compra por parte de Feliciano Canosa suponiendo que es una empresa de compra-venta de aparatos de imagen y sonido.

c) Contabilice el caso anterior suponiendo que el IVA soportado no es deducible.

d) Contabilice la compra por parte de Feliciano Canosa suponiendo que es una empresa de compra-venta de muebles y que los bienes adquiridos se utilizarán para mostrar vídeos en su exposición de venta.

e) Contabilice el caso anterior suponiendo que el IVA soportado no es deducible.

\begin{tabular}{|l|l|l|l|}
\hline a) & & & \\
\hline & & & \\
\hline b) & & & \\
\hline
\end{tabular}

\begin{tabular}{|l|l|l|l|}
\hline & & & \\
\hline$c)$ & & & \\
\hline & & & \\
\hline$d)$ & & & \\
\hline & & & \\
\hline$e)$ & & & \\
\hline & & & \\
\hline
\end{tabular}

\section{Ejercicio 9. Variación de existencias}

El 01 de enero de 2000 CARREFOUR SA tenía mercaderías en almacén por valor de $210.000,00 €$. A final del año 2000 procede a regularizar el valor de estas sabiendo que, según recuento físico, el valor de las mismas a 31 de diciembre de 2000, es de $240.000,00 €$.

\begin{tabular}{|l|l|l|l|}
\hline 31 diciembre 00 & & & \\
\hline & & & \\
\hline
\end{tabular}

\section{Ejercicio 10. Cálculo de margen comercial}

Siguiendo con los datos del ejercicio 9 anterior, calcule el margen comercial de 2000 sabiendo que la cifra neta de ventas ha sido de $2.360 .000,00 €$ y la de compras de $1.830 .000,00 €$. 
Ejercicio 11. Regularización de existencias y cálculo de margen comercial NESTLÉ SA inicio el año 2000 con mercancías por valor de 3.400.000,00 €. Durante el año compró mercancías por importe de 23.000.000,00 € y vendió mercancías por importe de 40.000.000,00 €. El recuento físico final de existencias en almacén a 31 de diciembre ascendió a 3.500.000,00 €. Calcule el margen comercial del año.

Margen comercial $=$

\section{Ejercicio 12. Compra-venta y liquidación de IVA}

Contabilice las siguientes operaciones realizadas por la empresa EL SOL NACIENTE SA durante el segundo trimestre de 2000 (todas las operaciones están sujetas a IVA 18\%):

a) Vende a crédito mercancías por $5.000 €$ más el IVA.

b) El cliente anterior satisface en efectivo su deuda.

c) Compra mercancías a crédito por $4.000 €$, pagando en efectivo $150 €$ de portes a su cargo. A los importes anteriores debe añadirse el IVA.

d) Vende mercancías a crédito por $3.540 €$ (en dicho importe se incluye el IVA).

e) Liquidación del IVA correspondiente a las operaciones de este trimestre.

\begin{tabular}{|l|l|l|l|}
\hline a) & & & \\
\hline b) & & & \\
\hline$c)$ & & & \\
\hline & & & \\
\hline d) & & & \\
\hline e) 20 julio 00 & & & \\
\hline
\end{tabular}

Ejercicio 13. Compra-venta y liquidación trimestral de IVA

Contabilice las operaciones siguientes de la empresa ALPHA SA realizadas en el primer trimestre del año 2000 y aplicando un IVA del $18 \%$ a todas las operaciones excepto que se indique lo contrario:

a) Compra en efectivo 3.600 uds. a 15,00 € según factura de «Comercial Gómez».

b) Compra 5.000 uds. a 10,00 €, a crédito, según factura de «Comercial A».Asimismo se paga mediante cheque bancario al transportista $0,70 € /$ ud. en concepto de portes.

c) Venta a crédito de 3.500 uds. a 20,00 € a «Suministros Llopis». Se pagan 400,00€ en concepto de portes a cargo de la empresa vendedora. 
d) Venta en efectivo a un cliente de 1.500 uds a 20,00 €/ud.

e) Realice los asientos de liquidación del IVA de la empresa suponiendo que en el trimestre no ha realizado ninguna operación más que las indicadas.

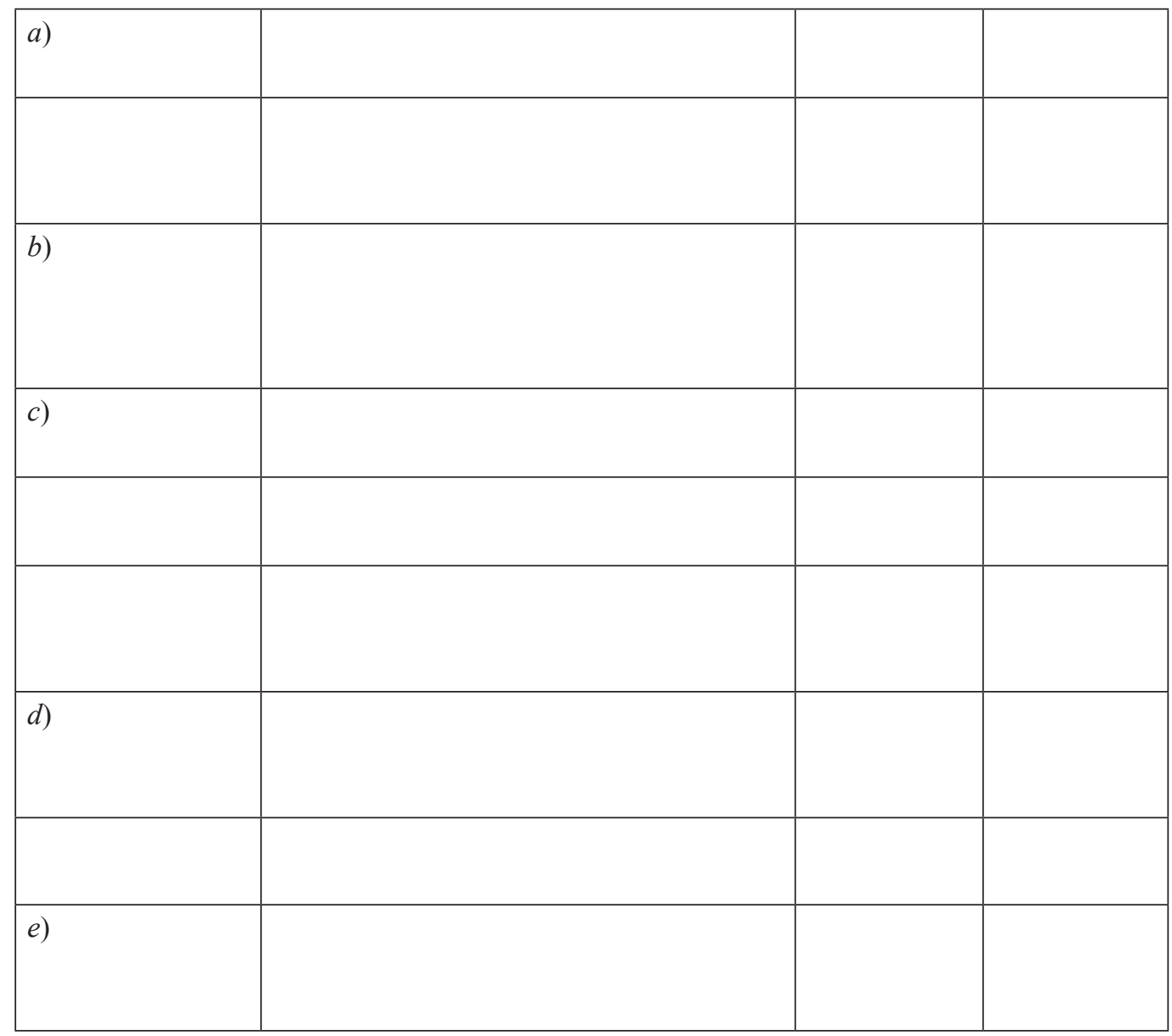

\section{Ejercicio 14. Liquidación de IVA}

Realice los asientos de la liquidación del IVA del segundo trimestre de 2000 de la empresa TAPIZADOS CASTELLÓN SA teniendo en cuenta que:

- IVA soportado durante el trimestre

- IVA repercutido durante el trimestre

A la fecha de la liquidación del Iva la empresa posee un saldo a su favor frente a la Hacienda Pública por IVA a compensar de $5.000 €$, proveniente del primer trimestre del año, el cual es aplicado en dicha liquidación.

\begin{tabular}{|l|l|l|l|}
\hline 20 julio 00 & & & \\
& & & \\
& & & \\
\hline
\end{tabular}




\section{Ejercicio 15. Liquidación de IVA}

La empresa AGROESTE SL ha presentado los siguientes saldos en sus cuentas de IVA durante el año 2000:

\begin{tabular}{|l|r|r|}
\hline & (472) H. P. IVA soportado & (477) H. P. IVA repercutido \\
\hline Primer trimestre & $4.000,00$ & $4.100,00$ \\
\hline Segundo trimestre & $2.100,00$ & $2.300,00$ \\
\hline Tercer trimestre & $6.400,00$ & $5.600,00$ \\
\hline Cuarto trimestre & $1.200,00$ & $1.500,00$ \\
\hline
\end{tabular}

Contabilice las cuatro liquidaciones de IVA del año.

\begin{tabular}{|l|l|l|l|}
\hline 1er trimestre 00 & & & \\
\hline $2^{\circ}$ trimestre 00 & & & \\
\hline 3er trimestre 00 & & & \\
& & & \\
\hline $4^{\circ}$ trimestre 00 & & & \\
\hline
\end{tabular}

\section{Ejercicio 16. Operaciones con IVA deducible y no deducible}

Contabilice las siguientes operaciones realizadas por la empresa PAPELERÍA EL MARTILLO SL:

a) Recibe la factura $\mathrm{n}^{\mathrm{o}} 18$ de Talleres Rodríguez, por reparaciones de un vehículo de turismo propiedad de la misma de 250,00 €, más el 18\% de IVA, (el IVA no es deducible).

b) La empresa adquiere a crédito a un proveedor de Portugal mercancías para su venta por $2.000,00 €$ más IVA deducible del 18\%.

c) Recibe una factura de restaurante La Noche por comida atención a clientes de $200 €$, más el $8 \%$ de IVA, aún no pagada. El IVA no es deducible.

d) Factura de compra ${ }^{\circ} 1023$ de Automóviles Rápidos SA de un Audi A4 para viajes del Director General de $30.000 €$, más el 18\% de IVA. El IVA no es deducible.

\begin{tabular}{|l|l|l|l|}
\hline a) & & & \\
\hline & & & \\
\hline
\end{tabular}




\begin{tabular}{|l|l|l|l|}
\hline b) & & & \\
\hline$c)$ & & & \\
\hline$d)$ & & & \\
\hline
\end{tabular}

\section{Ejercicio 17. Operaciones intracomunitarias e IVA}

Contabilice las siguientes operaciones intracomunitarias (IVA aplicable en su caso $18 \%$ ).

a) La empresa MNO S.A. compra a crédito materias primas a Italia por $6.000 €$.

b) Después de transformarlas exporta a crédito el producto terminado correspondiente a Alemania por $9.000 €$.

\begin{tabular}{|l|l|l|l|}
\hline a) & & & \\
& & & \\
\hline$b)$ & & & \\
\hline
\end{tabular}

\section{Ejercicio 18. Importación con IVA}

La empresa ALFA SA adquiere a crédito, el 8 de agosto de 2000, a una empresa americana mercancías para venta por $10.000 €$. Se paga en la aduana el IVA de la operación (18\%). Además se pagan $100 €$ por aranceles y $120 €$ por honorarios agente de aduanas, importes que no están sujetos a IVA.

\begin{tabular}{|l|l|l|l|}
\hline 8 agosto 00 & & & \\
& & & \\
\hline & & & \\
\hline
\end{tabular}

\section{Ejercicio 19. Gastos de electricidad mediante cargo bancario}

El 1 de mayo se recibe un extracto bancario en el que figura el pago del recibo de electricidad del mes de abril por importe de 240,00 € más el IVA del 18\%.

\begin{tabular}{|l|l|l|l|}
\hline 1 mayo 00 & & & \\
& & & \\
\hline & & & \\
\hline
\end{tabular}




\section{Ejercicio 20. Gastos de publicidad a crédito}

La empresa ALCAMPO SA recibe, el 1 de julio de 2000, la factura de la campaña de publicidad de verano que ha ascendido a 120.000,00€ más el IVA del 18\%. Este importe se pagará en los próximos 60 días.

\begin{tabular}{|l|l|l|l|}
\hline 1 julio 00 & & & \\
\hline
\end{tabular}

\section{Ejercicio 21. Gastos por primas de seguros}

Por correo llega, el 3 de marzo de 2000, el recibo del seguro de un vehículo de la empresa por importe de 360,00€. El importe se paga tres días más tarde. Operación no sujeta a IVA.

\begin{tabular}{|l|l|l|l|}
\hline 3 marzo 00 & & & \\
\hline
\end{tabular}

\section{Ejercicio 22. Tributos}

Registre el devengo y pago en efectivo el 1 de junio de 2000 el impuesto sobre vehículos de tracción mecánica (IVTM) del año 2000 que asciende a 65,00 €. Operación no sujeta a IVA.

\begin{tabular}{|l|l|l|l|}
\hline 1 junio 00 & & & \\
\hline & & & \\
& & & \\
\hline
\end{tabular}

\section{Ejercicio 23. Nómina mensual}

Contabilice la nómina del mes de febrero de 2000, de la empresa ASESORES UNIDOS sL que asciende a $6.300,00 €$ en sueldos y salarios y $1.600,00 €$ en concepto de seguridad Social. Se retienen 1.000,00 € en concepto de IRPF y 400,00 € por Seguridad Social a cargo del trabajador. Todos los importes quedan pendientes de pago.

\begin{tabular}{|l|l|l|l|}
\hline 28 febrero 00 & & & \\
\hline & & & \\
& & & \\
\hline
\end{tabular}

\section{Ejercicio 24. Nómina mensual}

Contabilice el devengo y pago mediante transferencia de la nómina del mes de marzo de 2000 de la empresa UNISA sabiendo que:

\begin{tabular}{|l|r|}
\hline Sueldo bruto devengado & 12.000 \\
\hline Descuento a trabajadores por cuota obrera Seguridad Social & 750 \\
\hline Retención IRPF & 1.500 \\
\hline Cuota patronal Seguridad Social & 2.750 \\
\hline
\end{tabular}


Los importes adeudados a la Hacienda y Seguridad Social quedan pendientes de pago.

\begin{tabular}{|l|l|l|l|}
\hline 31 marzo 00 & & & \\
& & & \\
\hline & & & \\
\hline & & & \\
\hline & & & \\
\hline
\end{tabular}

\section{Ejercicio 25. Anticipo a un trabajador}

Contabilice la concesión, el día 4 de abril de 2000, de un anticipo en efectivo de $500 €$ de la empresa FOSFOROS SA a uno de sus trabajadores a cuenta de la nómina del mes.

\begin{tabular}{|l|l|l|l|}
\hline 4 abril 00 & & & \\
& & & \\
\hline
\end{tabular}

\section{Ejercicio 26. Nómina mensual}

La nómina de abril de 2000 de la empresa FOSFOROS SA es la siguiente (datos para todos los trabajadores):

a) Sueldo total bruto: $90.000 €$.

b) Retención Seguridad Social cargo de los trabajadores: $5.000 €$.

c) Retención IRPF: $15.000 €$.

d) Se descontará de la nómina el anticipo del ejercicio anterior.

e) El importe líquido se pagará el día cinco del mes siguiente.

Contabilice:

a) El devengo de la nómina, sin ningún pago.

b) El pago mediante cheque del importe líquido de la nómina.

c) La cuota empresarial de la Seguridad Social de abril de la empresa que asciende a $25.000 €$.

d) El pago, a finales del mes siguiente, de la deuda que mantiene la empresa con la Seguridad Social a través de la cuenta bancaria.

e) El pago al final de segundo trimestre del año de los importes retenidos a cuenta del IRPF, sabiendo que en mayo se retuvieron $15.500 €$ y en junio $15.800 €$. 


\begin{tabular}{|l|l|l|l|}
\hline a) 30 abril 00 & & & \\
\hline b) 30 abril 00 & & & \\
\hline c) 30 abril 00 & & & \\
\hline d) 31 marzo 00 & & & \\
\hline e) 20 junio 00 & & & \\
& & & \\
\hline
\end{tabular}

\section{Ejercicio 27. Contabilización de nóminas}

Contabilice lo que proceda a 31 de enero de 09 con la siguiente información sobre una nómina de un empleado y el correspondiente documento TC1 para la Seguridad Social del mes de enero de 09.

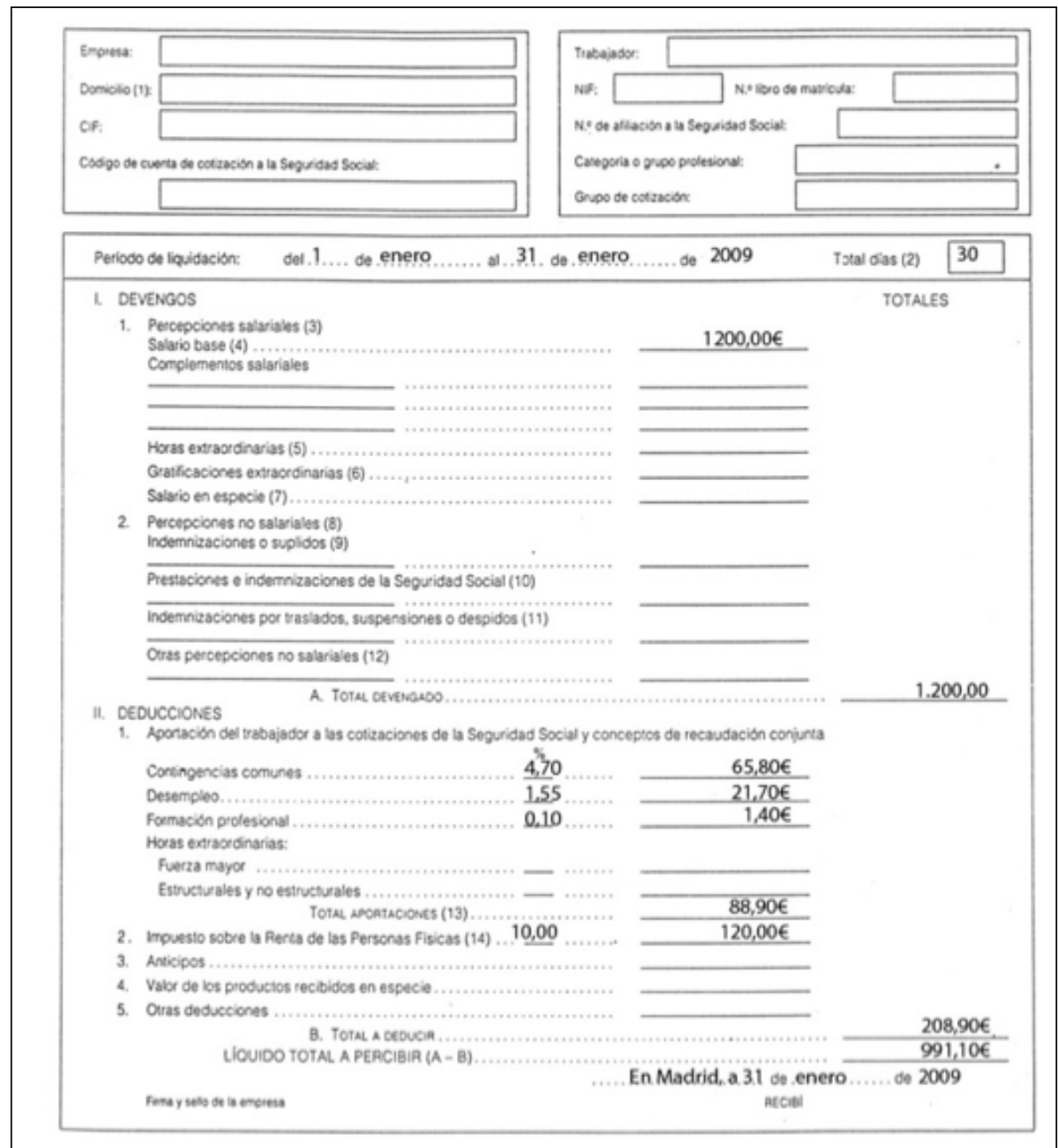



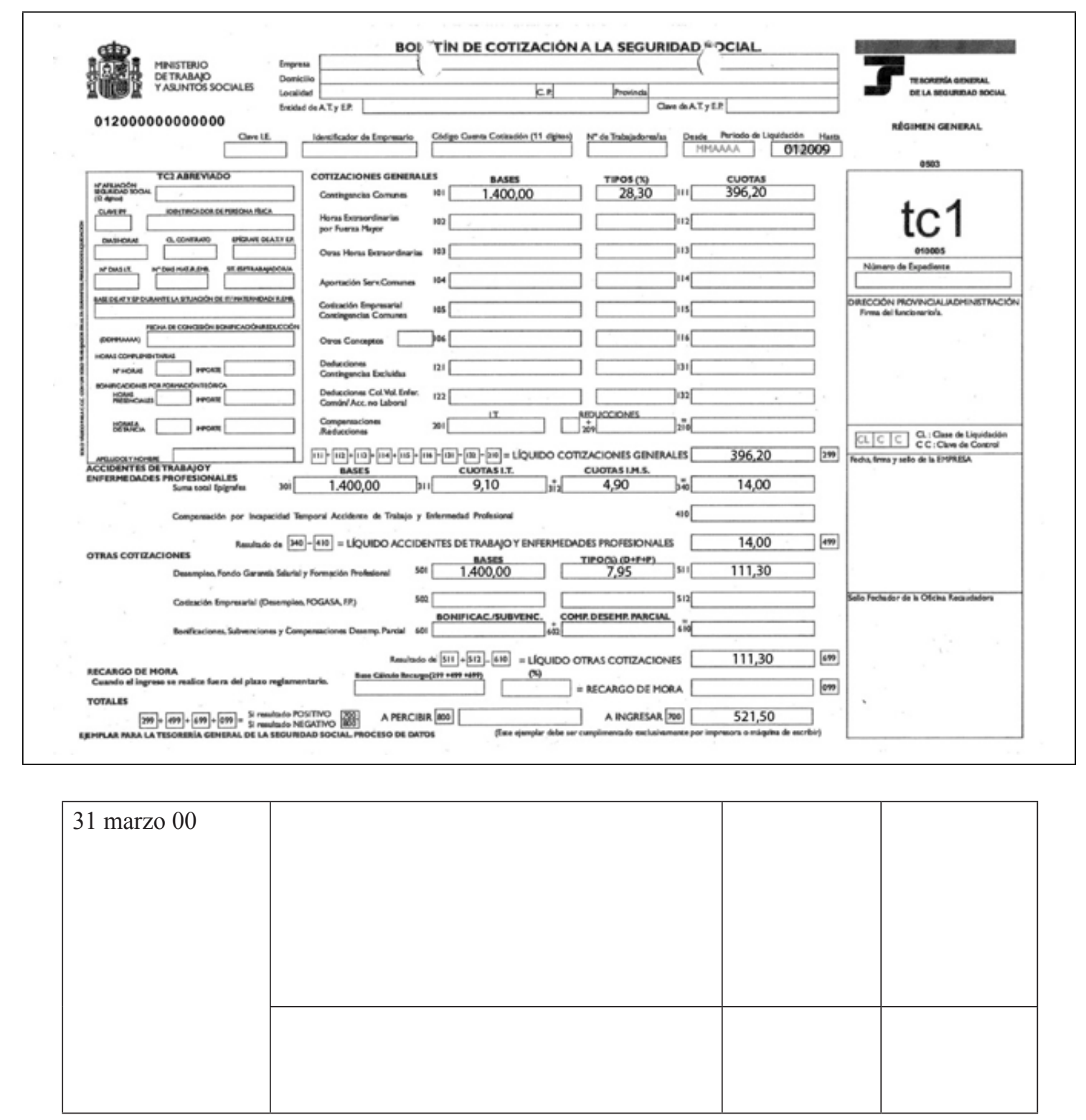

\section{Ejercicio 28. Ingresos por arrendamientos}

La empresa TÉCNICA SL tiene arrendado un local comercial de su propiedad. El 30 de septiembre de 2000 emite la factura de alquiler por importe de 750,00 € más IVA del $18 \%$. El inquilino la paga en efectivo una semana más tarde.

\begin{tabular}{|l|l|l|l|}
\hline 30 septiembre 00 & & & \\
& & & \\
\hline 7 octubre 00 & & & \\
& & & \\
\hline
\end{tabular}




\section{Ejercicio 29. Subvenciones de explotación}

El 1 de abril de 2000 la empresa concesionaria del transporte urbano de Castellón recibe una transferencia correspondiente a una subvención a la explotación por el servicio prestado y por importe de 20.000,00€.

\begin{tabular}{|l|l|l|l|}
\hline 1 abril 00 & & & \\
\hline & & & \\
& & & \\
\hline
\end{tabular}

\section{Ejercicio 30. Compra de inmovilizado intangible}

La empresa TURISTIC SL adquiere, el 1 de junio de 2000, del Ayuntamiento de Castellón el derecho a la explotación en régimen de concesión administrativa y por 5 años de un bar-restaurante situado en la playa del municipio. Se pacta un importe de 50.000,00 € para todo el período de la concesión, importe que se pagará a partes iguales entre los 5 años. Operación no sujeta a IVA.

\begin{tabular}{|l|l|l|l|}
\hline 1 junio 00 & & & \\
& & & \\
\hline
\end{tabular}

\section{Ejercicio 31. Compra de inmovilizado material}

El 1 de marzo de 2000 se compra una máquina por importe de $2.400,00 €$ más IVA del $18 \%$. Se paga la mitad en efectivo y la otra mitad queda aplazada 60 días. La instalación de la máquina en la empresa supone un coste de 300,00 € más IVA del $18 \%$, que se pagan en efectivo.

\begin{tabular}{|l|l|l|l|}
\hline 1 marzo 00 & & & \\
\hline & & & \\
\hline & & & \\
\hline & & & \\
\hline & & & \\
\hline
\end{tabular}




\section{Ejercicio 32. Compra de inversión inmobiliaria}

La empresa ANTARES SL, dedicada a la compraventa de vehículos, adquiere el 6 de agosto de 2000 un local comercial en primera línea de playa por 400.000,00 euros, los gastos de notaría y tributos del mismo asciende a 2.000,00 €. Todos los importes se satisfacen en efectivo. Desea dedicar este local al alquiler para algún bar o restaurante. IVA aplicable a la compra 18\%, los gastos de notaría y tributos no están sujetos a IVA.

\begin{tabular}{|l|l|l|l|}
\hline 6 agosto 00 & & & \\
& & & \\
\hline & & & \\
\hline & & & \\
\hline & & & \\
\hline
\end{tabular}

\section{Ejercicio 33. Venta de inmovilizado material a crédito}

ATMOSPHERA CLOTHES SL vende el 12 de junio de 2000 un local comercial que le costó $30.000,00 €$ por $35.000,00 €$ más IVA del 18\%. El importe queda pendiente de cobro.

\begin{tabular}{|l|l|l|l|}
\hline 12 junio 00 & & & \\
& & & \\
& & & \\
\hline
\end{tabular}

\section{Ejercicio 34. Venta de inmovilizado material al contado}

AZULEJOS ALCORA SL vende el 22 de octubre de 2000 una máquina usada por 6.000,00€ más IVA del $18 \%$ y obtiene unas pérdidas de $500 €$. El importe se cobra en efectivo.

\begin{tabular}{|l|l|l|l|}
\hline 22 octubre 00 & & & \\
& & & \\
\hline & & & \\
\hline & & & \\
\hline
\end{tabular}




\section{Ejercicio 35. Compra de acciones}

El 5 de abril de 2000, INVESTMENT SL adquiere como inversión permanente 500 acciones de UlTRAMARINOS SA a un precio de 23,00 €/acción. El importe se paga a través de la cuenta bancaria. Operación no sujeta a IVA.

5 abril 00

\section{Ejercicio 36. Devengo de dividendos}

Siguiendo con el ejercicio anterior, el 5 de mayo de 02 ULTRAMARINOS SL anuncia el reparto de un dividendo, correspondiente a los beneficios de 01 , de $2 € /$ acción, importe que se cobra dos semanas más tarde (en cuenta bancaria). Operación no sujeta a IVA.

\begin{tabular}{|l|l|l|l|}
\hline 5 mayo 00 & & & \\
\hline 29 mayo 00 & & & \\
\hline
\end{tabular}

\section{Ejercicio 37. Venta de acciones}

El 3 de agosto de 02, INVESTMENT SL vende las acciones del ejercicio 35 anterior a $34,00 € /$ acción. El importe se cobra en la cuenta bancaria. Operación no sujeta a IVA.

\begin{tabular}{|l|l|l|l|}
\hline 3 agosto 00 & & & \\
& & & \\
& & & \\
\hline
\end{tabular}

\section{Ejercicio 38. Compra de bonos}

INVESTMENT SL adquiere, el 5 de abril de 2000, a través de la cuenta bancaria, Bonos del Tesoro por importe de 100.000,00 como inversión a tres años. Operación no sujeta a IVA.

5 abril 00

\section{Ejercicio 39. Devengo de intereses de bonos}

Siguiendo con el ejercicio anterior, un mes más tarde los bonos generan unos intereses a favor por importe de 1.200,00€, que se cobran en la cuenta bancaria. Operación no sujeta a IVA.

\begin{tabular}{|l|l|l|l|}
\hline 5 mayo 00 & & & \\
\hline & & & \\
& & & \\
\hline
\end{tabular}




\section{Ejercicio 40. Cobro al vencimiento de bonos}

Llegado el vencimiento, 5 abril 03, INVESTMENT SL cobra el valor de los bonos del ejercicio 38, y se ingresa el importe en la cuenta bancaria. Operación no sujeta a IVA.

\begin{tabular}{|l|l|l|l|}
\hline 5 abril 03 & & & \\
& & & \\
\hline
\end{tabular}

Ejercicio 41. Registro de concesión de crédito a corto plazo

El 1 de noviembre de 2000, TURRONES GARCÍA SA concede un crédito a un tercero por valor de 10.000,00 €. Este importe se paga en efectivo. El crédito debe devolverse en su totalidad a los 5 años. Operación no sujeta a IVA.

\begin{tabular}{|l|l|l|l|}
\hline 1 noviembre 00 & & & \\
& & & \\
\hline
\end{tabular}

\section{Ejercicio 42. Registro de intereses de créditos a favor}

Los intereses a favor de la empresa del crédito del ejercicio anterior, y que se cobran el 1 de diciembre de 2000, ascienden a 300,00€. Este importe que se recibe por transferencia bancaria. Operación no sujeta a IVA.

\begin{tabular}{|l|l|l|l|}
\hline 1 diciembre 00 & & & \\
\hline & & & \\
\hline & & & \\
\hline
\end{tabular}

\section{Ejercicio 43. Cobro de parte de créditos}

NOGOYA SL cobra, el 7 de julio de 2000, 3.000,00 como devolución de parte de un crédito a corto plazo concedido a un tercero con anterioridad. Operación no sujeta a IVA.

\begin{tabular}{|l|l|l|l|}
\hline 3 marzo 00 & & & \\
\hline
\end{tabular}

\section{Ejercicio 44. Venta de obligaciones del Estado}

INVESTMENT tiene invertidos 5.000,00 $€$ en obligaciones del Estado desde hace dos años y ha ido cobrando periódicamente los intereses correspondientes. El 4 de junio de 2000 decide vender dichos bonos en la Bolsa de Madrid, percibiendo $5.120,00 €$ por los mismos. El importe se cobra en la cuenta bancaria. Operación no sujeta a IVA.

\begin{tabular}{|l|l|l|l|}
\hline 4 junio 00 & & & \\
& & & \\
\end{tabular}




\section{Ejercicio 45. Registro de intereses de cuenta bancaria}

Según una comunicación de BANCAJA, recibida el 7 de junio de 2000, la cuenta corriente que mantiene la empresa VIAJES ORIENTALES SA ha devengado unos intereses a su favor de 100,00 € durante el segundo trimestre del año. Operación no sujeta a IVA.

\begin{tabular}{|l|l|l|l|}
\hline 3 marzo 00 & & & \\
& & & \\
\hline
\end{tabular}

\section{Ejercicio 46. Obtención de préstamos}

VITOLAS SA obtiene, el 1 de febrero de 2000, un préstamo de una entidad financiera por 200.000,00 € que ingresa en su cuenta corriente. El préstamo se devolverá en cuotas iguales durante 5 años. Operación no sujeta a IVA.

3 marzo 00

$\mid$

\begin{tabular}{|l|l|}
\hline & \\
\hline
\end{tabular}

\section{Ejercicio 47. Registro de devolución de principal de préstamos}

VIAJES ORIENTALES SA paga, el 2 de julio de 2000 y mediante cargo en la cuenta corriente, 5.000,00 € en concepto de devolución de parte del préstamo que obtuvo con anterioridad. Operación no sujeta a IVA.

\begin{tabular}{|l|l|l|l|}
\hline 3 marzo 00 & & & \\
\hline
\end{tabular}

\section{Ejercicio 48. Registro de intereses de préstamos}

Contabilice el devengo de los gastos por intereses del mes de mayo de un préstamo obtenido por la empresa NAGOYA SL por importe de 565,00€. Operación no sujeta a IVA.

\begin{tabular}{|l|l|l|l|}
\hline 3 marzo 00 & & & \\
& & & \\
\hline
\end{tabular}

\section{Ejercicio 49. Constitución de una empresa}

Un conjunto de inversores constituye, el 1 de septiembre de 2000, la empresa ALONDRA SL y para ello aportan en conjunto un capital de 100.000,00 €, importe que se deposita en una cuenta bancaria a nombre de la nueva empresa. Operación no sujeta a IVA.

\begin{tabular}{|l|l|l|l|}
\hline 3 marzo 00 & & & \\
& & & \\
\hline
\end{tabular}




\section{Ejercicio 50. Operaciones comerciales}

ULTRAMARINOS SA tiene a inicios de año 2000 mercaderías en almacén por valor de $230.000,00 €$. Durante el año realiza compras por importe de $2.450 .000,00 € \mathrm{y}$ ventas por 3.100.000,00. El inventario físico valorado al final del año asciende a $180.000,00 €$.

Se pide que contabilice las compras y ventas a crédito (IVA aplicable del 18\%), la regularización final de mercaderías y calcule el resultado comercial.

\begin{tabular}{|l|l|l|l|}
\hline 00 & & & \\
\hline 31 diciembre 00 & & & \\
\hline & & & \\
\hline $\begin{array}{l}\text { Resultado } \\
\text { comercial }=\end{array}$ & & & \\
\hline
\end{tabular}

\section{Ejercicio 51. Operaciones comerciales}

ZAPATERÍAS SA realiza las siguientes operaciones con sus mercancías durante 2000:

- Inicialmente tiene 100 uds. en almacén valoradas a $10 € /$ ud.

- Compra 1.000 uds. a $10 € /$ ud.

- Vende 900 uds. a un precio de venta de $15 € /$ ud.

Se pide que contabilice la compra y la venta a crédito (IVA aplicable 18\%), el asiento de regularización de mercaderías a final del año y calcule el margen comercial.

\begin{tabular}{|l|l|l|l|}
\hline 00 & & & \\
\hline & & & \\
\hline 31 diciembre 00 & & & \\
\hline & & & \\
\hline Resultado comercial $=$ & & \\
\hline
\end{tabular}




\section{Ejercicio 52. Inversiones en inmovilizado material}

La empresa MOBILIARIO URBANO SL, recién creada, adquiere el 1 de febrero de 2000, para iniciar su actividad (todas las operaciones están sujetas a un 18\% de IVA):

- Una nave para almacén y oficinas por importe de 400.000,00 €. Se paga la mitad al contado y el resto se pagará a los tres meses.

- Mobiliario diverso para equipar sus oficinas por 30.000,00 € que se pagan al contado.

- Dos camiones de reparto por un importe de 40.000,00 € cada uno, ambos se pagarán en seis meses.

Transcurrido un mes cree que las inversiones realizadas son excesivas por lo que vende uno de los camiones (se supondrá que no se ha depreciado durante el mes) por $30.000,00 €$, importe que cobrará en 6 meses.

Se pide que contabilice las operaciones anteriores.

\begin{tabular}{|l|l|l|l|}
\hline 1 febrero 00 & & & \\
\hline & & & \\
\hline 1 febrero 00 & & & \\
\hline 1 febrero 00 & & & \\
\hline 1 marzo 00 & & & \\
& & & \\
& & & \\
\hline
\end{tabular}

\section{Ejercicio 53. Inversiones en inversiones inmobiliarias}

ELECTRODOMÉSticos SL ha adquirido, el 24 de mayo de 2000, un local comercial céntrico por $300.000 €$, ascendiendo los tributos de transmisiones y otros gastos a $20.000,00 €$, importes que paga mediante transferencia bancaria. Desea destinar el local al alquiler para algún negocio.

El 1 de julio de 2000 alquila el local comercial a otra empresa pactando un alquiler mensual de 2.000,00 € que se paga en efectivo a los 5 días de terminado el mes. El 1 de agosto de 01 vende el local comercial por 240.000,00 € cobrando la mitad mediante transferencia bancaria y quedando el resto aplazado 4 meses.

Se pide que contabilice la compra del inmueble, el derecho alquiler el 31 de julio y el cobro del mismo y la venta en agosto de 01 . Las operaciones de compra-venta están sujetas a IVA del 18\% (excepto tributos y otros gastos de transmisión). 


\begin{tabular}{|l|l|l|l|}
\hline 24 mayo 00 & & & \\
\hline & & & \\
\hline 31 julio 00 & & & \\
\hline 5 agosto 00 & & & \\
\hline 1 agosto 01 & & & \\
& & & \\
\hline
\end{tabular}

\section{Ejercicio 54. Inversiones financieras. Acciones}

STOCKFUND, empresa de inversión, adquiere como inversión a corto plazo el 5 de enero de 2000 acciones de ORANGE SA por importe de 30.000,00 €.

$\mathrm{Al}$ año siguiente, el 5 de mayo, recibe dividendos de su inversión por importe de $1.500,00 €$. Quince días más tarde vende las acciones por 31.000,00€.

Se pide que contabilice las operaciones anteriores (operaciones no sujetas a IVA). Todos los pagos y cobros se realizan a través de la cuenta bancaria.

\begin{tabular}{|l|l|l|l|}
\hline 5 enero 00 & \multicolumn{2}{|l|}{} & \\
\hline Devengo y cobro de dividendos & & \\
\hline 5 mayo 01 & & & \\
\hline & & & \\
\hline Venta & & & \\
\hline 2 mayo 01 & & & \\
\hline
\end{tabular}

\section{Ejercicio 55. Inversiones financieras. Obligaciones y bonos}

El 1 de enero de 2000, STOCKFUND, empresa de inversión, adquiere como inversión a corto plazo 1.000 bonos del Bonos del Tesoro español con un valor de 1.000,00 € cada uno.

Estos bonos generan un interés del 6\% anual. Al final del mes de enero registra el derecho al cobro de los intereses correspondientes al mes y un día más tarde los cobra. El 3 de febrero vende los bonos en la bolsa a $990 € /$ bono. 
Se pide que contabilice las operaciones anteriores (operaciones no sujetas a IVA). Todos los pagos y cobros se realizan a través de la cuenta bancaria.

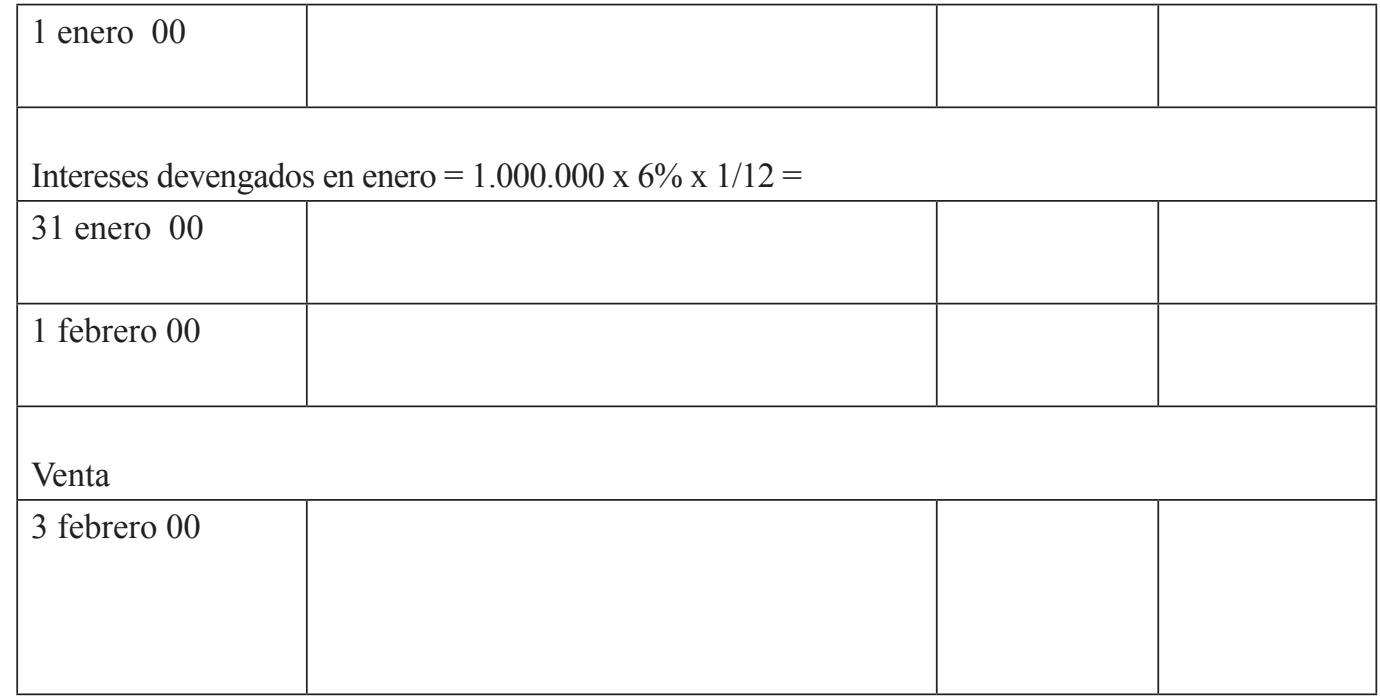

\section{Ejercicio 56. Financiación ajena. Préstamos}

El 1 de junio de 2000 CARREFOUR SA ha obtenido un préstamo del Banco de Santander por $400.000,00 €$ a un tipo de interés del $4 \%$ anual y que se devolverá según un calendario de pagos acordado que supone que $100.000,00 €$ son a corto plazo y el resto a largo plazo.

Cada mes va pagando los intereses y devuelve el 1 de septiembre 50.000,00€.

Se pide que contabilice la obtención del préstamo, el reconocimiento y pago de los intereses del mes de junio y la devolución parcial del 1 de septiembre. Todos los pagos y cobros se realizan a través de la cuenta bancaria. Las operaciones no están sujetas a IVA.

\begin{tabular}{|l|l|l|l|}
\hline 1 junio 2010 & \multicolumn{2}{|l|}{} & \\
& \multicolumn{2}{|l|}{} & \\
\hline Intereses devengados en enero $=$ & & \\
\hline 30 junio 00 & & & \\
\hline 30 junio 00 & & & \\
\hline Devolución del principal & & & \\
\hline 1 septiembre 00 & & & \\
\hline
\end{tabular}




\section{Ejercicio 57. Contabilización de extracto bancario}

A continuación figura un extracto bancario, analice las operaciones y muestre como podrían contabilizarse las operaciones hasta el 25 de marzo de 03 (omita la existencia de IVA).

\begin{tabular}{|c|c|c|c|c|c|}
\hline \multicolumn{2}{|c|}{$\begin{array}{l}\text { SUCURSAL } 4108 \\
\text { AVDA. DE GALICIA } 25 \\
33005 \text { OVIEDO }\end{array}$} & $\begin{array}{l}\text { EXTRACTO DE SU CUENTA } \\
\text { COOIGO CUENTA CLIENTE } \\
\text { TITULAR: OlaYa Robi BITO }\end{array}$ & 410842 & \multirow{2}{*}{\multicolumn{2}{|c|}{$\begin{array}{cr}\text { FECHA } & \text { 4.ABR.2003 } \\
\text { PAGINA } & 001 \\
\text { SALDO }\end{array}$}} \\
\hline FECHA & CONCEPTO & VALOR & IMPORTE & & \\
\hline $\begin{array}{l}15.03 .2003 \\
15.03 .2003 \\
19.03 .2003 \\
19.03 .2003 \\
19.03 .2003 \\
20.03 .2003 \\
21.03 .2003 \\
21.03 .2003 \\
23.03 .2003 \\
24.03 .2003 \\
25.03 .2003 \\
26.03 .2003 \\
26.03 .2003 \\
27.03 .2003 \\
27.03 .2003\end{array}$ & $\begin{array}{l}\text { SALDO ANTERIOR } \ldots \ldots \ldots \ldots \\
\text { CARGO COMPRA } \\
\text { REINTEGRO CAJERO AUTOHATICO } \\
\text { INGRESO EN EFECTIVO } \\
\text { CARGO POR COBRO DE SERVICIO } \\
\text { CARGO TRASPASO SALDO } \\
\text { PAGO CHEQUE COHPENSADO } 8575 \\
\text { CARGO COMPRA } \\
\text { INTERESES } \\
\text { CARGO COMPRA } \\
\text { RECIBO DE TELEFONO } \\
\text { CARGO COMPRA } \\
\text { CARGO COMPRA } \\
\text { INGRESO EN EFECTIVO } \\
\text { CARGO POR COBRO DE SERVICIO }\end{array}$ & \begin{tabular}{|}
3.03 .2003 \\
19.03 .2003 \\
19.03 .2003 \\
19.03 .2003 \\
20.03 .2003 \\
20.03 .2003 \\
21.03 .2003 \\
23.03 .2003 \\
24.03 .2003 \\
25.03 .2003 \\
26.03 .2003 \\
26.03 .2003 \\
28.03 .2003 \\
27.03 .2003
\end{tabular} & $\begin{array}{r}-3,17 \\
-150,00 \\
7.000,00 \\
-0,60 \\
-657,32 \\
-5.171,81 \\
-195,01 \\
-0,39 \\
-57,04 \\
-48,06 \\
-49,19 \\
-63,07 \\
6.000,00 \\
-0,60\end{array}$ & & $\begin{array}{l}1.228,33 \\
1.225,16 \\
1.075,16 \\
8.075,16 \\
8.074,56 \\
7.417,24 \\
2.245,43 \\
2.050,42 \\
2.050,03 \\
1.992,99 \\
1.944,93 \\
1.895,74 \\
1.832,67 \\
7.832,67 \\
7.832,07\end{array}$ \\
\hline & & & 000302 & 08.04 & 040052530 \\
\hline
\end{tabular}

\begin{tabular}{|l|l|l|l|}
\hline 15 marzo 03 & & & \\
\hline 19 marzo 03 & & & \\
\hline 19 marzo 03 & & & \\
\hline 19 marzo 03 & & & \\
\hline 21 marzo 03 & & & \\
\hline 21 marzo 03 & & & \\
\hline 21 marzo 03 & & & \\
\hline 23 marzo 03 & & & \\
\hline 24 marzo 03 & & & \\
\hline 25 marzo 03 & & & \\
\hline
\end{tabular}




\section{Casos}

Caso 1. Registro de transacciones y elaboración de cuentas anuales

Con el balance y la cuenta de pérdidas y ganancias de INDITEX incluidos en el caso 1 del tema 2 anterior:

a) Abra las cuentas representativas de la situación patrimonial correspondiente al último año de los incluidos en el balance de dicha empresa y registre el saldo inicial de las mismas.

b) Plantee al menos 10 transacciones detalladas que podría realizar dicha empresa (compras, ventas, prestación de servicios, gastos, cobros, pagos, obtención o devolución de préstamos, etc.).

c) Registre dichas operaciones en un diario y traspáselos a las cuentas abiertas con anterioridad.

d) Elabore un balance de comprobación de sumas y saldos tras las operaciones anteriores.

e) Elabore un balance y una cuenta de pérdidas y ganancias tras las operaciones anteriores.

\section{Caso 2. Registro de transacciones y elaboración de cuentas anuales}

a) Obtenga el balance de una empresa de su elección de entre las cotizadas en la Bolsa de Madrid de un sector no financiero. La información puede obtenerse en las página web de la Comisión Nacional del Mercado de Valores (http:lwww. cnmv.es) o en la base de datos SABI disponible en la biblioteca de la UJI.

b) Abra las cuentas representativas de la situación patrimonial correspondiente al último año de los incluidos en el balance de dicha empresa y registre el saldo inicial de las mismas.

c) Plantee al menos 10 transacciones detalladas que podría realizar dicha empresa (compras, ventas, prestación de servicios, gastos, cobros, pagos, obtención o devolución de préstamos, etc.).

d) Registre dichas operaciones en un diario y traspáselos a las cuentas abiertas con anterioridad.

e) Elabore un balance de comprobación de sumas y saldos tras las operaciones anteriores.

f) Elabore un balance y una cuenta de pérdidas y ganancias tras las operaciones anteriores.

\section{Caso 3. Trabajo con documentos reales}

Póngase en contacto con alguna empresa del entorno, familiares o amigos y consiga una muestra de al menos diez documentos reales, entre los que se incluirán al menos los siguientes:

- Una factura por compra de bienes.

- Una factura por venta de bienes o servicios prestados.

- Un recibo de electricidad.

- Un recibo de agua.

- Un extracto bancario con varias operaciones.

- Una nómina.

- Un documento de cotización a la Seguridad Social Tc1.

Analice los anteriores documentos y proceda a realizar los asientos a que daría lugar cada uno de ellos. 


\section{TEMA 5}

\section{El ciclo contable}

\section{INTRODUCCIÓN}

En este tema se muestra el procedimiento de registro contable básico de distintas transacciones empresariales, y estas se clasifican según su naturaleza. Así se distinguen transacciones de tipo comercial, compras y ventas, de otro tipo de ingresos y gastos. Asimismo se introduce la problemática del registro de operaciones de inversión y financiación.

\section{CONTENIDO}

5.1. Concepto de período y ciclo contable

5.2. Apertura de la contabilidad

5.3. Fase de registro de transacciones durante el ejercicio

5.4. Los ajustes de fin de período

5.5. Balance de comprobación final. Liquidación y cierre contable

5.6. Elaboración de cuentas anuales 


\subsection{Concepto de período y ciclo contable}

Como se deduce de su nombre, en España existe la obligación general de presentar las cuentas anuales por períodos de un año. Cada uno de estos períodos anuales se denomina ejercicio económico o período contable.

Para la gran mayoría de empresas el período contable coincide con el año natural, empezando el 1 de enero y terminando el 31 de diciembre. No obstante, en algunos sectores específicos el período contable empieza y termina en otras fechas.

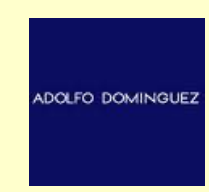

\section{Ejemplo 5.1. Períodos contables distintos del año natural}

Las empresas productoras o vendedoras de artículos con ciclos estacionales marcados y cuyo período alto de actividad coincide con el fin del año natural suelen tener ejercicios económicos con fechas de inicio y final distintas de dicho año natural. Por ejemplo, una empresa productora de turrón y otros productos navideños podría tener un período contable que se iniciase el 1 de marzo de cada año y terminar el 28 de febrero.

De esta forma los informes contables, elaborados con fecha 28 de febrero, recogerían todas las ventas, cobros, existencias de mercaderías y otros datos correspondientes a la campaña navideña cerrada. Otros ejemplos son: empresas de juguetes, productoras o exportadoras de productos agrícolas, empresas de auditoría, etc.

Por ejemplo, la fecha de cierre de las cuentas anuales de la empresa ADOLFO DOMINGUEZ es el 28 de febrero, que es cuando termina para este tipo de empresas la campaña de invierno o navidad (ver tema 2).

\section{Ciclo contable}

La necesidad de elaborar las cuentas anuales para cada ejercicio económico con una duración de un año se materializa, desde el punto de vista del registro contable, en la realización de un conjunto de operaciones que se repite en todos ellos y que dan lugar al denominado ciclo contable, cuyas fases se muestran en la siguiente ilustración.

FASE DEL CICLO CONTABLE

1 de enero

APERTURA DE LA CONTABILIDAD Asiento de apertura

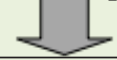

Del 1 de enero al 31 de diciembre TRANSACCIONES DEL PERÍODO

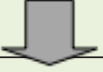

31 de diciembre AJUSTES DE FIN DE PERÍODO

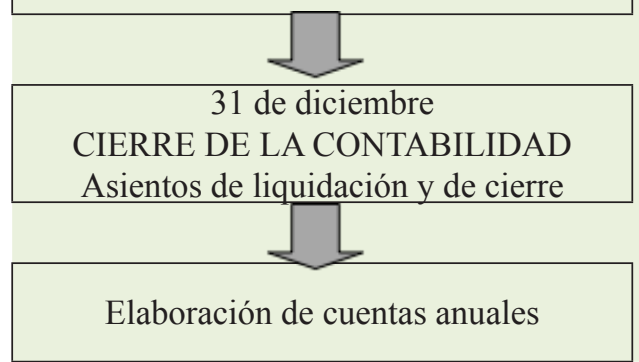

\section{OBJETO}

Abrir las cuentas con la situación inicial de la empresa.

Registro de todas las transacciones del período en el diario y las cuentas.

Registro de ajustes en elementos de las cuentas anuales para que estas puedan presentar la imagen fiel de la situación patrimonial y financiera y los resultados obtenidos.

Cierre de cuentas a final del período.

Elaboración de las cuentas anuales.

Ilustración 5.1. Las fases del ciclo contable para un período anual común 


\subsection{Apertura de la contabilidad}

La contabilidad se abre al inicio de cada ciclo contable, generalmente el 1 de enero de cada año, mediante el reconocimiento de la situación patrimonial y financiera inicial de la empresa, es decir, de sus activos, pasivos y patrimonio neto. Esta situación inicial no es otra que la situación patrimonial y financiera existente al final del ejercicio económico anterior.

Este reconocimiento se hace a través del denominado asiento de apertura, en el que se cargan todas las cuentas contables de activos, pasivos y patrimonio neto que a inicio del ejercicio deban presentar un saldo deudor y se abonan todas las cuentas activos, pasivos y patrimonio neto que deban presentar un saldo inicial acreedor.

Se trata de un asiento meramente técnico, puesto que no responde a ninguna variación patrimonial, es decir, no se ha producido ninguna operación o transacción que registrar. Su objetivo es dar de alta todas las cuentas representativas de elementos de las cuentas anuales con el saldo correspondiente al valor inicial de dichos elementos. Al mismo tiempo se genera el primer apunte en el diario, constituido por el propio asiento de apertura.

\begin{tabular}{|c|c|c|c|}
\hline \multirow{2}{*}{\multicolumn{4}{|c|}{$\begin{array}{l}\text { Ejemplo 5.2. Asiento de apertura } \\
\text { La empresa PROYECTOS SA, dedicada a prestar servicios profesior } \\
\text { ingeniería, presenta la siguiente situación financiera y patrimor } \\
\text { Proyectos SA } \\
\text { Balance a } 1 \text { de enero de } 2000\end{array}$}} \\
\hline & & & \\
\hline \multicolumn{2}{|l|}{ ACTIVO } & \multicolumn{2}{|c|}{ PATRIMONIO NETO Y PASIVO } \\
\hline Activo no corriente & $105.000,00$ & Patrimonio neto & $70.000,00$ \\
\hline \multirow{2}{*}{$\begin{array}{l}\text { Inmovilizado intangible } \\
203 \text { Patentes y marcas } \\
\text { Inmovilizado tangible } \\
210 \text { Terrenos } \\
211 \text { Construcciones } \\
216 \text { Mobiliario } \\
\text { Inversiones financieras a l.p. } \\
252 \text { Créditos a largo plazo }\end{array}$} & \multirow{2}{*}{$\begin{array}{r}\mathbf{1 0 . 0 0 0 , 0 0} \\
10.000,00 \\
\mathbf{9 0 . 0 0 0 , 0 0} \\
5.000 .00 \\
70.000,00 \\
15.000,00 \\
\mathbf{5 . 0 0 0 , 0 0} \\
5.000,00\end{array}$} & $\begin{array}{l}\text { Fondos propios } \\
\text { 100 Capital } \\
113 \text { Reservas } \\
129 \text { Pérdidas y ganancias }\end{array}$ & $\begin{array}{l}70.000 .00 \\
20.000,00 \\
40.000,00 \\
10.000,00\end{array}$ \\
\hline & & Pasivo no corriente & $30.000,00$ \\
\hline Activo corriente & $16.000,00$ & & \\
\hline \multirow[b]{3}{*}{$\begin{array}{l}\text { Existencias } \\
\quad 328 \text { Material de oficina } \\
\text { Deudores comerciales } \\
\quad 430 \text { Clientes } \\
\text { Inversiones financieras c.p. } \\
540 \text { Acciones a corto plazo } \\
\text { Periodificaciones corto plazo } \\
\text { Efectivo y medios líquidos } \\
570 \text { Caja } \\
572 \text { Bancos c/c }\end{array}$} & \multirow[b]{3}{*}{$\begin{array}{r}\mathbf{1 . 0 0 0 , 0 0} \\
1.000,00 \\
\mathbf{8 . 0 0 0 , 0 0} \\
8.000,00 \\
\mathbf{3 . 0 0 0 , 0 0} \\
3.000,00 \\
\mathbf{0 , 0 0} \\
\mathbf{4 . 0 0 0 , 0 0} \\
500,00 \\
3.500,00\end{array}$} & $\begin{array}{l}\text { Deudas a largo plazo } \\
170 \text { Préstamos a largo plazo }\end{array}$ & $\begin{array}{l}\mathbf{3 0 . 0 0 0 , 0 0} \\
30.000,00\end{array}$ \\
\hline & & Pasivo corriente & $21.000,00$ \\
\hline & & $\begin{array}{l}\text { Deudas a corto plazo } \\
\quad 520 \text { Préstamos a corto plazo } \\
\text { Acreedores a corto plazo } \\
\quad 400 \text { Proveedores } \\
\quad 475 \text { H. P. Acreedora } \\
\text { Periodificaciones corto plazo }\end{array}$ & $\begin{array}{r}\mathbf{1 3 . 0 0 0 , 0 0} \\
13.000,00 \\
\mathbf{8 . 0 0 0 , 0 0} \\
6.000,00 \\
2.000,00 \\
\mathbf{0 , 0 0}\end{array}$ \\
\hline TOTAL & $121.000,00$ & TOTAL & $121.000,00$ \\
\hline
\end{tabular}


El asiento de apertura a contabilizar sería:

\begin{tabular}{|c|c|c|c|c|}
\hline Asiento & Fecha & Cuentas & Debe & Haber \\
\hline 1 & 01/010/00 & $\begin{array}{l}\text { 203. Patentes y marcas (A) } \\
\text { 210. Terrenos (A) } \\
\text { 211. Construcciones (A) } \\
\text { 216. Mobiliario (A) } \\
\text { 542. Créditos a largo plazo (A) } \\
\text { 328. Material de oficina (A) } \\
\text { 430. Clientes (A) } \\
\text { 540. Acciones a corto plazo (A) } \\
\text { 570. Caja (A) } \\
\text { 572. Bancos (A) } \\
\text { 100. Capital social (N) } \\
\text { 113. Reservas (N) } \\
\text { 129. Pérdidas y ganancias (N) } \\
\text { 170. Préstamos a 1.p. (P) } \\
\text { 520. Préstamos a c.p. (P) } \\
\text { 400. Proveedores (P) } \\
\text { 475. Hacienda Pca. Acreedora (P) }\end{array}$ & $\begin{array}{r}10.000,00 \\
5.000,00 \\
70.000,00 \\
15.000,00 \\
5.000,00 \\
1.000,00 \\
8.000,00 \\
3.000,00 \\
500,00 \\
3.500,00\end{array}$ & $\begin{array}{r}20.000,00 \\
40.000,00 \\
10.000,00 \\
30.000,00 \\
13.000,00 \\
6.000,00 \\
2.000,00\end{array}$ \\
\hline
\end{tabular}

Este asiento, como todos, deberá traspasarse a las cuentas de mayor de los elementos correspondientes.

\subsection{Fase de registro de transacciones durante el ejercicio}

Una vez realizado el asiento de apertura todas las cuentas muestran un saldo inicial que representa el valor del elemento representado (activo, pasivo y patrimonio neto) a 1 de enero del ejercicio económico que empieza.

En esta fase se registran, a lo largo del año, las distintas transacciones que va realizando la empresa, de acuerdo al procedimiento visto en el tema anterior. Es decir, cada transacción será objeto de análisis y registro en el diario y las cuentas.

Periódicamente durante esta fase, al menos cada trimestre, también se prepararán balances de comprobación de sumas y saldos.

\footnotetext{
Ejemplo 5.3. Transacciones del ejercicio

Las transacciones que ha realizado la empresa PROYECTOS SA durante el año 2000 han sido las que se indican a continuación. Para simplificar se indicará una sola operación por tipo sin indicar la fecha de la misma. Además se inician la operaciones con el $\mathrm{n}^{\circ} 2$ considerando que la primera es el asiento de apertura:

1. Ha cobrado a través de la cuenta bancaria por servicios de ingeniería un importe de $250.000,00 €$ más IVA $18 \%$.

2. Ha cobrado en efectivo $10.000 €$ por servicios de ingeniería mas IVA $18 \%$.

3. Ha prestado servicios de ingeniería por $20.000,00 €$ que están pendientes de cobro. IVA $18 \%$.

4. Se han devengado y pagado por sueldos y salarios de su personal un importe de $180.000,00 €$, todos a través de la cuenta corriente bancaria.

5. Los sueldos y salarios devengados y pendientes de pago a final de año ascienden a 10.000,00€.

6. Ha pagado en efectivo tasas y tributos municipales por importe de $1.000,00 €$.

7. Ha decidido traspasar el saldo de la cuenta de pérdidas y ganancias (resultado del año anterior) como reservas voluntarias.
} 
8. Ha vendido parte de las acciones a corto plazo que aparecen en el balance. El precio de venta es de 1.500,00 €, mientras que el valor contable de las acciones vendidas es de 1.000,00€. El cobro se ha realizado a través de la cuenta bancaria.

9. Ha pagado en efectivo por arrendamientos de locales comerciales $3.000,00 €$ durante el año más IVA $18 \%$ deducible.

10. Ha pagado en efectivo facturas de electricidad por un importe de $3.000,00 €$ más IVA $18 \%$ deducible.

11. Ha registrado gastos por intereses del préstamo a largo plazo que aparece en el Balance inicial por importe de $1.600,00 €$, estos intereses se cargaron en la cuenta bancaria

12. Ha concedido varios créditos a corto plazo a sus empleados por importe de $8.000,00 €$, el importe se satisfizo por transferencia bancaria.

13. Ha cobrado intereses de esos créditos en efectivo por importe de 100,00€.

14. Ha pagado a través de la cuenta corriente bancaria una campaña publicitaria de coste $6.000,00 €$ más IVA $18 \%$.

15. Devuelve, con cargo a la cuenta bancaria, 5.000,00 € del préstamo a corto plazo que figura en el balance inicial.

El registro de estas operaciones durante el ejercicio será:

\begin{tabular}{|c|c|c|c|c|}
\hline Asiento & Fecha & Cuentas & Debe & Haber \\
\hline 2 & $\mathrm{xx} / \mathrm{xx} / 00$ & $\begin{array}{l}\text { 572. Bancos c/c (A) } \\
\text { 705. Prestación de servicios (I) } \\
\text { 477. H. P. IVA repercutido (P) }\end{array}$ & $295.000,00$ & $\begin{array}{r}250.000,00 \\
45.000,00 \\
\end{array}$ \\
\hline 3 & $\mathrm{xx} / \mathrm{xx} / 00$ & $\begin{array}{l}\text { 570. Caja (A) } \\
\text { 705. Prestación de servicios (I) } \\
\text { 477. H. P. IVA repercutido (P) }\end{array}$ & $11.800,00$ & $\begin{array}{r}10.000,00 \\
1.800,00\end{array}$ \\
\hline 4 & $\mathrm{xx} / \mathrm{xx} / 00$ & $\begin{array}{l}\text { 430. Clientes (A) } \\
\text { 705. Prestación de servicios (I) } \\
\text { 477. H. P. IVA repercutido (P) }\end{array}$ & $23.600,00$ & $\begin{array}{r}20.000,00 \\
3.600,00\end{array}$ \\
\hline 5 & $\mathrm{xx} / \mathrm{xx} / 00$ & $\begin{array}{l}\text { 640. Sueldos y salarios }(\mathrm{G}) \\
572 . \text { Bancos } \mathrm{c} / \mathrm{c}(\mathrm{A})\end{array}$ & $180.000,00$ & $180.000,00$ \\
\hline 6 & $\mathrm{xx} / \mathrm{xx} / 00$ & $\begin{array}{l}\text { 640. Sueldos y salarios }(\mathrm{G}) \\
\text { 465. Remuneraciones ptes. pago }(\mathrm{P})\end{array}$ & $10.000,00$ & $10.000,00$ \\
\hline 7 & $\mathrm{xx} / \mathrm{xx} / 00$ & $\begin{array}{l}\text { 631. Tributos }(\mathrm{G}) \\
\text { 570. Caja (A) }\end{array}$ & $1.000,00$ & $1.000,00$ \\
\hline 8 & $\mathrm{xx} / \mathrm{xx} / 00$ & $\begin{array}{c}\text { 129. Pérdidas y ganancias }(\mathrm{N}) \\
\text { 113. Reservas }(\mathrm{N})\end{array}$ & $10.000,00$ & $10.000,00$ \\
\hline 9 & $\mathrm{xx} / \mathrm{xx} / 00$ & $\begin{array}{l}\text { 572. Bancos c/c (A) } \\
\text { 540. Acciones a corto plazo (A) } \\
\text { 766. Beneficios en valores negociables (I) }\end{array}$ & $1.500,00$ & $\begin{array}{r}1.000 .00 \\
500,00\end{array}$ \\
\hline 10 & $\mathrm{xx} / \mathrm{xx} / 00$ & $\begin{array}{l}\text { 621. Arrendamientos (G) } \\
\text { 472. H. P. IVA soportado (A) } \\
\text { 570. Caja (A) }\end{array}$ & $\begin{array}{r}3.000,00 \\
540 ., 00\end{array}$ & $3.540,00$ \\
\hline 11 & $\mathrm{xx} / \mathrm{xx} / 00$ & $\begin{array}{l}\text { 628. Suministros }(\mathrm{G}) \\
\text { 472. H. P. IVA soportado (A) } \\
\text { 570. Caja (A) }\end{array}$ & $\begin{array}{r}3.000,00 \\
540.00\end{array}$ & $3.540,00$ \\
\hline 12 & $\mathrm{xx} / \mathrm{xx} / 00$ & $\begin{array}{l}\text { 662. Gastos por intereses de deudas }(\mathrm{G}) \\
572 . \text { Bancos } \mathrm{c} / \mathrm{c}(\mathrm{A})\end{array}$ & $1.600,00$ & $1.600,00$ \\
\hline 13 & $\mathrm{xx} / \mathrm{xx} / 00$ & $\begin{array}{l}\text { 542. Créditos a corto plazo (A). } \\
\text { 572. Bancos c/c (A) }\end{array}$ & $8.000,00$ & $8.000,00$ \\
\hline 14 & $\mathrm{xx} / \mathrm{xx} / 00$ & $\begin{array}{l}\text { 570. Caja (A) } \\
\text { 762. Ingresos por intereses cdtos. (I) }\end{array}$ & 100,00 & 100,00 \\
\hline 15 & $\mathrm{xx} / \mathrm{xx} / 00$ & $\begin{array}{l}\text { 627. Publicidad, propaganda y RRPP (G) } \\
\text { 472. H. P. IVA soportado (A) } \\
\text { 572. Bancos c/c (A) }\end{array}$ & $\begin{array}{l}6.000,00 \\
1.080,00\end{array}$ & $7.080,00$ \\
\hline 16 & $\mathrm{xx} / \mathrm{xx} / 00$ & $\begin{array}{c}520 \text { Préstamos a corto plazo. (P) } \\
572 . \text { Bancos c/c (A) }\end{array}$ & $5.000,00$ & $5.000,00$ \\
\hline
\end{tabular}




\subsection{Los ajustes de fin de período}

Una vez contabilizadas todas las transacciones del ejercicio, y previamente a la elaboración de las cuentas anuales, debe procederse a realizar determinados ajustes en la contabilidad como consecuencia de la aplicación de los principios contables, los criterios de reconocimiento y valoración y las normas de presentación de cuentas anuales, incluidos en la normativa contable.

El objetivo de los ajustes a realizar es que la cuentas anuales presenten la «imagen fiel de la situación patrimonial y financiera y de los resultados obtenidos» del período a que hacen referencia.

Los ajustes adicionales a realizar dependerán de:

- Las normas de reconocimiento, valoración y presentación específicas aplicables a los distintos activos, pasivos, elementos de patrimonio neto, ingresos y gastos.

- La práctica concreta de la empresa en la contabilización diaria de las transacciones realizadas con dichos elementos que puede hacer que los valores registrados en los elementos de las cuentas anuales precisen de más o menos ajustes en aplicación de las normas anteriores.

Cabe decir que posiblemente sea necesario realizar ajustes en prácticamente todos los elementos de las cuentas anuales: mercaderías, instrumentos financieros, partidas en moneda extranjera, activos y pasivos por impuestos y otros muchos.

Finalmente debe señalarse que, desde el punto de vista técnico, es bastante frecuente que las empresas realicen un balance de comprobación de sumas y saldos previo a la fase de ajustes y uno posterior la misma.

\section{Tipos de ajustes y necesidad de realización}

Este tema pretende ofrecer una visión general del ciclo contable y, por lo tanto, no recoge exhaustivamente todas las situaciones que pueden obligar a una empresa a realizar un ajuste contable de fin de ejercicio en alguno de los elementos de las cuentas anuales.

Hasta el momento se han estudiado dos ajustes:

- La liquidación de IVA que las empresas realizan mensual o trimestralmente, y que obligará a una liquidación al final del año por el último mes o trimestre (ver apartado 4.2 del tema 4).

- La necesidad de ajustar la cuenta de mercaderías al valor de las existencias finales, mediante los asientos de «variación de existencias» cuando el procedimiento de contabilización utilizado era el de «desdoblamiento incompleto» (ver apartado 4.3 del tema 4). 
A continuación se mostrarán los siguientes ejemplos de ajustes y se justificará su necesidad:

a) Ajustes por aplicación del principio de devengo.

b) Ajustes por depreciaciones del inmovilizado intangible, material e inversiones inmobiliarias.

c) Ajustes por deterioro de valor de activos.

d) El impuesto de sociedades.

Otros ajustes, que son objeto de estudio en cursos más avanzados de contabilidad, serían:

- Ajustes del valor de activos y pasivos financieros a valor razonable.

- Liquidaciones de impuestos (pagos a cuenta, retenciones IRPF y otros).

- Ajustes por aplicación del criterio de valor razonable con variaciones imputadas a patrimonio neto.

- Reconocimiento de trabajos realizados para el inmovilizado, incluyendo activación de gastos financieros y de otro tipo.

- Reclasificaciones temporales de créditos y débitos desde largo a corto plazo.

- Pérdidas irreversibles de activos.

- Reconocimiento de gastos futuros inciertos (provisiones) y ajustes de los mismos por actualización financiera y por nuevas estimaciones.

- Transferencias a resultados de ajustes de valoración de patrimonio neto.

- Trasferencias a resultados de subvenciones de capital.

- Contabilización del efecto impositivo de las distintas transacciones.

a) Ajustes por aplicación del principio de devengo

El reconocimiento contable de gastos e ingresos se basa, entre otros, en el principio del devengo, el cual señala que la imputación de gastos e ingresos debe hacerse en función de la corriente real (intercambio o prestación) de bienes y servicios que los mismos representen y con independencia del momento en que se produzca la corriente monetaria o financiera (cobro o pago) derivada de ellos.

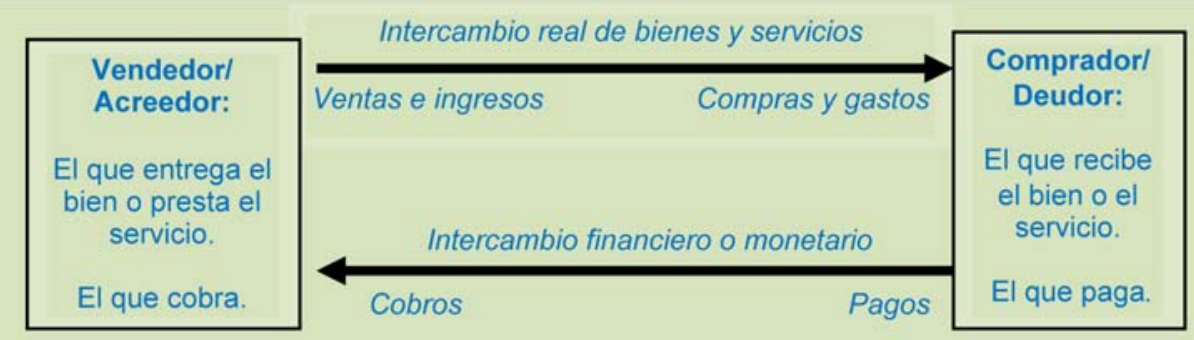

Este principio implica que: Ingresos $\neq$ cobros y gastos $\neq$ pagos.

Ilustración 5.2. Intercambios de bienes o servicios y financieros o monetarios 
Este principio contable supone que los intercambios económicos y los intercambios financieros son de naturaleza distinta y deben registrarse cada uno de ellos cuando se produzcan y con independencia de que el otro se dé simultáneamente o no (el intercambio monetario puede darse antes o después del intercambio de bienes o servicios).

Así, los conceptos de ingreso y cobro y de gasto y pago no son equivalentes.

\section{a.1) Ajustes por gastos e ingresos devengados y no registrados}

Es práctica habitual en las empresas proceder al registro contable de ingresos y gastos cuando tienen a su disposición los documentos justificativos, facturas u otros, y en ocasiones cuando se producen los cobros/pagos.

Esta forma de proceder es correcta siempre y cuando no deba procederse a la elaboración de las cuentas anuales, puesto que en ese momento deben estar registrados todos los ingresos y gastos del período con independencia de si se dispone de justificación documental o si se ha producido el cobro o pago. En la ilustración siguiente se explican algunos casos habituales de este tipo de circunstancias.

A finales de ejercicio, 31 de diciembre, puede quedar pendiente de pago la nómina del mes, o el recibo de alquiler del local comercial, o una compra de la que no se tiene la factura, o cualquier otro gasto.

Muchas deudas y créditos financieros devengan intereses a favor del prestatario/inversor por el mero paso del tiempo. Estos intereses de reintegran en cuotas con unas fechas de vencimiento establecidas y periódicas (que también suelen incluir la devolución de parte del capital prestado), por ejemplo a través de pagos mensuales.

La práctica de las empresas en el registro contable de estas operaciones es contabilizar los pagos/cobros mensuales, y los gastos/ingresos por intereses correspondientes, en las fechas de vencimiento cuando se realiza el pago/cobro que es cuando se dispone del documento justificativo correspondiente.

Por lo tanto, a 31 de diciembre y si una empresa tiene activos y pasivos financieros que devenguen intereses, existirá un valor de intereses devengados que deberán pagarse/cobrarse al vencimiento de la próxima cuota y que corresponden al ejercicio contable que va a cerrarse. En concreto serán los intereses devengados desde la fecha de pago de la última cuota de intereses hasta el 31 de diciembre.

En todos estos casos uno de los ajustes a realizar a fin de ejercicio será reconocer, de la forma habitual, los gastos que representan dichas operaciones. Lo mismo ocurriría en el caso de ingresos devengados a 31 de diciembre y no registrados todavía.

Ilustración 5.3. Gastos e ingresos devengados y no registrados

El registro de gastos e ingresos devengados y no registrados, se realiza de la forma habitual en las cuentas que proceda. 
Ejemplo 5.4. Registro del intereses devengados y no vencidos de préstamos

Siguiendo con el ejemplo, supóngase que desde la última fecha de pago (20 de noviembre de 2000) y hasta el 31/12/00 el préstamo a largo plazo de la empresa PROYECTOS SA ha devengado unos intereses de 200,00 € y que no se pagarán hasta el próximo vencimiento ( 20 de febrero de 01). Durante el año la empresa ha ido reconociendo los gastos correspondientes por intereses en las fechas de pago (ver ejemplo 5.3 operación 12).

\begin{tabular}{|l|l|l|l|l|}
\hline Asiento & Fecha & Cuentas & Debe & Haber \\
\hline 17 & $31 / 12 / 00$ & $\begin{array}{l}\text { 662. Gastos por intereses de deudas (G) } \\
\text { 527. Intereses a pagar a c.p. (P) }\end{array}$ & 200,00 & 200,00 \\
\hline
\end{tabular}

\section{a.2) Ajustes por gastos e ingresos registrados y no devengados (ajustes por periodificación)}

En ocasiones, a fines de ejercicio, las empresas han registrado facturas que corresponden a servicios o actividades parcialmente pendientes de realizar $\mathrm{y}$, por lo tanto, parte de los gastos e ingresos registrados no se han devengado todavía.

En estos casos, debe realizarse un ajuste de fin de ejercicio eliminando los gastos e ingresos que se han registrado y reconociendo:

- En el caso de un gasto registrado y no devengado se reconoce un activo, por el valor de los servicios pendientes de recibir.

- En el caso de un ingreso registrado y no devengado se reconoce un pasivo, por el valor de los servicios pendientes de entregar o prestar.

Estos ajustes se denominan ajustes por periodificación.

\begin{tabular}{|l|l|}
\hline \multicolumn{1}{|c|}{ Activos por gastos anticipados } & Pasivos por ingresos anticipados \\
\hline 480. Gastos anticipados & 485. Ingresos anticipados \\
567. Intereses pagados por anticipado & 568. Intereses cobrados por anticipado \\
\hline \multicolumn{2}{|c|}{ Estas cuentas figuran en el activo corriente y pasivo corriente del balance en un apartado } \\
separado denominado «Periodificaciones a corto plazo».
\end{tabular}

Ilustración 5.4. Cuentas de ajustes por periodificación

\section{Ejemplo 5.5. Registro de gastos de publicidad anticipados}

Siguiendo con el ejemplo, supóngase que los gastos de publicidad por importe de $6.000,00 €$ que se indican en el punto 15 corresponden a una campaña publicitaria que se desarrollará uniformemente desde el 1 de diciembre de 2000 al 15 de enero de 2001.

En este caso una tercera parte de los gastos de publicidad no se devengan durante 2000 y hay que proceder al ajuste siguiente:

\begin{tabular}{|c|c|c|c|c|}
\hline Asiento & Fecha & Cuentas & Debe & Haber \\
\hline $\begin{array}{l}18 \\
31 / 12 / 00\end{array}$ & & $\begin{array}{l}\text { 480. Gastos anticipados (A) } \\
\text { 627. Publicidad, propaganda y RRPP (G) }\end{array}$ & $2.000,00$ & $2.000,00$ \\
\hline
\end{tabular}


b) Ajustes por depreciaciones de inmovilizado intangible, material e inversiones inmobiliarias

La mayoría de los inmovilizados intangibles, los inmovilizados materiales y las inversiones inmobiliarias sufren depreciaciones o pérdidas de valor de carácter previsible, pero inevitable y además irreversible (es decir, no recuperable). Estas depreciaciones se deben a la utilización del bien en la actividad de la empresa o simplemente al paso del tiempo y deben ser reconocidas (registradas o contabilizadas) como un gasto más de la explotación conforme se va produciendo. Evidentemente, si un bien no se deprecia no cabe registrar gasto alguno, como ocurre en el caso de los terrenos.

El reconocimiento contable de dichas depreciaciones recibe el nombre de «amortizaciones», y se dice que los bienes del inmovilizado intangible y material son objeto de amortización anual. También es común referirse a la «dotación anual a las amortizaciones» o al hecho de que un inmovilizado está parcial o totalmente amortizado.

La depreciación de valor del inmovilizado no se deduce o resta de la propia cuenta de este, sino que se utiliza una cuenta compensatoria que recibe la denominación de «amortización acumulada». De esta forma, en el mayor se mantienen dos cuentas:

- Una cuenta donde aparece registrado el inmovilizado por el valor al cual fue reconocido en el momento de su adquisición.

- Otra donde se recoge el importe acumulado de la amortización desde dicho momento.

\begin{tabular}{|c|c|}
\hline \multicolumn{1}{|c|}{ Gastos } & Cuentas compensatorias de activo \\
\hline 68. DOTACIONES PARA AMORTIZA- & 28. AMORTIZACIÓN ACUMULADA DEL \\
CIONES & INMOVILIZADO \\
680/681/682. Amortización del inmo- & 280/281/282. Amortización acumulada del \\
vilizado intangible / material / & inmovilizado intangible / material / \\
inversiones inmobiliarias & inversiones inmobiliarias \\
\hline
\end{tabular}

Ilustración 5.5. Cuentas de amortizaciones

El procedimiento más habitual para determinar el importe de la amortización anual de un bien (depreciación del año) es realizar estimaciones sobre la vida útil del mismo y suponiendo que se deprecia de forma uniforme a lo largo del tiempo (todos los años en la misma cuantía), siendo que al final de su vida útil no tendrá valor alguno.

Así, dado un inmovilizado de Valor inicial $=\mathrm{V}_{0} \mathrm{y}$ «n» años de vida útil, la amortización anual a reconocer como gasto a lo largo de dicha vida útil según este método es de: $A=V_{0} / n$

\section{Presentación en balance}

Las cuentas de amortización acumulada se presentan en el activo del balance restando del valor de los inmovilizados a los que hacen referencia, de forma que estos aparecen por su valor a la fecha del balance. Para expresar este hecho se utilizará el símbolo (-a) para indicar que la cuenta se sitúa en el activo pero restando.

Ilustración 5.6. Determinación y registro de amortizaciones de inmovilizado 


\section{Ejemplo 5.6. Amortizaciones del inmovilizado inmaterial y material}

Siguiendo con el ejemplo, se sabe que el inmovilizado de la empresa PROYECTOS SA se adquirió en su totalidad a finales del anterior, por lo que todavía no han sido objeto de amortización y los valores en balance reflejan su valor inicial.

Por tanto, la amortización a practicar durante 2000 será:

- Patentes y marcas, Valor inicial $15.000 €$, vida útil $=20$ años.

- Amortización anual $=15.000 / 20=750 €$

- Terrenos. No se amortizan.

- Construcciones, valor inicial $70.000 €$, vida útil $=70$ años.

- Amortización anual $=70.000 / 70=1.000 €$

- Mobiliario, valor inicial $15.000 €$, vida útil $=10$ años.

- Amortización anual 15.000/10 = $1.500 €$

El registro de las amortizaciones del año 2000 sería:

\begin{tabular}{|c|c|c|r|r|}
\hline Asiento & Fecha & \multicolumn{1}{|c|}{ Cuentas } & Debe & Haber \\
\hline 19 & $31 / 12 / 00$ & 680. Amortización de patentes y marcas (G) & 750,00 & \\
& & 681. Amortización de construcciones (G) & $1.000,00$ & \\
& & 681. Amortización de mobiliario (G) & $1.500,00$ & \\
& & 280. Amort. acumulada patentes y marcas & & 750,00 \\
& & $(-\mathrm{A})$ & & $1.000,00$ \\
& & 281. Amort. acumulada de construcciones & & $1.500,00$ \\
& & $(-\mathrm{A})$ & & \\
& & 281. Amortiz. acumulada de mobiliario & & \\
& & $(-\mathrm{A})$ & & \\
& & & &
\end{tabular}

c) Ajustes por deterioros de valor de activos

Además de la depreciación sistemática del inmovilizado indicada en epígrafe $b$ ) anterior, el valor de los activos de una empresa, inmovilizado u otros corrientes o no corrientes, puede disminuir esporádicamente por diversas razones.

Si la disminución de valor es permanente o irreversible debe darse de baja el activo registrando una pérdida, y si es reversible o recuperable surge lo que se denomina un «deterioro de valor». Los deterioros de valor deben reconocerse contablemente como un gasto por aplicación del principio de prudencia (que se estudiará en el tema 7).

Supóngase que la empresa constructora e inmobiliaria PROMOCIONES INMOBILIARIAS SA (PROMISA) posee un terreno cuyo valor contable es de $100.000 €$ y que dicho terreno es objeto de recalificación urbanística, por parte del Ayuntamiento, por lo que se disminuye el coeficiente de edificabilidad ( $\mathrm{m}^{2}$ que pueden edificarse por cada $\mathrm{m}^{2}$ de superficie). La decisión del Ayuntamiento no es todavía firme pero si se produjese la recalificación su valor sería de $75.000 €$.

En este caso existe un deterioro de $25.000 €$, importe que deberá considerarse gasto del período.

Ilustración 5.6. Existencia de deterioro en terrenos 
La empresa EL CORTE INGLÉS SA al final de la campaña navideña mantiene juguetes y otras mercancías relacionas con la navidad cuyo coste ascendió a $25.000 €$. En opinión de la Gerencia, dichos productos no se podrán vender si no se rebaja significativamente su precio de venta por lo que el valor de los mismos se estima en $15.000 €$.

En este caso existe un deterioro en el valor de las mercancías por importe de $10.000 €$ que deberá registrarse como gasto por deterioro.

Ilustración 5.7. Existencia de deterioro en mercaderías

En los registros del restaurante LA PAELLA aparece como cliente D. Luís García para el cual sirvió su banquete de boda y que le adeuda $5.000 €$. El cliente ha comunicado su intención de no pagar dicho importe debido al descontento que le produjo el servicio durante el banquete.

El restaurante debe evaluar el riesgo de incobrabilidad del importe. Quizá pueda negociar con el cliente y pueda recuperar una parte o quizá deba recurrir a presentar una demanda ante la justicia (pudiendo recuperar todo, parte o nada).

En todo caso, el riesgo de incobrabilidad debe considerarse como un deterioro de valor del activo y debe reconocerse un gasto por deterioro de $5.000 €$.

Ilustración 5.8. Existencia de deterioro en clientes

Habitualmente, la comprobación de existencia de deterioro en los activos se realiza al final del ejercicio, por lo que el registro contable de deterioros suele formar parte de los ajustes de fin de ejercicio, si bien podrían hacerse en cualquier momento a lo largo del período contable.

Los ajustes por deterioro, sea cual sea el activo afectado, tienen dos consecuencias generales:

1. El reconocimiento de un gasto del período por la cuantía del deterioro del activo que se trate, por lo que resultará afectada la cuenta de pérdidas y ganancias (en su caso podría haber una reversión de un deterioro anterior de un activo, lo cual supondría un ingreso).

2. El ajuste del valor contable del activo, lo cual repercutirá en la cuantía mostrada en el balance sobre el mismo.

El valor deteriorado no se deduce o resta de la propia cuenta del activo, sino que se utiliza una cuenta compensatoria que recibe la denominación de «deterioro de valor de...». De esta forma, en el mayor se mantienen dos cuentas:

- Una cuenta donde aparece registrado el activo por el valor al cual fue reconocido en el momento de su adquisición

- Otra donde se recoge el importe del deterioro registrado.

Con posterioridad es posible que se recupere la pérdida de valor del activo, en cuyo caso debe eliminarse la cuenta que registra el deterioro del activo y reconocer un ingreso por «reversión del deterioro». 


\begin{tabular}{|c|l|}
\hline $\begin{array}{c}\text { Cuentas de } \\
\text { deterioro }\end{array}$ & $\begin{array}{l}\text { 290/291/292. Deterioro de valor del inmovilizado intangible / material / inver- } \\
\text { siones inmobiliarias. } \\
\text { 297/298. Deterioro de valor de valores de deuda a largo plazo / de créditos largo } \\
\text { plazo. } \\
\text { 390/392. Deterioro de valor de existencias / de otros aprovisionamientos. } \\
\text { 490. Deterioro de valor de créditos comerciales. } \\
\text { 597/598. Deterioro de valor de vRD corto plazo / de créditos corto plazo. }\end{array}$ \\
\hline $\begin{array}{c}\text { Reconoci- } \\
\text { miento del } \\
\text { deterioro }\end{array}$ & $\begin{array}{l}\text { 69. PÉRDIDAS POR DETERIODO } \\
\text { 690/691/692. Pérdidas por deterioro del inmovilizado intangible, material o inver- } \\
\text { siones inmobiliarias. } \\
\text { 693. Pérdidas por deterioro de existencias. } \\
\text { 694. Pérdidas por deterioro de créditos comerciales. } \\
\text { 696/698. Pérdidas por deterioro de participaciones y valores representativos de } \\
\text { deuda a largo / a corto plazo. } \\
\text { 697/699. Pérdidas por deterioro de créditos a largo plazo / corto plazo. }\end{array}$ \\
\hline $\begin{array}{l}\text { Reversión } \\
\text { del deterioro }\end{array}$ & $\begin{array}{l}\text { 79. EXCESOS Y APLICACIONES DE PERDIDAS POR DETERIORO } \\
\text { 790/791/792. Reversión del deterioro del inmovilizado intangible, } \\
\text { material o inversiones inmobiliarias. } \\
793 . \text { Reversión del deterioro de existencias. } \\
794 . \text { Reversión del deterioro de créditos comerciales. } \\
\text { 796/798. Reversión del deterioro de participaciones y valores representativos de } \\
\text { deuda largo / corto plazo. } \\
\text { 797/799. Reversión del deterioro de créditos a largo plazo /corto plazo. }\end{array}$ \\
\hline $\begin{array}{l}\text { Presentación en balance } \\
\text { Las cuentas de deterioro se presentan en el activo del balance restando del valor de los activos a } \\
\text { los que hacen referencia, de forma que estos aparecen por su valor a la fecha del balance. Para } \\
\text { expresar este hecho se utilizará el símbolo (-A) para significar que la cuenta se sitúa en el activo } \\
\text { pero restando. }\end{array}$ \\
\hline
\end{tabular}

Ilustración 5.9. Cuentas de deterioro de activos

\section{Ejemplo 5.7. Deterioro de valor de un cliente}

Siguiendo con el ejemplo, se estima que existe un riesgo de incobrabilidad de un cliente que adeuda a la empresa $1.000 €$. La empresa considera dicho riesgo como un deterioro del valor del cliente.

El registro del deterioro sería:

\begin{tabular}{|c|c|c|c|c|}
\hline Asiento & Fecha & \multicolumn{1}{c|}{ Cuentas } & Debe & Haber \\
\hline 20 & $31 / 12 / 00$ & $\begin{array}{l}\text { 694. Pérdidas por deterioro de valor de créditos } \\
\text { comerciales }(\mathrm{G}) \\
\text { 490. Deterioro de valor créditos comerciales } \\
(-\mathrm{A})\end{array}$ & $1.000,00$ & $1.000,00$ \\
\hline
\end{tabular}

En el caso de que posteriormente, al final del año siguiente, se estime que sea posible cobrar la mitad del importe adeudado, se registraría la reversión del deterioro de la siguiente forma:

\begin{tabular}{|c|c|c|c|c|}
\hline Asiento & Fecha & Cuentas & Debe & Haber \\
\hline $\mathrm{x}$ & $31 / 12 / 01$ & $\begin{array}{c}\text { 490. Deterioro de valor de créditos comerciales } \\
(-\mathrm{A}) \quad \begin{array}{c}\text { 794. Reversión del deterioro de créditos } \\
\text { comerciales (I) }\end{array}\end{array}$ & & \\
\hline
\end{tabular}


d) Liquidación de IVA e impuesto sobre sociedades

Al final del ejercicio habrá que realizar la última liquidación del IVA de acuerdo a lo estudiado en el tema 4. En este ejemplo, los saldos de las cuentas de IVA soportado y repercutido a final del año son:

\begin{tabular}{r|c}
\multicolumn{2}{c}{ 472. H.P. IVA soportado } \\
\hline $540,00(10)$ & \\
$540,00(11)$ & \\
$1.080,00(15)$ & \\
\hline $\mathbf{S D}=\mathbf{2 . 1 6 0 , 0 0}$ & $\mathbf{S A}=\mathbf{0 , 0 0}$ \\
Saldo deudor $=\mathbf{2 . 1 6 0 , 0 0}$
\end{tabular}

\begin{tabular}{|c|c|}
\hline \multicolumn{2}{|c|}{ 477. H.P. IVA repercutido } \\
\hline & $\begin{array}{r}45.000,00(2) \\
1.800,00(3) \\
3.600,00(4)\end{array}$ \\
\hline $\mathrm{SD}=\mathbf{0 , 0 0}$ & $\mathrm{SA}=\mathbf{5 0 . 4 0 0 , 0 0}$ \\
\hline
\end{tabular}

El asiento de liquidación sería:

\begin{tabular}{|c|c|c|c|c|}
\hline \multicolumn{5}{|c|}{$\begin{array}{l}\text { Ejemplo 5.8. Liquidación del IVA } \\
\text { Se contabilizaría: }\end{array}$} \\
\hline Asiento & Fecha & Cuentas & Debe & Haber \\
\hline 21 & $31 / 12 / 00$ & $\begin{array}{l}\text { 477. H.P. IVA repercutido (P) } \\
\text { 472. H.P. IVA soportado (A) } \\
\text { 475. H.P. acreedora por IVA (P) }\end{array}$ & $50.400,00$ & $\begin{array}{r}2.160,00 \\
48.240,00\end{array}$ \\
\hline
\end{tabular}

Una vez realizados todos los ajustes, y valorados adecuadamente todos los ingresos y gastos del ejercicio puede determinarse el denominado «resultado antes de impuestos» como diferencia entre unos y otros.

En el caso de sociedades sujetas al impuesto sobre sociedades será necesario calcular entonces la cuantía del impuesto sobre beneficios. El tipo impositivo general del impuesto sobre beneficios en España es del 30\%, porcentaje que se aplica sobre la base imponible del impuesto. La base imponible del impuesto se calcula partiendo del resultado contable antes de impuestos y practicando una serie de ajustes fiscales regulados en la normativa del impuesto.

El reconocimiento contable del impuesto de sociedades puede llegar a ser muy complejo y es objeto de estudio en cursos avanzados de contabilidad. En este epígrafe únicamente se introducirá un caso de contabilización simple en el que el impuesto devengado coincide con la cuota a pagar. 
MAYOR de PROYECTOS SA

(tras el asiento 21, previo al cálculo del Impto. s/beneficios)

\begin{tabular}{l|r}
\hline \multicolumn{2}{c}{ 203. Patentes y marcas (A) } \\
\hline $10.000,00(1)$ & \\
\hline $\mathrm{SD}=\mathbf{1 0 . 0 0 0 , 0 0}$ & $\mathrm{SA}=\mathbf{0 , 0 0}$ \\
Saldo deudor $=\mathbf{1 0 . 0 0 0 , 0 0}$
\end{tabular}

\begin{tabular}{c|c}
\hline \multicolumn{2}{c}{ 216. Mobiliario (A) } \\
\hline $15.000,00(1)$ & \\
\hline $\mathrm{SD}=\mathbf{1 5 . 0 0 0 , 0 0}$ & $\mathrm{SA}=\mathbf{0 , 0 0}$ \\
Saldo deudor $=\mathbf{1 5 . 0 0 0 , 0 0}$
\end{tabular}

\begin{tabular}{r|r}
\hline \multicolumn{2}{|c}{ 430. Clientes (A) } \\
\hline $8.000,00(1)$ & \\
$23.600,00(4)$ & \\
\hline $\mathbf{S D}=\mathbf{3 1 . 6 0 0 , 0 0}$ & $\mathbf{S A}=\mathbf{0 , 0 0}$ \\
Saldo deudor $=\mathbf{3 1 . 6 0 0 , 0 0}$
\end{tabular}

\begin{tabular}{r|r}
\hline \multicolumn{2}{c}{ 210. Terrenos (A) } \\
\hline $5.000,00(1)$ & \\
\hline SD $=\mathbf{5 . 0 0 0 , 0 0}$ & SA = 0,00 \\
Saldo deudor $=\mathbf{5 . 0 0 0 , 0 0}$
\end{tabular}

\begin{tabular}{c|c}
\hline \multicolumn{2}{c}{ 252. Créditos l.p. (A) } \\
\hline $5.000,00(1)$ & \\
\hline $\mathbf{S D}=\mathbf{5 . 0 0 0 , 0 0}$ & $\mathbf{S A}=\mathbf{0 , 0 0}$ \\
Saldo deudor $=\mathbf{5 . 0 0 0 , 0 0}$
\end{tabular}

\begin{tabular}{r|r}
\hline \multicolumn{2}{c}{ 540. Acciones c.p. (A) } \\
\hline $3.000,00(1)$ & $1.000,00(9)$ \\
\hline & \\
\hline $\mathrm{SD}=\mathbf{3 . 0 0 0 , 0 0}$ & $\mathrm{SA}=\mathbf{1 . 0 0 0 , 0 0}$ \\
Saldo deudor $=\mathbf{2 . 0 0 0 , 0 0}$
\end{tabular}

\begin{tabular}{l|r}
\hline \multicolumn{2}{c}{ 211. Construcciones (A) } \\
\hline $70.000,00(1)$ & \\
\hline $\mathbf{S D}=\mathbf{7 0 . 0 0 0 , 0 0}$ & SA=0,00 \\
Saldo deudor $=\mathbf{7 0 . 0 0 0 , 0 0}$
\end{tabular}

\begin{tabular}{c|c}
\hline \multicolumn{2}{c}{ 328. Material oficina (A) } \\
\hline $1.000,00(1)$ & \\
\hline $\mathrm{SD}=\mathbf{1 . 0 0 0 , 0 0}$ & $\mathrm{SA}=\mathbf{0 , 0 0}$ \\
Saldo deudor $=\mathbf{1 . 0 0 0 , 0 0}$
\end{tabular}

\begin{tabular}{c|c}
\hline \multicolumn{2}{c}{ 542. Créditos corto plazo (A) } \\
\hline $8.000,00(13)$ & \\
\hline & \\
\hline $\mathbf{S D}=\mathbf{8 . 0 0 0 , 0 0}$ & $\mathbf{S A}=\mathbf{0 , 0 0}$ \\
Saldo deudor $=\mathbf{8 . 0 0 0 , 0 0}$
\end{tabular}

\begin{tabular}{r|r}
\hline \multicolumn{2}{|c}{ 572. Bancos c/c (A) } \\
\hline $3.500,00(1)$ & $180.000,00(5)$ \\
$295.000,00(2)$ & $1.600,00(12)$ \\
$1.500,00(9)$ & $8.000,00(13)$ \\
& $7.080,00(15)$ \\
& $5.000,00(16)$ \\
\hline SD = 300.000.00 & SA= 201.680,00 \\
Saldo deudor $=\mathbf{9 9 . 3 2 0 , 0 0}$
\end{tabular}

Saldo deudor $=99.320,00$

\begin{tabular}{l|r}
\hline \multicolumn{2}{c}{ 281. AA Mobiliario (-A) } \\
\hline & $1.500,00(19)$ \\
\hline $\mathrm{SD}=\mathbf{0 , 0 0}$ & $\mathrm{SA}=\mathbf{1 . 5 0 0 , 0 0}$ \\
Saldo acreedor $=\mathbf{1 . 5 0 0 , 0 0}$
\end{tabular}

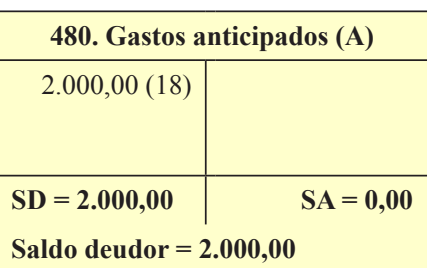

\begin{tabular}{l|r|}
\hline \multicolumn{2}{|c|}{ 475. Hda. Pca. Acreedora (P) } \\
\hline & $2.000,00(1)$ \\
\hline & $\mathbf{S A}=\mathbf{2 . 0 0 0 , 0 0}$ \\
$\mathrm{SD}=\mathbf{0 , 0 0}$ & $\mathbf{2 . 0 0 0 , 0 0}$
\end{tabular}

\begin{tabular}{r|r}
\multicolumn{2}{|c}{$\mathbf{5 7 0 .}$ Caja (A) } \\
\hline $500,00(1)$ & $1.000,00(7)$ \\
$11.800,00(3)$ & $3.540,00(10)$ \\
$100,00(14)$ & $3.540,00(11)$ \\
& \\
\hline SD = 12.400,00 & SA $=\mathbf{8 . 0 8 0 , 0 0}$
\end{tabular}

Saldo deudor $=4.320,00$

\begin{tabular}{l|r}
\hline \multicolumn{2}{c}{ 280. AA Patentes (-A) } \\
\hline & $750,00(19)$ \\
\hline $\mathrm{SD}=\mathbf{0 , 0 0}$ & $\mathrm{SA}=\mathbf{7 5 0 , 0 0}$ \\
Saldo acreedor $=\mathbf{7 5 0 , 0 0}$
\end{tabular}

\begin{tabular}{r|r}
\hline \multicolumn{2}{c}{ 472. H.P. IVA soportado } \\
\hline $540,00(10)$ & $2.160,00(21)$ \\
$540,00(11)$ & \\
$1.080,00(15)$ & \\
\hline $\mathbf{S D}=\mathbf{2 . 1 6 0 , 0 0}$ & $\mathbf{S A}=\mathbf{2 . 1 6 0 , 0 0}$ \\
Saldo deudor $=\mathbf{0 , 0 0}$
\end{tabular}

\begin{tabular}{l|r|}
\hline \multicolumn{1}{|c|}{ 170. Préstamos largo plazo $(\mathbf{P})$} \\
\hline & $30.000,00(1)$ \\
\hline & $\mathbf{S A}=\mathbf{3 0 . 0 0 0 , 0 0}$ \\
\hline $\mathrm{SD}=\mathbf{0 , 0 0}$ & $\mathbf{3 0 . 0 0 0 , 0 0}$
\end{tabular}

490. Deterioro de valor de cdtos comerciales (-A)

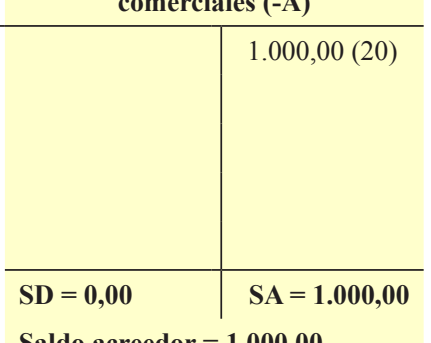

Saldo acreedor $=\mathbf{1 . 0 0 0 , 0 0}$

\begin{tabular}{l|c}
\hline \multicolumn{2}{c}{ 281. AA Construcciones (-A) } \\
\hline & $1.000,00(19)$ \\
\hline $\mathrm{SD}=\mathbf{0 , 0 0}$ & $\mathbf{S A}=\mathbf{1 . 0 0 0 , 0 0}$ \\
Saldo acreedor $=\mathbf{1 . 0 0 0 , 0 0}$
\end{tabular}

Saldo acreedor $=\mathbf{1 . 0 0 0 , 0 0}$

\begin{tabular}{r|r}
\hline \multicolumn{2}{c}{ 477. H.P. IVA repercutido } \\
\hline $50.400,00(21)$ & $45.000,00(2)$ \\
& $1.800,00(3)$ \\
& $3.600,00(4)$ \\
\hline SD $=\mathbf{5 0 . 4 0 0 , 0 0}$ & SA $=\mathbf{5 0 . 4 0 0 , 0 0}$ \\
Saldo $=\mathbf{0 , 0 0}$ & \\
\end{tabular}

\begin{tabular}{|c|r|}
\hline \multicolumn{2}{|c|}{ 520. Préstamos corto plazo (P) } \\
\hline $5.000,00(16)$ & $13.000,00(1)$ \\
\hline & \\
\hline $\mathrm{SD}=\mathbf{5 . 0 0 0 , 0 0}$ & $\mathrm{SA}=\mathbf{1 3 . 0 0 0 , 0 0}$ \\
Saldo acreedor $=\mathbf{8 . 0 0 0 , 0 0}$
\end{tabular}




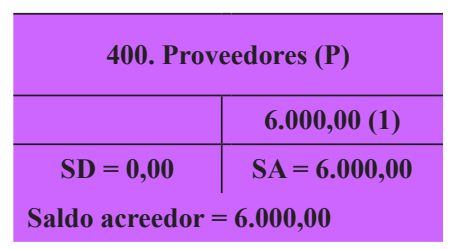

\begin{tabular}{l|c}
\hline \multicolumn{2}{|c|}{ 100. Capital (N) } \\
\hline & $20.000,00(1)$ \\
\hline & \\
\hline $\mathbf{S D}=\mathbf{0 , 0 0}$ & $\mathbf{S A}=\mathbf{2 0 . 0 0 0 , 0 0}$ \\
Saldo acreedor $=\mathbf{2 0 . 0 0 0 , 0 0}$
\end{tabular}

\begin{tabular}{l|r|}
\hline \multicolumn{2}{|c|}{ 705. Prestación servicios (I) } \\
\hline & $250.000,00(2)$ \\
\hline & $10.000,00(3)$ \\
\hline & $20.000,00(4)$ \\
\hline SD $=\mathbf{0 , 0 0}$ & SA $=\mathbf{2 8 0 . 0 0 0 , 0 0}$ \\
Saldo acreedor $=\mathbf{2 8 0 . 0 0 0 , 0 0}$
\end{tabular}

\begin{tabular}{l|c|}
\hline \multicolumn{2}{c}{ 631. Tributos (G) } \\
\hline $1.000,00(7)$ & \\
\hline & \\
\hline SD $=\mathbf{1 . 0 0 0 , 0 0}$ & \multicolumn{1}{|c|}{ SA $=\mathbf{0 , 0 0}$} \\
Saldo deudor $=\mathbf{1 . 0 0 0 , 0 0}$
\end{tabular}

\begin{tabular}{|l|l|}
\hline \multicolumn{2}{|c|}{ 628. Suministros (G) } \\
\hline $3.000,00(11)$ & \\
\hline & \\
\hline $\mathrm{SD}=\mathbf{3 . 0 0 0 , 0 0}$ & \multicolumn{1}{|c|}{$\mathrm{SA}=\mathbf{0 , 0 0}$} \\
Saldo deudor $=\mathbf{3 . 0 0 0 , 0 0}$ \\
\hline
\end{tabular}

681. Amortización mobiliario (G)

\begin{tabular}{|l|l|}
\hline $1.500,00(19)$ & \\
\hline SD $=\mathbf{1 . 5 0 0 , 0 0}$ & SA $=\mathbf{0 , 0 0}$ \\
Saldo deudor $=\mathbf{1 . 5 0 0 , 0 0}$
\end{tabular}

694. Pérdidas deterioro de valor (G)

\begin{tabular}{c|c|}
\hline $1.000,00(20)$ & \\
\hline SD $=\mathbf{1 . 0 0 0 , 0 0}$ & SA $=\mathbf{0 , 0 0}$ \\
Saldo deudor $=\mathbf{1 . 0 0 0 , 0 0}$
\end{tabular}

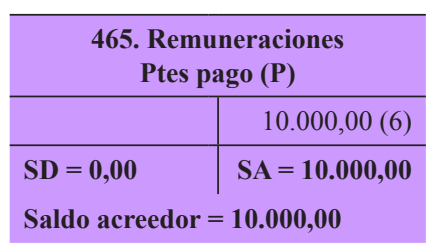

527. Intereses a pagar c.p. (P)

\begin{tabular}{l|r} 
& $200,00(17)$ \\
\hline SD $=\mathbf{0 , 0 0}$ & SA $=\mathbf{2 0 0 , 0 0}$ \\
Saldo acreedor $=\mathbf{2 0 0 , 0 0}$
\end{tabular}

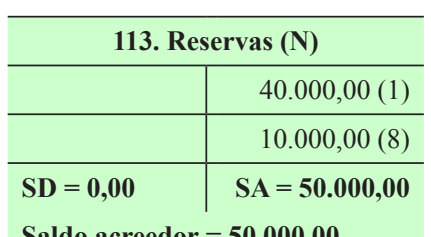

Saldo acreedor $=\mathbf{5 0 . 0 0 0 , 0 0}$

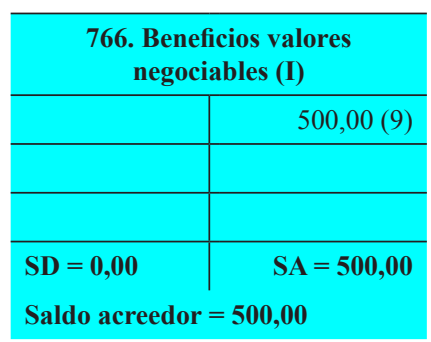

\begin{tabular}{|r|r|}
\hline \multicolumn{2}{c}{ 640. Sueldos y salarios $(\mathbf{G})$} \\
\hline $180.000,00(5)$ & \\
\hline $10.000,00(6)$ & \\
\hline SD $=\mathbf{1 9 0 . 0 0 0 , 0 0}$ & $\mathbf{S A}=\mathbf{0 , 0 0}$ \\
Saldo deudor $=\mathbf{1 9 0 . 0 0 0 , 0 0}$
\end{tabular}

\begin{tabular}{|c|c|}
\hline \multicolumn{2}{|c|}{$\begin{array}{l}\text { 662. Gastos por intereses deudas } \\
\text { (G) }\end{array}$} \\
\hline $1.600,00(12)$ & \\
\hline \multicolumn{2}{|l|}{$200,00(17)$} \\
\hline $\mathrm{SD}=1.800,00$ & $\mathrm{SA}=\mathbf{0 , 0 0}$ \\
\hline Saldo deudor $=$ & \\
\hline
\end{tabular}

680. Amortización patentes (G)

\begin{tabular}{l|l}
\hline $\mathbf{7 5 0 , 0 0 ( 1 9 )}$ & \\
\hline $\mathbf{S D}=\mathbf{7 5 0 , 0 0}$ & $\mathbf{S A}=\mathbf{0 , 0 0}$ \\
Saldo deudor $=\mathbf{7 5 0 , 0 0}$
\end{tabular}

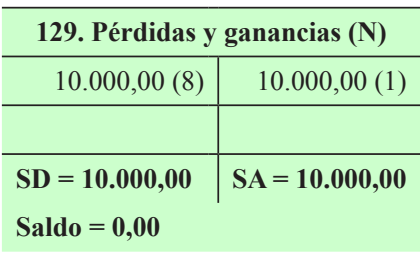

762. Ingres. por intereses créditos (I)

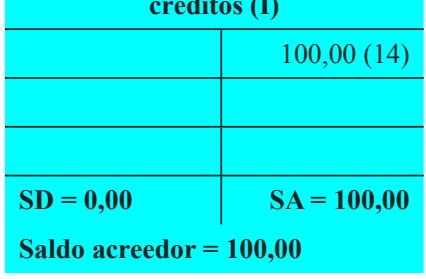

621. Arrendamientos (G)

\begin{tabular}{r|r}
\hline $3.000,00(10)$ & \\
\hline $\mathrm{SD}=\mathbf{3 . 0 0 0 , 0 0}$ & $\mathrm{SA}=\mathbf{0 , 0 0}$ \\
Saldo deudor $=\mathbf{3 . 0 0 0 , 0 0}$
\end{tabular}

627. Publicidad, prop. rp. (G)

\begin{tabular}{r|l}
\hline $6.000,00(15)$ & $2.000,00(18)$ \\
\hline & \\
\hline SD $=\mathbf{6 . 0 0 0 , 0 0}$ & SA $=\mathbf{2 . 0 0 0 , 0 0}$ \\
Saldo deudor $=\mathbf{4 . 0 0 0 , 0 0}$
\end{tabular}

\begin{tabular}{|c|}
\hline \multicolumn{2}{c}{$\begin{array}{c}\text { 681. Amortización } \\
\text { construcciones }(\mathbf{G})\end{array}$} \\
\hline $1.000,00(19)$ \\
$\mathrm{SD}=\mathbf{1 . 0 0 0 , 0 0}$ \\
Saldo deudor $=\mathbf{1 . 0 0 0 , 0 0}$
\end{tabular}




\begin{tabular}{|c|c|c|c|}
\hline $\begin{array}{l}\text { Prestación de servicios } \\
\text { Beneficios en valores negociables } \\
\text { Ingresos por intereses de créditos }\end{array}$ & $\begin{array}{r}280.000,00 \\
500,00 \\
100,00\end{array}$ & $\begin{array}{l}\text { Ingresos: } \\
280.600,00\end{array}$ & \\
\hline $\begin{array}{l}\text { Sueldos y salarios } \\
\text { Tributos } \\
\text { Arrendamientos } \\
\text { Suministros } \\
\text { Gastos por intereses de deudas } \\
\text { Publicidad, propaganda y relaciones públ. } \\
\text { Amortización de patentes } \\
\text { Amortización de construcciones } \\
\text { Amortización de mobiliario } \\
\text { Pérdidas por deterioro de valor }\end{array}$ & $\begin{array}{r}190.000,00 \\
1.000,00 \\
3.000,00 \\
3.000,00 \\
1.800,00 \\
4.000,00 \\
750,00 \\
1.000,00 \\
1.500,00 \\
1.000,00\end{array}$ & $\begin{array}{l}\text { Gastos: } \\
\text { 207.050,00 }\end{array}$ & $\begin{array}{l}\text { Resultado antes } \\
\text { de impuestos: } \\
\text { 73.550,00 }\end{array}$ \\
\hline
\end{tabular}

El reconocimiento contable del impuesto sobre beneficios supone su registro como gasto en una cuenta de gastos, y el reconocimiento de una deuda con la Hacienda Pública por el importe a pagar (suponiendo que no se han realizado pagos a cuenta del impuesto durante el ejercicio).

\section{Ejemplo 5.9. Contabilización del impuesto sobre beneficios}

El impuesto sobre beneficios devengado es de 73.550,00 € x $30 \%=22.065,00 €$

Se contabilizaría:

\begin{tabular}{|c|c|c|c|c|}
\hline Asiento & Fecha & Cuentas & Debe & Haber \\
\hline 22 & $31 / 12 / 00$ & $\begin{array}{c}\text { 630. Impuesto sobre beneficios (G) } \\
\text { 4752. H.P. acreedora por Impto.s/ } \\
\text { sociedades (P) }\end{array}$ & $22.065,00$ & \\
& & & $22.065,00$ \\
\hline
\end{tabular}

\begin{tabular}{|c|c|c|c|}
\hline & & \multicolumn{2}{|c|}{ Nuevas cuentas de mayor } \\
\hline \multicolumn{2}{|c|}{$\begin{array}{l}\text { 630. Impuesto sobre } \\
\text { beneficios }(G)\end{array}$} & \multicolumn{2}{|c|}{ 4752. Hda. Pca. Acreed. (P) } \\
\hline $22.065,00(22)$ & & & $\begin{array}{l}48.240,00(21) \\
22.065,00(22)\end{array}$ \\
\hline $\mathbf{S D}=22.065,00$ & $\mathrm{SA}=\mathbf{0 , 0 0}$ & $\mathrm{SD}=$ & $\mathrm{SA}=\mathbf{7 0 . 3 0 5 , 0 0}$ \\
\hline \multicolumn{2}{|c|}{ Saldo deudor $=22.065,00$} & \multicolumn{2}{|c|}{ Saldo acreedor $=70.305,00$} \\
\hline
\end{tabular}

\section{Momento de realización de los ajustes de fin de período}

Aunque formalmente la fecha de contabilización de los ajustes de fin de ejercicio suele ser la misma que la fecha de cierre contable, generalmente el 31 de diciembre, en realidad la fase de «ajustes de fin de ejercicio» suele ser bastante larga (puede requerir varias semanas) y se realiza física y temporalmente cuando ya está iniciado el ejercicio siguiente, aunque se registren los asientos con fecha 31 de diciembre.

Por otra parte, dado que el objetivo de los ajustes comentados es adecuar la información contenida en las cuentas a la situación patrimonial y financiera existente 
a fin de período, si por cualquier razón debieran elaborarse informes contables, como el balance y la cuenta de pérdidas y ganancias, o parte de las mismas en cualquier otra fecha, sería preciso realizar también dichos ajustes.

Muchas empresas suelen elaborar informes financieros mensualmente, por ejemplo el balance y la cuenta de pérdidas y ganancias, para mantener informada a la Dirección de la compañía y ser útil para la gestión continua de la misma.

En este caso, cada fin de mes deben realizarse todos aquellos ajustes de fin de período que proceda, similares a los vistos en este apartado, al objeto de que la información contenida en dichos informes sea correcta. Así, deberá procederse a amortizar el inmovilizado, reconocer ingresos y gastos según el principio de devengo, reconocer deterioros, ajustar las valoraciones de activos y pasivos, etc.

Ilustración 5.10. Realización de ajustes de fin de período

\subsection{Balance de comprobación. Liquidación y cierre contable}

Tras la realización de todos los ajustes las empresas preparan un balance de comprobación de sumas y saldos final, referido a 31 de diciembre y que, para la empresa utilizada a lo largo de este tema, sería el que se muestra a continuación.

\begin{tabular}{|c|c|c|c|c|}
\hline \multicolumn{5}{|c|}{ Ejemplo 5.10. Balance de comprobación de sumas y saldos } \\
\hline \multicolumn{5}{|c|}{$\begin{array}{c}\text { PROYECTOS SA } \\
\text { Balance de sumas y saldos del } 1 \text { de enero de } 00 \text { a } 31 \text { de diciembre de } 2000 \\
\text { (Previo a la liquidación del ejercicio) }\end{array}$} \\
\hline Cuenta & $\begin{array}{c}\text { Suma } \\
\text { deudora }\end{array}$ & $\begin{array}{c}\text { Suma } \\
\text { acreedora }\end{array}$ & $\begin{array}{l}\text { Saldo } \\
\text { deudor }\end{array}$ & $\begin{array}{c}\text { Saldo } \\
\text { acreedor }\end{array}$ \\
\hline 100. Capital social (N) & & $20.000,00$ & & $20.000,00$ \\
\hline 113. Reservas (N) & & $50.000,00$ & & $50.000,00$ \\
\hline 129. Pérdidas y ganancias $(\mathrm{N})$ & $10.000,00$ & $10.000,00$ & & \\
\hline 170. Préstamos 1.p. (P) & & $30.000,00$ & & $30.000,00$ \\
\hline 203. Patentes (A) & $10.000,00$ & & $10.000,00$ & \\
\hline 210. Terrenos (A) & $5.000,00$ & & $5.000,00$ & \\
\hline 211. Construcciones (A) & $70.000,00$ & & $70.000,00$ & \\
\hline 216. Mobiliario (A) & $15.000,00$ & & $15.000,00$ & \\
\hline 252. Créditos largo plazo (A). & $5.000,00$ & & $5.000,00$ & \\
\hline 280. Am. acum. patentes (-A) & & 750,00 & & 750,00 \\
\hline 281. Am. acum. construcciones (-A) & & $1.000,00$ & & $1.000,00$ \\
\hline 281. Am. acum. mobiliario (-A) & & $1.500,00$ & & $1.500,00$ \\
\hline 328. Material de oficina (A) & $1.000,00$ & & $1.000,00$ & \\
\hline 430. Clientes (A) & $31.600,00$ & & $31.600,00$ & \\
\hline 472. H. P. IVA soportado & $2.160,00$ & $2.160,00$ & & \\
\hline 477. H. P. IVA repercutido & $50.400,00$ & $50.400,00$ & & \\
\hline 480. Gastos anticipados (A) & $2.000,00$ & & $2.000,00$ & \\
\hline $\begin{array}{l}\text { 490. Deterioro de valor de cdtos. comer- } \\
\text { ciales (-A) }\end{array}$ & & $1.000,00$ & & $1.000,00$ \\
\hline 540. Acciones corto plazo (A) & $3.000,00$ & $1.000,00$ & $2.000,00$ & \\
\hline
\end{tabular}




\begin{tabular}{|l|r|r|r|r|}
\hline 542. Créditos corto plazo (A) & $8.000,00$ & & $8.000,00$ & \\
\hline 570. Caja (A) & $10.400,00$ & $8.080,00$ & $4.320,00$ & \\
\hline 572. Bancos c/c (A) & $300.000,00$ & $201.680,00$ & $99.320,00$ & \\
\hline 400. Proveedores (P) & & $6.000,00$ & & $6.000,00$ \\
\hline 520. Préstamos c.p. (P) & $5.000,00$ & $13.000,00$ & & $8.000,00$ \\
\hline 465. Remuneraciones ptes. (P) & & $8.000,00$ & & $8.000,00$ \\
\hline 475. Hda. pca. acreedora (P) & & $2.000,00$ & & $2.000,00$ \\
\hline 475. Hda. pca. acreedora (P) & & $70.305,00$ & & $70.305,00$ \\
\hline 527. Intereses pagar corto plazo (P) & & 200,00 & & 200,00 \\
\hline 622. Arrendamientos (G) & $3.000,00$ & & $3.000,00$ & \\
\hline 628. Suministros (G) & $3.000,00$ & & $3.000,00$ & \\
\hline 627. Publicidad, propaganda y r.l. (G) & $6.000,00$ & $2.000,00$ & $4.000,00$ & \\
\hline 630. Impuesto sobre beneficios (G) & $22.065,00$ & & $22.065,00$ & \\
\hline 631. Tributos (G) & $1.000,00$ & & $1.000,00$ & \\
\hline 640. Sueldos y salarios & $190.000,00$ & & $190.000,00$ & \\
\hline 662. Gastos por intereses deudas (G) & $1.800,00$ & & $1.800,00$ & \\
\hline 680. Amortización patentes (G) & 750,00 & & 750,00 & \\
\hline 681. Amortización construcciones (G) & $1.000,00$ & & $1.000,00$ & \\
\hline 681. Amortización mobiliario (G) & $1.500,00$ & & $1.500,00$ & \\
\hline $\begin{array}{l}\text { 694. Deterioro de valor de cdtos. comer- } \\
\text { ciales (G) }\end{array}$ & $1.000,00$ & & $1.000,00$ & \\
\hline 705. Prestación de servicios (I) & & $280.000,00$ & & $280.000,00$ \\
\hline 762. Ingresos por intereses créditos (I) & & 100,00 & & 100,00 \\
\hline 766. B en valores negociables (I) & & 500,00 & & 500,00 \\
\hline & $\mathbf{7 5 9 . 6 7 5 , 0 0}$ & $\mathbf{7 5 9 . 6 7 5 , 0 0}$ & $\mathbf{4 7 9 . 3 5 5 , 0 0}$ & $\mathbf{4 7 9 . 3 5 5 , 0 0}$ \\
\hline
\end{tabular}

El cierre de la contabilidad se realiza a través de los asientos denominados «asientos de liquidación de ingresos y gastos» $\mathrm{y}$ «asiento de cierre». Al igual que el asiento de apertura estos asientos finales son meramente técnicos, puesto que no responden a ninguna variación patrimonial, es decir, no se ha producido ninguna operación o transacción que registrar. Ambos asientos están completamente automatizados en las aplicaciones informáticas.

\section{Asientos de liquidación de ingresos y gastos}

Los asientos de liquidación de ingresos y gastos consisten en traspasar los saldos de todas las cuentas de ingresos y gastos utilizadas durante el ejercicio a la «129. Cuenta de pérdidas y ganancias (n)». La cuenta de mayor con esa denominación no debe confundirse con el informe que forma parte de las cuentas anuales y que tiene el mismo nombre.

La finalidad de estos asientos es dejar saldadas todas las cuentas de ingresos y gastos (dejarlas con saldo 0) y acumular sus saldos en la cuenta de mayor «129. Pérdidas y ganancias» $\mathrm{u}$ otras cuentas de mayor patrimonio neto. 
En relación a la «129. Cuenta de pérdidas y ganancias», su saldo representará el resultado del ejercicio después de impuestos. Dado que los ingresos originan un abono en la dicha cuenta y los gastos un cargo en la misma, un saldo acreedor significará beneficios y un saldo deudor significará pérdidas.

Ejemplo 5.11. Asientos de liquidación de ingresos y gastos

(Ver balance de comprobación de sumas y saldos donde figuran los saldos finales de las cuentas.)

\begin{tabular}{|c|c|c|c|c|}
\hline Asiento & Fecha & Cuentas & Debe & Haber \\
\hline 28 & $31 / 12 / 00$ & $\begin{array}{l}\text { 705. Prestación de servicios (I) } \\
\text { 766. } \mathrm{B}^{\mathrm{o}} \text { en valores negociables (I) } \\
\text { 762. Ingresos por intereses créditos (I) } \\
\text { 129. Pérdidas y ganancias }\end{array}$ & $\begin{array}{r}280.000,00 \\
500,00 \\
100,00\end{array}$ & $280.600,00$ \\
\hline 29 & & $\begin{array}{l}\text { 129. Pérdidas y ganancias }(\mathrm{N}) \\
\text { 631. Tributos }(\mathrm{G}) \\
\text { 640. Sueldos y salarios } \\
\text { 621. Arrendamientos }(\mathrm{G}) \\
\text { 628. Suministros }(\mathrm{G}) \\
\text { 662. Gastos por intereses deudas }(\mathrm{G}) \\
\text { 627. Publicidad, propaganda y r.1. }(\mathrm{G}) \\
\text { 680. Amortización patentes }(\mathrm{G}) \\
\text { 681. Amortización construcciones }(\mathrm{G}) \\
\text { 681. Amortización mobiliario }(\mathrm{G}) \\
\text { 694. Pérdidas deterioro de cdtos. com. } \\
\text { 630. Impuesto sobre beneficios }(\mathrm{G})\end{array}$ & $229.115,00$ & $\begin{array}{r}1.000,00 \\
190.000,00 \\
3.000,00 \\
3.000,00 \\
1.800,00 \\
4.000,00 \\
750,00 \\
1.000,00 \\
1.500,00 \\
1.000,00 \\
22.065,00\end{array}$ \\
\hline
\end{tabular}

La cuenta 129 presentaria un saldo de 51.485,00.

En lugar de dos asientos puede realizarse uno sólo con todas las cuentas de ingresos y gastos, cargando o abonando la cuenta 129 por la diferencia entre ambos.

Estos asientos se traspasará a las cuentas de mayor correspondientes.

Obsérvese que tras estos asientos todas las cuentas de ingresos y gastos quedarán con saldo 0 , es decir, saldadas.

Obsérvese también que el saldo en la cuenta «Pérdidas y ganancias» es el resultado del ejercicio (beneficios) ya deducidos los impuestos: $73.550,00-22.065,00=51.485,00$. 


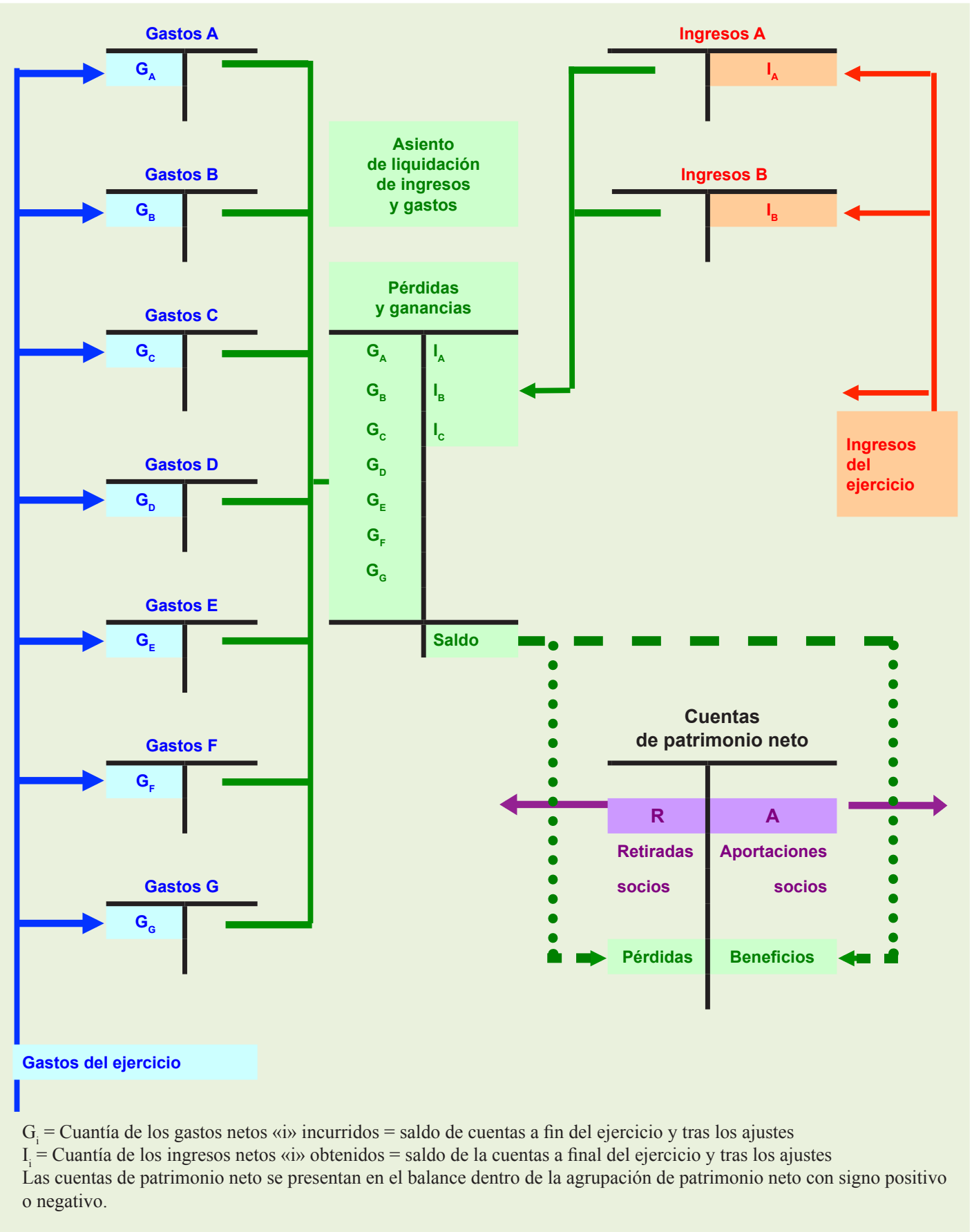

Ilustración 5.11. Esquema de los asientos de liquidación de ingresos y gastos y su relación con la cuenta de pérdidas y ganancias y cuentas del patrimonio neto

\section{Asiento de cierre}

Una vez liquidado el ejercicio, únicamente quedan con saldo las cuentas patrimoniales o de balance que son objeto de cancelación mediante el asiento de cierre en el que se cargan todas las cuentas patrimoniales que a finales del ejercicio presentan un saldo acreedor y se abonan todas las cuentas patrimoniales que presentan un saldo final deudor. 
Se trata de un asiento meramente técnico, puesto que no responde a ninguna variación patrimonial, es decir, no se ha producido ninguna operación o transacción que registrar. Su objetivo es dar de baja todas las cuentas representativas de elementos patrimoniales con el saldo correspondiente al valor final de dichos elementos. Tras este asiento, que siempre es el último del año, no queda ninguna cuenta abierta y se dice que se ha cerrado la contabilidad.

El contrario a este asiento de cierre de 31 de diciembre será el asiento de apertura del 1 de enero del año siguiente.

\section{Ejemplo 5.12. Asiento de cierre}

(Ver balance de comprobación de sumas y saldos donde figuran los saldos finales de las cuentas.)

\begin{tabular}{|c|c|c|c|c|}
\hline Asiento & Fecha & Cuentas & Debe & Haber \\
\hline 30 & $31 / 12 / 00$ & $\begin{array}{l}\text { 100. Capital social (N) } \\
\text { 112 Reservas (N) } \\
\text { 170. Préstamos l.p. (P) } \\
\text { 280. Am. acum. patentes (-A) } \\
\text { 281. Am. acum. construcciones (-A) } \\
\text { 281. Am. acum. mobiliario (-A) } \\
\text { 475. Hda. pca. acreedora (P) } \\
\text { 520. Préstamos c.p. (P) } \\
\text { 465. Remuneraciones ptes (P) } \\
\text { 527. Intereses pagar c.p. (P) } \\
\text { 400. Proveedores (P) } \\
\text { 475. Hda. pca. acreedora (P) } \\
\text { 490. Deterioro de valor de cdtos. com. (-A) } \\
\text { 129. Pérdidas y ganancias (N) } \\
\text { 203. Patentes (A) } \\
\text { 210. Terrenos (A) } \\
\text { 211. Construcciones (A) } \\
\text { 216. Mobiliario (A) } \\
\text { 252. Créditos l.p (A). } \\
\text { 328. Material de oficina (A) } \\
\text { 430. Clientes (A) } \\
\text { 480. Gastos anticipados (A) } \\
\text { 540. Acciones c.p. (A) } \\
\text { 542. Créditos c.p. (A) } \\
\text { 572. Bancos c/c (A) } \\
\text { 570. Caja (A) }\end{array}$ & $\begin{array}{r}20.000,00 \\
50.000,00 \\
30.000,00 \\
750,00 \\
1.000,00 \\
1.500,00 \\
2.000,00 \\
8.000,00 \\
8.000,00 \\
200,00 \\
6.000,00 \\
70.305,00 \\
1.000,00 \\
51.485,00\end{array}$ & $\begin{array}{r}10.000,00 \\
5.000,00 \\
70.000,00 \\
15.000,00 \\
5.000,00 \\
1.000,00 \\
31.600,00 \\
2.000,00 \\
2.000,00 \\
8.000,00 \\
98.320,00 \\
2.320,00\end{array}$ \\
\hline \multicolumn{5}{|c|}{$\begin{array}{l}\text { Este asiento se traspasará a las cuentas de mayor correspondientes. } \\
\text { Tras este asiento todas las cuentas quedarán con saldo } 0 \text {, es decir, saldadas. } \\
\text { Obsérvese también que la cuenta «Pérdidas y ganancias» se salda por el resultado del ejercicio tras } \\
\text { los impuestos: } 51.485,00 \text {. }\end{array}$} \\
\hline
\end{tabular}




\subsection{Elaboración de cuentas anuales}

Utilizando los saldos finales del balance de comprobación de sumas y saldos puede elaborarse directamente el balance y la cuenta de pérdidas y ganancias del ejercicio. A continuación se muestran los informes contables que se derivan del anterior balance de comprobación de sumas y saldos para la empresa tomada como ejemplo a lo largo de este tema.

\begin{tabular}{|c|c|}
\hline \multicolumn{2}{|l|}{ Ejemplo 5.13. Cuenta de pérdidas y ganancias } \\
\hline \multicolumn{2}{|c|}{$\begin{array}{l}\text { Proyectos SA } \\
\text { Cuenta de pérdidas y ganancias del período 01/01/00 a 31/12/00 }\end{array}$} \\
\hline $\begin{array}{l}\text { 1. Importe de la cifra de negocios } \\
\cdot 705 \text {. Prestación de servicios }\end{array}$ & $\begin{array}{l}+\mathbf{2 8 0 . 0 0 0 , 0 0} \\
280.000,00\end{array}$ \\
\hline 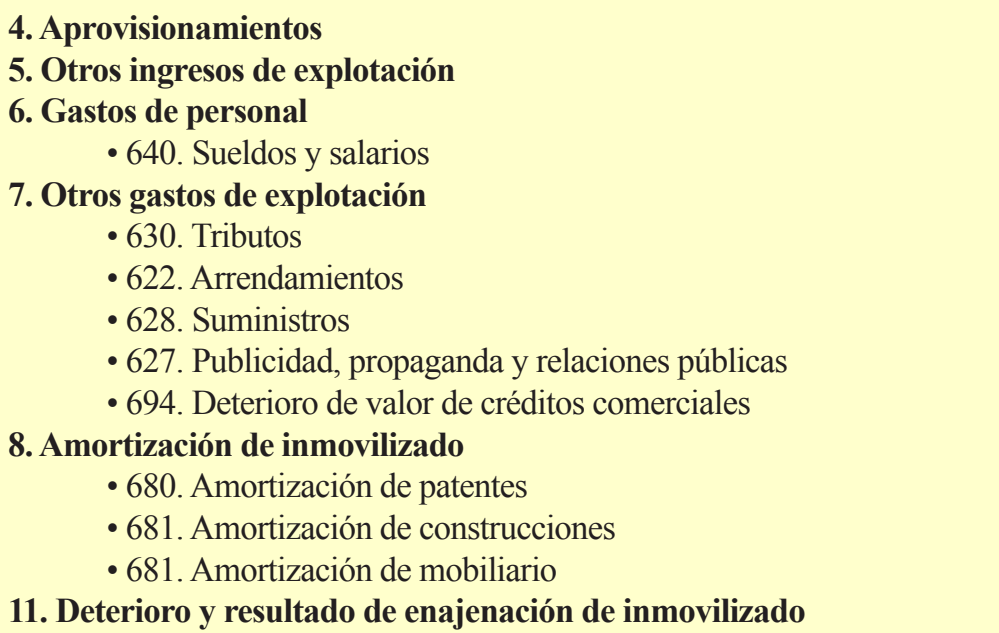 & $\begin{array}{c}\mathbf{0 , 0 0} \\
\mathbf{0 , 0 0} \\
\mathbf{- 1 9 0 . 0 0 0 , 0 0} \\
-190.000,00 \\
\mathbf{- 1 2 . 0 0 0 , 0 0} \\
-1.000,00 \\
-3.000,00 \\
-3.000,00 \\
-4.000,00 \\
-1.000,00 \\
\mathbf{- 3 . 2 5 0 , 0 0} \\
-750,00 \\
-1.000,00 \\
-1.500,00 \\
\mathbf{0 , 0 0}\end{array}$ \\
\hline A1. Resultado de explotación $=4+5+6+7+8+11$ & $+74.750,00$ \\
\hline $\begin{array}{l}\text { 12. Ingresos financieros } \\
\cdot 762 \text {. Ingresos por intereses de créditos } \\
\text { 13. Gastos financieros } \\
\quad 662 \text {. Gastos por intereses de deudas } \\
\text { 16. Deterioro y resultado por enajenación de instrumentos financieros } \\
\quad \text { - } 766 \text {. Beneficios en valores negociables }\end{array}$ & $\begin{array}{l}+\mathbf{1 0 0 , 0 0} \\
\quad 100,00 \\
-\mathbf{1 . 8 0 0 , 0 0} \\
-1.800,00 \\
+\mathbf{5 0 0 , 0 0} \\
\quad 500,00\end{array}$ \\
\hline A2. Resultado financiero $=12+13+16$ & $-1.200,00$ \\
\hline A3. Resultado antes de impuestos $=\mathbf{A} 1+\mathbf{A} 2$ & $+73.550,00$ \\
\hline $\begin{array}{l}\text { 17. Impuesto sobre beneficios } \\
\cdot 630 \text {. Impuesto sobre beneficios }\end{array}$ & $\begin{array}{r}\mathbf{- 2 0 . 0 6 5 , 0 0} \\
-20.065,00\end{array}$ \\
\hline A3. Resultado del ejercicio $=\mathbf{A} 2+17$ & $+51.485,00$ \\
\hline
\end{tabular}




\begin{tabular}{|c|c|c|c|}
\hline \multicolumn{4}{|l|}{ Ejemplo 5.14. Balance } \\
\hline \multicolumn{4}{|c|}{$\begin{array}{c}\text { Proyectos SA } \\
\text { Balance a 31/12/00 }\end{array}$} \\
\hline \multicolumn{2}{|l|}{ ACTIVO } & \multicolumn{2}{|c|}{ PATRIMONIO NETO Y PASIVO } \\
\hline A) ACTIVO NO CORRIENTE & $101.750,00$ & A) PATRIMONIO NETO & $121.485,00$ \\
\hline \multirow{3}{*}{$\begin{array}{l}\text { I) Inmovilizado intangible } \\
\text { 203. Patentes } \\
\text { 280. AA Patentes } \\
\text { II) Inmovilizado material } \\
\text { 210. Terrenos } \\
\text { 211. Construcciones } \\
\text { 281. AA Construcciones } \\
\text { 216. Mobiliario } \\
\text { 281. AA Mobiliario } \\
\text { IV) Inmovilizado Financiero } \\
\text { 252. Créditos largo plazo }\end{array}$} & \multirow{3}{*}{$\begin{array}{r}\mathbf{9 . 2 5 0 , 0 0} \\
10.000,00 \\
(750,00) \\
\mathbf{8 7 . 5 0 0 , 0 0} \\
5.000,00 \\
70.000,00 \\
(1.000,00) \\
15.000,00 \\
(1.500,00) \\
\mathbf{5 . 0 0 0 , 0 0} \\
5.000,00\end{array}$} & $\begin{array}{l}\text { A-1) Fondos propios } \\
\text { 100. Capital } \\
\text { 113. Reservas } \\
\text { 129. Pérdidas y ganancias } \\
\text { A-3) Subvenciones }\end{array}$ & $\begin{array}{r}\mathbf{1 2 1 . 4 8 5 , 0 0} \\
20.000,00 \\
50.000,00 \\
51.485,00 \\
\mathbf{0 , 0 0}\end{array}$ \\
\hline & & B) PASIVO NO CORRIENTE & $30.000,00$ \\
\hline & & $\begin{array}{l}\text { II) Deudas a largo plazo } \\
\text { 170. Préstamos a largo plazo }\end{array}$ & $\begin{array}{l}\mathbf{3 0 . 0 0 0 , 0 0} \\
30.000,00\end{array}$ \\
\hline B) ACTIVO CORRIENTE & $144.240,00$ & C) PASIVO CORRIENTE & $94.505,00$ \\
\hline $\begin{array}{l}\text { II) Existencias } \\
\text { 320. Material oficina } \\
\text { III) Deudores comerciales } \\
\text { 430. Clientes } \\
\text { 490. Deterioro valor cdtos. } \\
\text { com. } \\
\text { V) Inversiones fin. corto plazo } \\
\text { 540. Acciones corto plazo } \\
\text { 542. Créditos corto plazo } \\
\text { VI) Periodificaciones a c.p. } \\
\text { 480. Gastos anticipados } \\
\text { VII) Efectivo y medios líquidos } \\
\text { 570. Caja } \\
\text { 572. Bancos }\end{array}$ & \begin{tabular}{r|}
$\mathbf{1 . 0 0 0 , 0 0}$ \\
$1.000,00$ \\
$\mathbf{3 0 . 6 0 0 , 0 0}$ \\
$31.600,00$ \\
$(1.000,00)$ \\
$\mathbf{1 0 . 0 0 0 , 0 0}$ \\
$2.000,00$ \\
$8.000,00$ \\
$\mathbf{2 . 0 0 0 , 0 0}$ \\
2.000 .00 \\
$\mathbf{1 0 0 . 6 4 0 , 0 0}$ \\
$2.320,00$ \\
$98.320,00$
\end{tabular} & \begin{tabular}{|l} 
III) Deudas a corto plazo \\
520. Préstamos corto plazo \\
527. Intereses a pagar corto \\
plazo \\
V) Acreedores comerciales \\
400. Proveedores \\
465. Remuneraciones ptes. \\
pago \\
475. H. P. acreedora \\
475. H. P acreedora \\
VI) Periodificaciones a c.p.
\end{tabular} & $\begin{array}{r}\mathbf{8 . 2 0 0 , 0 0} \\
8.000,00 \\
200,00 \\
\mathbf{8 6 . 3 0 5 , 0 0} \\
6.000,00 \\
8.000,00 \\
2.000,00 \\
70.305 .00 \\
\mathbf{0 , 0 0}\end{array}$ \\
\hline TOTAL & $245.990,00$ & TOTAL & $245.990,00$ \\
\hline
\end{tabular}




\section{Material para prácticas}

\section{Preguntas test}

1. La cuenta «Deterioro de valor de existencias de mercaderías» expresa:

a) La diferencia entre el valor de las existencias iniciales y finales.

b) Las pérdidas recuperables que se ponen de manifiesto con respecto al inventario de existencias al final del ejercicio.

c) Las pérdidas irreversibles de las existencias.

d) Corresponde a una depreciación sistemática de las existencias.

2. En la periodificación de ingresos y gastos de final del ejercicio:

a) Se registran como gastos anticipados los importes pagados y contabilizados como gasto que corresponden al ejercicio que se cierra.

b) Se registran como gastos anticipados los importes pendientes de pago y no contabilizados que corresponden al ejercicio que se cierra.

c) Se registran como gastos anticipados los importes pagados y contabilizados como gasto que corresponden al siguiente ejercicio.

d) Se registran como gastos anticipados los importes pendientes de pago y no contabilizados que corresponden al siguiente ejercicio.

3. Los deterioros de valor de elementos patrimoniales de activo:

a) Recogen las pérdidas irrecuperables de los mismos.

b) Recogen una estimación sobre las perdidas reversibles de carácter sistemático.

c) Se registran a finales de ejercicio por aplicación del principio de correlación de devengo.

d) Se registran por aplicación del principio de prudencia.

4. En relación a la cuenta «480. Gastos anticipados», señale la afirmación correcta:

a) Se carga al inicio de cada ejercicio, con abono a la correspondiente cuenta del grupo 6.

b) Se abona al cierre del ejercicio, con cargo a las cuentas del grupo 6 que hayan registrado los gastos a imputar al ejercicio posterior.

c) En el balance figurará en el activo no corriente.

d) En el balance figurará en el activo corriente.

5. La cuenta «485. Ingresos anticipados»:

a) Figurará en el pasivo no corriente del balance.

b) Como toda cuenta de ingresos se salda con abono a pérdidas y ganancias.

c) Es una cuenta con saldo deudor.

d) Ninguna de las anteriores.

6. Las cuentas de deterioro de valor de activos:

a) Son correcciones valorativas de activos por disminuciones de valor recuperables.

b) Recogen las pérdidas irreversibles de los mismos. 
c) Recogen una estimación sobre las perdidas recuperables de carácter sistemático.

d) Se reconocen a finales de ejercicio por aplicación del principio de devengo.

7. El traslado de las cuentas de ingresos y gastos en los asientos de liquidación:

a) Se realiza antes de la regularización de existencias.

b) Deja saldadas las cuentas de activos, pasivos y patrimonio neto.

c) Se realiza cada trimestre.

d) Deja saldadas las cuentas de ingresos y gastos.

8. Mediante el asiento de liquidación a final de ejercicio:

a) Se contabilizan las correcciones valorativas de los activos.

b) Se reclasifican aquellas cuentas que siendo activos están registradas como pasivos.

c) Se saldan las cuentas de ingresos y gastos obteniéndose el resultado del ejercicio.

d) Se confeccionan las cuentas anuales.

9. Los ajustes por periodificación sirven para eliminar:

a) Gastos contabilizados durante el ejercicio y que corresponden al siguiente.

b) Saldos de clientes deteriorados.

c) Intereses pagados durante el ejercicio y que corresponden al mismo.

d) Intereses no contabilizados que corresponden al ejercicio siguiente.

10. Señale cuál de las siguientes afirmaciones es correcta:

a) El asiento de apertura del libro diario es idéntico al asiento de cierre del ejercicio anterior.

b) Mediante las operaciones de liquidación se determina el resultado del ejercicio.

c) Las operaciones de periodificación se incluyen en el asiento de apertura.

d) Todas las afirmaciones anteriores son correctas.

11. Indique cuál de las siguientes afirmaciones es la correcta:
a) Amortización y periodificación son términos equivalentes.
b) Todos los bienes de inmovilizado deben amortizarse.
c) La amortización afecta al resultado contable.
d) La amortización no afecta a las cuentas de balance.

12. Señala la afirmación falsa. El balance de sumas y saldos:

a) Permite detectar posibles errores aritméticos o de traslación.

b) Se puede realizar en cualquier momento.

c) Solo puede redactarse cuando están registrados todos los hechos contables del ejercicio.

d) Entre otras, tiene la finalidad de ofrecer una síntesis del libro mayor.

13. Las cuentas de amortización acumulada:

a) Figuran en el activo del balance con signo negativo.

b) Figuran en el pasivo del balance con signo negativo. 
c) Figuran en el activo del balance con signo positivo.

d) Figuran en el pasivo del balance con signo positivo.

14. La cuenta «282. Amortización acumulada del inmovilizado material», figura:
a) En el pasivo no corriente con signo positivo.
b) En el activo corriente con signo negativo.
c) En el pasivo no corriente con signo negativo.
d) En el activo no corriente con signo negativo.

15. Es necesario realizar «ajustes de fin de período»:

a) Todos los meses.

b) Solamente a fines de cada año.

c) Cuando haya que elaborar un balance y cuenta de pérdidas y ganancias.

d) Cuando el número de operaciones contabilizadas sea muy elevado.

16. En un balance de sumas y saldos:

a) La suma de las sumas deudoras de las cuentas debe ser igual a la suma de los saldos deudores de las cuentas.

b) La suma de las sumas deudoras de las cuentas debe ser igual a la suma de las sumas acreedoras de las cuentas.

c) La suma de los saldos deudores debe ser igual a la suma de los saldos deudores de cuentas de activo y de gastos.

d) Ninguna de las anteriores.

\section{SOLUCIONES AL TEST:}

\begin{tabular}{|l|l|l|l|l|}
\hline 1. & 2. & 3. & 4. & 5. \\
\hline 6. & 7. & 8. & 9. & 10. \\
\hline 11. & 12. & 13. & 14. & 15. \\
\hline 16. & & & & \\
\hline
\end{tabular}




\section{Cuestiones teóricas}

1. Defina qué se entiende por ejercicio contable.

2. ¿Cuál es la duración de un ejercicio contable y cuáles son su fecha de inicio y final?

3. Puede, o debe, una empresa elaborar las cuentas anuales, o parte de ellas con mayor periodicidad que la anual. ¿Por qué?

4. Indique las fases en que se divide el ciclo contable.

5. Explique en qué consiste el asiento de apertura y la transacción que justifica el mismo.

6. ¿Por qué deben realizarse ajustes al fin del ejercicio si durante el mismo se han ido contabilizando todas las transacciones ocurridas?

7. Explique el principio de devengo.

8. Compare el principio de devengo con el criterio de caja desde el punto de vista de sus efectos sobre los resultados obtenidos y la situación patrimonial.

9. Explique detalladamente un caso de ajustes por aplicación del devengo en el que proceda registrar un gasto devengado y no contabilizado.

10. Explique detalladamente un caso de ajustes por aplicación del devengo en que proceda eliminar un gasto registrado y no devengado.

11. Defina amortización del inmovilizado.

12. Indique un procedimiento para calcular la amortización de un período de un inmovilizado.

13. ¿Qué recogen las cuentas de amortización acumulada y dónde se sitúan en el balance?

14. ¿Qué repercusiones tiene, sobre el balance y la cuenta de pérdidas y ganancias, el reconocimiento de un deterioro de un activo?

15. ¿Cuándo existe deterioro de valor en el inmovilizado material o inmaterial?

16. ¿Cuando existe deterioro de valor en existencias? ¿Cómo se calcula?

17. ¿Qué significa que haya deterioro de valor en cuentas de clientes, deudores o créditos?

18. Explique el procedimiento básico de determinación del impuesto sobre beneficios de un ejercicio económico.

19. Explique en qué consiste el asiento de liquidación de ingresos y gastos y su objetivo.

20. Comente la siguiente expresión: «Cuando una empresa vaya a cerrar su negocio, y tras registrar su baja en el Registro Mercantil, procederá a contabilizar el asiento de cierre del negocio»».

21. Explique en qué consiste el asiento de cierre y su objetivo. 


\section{Ejercicios}

Ejercicio 1. Asiento de apertura

Contabilice el asiento de apertura correspondiente al ejercicio 2000 de la empresa FORJADOS CASTELLÓN SA que presenta el siguiente balance a 01/01/00.

\begin{tabular}{|c|c|c|c|}
\hline \multicolumn{4}{|c|}{$\begin{array}{l}\text { FORJADOS CASTELLÓN SA } \\
\text { Balance a } 01 \text { de enero de } 2000\end{array}$} \\
\hline \multicolumn{2}{|l|}{ ACTIVO } & \multicolumn{2}{|c|}{ PASIVO Y PATRIMONIO NETO } \\
\hline ACTIVO NO & $40.000,00$ & PATRIMONIO NETO & $15.000,00$ \\
\hline CORRIENTE & $20.000,00$ & 100. Capital & $10.000,00$ \\
\hline 211. Construcciones & $5.000,00$ & 113. Reservas & $5.000,00$ \\
\hline 216. Mobiliario & $6.000,00$ & & \\
\hline 218. Vehículos & $9.000,00$ & PASIVO NO CORRIENTE & $20.000,00$ \\
\hline 250. Acciones a largo plazo & $30.000,00$ & 170. Préstamos a l.p. & $20.000,00$ \\
\hline ACTIVO CORRIENTE & $12.000,00$ & PASIVO CORRIENTE & $35.000,00$ \\
\hline 300. Mercancías & $6.000,00$ & 400. Proveedores & $23.000,00$ \\
\hline 430. Clientes & 4.000 .00 & 410. Acreedores diversos & $5.000,00$ \\
\hline 542. Créditos a c.p. & $8.000,00$ & 475. Hda. Pública Acreedora & $4.000,00$ \\
\hline 570. Efectivo & & 520. Préstamos a c.p. & $3.000,00$ \\
\hline Total & $70.000,00$ & Total & $70.000,00$ \\
\hline
\end{tabular}

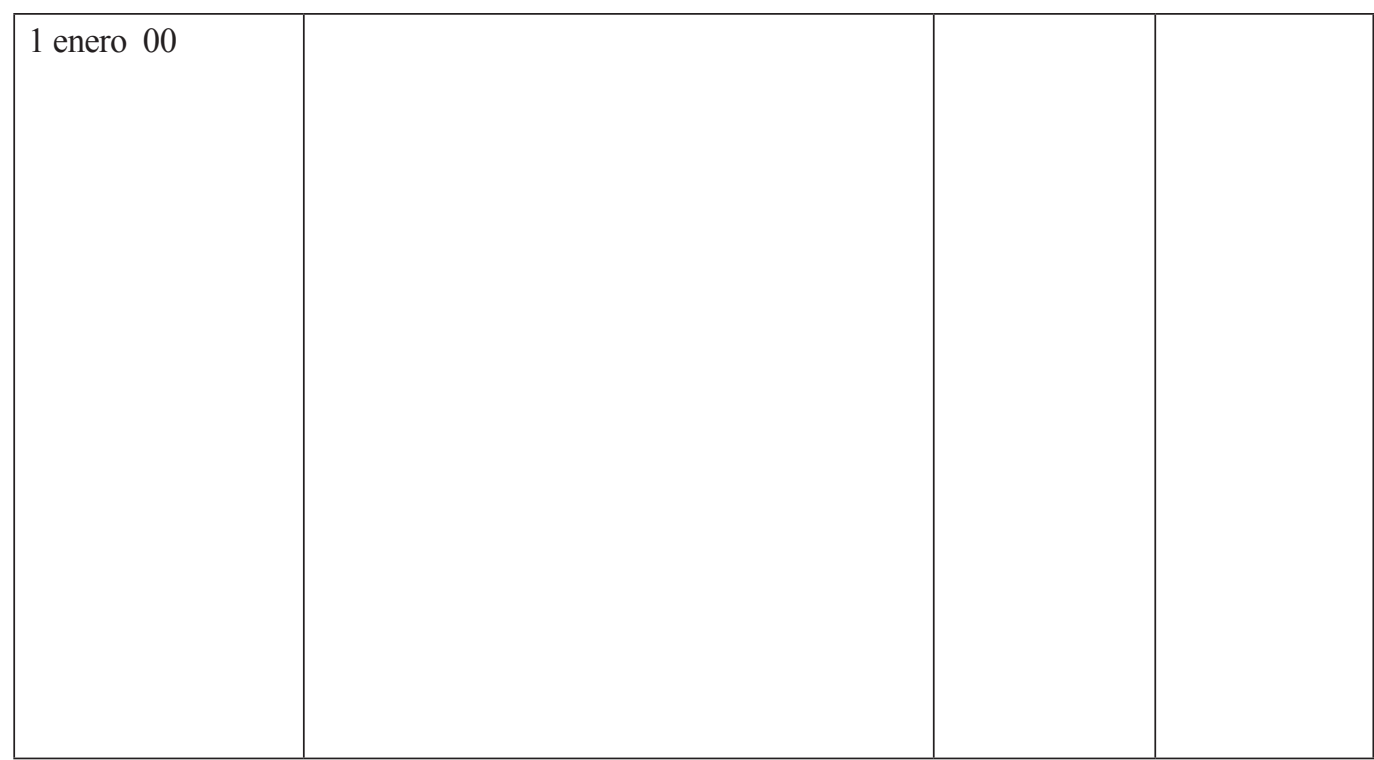

\section{Ejercicio 2. Intereses en contra devengados y no vencidos}

La empresa JUGUETES MARTíNEZ SL obtuvo el 1 de mayo de 2000 un préstamo de $10.000,00 €$ que contabilizó en dicha fecha. Dicho préstamo solo le obliga a pagar cuotas de intereses trimestrales de 600,00 € ya que la devolución del principal se hará en su totalidad en un año. La empresa ha contabilizado en el momento del pago las cuotas de 1 de agosto y 1 de noviembre. Contabilice el ajuste que proceda a 31 de diciembre de 2000 y justifique el mismo.

31 diciembre 00 


\section{Ejercicio 3. Intereses en contra devengados y no vencidos}

EL BANCO SANTANDER concedió un préstamo a largo plazo el 10 de diciembre de 00 a la empresa VIAJES EXótiCOS SA. La primer cuota del préstamo que vence el 10 de enero de 01 , y lógicamente aún no está contabilizada. Dicha cuota asciende a $1.400 €(400 €$ de intereses y $1.000,00 €$ de devolución del principal). Realice el ajuste que deberá hacer VIAJES EXÓTICOS SA a final del año 2000 en relación a los intereses de dicho préstamo y justifique el mismo.

31 diciembre 00

\section{Ejercicio 4. Intereses a favor devengados y no vencidos}

Con los datos del ejercicio 3 anterior, contabilice el ajuste de fin de ejercicio 2000 correspondiente a la contabilidad del BANCO DE SANTANDER y justifique el mismo

31 diciembre 00

\section{Ejercicio 5. Gastos anticipados}

RENTING SA pagó el 1 de agosto de 2000 el seguro anual de un vehículo por importe de $600,00 €$, contabilizando en dicha fecha el importe como gastos por primas de seguros. Contabilice el ajuste por periodificación que proceda a 31 de diciembre.

Corresponden al ejercicio siguiente

31 diciembre 00

\section{Ejercicio 6. Ingresos anticipados}

IMMOBLES SA ha cobrado el 1 de diciembre 12.000,00€ correspondientes al alquiler de 6 meses de un local de su propiedad, contabilizando en dicha fecha el importe recibido como ingresos por arrendamientos. Contabilice el ajuste por periodificación que proceda a 31 de diciembre.

Corresponden al ejercicio siguiente

31 diciembre 00

\section{Ejercicio 7. Amortización de inmovilizado}

La empresa ALQUILER DE VeHÍculos SL tiene un Ford Focus que adquirió el 1 de mayo de 2000 y de valor de adquisición 20.000,00 € y vida útil 5 años. Determine el importe de la amortización correspondiente a un año completo y contabilice dicha cuota de amortización para el año 2000.

31 diciembre 00 


\section{Ejercicio 8. Amortización de inmovilizado}

La empresa FoODS SL tiene una patente registrada el 1 de junio de 2000 y de valor de adquisición 10.000,00 $€$ y vida útil 20 años. Determine el importe de la amortización correspondiente a un año completo y contabilice la cuota de amortización que corresponda a la parte del año 00 .

31 diciembre 00

\section{Ejercicio 9. Deterioro de mercancías}

La empresa INFORMAL WEAR SL mantiene en su almacén prendas diversas cuyo coste fue de 15.000,00 euros. A 31 de diciembre estima que el valor de las mismas es de $12.000,00$. Justifique si procede realizar un ajuste de fin de ejercicio y, en su caso, contabilícelo.

31 diciembre 00

\section{Ejercicio 10. Deterioro de inmovilizado}

La empresa MEDITERRANEAN TILES SA tiene un equipo productivo de tres años de antigüedad y que aparece registrado contablemente con un valor de 650.000,00€. Debido a las constantes mejoras tecnológicas en su sector el equipo está algo obsoleto y está planteándose cambiar su equipo actual, ha solicitado precios de equipos nuevos y ha estimado el valor del equipo que posee en 500.000,00 € (es el valor que percibiría al vender su equipo como usado y comprar un equipo nuevo). Justifique si procede realizar un ajuste de fin de ejercicio y, en su caso, contabilícelo.

\begin{tabular}{|l|l|l|l|}
\hline \multicolumn{3}{|l|}{} \\
\hline 31 diciembre 00 & & & \\
\hline
\end{tabular}

\section{Ejercicio 11. Deterioro en créditos comerciales}

La empresa DELICATESSEN SL tiene un cliente cuyo crédito de 1.300,00 € vencía el 9 de diciembre y que a la fecha de fin de ejercicio todavía no ha pagado. Puestos en contacto con él ha manifestado que está teniendo problemas de tesorería pero que pagará más adelante. La empresa consulta con otros proveedores de dicho cliente y parece confirmar que tendrá más dificultades de cobro que las previstas. Tras evaluar atentamente la situación estima que logrará cobrar la mitad del importe que se le debe. Justifique si procede realizar un ajuste de fin de ejercicio y, en su caso, contabilícelo.

\begin{tabular}{|l|l|l|l|}
\hline \multicolumn{3}{|l|}{$\mid$} \\
\hline 31 diciembre 00 & & & \\
\hline
\end{tabular}




\section{Ejercicio 12. Impuesto sobre beneficios}

La empresa EL CORTE INGLÉS SA ha obtenido en 2000 un beneficio antes de impuestos de 100.000,00 €. El tipo impositivo aplicable es del 30\%. Contabilice el impuesto, a 31 de diciembre de 2000, que queda pendiente de pago.

31 diciembre 00

\section{Ejercicio 13. Asiento de liquidación de ingresos y gastos}

Contabilice el asiento de liquidación de ingresos y gastos para la empresa PINTURAS Y DECORACIÓN SL que presenta el siguiente balance de saldos a final del ejercicio 2000 tras los ajustes de fin de ejercicio. Indique el resultado obtenido durante el ejercicio o saldo de la cuenta de pérdidas y ganancias.

\begin{tabular}{|c|c|c|}
\hline CUENTAS & Saldos deudores & Saldos acreedores \\
\hline 100. Capital social $(\mathrm{N})$ & & $14.400,00$ \\
\hline 113. Reservas voluntarias $(\mathrm{N})$ & & $19.000,00$ \\
\hline 170. Deudas a 1.p. con entidades de crédito (P) & & $12.000,00$ \\
\hline 203. Propiedad industrial (patentes) (A) & $1.400,00$ & \\
\hline 210. Terrenos y bienes naturales (A) & $10.000,00$ & \\
\hline 211. Construcciones $(\mathrm{A})$ & $30.000,00$ & \\
\hline 213. Maquinaria $(\mathrm{A})$ & $2.700,00$ & \\
\hline 216. Mobiliario (A) & $5.000,00$ & \\
\hline 250. Inversiones financieras en acciones (A) & $3.000,00$ & \\
\hline 300. Mercaderías(A) & $3.300,00$ & \\
\hline 400. Proveedores $(\mathrm{P})$ & & $21.200,00$ \\
\hline 410. Acreedores por prestación de servicios $(\mathrm{P})$ & & $11.000,00$ \\
\hline 430. Clientes $(\mathrm{A})$ & $12.500,00$ & \\
\hline 440. Deudores diversos (A) & $6.500,00$ & \\
\hline 465. Remuneraciones pendientes de pago $(\mathrm{P})$ & & $3.500,00$ \\
\hline 475. Hacienda Pública acreedora $(\mathrm{P})$ & & $1.200,00$ \\
\hline 520. Deudas c.p. entidades de crédito (P) & & $3.000,00$ \\
\hline 540. Inversión en acciones a corto plazo (A) & $7.000,00$ & \\
\hline 572. Bancos $(\mathrm{A})$ & $13.600,00$ & \\
\hline 600. Compras de mercaderías $(\mathrm{G})$ & $8.500,00$ & \\
\hline 610. Variación de existencias $(\mathrm{G})$ & $1.000,00$ & \\
\hline 622. Servicios de profesionales independientes $(\mathrm{G})$ & $1.000,00$ & \\
\hline 624. Transportes $(\mathrm{G})$ & 500,00 & \\
\hline 628. Suministros $(\mathrm{G})$ & $2.100,00$ & \\
\hline 640. Sueldos y salarios $(G)$ & $7.000,00$ & \\
\hline 642. Seguridad Social a cargo de la empresa (G) & $1.500,00$ & \\
\hline 662. Gastos financieros $(\mathrm{G})$ & $1.300,00$ & \\
\hline 700. Ventas de mercaderías (I) & & $29.000,00$ \\
\hline 752. Ingresos por arrendamientos (I) & & $3.600,00$ \\
\hline SUMAS TOTALES & $\mathbf{1 1 7 . 9 0 0 , 0 0}$ & $\mathbf{1 1 7 . 9 0 0 , 0 0}$ \\
\hline
\end{tabular}




\begin{tabular}{|l|l|l|l|}
\hline 31 diciembre 00 & & & \\
\hline 31 diciembre 00 & & & \\
\hline $\begin{array}{l}\text { El resultado } \\
\text { obtenido será: }\end{array}$ & & & \\
\hline
\end{tabular}

\section{Ejercicio 14. Asiento de cierre}

Con los datos del ejercicio anterior contabilice el asiento de cierre del ejercicio 2000 para la empresa PINTURAS Y DECORACIÓN SL. Para el mismo tenga en cuenta el saldo obtenido en la cuenta de pérdidas y ganancias.

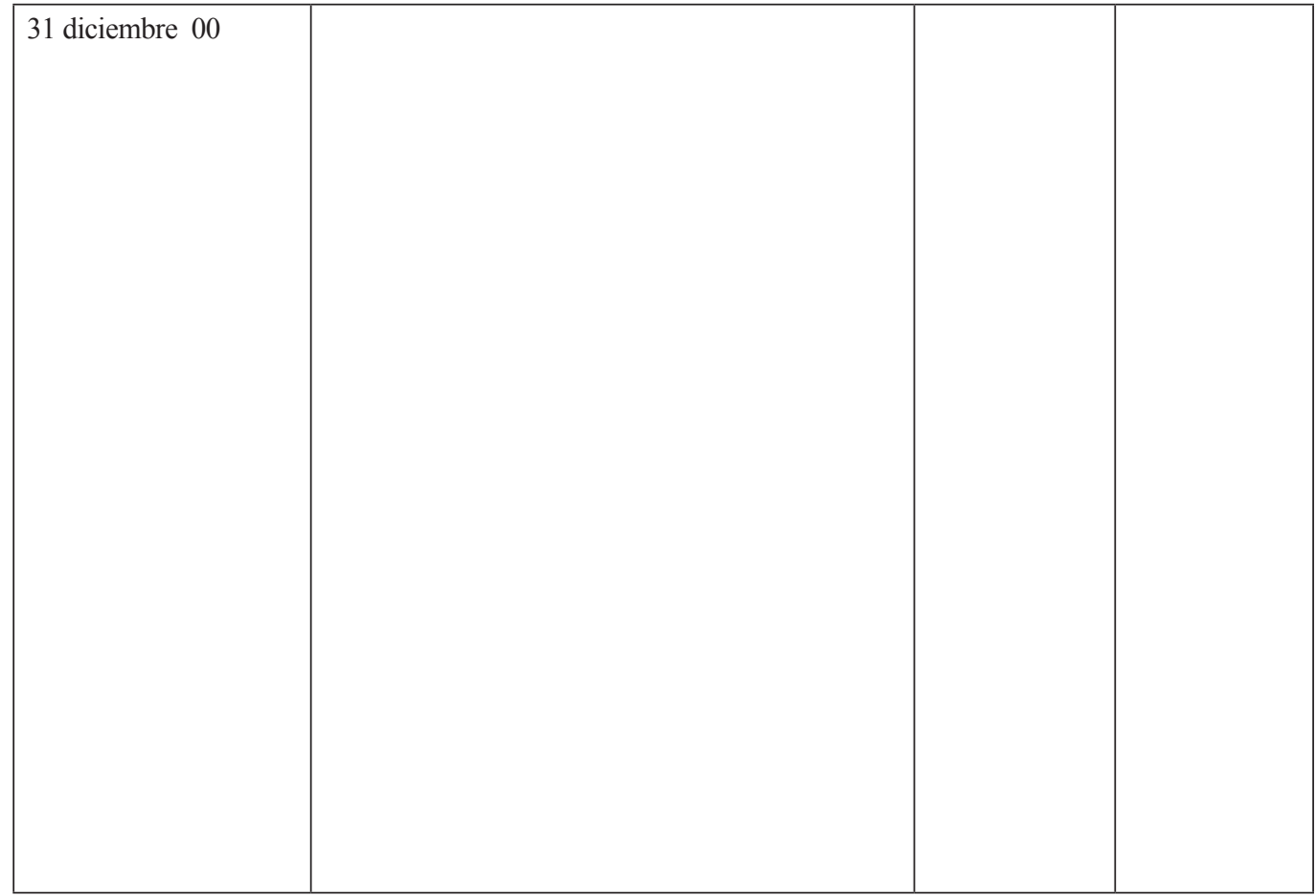

\section{Ejercicio 15. Contabilización de ajustes de fin de ejercicio}

Se presentan diversas situaciones de la empresa TOTAL EXPRESS SL con información para la contabilización de los ajustes de fin de ejercicio que proceda. En todos los casos las transacciones corresponden al ejercicio 2000 y los ajustes al 31 de diciembre de dicho año.

a) Obtuvo el 5 de diciembre un préstamo a corto plazo de $20.000 €$ al $6 \%$ anual. Los intereses de pagan por meses vencidos cada 5 del mes. Están pendiente de registrar los intereses devengados por dicho préstamo hasta fines de ejercicio

b) Obtuvo el 15 de septiembre un préstamo a corto plazo de $10.000 €$ al $4 \%$ anual. Los intereses de pagan por meses vencidos cada 15 del mes. Están pendiente de registrar los intereses devengados a 31 de diciembre desde el último pago de intereses. 
c) El 15 de octubre concedió un préstamo a largo plazo de $30.000 €$ al 5\% anual. Los intereses se cobran por trimestres vencidos. Están pendiente de registro los intereses devengados a 31 de diciembre desde el último cobro de intereses.

d) El 15 de diciembre ha registrado como gasto una factura de alquiler por un mes de un vehículo comercial y por importe de 500,00€.

e) El 10 de diciembre emite anticipadamente una factura a un cliente por prestación de servicios de 1.000,00 €. La empresa estima a 31 de diciembre que el valor de los servicios efectivamente prestados a dicha fecha asciende a $800,00 €$.

f) Realizados todos los ajustes del ejercicio, contabilice el devengo del impuesto de sociedades del año que asciende a $450.000 €$.

a) Intereses devengados

\begin{tabular}{|l|l|l|l|}
\hline 31 diciembre 00 & & & \\
\hline
\end{tabular}

b) Intereses de deudas

\begin{tabular}{|l|l|l|l|}
\hline 31 diciembre 00 & & & \\
\hline
\end{tabular}

c) Intereses devengados

\begin{tabular}{|l|l|l|l|}
\hline 31 diciembre 00 & & & \\
\hline
\end{tabular}

d) Gastos anticipados

\begin{tabular}{|l|l|l|l|}
\hline 31 diciembre 00 & & & \\
\hline
\end{tabular}

e) Ingresos anticipados

\begin{tabular}{|l|l|l|l|}
\hline 31 diciembre 00 & & & \\
\hline
\end{tabular}

f) Impuesto sobre beneficios

\begin{tabular}{|l|l|l|l|}
\hline 31 diciembre 00 & & & \\
\hline
\end{tabular}

\section{Ejercicio 16. Correcciones valorativas}

A continuación se presentan diversas situaciones que originan, o pueden originar, correcciones valorativas de elementos de activo de la empresa ALCAMPO SA. Identifique el tipo de corrección valorativa de qué se trata y, en su caso, contabilícela.

a) A 31 de diciembre, y tras realizar un inventario valorado, se estima que mercancías cuyo valor contable es de $4.000 €$ tienen un valor de $3.000 €$.

b) A 31 de diciembre la depreciación por uso durante el ejercicio de las instalaciones asciende a $15.000 €$.

c) Un congelador de la sección de «Pescadería» y que aparece registrado contablemente por $25.000 €$ tiene un valor de $10.000 €$.

d) Un cliente de la empresa que adeudaba $300 €$ no ha pagado la factura en la fecha de vencimiento, la empresa estima que existe un riesgo de insolvencia por dicho importe.

e) En años anteriores había registrado un deterioro de mobiliario por importe de $2.000,00 €$. Al finalizar este año, se estima que se ha recuperado el valor. 
f) Han desaparecido las circunstancias que hicieron que un crédito a corto plazo por 5.000,00 fuese considerado deteriorado.

a) Deterioro existencias

31 diciembre 00

b) Amortización instalaciones

\begin{tabular}{|l|l|l|l|}
\hline 31 diciembre 00 & & & \\
\hline
\end{tabular}

c) Deterioro inmovilizado material

31 diciembre 00

d) Deterioro créditos comerciales

\begin{tabular}{|l|l|l|l|}
\hline 31 diciembre 00 & & & \\
\hline
\end{tabular}

e) Reversión de deterioro

\begin{tabular}{|l|l|l|l|}
\hline 31 diciembre 00 & & & \\
\hline
\end{tabular}

f) Reversión de deterioro

\begin{tabular}{|l|l|l|l|}
\hline 31 diciembre 00 & & & \\
\hline
\end{tabular}

\section{Ejercicio 17. Cierre de ejercicio económico}

La empresa TIMON SL presenta el siguiente balance de saldos antes de los ajustes de fin del ejercicio de 2000 (datos en miles de euros):

\begin{tabular}{|l|r|r|}
\hline \multicolumn{1}{|c|}{ CUENTAS } & \multicolumn{2}{c|}{ SALDOS ANTES DE AJUSTES } \\
\hline 100. Capital social (N) & Saldos deudores & \multicolumn{1}{|c|}{ Saldos acreedores } \\
\hline 113. Reservas (N) & & 40.000 \\
\hline 170. Préstamos a 1.p. (P) & 25.000 & 13.000 \\
\hline 211. Construcciones (A) & 15.000 & 15.700 \\
\hline 216. Mobiliario (A) & 2.700 & 11.000 \\
\hline 218. Vehículos (A) & 4.300 & \\
\hline 300. Mercaderías (A) & & \\
\hline 400. Proveedores (P) & & 2.200 \\
\hline 410. Acreedores diversos (P) & 67.500 & 2.500 \\
\hline 430. Clientes (A) & 4.800 & 3.000 \\
\hline 440. Deudores diversos(A) & & \\
\hline 475. H. P. acreedora (P) & & \\
\hline 476. Org. Seguridad Social, acreedores (P) & & \\
\hline 520. Préstamos a c.p. (P) & 3.000 & \\
\hline 540. Inversiones financieras temporales(A) & 13.600 & \\
\hline 572. Bancos c/c (A) & & \\
\hline
\end{tabular}




\begin{tabular}{|l|r|r|}
\hline 600. Compras de mercaderías $(\mathrm{G})$ & 8.400 & \\
\hline 621. Arrendamientos y cánones $(\mathrm{G})$ & 2.100 & \\
\hline 640. Sueldos y salarios $(\mathrm{G})$ & 17.000 & \\
\hline 642. Seguridad Social a cargo de la empresa (G) & 1.500 & \\
\hline 662. Gastos financieros $(\mathrm{G})$ & 3.300 & 69.000 \\
\hline 700. Ventas de mercaderías (I) & & 3.600 \\
\hline 752. Ingresos por arrendamientos (I) & & $\mathbf{1 6 8 . 2 0 0}$ \\
\hline \multicolumn{1}{|c|}{ TOTALES } & $\mathbf{1 6 8 . 2 0 0}$ & \\
\hline
\end{tabular}

Información adicional para la realización de los ajustes de fin de ejercicio (importes en euros):

1. Faltan por contabilizar los intereses del mes de diciembre del préstamo que figura en balance en la cuenta «Préstamos a largo plazo». El tipo de interés pactado es del $6 \%$ anual.

2. El impuesto de sociedades del ejercicio asciende a $3.000 €$.

Se pide que:

a) Contabilice los ajustes de fin de período que proceda según la información anterior.

b) Incluya en el balance de comprobación de saldos las cuentas afectadas por los anteriores ajustes, creando las filas que necesite para ello y recalcule los totales.

c) Contabilice el asiento de liquidación.

d) Contabilice el asiento de cierre.

a) Ajustes de fin de período

1. Intereses devengados

31 diciembre 00

2. Impuesto sobre beneficios

31 diciembre 00

b) Balance de comprobación tras los ajustes

\begin{tabular}{|l|l|l|}
\hline \multicolumn{1}{|c|}{ CUENTAS } & \multicolumn{2}{c|}{ SALDOS ANTES DE AJUSTES } \\
\hline 100. Capital social (N) & Saldos deudores & Saldos acreedores \\
\hline 113. Reservas voluntarias (N) & & \\
\hline 170. Préstamos a 1.p. (P) & & \\
\hline 211. Construcciones (A) & & \\
\hline 216. Mobiliario (A) & & \\
\hline 218. Vehículos (A) & & \\
\hline 300. Mercaderías (A) & & \\
\hline 400. Proveedores (P) & & \\
\hline
\end{tabular}




\begin{tabular}{|l|l|l|}
\hline 410. Acreedores diversos (P) & & \\
\hline 430. Clientes (A) & & \\
\hline 440. Deudores diversos(A) & & \\
\hline 475. H. P. acreedora (P) & & \\
\hline 476. Org. Seguridad Social, acreedores (P) & & \\
\hline 520. Préstamos a c.p. (P) & & \\
\hline 527. Intereses c.p. de deudas (P) & & \\
\hline 540. Inversiones financieras temporales(A) & & \\
\hline 572. Bancos c/c (A) & & \\
\hline 600. Compras de mercaderías (G) & & \\
\hline 621. Arrendamientos y cánones (G) & & \\
\hline 630. Impuesto sobre beneficios (G) & & \\
\hline 640. Sueldos y salarios (G) & & \\
\hline 642. Seguridad Social a cargo de la empresa (G) & & \\
\hline 662. Gastos financieros (G) & & \\
\hline 700. Ventas de mercaderías (I) & & \\
\hline 752. Ingresos por arrendamientos (I) & & \\
\hline \multicolumn{1}{|c|}{ TOTALES } & & \\
\hline
\end{tabular}

c) Asiento de liquidación de ingresos y gastos

\begin{tabular}{|l|l|l|l|}
\hline 31 diciembre 00 & & & \\
& & & \\
\hline 31 diciembre 00 & & & \\
\hline
\end{tabular}

Saldo de la cuenta 129. P y G =

\section{d) Asiento de cierre}

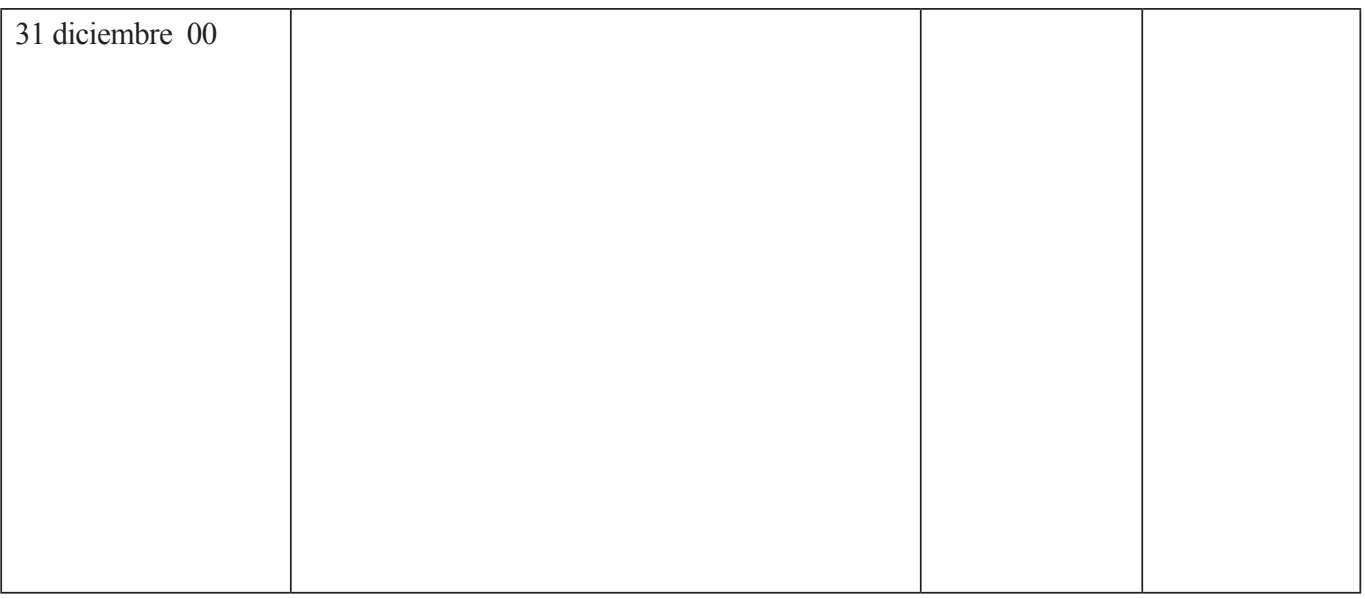




\section{Ejercicio 18. Ciclo contable completo}

La empresa JUGUETES SA presenta el siguiente balance de situación a 1 de enero de 2000.

\begin{tabular}{|c|c|c|c|}
\hline \multicolumn{4}{|c|}{$\begin{array}{c}\text { JUGUETES SA } \\
\text { BALANCE a } 01 \text { de enero de } 2000 \text { (datos en euros) }\end{array}$} \\
\hline \multicolumn{2}{|c|}{ ACTIVO } & \multicolumn{2}{|c|}{ PASIVO Y PATRIMONIO NETO } \\
\hline NO CORRIENTE & $1.000 .000,00$ & PATRIMONIO NETO & $750.000,00$ \\
\hline 211. Local comercial & $700.000,00$ & 100. Capital & $600.000,00$ \\
\hline 218. Vehículos & $300.000,00$ & 113. Reservas & $150.000,00$ \\
\hline & & PASIVO NO CORRIENTE & $500.000,00$ \\
\hline CORRIENTE & $600.000,00$ & 170. Préstamos a largo plazo & $500.000,00$ \\
\hline 430. Clientes & $200.000,00$ & PASIVO CORRIENTE & $350.000,00$ \\
\hline 300. Mercancías & $100.000,00$ & 400. Proveedores & $300.000,00$ \\
\hline 572. Bancos c/c & $300.000,00$ & 475. Hda. Pública Acreedora & $50.000,00$ \\
\hline Total & $1.600 .000,00$ & Total & $1.600 .000,00$ \\
\hline
\end{tabular}

Durante el año 2000 realiza las siguientes transacciones (cuando proceda se aplicará un IVA del 18\%):

1. Compra mercancías a crédito por importe de 400.000,00€.

2. Paga con un cheque a los proveedores $50.000,00 €$.

3. Vende mercancías a crédito por importe de 700.000,00€.

4. Cobra en efectivo $70.000,00 €$ de sus clientes.

5. Paga con cheque la nómina de los empleados que asciende a 50.000,00 € por sueldos (no hay retenciones por IRPF ni Seguridad Social). Los gastos por seguridad social a cargo de la empresa, 10.000,00 $€$ quedan pendientes de pago.

6. Paga a través de la cuenta corriente bancaria los gastos de electricidad, teléfono y agua, que ascienden a $2.000,00 €, 5.000,00 €$ y $3.000 €$ respectivamente.

7. Le cargan en la cuenta bancaria 4.000,00 € de intereses del préstamo que figura en el pasivo del balance.

8. Devuelve 30.000,00 € del principal del préstamo anterior.

9. La cuenta bancaria genera unos intereses a favor por importe de $1.000 €$.

10. Compra unas acciones a corto plazo mediante transferencia bancaria por $60.000,00 €$.

Para proceder a los ajustes de fin de período se debe tener en cuenta la siguiente información:

11. Los intereses devengados del préstamo a largo plazo que figura en el pasivo y no vencidos (no contabilizados aún) a final del año ascienden a 1.500,00 €.

12. Las existencias finales en almacén, según recuento físico ascienden a $150.000,00 €$.

13. Se estima que existen clientes con riesgo de insolvencia, por lo que se estima un deterioro por importe de 500,00€.

14. Los elementos de inmovilizado se amortizan en un $10 \%$ de su valor en balance.

15. Debe liquidarse el iva que queda pendiente de pago.

16. El impuesto de sociedades asciende a 20.000,00€.

Se pide que:

a) Abra la contabilidad a 1 de enero mediante el asiento de apertura.

b) Contabilice las operaciones realizadas durante el año y las pase al mayor. 
c) Contabilice los ajustes de fin de período que proceda y los pase al mayor.

d) Elabore un balance de comprobación de sumas y saldos tras los ajustes.

e) Contabilice el asiento de liquidación de ingresos y gastos.

f) Contabilice el asiento de cierre.

g) Elabore la cuenta de pérdidas y ganancias del año 2000.

h) Elabore el balance a 31 de diciembre de 2000.

a) Asiento de apertura

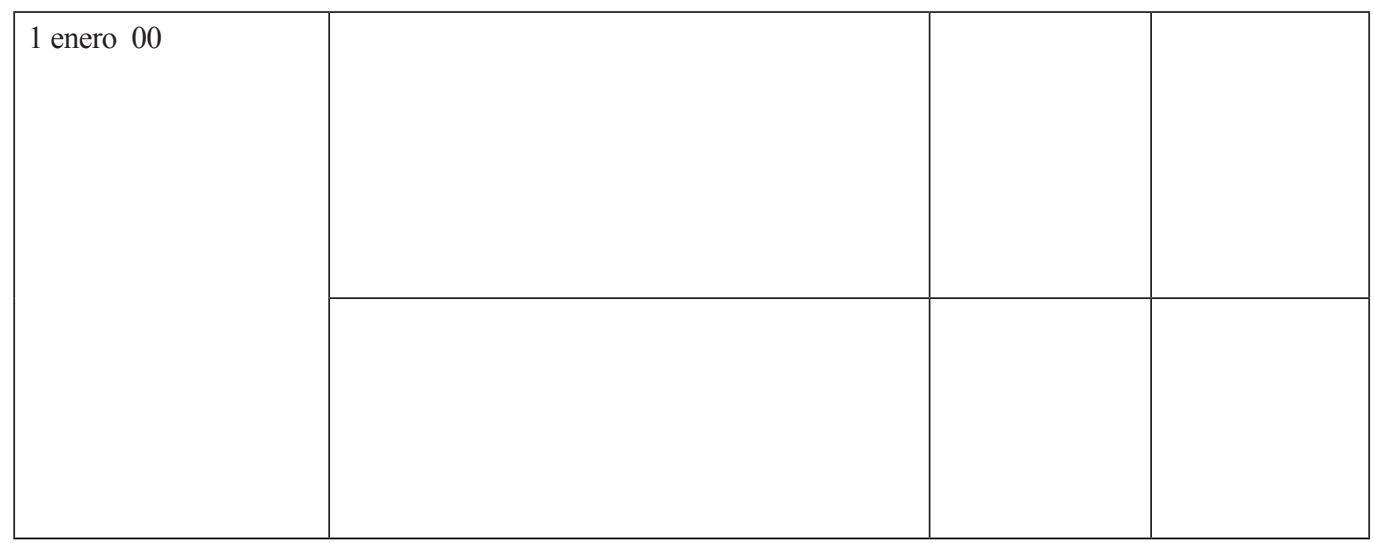

b) Operaciones del ejercicio

\begin{tabular}{|l|l|l|l|}
\hline 2. Compra mercaderías & & & \\
\hline 3. Pago a proveedores & & & \\
\hline 4. Venta mercaderías & & & \\
\hline 5. Cobro de clientes & & & \\
\hline
\end{tabular}

\begin{tabular}{|l|l|l|l|}
\hline 6. Nómina & & & \\
\hline & & & \\
& & & \\
\hline
\end{tabular}

\begin{tabular}{|l|l|l|l|}
\hline 7. Suministros & & & \\
\hline
\end{tabular}

\begin{tabular}{|l|l|l|l|}
\hline 8. Intereses & & & \\
\hline
\end{tabular}

\begin{tabular}{|l|l|l|l|}
\hline 9. Devolución préstamo & & & \\
\hline 10. Intereses cuenta & & & \\
\hline
\end{tabular}

11. Compra acciones 
c) Ajustes de fin de ejercicio

\begin{tabular}{|l|l|l|l|}
\hline 12. Intereses devengados & & & \\
\hline $\begin{array}{l}\text { 13. Regularización } \\
\text { existencias }\end{array}$ & & & \\
\cline { 2 - 5 } & & & \\
\hline 14. Deterioro clientes & & & \\
\hline 15. Amortización & & & \\
\hline \begin{tabular}{l|l|l|l|} 
16. Liquidación IVA6 & & & \\
\hline \begin{tabular}{|l|l|l|} 
17. Impuestos/ \\
beneficios
\end{tabular} & & & \\
\hline
\end{tabular}
\end{tabular}

MAYOR JUGUETES SA, tras todas las operaciones y ajustes

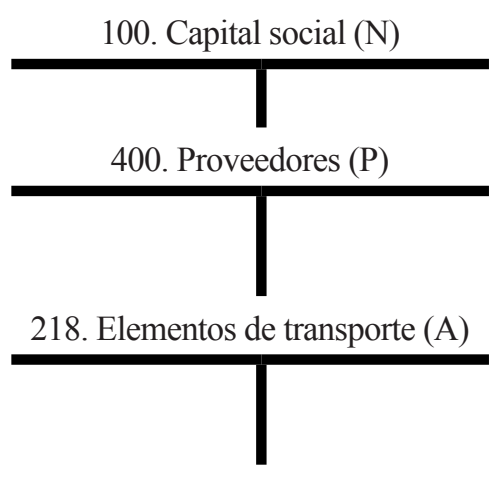

572. Bancos c/c (A)

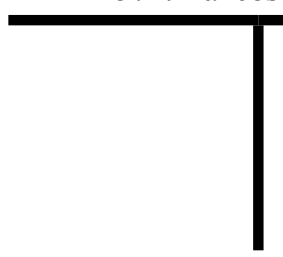

640. Sueldos y salarios $(\mathrm{G})$

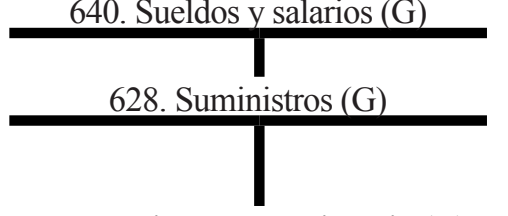

540. IFT instrum. patrimonio (A)

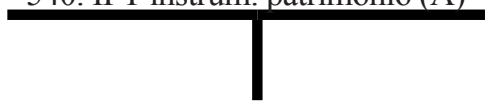

694. Pérdidas det. valor créditos

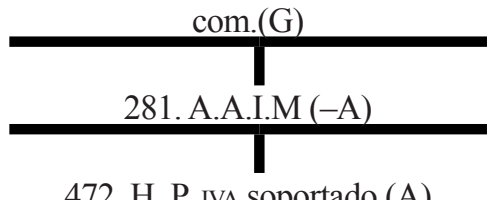

472. H. P. IVA soportado (A)

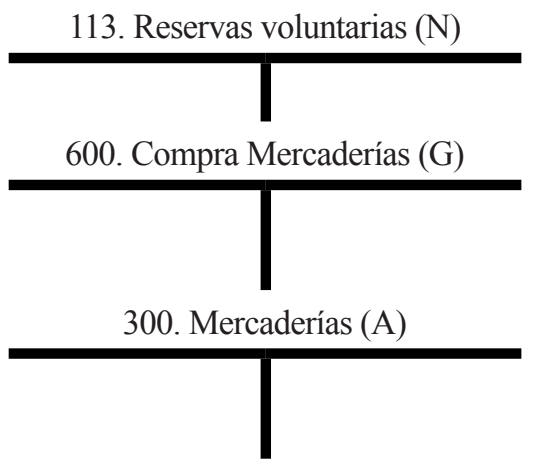

475. Hda. Pca. acreedora (P)

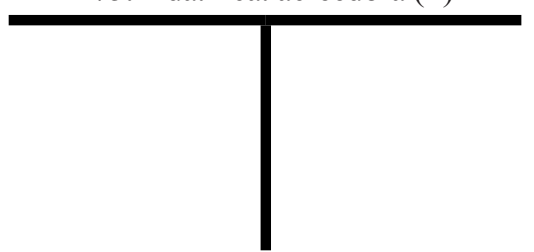

642. Seg. Social c/empresa $(\mathrm{G})$

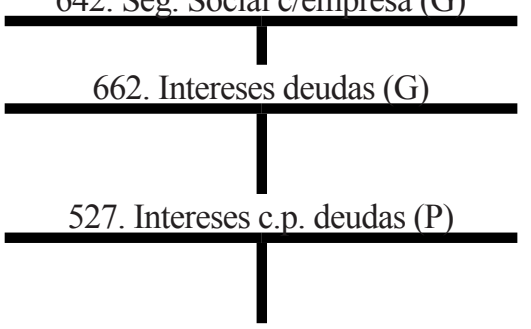

490. Deterioro valor cdtos. com. (-A)

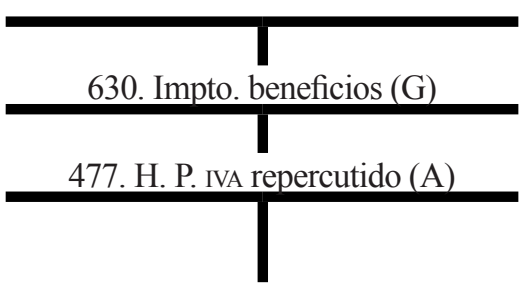

170. Préstamos 1.p. (P)

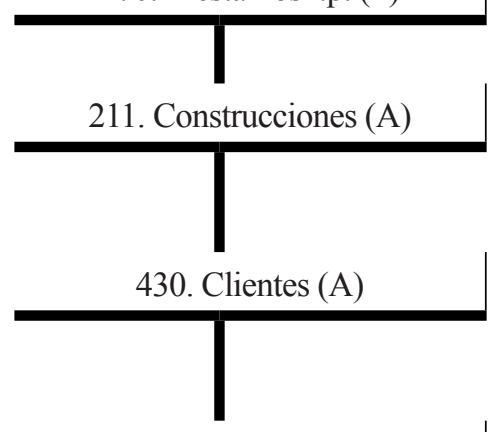

700. Venta mercaderías (I)

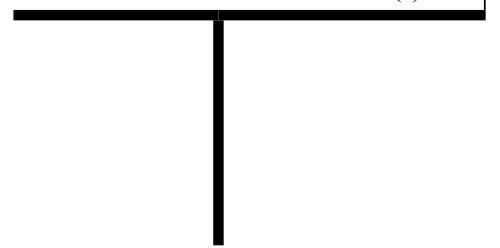

476. Org. Seg. Social Acreed. (P)

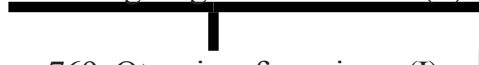

769. Otros ing. financieros (I)

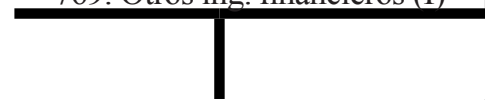

610. Variación existencias $(\mathrm{G})$

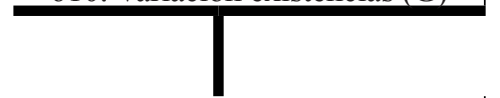

681. Amortización I. M. (G)

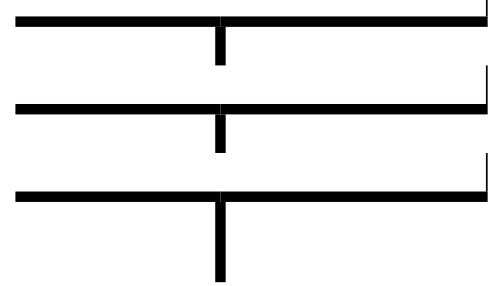


d) Balance de comprobacion de sumas y saldos

\begin{tabular}{|l|l|l|l|l|}
\hline \multicolumn{5}{|c|}{ JULANCE DE COMPROBACIÓN DE SUMAS Y SALDOS } \\
01-01-00 A 31-12-00 \\
\hline \multicolumn{1}{|c|}{ CUENTAS } & $\begin{array}{c}\text { Sumas } \\
\text { deudoras }\end{array}$ & $\begin{array}{c}\text { Sumas } \\
\text { acreedoras }\end{array}$ & $\begin{array}{c}\text { Saldos } \\
\text { deudores }\end{array}$ & $\begin{array}{c}\text { Saldos } \\
\text { acreedores }\end{array}$ \\
\hline 100. Capital social (N) & & & & \\
\hline 113. Reservas voluntarias (N) & & & & \\
\hline 170. Préstamos a L/P (P) & & & & \\
\hline 211. Construcciones (A) & & & & \\
\hline 218. Elementos de transporte (A) & & & & \\
\hline 281. A.A.I.M (-A) & & & & \\
\hline 300. Mercaderías (A) & & & & \\
\hline 400. Proveedores (P) & & & & \\
\hline 430. Clientes (A) & & & & \\
\hline 472. H. P. IVA soportado A) & & & & \\
\hline 475. H. P. acreedora (P) & & & & \\
\hline 476. Org. Seg. Social Acreed. (P) & & & & \\
\hline 477. H. P. IVA repercutido (P) & & & & \\
\hline 490. Deterioro valor cdtos com (-A) & & & & \\
\hline 527. Intereses c.p. deudas (P) & & & & \\
\hline 540. IFT instrum. patrimonio (A) & & & & \\
\hline 572. Bancos c/c (A) & & & & \\
\hline 600. Compra mercaderías (G) & & & & \\
\hline 610. Variación existencias (G) & & & & \\
\hline 628. Suministros (G) & & & & \\
\hline 630. Impto. beneficios (G) & & & & \\
\hline 640. Sueldos y salarios (G & & & & \\
\hline 642. Seg. Social c/empresa (G) & & & & \\
\hline 662. Intereses deudas (G) & & & & \\
\hline 681. Amortización I.M. (G) & & & & \\
\hline 694. Pérdidas det. valor créditos com.(G) & & & & \\
\hline 700. Venta mercaderías (I) & & & & \\
\hline 769. Otros ing. financieros (I) & & & & \\
\hline & & & & \\
\hline
\end{tabular}

e) Asiento de liquidación de ingresos y gastos

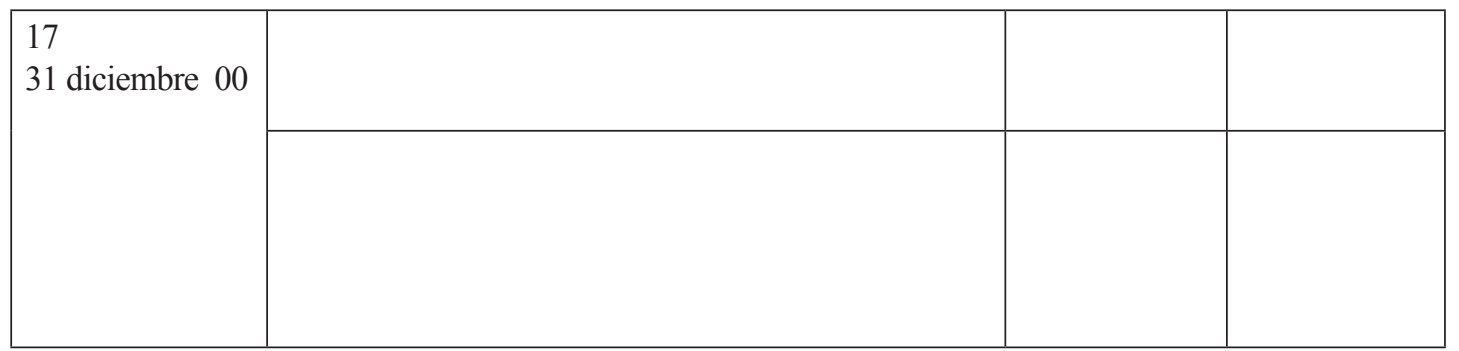

Saldo 129. Pérdidas y ganancias $=$ 
f) Asiento de cierre

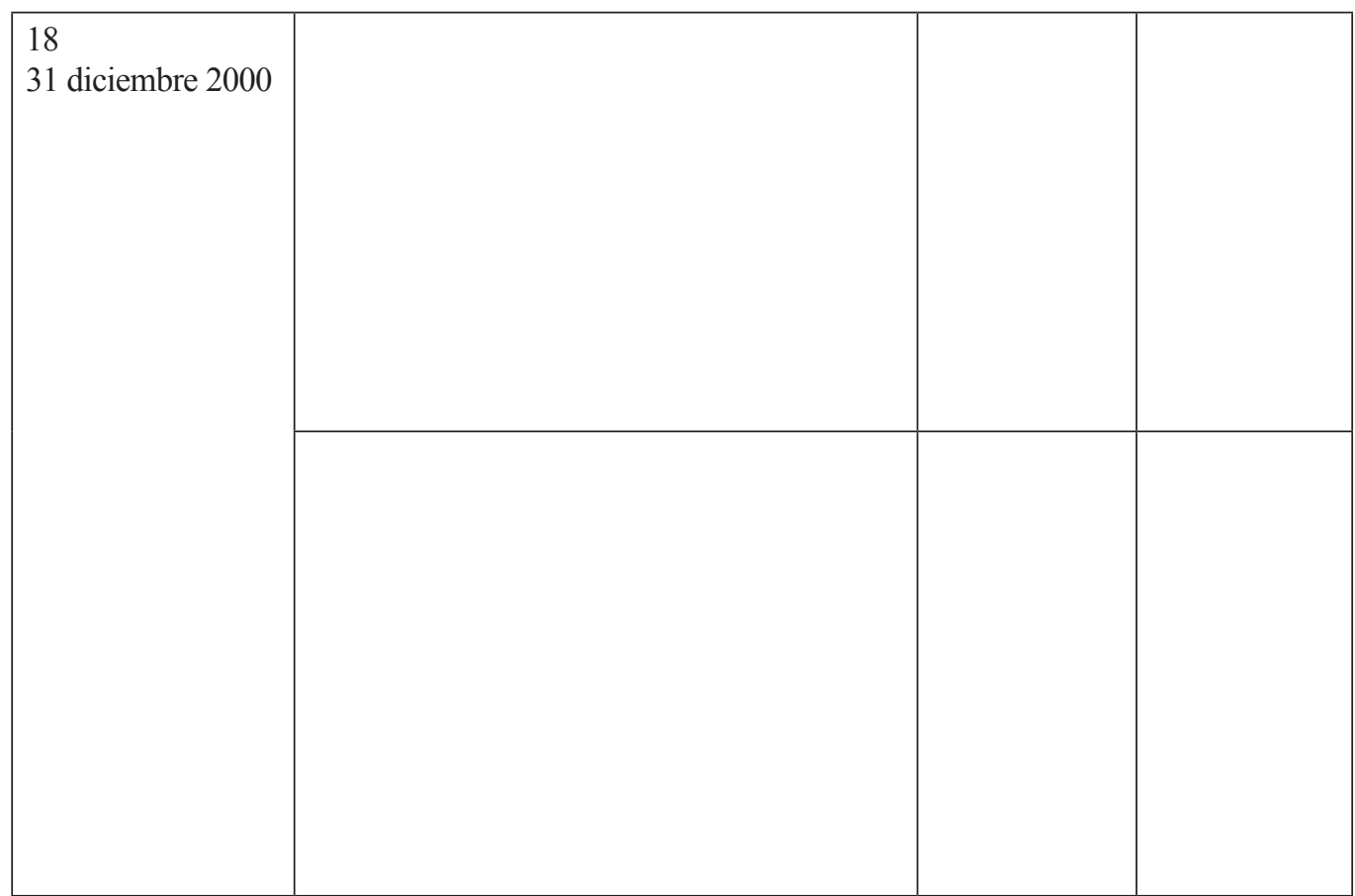

g) Cuenta de pérdidas y ganancias

\begin{tabular}{|l|l|}
\hline \multicolumn{2}{|c|}{ JUGUETES SA } \\
Cuenta de pérdidas y ganancias del período 01/01/00 a 31/12/00 \\
\hline 4. Aprovisionamientos & \\
5. Otros ingresos de explotación & \\
6. Gastos de personal & \\
7. Otros gastos de explotación & \\
8. Amortizaciones del inmovilizado & \\
11. Deterioro y resultado por enajenaciones de inmovilizado & \\
\hline A.1) RESULTADO DE EXPLOTACIÓN $=(1)+(4)+(5)+(6)+(7)+(8)+(11)$ & \\
\hline 12. Ingresos financieros & \\
13. Gastos financieros & \\
16. Deterioro y resultado por enajenaciones de instrumentos financieros & \\
\hline A.2) RESULTADO FINANCIERO $=(12)+(13)+(16)$ & \\
\hline A.3) RESULTADO ANTES DE IMPUESTOS $=($ A.1 $)+($ A. 2$)$ & \\
\hline 17. Impuesto sobre beneficios & \\
\hline A.4) RESULTADO DEL EJERCICIO $=($ A.3 $)+(17)$ & \\
\hline
\end{tabular}


h) Balance

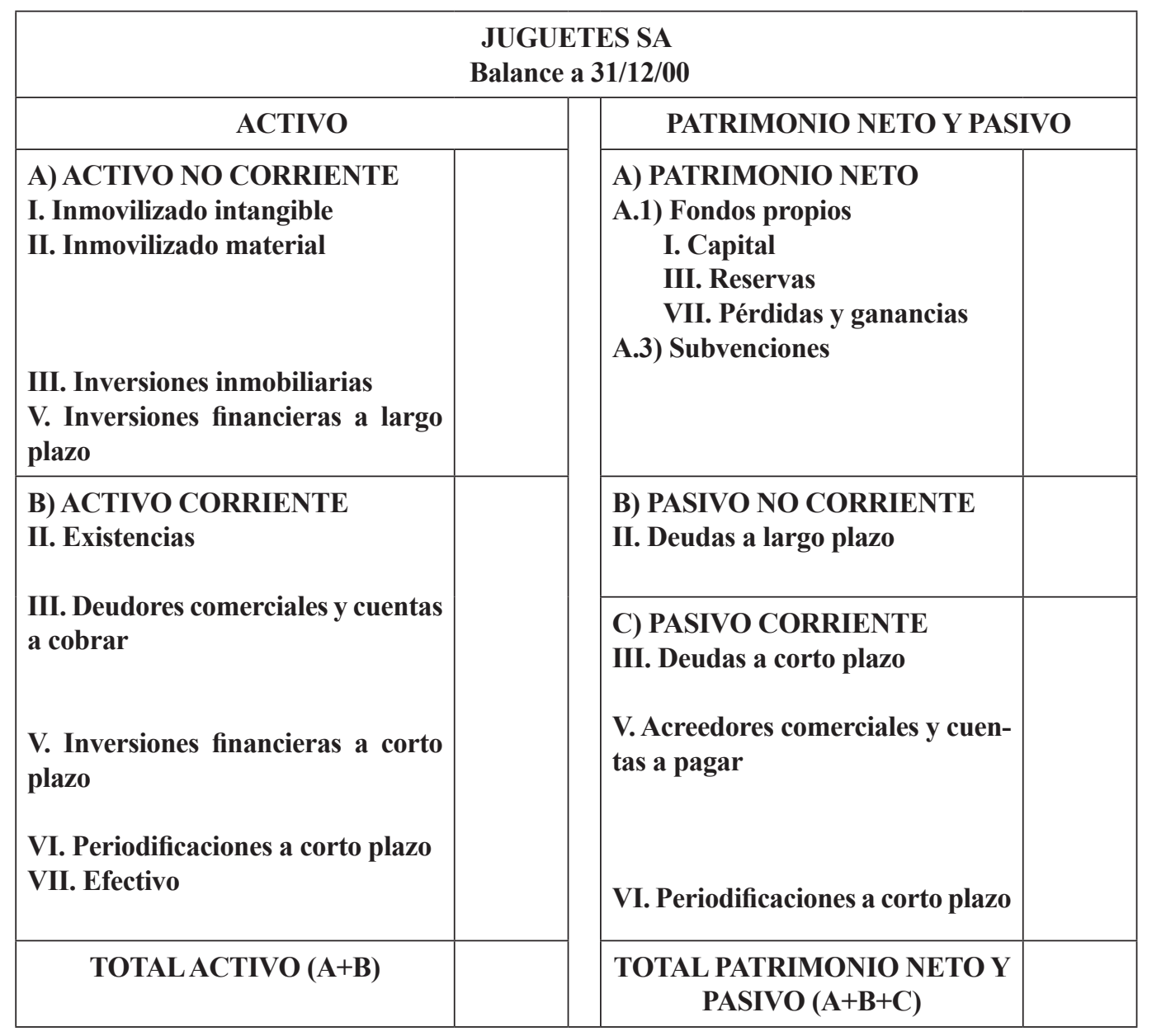

Ejercicio 19. Ciclo contable completo

La empresa PNEUMATIQUES SA presentó el siguiente balance a 1 de enero de 2000:

\begin{tabular}{|c|c|c|c|}
\hline \multicolumn{4}{|c|}{$\begin{array}{l}\text { PNEUMATIQUES SA } \\
\text { BALANCE a } 01 \text { de enero de } 2000 \text { (datos en euros) }\end{array}$} \\
\hline \multicolumn{2}{|l|}{ ACTIVO } & \multicolumn{2}{|c|}{ PASIVO Y PATRIMONIO NETO } \\
\hline $\begin{array}{l}\text { NO CORRIENTE } \\
\text { 211. Construcciones } \\
\text { 218. Elementos transporte } \\
\text { 213. Maquinaria } \\
\text { 252. Créditos a largo plazo } \\
\text { CORRIENTE } \\
\text { 300. Mercancías } \\
\text { 430. Clientes } \\
\text { 572. Bancos c/c } \\
\text { 570. Caja }\end{array}$ & $\begin{array}{c}\mathbf{5 5 0 . 0 0 0 , 0 0} \\
200.000,00 \\
100.000,00 \\
200.000,00 \\
50.000,00 \\
\mathbf{5 7 0 . 0 0 0 , 0 0} \\
200.000,00 \\
110.000,00 \\
250.000,00 \\
10.000,00\end{array}$ & $\begin{array}{l}\text { PATRIMONIO NETO } \\
\text { 100. Capital social } \\
\text { 113. Reservas voluntarias } \\
\text { PASIVO NO CORRIENTE } \\
\text { 170. Préstamos a largo plazo } \\
\text { PASIVO CORRIENTE } \\
\text { 520. Préstamos a corto plazo } \\
\text { 400. Proveedores } \\
\text { 476. Seguridad Social } \\
\text { acreedora } \\
\text { 475. Hacienda Pública } \\
\text { acreedora }\end{array}$ & $\begin{array}{c}\mathbf{5 5 0 . 0 0 0 , 0 0} \\
500.000,00 \\
50.000,00 \\
\mathbf{3 0 0 . 0 0 0 , 0 0} \\
300.000,00 \\
\mathbf{2 7 0 . 0 0 0 , 0 0} \\
200.000,00 \\
40.000,00 \\
10.000,00 \\
20.000,00\end{array}$ \\
\hline Total & $1.120 .000,00$ & Total & $1.120 .000,00$ \\
\hline
\end{tabular}


Durante el año 2000 la empresa realizó las siguientes operaciones (se trata de operaciones agregadas por lo que no se indican fechas y debe considerarse un IVA del $18 \%$ en las operaciones que proceda):

1. Compró mercancías a crédito por importe de 300.000,00€.

2. Pagó con un cheque a los proveedores $20.000,00 €$.

3. Obtuvo préstamos a corto plazo por importe de $200.000,00 €$ que se ingresa en el banco.

4. Vendió mercancías en efectivo por importe de 500.000,00€.

5. Ingresó en el banco $450.000,00 €$ de cobros anteriores.

6. Cobró en efectivo 80.000,00 € de sus clientes.

7. Pagó mediante transferencia las nóminas de los empleados que ascienden a $40.000,00 €$ y la seguridad social por $10.000,00 €$.

8. Pagó a través de la cuenta corriente bancaria los gastos de electricidad y agua, que ascienden a $4.000 €$ y $3.000,00 €$ respectivamente.

9. Le cargaron en la cuenta bancaria 3.000.00 $€$ de intereses de los préstamos a largo plazo que figuran en el pasivo del balance.

10. Le cargaron en la cuenta bancaria $2.000 .00 €$ de intereses de los préstamos a corto plazo que figuran en el pasivo del balance. Asimismo devolvió $100.000 .00 €$ del principal.

11. Cobró a través el banco $1.000 .00 €$ correspondientes a intereses de los créditos que figuran en el activo del balance.

12. La cuenta bancaria generó unos intereses a favor por importe de $500.00 €$.

13. Compró acciones a corto plazo con cargo a la cuenta corriente cuyo coste fue de $40.000 .00 €$.

14. El último día del año compró nuevas máquinas por importe de $50.000 .00 €$, el importe quedó pendiente de pago a largo plazo.

15. El primer día del año vendió un vehículo que figuraba en balance por $40.000,00 €$ por $60.000,00 €$, importe que se ingresó en el banco.

Para proceder a los ajustes de fin de período se debe tener en cuenta la siguiente información:

16. Falta contabilizar la nómina del mes de diciembre, pendiente de pago, que asciende a $4.000,00 €$.

17. Está pendiente de contabilizar los costes de seguridad social a cargo de la empresa de diciembre que ascienden a 1.500,00€.

18. Los intereses de préstamos a largo plazo y no vencidos a fin del trimestre ascienden a $1.000,00 €$.

19. Los intereses devengados de créditos y no vencidos (aún no contabilizados) a final del año ascienden a 50,00 €.

20. El valor de las existencias finales en almacén asciende a 150.000,00€.

21. Parte de los gastos de electricidad pagados en el punto 9, por importe de $1.000,00 €$, corresponden a un pago anticipado a cuenta del consumo del próximo año.

22. Se estima que existe deterioro del local comercial por $30.000,00 €$.

23. El local comercial se amortiza en un $4 \%$ de su valor contable y el resto del inmovilizado en un $10 \%$. La maquinaria adquirida al final del año no se amortiza. El vehículo que vendió a inicios de año no debe amortizarse. 
24. Se liquida el IVA, por lo que quedan el importe pendiente de pago.

25. El impuesto de sociedades del ejercicio asciende a 15.000,00€.

Se pide que:

a) Abra la contabilidad a 1 de enero de 2000 mediante el asiento de apertura.

b) Contabilice las operaciones realizadas durante el año y las traspase al mayor.

c) Contabilice los ajustes de fin de período que proceda y los traspase al mayor.

d) Elabore un balance de comprobación de sumas y saldos tras los anteriores ajustes.

e) Contabilice el asiento de liquidación de ingresos y gastos.

f) Contabilice el asiento de cierre.

g) Elabore la cuenta de pérdidas y ganancias del año 2000.

h) Elabore el balance a 31 de diciembre de 2000.

a) Asiento de apertura

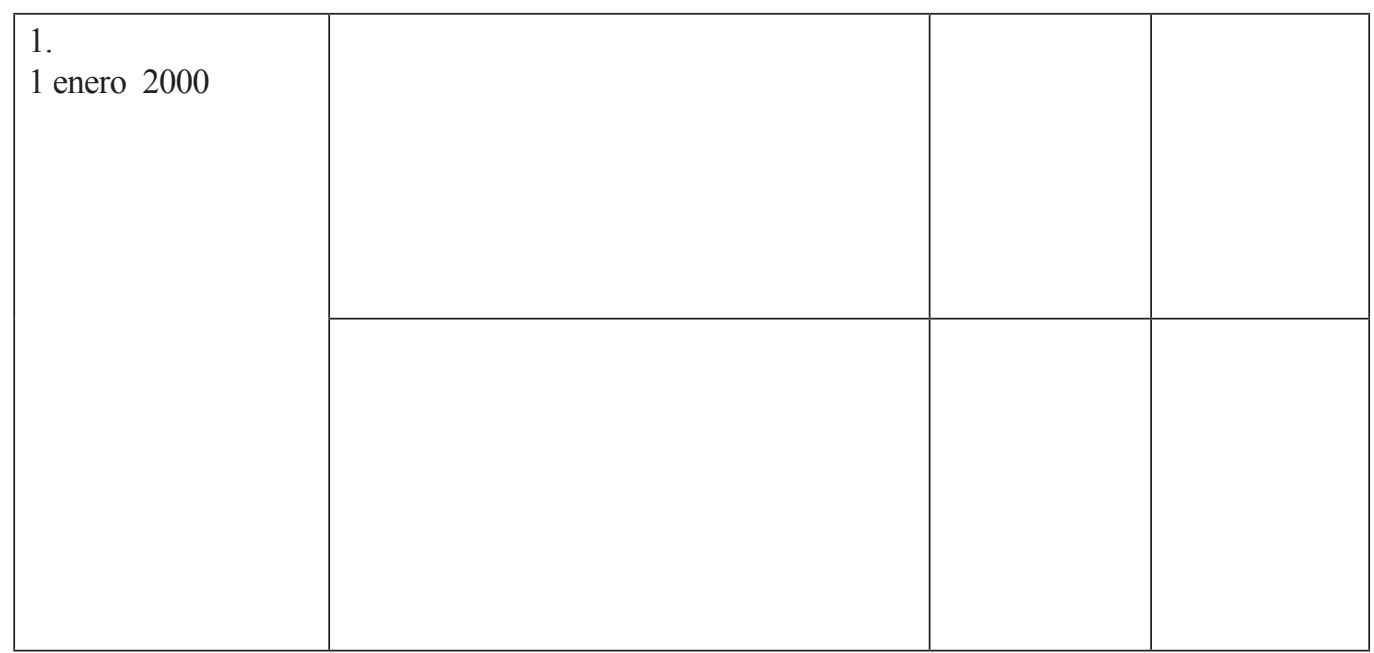

b) Operaciones del ejercicio

\begin{tabular}{|l|l|l|l|}
\hline $\begin{array}{l}\text { 2. Compra } \\
\text { mercaderías }\end{array}$ & & & \\
\hline 3. Pago a proveedores & & & \\
\hline 4. Obtención ptmo. & & & \\
\hline 5. Venta mercaderías & & & \\
\hline 6. Ingreso en cuenta & & & \\
\hline
\end{tabular}




\begin{tabular}{|l|l|l|l|}
\hline 7. Cobro clientes & & & \\
\hline
\end{tabular}

\begin{tabular}{|l|l|l|l|}
\hline 8. Nómina & & & \\
\hline
\end{tabular}

\begin{tabular}{|l|l|l|l|}
\hline 9. Suministros & & & \\
\hline
\end{tabular}

\begin{tabular}{|l|l|l|l|}
\hline 10. Intereses ptmo. & & & \\
\hline
\end{tabular}

\begin{tabular}{|l|l|l|l|}
\hline $\begin{array}{l}\text { 11. Intereses y } \\
\text { devolución ptmo. }\end{array}$ & & \\
\hline
\end{tabular}

\begin{tabular}{|l|l|l|l|}
\hline 12. Intereses cdto. & & & \\
\hline
\end{tabular}

\begin{tabular}{|l|l|l|l|}
\hline 13. Intereses cuenta & & & \\
\hline
\end{tabular}

\begin{tabular}{|l|l|l|l|}
\hline 14. Compra acciones & & & \\
\hline
\end{tabular}

\begin{tabular}{|l|l|l|l|}
\hline 15. Compra máquina & & & \\
\hline
\end{tabular}

16. Venta vehículo

\section{b) Ajustes de fin de ejercicio}

\begin{tabular}{|l|l|l|l|}
\hline 17. Nómina \\
31 diciembre 00 & & & \\
\hline
\end{tabular}

\begin{tabular}{|l|l|l|l|}
\hline $\begin{array}{l}\text { 18. Seguridad Social } \\
31 \text { diciembre } 00\end{array}$ & & & \\
\hline
\end{tabular}

\begin{tabular}{|l|l|l|l|}
\hline $\begin{array}{l}\text { 19. Intereses ptmo. } \\
31 \text { diciembre } 00\end{array}$ & & & \\
\hline
\end{tabular}

\begin{tabular}{|l|l|l|l|}
\hline 20. Intereses cdtos. & & & \\
31 diciembre 00 & & & \\
\hline
\end{tabular}

\begin{tabular}{|l|l|l|l|}
\hline $\begin{array}{l}\text { 21. Variación exist. } \\
31 \text { diciembre } 00\end{array}$ & & & \\
& & & \\
\cline { 2 - 4 } & & & \\
\hline
\end{tabular}

22. Pagos anticipados

31 diciembre 00

\begin{tabular}{|l|l|l|l|}
\hline 23. Deterioro IM & & & \\
31 diciembre 00 & & & \\
\hline
\end{tabular}

\section{Amortización $=$}




\begin{tabular}{|l|l|l|l|}
\hline $\begin{array}{l}\text { 24. Amortización } \\
31 \text { diciembre } 00\end{array}$ & & & \\
\hline
\end{tabular}

\begin{tabular}{|l|l|l|l|}
\hline $\begin{array}{l}\text { 25. Liquidación IVA } \\
31 \text { diciembre } 00\end{array}$ & & & \\
& & & \\
\hline
\end{tabular}

26. Impto. beneficios

31 diciembre 00

MAYOR PNEUMATIQUES SA, tras todas las operaciones y ajustes
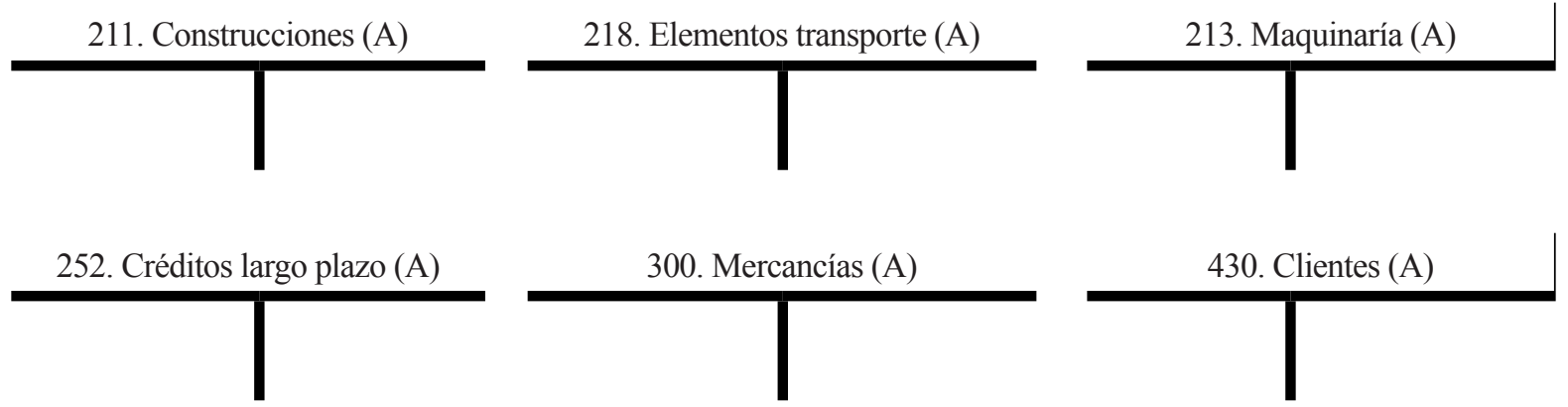

572. Bancos c/c (A)
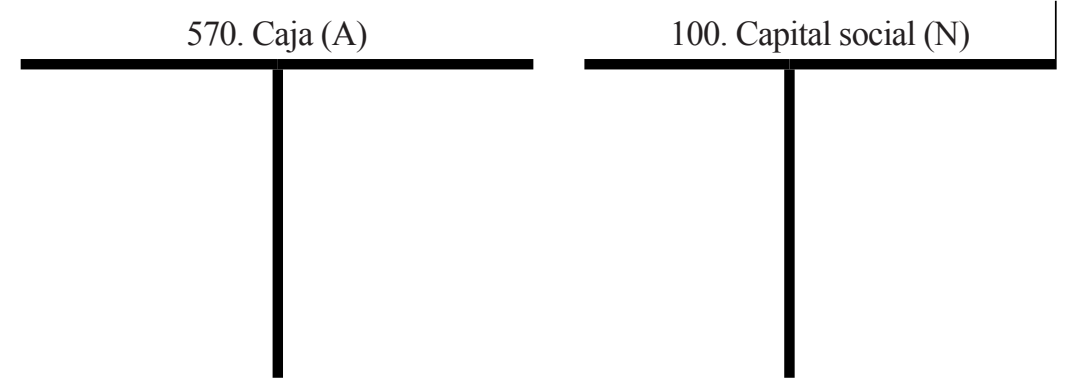

113. Reservas voluntarias (N)
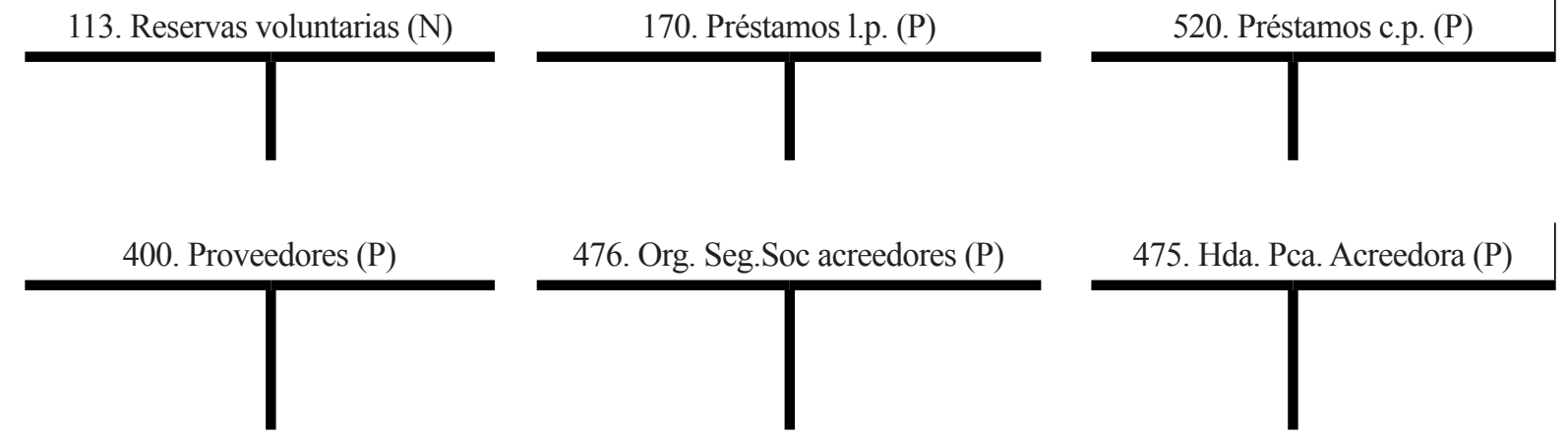

475. Hda. Pca. Acreedora (P)
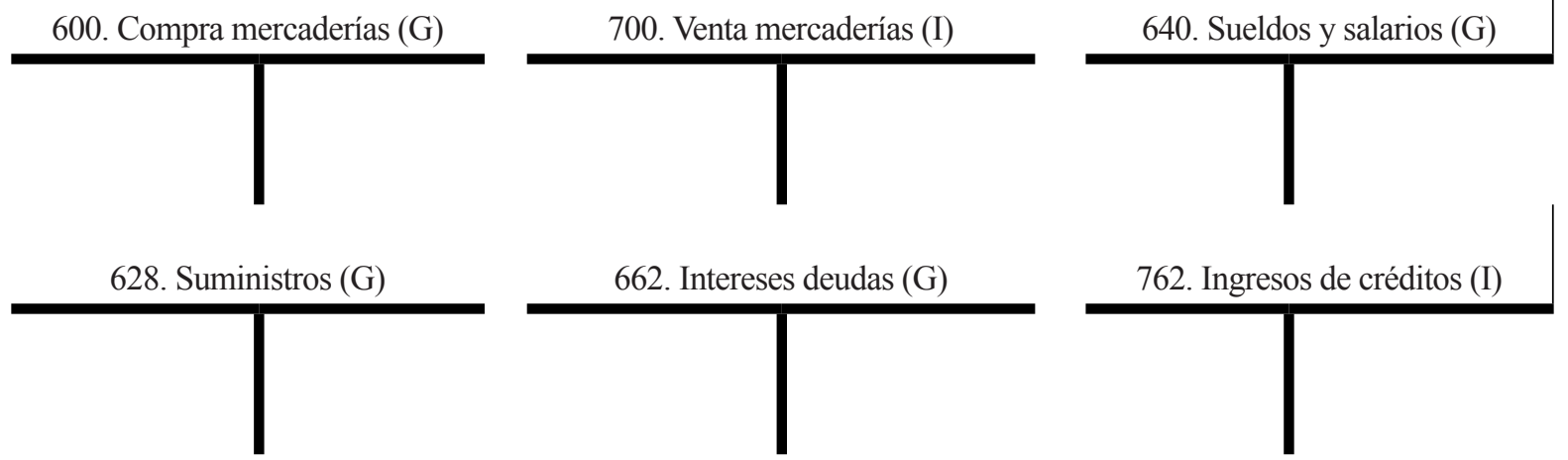

762. Ingresos de créditos (I) 
769. Otros ingresos financieros (I)

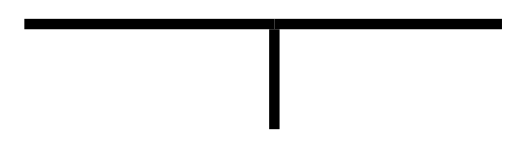

173. Proveedores inmov. 1.p. (P)

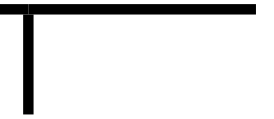

642. Seg. Social c/empresa (P)

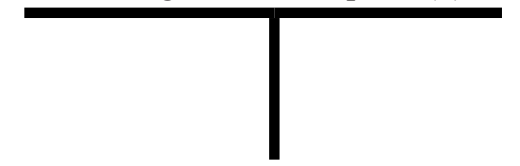

691. Pérdidas por deterioro de IM (G)

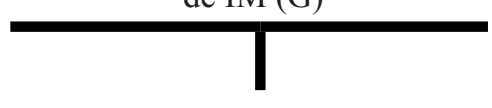

281. Amort. Acum. Inmov. Mat. (-A)

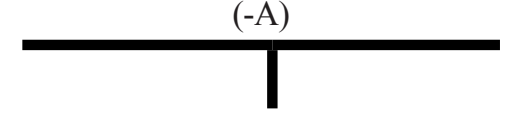

472. H. P. IVA soportado (A)
540. Inv. fin. temporales instr. patrimonio (A)

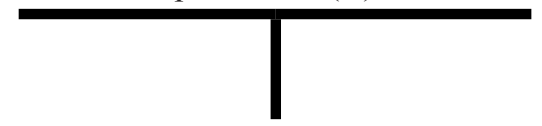

771. Beneficios proced. inmoviliz (I)

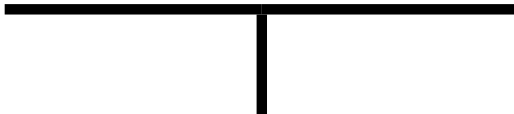

527. Intereses c.p. deudas (P)

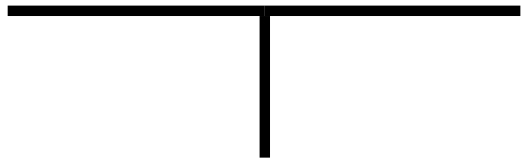

291. Deterioro de valor de IM (-A)

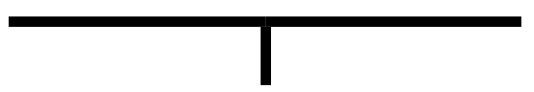

630. Impto beneficios $(\mathrm{G})$

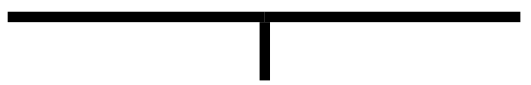

477. H. P. IVA repercutido (P)
480. Gastos anticipados

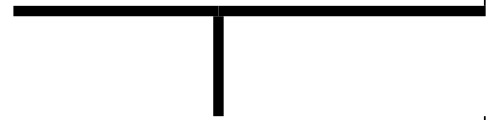

465. Remun. ptes. pago $(\mathrm{P})$

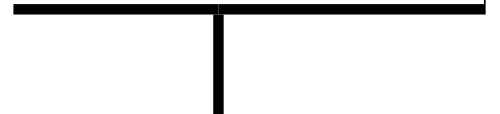

546. Intereses c.p. créditos (A)

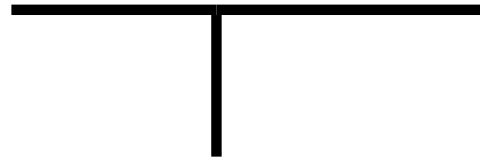

681. Amort. inmov. material $(\mathrm{G})$

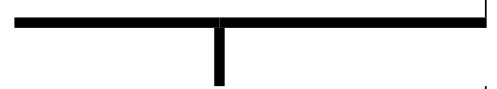

610. Variación existencias $(\mathrm{G})$
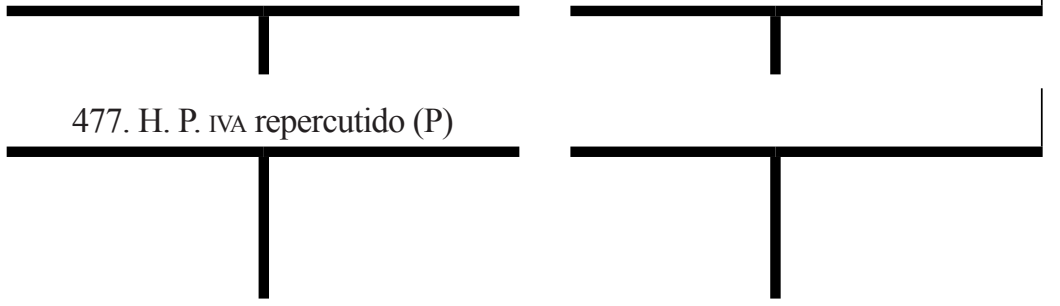

d) Balance de comprobacion de sumas y saldos

\begin{tabular}{|l|l|l|l|l|}
\hline \multicolumn{7}{|c|}{ PNEUMATIQUES SA } \\
BALANCE DE COMPROBACIÓN DE SUMAS Y SALDOS 01-01-00 A 31-12-00 \\
\hline CUENTAS & $\begin{array}{c}\text { Sumas } \\
\text { deudoras }\end{array}$ & $\begin{array}{c}\text { Sumas } \\
\text { acreedoras }\end{array}$ & $\begin{array}{c}\text { Saldos } \\
\text { deudores }\end{array}$ & $\begin{array}{c}\text { Saldos } \\
\text { acreedores }\end{array}$ \\
\hline 100. Capital social (N) & & & & \\
\hline 113. Reservas voluntarias (N) & & & & \\
\hline 170. Préstamos l.p. (P) & & & & \\
\hline 173. Proveedores inmov. l.p. (P) & & & & \\
\hline 211. Construcciones (A) & & & & \\
\hline 213. Maquinaría (A) & & & & \\
\hline 218. Elementos transporte (A) & & & & \\
\hline 252. Créditos largo plazo (A) & & & & \\
\hline 281. Amort. Acum. Inmov. Mat. (-A) & & & & \\
\hline 291. Deterioro de valor de IM (-A) & & & & \\
\hline 300. Mercancías (A) & & & & \\
\hline 400. Proveedores (P) & & & & \\
\hline 430. Clientes (A) & & & & \\
\hline
\end{tabular}




\begin{tabular}{|l|l|l|l|l|}
\hline 465. Remun. ptes. pago (P) & & & & \\
\hline 472. H. P. IVA soportado (A) & & & & \\
\hline 475. Hda. Pca. acreedora (P) & & & & \\
\hline 476. Org. Seg. Soc. acreedores (P) & & & & \\
\hline 477. H. P. IvA repercutido (P) & & & & \\
\hline 480. Gastos anticipados (A) & & & & \\
\hline 520. Préstamos c.p. (P) & & & & \\
\hline 527. Intereses c.p. deudas (P) & & & & \\
\hline $\begin{array}{l}\text { 540. Inv fin.temporales instr. } \\
\text { patrimonio (A) }\end{array}$ & & & & \\
\hline 546. Intereses c.p. créditos (A) & & & & \\
\hline 570. Caja (A) & & & & \\
\hline 572. Bancos c/c (A) & & & & \\
\hline 600. Compra mercaderías (G) & & & & \\
\hline 610. Variación existencias (G) & & & & \\
\hline 628. Suministros (G) & & & & \\
\hline 630. Impto beneficios (G) & & & & \\
\hline 640. Sueldos y salarios (G) & & & & \\
\hline 642. Seg. Social c/empresa (P) & & & & \\
\hline 662. Intereses deudas (G) & & & & \\
\hline 681. Amort. inmov. material (G) & & & & \\
\hline 691. Pérdidas por deterioro de IM(G) & & & & \\
\hline 700. Venta mercaderías (I) & & & & \\
\hline 762. Ingresos de créditos (I) & & & & \\
\hline 769. Otros ingresos financieros (I) & & & & \\
\hline 771. Beneficios proced. inmoviliz. (I) & & & & \\
\hline & & & & \\
\hline
\end{tabular}

e) Asiento de liquidación de ingresos y gastos

\begin{tabular}{|l|l|l|l|}
\hline $\begin{array}{l}26 . \\
31 \text { diciembre } 00\end{array}$ & & & \\
& & & \\
\cline { 2 - 4 } & & & \\
& & & \\
\end{tabular}

Saldo 129. Pérdidas y ganancias $=$ 
f) Asiento de cierre

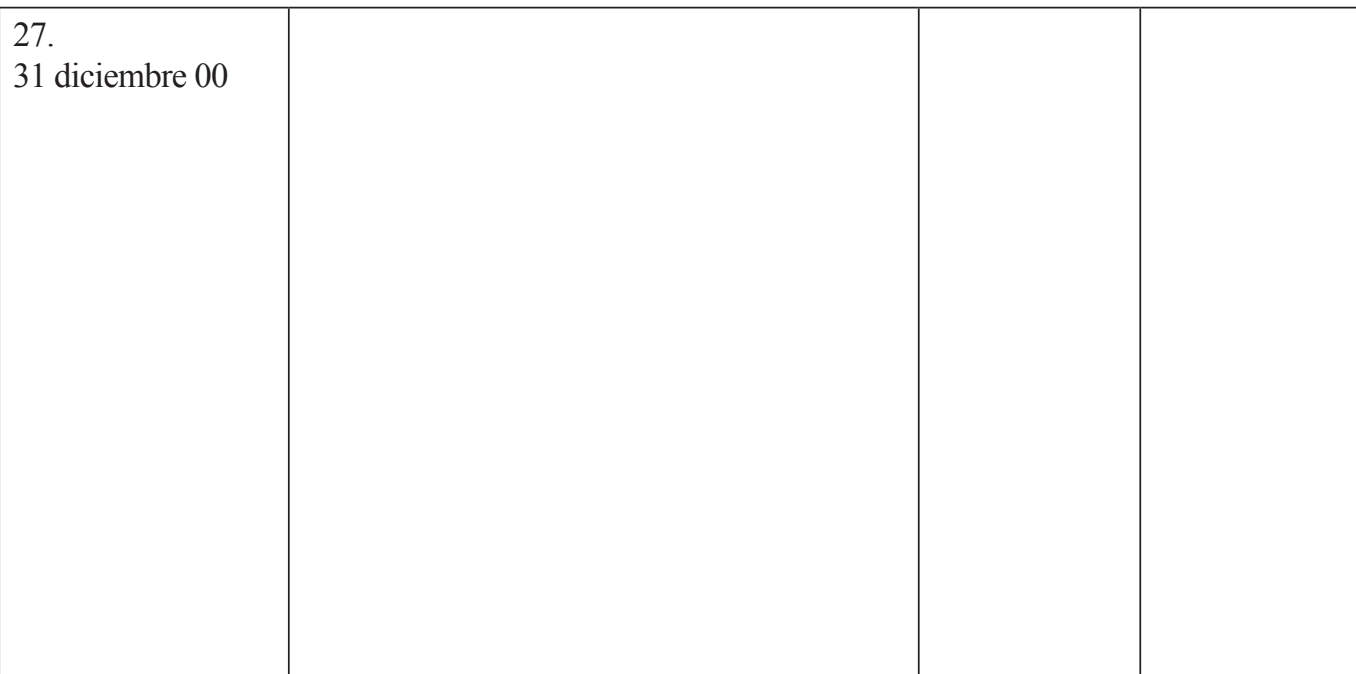

g) Cuenta de pérdidas y ganancias

\begin{tabular}{|l|l|}
\hline \multicolumn{1}{|c|}{ PNEUMATIQUES SA } \\
\multicolumn{1}{|c|}{ Cuenta de pérdidas y ganancias del período 01/01/00 a 31/12/00 } \\
\hline 1. Importe de la cifra de negocios & \\
4. Aprovisionamientos & \\
5. Otros ingresos de explotación \\
6. Gastos de personal \\
7. Otros gastos de explotación & \\
8. Amortizaciones del inmovilizado & \\
11. Deterioro y resultado por enajenaciones de inmovilizado & \\
\hline 13. Gastos financieros & \\
16. Deterioro y resultado por enajenaciones de instrumentos financieros & \\
\hline A.2) RESULTADO FINANCIERO = (12)+(13) $+(16)$ & \\
\hline A.3) RESULTADO ANTES DE IMPUESTOS $=($ A.1 $)+(A .2)$ & \\
\hline 17. Impuesto sobre beneficios & \\
\hline A.4) RESULTADO DEL EJERCICIO = (A.3) $+(17)$ & \\
\hline A.1) RESULTADO DE EXPLOTACIÓN $=(1)+(4)+(5)+(6)+(7)+(8)+(11)$ & \\
\hline 12. Ingresos financieros & \\
\end{tabular}


h) Balance

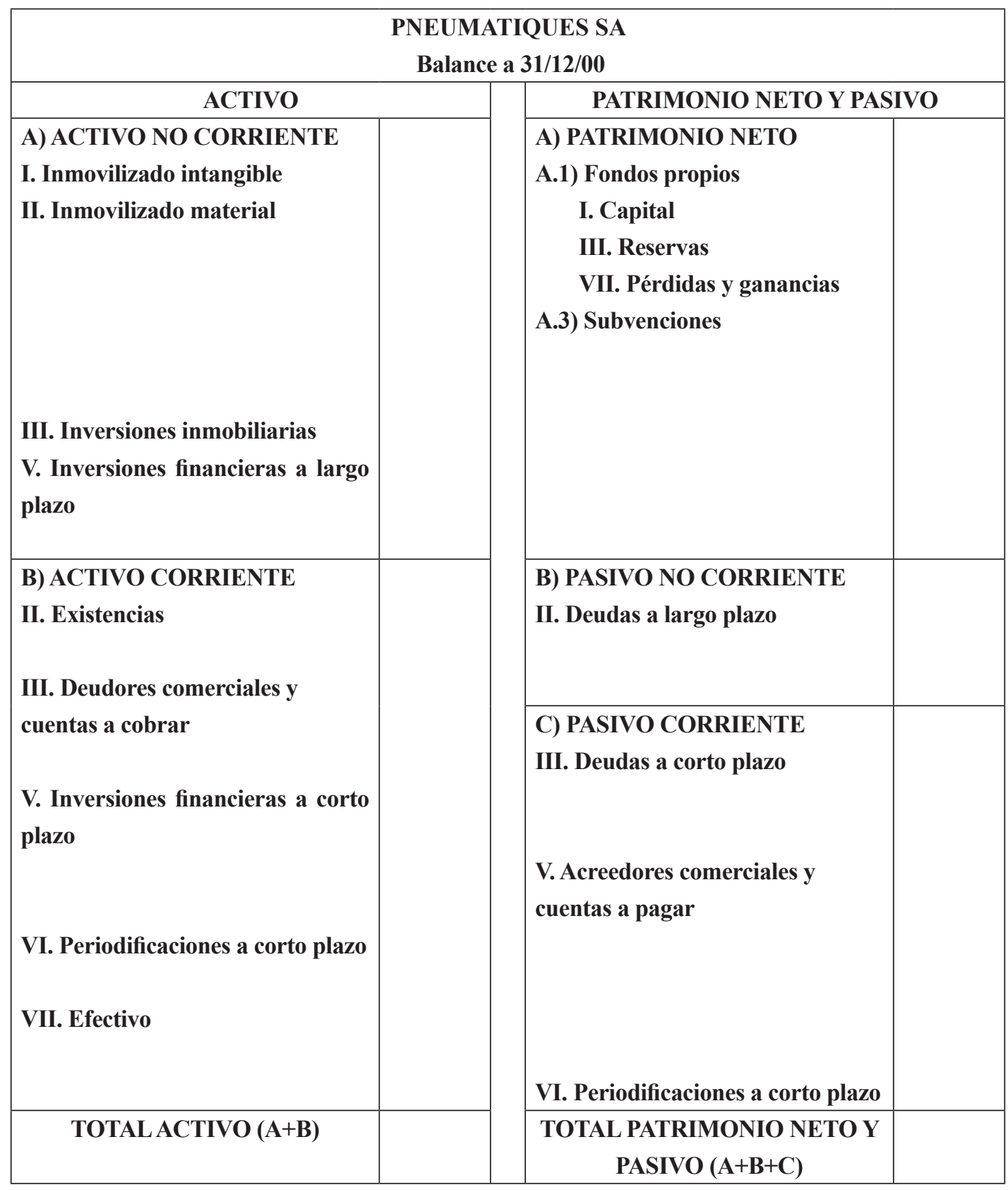




\section{Casos}

Caso 1. Registro de transacciones y elaboración de cuentas anuales

Partiendo del balance y cuenta de pérdidas y ganancias de INDITEX incluidos en el caso 1 del tema 3:

a) Abra las cuentas representativas de la situación patrimonial correspondiente al último año de los incluidos en el balance de dicha empresa y suponga que representan la situación final antes de los ajustes de fin de ejercicio.

b) Plantee al menos 5 ajustes de fin de ejercicio detallados que podría realizar dicha empresa sobre la situación anterior.

c) Registre dichas operaciones en un diario y traspáselos a las cuentas abiertas con anterioridad.

d) Realice los asientos de liquidación de ingresos y gastos y de cierre.

e) Elabore un nuevo balance y una cuenta de pérdidas y ganancias, tras los ajustes anteriores.

\section{Caso 2. Registro de transacciones y elaboración de cuentas anuales}

a) Obtenga el balance de una empresa de su elección de entre las cotizadas en la bolsa de madrid. La información puede obtenerse en las páginas web de las empresas correspondientes, buscando las cuentas anuales en los apartados de información para accionistas e inversores.

b) Abra las cuentas representativas de la situación patrimonial correspondiente al último año de los incluidos en el balance de dicha empresa y suponga que representan la situación final antes de ajustes de fin de ejercicio.

d) Plantee al menos 5 ajustes de fin de ejercicio detallados que podría realizar dicha empresa sobre la situación anterior.

d) Registre dichas operaciones en un diario y traspáselos a las cuentas abiertas con anterioridad.

e) Realice los asientos de liquidación de ingresos y gastos y de cierre.

f) Elabore un nuevo balance y una cuenta de pérdidas y ganancias tras los ajustes anteriores.

\section{Caso 3. Cuentas previsionales}

Partiendo de su solución al caso 3 del tema 2 y suponiendo que todas las transacciones se han realizado de acuerdo a las previsiones:

a) Registre en diario y mayor las transacciones de los puntos 2, 3 y 4 .

b) Identifique al menos 5 ajustes de fin de ejercicio que posiblemente tenga que realizar en la empresa y regístrelos en el diario y mayor.

c) Prepare un balance de comprobación de sumas y saldos a 31 de diciembre tras los ajustes anteriores.

d) Realice los asientos de liquidación de ingresos y gastos y el de cierre.

e) Elabore la cuenta de pérdidas y ganancias y el balance para el primer año.

\section{Caso 4. Ciclos contables}

Busque en la web de la CNMv las cuentas anuales de 10 empresas que cotizan en bolsa para el último ejercicio económico. ¿Cuántas cierran su ejercicio contable el 31 de diciembre y cuántas en otra fecha diferente? Explique las razones por las que cree que estas últimas no cierran a 31 de diciembre. 


\section{Análisis e interpretación de la información contable}

INTRODUCCIÓN

En este tema se introducen las técnicas de análisis de la información incluida en algunos de los informes contables externos, balance y cuenta de pérdidas y ganancias, resaltando la utilidad que la misma tiene para sus distintos usuarios.

También se describen aspectos básicos del control y cálculo de costes, mostrando ejemplos de informes internos sobre costes y su utilidad para la gestión.

\section{CONTENIDO}

6.1. Análisis del balance: situación patrimonial y financiera

6.2. Análisis de vuenta de pérdidas y ganancias: resultados y rentabilidad

6.3. Cálculo y determinación de costes

6.4. Informes internos de costes 


\subsection{Análisis del balance: situación patrimonial y financiera}

El análisis de la información financiera constituye por sí mismo un área de estudio de la contabilidad, tal y como se indicó en el tema 1. Por ello, el objetivo de este tema es solo introducir algunas herramientas básicas del análisis contable para visualizar la utilidad de la información contenida en el balance y la cuenta de pérdidas y ganancias. En este apartado se mostrará:

- Un análisis básico del equilibrio patrimonial y financiero, mediante el estudio de variaciones y estructura de masas patrimoniales así como la correlación entre estas.

- Algunos indicadores de solvencia.

- Algunos indicadores de endeudamiento.

En el análisis patrimonial y financiero, el punto fundamental de partida lo constituyen, las cinco masas fundamentales básicas que componen la estructura del patrimonio empresarial: el Activo No Corriente (ANC), el Activo Corriente (AC), el Patrimonio Neto (N), el Pasivo No Corriente (PNC) y el Pasivo Corriente (PC).

Expresado en forma de ecuación del patrimonio: $\mathrm{ANC}+\mathrm{AC}=\mathrm{N}+\mathrm{PNC}+\mathrm{PC}$.

A continuación se muestra el balance de INDITEX SA que se incluyó en el caso 1 del tema 2, resumiendo su contenido en masas patrimoniales más adecuadas para el análisis básico que se pretende introducir de este tema (valores en miles de euros).

\begin{tabular}{|c|c|c|c|c|c|}
\hline \multicolumn{3}{|c|}{ Estructura Económica } & \multicolumn{3}{|c|}{ Estructura Financiera } \\
\hline & 2009 & 2008 & & 2009 & 2008 \\
\hline $\begin{array}{l}\text { ACTIVO NO } \\
\text { CORRIENTE }\end{array}$ & 2.513.889 & 2.330 .014 & PATRIMONIO NETO & 2.017.194 & 1.846 .406 \\
\hline Inmovilizado intangible & 10.656 & 9.591 & FONDOS PROPIOS & 2.009 .192 & 1.810 .376 \\
\hline Inmovilizado material & 103.586 & 110.303 & Capital & 93.500 & 93.500 \\
\hline Inversiones inmobiliarias & 299.319 & 299.922 & Reservas & 1.042 .645 & 1.033 .532 \\
\hline $\begin{array}{l}\text { Inversiones financieras a } \\
\text { 1.p. }\end{array}$ & 2.100 .328 & 1.910 .198 & Pérdidas y ganancias & 873.047 & 683.344 \\
\hline & & & $\begin{array}{l}\text { AJUSTES POR CAMBIO } \\
\text { VALOR }\end{array}$ & 6.208 & 22.566 \\
\hline ACTIVO CORRIENTE & 1.312 .792 & 1.546 .288 & SUBVENCIONES & 1.794 & 13.464 \\
\hline Existencias & 270.809 & 337.005 & & & \\
\hline $\begin{array}{l}\text { Deudores comerciales y } \\
\text { otros }\end{array}$ & 402.025 & 482.892 & PASIVO NO CORRIENTE & 200.942 & 192.525 \\
\hline $\begin{array}{l}\text { Inversiones financieras a } \\
\text { c.p. }\end{array}$ & 580.484 & 598.905 & & & \\
\hline Efectivo & 59.474 & 127.486 & PASIVO CORRIENTE & 1.608 .545 & 1.837 .371 \\
\hline TOTAL ACTIVO & 3.826 .681 & 3.876.302 & TOTAL PASIVO & 3.826 .681 & 3.876 .302 \\
\hline
\end{tabular}




\section{Variación del valor de los activos, patrimonio neto y pasivos}

En el siguiente ejemplo se muestra un análisis de las variaciones en el valor de las grandes masas patrimoniales que componen el balance para el caso de INDITEX (valores en miles de euros).

\begin{tabular}{|l|c|c|r|r|}
\hline \multicolumn{6}{|l|}{ Ejemplo 6.1. Variaciones en masas patrimoniales del balance de INDITEX } \\
\hline & $\mathbf{2 0 0 9}$ & $\mathbf{2 0 0 8}$ & Diferencia 09/08 & $\mathbf{\% 0 9 / 0 8}$ \\
\hline ACTIVO NO CORRIENTE & 2.513 .889 & 2.330 .014 & 183.875 & $7,89 \%$ \\
\hline ACTIVO CORRIENTE & 1.312 .792 & 1.546 .288 & -233.496 & $-15,10 \%$ \\
\hline TOTAL ACTIVO & $\mathbf{3 . 8 2 6 . 6 8 1}$ & $\mathbf{3 . 8 7 6 . 3 0 2}$ & $\mathbf{- 4 9 . 6 2 1}$ & $\mathbf{- 1 , 2 8 \%}$ \\
\hline & $\mathbf{2 0 0 9}$ & $\mathbf{2 0 0 8}$ & Diferencia $\mathbf{0 9} / \mathbf{0 8}$ & $\mathbf{\%} \mathbf{0 9 / 0 8}$ \\
\hline PATRIMONIO NETO & 2.017 .194 & 1.846 .406 & 170.788 & $9,25 \%$ \\
\hline PASIVO NO CORRIENTE & 200.942 & 192.525 & 8.417 & $4,37 \%$ \\
\hline PASIVO CORRIENTE & 1.608 .545 & 1.837 .371 & -228.826 & $-12,45 \%$ \\
\hline $\begin{array}{l}\text { TOTAL PATRIMONIO } \\
\text { NETO Y PASIVO }\end{array}$ & $\mathbf{3 . 8 2 6 . 6 8 1}$ & $\mathbf{3 . 8 7 6 . 3 0 2}$ & $\mathbf{- 4 9 . 6 2 1}$ & $\mathbf{- 1 , 2 8 \%}$ \\
\hline
\end{tabular}

\section{El equilibrio patrimonial y financiero}

El equilibrio patrimonial y financiero depende de:

1. La composición de la estructura económica, proporción entre activo no corriente, inversiones permanentes necesarias para llevar a cabo el desarrollo de la actividad, y el activo corriente, vinculado a la propia actividad de explotación. Esta proporción depende de factores tan diversos, como el tipo de actividad, su grado de mecanización, la localización geográfica, el sector al que pertenece, etc.

2. La composición de la estructura financiera de la empresa. La adecuada relación entre los recursos, pasivos o patrimonio neto, será la que permita un adecuado funcionamiento de la empresa desde el punto de vista financiero.

3. La adecuada relación entre las masas patrimoniales de activo y pasivo que sean correlativas respecto al grado de conversión en disponible y exigible inmediato, así como también, en general, entre los componentes de activo y pasivo corriente y los de la estructura patrimonial no corriente.

Una empresa se encuentra en equilibrio desde el punto de vista financiero cuando tiene capacidad para poder hacer frente a las deudas a sus vencimientos respectivos. La capacidad de hacer frente a las deudas a corto, se habla entonces de equilibrio financiero a corto plazo,

La situación de equilibrio o solvencia a largo plazo, no depende tanto de la situación y estructura patrimonial que presente la empresa desde el punto de vista financiero, sino más de la capacidad generadora de recursos en el tiempo. 


\section{Análisis de composición de la estructura económica y financiera}

En el siguiente ejemplo se muestra un análisis de la estructura o composición porcentual de activos y pasivos que componen el balance para el caso de INDITEX (valores en miles de euros).

\begin{tabular}{|l|c|c|c|c|}
\hline \multicolumn{6}{|l|}{ Ejemplo 6.2. Composición por masas patrimoniales del balance de INDITEX } \\
\hline & $\mathbf{2 0 0 9}$ & $\mathbf{2 0 0 8}$ & $\mathbf{\%} \mathbf{2 0 0 9}$ & $\mathbf{\% ~ 2 0 0 8}$ \\
\hline ACTIVO NO CORRIENTE & 2.513 .889 & 2.330 .014 & $65,7 \%$ & $60,1 \%$ \\
\hline ACTIVO CORRIENTE & 1.312 .792 & 1.546 .288 & $34,3 \%$ & $39,9 \%$ \\
\hline TOTAL ACTIVO & $\mathbf{3 . 8 2 6 . 6 8 1}$ & $\mathbf{3 . 8 7 6 . 3 0 2}$ & $\mathbf{1 0 0 , 0 \%}$ & $\mathbf{1 0 0 , 0 \%}$ \\
\hline & $\mathbf{2 0 0 9}$ & $\mathbf{2 0 0 8}$ & $\mathbf{\%} \mathbf{2 0 0 9}$ & $\mathbf{\% 2} \mathbf{2 0 0 8}$ \\
\hline PATRIMONIO NETO & 2.017 .194 & 1.846 .406 & $52,7 \%$ & $47,6 \%$ \\
\hline PASIVO NO CORRIENTE & 200.942 & 192.525 & $5,3 \%$ & $5,0 \%$ \\
\hline PASIVO CORRIENTE & 1.608 .545 & 1.837 .371 & $42,0 \%$ & $47,4 \%$ \\
\hline $\begin{array}{l}\text { TOTAL PATRIMONIO } \\
\text { NETO Y PASIVO }\end{array}$ & $\mathbf{3 . 8 2 6 . 6 8 1}$ & $\mathbf{3 . 8 7 6 . 3 0 2}$ & $\mathbf{1 0 0 , 0 \%}$ & $\mathbf{1 0 0 , 0 \%}$ \\
\hline
\end{tabular}

\section{Correlaciones entre masas patrimoniales}

Como regla general, una situación de equilibrio financiero supone una estructura patrimonial como la mostrada en la ilustración siguiente, aunque debe tenerse en cuenta que cada sector tiene su estructura patrimonial particular. Además, la estructura de cada empresa dependerá del volumen de actividad, de la política financiera a corto plazo, de la eficacia en la gestión de la tesorería, de la gestión de cobros y pagos, etc.

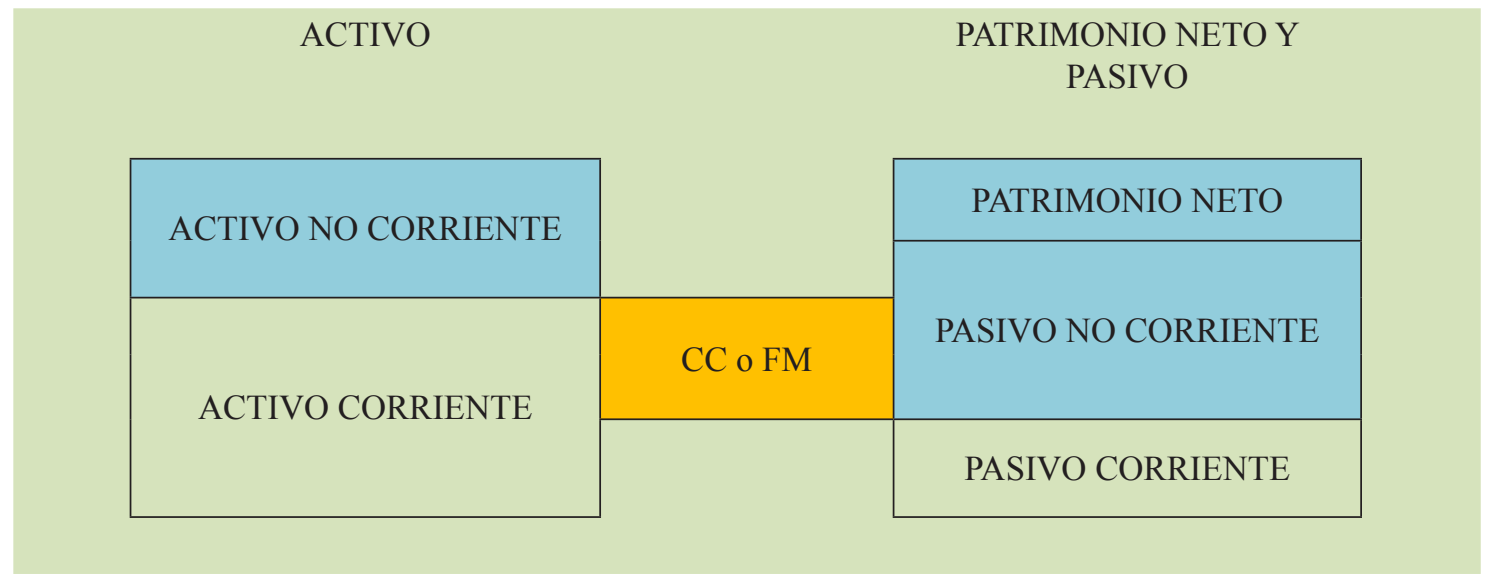

Ilustración 6.1. Análisis gráfico de masas patrimoniales

Se denomina Capital Corriente (CC) o Fondo de Maniobra (FM) a AC - PC, y se parte de la base de que existe equilibrio financiero a corto plazo si el $\mathrm{CC}>0$. 
Las ideas básicas respecto al equilibrio financiero son:

- El activo no corriente debe estar financiado mediante fuentes de financiación permanente, bien pasivo no corriente o bien patrimonio propio.

- El exceso de financiación permanente sobre el activo no corriente servirá para cubrir parte del Activo Corriente

\section{Indicadores de solvencia a corto plazo}

Por solvencia se entiende la evaluación de la capacidad de la empresa de hacer frente a las deudas a corto plazo. Los indicadores, ratios, más utilizados son los que se muestran en el cuadro siguiente para el caso de INDITEX y que luego se comentan.

\begin{tabular}{|l|c|r|r|}
\hline Ejemplo 6.3. Indicadores de solvencia a corto plazo de INDITEX \\
\hline Indicador / Ratio & Expresión & $\mathbf{2 0 0 9}$ & $\mathbf{2 0 0 8}$ \\
\hline Ratio de solvencia a corto plazo & AC / PC & 0,82 & 0,84 \\
\hline Test del ácido & (AC - E) / PC & 0,65 & 0,66 \\
\hline Ratio de tesorería intermedia & $(\mathrm{IFT}+\mathrm{T}) / \mathrm{PC}$ & 0,40 & 0,40 \\
\hline Ratio de tesorería inmediata & $\mathrm{T} / \mathrm{PC}$ & 0,04 & 0,07 \\
\hline Siendo: & & & \\
AC: Activo corriente & & \\
PC: Pasivo corriente \\
E: Existencias \\
IFT: Inversiones financieras temporales \\
T: Tesorería
\end{tabular}

\section{Ratio de circulante o de solvencia a corto plazo}

Trata de medir la capacidad de la empresa para hacer frente a las deudas que se deriven del ciclo de explotación. En principio debería ser superior a la unidad.

Su análisis e interpretación requiere de un mayor nivel de concreción en cuanto a los componentes del activo corriente y del valor de los ratios que se comentan a continuación.

\section{Test del ácido}

Este ratio compara únicamente las partidas monetarias de activo (tesorería, y valores realizable en dinero: inversiones financieras temporales y deudores) con el pasivo corriente.

Supone un avance respecto a la determinación de la liquidez y solvencia de las empresas ya que compara el activo corriente deducidas las existencias que son valores realizables pero que están condicionados a una venta previa para su cobro posterior. Permite, por tanto, mostrar de forma más eficaz la liquidez de la empresa. 


\section{Ratio de tesorería intermedia}

Este ratio compara al pasivo corriente con los elementos de activo corriente que o bien son dinero efectivo o son inmediatamente realizables al tratarse de inversiones financieras temporales (las cuales pueden realizarse sin afectar a la actividad de explotación de la empresa).

En función del plazo de vencimiento del pasivo corriente este ratio debería estar más o menos próximo a la unidad.

\section{Ratio de tesorería inmediata}

Se suele considerar o partir de un valor mínimo del 0,10 , que se toma como relación de garantía.

\section{Indicadores de endeudamiento}

Los ratios de endeudamiento comparan, en la mayoría de los casos, las masas que representan endeudamiento con el resto de la financiación. Los indicadores más utilizados son los que se muestran en el ejemplo siguiente para el caso de INDITEX y que luego se comentan.

\begin{tabular}{|l|c|r|r|}
\hline Ejemplo 6.4. Indicadores de endeudamiento de INDITEX \\
\hline Indicador / Ratio & Expresión & $\mathbf{2 0 0 9}$ & $\mathbf{2 0 0 8}$ \\
\hline Ratio de endeudamiento (1) & $\mathrm{P} /(\mathrm{N}+\mathrm{P})$ & 0,47 & 0,52 \\
\hline Ratio de endeudamiento (2) & $\mathrm{P} / \mathrm{N}$ & 0,90 & 1,10 \\
\hline Pasivo no corriente sobre financiación total & $\mathrm{PNC} /(\mathrm{N}+\mathrm{P})$ & 0,05 & 0,05 \\
\hline Pasivo corriente sobre financiación total & $\mathrm{PC} /(\mathrm{N}+\mathrm{P})$ & 0,42 & 0,47 \\
\hline Pasivo no corriente sobre pasivo & $\mathrm{PNC} / \mathrm{P}$ & 0,11 & 0,09 \\
\hline Pasivo corriente sobre pasivo & $\mathrm{PC} / \mathrm{P}$ & 0,89 & 0,91 \\
\hline $\begin{array}{l}\text { Siendo: } \\
\text { P: Pasivo } \\
\text { PC: Pasivo corriente } \\
\text { PNC: Pasivo no corriente } \\
\text { N: Patrimonio neto }\end{array}$ & & \\
\hline
\end{tabular}

Ratios de endeudamiento (1) y (2)

Muestra la relación entre las fuentes de financiación comparando el endeudamiento total bien con la financiación total o solo con la financiación propia.

Comparación de deudas sobre fuentes de financiación (calidad de la deuda)

Comparan la deuda a largo o a corto plazo respecto al total de financiación o bien solo respecto al pasivo. 


\subsection{Análisis de cuenta de pérdidas y ganancias: resultados y rentabilidad}

En relación a la cuenta de pérdidas y ganancias y la generación de beneficios en este apartado se mostrarán los aspectos básicos de:

- El análisis de composición y variación del resultado.

- El cálculo de la rentabilidad económica.

- El cálculo de la rentabilidad financiera.

A continuación se muestra la cuenta de pérdidas y ganancias de INDITEX SA que se incluyó en el caso 2 del tema 2, resumiendo su contenido en agrupaciones más adecuadas para el análisis básico que se pretende introducir de este tema (valores en miles de euros).

\begin{tabular}{|lrr|}
\hline & \multicolumn{1}{l}{} & \multicolumn{1}{l}{$\mathbf{2 0 0 8}$} \\
Importe neto cifra negocios & $\mathbf{4 . 1 0 2 . 4 6 4}$ & $\mathbf{3 . 7 3 3 . 0 6 2}$ \\
Aprovisionamientos & -2.842 .240 & -2.603 .290 \\
Otros ingresos de explotación & 144.728 & 149.008 \\
Gastos de personal & -96.542 & -94.307 \\
Otros gastos de explotación & -352.279 & -349.574 \\
Amortización de inmovilizado & -30.382 & -26.999 \\
Otros resultados & -4.236 & -3.916 \\
RESULTADO DE EXPLOTACIÓN & $\mathbf{9 2 3 . 5 2 2}$ & $\mathbf{8 0 5 . 9 9 2}$ \\
& & \\
Ingresos financieros & 9.599 & 30.485 \\
Gastos financieros & -13.820 & -41.225 \\
Otros resultados financieros & -25.558 & -42.812 \\
RESULTADO FINANCIERO & $\mathbf{- 2 9 . 7 7 9}$ & $\mathbf{- 5 3 . 5 5 2}$ \\
& & \\
RESULTADO ANTES DE IMPUESTOS & $\mathbf{8 9 3 . 7 4 3}$ & $\mathbf{7 5 2 . 4 4 0}$ \\
Impuesto sobre beneficios & -20.696 & -69.096 \\
RESULTADO DEL EJERCICIO & $\mathbf{8 7 3 . 0 4 7}$ & $\mathbf{6 8 3 . 3 4 4}$ \\
\hline
\end{tabular}

\section{Variación de ingresos, gastos y resultados}

En el siguiente ejemplo se muestra un análisis de las variaciones en el valor de las grandes componentes de la cuenta de pérdidas y ganancias para el caso de INDITEX (valores en miles de euros). 


\begin{tabular}{|l|r|r|r|r|}
\hline Ejemplo 6.5. Variaciones en de ingresos y gastos de INDITEX \\
\hline & \multicolumn{1}{|c|}{$\mathbf{2 0 0 9}$} & \multicolumn{1}{c|}{$\mathbf{2 0 0 8}$} & \multicolumn{1}{c|}{$\begin{array}{c}\text { Diferencia } \\
\mathbf{0 9 - 0 8}\end{array}$} & \multicolumn{1}{c|}{$\mathbf{\% ~ 0 9 / 0 8}$} \\
\hline Importe neto cifra negocios & $\mathbf{4 . 1 0 2 . 4 6 4}$ & $\mathbf{3 . 7 3 3 . 0 6 2}$ & $\mathbf{3 6 9 . 4 0 2}$ & $\mathbf{9 , 9 0 \%}$ \\
\hline Aprovisionamientos & -2.842 .240 & -2.603 .290 & -238.950 & $9,18 \%$ \\
\hline Otros ingresos de explotación & 144.728 & 149.008 & -4.280 & $-2,87 \%$ \\
\hline Gastos de personal & -96.542 & -94.307 & -2.235 & $2,37 \%$ \\
\hline Otros gastos de explotación & -352.279 & -349.574 & -2.705 & $0,77 \%$ \\
\hline Amortización de inmovilizado & -30.382 & -26.999 & -3.383 & $12,53 \%$ \\
\hline Otros resultados & -4.236 & -3.916 & -320 & $8,17 \%$ \\
\hline RESULTADO DE EXPLOTACIÓN & $\mathbf{9 2 3 . 5 2 2}$ & $\mathbf{8 0 5 . 9 9 2}$ & $\mathbf{1 1 7 . 5 3 0}$ & $\mathbf{1 4 , 5 8 \%}$ \\
\hline Ingresos financieros & 9.599 & 30.485 & -20.886 & $-68,51 \%$ \\
\hline Gastos financieros & -13.820 & -41.225 & 27.405 & $-66,48 \%$ \\
\hline Otros resultados financieros & -25.558 & -42.812 & 17.254 & $-40,30 \%$ \\
\hline RESULTADO FINANCIERO & $\mathbf{- 2 9 . 7 7 9}$ & $\mathbf{- 5 3 . 5 5 2}$ & $\mathbf{2 3 . 7 7 3}$ & $\mathbf{- 4 4 , 3 9 \%}$ \\
\hline RESULTADO ANTES DE IMPUESTOS & $\mathbf{8 9 3 . 7 4 3}$ & $\mathbf{7 5 2 . 4 4 0}$ & $\mathbf{1 4 1 . 3 0 3}$ & $\mathbf{1 8 , 7 8 \%}$ \\
\hline Impuesto sobre beneficios & -20.696 & -69.096 & 48.400 & $-70,05 \%$ \\
\hline RESULTADO DEL EJERCICIO & $\mathbf{8 7 3 . 0 4 7}$ & $\mathbf{6 8 3 . 3 4 4}$ & $\mathbf{1 8 9 . 7 0 3}$ & $\mathbf{2 7 , 7 6 \%}$ \\
\hline
\end{tabular}

\section{Análisis de composición resultado}

En el siguiente ejemplo se muestra para el caso de INDITEX un análisis de la composición de la cuenta de pérdidas y ganancias, tomando como valor de partida (100\%) la cifra de negocios (valores en miles de euros).

\begin{tabular}{|l|r|r|r|r|}
\hline Ejemplo 6.6. Importancia relativa de ingresos y gastos en INDITEX \\
\hline & \multicolumn{1}{|c|}{$\mathbf{2 0 0 9}$} & \multicolumn{1}{c|}{$\mathbf{2 0 0 8}$} & $\mathbf{0} \mathbf{2 0 0 9}$ & $\mathbf{\%} \mathbf{2 0 0 8}$ \\
\hline Importe neto cifra negocios & $\mathbf{4 . 1 0 2 . 4 6 4}$ & $\mathbf{3 . 7 3 3 . 0 6 2}$ & $\mathbf{1 0 0 , 0 0 \%}$ & $\mathbf{1 0 0 , 0 0 \%}$ \\
\hline Aprovisionamientos & -2.842 .240 & -2.603 .290 & $-69,28 \%$ & $-69,74 \%$ \\
\hline Otros ingresos de explotación & 144.728 & 149.008 & $3,53 \%$ & $3,99 \%$ \\
\hline Gastos de personal & -96.542 & -94.307 & $-2,35 \%$ & $-2,53 \%$ \\
\hline Otros gastos de explotación & -352.279 & -349.574 & $-8,59 \%$ & $-9,36 \%$ \\
\hline Amortización de inmovilizado & -30.382 & -26.999 & $-0,74 \%$ & $-0,72 \%$ \\
\hline Otros resultados & -4.236 & -3.916 & $-0,10 \%$ & $-0,10 \%$ \\
\hline RESULTADO DE EXPLOTACIÓN & $\mathbf{9 2 3 . 5 2 2}$ & $\mathbf{8 0 5 . 9 9 2}$ & $\mathbf{2 2 , 5 1 \%}$ & $\mathbf{2 1 , 5 9 \%}$ \\
\hline Ingresos financieros & 9.599 & 30.485 & $0,23 \%$ & $0,82 \%$ \\
\hline Gastos financieros & -13.820 & -41.225 & $-0,34 \%$ & $-1,10 \%$ \\
\hline Otros resultados financieros & -25.558 & -42.812 & $-0,62 \%$ & $-1,15 \%$ \\
\hline RESULTADO FINANCIERO & $\mathbf{- 2 9 . 7 7 9}$ & $\mathbf{- 5 3 . 5 5 2}$ & $\mathbf{- 0 , 7 3 \%}$ & $\mathbf{- 1 , 4 3 \%}$ \\
\hline RESULTADO ANTES DE IMPUESTOS & $\mathbf{8 9 3 . 7 4 3}$ & $\mathbf{7 5 2 . 4 4 0}$ & $\mathbf{2 1 , 7 9 \%}$ & $\mathbf{2 0 , 1 6 \%}$ \\
\hline Impuesto sobre beneficios & -20.696 & -69.096 & $-0,50 \%$ & $-1,85 \%$ \\
\hline RESULTADO DEL EJERCICIO & $\mathbf{8 7 3 . 0 4 7}$ & $\mathbf{6 8 3 . 3 4 4}$ & $\mathbf{2 1 , 2 8 \%}$ & $\mathbf{1 8 , 3 1 \%}$ \\
\hline
\end{tabular}




\section{EBIT y EBITDA}

Se trata de dos términos anglosajones basados en resultado para indicar la capacidad de generación de recursos de la empresa.

- $\mathbf{E B I T}=$ Earnings Before Interest and Taxes $=$ Resultado de explotación

- $\quad$ EBITDA = Ebit and Before Depreciation and Amortization = Resultado de explotación más deterioros y amortizaciones.

El EBITDA elimina el sesgo de la estructura financiera (gastos financieros), del entorno fiscal (a través de los impuestos) y de los gastos de infraestructura (amortizaciones). De esta forma, permite obtener una idea del rendimiento operativo de las empresas, y comparar lo bien o mal que lo hacen distintas empresas o sectores en el ámbito puramente operativo. Desde este punto de vista, es un buen indicador de la rentabilidad del negocio.

No obstante, al descontar las depreciaciones y las amortizaciones (de grandes inversiones en bienes inmovilizados) y también los gastos financieros, ofrece cifras razonables, por pocos ingresos que se tengan.

Esta medida excluye muchos gastos, en ocasiones casi la totalidad según la estructura de costes de la empresa, por lo que ha recibido muchas críticas. Así, se considera que el EBITDA es una trampa de las empresas que no tienen buenos resultados y que el futuro de la empresa solo se asegura con resultados reales satisfactorios, el beneficio neto después de impuestos.

\section{Rentabilidad económica y financiera}

Los indicadores o ratios de rentabilidad determinan el rendimiento obtenido de una inversión, siendo los más importantes los de rentabilidad económica y de rentabilidad financiera. En el siguiente ejemplo se muestran dichos indicadores para el caso de INDITEX y se comentan a continuación.

\begin{tabular}{|c|c|c|c|}
\hline \multicolumn{4}{|c|}{ Ejemplo 6.7. Variaciones en masas patrimoniales del balance } \\
\hline Indicador de rentabilidad & Expresión & 2009 & 2008 \\
\hline Rentabilidad económica & $\mathrm{R}_{\mathrm{ex}} / \mathrm{A}$ & $24,13 \%$ & $20,79 \%$ \\
\hline Rentabilidad financiera & $\mathrm{R} / \mathrm{N}$ & $43,28 \%$ & $37,01 \%$ \\
\hline $\begin{array}{l}\text { Siendo: } \\
\qquad \begin{array}{l}\mathrm{R}_{\mathrm{ex}}: \text { Resultado de explotació } \\
\mathrm{R}: \text { Resultado del ejercicio } \\
\text { A: Activo } \\
\text { N: Patrimonio neto }\end{array}\end{array}$ & & & \\
\hline
\end{tabular}




\section{Rentabilidad económica}

También denominada rendimiento, rentabilidad de las inversiones totales o en expresión inglesa ROI (Return On Investment) o ROA (Return On Assets).

Mide la rentabilidad de los fondos invertidos con independencia del origen de la financiación. Es evidente que cuanto mayor sea el rendimiento mayor productividad se está obteniendo de los recursos invertidos.

Esta rentabilidad es de utilidad para las decisiones de nuevas inversiones y para elegir las distintas formas de financiación de la misma en función del coste de los recursos financieros que implicarán. Así, una nueva inversión será conveniente sí:

\section{Rentabilidad económica $(\mathrm{RE})>$ Coste medio de financiación $\left(\mathrm{C}_{\mathrm{f}}\right)$}

\section{Rentabilidad financiera}

También denominada rentabilidad de los fondos o capitales propios, o en inglés, ROE (Return On Equity).

Para las empresas privadas este ratio es de la mayor importancia ya que mide el beneficio neto generado en relación a las inversiones realizadas por los propietarios (directas, capital y prima de emisión, o bien por las retenciones sobre beneficios de años anteriores o reservas).

Cuanto mayor sea este ratio mejor para los accionistas. En todo caso deberá exigirse que sea positivo y que cumplan con las expectativas que tenían los inversores en el momento de decidir su aportación a la empresa. Debe tenerse en cuenta que los inversores siempre van a comparar la rentabilidad que obtengan en una empresa con la rentabilidad que podrían obtener de inversiones alternativas, es decir con lo que en términos económicos se conoce como coste de oportunidad de su inversión. Muchas veces el referente lo constituyen las inversiones sin riesgos, por ejemplo en valores del Estado. 


\subsection{Cálculo y determinación de costes}

El cálculo de costes surgió en las empresas industriales y paulatinamente los conceptos de coste y los procedimientos de cálculo fueron extendiéndose a todo tipo de empresas, tanto comerciales como de servicios.

La información sobre costes es útil a dos propósitos:

1. Proporcionar la información necesaria que requiere la contabilidad financiera para el balance (valoración de productos fabricados internamente) y la cuenta de pérdidas y ganancias (coste de los productos vendidos).

2. Proporcionar información a los usuarios internos sobre los costes de los procesos y actividades internas para la gestión operativa y estratégica de las empresas.

En las empresas industriales (fabricación de alimentos, vehículos, azulejos, muebles, etc.), los hechos económicos fundamentales del ciclo interno están determinados por la producción y los costes de transformación de materias primas en productos terminados.

En las empresas comerciales o de servicios ese ciclo interno prácticamente no existe; no obstante, los procedimientos y conceptos de cálculo de costes también son de aplicación. El objetivo en estas es, entre otros, el cálculo de costes y rendimientos por líneas de productos, de servicios, de actividades, de clientes, etc.

\section{Costes y su repercusión en balance y cuenta de pérdidas y ganancias}

El concepto de coste hace referencia al valor «sacrificado» para conseguir un objetivo concreto. En el ámbito de la empresa puede considerarse como el importe a satisfacer para la adquisición de bienes o servicios. Cuando una empresa industrial compra materias primas para incorporar a la producción se produce un coste y también cuando se adquiere un edificio, o cuando se paga a los trabajadores, o el agua y la electricidad, etc.

Los costes en los que incurre una empresa para la adquisición de bienes y servicios pueden clasificarse en:

- Costes de inversiones. Se trata del coste de adquisición del inmovilizado de la empresa (edificios, maquinaria, mobiliario, elementos de transporte, etc.). Los elementos de inmovilizado son activos que se deprecian a lo largo del tiempo, reflejándose este hecho en la amortización contable.

- La amortización de los bienes de inmovilizado relacionados con la actividad productiva se incorporan como mayor coste de los bienes fabricados por la empresa en dicho año. 
- La amortización de inmovilizados no afectos a la producción se considera un gasto o coste del período.

- Costes del producto o de bienes inventariables. Para empresas comerciales son los costes de adquisición de bienes destinados a su venta sin transformación (mercancías). Para empresas industriales son los costes de adquisición de bienes (materias primas) y servicios (mano de obra, energía y otros) usados para obtener productos para la venta. Como se ha dicho en el párrafo anterior, las amortizaciones de los elementos de inmovilizado relacionados con la función de producción se consideran parte del coste de los productos fabricados.

- Estos costes se registran como existencias (mercancías, materias primas, productos en curso, productos terminados),

- y se van convirtiendo en gastos conforme se venden.

- Costes registrados como gastos del período. Se trata de costes de bienes y servicios adquiridos que se reconocen como gastos en el período en que se incurre en ellos y corresponden a amortizaciones de inversiones, consumo de bienes inventariables o de servicios de funciones diferentes a la producción (comerciales, distribución, administración, etc.).

\begin{tabular}{|c|c|c|c|}
\hline & $\begin{array}{l}\text { Empresa industrial } \\
\text { (PORCELANOSA) }\end{array}$ & $\begin{array}{l}\text { Empresa comercial } \\
\text { (CARREFOUR) }\end{array}$ & $\begin{array}{l}\text { Empresa de servicios } \\
\text { (VIAJES ORANGE) }\end{array}$ \\
\hline $\begin{array}{l}\text { Costes de } \\
\text { inversiones }\end{array}$ & \multicolumn{3}{|c|}{$\begin{array}{l}\text { Costes de bienes de inmovilizado, intangible y material, adquiridos para el desarrollo } \\
\text { de la actividad (edificios, maquinaria, mobiliario, etc.) }\end{array}$} \\
\hline $\begin{array}{c}\text { Costes del } \\
\text { producto o } \\
\text { inventariables }\end{array}$ & $\begin{array}{l}\text { Costes de los bienes y } \\
\text { servicios usados para } \\
\text { la producción (materias } \\
\text { primas, mano de obra, y } \\
\text { otros costes generales). } \\
\text { Incluye amortizaciones de } \\
\text { inmovilizados usados para } \\
\text { producción. }\end{array}$ & $\begin{array}{l}\text { Costes de las mercancías } \\
\text { adquiridas para su venta } \\
\text { sin transformación }\end{array}$ & $\begin{array}{l}\text { Los servicios no pueden } \\
\text { almacenarse, no hay } \\
\text { inventarios ni costes de } \\
\text { producto. }\end{array}$ \\
\hline $\begin{array}{l}\text { Gastos del } \\
\text { período }\end{array}$ & $\begin{array}{l}\text { Costes de mantenimiento } \\
\text { de actividades que no } \\
\text { son de producción, como } \\
\text { comerciales, distribución, } \\
\text { investigación, y de } \\
\text { administración (personal, } \\
\text { energía, amortizaciones). }\end{array}$ & $\begin{array}{l}\text { Costes de mantenimiento } \\
\text { de la actividad (personal, } \\
\text { energía, material oficina, } \\
\text { amortizaciones de } \\
\text { inmovilizado. }\end{array}$ & $\begin{array}{l}\text { Costes de realización } \\
\text { y mantenimiento de } \\
\text { la actividad (personal, } \\
\text { energía, material oficina, } \\
\text { amortizaciones del } \\
\text { inmovilizado, etc.). }\end{array}$ \\
\hline
\end{tabular}

Ilustración 6.2. Categorías de coste según actividad de la empresa 


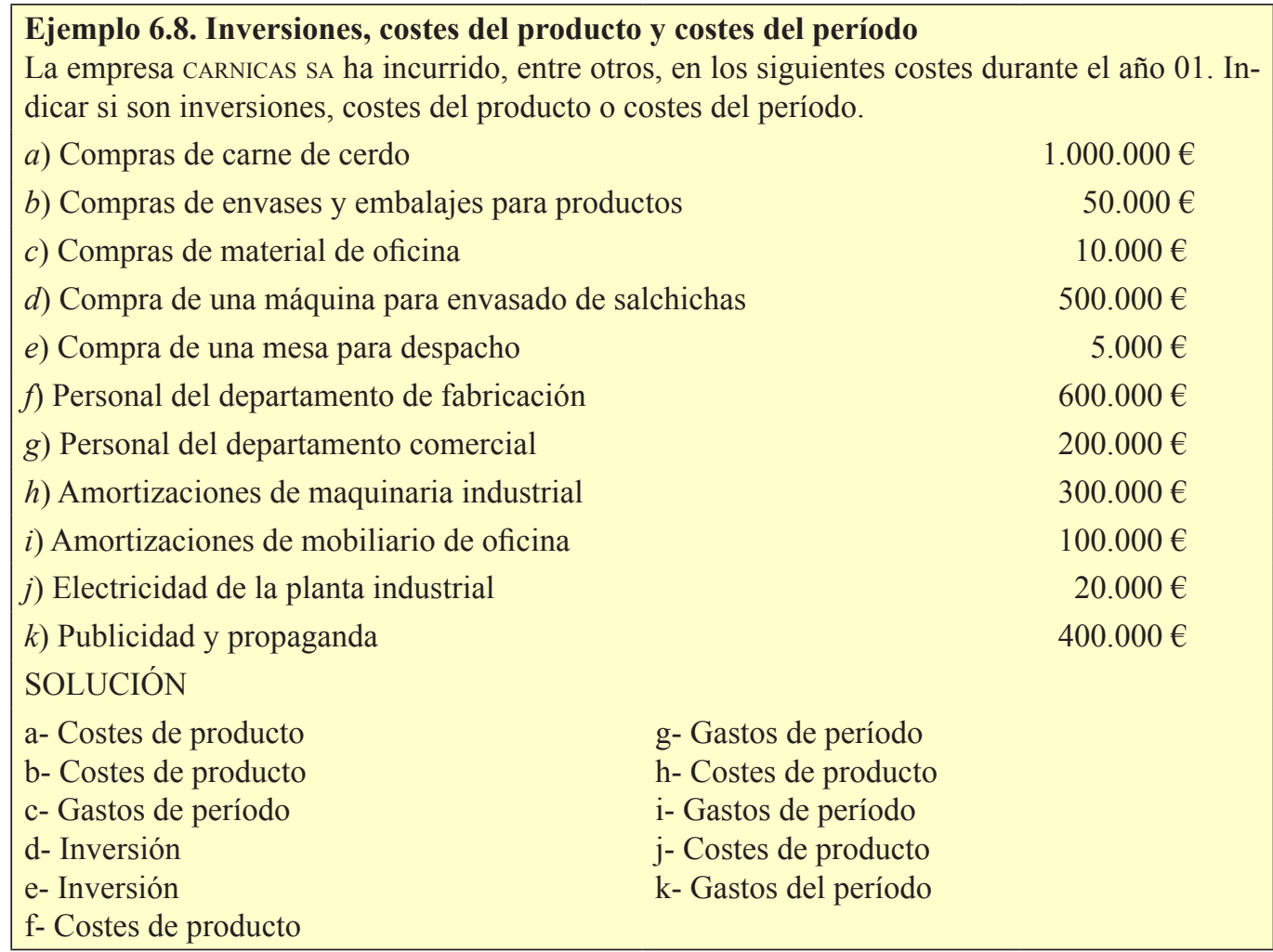

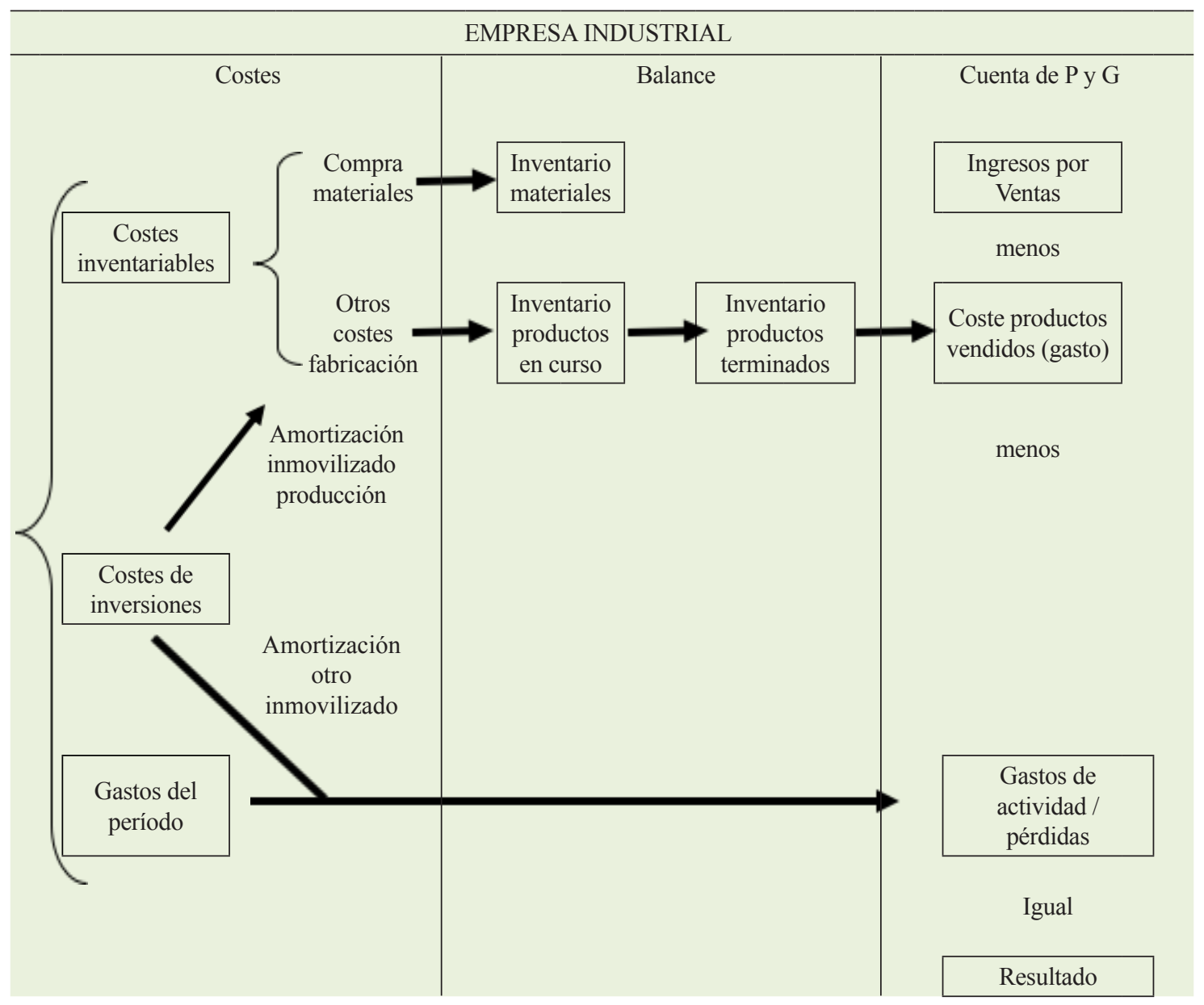

Ilustración 6.3. Repercusiones sobre el balance y la cuentas de pérdidas y ganancias de los costes en empresa industrial 


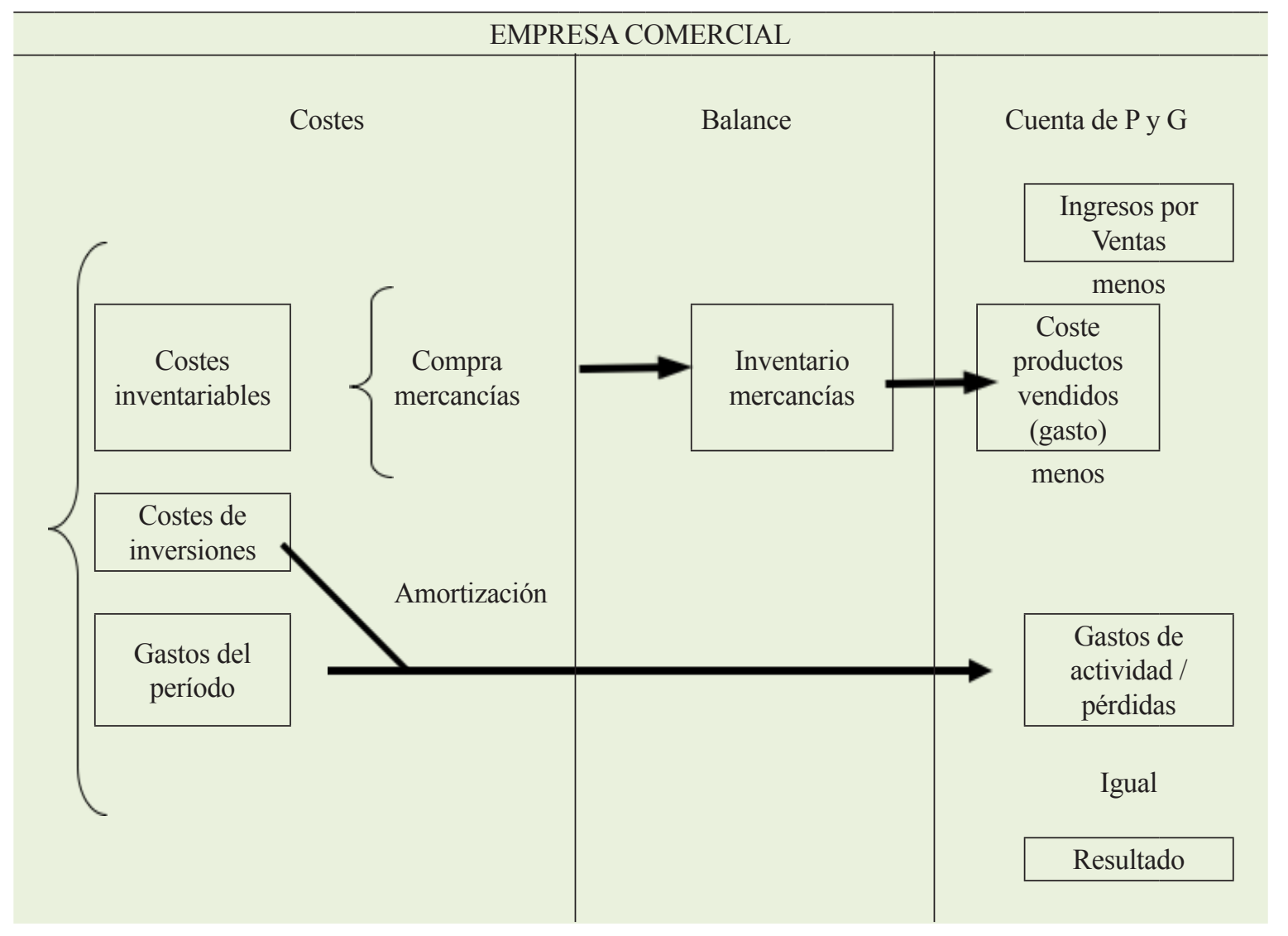

Ilustración 6.4. Repercusiones sobre el balance y la cuentas de pérdidas y ganancias de los costes en empresa comercial

\section{El coste de producción}

La fabricación de todo producto exige la utilización de tres tipos de factores productivos: materias primas o materiales, el trabajo desarrollado por los trabajadores de fábrica o mano de obra de fabricación, y otros factores productivos que suponen costes, denominados costes generales de fabricación (máquinas, herramientas, planta industrial, vehículos, energía, electricidad, agua, teléfono, seguros, reparaciones, mantenimiento, impuestos, etc.).

El coste de estos factores productivos debe ser imputado o acumulado para calcular el coste de producción de un producto. Suelen utilizarse tres conceptos clave que forman parte del coste de producción y que suelen denominarse «componentes básicos del coste de producción»:

- Coste de Materiales Directos (MD). Son los costes de los materiales para los que la empresa realiza un seguimiento hasta el producto. Esto implica controlar las unidades físicas de material utilizadas para la fabricación de los productos y el coste de las mismas.

- Coste de Mano de Obra Directa (MOD). Son los costes del personal de fabricación para los que la empresa realiza un seguimiento hasta el producto. Esto implica controlar las horas utilizadas para la fabricación de cada producto y el coste de las mismas. 
- Costes Indirectos de Fabricación (CIF). Se trata del resto de costes de producción (incluyendo costes de materiales y mano de obra indirectas) para los cuales no se realiza un seguimiento hasta el producto. Estos costes se reparten entre los productos fabricados aplicando prorrateos o criterios de reparto. Por ejemplo, el coste de amortización de la planta industrial puede repartirse entre todos los productos fabricados según el número de unidades fabricadas.

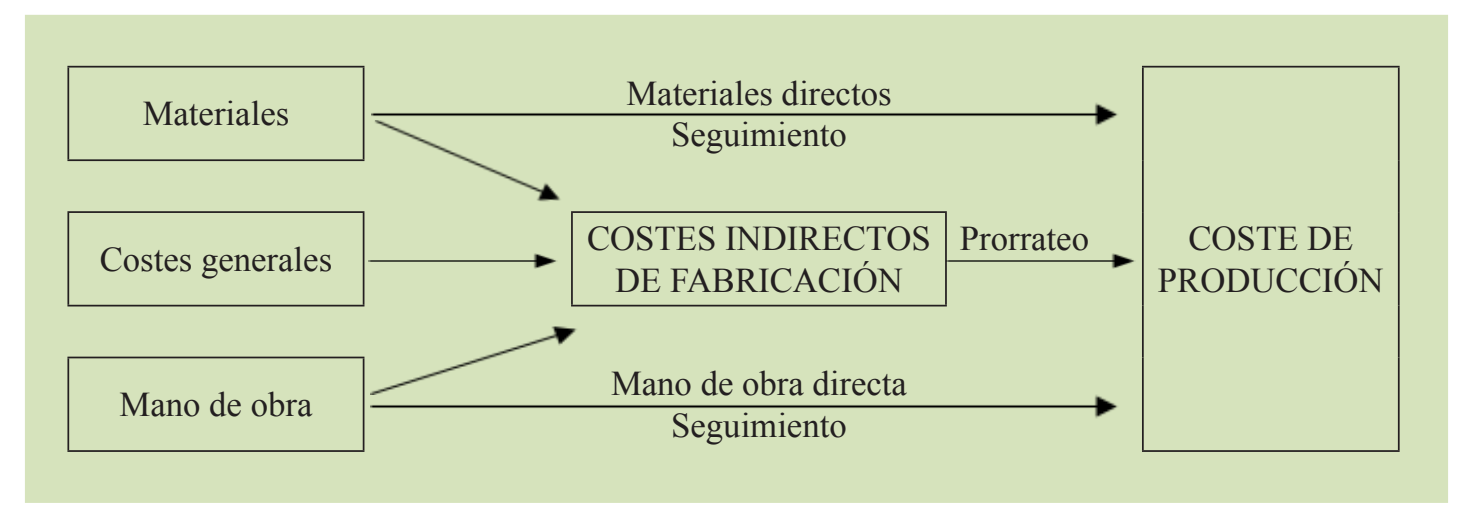

Ilustración 6.5. Componentes básicos del coste de producción

\section{Ejemplo 6.9. Costes de materiales directos}

La empresa MOBLE SA, fabricante de muebles, para calcular los costes de fabricación de sus mesas de madera generalmente hará un seguimiento de los costes de la madera utilizada dado que el coste de la madera es un componente fundamental de la fabricación de mesas. Así, los costes de madera constituirían para esta empresa un coste directo del producto «mesas de madera».

\footnotetext{
Ejemplo 6.10. Costes de materiales indirectos

La empresa MOBLE SA en general no efectuará un seguimiento respecto del coste del papel de lija consumido para la fabricación de las mesas de madera, porque la importancia de dicho coste no justifica que esto se haga. En lugar de ello hace una imputación basada en un prorrateo o criterio de reparto, así, reparte todo el coste del papel de lija consumido entre todos los productos fabricados (mesas, sillas, armarios, etc.) proporcionalmente a los $\mathrm{m}^{2}$ de madera consumidos para la fabricación de cada uno de esos productos. La hipótesis que justifica este reparto es que se supone que cuantos más $\mathrm{m}^{2}$ de madera se usen más papel de lija se habrá utilizado.
} 


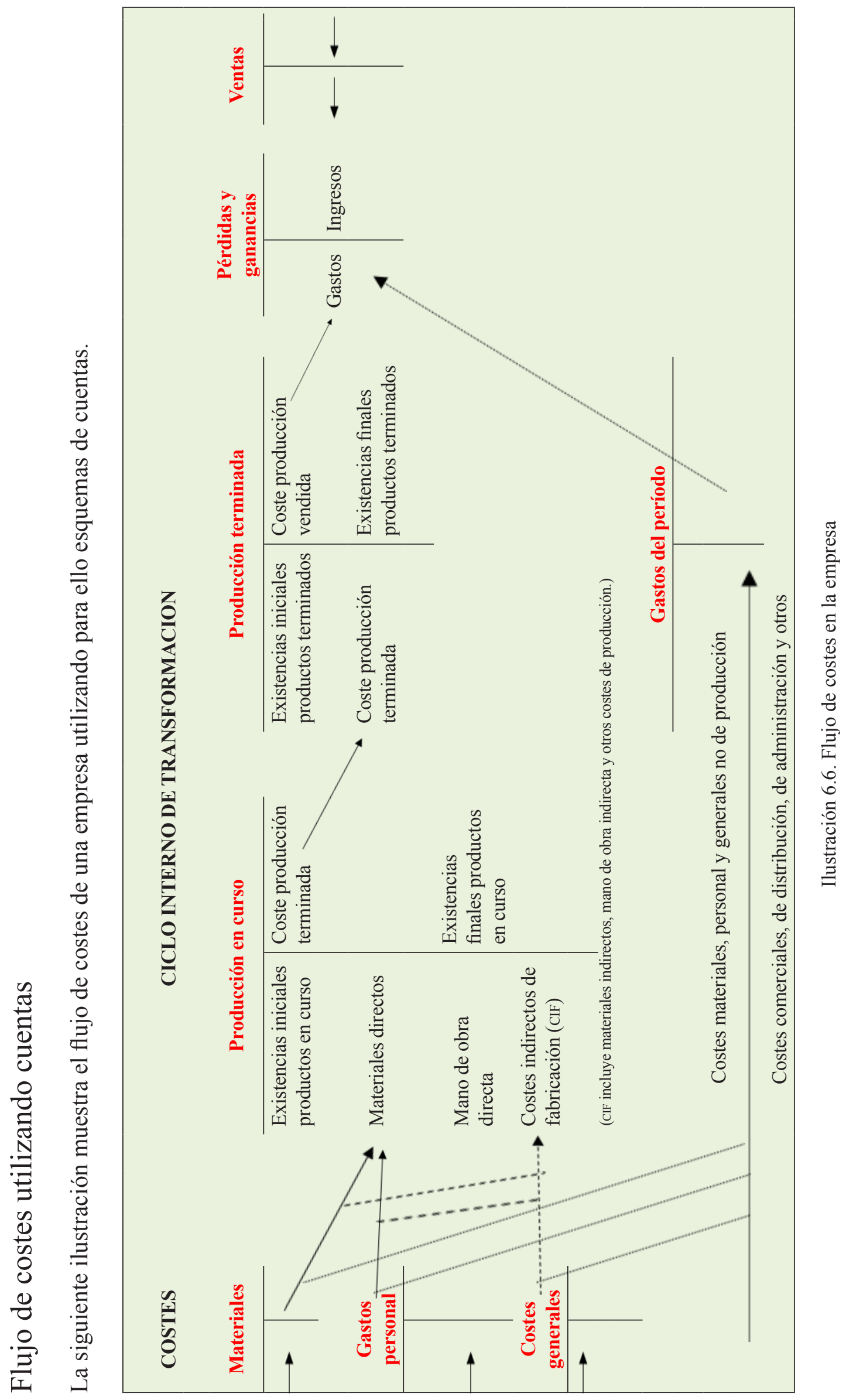




\section{Comportamiento de los costes: costes fijos y variables}

El estudio del comportamiento de los costes es una cuestión vital para la toma de decisiones empresariales, tanto en el área de la planificación de actividades como del control de la gestión.

Muchos de los costes en que incurre una empresa varían dependiendo del tipo y nivel de las actividades que se realicen, mientras que otros permanecen más o menos estables con independencia de las mismas. Según se comporte el coste ante variaciones en la actividad, los costes suelen clasificarse en fijos y variables.

Los costes fijos son aquellos cuyo importe total no varía aunque cambie el nivel de actividad o de factores de coste. Dado que el importe total es constante, cuanto mayor sea el nivel de actividad menor será el coste por unidad de actividad.

\section{Ejemplo 6.11. Costes fijos}

Para su planta de Valencia, la empresa COCA-COLA paga todos los años $10.000 €$ en concepto de seguro contra incendios. El coste del seguro es fijo e independiente la cantidad de litros de Coca-Cola que fabrica.

Por otra parte, si la empresa fabrica en un año 100.000 litros el coste por unidad (por litro) será de $0,10 €$, pero si fabrica 1.000.000 litros el coste unitario solo será de $0,01 € /$ litro.

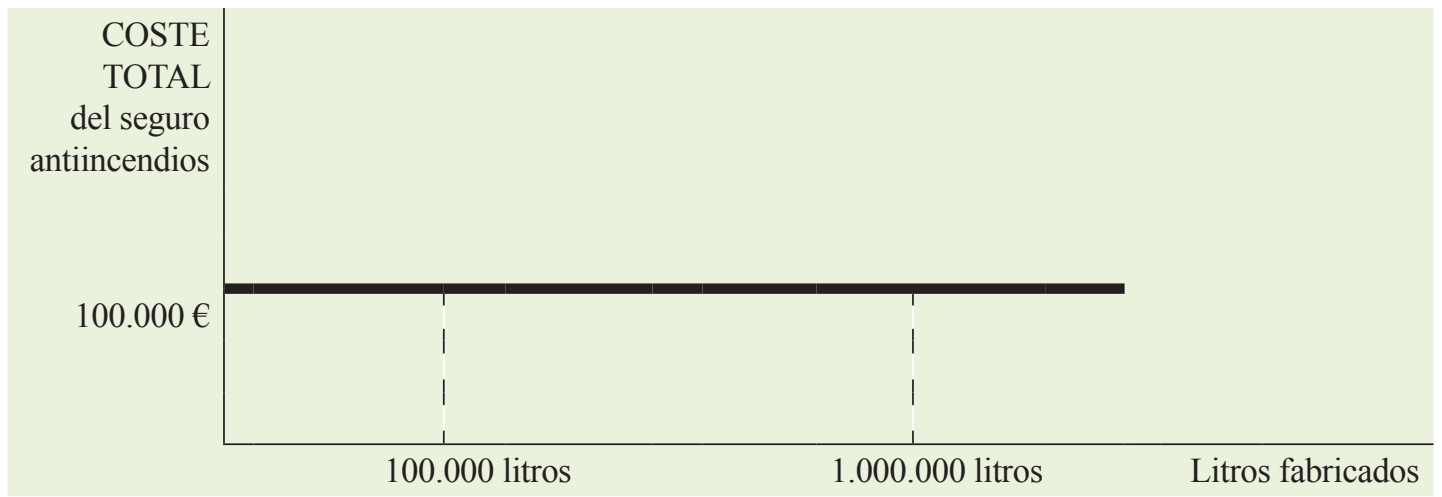

Ilustración 6.7. Representación gráfica del coste fijo total

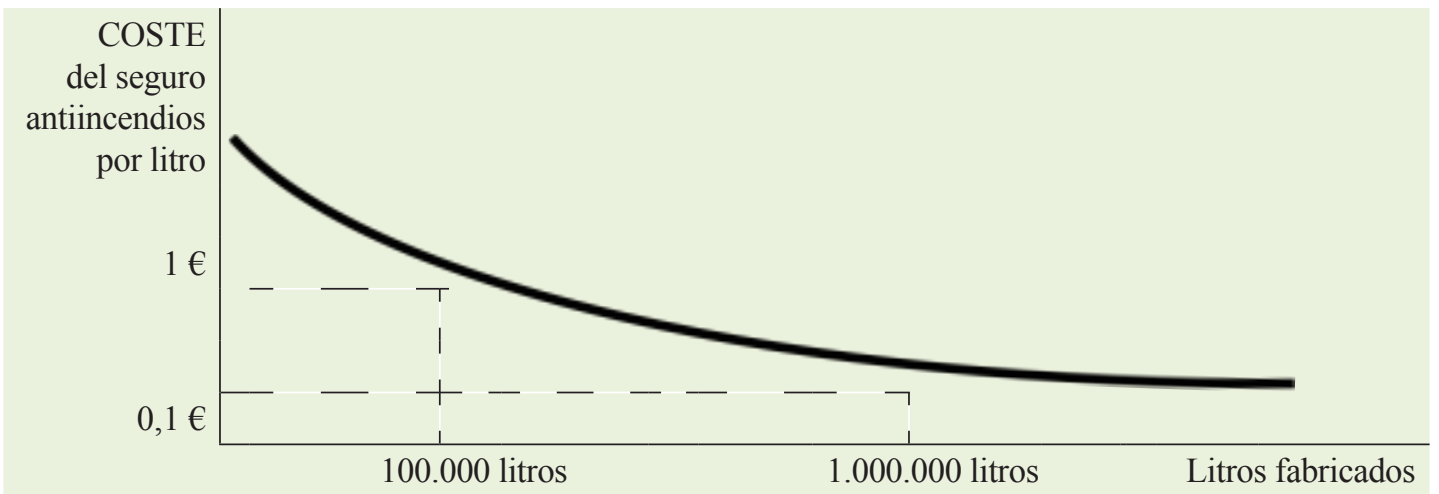

Ilustración 6.8. Representación gráfica del coste fijo unitario 
Los costes variables son aquellos cuyo importe total varía en proporción a los cambios en el nivel de una actividad medida a través de los factores de coste. En general se supondrá que estos costes permanecen constantes para cada unidad de actividad.

\section{Ejemplo 6.12. Costes variables \\ Para su planta de Valencia, COCA-COLA utiliza como materia prima fundamental el jarabe de cola adquirido a la matriz americana. Cada litro de Coca-Cola que se fabrica incorpora $10 \mathrm{gr}$ de ja- rabe de cola cuyo coste es de $50 € / \mathrm{kg}$. El coste total de jarabe de cola varía proporcionalmente conforme varía el nivel de producción. Así si fabrica 100.000 litros deberá consumir $1.000 \mathrm{~kg}$ de jarabe que suponen un coste de $50.000 €$ y si fabrica 1.000 .000 litros, el coste ascenderá a $1.000 .000 \times 0,01 \times 50=500.000 €$. \\ Por otra parte, el coste unitario (por litro) permanecerá constante con independencia del nivel de producción, siendo siempre de $0,10 \times 50=0,5 €$ /litro.}

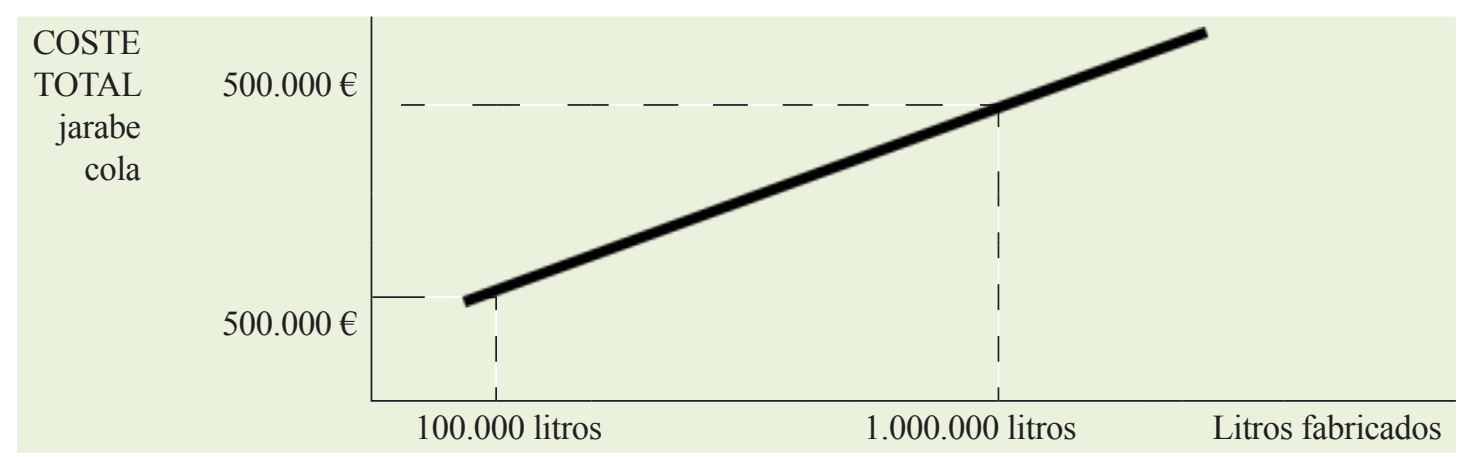

Ilustración 6.9. Representación gráfica del coste variable total

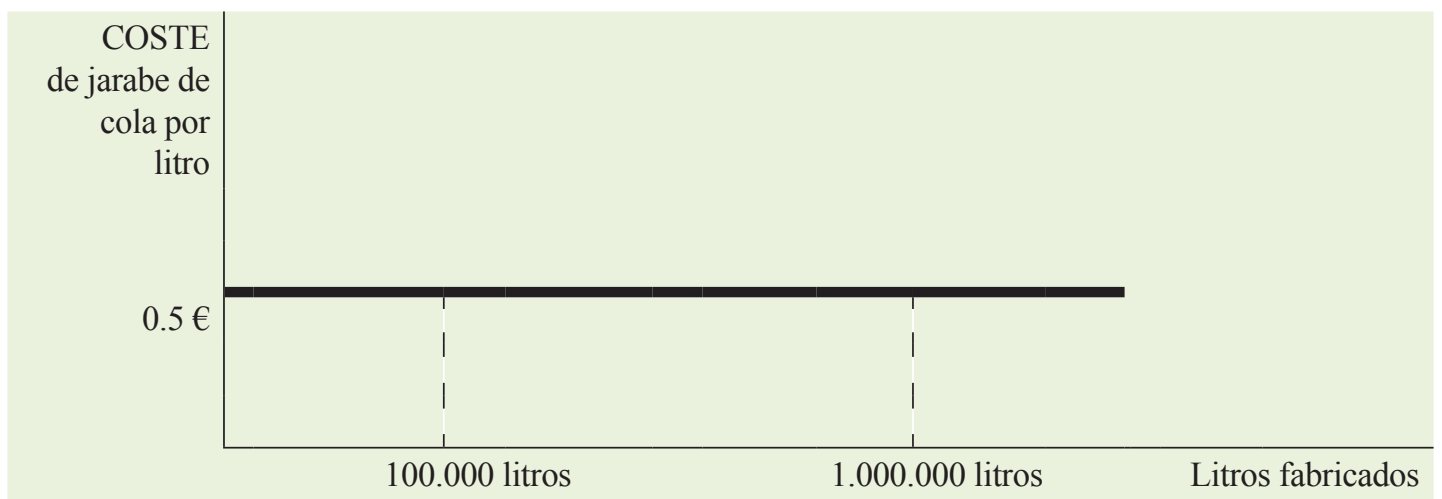

Ilustración 6.10. Representación gráfica del coste variable unitario 


\subsection{Informes internos de costes}

Los informes internos de costes se diseñan a medida de las necesidades de gestión de las empresas, por lo que son muchos los tipos o estructuras de informes que se pueden elaborar.

Estos informes pueden referirse a productos, departamentos, clientes, servicios, etc. No obstante, dado que estas empresas suelen organizar su actividad en secciones o departamentos además de los informes sobre resultados generales de la empresa, son particularmente importantes los informes sobre costes de departamentos

\section{Informes en empresas industriales}

Una multinacional como puede ser FORD puede elaborar informes por productos (Fiesta, Focus, Mondeo, etc.), por áreas geográficas (Europa, Asia, América, etc.), por divisiones (Ford España, Ford Alemania, etc.). Dentro de cada división puede preparar informes por departamentos (montaje de motores, carrocería, pintado, administración, etc.), por tipo de clientes (empresas, particulares, administraciones públicas, etc.), por actividades (diseño, investigación, ventas, reparaciones en garantía, etc.).

De entre los diversos tipos de informes posibles que puede elaborar una empresa industrial en las ilustraciones siguientes se muestra:

- Un informe sobre del coste de producción.

- Un estado de resultados que distingue dos líneas de productos

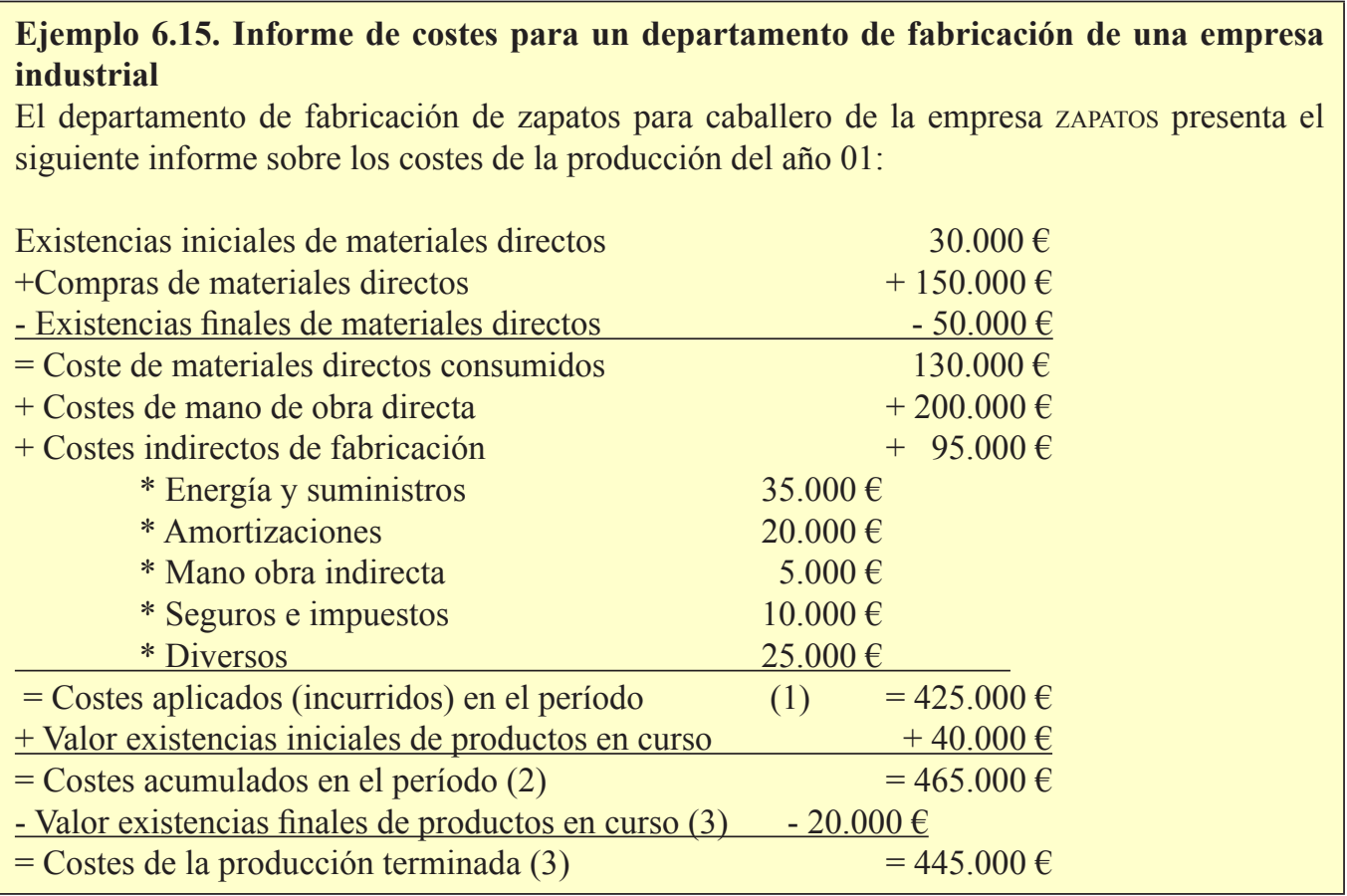


Notas:

(1) Los costes aplicados en un período son la suma de todos los costes incurridos para la actividad de producción realizada ese período (materiales y mano de obra directa y CIF del período).

(2) $\mathrm{Si}$ a los costes incurridos se les suma el valor de las existencias iniciales de productos en curso se obtiene el total de costes acumulados en el período.

(3) El total de costes acumulados en un período se distribuye entre el coste de los productos terminados y el coste de los productos en curso (no terminados) en el período.

\section{Ejemplo 6.16. Informe de resultados de una empresa industrial}

La empresa industrial ZAPATOS presenta el siguiente informe de resultados del año 01:

\begin{tabular}{lccr} 
Productos & Zapatos caballero & Zapatos señora & \multicolumn{1}{c}{ Total } \\
\hline Ventas brutas & 710.000 & 605.000 & 1.315 .000 \\
- Devoluciones, descuentos $\ldots$ & -10.000 & -5.000 & -15.000 \\
\hline = Ventas netas (1) & 700.000 & 600.000 & 1.300 .000
\end{tabular}

- Coste de los productos vendidos

Existencias iniciales productos terminados $50.000 \quad 60.000$

+ Coste de productos terminados $\quad+445.000 \quad+360.000$

\begin{tabular}{lll} 
- Existencias finales de productos & -30.000 & -20.000 \\
\hline terminados & -465.000
\end{tabular}

$=$ Coste de los productos vendidos $\quad-465.000 \quad-400.000 \quad-865.000$

$\begin{array}{lrr}=\text { Margen industrial o Margen bruto } \quad 235.000 & 200.000 & 435.000\end{array}$

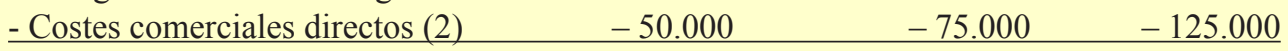

$\begin{array}{lrr}=\text { Margen comercial bruto } & 185.000 & 125.000\end{array}$

- Costes comerciales generales (3) $\quad-120.000$

$=$ Margen comercial neto $\quad 290.000$

- Costes de administración(4) $\quad-70.000$

- Otros costes (5) $\quad-40.000$

$\begin{array}{lr}=\text { Resultado } & 180.000\end{array}$

Notas:

(1) Las ventas netas se calculan deduciendo de las ventas brutas: las devoluciones de ventas, descuentos comerciales y otros conceptos sobre cada uno de los productos.

(2) En ocasiones las empresas realizan un seguimiento por productos de algunos de los costes comerciales por lo que es posible imputarlos directamente a los mismos, permitiendo el cálculo de determinados márgenes comerciales. Podrían tratarse de comisiones de vendedores, costes de distribución o transporte, costes de promoción como vales de compra, etc.

(3) Los costes comerciales generales son aquellos para los que no se hace un seguimiento por productos por lo que se deducen del total.

(4) Los costes de administración se deducirán en general del importe total ya que no suele realizarse un seguimiento por productos.

(5) Dentro de otros costes podrían incluirse costes de investigación y desarrollo, costes financieros y demás no incluidos en partidas anteriores. Normalmente también se deducirán de los importes totales. 


\section{Informes en empresas comerciales}

Una multinacional como CARREFOUR puede elaborar informes por divisiones (Carrefour España, Carrefour Francia, etc.), por centros (Madrid, Valencia, Castellón, etc.). Dentro de cada centro se preparan informes por departamentos de venta (alimentación, bebidas, confección, calzado, deportes, etc.).

Se muestra en la siguiente ilustración un ejemplo de informe de resultados por departamentos o líneas de productos.

\begin{tabular}{|c|c|c|c|c|c|c|}
\hline \multicolumn{7}{|c|}{$\begin{array}{l}\text { Ejemplo 6.17. Informe de costes y resultados en una empresa comercial } \\
\text { SUPERMERCADOS GARCÍA presenta el siguiente informe sobre resultados del primer trimestre de 01: }\end{array}$} \\
\hline & $\begin{array}{l}\text { Carnice- } \\
\text { ría Char- } \\
\text { cutería } \\
\end{array}$ & $\begin{array}{l}\text { Pescade- } \\
\text { ría }\end{array}$ & $\begin{array}{l}\text { Hogar- } \\
\text { Limpieza }\end{array}$ & 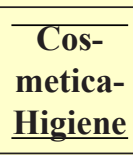 & $\begin{array}{c}\begin{array}{c}\text { Resto } \\
\text { secciones }\end{array} \\
\end{array}$ & TOTAL \\
\hline Ingreso por bruto ventas & 550.000 & 145.000 & 370.000 & 170.000 & 125.000 & 1.360 .000 \\
\hline - Devoluciones, descuentos, ... (1) & -10.000 & -5.000 & -20.000 & 0 & -5.000 & -40.000 \\
\hline Ingreso neto por ventas & 540.000 & 140.000 & 350.000 & $\underline{170.000}$ & 120.000 & 1.320 .000 \\
\hline -Costes directos variables (2) & -250.000 & -70.000 & -170.000 & -30.000 & -50.000 & -570.000 \\
\hline Coste de ventas & -230.000 & -65.000 & -160.000 & -30.000 & $\overline{-46.000}$ & -531.000 \\
\hline Costes de mermas o pérdidas & -20.000 & -5.000 & -10.000 & 0 & -4.000 & -39.000 \\
\hline Margen comercial bruto & 290.000 & 70.000 & 180.000 & $\underline{140.000}$ & 70.000 & 750.000 \\
\hline -Costes directos fijos (3) & -60.000 & -35.000 & -5.000 & -8.000 & -10.000 & -118.000 \\
\hline Personal & $\overline{-40.000}$ & $\overline{-20.000}$ & 0 & 0 & 0 & -60.000 \\
\hline Otros costes directos & -20.000 & -15.000 & -5.000 & -8.000 & -10.000 & -58.000 \\
\hline Margen comercial neto & $\overline{230.000}$ & 35.000 & $\overline{175.000}$ & $\underline{132.000}$ & 60.000 & 632.000 \\
\hline Costes indirectos (4) & -75.000 & -21.000 & -51.000 & -9.000 & -15.000 & -171.000 \\
\hline Resultado neto departamento (5) & 155.000 & 14.000 & 124.000 & $\underline{123.000}$ & 45.000 & 461.000 \\
\hline Costes de estructura (6) & & & & & & 267.000 \\
\hline Resultado & & & & & & 194.000 \\
\hline
\end{tabular}


Notas al informe de resultados:

(1) La empresa divide su actividad en cuatro líneas de productos, que identifica con departamentos, y que son los que aparecen en las columnas de la tabla.

(2) La empresa controla de forma rigurosa las devoluciones y descuentos por línea de productos e informa en la forma que expresa el informe: deduciéndolos de las ventas brutas para obtener la cifra de ventas netas.

(3) La empresa hace un seguimiento de dos tipos de costes directos variables respecto a cada línea de productos. En primer lugar, controla los ingresos y costes de cada producto clasificándolos por líneas o departamentos. Para ello es necesario que cada vez que se produce una venta se lleve el control del tipo de productos vendidos, así como un inventario permanente para el control de su coste. También realiza un seguimiento de las mermas por tipo de producto (roturas, pérdidas, robos, caducidad de perecederos). La diferencia entre los ingresos netos por ventas y estos costes directos proporciona el margen comercial bruto de cada línea (departamento) informando a la empresa de la rentabilidad bruta de cada una de ellas.

(4) La empresa hace un seguimiento de dos tipos de costes directos fijos respecto a líneas de productos (departamentos), el de cierto personal adscrito a las mismas y el de otros costes directos como las amortizaciones de instalaciones (congeladores, refrigeradores, ...). En carnicería y pescadería se dispone de personal específico para la venta al corte o según pedido. El resto de departamentos no dispone de personal propio. No obstante, sí que requerirán trabajos de reposición, limpieza, etc. cuyos costes se incorporarán junto al resto de costes indirectos.

(5) Los costes indirectos que engloba aquí la empresa corresponden a costes de aprovisionamiento (de almacenamiento, de reposición de productos, ...), de limpieza de la tienda y otros costes tales como, electricidad, suministros, etc. Estos costes han requerido para su asignación de un criterio de reparto, en concreto se han repartido en función del coste de los productos vendidos por cada departamento.

(6) Resultado por departamento proporciona información sobre la rentabilidad de cada línea de productos partiendo de los márgenes comerciales bruto y neto y restando los costes indirectos. Con ello se dispone de un dato importante para evaluar el rendimiento de cada línea de productos o departamento e incluso del responsable de cada departamento. La información sobre márgenes en cascada puede se utiliza para reforzar la venta de líneas de productos, reducir otros, etc.

(7) Los costes de estructura engloban los costes cuya asignación a departamentos se considera arbitraria y que por lo tanto cabe considerar globalmente. Dentro de estos costes podríamos se incluyen costes de personal de seguridad, de cajeros y de administración y comercial. También se incluirían costes de seguros, tributos, y amortización de equipos de los servicios administrativo y comercial, material de oficina y resto de costes. 


\section{Material para prácticas}

\section{Preguntas test}

1. Una empresa presenta una situación patrimonial de desequilibrio financiero si:

a) El activo es mayor que el pasivo.

b) El activo es menor que el pasivo más el patrimonio neto.

c) Nunca se puede presentar una situación de desequilibrio financiero.

d) El activo es menor al pasivo.

2. El fondo de maniobra o capital corriente se define como:

a) Activo no corriente menos activo corriente.

b) Pasivo no corriente menos activo corriente.

c) Activo corriente menos pasivo corriente.

d) Patrimonio neto menos pasivo corriente.

3. Un ratio de endeudamiento muy utilizado es:
a) Activo / patrimonio neto.
b) Pasivo / patrimonio neto.
c) Gastos / patrimonio neto.
d) Gastos / pasivo.

4. El EBITDA se define como:

a) Resultado antes de impuestos más deterioros y amortizaciones.

b) Resultado de explotación menos deterioros y amortizaciones.

c) Resultado de explotación más deterioros y amortizaciones.

d) Resultado antes de impuestos menos deterioros y amortizaciones.

5. La rentabilidad económica:

a) Mide la rentabilidad de los fondos invertidos por los propietarios.

b) Mide la rentabilidad de los fondos ajenos invertidos.

c) Mide la rentabilidad de los fondos invertidos con independencia del origen de la financiación.

d) Todas las anteriores.

6. La rentabilidad financiera:

a) Mide la rentabilidad de los fondos invertidos por los propietarios.

b) Mide la rentabilidad de los fondos ajenos invertidos.

c) Mide la rentabilidad de los fondos invertidos con independencia del origen de la financiación.

d) Ninguna de las anteriores.

7. Serían costes inventariables para una empresa industrial:

a) Los costes de materiales, mano de obra y demás los costes fabricación.

b) Los costes de producción más los costes administrativos y comerciales.

c) Los materiales directos, la mano de obra directa y los costes del período.

d) Los costes comerciales y de administración. 
8. Los componentes básicos del coste de producción son:

a) Materiales directos, materiales indirectos y mano de obra.

b) Materiales directos, mano de obra directa y costes indirectos de fabricación.

c) Materiales directos, mano de obra directa y costes directos de fabricación.

d) Materiales, mano de obra y costes administrativos.

9. En relación al comportamiento de los costes señale la respuesta correcta:

a) El coste variable unitario permanece constante.

b) El coste variable total permanece constante.

c) El coste fijo total crece proporcionalmente al crecimiento del nivel de actividad.

d) El coste fijo unitario crece proporcionalmente al crecimiento nivel de actividad.

10. En una empresa fabricante de muebles, la cuota anual del 10\% de amortización de una máquina de lijar tablas de madera supone:

a) Un coste variable.

b) Un coste del período.

c) Un coste inventariable.

d) Ninguna de las anteriores.

\section{SOLUCIONES AL TEST:}

\begin{tabular}{|l|l|l|l|l|}
\hline 1. & 2. & 3. & 4. & 5. \\
\hline 6. & 7. & 8. & 9. & 10. \\
\hline
\end{tabular}




\section{Cuestiones teóricas}

1. ¿Qué muestra un análisis de variación de masas patrimoniales del balance?

2. ¿Qué muestra un análisis de composición de masas patrimoniales del balance?

3. ¿Cómo es la composición de masas patrimoniales que suele identificarse como situación de equilibrio financiero? ¿Por qué?

4. Defina el capital corriente o fondo de maniobra e indique qué expresa.

5. Defina el ratio de solvencia a corto plazo y su utilidad.

6. Defina el test del ácido y su utilidad.

7. Defina el ratio de tesorería inmediata y su utilidad.

8. Indique dos ratios relacionados con el endeudamiento y su utilidad.

9. ¿Qué muestra un análisis de variación de ingresos, gastos y resultados?

10. ¿Qué muestra un análisis de composición de la cuenta de resultados?

11. Defina el EBITDA e indique cómo se calcula.

12. Defina rentabilidad económica y su utilidad.

13. Defina rentabilidad financiera y su utilidad.

14. Defina costes de inversión, costes inventariables y gastos del período.

15. Explique la repercusión de los costes de inversiones en el balance y la cuenta de resultados de una empresa industrial.

16. Explique la repercusión de los costes de inversiones en el balance y la cuenta de resultados de una empresa comercial.

17. ¿Cuáles son los tres componentes básicos del coste de producción?

18. Diferencie entre costes directos e indirectos y el procedimiento de imputación a productos.

19. Defina y cite las características de los costes fijos.

20. Defina y cite las características de los costes variables.

21. Indique qué información básica suele recoger un informe interno de costes de producción.

22. Indique qué información sobre costes suele aparecer en informes internos de resultados en empresas comerciales. 


\section{Ejercicios}

Los ejercicios 1 a 9 siguientes se basarán en el balance de FOMENTO DE CONSTRUCCIONES Y CONTRATAS SA que se muestra a continuación (valores en miles de euros).

\begin{tabular}{|c|c|c|c|c|c|}
\hline & 2009 & 2008 & & 2009 & 2008 \\
\hline \multicolumn{6}{|l|}{ ACTIVO } \\
\hline NO CORRIENTE & 4.285.179 & 3.466 .161 & PATRIMONIO NETO & 1.253 .585 & 1.233 .5470 \\
\hline Inmovilizado intangible & 26.604 & 27.212 & FONDOS PROPIOS & 1.272.707 & 1.257.226 \\
\hline Inmovilizado material & 537.512 & 459.676 & Capital & 127.303 & 127.303 \\
\hline Inversiones inmobiliarias & 230.512 & 232.032 & Reservas & 890.526 & 787.017 \\
\hline \multirow[t]{2}{*}{ Inversiones financieras a 1.p. } & 3.490 .551 & 2.747 .241 & Pérdidas y ganancias & 254.878 & 342.906 \\
\hline & & & $\begin{array}{l}\text { AJUSTES } \\
\text { POR CAMBIO VALOR }\end{array}$ & -21.724 & -26.540 \\
\hline $\begin{array}{l}\text { ACTIVO } \\
\text { CORRIENTE }\end{array}$ & 2.614.542 & 2.152.351 & SUBVENCIONES & 2.602 & 2.861 \\
\hline Existencias & 6.146 & 7.135 & & & \\
\hline Deudores comerciales y otros & 756.797 & 724.547 & $\begin{array}{l}\text { PASIVO } \\
\text { NO CORRIENTE }\end{array}$ & 4.552.262 & 3.134.300 \\
\hline Inversiones financieras a c.p. & 1.805 .405 & 1.343 .100 & & & \\
\hline Efectivo & 46.194 & 77.569 & PASIVO CORRIENTE & 1.093 .874 & 1.250 .665 \\
\hline TOTAL ACTIVO & 6.899 .721 & 5.618 .512 & TOTAL PASIVO & 6.899 .721 & 5.618.512 \\
\hline \multicolumn{3}{|c|}{ Estructura Económica } & \multicolumn{3}{|c|}{ Estructura Financiera } \\
\hline
\end{tabular}

Ejercicio 1. Análisis de variación de masas patrimoniales

Realice un análisis de variación de masas patrimoniales del balance para los dos años y comente los resultados.

\begin{tabular}{|l|l|l|l|l|l|}
\hline & $\begin{array}{c}\text { Diferencia } \\
\mathbf{0 9 - 0 8}\end{array}$ & $\begin{array}{c}\% \\
\mathbf{0 9 / 0 8}\end{array}$ & & $\begin{array}{c}\text { Diferencia } \\
\mathbf{0 9 - 0 8}\end{array}$ & $\begin{array}{c}\mathbf{\%} \\
\mathbf{0 9 / 0 8}\end{array}$ \\
\hline $\begin{array}{l}\text { ACTIVO } \\
\text { NO CORRIENTE }\end{array}$ & & & PATRIMONIO NETO & & \\
\hline Inmovilizado intangible & & & FONDOS PROPIOS & & \\
\hline Inmovilizado material & & & Capital & & \\
\hline Inversiones inmobiliarias & & & Reservas & & \\
\hline Inversiones financieras a l.p. & & & Pérdidas y ganancias & & \\
\hline ACTIVO CORRIENTE & & & $\begin{array}{l}\text { AJUSTES } \\
\text { POR CAMBIO VALOR }\end{array}$ & & \\
\hline Existencias & & & SUBVENCIONES & & \\
\hline Deudores comerciales y otros & & & & & \\
\hline Inversiones financieras a c.p. & & & PASIVO NO CORRIENTE & & \\
\hline Efectivo & & & PASIVO CORRIENTE & & \\
\hline TOTAL ACTIVO & & & TOTAL PASIVO & & \\
\hline
\end{tabular}


Ejercicio 2. Análisis de composición de masas patrimoniales

Realice un análisis de composición de masas patrimoniales del balance para los dos años y comente los resultados.

\begin{tabular}{|l|l|l|l|l|l|}
\hline & $\mathbf{2 0 0 9}$ & $\mathbf{2 0 0 8}$ & & $\mathbf{2 0 0 9}$ & $\mathbf{2 0 0 8}$ \\
\hline $\begin{array}{l}\text { ACTIVO } \\
\text { NO CORRIENTE }\end{array}$ & & & PATRIMONIO NETO & & \\
\hline Inmovilizado Intangible & & & FONDOS PROPIOS & & \\
\hline Inmovilizado material & & & Capital & & \\
\hline Inversiones inmobiliarias & & & Reservas & & \\
\hline Inversiones financieras a l.p. & & & Pérdidas y ganancias & & \\
\hline ACTIVO CORRIENTE & & & $\begin{array}{l}\text { AJUSTES } \\
\text { POR CAMBIO VALOR }\end{array}$ & & \\
\hline Existencias & & & SUBVENCIONES & & \\
\hline Deudores comerciales y otros & & & & & \\
\hline Inversiones financieras a c.p. & & & PASIVO NO CORRIENTE & & \\
\hline Efectivo & & & PASIVO CORRIENTE & & \\
\hline TOTAL ACTIVO & & & TOTAL PASIVO & & \\
\hline
\end{tabular}

Ejercicio 3. Capital corriente

Calcule el capital corriente para los dos años y comente los resultados.

\begin{tabular}{|l|l|l|l|}
\hline & $\mathbf{2 0 0 9}$ & $\mathbf{2 0 0 8}$ & Variación \\
\hline Capital corriente o fondo de maniobra $=\mathrm{AC}-\mathrm{PC}$ & & & \\
\hline & & & \\
\hline
\end{tabular}

Ejercicio 4. Ratio de solvencia a corto plazo

Calcule el ratio de solvencia a corto plazo para los dos años y comente los resultados.

\begin{tabular}{|l|l|l|}
\hline & 2009 & 2008 \\
\hline Ratio de solvencia $=$ AC / PC & & \\
\hline & & \\
& & \\
\hline
\end{tabular}

\section{Ejercicio 5. Test del ácido}

Calcule el test del ácido para los dos años y comente los resultados.

\begin{tabular}{|l|l|l|}
\hline & $\mathbf{2 0 0 9}$ & $\mathbf{2 0 0 8}$ \\
\hline Test del acido $=(\mathrm{AC}-$ Existencias $) / \mathrm{PC}$ & & \\
\hline & & \\
\hline
\end{tabular}


Ejercicio 6. Ratio de tesorería intermedia

Calcule el ratio de tesorería intermedia para los dos años y comente los resultados.

\begin{tabular}{|l|c|c|}
\hline & $\mathbf{2 0 0 9}$ & $\mathbf{2 0 0 8}$ \\
\hline Ratio de Tesorería intermedia $=($ Efectivo + IFT $) /$ PC & & \\
\hline \multicolumn{2}{|l|}{} \\
\hline
\end{tabular}

\section{Ejercicio 7. Ratio de tesorería inmediata}

Calcule el ratio de tesorería inmediata para los dos años y comente los resultados.

\begin{tabular}{|l|c|c|}
\hline & $\mathbf{2 0 0 9}$ & \multicolumn{1}{c|}{$\mathbf{2 0 0 8}$} \\
\hline Ratio de tesorería inmediata = Efectivo / PC & & \\
\hline $\begin{array}{l}\text { Es bajo pero normal, no es necesario que sea superior ya que la solvencia a corto plazo parece } \\
\text { garantizada con los ratios anteriores. }\end{array}$
\end{tabular}

\section{Ejercicio 8. Ratio endeudamiento}

Calcule el ratio de endeudamiento $(\mathrm{P} /(\mathrm{P}+\mathrm{N})$ para los dos años y comente los resultados.

\begin{tabular}{|l|c|c|}
\hline & 2009 & 2008 \\
\hline Ratio endeudamiento $=\mathrm{P} /(\mathrm{P}+\mathrm{N})$ & & \\
\hline
\end{tabular}

\section{Ejercicio 9. Ratio endeudamiento}

Calcule el ratio de endeudamiento $(\mathrm{PC} /(\mathrm{P}+\mathrm{N})$ para los dos años y comente los resultados.

\begin{tabular}{|l|c|c|}
\hline & 2009 & 2008 \\
\hline Ratio endeudamiento $=\mathrm{PC} /(\mathrm{P}+\mathrm{N})$ & & \\
\hline
\end{tabular}

Los ejercicios 10 a 14 siguientes se basarán en la cuenta de pérdidas y ganancias de FOMENTO DE CONSTRUCCIONES Y CONTRATAS SA, que se incluye a continuación, y en el balance mostrado con anterioridad (valores en miles de euros). 


\begin{tabular}{|lrr|}
\hline & $\mathbf{2 0 0 9}$ & \multicolumn{2}{c|}{$\mathbf{2 0 0 8}$} \\
Importe neto cifra negocios & $\mathbf{1 . 5 5 7 . 9 4 4}$ & $\mathbf{1 . 5 4 0 . 3 1 4}$ \\
Aprovisionamientos & \multicolumn{2}{c|}{-195.719} \\
Otros ingresos de explotación & -189.725 \\
Gastos de Personal & 77.528 & 101.560 \\
Otros gastos de explotación & -788.543 & -757.432 \\
Amortización de inmovilizado & -192.027 & -185.124 \\
Otros resultados & -83.912 & -71.278 \\
RESULTADO DE EXPLOTACIÓN & 21.859 & 32.752 \\
Ingresos financieros & $\mathbf{3 9 7 . 1 3 0}$ & $\mathbf{4 7 1 . 0 6 7}$ \\
Gastos financieros & 6.286 & 19.300 \\
Otros resultados financieros & -117.040 & -183.171 \\
RESULTADO FINANCIERO & -6.052 & 70.616 \\
RESULTADO ANTES DE IMPUESTOS & $\mathbf{- 1 1 6 . 8 0 6}$ & $\mathbf{- 9 3 . 2 5 5}$ \\
Impuesto sobre beneficios & $\mathbf{2 8 0 . 3 2 4}$ & $\mathbf{3 7 7 . 8 1 2}$ \\
RESULTADO DEL EJERCICIO & -25.626 & -34.906 \\
\hline
\end{tabular}

\section{Ejercicio 10. Análisis de variación de ingresos y gastos}

Realice un análisis de variación de ingresos y gastos de la cuenta de pérdidas y ganancias del balance para los dos años y comente los resultados.

\begin{tabular}{|l|l|l|l|l|}
\hline & $\mathbf{2 0 0 9}$ & $\mathbf{2 0 0 8}$ & $\begin{array}{c}\text { Diferencia } \\
\mathbf{0 9 - 0 8}\end{array}$ & $\mathbf{\%} \mathbf{0 9 / 0 8}$ \\
\hline Importe neto cifra negocios & & & & \\
\hline Aprovisionamientos & & & & \\
\hline Otros ingresos de explotación & & & & \\
\hline Gastos de Personal & & & & \\
\hline Otros gastos de explotación & & & & \\
\hline Amortización de inmovilizado & & & & \\
\hline Otros resultados & & & & \\
\hline RESULTADO DE EXPLOTACIÓN & & & & \\
\hline Ingresos financieros & & & & \\
\hline Gastos financieros & & & & \\
\hline Otros resultados financieros & & & & \\
\hline RESULTADO FINANCIERO & & & & \\
\hline RESULTADO ANTES DE IMPUESTOS & & & & \\
\hline Impuesto sobre beneficios & & & & \\
\hline RESULTADO DEL EJERCICIO & & & & \\
\hline & & & & \\
\hline
\end{tabular}




\section{Ejercicio 11. Análisis de composición del resultado}

Realice un análisis de composición del resultado para los dos años y comente los resultados.

\begin{tabular}{|l|l|l|}
\hline & $\mathbf{2 0 0 9}$ & $\mathbf{2 0 0 8}$ \\
\hline Importe neto cifra negocios & & \\
\hline Aprovisionamientos & & \\
\hline Otros ingresos de explotación & & \\
\hline Gastos de personal & & \\
\hline Otros gastos de explotación & & \\
\hline Amortización de inmovilizado & & \\
\hline Otros resultados & & \\
\hline RESULTADO DE EXPLOTACIÓN & & \\
\hline Ingresos financieros & & \\
\hline Gastos financieros & & \\
\hline Otros resultados financieros & & \\
\hline RESULTADO FINANCIERO & & \\
\hline RESULTADO ANTES DE IMPUESTOS & & \\
\hline Impuesto sobre beneficios & & \\
\hline RESULTADO DEL EJERCICIO & & \\
\hline & & \\
\end{tabular}

\section{Ejercicio 12. EBITDA}

Calcule el EBITDA para los dos años y comente los resultados.

\begin{tabular}{|l|l|l|}
\hline & $\mathbf{2 0 0 9}$ & $\mathbf{2 0 0 8}$ \\
\hline EBITDA & & \\
\hline & & \\
\hline
\end{tabular}

\section{Ejercicio 13. Rentabilidad económica}

Calcule la rentabilidad económica para los dos años y comente los resultados.

\begin{tabular}{|l|c|c|}
\hline & $\mathbf{2 0 0 9}$ & $\mathbf{2 0 0 8}$ \\
\hline Rentabilidad económica & & $8,38 \%$ \\
\hline & \\
\hline
\end{tabular}

\section{Ejercicio 14. Rentabilidad financiera}

Calcule la rentabilidad financiera para los dos años y comente los resultados.

\begin{tabular}{|l|c|c|}
\hline & $\mathbf{2 0 0 9}$ & $\mathbf{2 0 0 8}$ \\
\hline Rentabilidad financiera & & $27,80 \%$ \\
\hline & \\
\hline
\end{tabular}




\section{Ejercicio 15. Costes como activos y como gastos}

La empresa UTILPROF, que se dedica a la fabricación de herramientas para la construcción, ha incurrido en los siguientes costes como consecuencia de su actividad (valores en $€$ ).

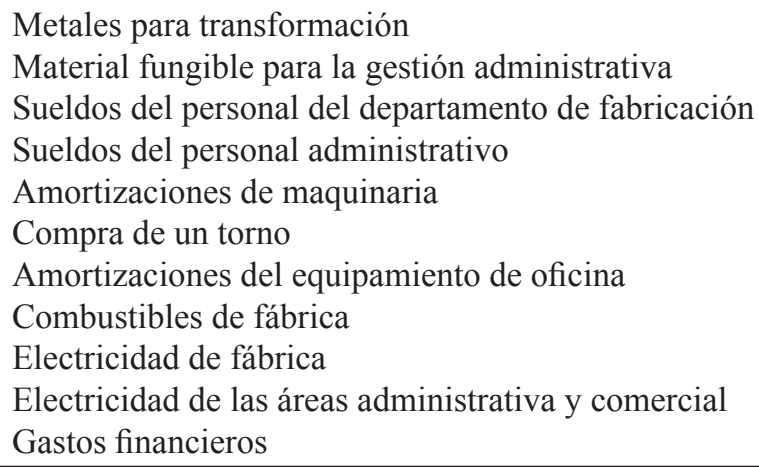

$100.000,00$

$2.000,00$

$125.000,00$

$40.000,00$

$50.000,00$

$3.000,00$

$10.000,00$

$9.000,00$

$15.000,00$

$5.000,00$ $20.000,00$

Determine los costes de inversiones, los costes del producto o inventariables y aquellos que deben imputarse directamente como gastos del período.

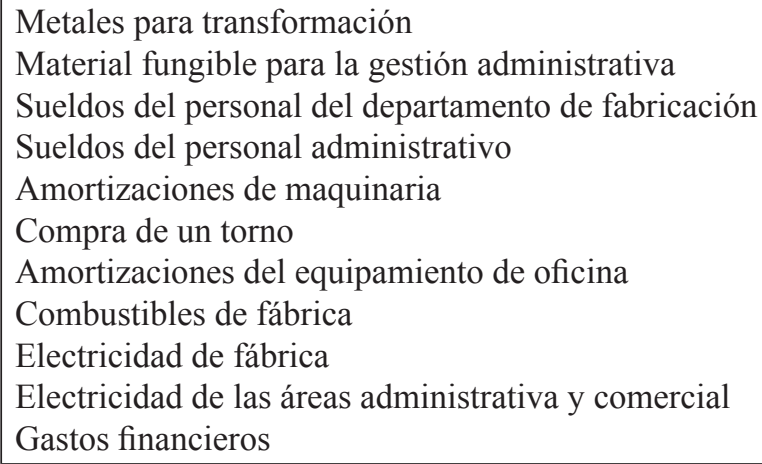

\section{Ejercicio 16. Costes como activos y como gastos}

La empresa CASTELUZ, dedicada a la fabricación de lámparas, presenta la siguiente información:

\begin{tabular}{|l|c|c|c|c|}
\hline \multirow{2}{*}{} & \multicolumn{2}{|c|}{ Cantidades } & \multicolumn{2}{c|}{ Importes totales $(€)$} \\
\cline { 2 - 5 } & Producida & Vendida & Costes & Ventas \\
\hline Lámpara de techo & 10 & 9 & 100 & 150 \\
\hline Lámpara de pie & 15 & 14 & 300 & 350 \\
\hline Lámpara flexo & 30 & 20 & 150 & 180 \\
\hline
\end{tabular}

Se pide que:

a) Calcule los ingresos y los costes totales.

b) Sabiendo que 5 lámparas flexo han tenido que ser destruidas dado que fueron mal almacenadas y se deterioraron irreparablemente, calcule la pérdida sufrida por este concepto.

c) Calcule los costes que se considerarán gastos del ejercicio.

d) Calcule los costes que se clasificarán como activos.

e) Determine el resultado. 


\begin{tabular}{|l|l|l|c|c|c|c|c|c|c|c|}
\hline & \multicolumn{3}{|c|}{ En unidades físicas } & \multicolumn{5}{c|}{ Costes } \\
\hline & $\begin{array}{c}\text { Produc- } \\
\text { ción }\end{array}$ & Ventas & $\begin{array}{c}\text { Existen- } \\
\text { cias } \\
\text { finales }\end{array}$ & $\begin{array}{c}\text { Pérdi- } \\
\text { das }\end{array}$ & $\begin{array}{c}\text { Coste } \\
\text { unita- } \\
\text { rio }\end{array}$ & $\begin{array}{c}\text { Costes } \\
\text { totales }\end{array}$ & $\begin{array}{c}\text { Coste } \\
\text { de ven- } \\
\text { tas }\end{array}$ & $\begin{array}{c}\text { Pérdi- } \\
\text { das }\end{array}$ & $\begin{array}{c}\text { Existen- } \\
\text { cias } \\
\text { finales }\end{array}$ & $\begin{array}{c}\text { Ingre- } \\
\text { sos } \\
\text { totales }\end{array}$ \\
\hline Lámpara de techo & & & & & & & & & & \\
\hline Lámpara de pie & & & & & & & & & & \\
\hline Lámpara flexo & & & & & & & & & & \\
\hline SOLUCIONES & & & & & & & & & \\
\hline \\
e) El resultado será =
\end{tabular}

\section{Ejercicio 17. Costes directos e indirectos}

La empresa HERRAMAZA se dedica a la fabricación de herramientas diversas. Para ello incurre en los siguientes costes:

1) Electricidad de la fábrica.

2) Piezas de acero para la elaboración de herramientas.

3) Trabajadores de la sección de montaje de piezas.

4) Seguro contra incendios.

5) Agua para la refrigeración de máquinas.

6) Trabajadores de la sección de pintado de herramientas.

Determine cuáles de los anteriores costes serían directos e indirectos respecto a los productos.
1) Electricidad de la fábrica
2) Piezas de acero para la elaboración de herramientas
3) Trabajadores de la sección de montaje de piezas
4) Seguro contra incendios
5) Agua para la refrigeración de máquinas
6) Trabajadores de la sección de pintado de herramientas

\section{Ejercicio 18. Costes directos e indirectos}

Suponga ahora que se conoce que para cada máquina de la empresa HERRAMAZA del ejercicio anterior existe un contador de electricidad y se controla informáticamente el consumo incurrido para la fabricación de cada lote de herramientas. Por otra parte, los trabajadores de la sección de pintado no llevan ninguna ficha para indicar cuánto tiempo han dedicado a pintar cada lote herramientas de un determinado tipo.

Determine de cuál sería en este caso la consideración de los costes 1) y 6) del ejercicio anterior.

6) 


\section{Ejercicio 19. Costes fijos y variables}

La empresa HERRAMAZA fabrica unos destornilladores incurriendo en los siguientes costes:

Coste variable unitario por destornillador $5 €$

Costes fijos (entre 1.000-12.000 uds.) $\quad 10.000 €$

Costes fijos (entre 12.000-20.000 uds.) $15.000 €$

Calcule los costes totales de producción, y los costes por unidad, para un volumen de $5.000,10.000$ y 15.000 uds.

\begin{tabular}{|l|l|l|}
\hline \multicolumn{1}{|c|}{ Nivel Actividad } & Coste Total & Coste por unidad \\
\hline Para 5.000 uds. & & \\
\hline Para 10.000 uds. & & \\
\hline Para 20.000 uds. & & \\
\hline
\end{tabular}

\section{Ejercicio 20. Costes fijos y variables}

La empresa de reprografía СоРҮтот utiliza fotocopiadoras que alquila por $10.000 € /$ año cada una y cuya capacidad de fotocopiado es de 50.000 fotocopias anuales por máquina.

Se pide que:

a) Represente gráficamente los costes totales anuales en los que se incurriría por el alquiler de una fotocopiadora.

b) Represente el coste unitario para un intervalo de actividad de 0 a 50.000 fotocopias.

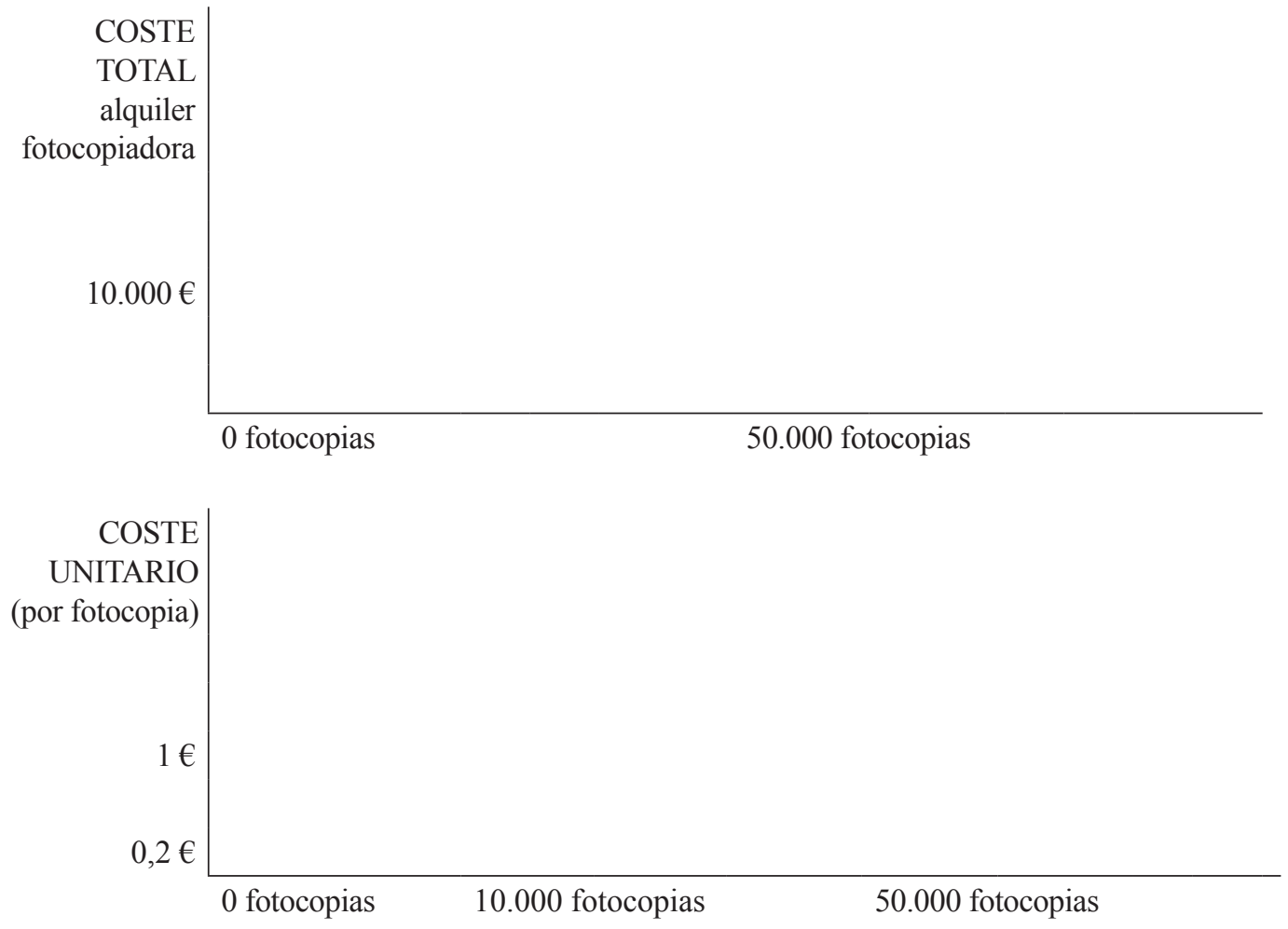




\section{Ejercicio 21. Costes fijos y variables}

La imprenta COLORPRINT, para la confección de unas camisetas que servirán para recaudar fondos para el viaje de fin de carrera, precisa confeccionar una maqueta original con un coste de $600 €$ y que permite realizar 1.000 camisetas como máximo.

Se pide que:

a) Indique de qué tipo de coste respecto a la producción se trata.

b) Calcule y represente gráficamente el coste unitario y total para 1, 250, 500, 750 y 1.000 camisetas.

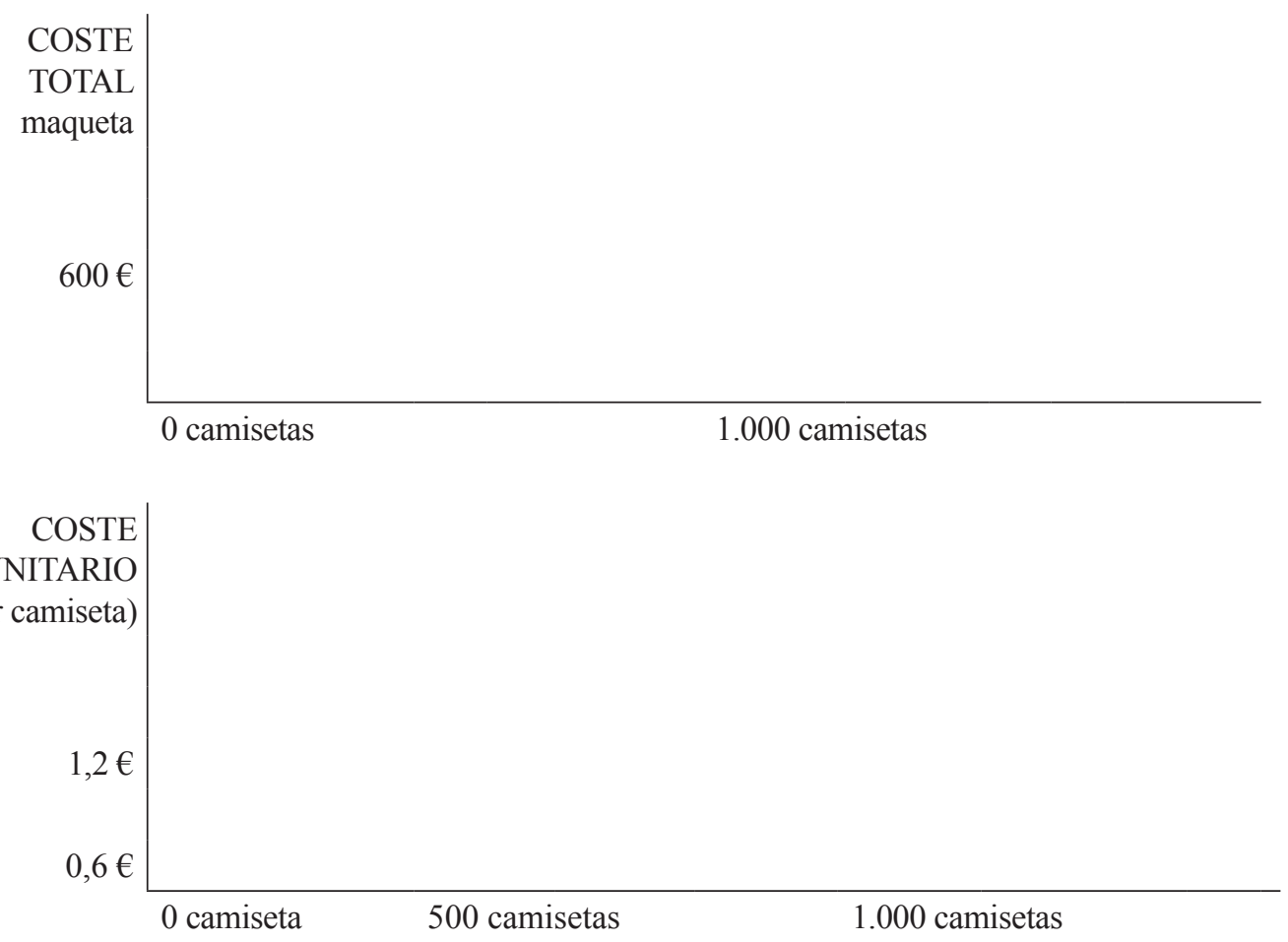

\section{Ejercicio 22. Costes fijos y variables.}

La imprenta COLORPRINT incurre también en unos costes de impresión de camisetas, que ascienden a $3 €$ por camiseta en concepto de mano de obra directa y pintura. (Las camisetas blancas se las proporcionan los estudiantes).

Se pide que:

a) Indique de qué tipo de coste respecto a la producción se trata.

b) Represente gráficamente el coste unitario y total de la impresión de las camisetas para un intervalo de 300 a 500 camisetas.

Es un coste variable.

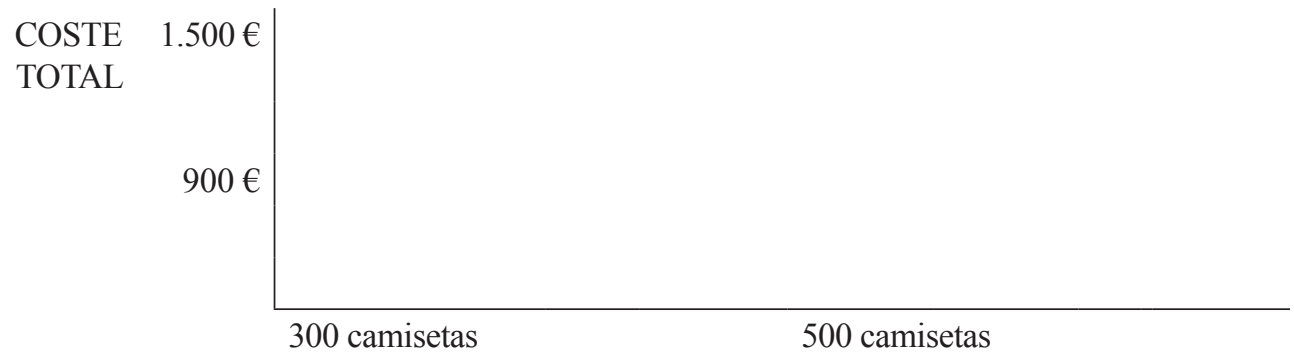




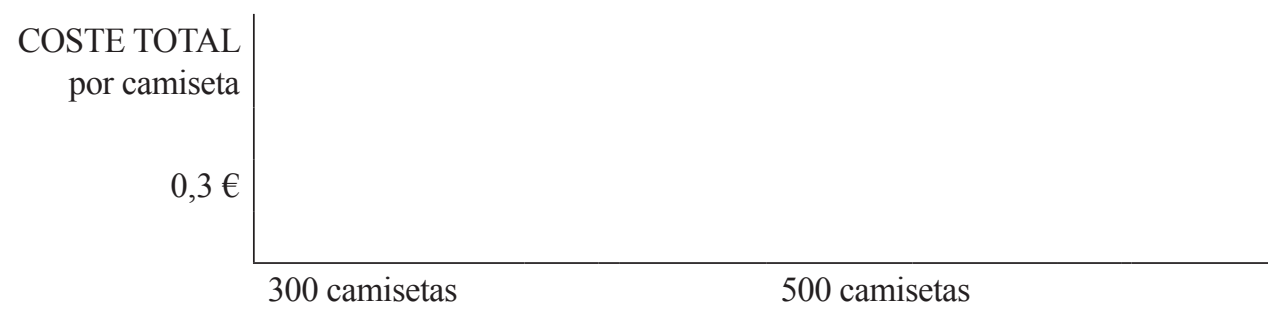

\section{Ejercicio 23. Costes fijos y variables}

La empresa TORNICAS se dedica a fabricar tornillos. Para ello precisa del uso de metales. La producción terminada se presenta en cajas de 100 tornillos. El peso de cada tornillo es de 2,5 gramos y el coste por $\mathrm{Kg}$ de metal en bruto es de 5,00 €.

Represente gráficamente el coste total y el coste unitario de materiales respecto a la producción en cajas de 1.000 a 3.000 cajas de 100 tornillos.

Es un coste variable.

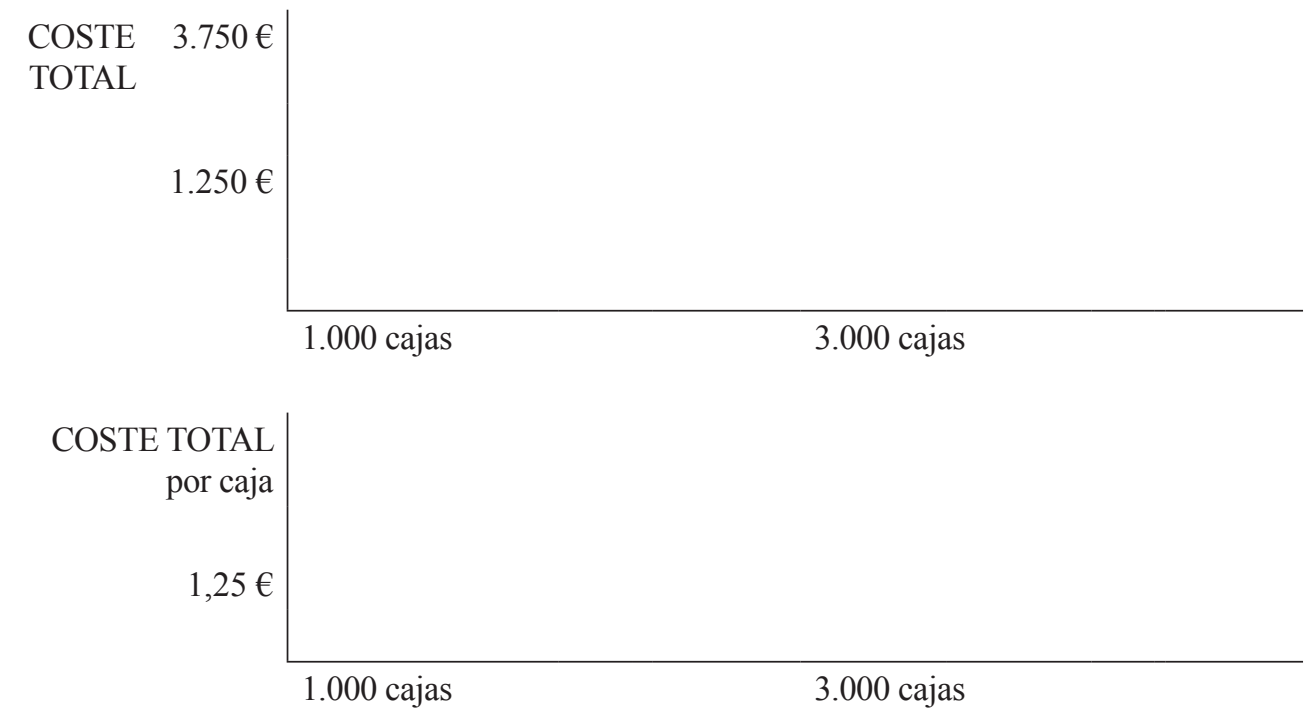

\section{Ejercicio 24. Costes fijos y variables}

La empresa textil CONFECCIONES fabrica unas camisas para las que cuenta con la siguiente información.

- Coste variable por unidad (tela para camisas, botones, etc.) $10 €$

- Coste fijo mensual (amortización máquinas, seguros, etc.) $200.000 €$

Confeccione las gráficas representando los costes totales unitarios y su desglose en fijos y variables para los siguientes niveles de producción: 15.000, 20.000, 25.000 y 30.000 camisas.

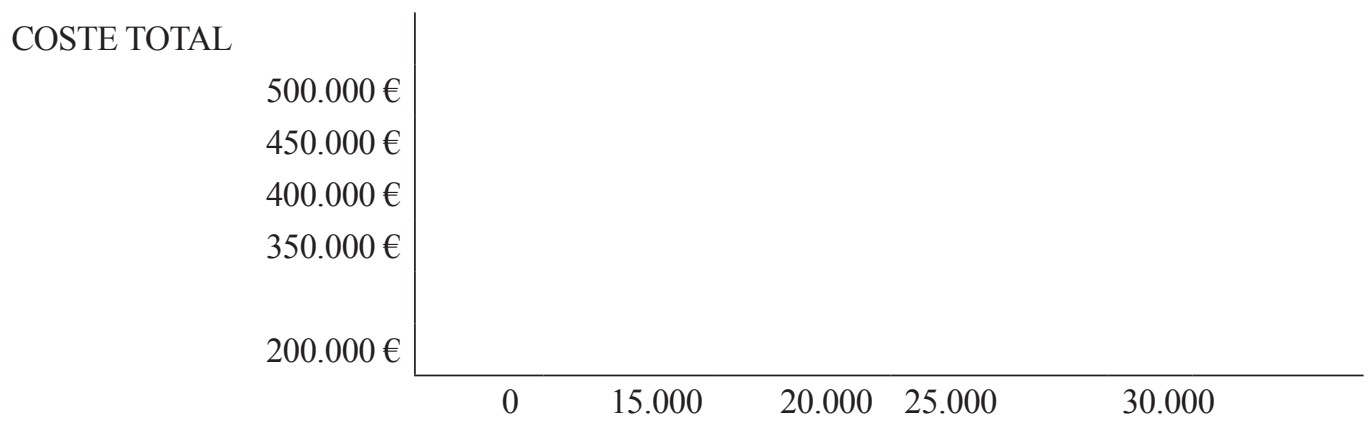


COSTE TOTAL por camiseta

$$
\begin{aligned}
& 23,33 \\
& 20,00 \\
& 18,00 \\
& 16,67
\end{aligned}
$$

$\begin{array}{llll}15.000 & 20.000 & 25.000 & 30.000\end{array}$

\section{Ejercicio 25. Análisis del Balance}

\begin{tabular}{|c|c|c|c|c|c|}
\hline & ENAGAS & $\begin{array}{c}\text { GAS } \\
\text { NATURAL }\end{array}$ & & ENAGAS & $\begin{array}{c}\text { GAS } \\
\text { NATURAL } \\
\end{array}$ \\
\hline $\begin{array}{l}\text { ACTIVO } \\
\text { NO CORRIENTE }\end{array}$ & 5.090 .176 & 29.313.000 & PATRIMONIO NETO & 1.774 .431 & 9.932 .000 \\
\hline Inmovilizado intangible & 29.590 & 4.459 .000 & FONDOS PROPIOS & 1.582 .921 & 10.008 .000 \\
\hline Inmovilizado material & 4.946 .397 & 8.556 .000 & Capital & 358.101 & 922.000 \\
\hline Inversiones inmobiliarias & 0 & 0 & Reservas & 927.549 & 8.009 .000 \\
\hline Inversiones financieras 1.p. & 2.100 .328 & 16.298 .000 & $\begin{array}{l}\text { Pérdidas y ganancias } \\
\text { AJUSTES } \\
\text { POR CAMBIO VALOR }\end{array}$ & 297.271 & 1.077 .000 \\
\hline ACTIVO CORRIENTE & 1.312.792 & 3.777 .000 & SUBVENCIONES & 203.684 & 7.000 \\
\hline Existencias & 270.809 & 277.000 & & & \\
\hline $\begin{array}{l}\text { Deudores comerciales y otros } \\
\text { Inversiones financieras a c.p. }\end{array}$ & $\begin{array}{l}402.025 \\
580.484\end{array}$ & $\begin{array}{r}560.000 \\
2.698 .000\end{array}$ & $\begin{array}{l}\text { PASIVO } \\
\text { NO CORRIENTE }\end{array}$ & 3.511.771 & 19.238.000 \\
\hline Efectivo & 59.474 & 242.000 & PASIVO CORRIENTE & 824.262 & 3.920 .000 \\
\hline $\begin{array}{l}\text { TOTAL ACTIVO } \\
\text { Estructura Económica }\end{array}$ & 6.402 .968 & 33.090 .000 & $\begin{array}{l}\text { TOTAL PASIVO } \\
\text { Estructura Financiera }\end{array}$ & 6.402 .968 & 33.090 .000 \\
\hline
\end{tabular}

A continuación se muestran los balances del año 2009 para las empresas ENAGAS y GAS NATURAL del año 2009 (valores en miles de euros). Calcule el capital corriente y los ratios relevantes de solvencia y endeudamiento y compare a las dos empresas.

\begin{tabular}{|l|c|c|c|}
\hline & & ENAGAS & GAS NATURAL \\
\hline Capital corriente & $\mathrm{AC}-\mathrm{PC}$ & & \\
\hline Solvencia corto plazo & $\mathrm{AC} / \mathrm{PC}$ & & \\
\hline Test del ácido & $(\mathrm{AC}-\mathrm{E}) / \mathrm{PC}$ & & \\
\hline Ratio de tesorería intermedia & $(\mathrm{IFT}+\mathrm{E}) / \mathrm{PC}$ & & \\
\hline Ratio de tesorería inmediata & $\mathrm{E} / \mathrm{PC}$ & & \\
\hline Ratio endeudamiento & $\mathrm{P} /(\mathrm{N}+\mathrm{P})$ & & \\
\hline Ratio endeudamiento & $\mathrm{P} / \mathrm{N}$ & & \\
\hline Pasivo no corriente sobre financiación total & $\mathrm{PNC} /(\mathrm{N}+\mathrm{P})$ & & \\
\hline Pasivo corriente sobre financiación total & $\mathrm{PC} /(\mathrm{N}+\mathrm{P})$ & & \\
\hline Pasivo no corriente sobre pasivo & $\mathrm{PNC} / \mathrm{P}$ & & \\
\hline Pasivo corriente sobre pasivo & $\mathrm{PC} / \mathrm{P}$ & & \\
\hline
\end{tabular}




\section{Ejercicio 26. Análisis de cuenta de pérdidas y ganancias}

A continuación se muestran las cuentas de pérdidas y ganancias del año 2009 para las empresas ENAGAS y GAS NATURAL del año 2009 (valores en miles de euros). Calcule el EBITDA y la rentabilidad económica y financiera y compare a las dos empresas.

\begin{tabular}{|l|r|r|}
\hline & \multicolumn{1}{|c|}{ ENAGAS } & GAS NATURAL \\
\hline Importe neto cifra negocios & $\mathbf{8 8 2 . 6 6 5}$ & $\mathbf{3 . 0 6 2 . 0 0 0}$ \\
\hline Aprovisionamientos & -6.300 & -2.309 .000 \\
\hline Otros ingresos de explotación & 29.779 & 207.000 \\
\hline Gastos de personal & -76.858 & -195.000 \\
\hline Otros gastos de explotación & -151.953 & -499.000 \\
\hline Amortización de inmovilizado & -237.362 & -328.000 \\
\hline Otros resultados & 25.694 & 132.000 \\
\hline RESULTADO DE EXPLOTACIÓN & $\mathbf{4 6 5 . 6 6 5}$ & $\mathbf{7 0 . 0 0 0}$ \\
\hline Ingresos financieros & 24.832 & 1.419 .000 \\
\hline Gastos financieros & -72.256 & -743.000 \\
\hline Otros resultados financieros & -779 & 232.000 \\
\hline RESULTADO FINANCIERO & $\mathbf{- 4 8 . 2 0 3}$ & $\mathbf{9 0 8 . 0 0 0}$ \\
\hline RESULTADO ANTES DE IMPUESTOS & $\mathbf{4 1 7 . 4 6 2}$ & $\mathbf{9 7 8 . 0 0 0}$ \\
\hline Impuesto sobre beneficios & -120.191 & 99.000 \\
\hline RESULTADO DEL EJERCICIO & $\mathbf{2 9 7 . 2 7 1}$ & $\mathbf{1 . 0 7 7 . 0 0 0}$ \\
\hline
\end{tabular}

\begin{tabular}{|l|l|l|}
\hline & ENAGAS & GAS NATURAL \\
\hline EBITDA & & \\
\hline Rentabilidad económica & & \\
\hline Rentabilidad financiera & & \\
\hline
\end{tabular}

Ejercicio 27. Costes como activos y como gastos. Coste de producción

La empresa TEXTCAS fabrica dos productos: camisetas y pantalones, y presenta la siguiente información en relación a sus costes (importes en $€$ ):

\begin{tabular}{|l|r|}
\hline Adquisición de maquinaria & $50.000,00$ \\
Consumo de materiales (algodón, poliéster, etc.) & $15.000,00$ \\
Mano de obra de fabricación & $20.000,00$ \\
Personal de administración y comercial & $2.000,00$ \\
Arrendamiento de planta industrial & $5.000,00$ \\
Adquisición de ordenadores para oficina & $3.000,00$ \\
Arrendamiento de oficinas & $3.000,00$ \\
Amortización de maquinaria & $5.000,00$ \\
Reparaciones y mantenimiento & $1.000,00$ \\
Gastos diversos de fabricación & $6.000,00$ \\
Gastos de marketing & $1.000,00$ \\
Gastos de administración & $3.000,00$ \\
\hline
\end{tabular}

Para el 75\% del coste de los materiales y el $80 \%$ del coste de mano de obra de fabricación se realiza un seguimiento hasta los productos fabricados. El resto del coste asigna de modo indirecto. 
Se pide que:

a) Determine los costes por inversiones.

b) Determine los costes del producto o inventariables.

c) Determine los gastos del período.

d) Determine los elementos básicos del coste de producción.

\begin{tabular}{|l|r|}
\hline Adquisición de maquinaria & $50.000,00$ \\
Consumo de materiales (algodón, poliéster, etc.) & $\mathbf{1 5 . 0 0 0 , 0 0}$ \\
Mano de obra de fabricación & $\mathbf{2 0 . 0 0 0 , 0 0}$ \\
Personal de administración y comercial & $2.000,00$ \\
Arrendamiento de planta industrial & $\mathbf{5 . 0 0 0 , 0 0}$ \\
Adquisición de ordenadores para oficina & $3.000,00$ \\
Arrendamiento de oficinas & $3.000,00$ \\
Amortización de maquinaria & $\mathbf{5 . 0 0 0 , 0 0}$ \\
Reparaciones y mantenimiento & $\mathbf{1 . 0 0 0 , 0 0}$ \\
Gastos diversos de fabricación & $\mathbf{6 . 0 0 0 , 0 0}$ \\
Gastos de marketing & $1.000,00$ \\
Gastos de administración & $3.000,00$ \\
\hline Elementos básicos del coste de producción \\
\hline
\end{tabular}

\section{Ejercicio 28. Coste de producción}

La empresa MOBLE, dedicada a la fabricación de muebles de oficina, ha fabricado en 2010: 10.000 mesas, 5.000 estanterías y 5.000 cajoneras y presenta la siguiente información respecto a los costes incurridos durante el año 2000:

Respecto a los costes de materiales se sabe que se han consumido materiales:

- Por valor de $400.000 €$ para la fabricación de mesas.

- Por valor de $500.000 €$ para la fabricación de estanterías.

- Por valor de $300.000 €$ para la fabricación de cajoneras.

- Además se han consumido materiales de escaso valor significativo para los tres productos con un valor global de $300.000 €$.

Respecto a los costes de mano de obra se sabe que en la fabricación:

- De mesas han intervenido empleados cuyo coste ha sido $600.000 €$.

- De estanterías han intervenido empleados cuyo coste ha sido $400.000 €$.

- De cajoneras han intervenido empleados cuyo coste ha sido $800.000 €$.

- Además el personal de mantenimiento, control de calidad y supervisión, que ha desarrollado su trabajo para los tres productos, ha supuesto un coste 1.000.000€.

Respecto a los costes generales de fabricación se sabe que:

- El coste de amortización de la nave industrial asciende a $100.000 €$.

- La amortización del equipo industrial ha ascendido a $300.000 €$.

- El coste de electricidad y energía asciende a $60.000 €$.

- Otros costes (seguros, vigilancia, limpieza, etc.) han ascendido a $80.000 €$.

Se pide que:

a) Identifique los costes directos de materiales y mano de obra directa por productos.

b) Identifique los costes indirectos de fabricación y proponer razonadamente criterios de reparto de los mismos entre los productos fabricados.

c) Calcule el coste total y unitario de producción de los tres productos. 


\begin{tabular}{|c|c|c|c|c|}
\hline & \multirow{2}{*}{$\begin{array}{c}\text { Costes } \\
\text { indirectos }\end{array}$} & \multicolumn{3}{|c|}{ Costes directos } \\
\hline & & Mesas & Estanterías & Cajoneras \\
\hline \multicolumn{5}{|l|}{ Materiales } \\
\hline \multicolumn{5}{|l|}{ Mano de obra } \\
\hline \multicolumn{5}{|c|}{ Costes generales fabricación } \\
\hline \multicolumn{5}{|l|}{ Total costes } \\
\hline \multicolumn{5}{|c|}{$\begin{array}{l}\text { Criterio de prorrateo costes indirectos: coste de } \\
\text { mano de obra directa }\end{array}$} \\
\hline \multicolumn{5}{|l|}{ TOTAL } \\
\hline \multicolumn{5}{|l|}{ Unidades } \\
\hline Coste por unidad & & & & \\
\hline
\end{tabular}

Ejercicio 29. Elaboración de informe de producción

Elabore un informe de producción para el mes de febrero de 2000 del departamento de fabricación de chips de la empresa ELECTRONICS CO., y calcule el coste de la producción terminada, total y por unidad, teniendo en cuenta la siguiente información:

\begin{tabular}{|l|r|}
\hline & \multicolumn{1}{|c|}{ Importe (euros) } \\
\hline Existencias iniciales de materiales directos & $10.000,00$ \\
\hline Compras de materiales directos & $50.000,00$ \\
\hline Existencias finales de materiales directos & $4.000,00$ \\
\hline Existencias iniciales de productos en curso & $7.000,00$ \\
\hline Existencias finales de productos en curso & $2.000,00$ \\
\hline Coste de mano de obra del departamento en febrero & $36.000,00$ \\
\hline Costes generales (energía, amortizaciones, seguros, tributos etc.) & $15.000,00$ \\
\hline Unidades terminadas (chips) & $1.000 \mathrm{uds}$ \\
\hline
\end{tabular}

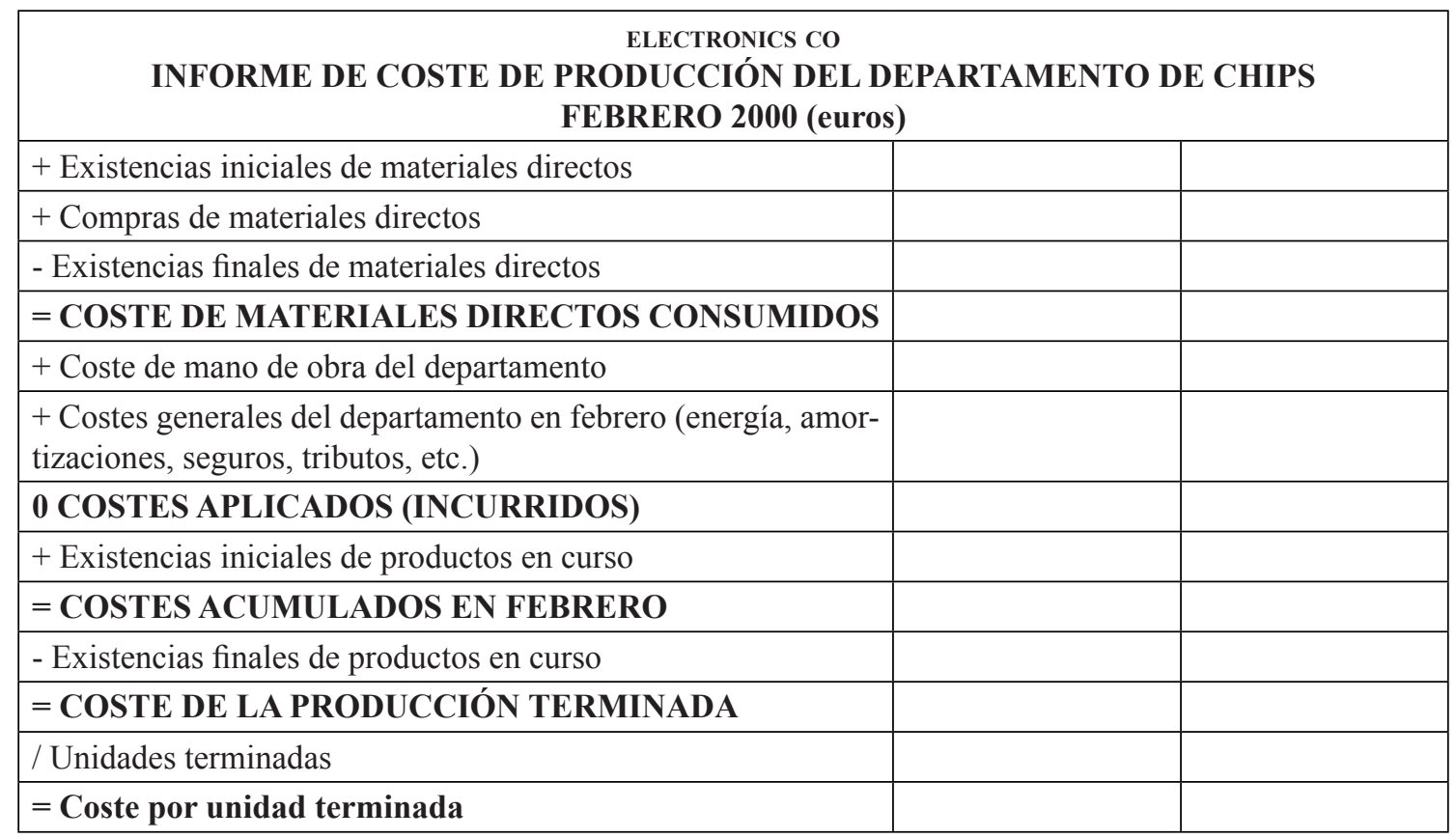


Ejercicio 30. Elaboración de informe de resultado en empresa industrial Elabore un informe de resultados para el mes de febrero de 2000 de la empresa MADERA, teniendo en cuenta la siguiente información (importes en euros):

\begin{tabular}{|l|r|r|r|r|}
\hline \multicolumn{1}{|c|}{ Concepto } & Producto A & Producto B & Producto C & Comunes \\
\hline Ventas brutas & $100.000,00$ & $120.000,00$ & $23.000,00$ & \\
\hline Devoluciones & $2.000,00$ & $6.000,00$ & $1.000,00$ & \\
\hline Existencias iniciales de productos & $6.000,00$ & $10.000,00$ & $4.000,00$ & \\
\hline Existencias finales de productos & $4.000,00$ & $15.000,00$ & $5.000,00$ & \\
\hline Coste de productos terminados & $60.000,00$ & $80.000,00$ & $15.000,00$ & \\
\hline Costes comerciales & $2.000,00$ & $4.000,00$ & 500,00 & $7.000,00$ \\
\hline Costes de administración & & & & $8.000,00$ \\
\hline
\end{tabular}

\begin{tabular}{|l|l|l|l|l|}
\hline \multicolumn{5}{|c|}{$\begin{array}{l}\text { MADERA SA } \\
\text { INORME DE RESULTADOS } \\
\text { FEBRERO 2000 (euros) }\end{array}$} \\
\hline \multicolumn{1}{|c|}{ Concepto } & Producto A & Producto B & Producto C & TOTAL \\
\hline + Ventas brutas & & & & \\
\hline - Devoluciones & & & & \\
\hline = VENTAS NETAS & & & & \\
\hline & & & & \\
\hline + Existencias iniciales de productos & & & & \\
\hline + Coste de productos terminados & & & & \\
\hline - Existencias finales de productos & & & & \\
\hline = COSTE PRODUCCION VENDIDA & & & & \\
\hline & & & & \\
\hline MARGEN BRUTO & & & & \\
\hline - Costes comerciales directos & & & & \\
\hline MARGEN COMERCIAL BRUTO & & & & \\
\hline - Costes comerciales comunes & & & & \\
\hline MARGEN COMERCIAL & & & & \\
\hline - Costes de administración & & & & \\
\hline RESULTADO & & & & \\
\hline
\end{tabular}




\section{Casos}

\section{Caso 1. Análisis de cuentas}

Obtenga los balances y cuentas de pérdidas y ganancias de cinco años de una empresa de su elección de entre las cotizadas en la Bolsa de Madrid de un sector no financiero. La información puede obtenerse en las página web de la Comisión

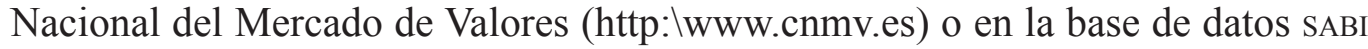
disponible en la biblioteca de la UJI. Utilice las técnicas, ratios e indicadores estudiados en este tema y analice la evolución de los mismos para todo el período apoyándose en gráficos.

\section{Caso 2. Comparación de informes contables}

Obtenga el balance y la cuenta de pérdidas y ganancias del último año de dos empresas de un mismo sector económico (por ejemplo FCC y FERROVIAL) de entre las cotizadas en la Bolsa de Madrid de un sector no financiero.

Analice y compare la situación económica y patrimonial, así como los resultados y rentabilidades de dichas empresas utilizando las técnicas e indicadores estudiados en este tema.

\section{Caso 3. Análisis de cuentas}

Obtenga el balance y la cuenta de pérdidas y ganancias de varios años de alguna empresa con la que tenga relación y realice un análisis patrimonial, financiero y de resultados utilizando las técnicas, ratios e indicadores estudiados en este tema.

\section{Caso 4. Informes de costes}

Obtenga informes internos de producción y de costes de varios años de alguna empresa con la que tenga relación. Efectúe una descripción de la información contenida en los mismos y señale la utilidad que proporcionan para la gestión. 


\section{TEMA 7}

\section{Normalización contable}

\section{INTRODUCCIÓN}

En este tema se justifica la necesidad de regulación contable y se presenta la normativa contable internacional y española. Dentro de la normativa española destaca el Plan General de Contabilidad como norma de mayor detalle. Se estudiará la estructura y contenido de dicha norma analizando alguna de sus partes en profundidad. Finalmente se presentarán las obligaciones mercantiles que afectan a las empresas en materia contable.

CONTENIDO

7.1. Comparabilidad de la información contable.

7.2. Normativa contable española

7.3. Estructura y contenido del Plan General de Contabilidad

7.4. El marco conceptual de la contabilidad en el Plan General de Contabilidad

7.5. Las otras partes de Plan General de Contabilidad

7.6. Obligaciones mercantiles en materia contable 


\subsection{Comparabilidad de la información contable}

De lo apuntado en el tema 1 se concluye que la información contable constituye, en el ámbito de los negocios y de los mercados de capitales y financieros, un bien de extraordinaria importancia.

También se deduce que los usuarios externos toman sus decisiones sobre la base de la información que proporcionan las empresas, debiendo confiar en ella y sin tener la posibilidad de comprobar personalmente la adecuación de esta información a la realidad de la empresa.

Por ello, se ha reconocido la necesidad de que la información contable a proporcionar a los usuarios externos esté regulada legalmente, de forma que se puedan conseguir dos objetivos:

- que los informes contables de las empresas sean fiables al basarse en principios y criterios de general aceptación, y

- que la información proporcionada por una empresa a lo largo del tiempo sea comparable y también que sea comparable la información proporcionada por distintas empresas.

\section{Normalización contable}

El establecimiento de normas comunes de contabilidad para la elaboración de los informes contables destinados a los usuarios externos y de aplicación a todas las empresas se denomina «normalización contable»y, dependiendo de los países, puede ser realizada por el Estado o por organizaciones profesionales.

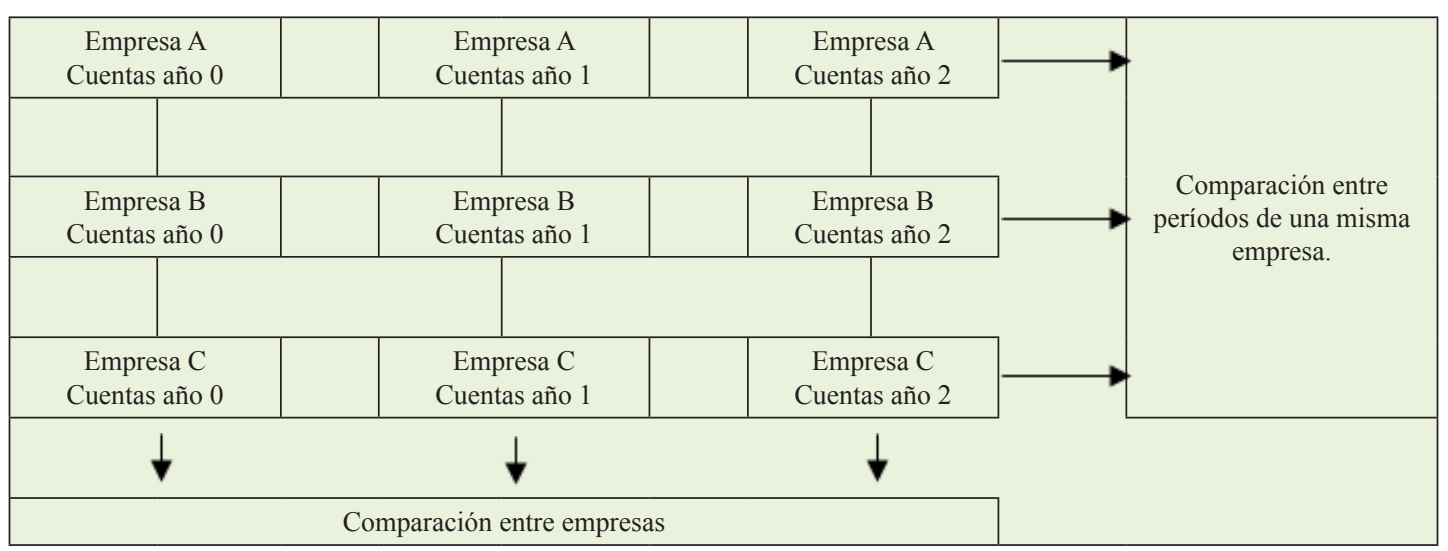

Ilustración 7.1. Objetivos de la normalización contable

En países incluidos en el denominado ámbito anglosajón (EEUU, Sudamérica, etc.) la regulación contable suele ser realizada por organismos profesionales independientes, formados por profesionales y entidades del ámbito contable, que emiten pronunciamientos que constituyen sus normas contables. 
Por ejemplo, en Estados Unidos el encargado es el Financial Accounting Standard Board (FASB). ${ }^{1}$

En países incluidos en el denominado ámbito continental como España, Francia, Alemania, etc., la regulación contable se realiza por parte del organismos públicos.

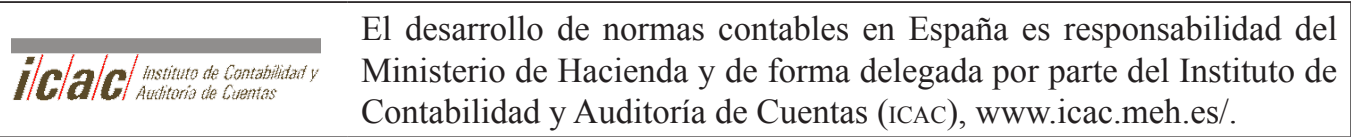

\section{Armonización contable internacional}

La internacionalización de la economía, la existencia de empresas multinacionales y la interrelación entre mercados bursátiles y de capitales ha hecho necesario que se trate de aproximar la normativa contable que se aplica en los distintos países en un proceso que se denomina «armonización contable» internacional.

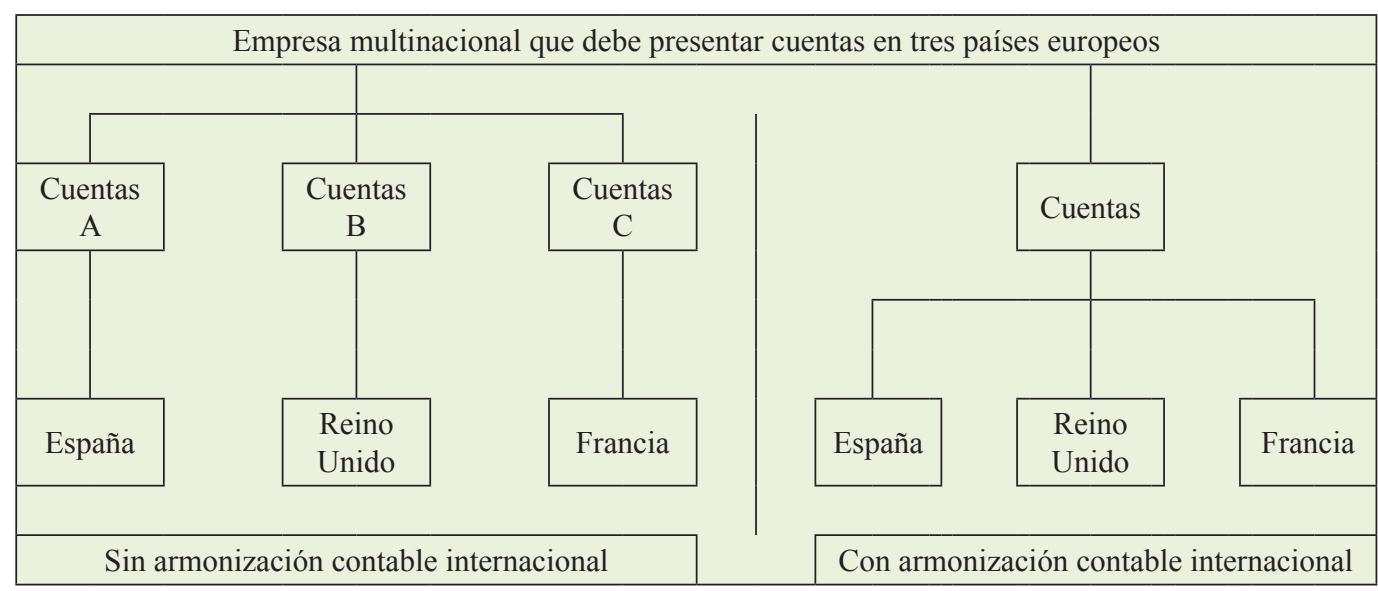

Ilustración 7.2. Armonización contable y multinacionales

$\begin{gathered}\text { International } \\ \text { Accounting Standards } \\ \text { Board }{ }^{\circledR}\end{gathered}$
$\begin{aligned} & \text { Como organismo de armonización internacional cabe destacar el } \\ & \text { International Accounting Standard Board (IASB). Desde su creación, } \\ & \text { en 1973, las normas del IASB han ido adquiriendo progresivamente }\end{aligned}$
$\begin{aligned} & \text { mayor importancia y están siendo aceptadas y utilizadas cada vez por más países. Las normas } \\ & \text { emitidas por el IASB reciben el nombre de Normas Internacionales de Información Financiera } \\ & \text { (NIIF) o Normas Internacionales de Contabilidad (NIC). Las normas del IASB pueden consultarse } \\ & \text { en www.iasb.org/. }\end{aligned}$

\section{-EFRAG} European Financial Reporting Advisory Group sar por la revisión del EFRAG (European Financial Reporting Advisory Group antes de ser aceptadas y publicadas como normas contables en la Unión). Las normas internacionales adoptadas por la Unión Europea pueden consultarse en www.ec.europa.eu/ internal_market/accounting/.

1. Sin perjuicio de que existan entidades públicas que emiten normas para colectivos específicos. Por ejemplo, la SEC (Securities and Exchange Commision) que emite normas contables para las empresas cotizadas en las bolsas de Estados Unidos. 
Desde el 1 de enero de 2005 es obligatorio que las empresas que cotizan en Mercados de Valores (bolsas) apliquen las normas internacionales adoptadas por la UE para sus estados contables consolidados (los que se elaboran para el conjunto de empresas que forman un grupo).

La normativa europea permitió que fueran los Estados miembros los que decidieran si ampliar la aplicación de las normas contables a los informes contables de las empresas individuales que cotizan en bolsa y también para el resto de empresas no cotizadas. En España se optó por no permitir la aplicación directa de las normas internacionales a las cuentas individuales de las empresas, coticen o no coticen en bolsa, sino que deberán aplicarse las normas contables emitidas por el Estado Español. No obstante, se permite su aplicación a los estados consolidados de las empresas no cotizadas.

Finalmente, debe señalarse que como consecuencia del proceso de armonización contable hacia el modelo del IASB que se ha vivido en todo el mundo, la normativa española ha sido objeto de una profunda reforma para adaptar las normas españolas a las normas internacionales de contabilidad, pero manteniendo algunos usos y costumbres contables existentes en nuestro país.

\subsection{Normativa contable española}

La normativa contable básica existente en España, y aplicable con carácter general a todas las empresas, es la siguiente: ${ }^{2}$

- Código de Comercio (de 1885 y modificaciones posteriores). Contiene las normas básicas y generales de carácter mercantil, entre las que se encuentran normas contables.

- Ley de Sociedades de Capital (Real Decreto Legislativo 1/2010, de 2 de julio). Contienen las normas que regulan el funcionamiento de las sociedades mercantiles, anónimas y limitadas fundamentalmente. Dentro de estas normas existen disposiciones relativas a la información contable a elaborar y presentar por las empresas.

- Plan General de Contabilidad (PGC). Esta norma suele ser objeto de adaptaciones sectoriales. Existen dos normas, una general (RD 1514/2007, de 16 de diciembre) y una específica para PYMES (RD 1515/2007, de 16 de diciembre).

- Resoluciones del ICAC. Las resoluciones del ICAC amplían aspectos o realizan aclaraciones o solucionan problemas en relación a la normativa contable anterior.

2. Como se ha comentado en el apartado anterior, algunas empresas y/o para algunos informes están sujetas directamente a normativa contable aprobada por la Unión Europea. 
Debe mencionarse que algunas empresas están sujetas a regulaciones contables específicas debido a la naturaleza de sus actividades, sector económico, a su negociación en mercados de capitales (bolsa) u otras razones. Por ejemplo, en España la Comisión Nacional del Mercado de Valores (CNMV) emite normas que contienen obligaciones de información contable adicionales en relación con las empresas cotizadas en bolsa. Las empresas del sector financiero y del sector de empresas de seguros tienen normativa contable específica. Algunos sectores económicos cuentan con adaptaciones del Plan General de Contabilidad a sus características (empresas constructoras, inmobiliarias, sociedades anónimas deportivas, etc.).

Adicionalmente existen otras normas, también de aplicación general a todas las empresas, que tratan aspectos específicos como la Auditoría Contable o revisión de cuentas, los estados financieros consolidados para grupos de empresas, etc.

En España existen asimismo organismos profesionales que emiten pronunciamientos contables con distinto valor. Los principios emitidos por la Asociación Española de Contabilidad y Administración de Empresas (AECA), el Instituto de Censores Jurados de Cuentas (ICJC) y otros, aunque no tienen el rango de norma contable obligatoria, pueden servir como guía en determinadas situaciones no específicamente reguladas por la normativa.

\section{El PGC y el PGC de PYMES}

Como se ha comentado, la norma general que con mayor detalle regula la contabilidad de empresas es el Plan General de Contabilidad, el cual es de aplicación a todo tipo de empresas y empresarios, sea cual sea su forma jurídica, individual o societaria.

En el PGC se incluyen dos formatos de cuentas anuales, uno normal y uno abreviado. Los criterios que permiten, voluntariamente, la aplicación de los formatos abreviados de cuentas anuales se muestran en la siguiente ilustración.

Asimismo las empresas que cumplan los criterios de presentación de balance, Estado de Cambios en el Patrimonio Neto (ECPN) y memoria abreviados pueden, voluntariamente, aplicar el PGC para PYMES.

Para aquellas empresas de pequeña dimensión, microempresas, se permite también la aplicación de criterios contables específicos para determinadas operaciones (arrendamiento financiero e impuesto de sociedades). 


\begin{tabular}{|c|c|c|c|c|c|}
\hline Normativa contable & \multicolumn{2}{|c|}{ PGC para PYMES } & \multicolumn{3}{|c|}{ PGC } \\
\hline \multirow[b]{2}{*}{$\begin{array}{l}\text { Formato de cuentas } \\
\text { anuales }\end{array}$} & $\begin{array}{l}\text { Microem- } \\
\text { presa }\end{array}$ & $\begin{array}{l}\text { Resto } \\
\text { PYMES }\end{array}$ & \multicolumn{2}{|c|}{ Modelo abreviado } & Modelo normal \\
\hline & \multicolumn{2}{|c|}{$\begin{array}{l}\text { Balance, pérdidas y ganancias, } \\
\text { estado de cambios en patrimo- } \\
\text { nio neto y memoria }\end{array}$} & $\begin{array}{l}\text { Balance, estado de } \\
\text { cambios en patrimo- } \\
\text { nio neto y memoria } \\
\text { abreviados } \\
\text { (No estado flujos } \\
\text { efectivo) }\end{array}$ & $\begin{array}{l}\text { Pérdidas y } \\
\text { ganancias } \\
\text { abreviada. } \\
\text { Resto normal }\end{array}$ & $\begin{array}{l}\text { Balance, pérdidas y } \\
\text { ganancias, estado de } \\
\text { cambios en patrimonio } \\
\text { neto, estado de flujos de } \\
\text { efectivo y memoria }\end{array}$ \\
\hline Condiciones & \multicolumn{4}{|c|}{$\begin{array}{l}\text { Durante dos ejercicios consecutivos deben reunir, a la fecha de cierre de } \\
\text { cada uno de ellos, al menos, dos de las circunstancias siguientes: }\end{array}$} & \\
\hline Total activo $(€)$ & $<1.000 .000$ & $<2.850 .000$ & $<2.850 .000$ & $<11.400 .000$ & Resto \\
\hline $\begin{array}{l}\text { Importe neto cifra } \\
\text { negocios }(€)\end{array}$ & $<2.000 .000$ & $<5.700 .000$ & $<5.700 .000$ & $<22.800 .000$ & Resto \\
\hline $\mathrm{N}^{\mathrm{o}}$ medio trabajadores & $<10$ & $<50$ & $<50$ & $<250$ & Resto \\
\hline $\begin{array}{l}\text { Criterios contables } \\
\text { especiales }\end{array}$ & Sí & & & & \\
\hline
\end{tabular}

Ilustración 7.3. Criterios para aplicación del PGC y PGC-PYMES y formatos de cuentas anuales

Para poder aplicar los formatos abreviados del PGC o bien el PGC de PYMEs, así como los criterios para microempresas es necesario que durante dos ejercicios consecutivos la empresa reúna, a la fecha de cierre de cada uno de ellos, al menos dos de las circunstancias señaladas en la ilustración anterior.

Las empresas perderán la facultad de aplicar los formatos abreviados, o el PGC de PYMES, o los criterios para microempresas si dejan de reunir, durante dos ejercicios consecutivos, a la fecha de cierre de cada uno de ellos, dos de las circunstancias señaladas en la ilustración anterior.

\subsection{Estructura y contenido del Plan General de Contabilidad}

El PGC se estructura en cinco partes, que se muestran en la ilustración 7.4.

Las partes primera, segunda y tercera son de aplicación obligatoria, y aunque las partes cuarta y quinta no lo son, prácticamente todas las empresas las siguen, a veces con pequeñas adaptaciones a sus necesidades.

En este tema se estudiará con detalle la parte primera, «Marco conceptual de la contabilidad».

El resto de partes se comentarán brevemente puesto que son propias de un curso más avanzado de contabilidad financiera. 


\begin{tabular}{|c|c|c|}
\hline PARTE & DENOMINACIÓN & CARÁCTER \\
\hline Primera & Marco conceptual de la contabilidad & Obligatorio \\
\hline \multicolumn{3}{|c|}{$\begin{array}{l}\text { El marco conceptual constituye el entramado de referencia básico de la contabilidad financiera en nues- } \\
\text { tro país y describe y sienta las bases de la misma. } \\
\text { Este marco conceptual está compuesto por: }\end{array}$} \\
\hline $\begin{array}{ll}\text { 1. } & \mathrm{D} \\
2 . & \mathrm{R} \\
3 . & \mathrm{P} \\
4 . & \mathrm{E} \\
5 . & \mathrm{C} \\
6 . & \mathrm{C}\end{array}$ & $\begin{array}{l}\text { finición de las cuentas anuales y objetivo } \\
\text { quisitos de la información a incluir en las } \\
\text { ncipios contables } \\
\text { mentos de las cuentas anuales } \\
\text { terios de registro y reconocimiento de los } \\
\text { terios de valoración }\end{array}$ & $\begin{array}{l}\text { las mismas } \\
\text { entas anuales } \\
\text { mentos de las cuentas anuales }\end{array}$ \\
\hline Segunda & Normas de registro y valoración & Obligatorio \\
\hline \multicolumn{3}{|c|}{$\begin{array}{l}\text { Las normas de registro y valoración constituyen el desarrollo de los principios contables y de los crite- } \\
\text { rios de reconocimiento y valoración y otros aspectos, recogidos en la parte primera, para su aplicación } \\
\text { concreta a los distintos elementos de las cuentas anuales. }\end{array}$} \\
\hline Tercera & Cuentas anuales & Obligatorio \\
\hline \multicolumn{3}{|c|}{$\begin{array}{l}\text { En esta parte de recogen las normas de formulación, elaboración y presentación de las cuentas anuales. } \\
\text { Se señala el contenido de las mismas y se muestran los formatos oficiales, normales y abreviados. }\end{array}$} \\
\hline Cuarta & Cuadro de cuentas & No obligatorio, facultativo \\
\hline \multicolumn{3}{|c|}{$\begin{array}{l}\text { Contiene un listado de códigos y denominaciones de cuentas representativas de los elementos de las cu } \\
\text { entas anuales. Las cuentas están clasificadas por niveles ( } 1 \text { dígito, } 2 \text { dígitos, etc.) y agrupadas de acuerdo } \\
\text { a su naturaleza. }\end{array}$} \\
\hline Quinta & Definiciones y relaciones contables & No obligatorio, facultativo (1) \\
\hline \multicolumn{3}{|c|}{$\begin{array}{l}\text { En esta parte se recoge, para las distintas cuentas incluidas en la parte cuarta, la definición de los ele- } \\
\text { mentos que deben incluirse en las mismas y los motivos de cargo y abono de las cuentas, mostrando con } \\
\text { ello las relaciones de entre ellas. }\end{array}$} \\
\hline
\end{tabular}

(1) Siempre que no se refiera a aspectos de valoración.

Ilustración 7.4. Estructura y contenido del PGC 


\subsection{El marco conceptual de la contabilidad en el PGC}

El entramado de referencia básico de la contabilidad financiera se conoce con el nombre de «marco conceptual» y describe y sienta las bases de la misma respondiendo a cuestiones como: ¿Cuáles son sus objetivos? ¿Cómo alcanzar esos objetivos? ¿Qué informes deben elaborarse? ¿Qué requisitos deben cumplir estos informes? ¿Cuál debe ser su contenido? ¿Qué criterios deben seguirse para su elaboración?, etc.

Las respuestas dadas a estas cuestiones constituyen las referencias indispensables que actúan de guía de la contabilidad financiera. El marco conceptual del Plan General de Contabilidad está compuesto por los elementos siguientes:

1. Definición de las cuentas anuales y objetivo de las mismas

2. Requisitos de la información a incluir en las cuentas anuales

3. Principios contables

4. Elementos de las cuentas anuales

5. Criterios de registro y reconocimiento de los elementos de las cuentas anuales

6. Criterios de valoración

\section{Definición de las cuentas anuales y objetivo de las mismas}

Las cuentas anuales comprenden el balance, la cuenta de pérdidas y ganancias, el estado de cambios en el patrimonio neto, el estado de flujos de efectivo y la memoria.

A lo largo de este texto se ha introducido el balance y la cuenta de pérdidas y ganancias. El resto de integrantes de las cuentas anuales se estudia en cursos más avanzados de contabilidad.

Las cuentas anuales deben redactarse con claridad, de forma que la información sea comprensible y útil para los usuarios al tomar sus decisiones económicas, por lo que deben mostrar la imagen fiel del patrimonio, de la situación financiera, y de los resultados de la empresa, de conformidad con las disposiciones legales.

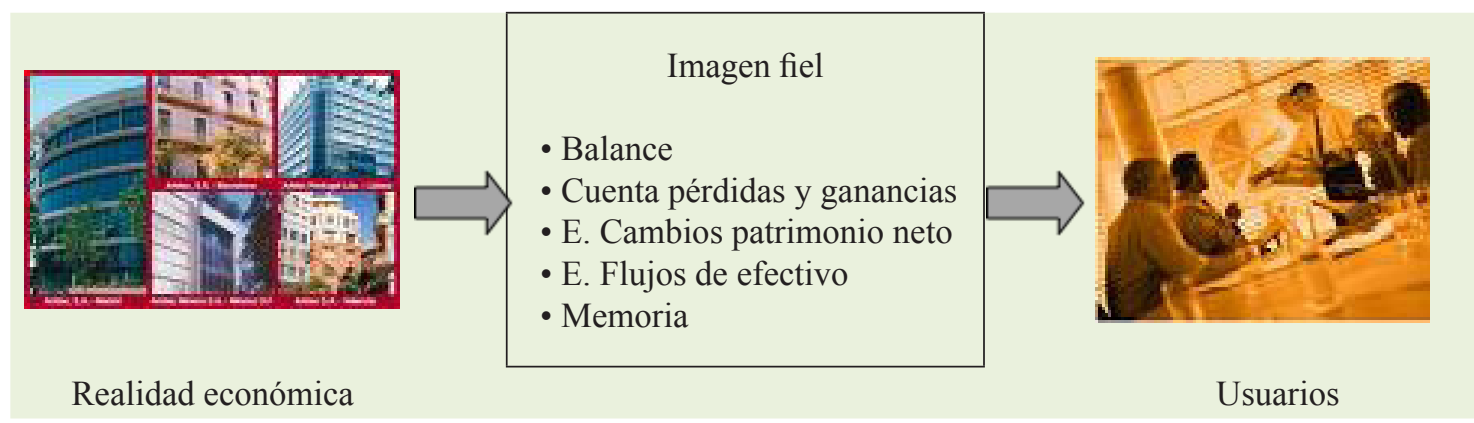

Ilustración 7.5. Objetivos de la normalización contable 
A dicha imagen fiel se llega por la aplicación sistemática y regular de los requisitos, principios y criterios contables incluidos en el Plan General de Contabilidad. La consecución de la imagen fiel se consigue cuando en la contabilización de las operaciones se atiende a la realidad económica de las mismas, la cual puede, en ocasiones, ser diferente de su forma jurídica.

Cuando la aplicación de los requisitos, principios y criterios contables del PGC no sea suficiente para mostrar la imagen fiel deberá suministrarse en la memoria la información complementaria que sea preciso para alcanzar este objetivo.

Incluso será posible la no aplicación de dichos requisitos, principios y criterios contables, en casos excepcionales, si se considera improcedente para conseguir la imagen fiel. Estos casos deberán motivarse en la memoria y se explicará la influencia que dicha no aplicación tiene sobre el patrimonio, los resultados y la situación financiera de la empresa.

\section{Requisitos de la información a incluir en las cuentas anuales}

Los requisitos de la información incluir en las cuentas anuales se estudiaron en el tema 1, apartado 4 .

\section{Principios contables}

Al objeto de que la información contable sea útil, se requiere que todas las empresas apliquen los mismos principios y criterios de registro, reconocimiento y valoración de los elementos de las cuentas anuales. La existencia de un conjunto básico y único de principios y criterios asegura la homogeneidad en el tratamiento contable y por lo tanto la comparabilidad de la información entre empresas.

Los principios contables recogidos en el PGC son los siguientes:

1. Principio de empresa en funcionamiento.

2. Principio de devengo.

3. Principio de uniformidad.

4. Principio de prudencia.

5. Principio de no compensación.

6. Principio de Importancia relativa.

En caso de conflicto entre principios contables, deberá prevalecer el que mejor conduzca a que las cuentas anuales expresen la imagen fiel del patrimonio, situación financiera y de los resultados de la empresa. 


\section{Principio de empresa en funcionamiento}

El principio de empresa en funcionamiento considera que, salvo prueba en contrario, la gestión de la empresa debe suponerse indefinida. En consecuencia, el valor registrado de un activo no pretende reflejar su valor a efectos de su enajenación. Se supone que los bienes poseídos por la empresa son usados por la misma para su actividad, sin que el objetivo sea su posible venta. De hecho, se está suponiendo que los activos no pueden venderse sin afectar gravemente a la actividad de la empresa.

En los casos en que no resulte aplicable este principio, la empresa aplicará las normas de valoración adecuadas para reflejar la imagen fiel de las operaciones tendentes a realizar el activo, cancelar las deudas y, en su caso, repartir el patrimonio neto resultante. Se informará en memoria de los aspectos significativos.

Una empresa utiliza para su actividad una nave industrial construida en un terreno, ambos valorados por su coste. Debido al desarrollo urbano, el valor razonable del terreno donde se asienta la nave ha aumentado mucho de valor. El principio de empresa en funcionamiento justifica que no deba reconocerse contablemente dicho incremento de valor, por cuanto la intención de la empresa es continuar con su actividad en dicho emplazamiento y no vender las instalaciones.

No obstante, si la empresa decidiese cambiar la ubicación de su actividad y califica las instalaciones hasta ahora usadas como «mantenidas para la venta» podría proceder a modificar el criterio de valoración, que pasaría del coste al valor razonable.

Ilustración 7.6. Principio de empresa en funcionamiento

\section{Principio de devengo}

Este principio se introdujo en el tema 5, apartado 4.

\section{Principio de uniformidad}

Este principio indica que, adoptado un criterio contable de entre un conjunto de alternativas posibles, deberá mantenerse en el tiempo y aplicarse para todos los elementos de las cuentas anuales de características similares.

Este criterio solo podrá ser modificado si cambian las circunstancias que justificaron la adopción inicial. En este caso deberá informarse en la memoria de dicho cambio, señalando la incidencia cualitativa y cuantitativa del cambio de criterio sobre las cuentas anuales. 


\section{Ejemplo 7.1. Uniformidad en la aplicación de un criterio}

La empresa AZULEJERA MODERNA SA, fabricante de pavimento y revestimiento cerámico, adquirió un horno para la cocción de sus productos en el año 2000 por valor de $100.000 €$. Para la contabilización de su amortización estimó su vida útil en 10 años, teniendo en cuenta un uso en turno diario de trabajo de 8 horas, y decidió considerar una depreciación constante anual. En consecuencia durante los años 2000 y 2001 amortizó dicho horno en un importe de 100.000/10 $=10.000$ euros/año.

Por aplicación del principio de uniformidad, este criterio deberá mantenerse a lo largo del tiempo, y en consecuencia deberá amortizarse el horno en cuotas de $10.000 €$ anuales. La empresa no puede, sin más, cambiar de criterio y reducir o ampliar la vida útil del horno (lo cual supondría aumentar o disminuir respectivamente la cuota anual de amortización).

\section{Ejemplo 7.2. Cambio en la aplicación de un criterio}

Siguiendo con el caso del ejemplo 7.1, supóngase que debido al incremento en la actividad de la empresa, durante el año 02 el horno ha empezado a ser utilizado en dos turnos diarios de trabajo, 16 horas. Ante esta situación, la empresa cree que la vida útil debe reducirse y ha estimado que, con este ritmo de utilización, la vida útil restante es de 4 años (la vida útil total pasa de 10 a 6 años). La amortización durante esos 4 años debería ser de $80.000 / 4=20.000 €(80.000$ es el valor aún no amortizado a inicios de $02=$ valor inicial - amortización de dos años $=100.000-2$ $\mathrm{x}$ 10.000).

En este caso han cambiado las circunstancias en que se basó la estimación inicial de la vida útil del horno, por lo que sería aceptable un cambio en el criterio inicial. En este caso en la memoria deberán justificarse las razones del cambio e informar sobre las repercusiones que este hecho ha tenido sobre las cuentas anuales.

\section{Principio de prudencia}

El principio de prudencia señala de forma general que en condiciones de incertidumbre las estimaciones y valoraciones a realizar deben ser conservadoras, sin que ello justifique que la valoración de los elementos patrimoniales no responda a la imagen fiel que deben reflejar las cuentas anuales. Además, este principio recoge expresamente:

- Únicamente se contabilizarán los beneficios obtenidos a hasta la fecha de cierre del ejercicio, sin perjuicio del tratamiento contable específico por el que deban regirse algunos activos o pasivos. Esto supone que, en general, los activos deben valorarse por su precio de adquisición.

- Por el contrario, deberán tenerse en cuenta todos los riesgos con origen en el ejercicio o en otro anterior. Esto puede suponer el reconocimiento como gasto de pérdidas potenciales futuras derivadas de las actividades de la empresa.

- Deberán tenerse en cuenta todas las depreciaciones y deterioros en el valor de los activos.

En el patrimonio de cualquier empresa existen bienes cuyo valor es superior al precio de adquisición (valor al que estarían registrados), como por ejemplo las existencias de mercaderías. El principio de prudencia indica que dicho mayor valor no pueden reconocerse si no se han «obtenido» o «realizado», es decir, si no se ha producido una venta que los haya puesto de manifiesto como mayores ingresos.

Ilustración 7.7. En general solo se reconocen los beneficios obtenidos 
Pese a que según el principio de prudencia solo deben contabilizarse los beneficios realizados, el criterio de valoración de algunos elementos patrimoniales (ciertos activos y pasivos financieros) indicados específicamente en las «Normas de registro y valoración del PGC» es el de valor razonable.

Esto supone que dichos activos y pasivos registran ingresos o gastos como consecuencia de sus cambios de valor, es decir, se trata de ingresos y gastos no realizados puesto que no se ha producido la venta o cancelación de los mismos.

Ilustración 7.8. Una excepción: ajustes por valoración a valor razonable

El principio de prudencia obliga a tener en cuenta los riesgos futuros derivados de situaciones de incertidumbre tales como: obligaciones en materia de pensiones con trabajadores, actuaciones medioambientales, riesgos por responsabilidades, etc.

En estos casos, si existe probabilidad de ocurrencia del riesgo y el valor actual del mismo puede estimarse, procede el reconocimiento de un gasto y el pasivo correspondiente. Estos pasivos reciben el nombre de provisiones.

Ilustración 7.9. Provisiones para riesgos y gastos

\section{Principio de no compensación}

Salvo que una norma lo disponga de forma expresa, no pueden compensarse partidas de activo y pasivo del balance, ni de ingresos y gastos de la cuenta de pérdidas y ganancias.

\section{Ejemplo 7.3. No compensación de ingresos y gastos}

Dada esta cuenta de pérdidas y ganancias:

Proyectos SA

Cuenta de pérdidas y ganancias del período 01/01/00 a 31/12/00

\begin{tabular}{|l|r|}
\hline 1. Importe de la cifra de negocios & $+280.000,00$ \\
\hline
\end{tabular}

2. Gastos de personal

3. Otros gastos de explotación

$190.000,00$

4. Amortización de inmovilizado

$-13.000,00$

A1. Resultado de explotación $=(1+2+3+4)$

$-4.250,00$

5. Ingresos financieros

- Ingresos por intereses de créditos

$+72.750,00$

- Beneficios en valores negociables

\section{Gastos financieros}

- Gastos por intereses de deudas

7. Variación en el valor razonable de instrumentos financieros

- Beneficios por valoración de IF a VR

\begin{tabular}{|r|r|}
\hline A2. Resultado financiero $(5+6+7)$ & $-700,00$ \\
\hline A3. Resultado antes de impuestos = A1+A2 & $+72.050,00$ \\
\hline 8. Impuesto sobre beneficios & $-21.615,00$ \\
\hline A4. Resultado del ejercicio = A3+8 & $+50.435,00$ \\
\hline
\end{tabular}

De acuerdo con el principio de no compensación, no pueden compensarse los ingresos financieros y los gastos financieros y presentar la cuantía neta resultante, por ejemplo en la forma: 


\section{Principio de importancia relativa}

Puede admitirse la no aplicación estricta de algún principio o criterio contable si la importancia relativa, en términos cuantitativos y/o cualitativos, de la variación que tal hecho produzca sea escasamente significativa, y en consecuencia no altere la imagen fiel que deben mostrar las cuentas anuales. Podrán agruparse partidas o importes cuya importancia no sea significativa junto con otros de similar naturaleza o función.

Cuando se compra un inmovilizado, debe registrase, según los principios y criterios contables aplicables, por su precio de adquisición. Este inmovilizado sufre generalmente una depreciación anual denominada amortización que debe recogerse como gasto año a año durante su vida útil.

No obstante, una grapadora de sobremesa, cuya vida útil supera fácilmente el año, no suele ser considerada como inmovilizado material y sujeta a amortización, sino que usualmente se considera material de oficina y como tal se registra como un gasto en el ejercicio económico de su adquisición.

En este caso, no es significativa la diferencia entre aplicar un tratamiento u otro debido al escaso valor de una grapadora y no está justificado económicamente el complejo tratamiento y control que conllevan las amortizaciones de inmovilizado.

Ilustración 7.10. Importancia relativa

\section{Elementos de las cuentas anuales}

Los elementos de las cuentas anuales son: activos, pasivos, patrimonio neto, ingresos y gastos. Estos elementos se estudiaron con detalle en el tema 2.

\section{Criterios de registro y reconocimiento de los elementos de las cuentas anuales}

Los criterios de registro y reconocimiento establecen las condiciones que deben cumplirse para que deba procederse al registro contable de activos, pasivos, patrimonio neto, ingresos y gastos.

El registro de los elementos procederá cuando, según la definición de los mismos, se cumplan:

- los criterios de probabilidad en la obtención o cesión de recursos que incorporen beneficios o rendimientos económicos y,

- su valor pueda determinarse con un adecuado grado de fiabilidad. El uso de estimaciones razonables no menoscaba la fiabilidad. 
En particular:

1. Los activos deben reconocerse en el balance cuando sea probable la obtención, a partir de los mismos, de beneficios o rendimientos económicos para la empresa en el futuro, y siempre que se puedan valorar con fiabilidad.

2. Los pasivos deben reconocerse en el balance cuando sea probable que, a su vencimiento y para liquidar la obligación, deban entregarse o cederse recursos que incorporen beneficios o rendimientos económicos futuros, y siempre que se puedan valorar con fiabilidad.

3. El reconocimiento de un ingreso tiene lugar como consecuencia de un incremento de los recursos de la empresa, y siempre que su cuantía pueda determinarse con fiabilidad.

4. El reconocimiento de un gasto tiene lugar como consecuencia de una disminución de los recursos de la empresa, y siempre que su cuantía pueda valorarse o estimarse con fiabilidad.

En el tema 3 se constató que, en cumplimiento de la «ecuación fundamental del patrimonio», el registro y reconocimiento de un elemento de las cuentas anuales conlleva necesariamente el registro o reconocimiento de otro u otros, de forma que:

- El reconocimiento de un activo implica el reconocimiento simultáneo de un pasivo, la disminución de otro activo o el reconocimiento de un ingreso u otros incrementos en el patrimonio neto.

- El reconocimiento de un pasivo implica el reconocimiento simultáneo de un activo, la disminución de otro pasivo o el reconocimiento de un gasto u otros decrementos en el patrimonio neto.

- El reconocimiento de un ingreso conlleva el reconocimiento simultáneo o el incremento de un activo, o la desaparición o disminución de un pasivo y, en ocasiones, el reconocimiento de un gasto.

- El reconocimiento de un gasto conlleva el reconocimiento simultáneo o el incremento de un pasivo, o la desaparición o disminución de un activo y, en ocasiones, el reconocimiento de un ingreso o de una partida de patrimonio neto.

Finalmente en este apartado del PGC se señala que, en todo caso, se registrarán en el período a que se refieren las cuentas anuales, los ingresos devengados en dicho período y los gastos del mismo relacionados con la obtención de dichos ingresos. Esta obligación suele denominarse en ocasiones «principio de correlación de ingresos y gastos». 


\section{Criterios de valoración}

Uno de los problemas fundamentales de la contabilidad es la determinación del valor monetario de los distintos elementos de las cuentas anuales. Por otra parte, otro aspecto fundamental es definir determinados conceptos de valor de forma que los usuarios de la contabilidad puedan comprender el significado y contenido exacto de los términos contables utilizados.

Los criterios de valoración incluidos en el PGC son:

1. Coste histórico o coste

2. Valor razonable

3. Valor neto realizable

4. Valor actual

5. Valor en uso

6. Costes de venta

7. Coste amortizado

8. Costes de transacción atribuibles a un activo o pasivo financiero

9. Valor contable o en libros

10. Valor residual

\section{Coste histórico o coste}

El coste histórico o coste de un activo es su precio de adquisición o coste de producción:

- El precio de adquisición es el importe en efectivo y partidas equivalentes pagadas o pendientes de pago más, en su caso y cuando proceda, el valor razonable de las demás contraprestaciones comprometidas derivadas de la adquisición, debiendo estar todas ellas directamente relacionadas con esta y ser necesarias para la puesta del activo en condiciones operativas.

- El coste de producción incluye el precio de adquisición de las materias primas y otras materias consumibles, el de los factores de producción directamente imputables al activo, y la fracción que razonablemente corresponda de los costes de producción indirectamente relacionados con el activo, en la medida en que se refieran al período de producción, construcción o fabricación, se basen en el nivel de utilización de la capacidad normal de trabajo de los medios de producción y sean necesarios para la puesta del activo en condiciones operativas.

El coste histórico o coste de un pasivo es el valor que corresponda a la contrapartida recibida a cambio de incurrir en la deuda o, en algunos casos, la cantidad de efectivo y otros activos líquidos equivalentes que se espere entregar para liquidar una deuda. 


\section{Ejemplo 7.4. Precio de adquisición}

En el balance de MERCADONA SA figura un terreno valorado por importe de 5.000,00 €. Este importe, que es su precio de adquisición, es la suma de todas las cuantías pagadas por la empresa relacionadas con la compra de dicho terreno y que fueron:

Pagado al anterior propietario

$4.500,00 €$

Pagado a Notaría y Gestoría

$125,00 €$

Pagado a Registro de la Propiedad

$75,00 €$

Pagado por Impuesto de Transmisiones Patrimoniales

$300,00 €$

$5.000,00 €$

\section{Valor razonable}

Es el importe por el que puede ser intercambiado un activo o liquidado un pasivo, entre partes interesadas y debidamente informadas, que realicen una transacción en condiciones de independencia mutua. El valor razonable se determinará sin deducir los costes de transacción en los que pudiera incurrirse en su enajenación. No tendrá en ningún caso el carácter de valor razonable el que sea resultado de una transacción forzada, urgente o como consecuencia de una situación de liquidación involuntaria.

Con carácter general, el valor razonable se calculará por referencia a un valor fiable de mercado. En este sentido, el precio cotizado en un mercado activo será la mejor referencia del valor razonable.

Para aquellos elementos respecto de los cuales no exista un mercado activo, el valor razonable se obtendrá, en su caso, mediante la aplicación de modelos y técnicas de valoración.

En cualquier caso, las técnicas de valoración empleadas deberán ser consistentes con las metodologías aceptadas y utilizadas por el mercado para la fijación de precios, debiéndose usar, si existe, la técnica de valoración empleada por el mercado que haya demostrado ser la que obtiene unas estimaciones más realistas de los precios.

Cuando corresponda aplicar la valoración por el valor razonable, los elementos que no puedan valorarse de manera fiable, ya sea por referencia a un valor de mercado o mediante la aplicación de los modelos y técnicas de valoración antes señalados, se valorarán, según proceda, por su coste amortizado o por su precio de adquisición o coste de producción, minorado, en su caso, por las partidas correctoras de su valor que pudieran corresponder.

\section{Ejemplo 7.5. Valor razonable}

La empresa INVESTMENTS SL tiene un bono del Estado a 3 años de valor nominal 10.000,00 y que el 5 de junio de 2000 cotizaba en la Bolsa de Madrid al 105\%.

El valor razonable del bono a 5 de junio de 00 es de: $10.000,00 \times 105 \%=10.500,0 €$ 


\section{Ejemplo 7.6. Valor razonable}

El 1 de abril de 2000 la empresa INVESTMENTS SL Tiene un bono de una empresa privada que no cotiza en bolsa. El nominal del bono es de 50.000,00 € y paga un interés anual del 5\% hasta el vencimiento en dos años. El tipo de interés de mercado en ese momento es del 7\% y la empresa desea conocer el valor razonable del bono.

El bono paga 2.500,00 de intereses anuales, aplicando un modelo de descuento financiero, entonces:

Valor razonable $=2.500 *(1+7 \%)^{-1}+(2.500+50.000) *(1+7 \%)^{-2}=48.191,92 €$

\section{Valor neto realizable}

De un activo es el importe que se puede obtener por su enajenación en el mercado, en el curso ordinario de las actividades, deduciendo los costes estimados necesarios para llevarla a cabo.

\section{Ejemplo 7.7. Valor neto realizable}

¿Cuál es el valor neto realizable de un activo si su precio de mercado es de $2.800 €$ pero se requiere para su venta el pago de gastos de transporte de $100 €$ y una comisión de venta de $200 €$ ?

El valor neto realizable es $=2.800,00-100,00-200,00=2.500,00$ euros

\section{Valor actual}

El valor actual es el importe de los flujos de efectivo a recibir o pagar en el curso normal del negocio, según se trate de un activo o de un pasivo, respectivamente, actualizados a un tipo de descuento adecuado.

\footnotetext{
Ejemplo 7.8. Valor actual de un pasivo

INDITEX SA tiene una deuda pendiente con un acreedor de 100.000,00 €. Dicha deuda debe cancelarse dentro de 2 años pero no genera intereses. Si el tipo de descuento de mercado es del 5\%, ¿cuál es el valor actual del pasivo?

Valor actual $=100.000,00 *(1+0,05)^{-2}=90.702,95$ euros
}

\section{Valor en uso}

De un activo es el valor actual de los flujos de efectivo esperados a través de su utilización en el curso normal del negocio, actualizados a un tipo de interés de mercado sin riesgo adecuado para el activo en cuestión.

\footnotetext{
Ejemplo 7.9. Valor en uso

La empresa MAQUINARIA SA se dedica al alquiler de maquinaria para obras. Tiene un moto-generador de vida útil 3 años que puede alquilar por $12.000 € /$ anuales. ¿Cuál es el valor de uso de dicho moto-generador? El tipo de interés de mercado sin riesgo es del 4\%.

Valor de uso: $12.000,00 *(1+0,04)^{-1}+12.000,00 *(1+0,04)^{-2}+12.000,00 *(1+0,04)^{-3}=$ $=33.301,09$ euros
} 


\section{Costes de venta}

Son los costes directamente atribuibles a la venta de un activo en los que la empresa no habría incurrido de no haber tomado la decisión de vender, excluidos los gastos financieros y los impuestos sobre beneficios. Se incluyen los gastos legales necesarios para transferir la propiedad del activo y las comisiones de venta.

\section{Ejemplo 7.10. Costes de venta}

La empresa MAQUINARIA SA se dedica a la exportación de maquinaria especializada a Estados Unidos, a su cargo van los gastos de aduanas, transporte y seguros de cada exportación. Además debe satisfacer a su comisionista en Nueva York un 1\% del importe de las máquinas vendidas. El 4 de abril vendió a una empresa americana una máquina por 10.000,00 €. Los costes de aduana, transporte y seguros de este envío ascendieron a $600,00 €$.

Costes de venta $=600+1 \% \times 10.000=700,00$ euros

\section{Coste amortizado}

El coste amortizado de un instrumento financiero es el importe al que inicialmente fue valorado un activo financiero o un pasivo financiero, menos los reembolsos de principal que se hubieran producido, más o menos, según proceda, la parte imputada en la cuenta de pérdidas y ganancias, mediante la utilización del método del tipo de interés efectivo, de la diferencia entre el importe inicial y el valor de reembolso en el vencimiento y, para el caso de los activos financieros, menos cualquier reducción de valor por deterioro que hubiera sido reconocida, ya sea directamente como una disminución del importe del activo o mediante una cuenta correctora de su valor.

El tipo de interés efectivo es el tipo de actualización que iguala el valor en libros de un instrumento financiero con los flujos de efectivo estimados a lo largo de la vida esperada del instrumento, a partir de sus condiciones contractuales y sin considerar las pérdidas por riesgo de crédito futuras; en su cálculo se incluirán las comisiones financieras que se carguen por adelantado en la concesión de financiación.

\section{Ejemplo 7.11. Coste amortizado de un pasivo financiero}

La empresa METALIZADOS SL obtiene el 1 de enero de 2000 un préstamo de BANCAJA de $50.000 €$ con unos gastos iniciales (comisión de apertura y corretajes) de $1.000 €$. El tipo de interés pactado es del $6 \%$ anual. El préstamo se amortizará por el método francés en 5 anualidades iguales de $11.869,82 €$.

El cuadro de amortización del préstamo proporcionado por BANCAJA es el siguiente:

\begin{tabular}{||c|c|r|r|r|r|}
\hline Período & $\begin{array}{c}\text { Capital } \\
\text { pendiente } \\
\text { inicial } \\
\mathbf{( 1 )}\end{array}$ & $\begin{array}{c}\text { Anualidad } \\
\mathbf{( 2 )}\end{array}$ & $\begin{array}{c}\text { Intereses } \\
\text { pagados } \\
\mathbf{( 3 ) = ( 1 )} \\
\mathbf{6 \%}\end{array}$ & $\begin{array}{c}\text { Reembolso } \\
\text { principal } \\
\mathbf{( 4 )}=\mathbf{( 2 )}-\mathbf{( 3 )}\end{array}$ & $\begin{array}{c}\text { Capital pendiente } \\
\text { final } \\
\mathbf{( 5 )}=\mathbf{( 1 )}-\mathbf{( 4 )}\end{array}$ \\
\hline $01 / 01 / 00-31 / 12 / 00$ & $50.000,00$ & $11.869,82$ & 3.000 .00 & $8.869,82$ & $41.130,18$ \\
\hline $01 / 01 / 01-31 / 12 / 01$ & $41.130,18$ & $11.869,82$ & $2.467,81$ & $9.402,01$ & $31.728,17$ \\
\hline $01 / 01 / 02-31 / 12 / 02$ & $31.728,17$ & $11.869,82$ & $1.903,69$ & $9.966,13$ & $21.762,04$ \\
\hline $01 / 01 / 03-31 / 12 / 03$ & $21.762,04$ & $11.869,82$ & $1.305,72$ & $10.564,10$ & $11.197,94$ \\
\hline $01 / 01 / 04-31 / 12 / 04$ & $11.197,94$ & $11.869,82$ & 671,88 & $11.197,94$ & 0,00 \\
\hline
\end{tabular}




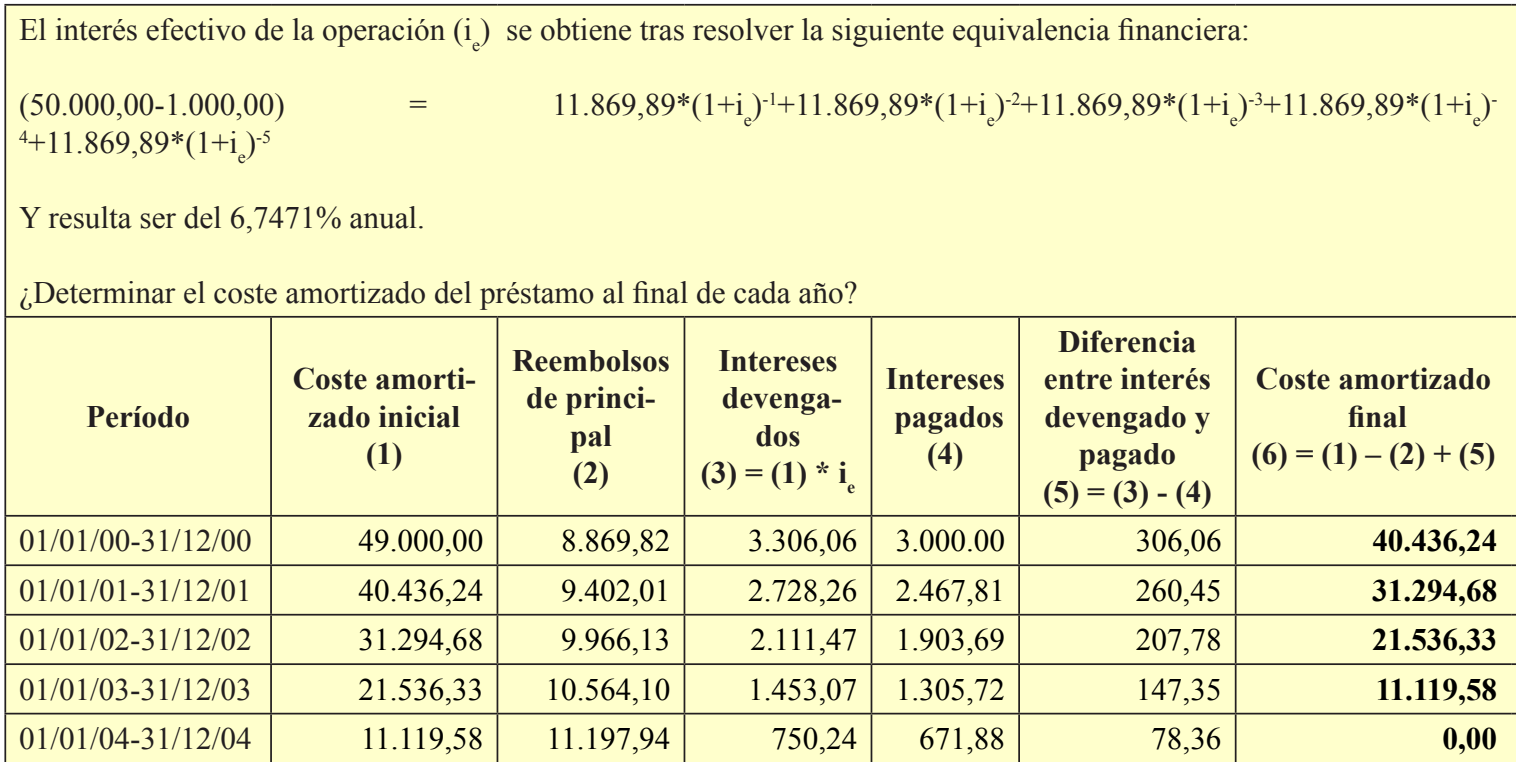

\section{Costes de transacción atribuibles a un activo o pasivo financiero}

Son los costes directamente atribuibles a la compra, emisión, enajenación de un activo financiero, o a la emisión o asunción de un pasivo financiero, en los que no se habría incurrido si la empresa no hubiera realizado la transacción.

Entre ellos se incluyen los honorarios y las comisiones pagadas a agentes, asesores e intermediarios, tales como las de corretaje, los gastos de intervención de fedatario público y otros, así como los impuestos y otros derechos que recaigan sobre la transacción, y se excluyen los gastos financieros, los costes de mantenimiento y los administrativos internos.

\section{Ejemplo 7.12. Costes de transacción de un activo financiero}

La empresa INVESTMENT ha adquirido 1.000 acciones de INTEL CO. en la Bolsa de Nueva York. Para poder efectuar dicha adquisición ha satisfecho 400,00 $€$ al intermediario financiero y $100,00 €$ por gastos de gestión a la Bolsa de Nueva York.

Los costes de transacción atribuibles a las acciones son $=400,00+100,00=500,00 €$

\section{Valor contable o en libros}

Es el importe por el que un activo o un pasivo se encuentra registrado en balance una vez deducida, en el caso de los activos, su amortización acumulada y cualquier ajuste valorativo por deterioro acumulado que se haya registrado.

\section{Ejemplo 7.13. Valor contable de un inmovilizado}

En el balance de PORCELANOSA SA figura maquinaria cuyo precio de adquisición fue de $40.000 €$. Esta maquinaria tiene una amortización acumulada en $15.000 €$ y tiene registrado un deterioro de valor de $2.000 €$.

El valor contable es $=40.000,00-15.000,00-2.000,00=23.000,00$ euros 


\section{Valor residual}

El valor residual de un activo es el importe que la empresa estima que podría obtener en el momento actual por su venta u otra forma de disposición, una vez deducidos los costes de venta, tomando en consideración que el activo hubiese alcanzado la antigüedad y demás condiciones que se espera que tenga al final de su vida útil.

La vida útil es el período durante el cual la empresa espera utilizar el activo amortizable o el número de unidades de producción que espera obtener del mismo. En particular, en el caso de activos sometidos a reversión, su vida útil es el período concesional cuando este sea inferior a la vida económica del activo.

La vida económica es el período durante el cual se espera que el activo sea utilizable por parte de uno o más usuarios o el número de unidades de producción que se espera obtener del activo por parte de uno o más usuarios.

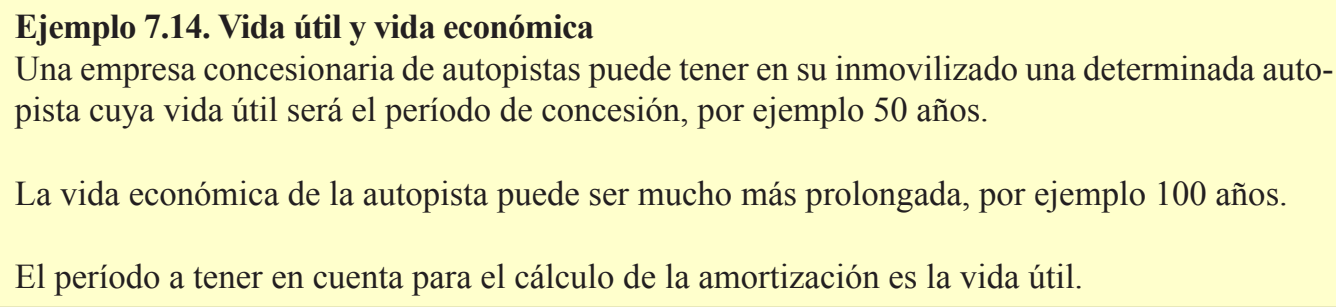

La determinación del valor residual es importante por cuanto determina el valor amortizable de un elemento de inmovilizado, y en consecuencia el importe de la amortización anual.

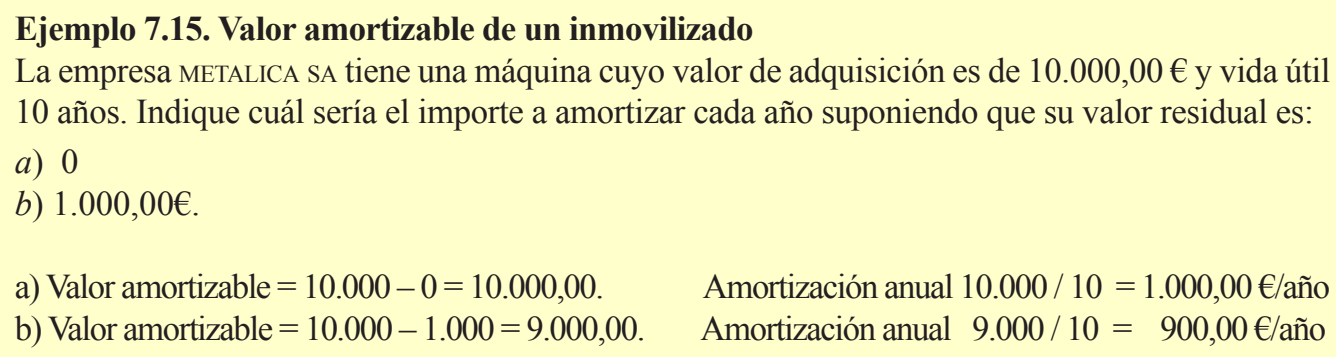

Cada elemento del patrimonio se valora según el criterio que se establece en la parte $2^{\mathrm{a}}$ del PGC relativa a «Normas de registro y valoración».

Ninguno de los criterios de valoración usado de forma aislada satisface íntegramente todos los atributos exigibles a la información (fiabilidad, relevancia, etc.) puesto que cada uno de ellos proporciona diferente información sobre el elemento patrimonial y es adecuado para distintos uso o en distintas situaciones.

En ocasiones, un elemento valorado hasta el momento con un determinado criterio debe proceder a valorarse por otro criterio para cumplir los objetivos que se pretenden.

En el siguiente gráfico se muestran distintos criterios de valoración relacionando cada uno de ellos con el tiempo. 


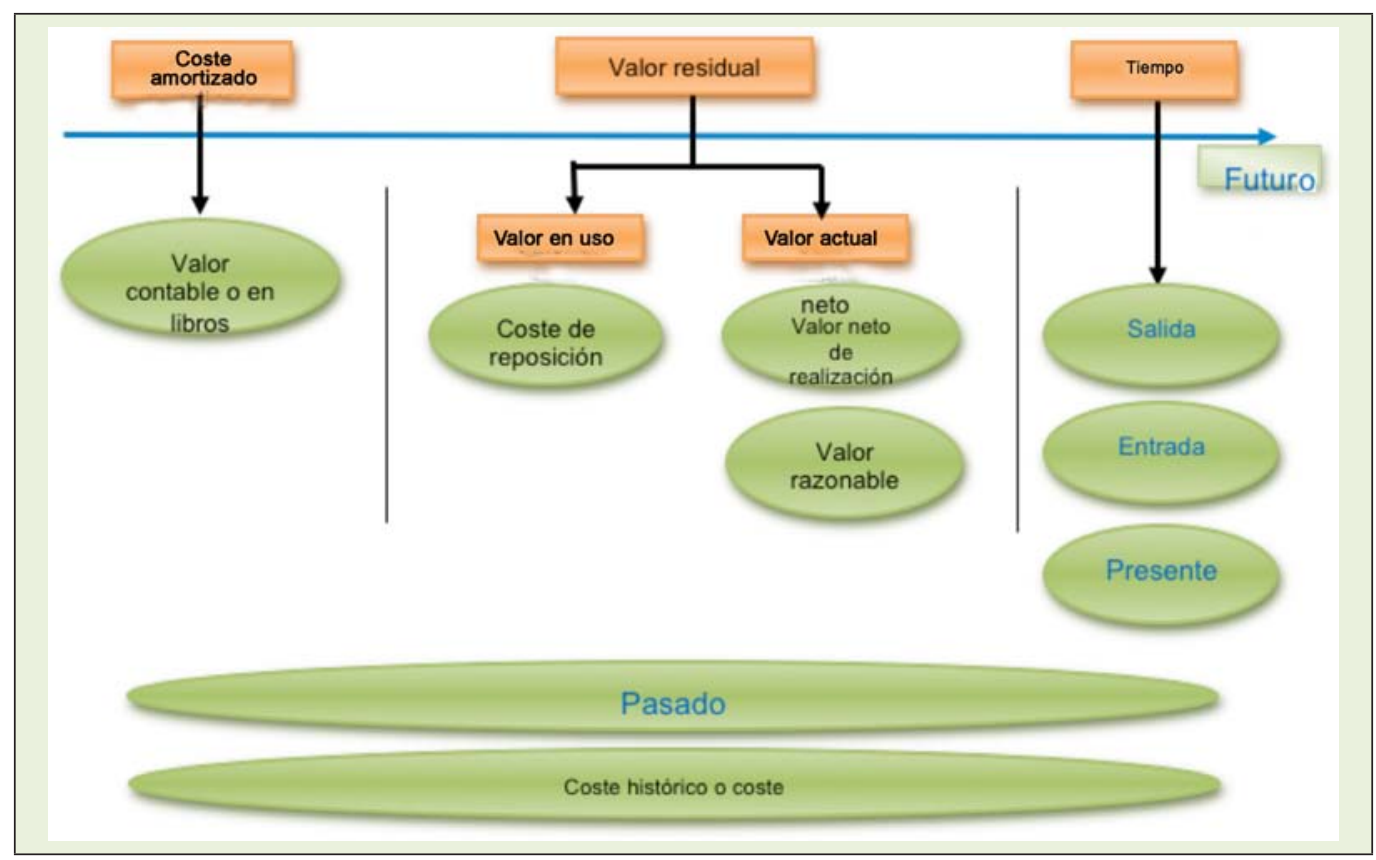

Ilustración 7.11. Diferentes criterios de valoración para diferentes usos

\subsection{Las otras partes del Plan General de Contabilidad}

Como se ha indicado en el apartado 3 de este tema, el PGC incluye las siguientes partes que van a describirse brevemente a continuación:

- Parte segunda: Normas de registro y valoración

- Parte tercera: Cuentas anuales

- Parte cuarta: Cuadro de cuentas

- Parte quinta: Definiciones y relaciones contables

\section{Normas de registro y valoración}

Los principios contables y los criterios de registro y reconocimiento contables, que se recogen en la parte primera del Plan General de Contabilidad, constituyen normas genéricas cuya aplicación práctica, en muchas ocasiones, no es inmediata, exigiendo por lo tanto su interpretación y adaptación a cada elemento de las cuentas anuales y a cada transacción y situación concreta.

Por ello, en la segunda parte del PGC, que es de aplicación obligatoria, se incluyen normas de registro y valoración que constituyen el desarrollo de los principios y criterios de reconocimiento y valoración de los activos, pasivos, elementos de patrimonio neto, ingresos y gastos.

A continuación, se muestra un listado de dichas normas que pueden consultarse en el PGC y son objeto de estudio en cursos avanzados de contabilidad. 


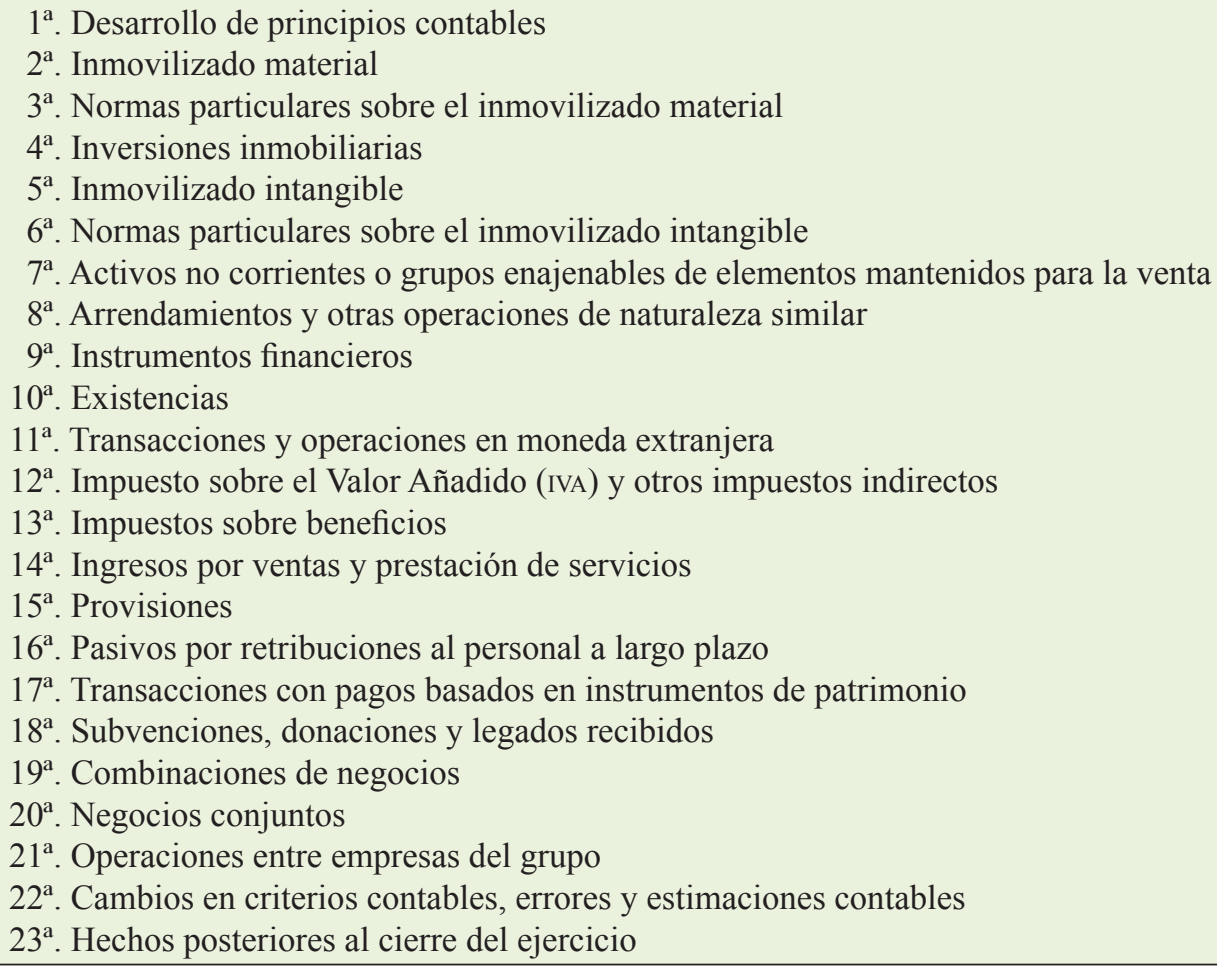

Ilustración 7.12. Listado de normas de registro y valoración

\section{Cuentas anuales}

En la tercera parte del PGC, que es de aplicación obligatoria, se señalan las normas que guían la formulación de las cuentas anuales. En esta parte, se indica la estructura, los formatos normalizados de cuentas anuales y se indican normas comunes y específicas para cada integrante las mismas.

A lo largo de este texto se ha introducido el balance y la cuenta de pérdidas y ganancias. El estudio en detalle de estos informes, así como del resto de integrantes de las cuentas anuales (estado de cambios en el patrimonio neto, estados de flujos de efectivo y memoria) se estudia en cursos más avanzados de contabilidad.

En el apartado 2 ya se ha comentado la existencia de dos formatos de las cuentas anuales, uno normal y otro abreviado, así como los criterios para la aplicación de uno u otro.

\section{Cuadro de cuentas}

En su cuarta parte, el PGC incluye un listado o cuadro de cuentas, que es facultativo, con códigos y denominaciones, que clasifica a estas en grupos, subgrupos y cuentas. En el tema 3, apartado 3.4, se incluyó un extracto de dicho cuadro de cuentas del PGC. 


\begin{tabular}{|c|c|}
\hline Grupo 1. Financiación básica & $\begin{array}{l}\text { Comprende el patrimonio neto y la financiación ajena a largo } \\
\text { plazo de la empresa destinados a financiar el activo no corrien- } \\
\text { te y un margen razonable del corriente. }\end{array}$ \\
\hline Grupo 2. Inmovilizado & $\begin{array}{l}\text { Comprende los elementos del patrimonio destinados a servir } \\
\text { de forma duradera en la actividad de la empresa. También in- } \\
\text { cluyen las inversiones financieras cuyo vencimiento, enajena- } \\
\text { ción o realización se espera habrá de producirse en un plazo } \\
\text { superior a un año. }\end{array}$ \\
\hline Grupo 3. Existencias & $\begin{array}{l}\text { Son activos poseídos para ser vendidos en el curso normal de } \\
\text { la explotación, en proceso de producción o en forma de ma- } \\
\text { teriales o suministros para ser consumidos en el proceso de } \\
\text { producción o en la prestación de servicios. } \\
\text { Mercancías, materias primas, otros aprovisionamientos, pro- } \\
\text { ductos en curso, terminados y otros. }\end{array}$ \\
\hline $\begin{array}{l}\text { Grupo 4. Acreedores y deudo- } \\
\text { res por operaciones comercia- } \\
\text { les }\end{array}$ & $\begin{array}{l}\text { Instrumentos financieros y cuentas que tengan su origen en } \\
\text { el tráfico de la empresa, así como cuentas con las Adminis- } \\
\text { traciones Públicas, incluso las que correspondan a saldos con } \\
\text { vencimiento superior a un año. } \\
\text { Para estas últimas, y a efectos de su clasificación, podrán utili- } \\
\text { zarse los subgrupos } 42 \text { y } 45 \text { o proceder a dicha reclasificación } \\
\text { en las propias cuentas. }\end{array}$ \\
\hline Grupo 5. Cuentas financieras & $\begin{array}{l}\text { Instrumentos financieros por operaciones no comerciales, es } \\
\text { decir, ajenas al tráfico con vencimiento no superior a un año y } \\
\text { medios líquidos disponibles. }\end{array}$ \\
\hline Grupo 6. Compras y gastos & $\begin{array}{l}\text { Aprovisionamientos de mercancías y demás bienes para venta } \\
\text { con o sin transformación. Comprende también todos los gas- } \\
\text { tos del ejercicio, incluidas las adquisiciones de servicios y de } \\
\text { materiales consumibles, la variación de existencias adquiridas } \\
\text { y otros gastos y pérdidas del ejercicio. }\end{array}$ \\
\hline Grupo 7. Ventas y ingresos & $\begin{array}{l}\text { Enajenación de bienes y prestación de servicios objeto de trá- } \\
\text { fico de la empresa y resto de ingresos, variación de existencias } \\
\text { y beneficios del ejercicio. }\end{array}$ \\
\hline $\begin{array}{l}\text { Grupo 8. Gastos imputados al } \\
\text { patrimonio neto }\end{array}$ & $\begin{array}{l}\text { Incluyen gastos y pérdidas por aplicación de los principios de } \\
\text { valoración de activos y pasivos, y otros conceptos, que deben } \\
\text { imputarse al patrimonio neto y no a los resultados del ejerci- } \\
\text { cio. }\end{array}$ \\
\hline $\begin{array}{l}\text { Grupo } 9 \text {. Ingresos imputados } \\
\text { al patrimonio neto }\end{array}$ & $\begin{array}{l}\text { Incluyen ingresos y ganancias por aplicación de los principios } \\
\text { de valoración de activos y pasivos, y otros conceptos, que } \\
\text { deben imputarse al patrimonio neto y no a los resultados del } \\
\text { ejercicio. }\end{array}$ \\
\hline
\end{tabular}

Ilustración 7.13. Grupos del cuadro de cuentas del PGC

Las cuentas de los grupos 1 a 5 también se denominan cuentas patrimoniales, representado activos, pasivos y elementos del patrimonio neto.

Las cuentas de los grupos 6 y 7 recogen ingresos y gastos imputables a resultados. Las cuentas de los grupos 6 y 7 se saldan al final de ejercicio con cargo / abono a la cuenta 129 .

Las cuentas de los grupos 8 y 9, que no se han estudiado en este texto, recogen ingresos y gastos que se imputan a cuentas de patrimonio neto diferentes de la 
cuenta de pérdidas y ganancias, de acuerdo a lo dispuesto en las normas contables. Estas cuentas son objeto de estudio en cursos más avanzados de contabilidad.

El cuadro de cuentas del PGC tiene una estructura tipo árbol, tal y como se muestra en la siguiente ilustración.

\begin{tabular}{|c|c|c|c|}
\hline GRUPO & SUBGRUPO & CUENTA & SUBCUENTA \\
\hline \multirow{6}{*}{$\begin{array}{l}\text { 4. Acreedores } \\
\text { y deudores por } \\
\text { operaciones } \\
\text { comerciales }\end{array}$} & \multirow[t]{2}{*}{ 40. Proveedores } & 400. Proveedores & $\begin{array}{l}\text { 4000. Proveedores (euros) } \\
\text { 4004. Proveedores (mon. extranjera) } \\
\text { 4009. Proveedores, facturas pendien- } \\
\text { tes de recibir o formalizar }\end{array}$ \\
\hline & & $\ldots$ & $\ldots$ \\
\hline & $\begin{array}{l}\text { 41. Acreedores } \\
\text { varios }\end{array}$ & $\begin{array}{l}\text { 410. Acreedores } \\
\text { por prestación de } \\
\text { servicios }\end{array}$ & $\ldots$ \\
\hline & \multirow{3}{*}{ 43. Clientes } & 430. Clientes & $\begin{array}{l}\text { 4300. Clientes (euros) } \\
\text { 4304. Clientes (moneda extranjera) } \\
\text { 4309. Clientes, facturas pendientes de } \\
\text { formalizar } \\
\end{array}$ \\
\hline & & $\begin{array}{l}\text { 431. Clientes, } \\
\text { efectos comer- } \\
\text { ciales a cobrar }\end{array}$ & $\begin{array}{l}\text { 4310. Efectos comerciales en cartera } \\
\text { 4311. Efectos comerciales descontados } \\
\text { 4312. Efectos com. gestión de cobro } \\
\text { 4315. Efectos comerciales impagados }\end{array}$ \\
\hline & & $\ldots$ & \\
\hline
\end{tabular}

Ilustración 7.14. Estructura del cuadro de cuentas del PGC

\section{Saber más: Adaptaciones del cuadro de cuentas de una empresa}

Cada empresa adapta el cuadro de cuentas previsto en el PGC a sus necesidades, realizando más o menos cambios según lo estime conveniente. Por ello, en la práctica empresarial pueden utilizarse además de, o en lugar de, las cuentas previstas en el PGC, otras cuentas, con otros códigos o denominaciones.

Por ejemplo, el subgrupo 62 del PGC incluye las siguientes cuentas:

620. Gastos en investigación y desarrollo del ejercicio

621. Arrendamientos y cánones

622. Reparaciones y conservación

623. Servicios de profesionales independientes

624. Transportes

625. Primas de seguros

626. Servicios bancarios y similares

627. Publicidad, propaganda y relaciones públicas

628. Suministros

629. Otros servicios

Una pequeña empresa que no necesite, o desee, tanto detalle en la información podría, si lo considera mejor, utilizar un subgrupo 62 formado por las siguientes cuentas: 
620. Alquileres

621. Reparaciones y conservación

623. Primas de seguros

624. Suministros

629. Otros servicios

O bien en lugar de la cuenta «624. Suministros» podría desear una mayor información de estos y utilizar:

624. Electricidad

625. Agua

626. Gas

627. Otros suministros

No obstante la misma información podría obtenerse con cuentas más desglosadas, por ejemplo:

624. Suministros

6240. Electricidad

6241. Agua

6242. Gas

6249. Otros suministros

Como se observa en los ejemplos anteriores las posibilidades son ilimitadas en cuanto al uso o no de las cuentas previstas en el PGC. Se observa que se pueden crear cuentas no previstas, o no utilizar las allí incluidas. También podrían cambiarse las denominaciones y realizar agrupaciones o desgloses de cuentas sin limitación.

\section{Definiciones y relaciones contables}

En la quinta parte del PGC, y para cada cuenta del «Cuadro de cuentas» se incluye el concepto y descripción del elemento (activo, pasivo, de patrimonio neto, ingreso o gasto) y sus relaciones, o motivos de cargo y abono, con otras cuentas.

Esta parte es facultativa, por lo que los movimientos de las cuentas que utilizarán las empresas podrían ser diferentes de los ahí señalados. No obstante, en algunos casos dichos movimientos, así como los comentarios que se incluyen, son muy ilustrativos y complementan la aplicación de las partes obligatorias del PGC.

La utilización por las empresas de las relaciones establecidas en esta parte facilita posteriormente la elaboración y presentación de la información requerida en las cuentas anuales. Por ello, pese a que no es de aplicación obligatoria, es mayoritariamente seguida en la práctica empresarial.

En la ilustración siguiente se muestra una muestra del contenido de esta parte del PGC, donde partiendo de un grupo se llega hasta las subcuentas. 
Grupo 5. Cuentas financieras. Instrumentos financieros por operaciones no comerciales, es decir, ajenas al tráfico con vencimiento no superior a un año y medios líquidos disponibles.

Subgrupo 52. Deudas a corto plazo por préstamos recibidos y otros conceptos. Financiación ajena a corto plazo no instrumentada en valores negociables ni contraída con personas o entidades que tengan la calificación de partes vinculadas, incluyendo los dividendos a pagar.

Las cuentas de este subgrupo figurarán en el pasivo corriente.

La parte de las deudas a largo plazo que tenga vencimiento a corto deberá figurar en el epígrafe: deudas a corto plazo; a estos efectos se traspasara a este subgrupo el importe que representen las deudas a largo plazo con vencimiento a corto de las cuentas correspondientes del subgrupo 17.

Cuenta 520. Deudas a corto plazo con entidades de crédito. Las contraídas con entidades de crédito por préstamos recibidos y otros débitos, convencimiento no superior a un año.

Subcuenta 5200. Préstamos a corto plazo de entidades de crédito. Cantidad que corresponde por este concepto de acuerdo con las estipulaciones del contrato.

a) Se abonará:

a.1) A la formalización de la deuda o del préstamo, por el importe recibido, minorado en los gastos de la transacción, salvo que se opte por su imputación directa a resultado en el momento inicial, con cargo, generalmente a cuentas del subgrupo 57.

a.2) Por el gasto financiero devengado hasta el valor de reembolso de la deuda con cargo, generalmente, a la cuenta 662 .

b) Se cargará por el reintegro, total o parcial, con abono a las cuentas del subgrupo 57.

Ilustración 7.15. Ejemplo de definiciones y relaciones contables

\section{Saber más: Definiciones y relaciones en la empresa}

Como se ha comentado en este tema, la parte cuarta del PGC, «Definiciones y relaciones contables», no es obligatoria. Por eso, aunque las definiciones y relaciones contables allí contenidas son ampliamente seguidas por la mayoría de las empresas, estas pueden utilizar variaciones en el funcionamiento de las cuentas.

Todas las variaciones serán aceptables siempre y cuando los informes elaborados por la empresa sobre la base de lo contabilizado cumplan con lo establecido en las partes primera, marco conceptual, segunda, normas de registro y valoración, y tercera, cuentas anuales, del PGC.

Como se vio en el tema 4, apartado 3, el registro contable que se incluye en el PGC para la regularización de existencias es:

\begin{tabular}{|c|c|r|c|c|}
\hline Asiento & Fecha & Cuentas & Debe & Haber \\
\hline $\mathrm{x}$ & $\mathrm{x}$ & $\begin{array}{r}\text { 610. Variación de existencias } \\
\text { 300. Existencias }\end{array}$ & $\begin{array}{c}\text { Valor existencias } \\
\text { iniciales }\end{array}$ & $\begin{array}{c}\text { Valor existencias } \\
\text { iniciales }\end{array}$ \\
\hline $\mathrm{x}$ & $\mathrm{x}$ & $\begin{array}{r}\text { 300. Variación de existencias } \\
\text { 610. Existencias }\end{array}$ & $\begin{array}{c}\text { Valor existencias } \\
\text { finales }\end{array}$ & $\begin{array}{c}\text { Valor existencias } \\
\text { finales }\end{array}$ \\
\hline
\end{tabular}

La misma repercusión se obtiene si se realiza un único asiento por la diferencia entre las existencias finales e iniciales.

Por ejemplo, en el caso de que las existencias finales sean mayores que las iniciales bastaría con contabilizar.

\begin{tabular}{|c|c|c|c|}
$\mathrm{X}$ & $\mathrm{x}$ & $\begin{array}{c}\text { 300. Variación de existencias } \\
\text { 610. Existencias }\end{array}$ & $\begin{array}{c}\text { Diferencia entre las existencias finales sobre } \\
\text { las iniciales }\end{array}$ \\
\hline
\end{tabular}




\subsection{Obligaciones mercantiles en materia contable}

El Código de Comercio, la Ley de Sociedades Anónimas y otras normas mercantiles, laborales, fiscales, medioambientales, etc., regulan determinadas obligaciones materiales en cuento a instrumentos de registro.

A continuación se comenta, de forma resumida, los aspectos principales de la regulación que afecta a los libros contables obligatorios para los comerciantes tal y como los define el Código de Comercio.

\section{Libros contables obligatorios (Código de Comercio, art. 25 a 33)}

Solo está prescrita la obligación de mantener dos libros contables obligatorios: el libro diario y el libro de inventarios y cuentas anuales.

\section{Libro diario}

Su formato, estructura y contenido será similar al visto en temas anteriores (ver apartado 3.8 del tema 3 ).

En el diario cabe la posibilidad de agrupar asientos similares realizando anotaciones hasta mensuales. Para ello, la empresa deberá contar con los libros auxiliares pertinentes que recojan detalladamente y justifiquen las anotaciones agrupadas realizadas (ver apartado 3.4 del tema 3, «Saber más»).

\section{Libro de inventarios y cuentas anuales}

En el que se incluirá:

- Un balance inicial detallado (es una relación valorada de todos los bienes, derechos y obligaciones de la empresa al comienzo del ejercicio. Este debe coincidir con el inventario de cierre del ejercicio anterior. La normativa, pese a requerir que sea detallado, no específica el nivel de detalle).

- Los balances de comprobación de sumas y saldos trimestrales.

- Un inventario de cierre (es un listado detallado de los elementos que constituyen el patrimonio de una empresa adecuadamente valorados).

- Las cuentas anuales.

\section{Formulación de cuentas anuales}

De acuerdo al art. 171 del TR de la LSA de los administradores están obligados a las cuentas anuales en el plazo máximo de tres meses contados a partir del fin de ejercicio. 
La legalización de los libros contables anteriores se realizará mediante diligencia en el Registro Mercantil de la provincia.

El plazo establecido para dicha legalización es de cuatro meses contados desde el cierre del ejercicio.

\section{Mantenimiento de libros y justificantes}

Según el Código de Comercio, los libros y justificantes de un ejercicio económico deben mantenerse seis años contados a partir del último asiento realizado.

\section{Depósito de cuentas anuales}

Además de la legalización de los libros contables, las sociedades mercantiles (sA y SL) están obligadas a depositar, es decir, entregar una copia para su archivo, de sus cuentas anuales al Registro Mercantil. De esta forma, dicha información se convierte en pública y puede ser consultada por parte de cualquier interesado. Los empresarios individuales no tienen obligación de depósito de cuentas.

Las cuentas anuales deben depositarse en el plazo de un mes desde su aprobación por las Juntas de Accionistas o de Socios.

\section{Otros informes y obligaciones mercantiles en materia de libros-registro}

Las sociedades mercantiles que deban presentar balance en formato normal están obligadas a elaborar y presentar anualmente, junto con las cuentas anuales, un informe de gestión donde se recoge el punto de vista de la dirección de la empresa sobre la marcha de la empresa, las actividades realizadas y otros aspectos.

Este informe no es propiamente un documento contable, pero habitualmente incluye una gran cantidad de información contable que se obtiene de los registros contables de la entidad.

Asimismo, estas empresas están obligadas a auditar sus cuentas por parte de expertos auditores independientes. El informe de auditoría se adjunta a las cuentas anuales. 
Finalmente las sociedades también deben mantener los siguientes libros mercantiles:

- Libro de actas, donde se transcriben las actas de las reuniones sociales.

- Libro de acciones nominativas, donde se registran dichas acciones (solo para el caso de que no sean acciones al portador).

Otros organismos, y para determinados sectores económicos o empresas (Banco España, Comisión Nacional de Mercados y Valores, etc.), establecen informes u obligaciones adicionales a los anteriores para las empresas por ellos reguladas.

\section{Otra normativa}

Toda empresa está sujeta a diversa normativa, laboral, fiscal, medioambiental etc. que puede requerir parcialmente información de naturaleza contable y que deberá ser obtenida de los propios registros contables de la entidad.

La naturaleza y tipo de los registros obligatorios derivados de la aplicación de estas normas dependerá de la actividad de la empresa, su forma jurídica y las opciones que permitan las mismas. 


\section{Material para prácticas}

\section{Preguntas test}

1. Son principios contables recogidos en el PGC:

a) El principio del precio de adquisición, el principio de devengo y el de importancia relativa.

b) El principio de caja, el principio de la empresa en funcionamiento y el principio de devengo.

c) El principio de la partida doble, el principio de no compensación y el principio de reconocimiento.

d) El principio de devengo, el principio de uniformidad y el principio de no compensación.

2. Señale la afirmación correcta:

a) El principio de correlación de gastos e ingresos establece que el resultado del ejercicio es la diferencia entre todos los ingresos cobrados y los gastos pagados.

b) El principio del devengo establece que los gastos e ingresos deben contabilizarse en el momento en que tenga lugar la corriente financiera con independencia de la corriente real de bienes y servicios.

c) No todas las empresas están sujetas a elaborar la contabilidad aplicando los principios contables.

d) El principio de prudencia está relacionado con la contabilización de correcciones valorativas de elementos de activo.

3. De acuerdo con el PGC, para reconocer un activo es necesario:

a) Que sea segura la obtención de beneficios del mismo.

b) Que sea probable la obtención de beneficios del mismo y el importe pueda estimarse con fiabilidad.

c) Que sea probable la obtención de beneficios y que los mismos puedan calcularse con exactitud.

d) Que sea segura la obtención de beneficios del mismo y el importe pueda calcularse con exactitud.

4. En relación al PGC, señalar cuál de las siguientes afirmaciones es correcta:

a) Las partes $4^{\mathrm{a}}$ «Cuadro de cuentas» y $5^{\mathrm{a}}$ «Definiciones y relaciones contables» no tienen carácter obligatorio para las empresas.

b) Es de aplicación voluntaria para los empresarios individuales.

c) Se estructura en seis partes.

d) La parte $2^{\mathrm{a}}$ «Normas de registro valoración» es de aplicación voluntaria.

5. En relación a la posibilidad de aplicar formatos abreviados en las cuentas anuales deben cumplirse:

a) Dos criterios de los indicados en el PGC durante tres años consecutivos.

b) Tres criterios de los indicados en el PGC durante tres años consecutivos. 
c) Dos criterios de los indicados en el PGC durante dos años consecutivos.

d) Tres criterios de los indicados en el PGC durante dos años consecutivos.

6. ¿Cuál de las siguientes afirmaciones es cierta?

a) El principio de prudencia impide la contabilización de pérdidas potenciales.

b) El principio del devengo implica contabilizar las operaciones en el momento de cobro y pago.

c) El principio del importancia relativa indica que solo hay que valorar correctamente los bienes más importantes.

d) Ningún principio contable es preferente respecto a los demás.

7. Los libros contables obligatorios según la legislación mercantil son:

a) Diario, mayor e inventarios.

b) Diario e inventario y cuentas anuales.

c) Diario, mayor e inventarios y cuentas anuales.

d) Balance, cuenta de pérdidas y ganancias y memoria.

8. De acuerdo al principio de prudencia que los elementos patrimoniales se valorarán:

a) De acuerdo con su valor razonable en cualquier caso.

b) Por el precio de adquisición si es inferior o igual al valor razonable.

c) Por el valor razonable siempre y cuando el precio de adquisición sea menor.

d) De acuerdo con su precio de adquisición en cualquier caso.

9. El valor razonable de un activo es:

a) Es el importe por el que puede ser intercambiado, entre partes interesadas e independientes debidamente informadas.

b) Es el importe por el que puede ser intercambiado, entre partes interesadas e independientes debidamente informadas deducidos los costes estimados de venta.

c) El valor al que aparece registrado en balance deducidos los costes estimados de venta.

d) El valor al que aparece registrado en balance.

10. El valor neto realizable de un activo es:

a) El importe que puede obtenerse por su venta en el mercado.

b) El importe que puede obtenerse por su venta en el mercado deducidos los costes estimados de venta.

c) El valor al que aparece registrado en balance una vez deducida su amortización acumulada y cualquier ajuste valorativo por deterioro registrado.

d) El valor al que aparece registrado en balance deducidos los costes estimados de venta.

11. El valor en uso de un activo inmovilizado:

a) El valor actual de los flujos de efectivo esperados a través de su utilización en el curso normal del negocio, actualizados a un tipo de interés de mercado sin riesgo. 
b) Es el valor actual de los flujos de efectivo pagados para su adquisición, actualizados a un tipo de interés de mercado sin riesgo adecuado para el activo en cuestión.

c) El valor al que aparece registrado en balance una vez deducida su amortización acumulada y cualquier ajuste valorativo por deterioro registrado.

d) Ninguna de las anteriores.

12. La vida útil de un activo amortizable:

a) Determina el importe al que debe registrarse en el momento de la adquisición.

b) Determina el importe al que debe registrarse en el momento de la venta

c) Es el período durante el cual la empresa espera utilizarlo.

d) Es el período durante el cual la empresa espera que el activo sea utilizable por uno o más usuarios.

13. ¿Cuál de los siguientes no es un principio contable según el PGC?
a) Principio de prudencia.
b) Principio del uniformidad.
c) Principio de importancia relativa.
d) Principio del dualidad.

14. ¿Cuál de los siguientes no es un criterio de valoración del PGC?

a) Valor neto contable.

b) Valor relativo.

c) Valor de uso.

d) Valor actual.

SOLUCIONES AL TEST:

\begin{tabular}{|l|l|l|l|l|}
\hline 1. & 2. & 3. & 4. & 5. \\
\hline 6. & 7. & 8. & 9. & 10. \\
\hline 11. & 12. & 13. & 14. & \\
\hline
\end{tabular}




\section{Cuestiones teóricas}

1. ¿Por qué es necesaria la regulación contable referida a la elaboración de información para usuarios externos?

2. ¿Qué se entiende por normalización contable y qué fines persigue?

3. ¿Qué se entiende por armonización contable y qué fines persigue?

4. ¿Qué es el IASB? ¿Son sus normas aplicables en España, en qué condiciones?

5. Cite las normas contables españolas más significativas.

6. Cite las partes en que se divide el PGC, señalando si son de aplicación obligatoria o no.

7. Explique qué es el marco conceptual del PGC y que elementos lo componen

8. Indique los informes integrantes de las cuentas anuales.

9. Cite los principios contables.

10. Explique el principio de prudencia.

11. Explique el principio de empresa en funcionamiento.

12. Explique el principio de uniformidad.

13. Explique el principio de no compensación.

14. Explique el principio de importancia relativa.

15. ¿Qué son los criterios de registro y reconocimiento contable?

16. Cite las dos condiciones necesarias para poder reconocer contablemente un activo.

17. Cite las dos condiciones necesarias para poder reconocer contablemente un pasivo.

18. Cite las dos condiciones necesarias para poder reconocer contablemente un ingreso.

19. Cite las dos condiciones necesarias para poder reconocer contablemente un gasto.

20. Cite los criterios de valoración que incluye el PGC.

21. Defina valor de uso de un activo.

22. Defina el valor actual de un pasivo financiero.

23. Defina el valor realizable neto.

24. Defina y diferencie entre el valor razonable y el valor de mercado.

25. Diferencie entre vida útil y vida económica de un activo.

26. ¿Qué es un cuadro de cuentas?

27. ¿Cuál es el contenido de la parte cuarta del PGC, definiciones y relaciones contables?

28. Cite los grupos de cuentas del PGC, indicando brevemente su contenido.

29. ¿Cuáles son los libros contables obligatorios?

30. ¿Cuál es el contenido del libro de inventarios y cuentas anuales.

31. ¿Cuál es el plazo para legalizar los libros contables, dónde se legalizan y cuánto tiempo debe mantenerlos la empresa? 


\section{Ejercicios}

Para los ejercicios del 1 al 13 indique: Suponiendo que se está a 31 de diciembre y en el proceso de cierre del ejercicio ¿Qué principios contables, o criterios de registro y reconocimiento o de valoración hay que aplicar en cada caso? ¿Qué consecuencias tiene su aplicación sobre el balance y la cuenta de pérdidas y ganancias?

Ejercicio 1. Principios contables y criterios de reconocimiento y valoración Para la realización de las ventas de un ejercicio una empresa ha incurrido en unos determinados gastos cuyos justificantes (facturas) no obran en su poder en el momento de cierre contable por lo que se decide esperarse e imputar los gastos al ejercicio siguiente cuando lleguen dichos justificantes.

Ejercicio 2. Principios contables y criterios de reconocimiento y valoración El 1 septiembre de 2000, momento en que se pagó, una empresa registró como gastos de 2000 por arrendamientos 12.000,00 €. Este importe corresponde al alquiler de un local comercial para los 6 meses siguientes.

Ejercicio 3. Principios contables y criterios de reconocimiento y valoración Una empresa adquiere varias herramientas para reparación de maquinaria de reducido importe (en total 100,00 €). El contable considera que no es necesario considerar estas herramientas, de larga vida útil, como inmovilizado y sujetas a amortización y que cabe la posibilidad de considerar la compra como un gasto dado que los importes no son significativos desde el punto de vista de la imagen fiel proporcionada por las cuentas anuales.

Ejercicio 4. Principios contables y criterios de reconocimiento y valoración Se ha comprado a una empresa en liquidación unas mercancías por 1.000,00€ que registró por ese valor, precio notablemente inferior a su valor de mercado que era de $3.000 €$. El gerente propone al contable que se ajuste el valor de las mercancías al valor de mercado ya que el coste ha sido realmente una verdadera ganga y no representa fielmente el valor de las mismas. 
Ejercicio 5. Principios contables y criterios de reconocimiento y valoración Una empresa posee un inmueble que le costó 40.000,00 € y según un proyecto municipal, que todavía no es firme, cabe la posibilidad de que se instale una actividad peligrosa cerca del mismo lo que, según estimación del contable, podría producir una disminución en su valor de mercado de 5.000,00€.

Ejercicio 6. Principios contables y criterios de reconocimiento y valoración Una empresa está obteniendo pérdidas durante el ejercicio 2000. El gerente, que no quiere presentar una información desfavorable a los accionistas desea que las ventas de la primera quincena de enero se contabilicen con fecha de diciembre, antes del cierre, al objeto de mejorar el resultado de la cuenta de pérdidas y ganancias.

Ejercicio 7. Principios contables y criterios de reconocimiento y valoración Una empresa vende sus mercancías habitualmente a plazos por lo que está pensando en contabilizar las ventas progresivamente conforme se cobran los plazos y no cuando se realiza la venta. En su opinión esto reflejaría mejor la imagen fiel de las actividades de la empresa.

Ejercicio 8. Principios contables y criterios de reconocimiento y valoración Se tiene conocimiento que un cliente, que adeuda a la empresa $1.000,00 €$ y cuyo cobro debe producirse dentro un mes, está incumpliendo sistemáticamente los pagos a otras empresas del sector. Comentarios recibidos por personas de estas empresas aseguran que no cabe tener mucha confianza en que dicho cliente vaya a pagar en el futuro los importes debidos.

\section{Ejercicio 9. Principios contables y criterios de reconocimiento y valoración}

El contable de una empresa opina que la cuenta de pérdidas y ganancias presenta excesiva complejidad para ser entendida por los accionistas, por lo que está considerando la posibilidad de simplificarla. Para ello, está pensando concretamente que en lugar de presentar los créditos comerciales y las deudas comerciales por separado presentar el importe neto diferencia de unos y otros. Piensa hacer lo mismo con los ingresos y gastos de naturaleza financiera. Con ello reduciría de cuatro 
a dos las partidas presentes en el balance y de cuatro a dos cuentas las presentadas en la cuenta de pérdidas y ganancias, siendo de más fácil compresión.

Ejercicio 10. Principios contables y criterios de reconocimiento y valoración La empresa viene amortizando una determinada maquinaría según una vida útil estimada de 8 años. Dado que el ejercicio económico ha sido muy favorable y se esperan grandes beneficios el gerente propone al contable considerar como gasto por amortización de la maquinaria un importe mayor dado que así reduciría el beneficio y los impuestos que habrá que pagar.

Ejercicio 11. Principios contables y criterios de reconocimiento y valoración El gerente de una empresa piensa que los valores que muestra el Balance no reflejan la imagen fiel de la empresa, ya que si se decidiese vender todos los activos el importe que se obtendría sería muy superior al registrado contablemente. Por ello, propone al contable revisar los valores de los activos de modo que muestren su valor neto de realización.

Ejercicio 12. Principios contables y criterios de reconocimiento y valoración La práctica habitual de una empresa, en cuanto al momento de registro de ingresos, consiste en anotar las facturas conforme van siendo cobradas. Al final del ejercicio, 31 de diciembre, quedan facturas pendientes de contabilizar por 10.000,00€. El jefe de ventas cree que no deberían contabilizarse hasta que se cobren ya que todos los años hay clientes que al final no pagan y está seguro de que habrá problemas de cobro con alguno de los actuales, aunque no sabe con cuáles.

Ejercicio 13. Principios contables y criterios de reconocimiento y valoración En la última reunión directiva, el contable de una empresa ha señalado al gerente al posibilidad de que se tenga que pagar $15.000,00 €$ por sanción debido a que una asociación ecologista ha interpuesto una demanda por deterioro medioambiental. Otras empresas en la misma situación ya han sido condenadas por hechos similares. No obstante, el gerente es optimista y cree que no van a perder el juicio ya que los abogados contratados son muy competentes. 


\section{Ejercicio 14. Precio de adquisición}

Construcciones METÁLICAS SL adquiere una máquina a un proveedor por $10.000 €$, los gastos de transporte y seguros hasta la planta ascienden a $500 €$ y el montaje de la máquina, para que esté en condiciones de funcionamiento, asciende a $1.500 €$. ¿Cuál es el precio de adquisición de la máquina?

Precio de adquisición $=$

\section{Ejercicio 15. Coste de producción}

Fabricar una tableta de chocolate requiere materiales directos (cacao, leche y otros) por importe de $0,70 €$, mano de obra directa de personal por importe de $0,30 €$, así como diversos costes indirectos (electricidad, amortizaciones etc.) por importe de $0,20 €$. ¿Cuál es el coste de producción de una tableta de chocolate?

Coste de producción $=$

\section{Ejercicio 16. Valor razonable}

Las acciones del BANCO POPULAR SA cotizan en la Bolsa de Madrid, ¿puede tomarse su valor de cotización como valor razonable de las mismas?

\section{Ejercicio 17. Valor razonable}

¿Cuál es el valor razonable hoy de un derecho de cobro de $10.000 €$ dentro de 3 años sabiendo que el tipo de interés para ese plazo es del 6\% anual? Aplicad un modelo de descuento de flujos de efectivo.

\section{Valor razonable $=$}

\section{Ejercicio 18. Valor realizable neto.}

La empresa EXPORT SA se dedica exclusivamente, como intermediario, a vender naranjas a diversos países americanos. El precio de venta es de $0,5 € / \mathrm{kg}$, pero corre a su cargo el coste el flete hasta el puerto de destino y que se estima en $1.000 €$ cada «contenedor», en el que caben $20 \mathrm{t}$ de naranjas. ¿Cuál es el valor realizable neto de las existencias de esta empresa que ascienden a 480 t de naranjas?

Valor razonable neto $=$ 


\section{Ejercicio 19. Valor actual}

¿Cuál es el valor actual de una deuda con un proveedor de $50.000 €$ y que vence dentro de dos años si el tipo de interés para plazos similares es del 5\% anual?

Valor actual $=$

\section{Ejercicio 20. Valor de uso}

Una empresa de alquiler de vehículos tiene un turismo del que puede obtener, según el alquiler medio histórico de este tipo de vehículos, un rendimiento anual neto de 100.000 euros y tiene una vida útil de 4 años. ¿Cuál es el valor de uso de dicho turismo si el tipo de interés de mercado es del $6 \%$ ?

Valor de uso $=$

\section{Ejercicio 21. Valor residual}

Una empresa amortiza de forma constante una máquina de coste $50.000 €$ en 10 años, siendo el valor residual de la misma de $10.000 €$. ¿Cuál es el importe de la amortización anual de la máquina?

\section{Amortización anual $=$}

\section{Ejercicio 22. Vida útil}

Una empresa explota una autopista en régimen de concesión administrativa durante 50 años. La construcción de la autopista supuso un coste de 10.000.000 euros y su valor residual es 0 . La vida económica de la autopista es de 100 años. ¿Qué importe deberá amortizar todos los años?

\section{Ejercicio 23. Valor neto contable}

Complete la siguiente tabla:

\begin{tabular}{|l|r|r|r|r|}
\hline \multicolumn{1}{|c|}{ Elemento } & $\begin{array}{c}\text { Precio adquisición / Valor } \\
\text { razonable inicial }\end{array}$ & $\begin{array}{c}\text { Amortización } \\
\text { acumulada }\end{array}$ & $\begin{array}{c}\text { Deterioro } \\
\text { de valor }\end{array}$ & Valor neto contable \\
\hline Construcciones & 230.000 & 110.000 & 0 & $?$ \\
\hline Maquinaria & 60.000 & $?$ & 10.000 & 30.000 \\
\hline Clientes & 30.000 & --- & $?$ & 25.000 \\
\hline Créditos a largo plazo & $?$ & --- & 15.000 & 25.000 \\
\hline
\end{tabular}

\begin{tabular}{|l|r|r|r|r|}
\hline \multicolumn{1}{|c|}{ Elemento } & $\begin{array}{c}\text { Precio adquisición / Valor } \\
\text { razonable inicial }\end{array}$ & $\begin{array}{c}\text { Amortización } \\
\text { acumulada }\end{array}$ & $\begin{array}{c}\text { Deterioro } \\
\text { de valor }\end{array}$ & Valor neto contable \\
\hline Construcciones & 230.000 & 110.000 & 0 & 30.000 \\
\hline Maquinaria & 60.000 & & 10.000 & 25.000 \\
\hline Clientes & 30.000 & --- & & 25.000 \\
\hline Créditos a largo plazo & & ---- & 15.000 & \\
\hline
\end{tabular}




\section{Ejercicio 24. Coste amortizado}

Determinar el coste amortizado de un préstamo al final de su primer año sabiendo que:

- Valor nominal inicial $=$ Coste amortizado inicial $=80.000 €$

- Tipo de interés nominal anual $=6 \%$

- Tipo de interés efectivo anual $=7 \%$

- Devolución de principal al final del año $=10.000 €$

Coste amortizado final $=$

\section{Ejercicio 25. Coste amortizado}

Dado el siguiente cuadro de amortización de un préstamo proporcionado por una entidad financiera:

\begin{tabular}{|c|r|r|r|r|r|}
\hline Período & $\begin{array}{c}\text { Capital } \\
\text { pendiente } \\
\text { inicial } \\
\mathbf{( 1 )}\end{array}$ & $\begin{array}{c}\text { Anualidad } \\
\mathbf{( 2 )}\end{array}$ & $\begin{array}{c}\text { Intereses } \\
\text { pagados } \\
\mathbf{( 3 )}=\mathbf{( 1 )} * \mathbf{5 \%}\end{array}$ & $\begin{array}{c}\text { Reembolso } \\
\text { principal } \\
\mathbf{( 4 )}=\mathbf{( 2 )}-\mathbf{( 3 )}\end{array}$ & $\begin{array}{c}\text { Capital } \\
\text { pendiente final } \\
\mathbf{( 5 )}=\mathbf{( 1 )}-\mathbf{( 4 )}\end{array}$ \\
\hline $01 / 01 / 00-31 / 12 / 00$ & $30.000,00$ & $11.500,00$ & $1.500,00$ & $10.000,00$ & $20.000,00$ \\
\hline $01 / 01 / 01-31 / 12 / 01$ & $20.000,00$ & $11.000,00$ & $1.000,00$ & $10.000,00$ & $10.000,00$ \\
\hline $01 / 01 / 02-31 / 12 / 02$ & $10.000,00$ & $10.500,00$ & 500,00 & $10.000,00$ & 0,00 \\
\hline
\end{tabular}

Sabiendo que los gastos de estudio y apertura del mismo ascienden a 2.000,00 y que el tipo de interés efectivo es del $8,83071 \%$, elabore el cuadro de coste amortizado del mismo.

\begin{tabular}{|c|c|c|c|c|c|}
\hline Período & $\begin{array}{c}\text { Coste } \\
\text { amortizado } \\
\text { inicial } \\
\text { (1) }\end{array}$ & $\begin{array}{c}\text { Intereses } \\
\text { devengados } \\
(2)=(1)^{*} \\
\mathbf{8 , 8 3 0 7 1 \%}\end{array}$ & $\begin{array}{c}\text { Intereses } \\
\text { pagados } \\
(3)\end{array}$ & $\begin{array}{c}\text { Reembolso } \\
\text { principal } \\
\text { (4) }\end{array}$ & $\begin{array}{c}\text { Coste } \\
\text { amortizado } \\
\text { final } \\
(5)=(1)+(2)- \\
(3)-(4)\end{array}$ \\
\hline \multicolumn{6}{|l|}{$01 / 01 / 00-31 / 12 / 00$} \\
\hline \multicolumn{6}{|l|}{$01 / 01 / 01-31 / 12 / 01$} \\
\hline $01 / 01 / 02-31 / 12 / 02$ & & & & & \\
\hline
\end{tabular}




\section{Casos}

\section{Caso 1. Las normas internacionales del IASB}

1. Realice una búsqueda a través de Internet de las normas internacionales de contabilidad aprobadas por el IASB. Elabore un listado de dichas normas y comente brevemente el objetivo o contenido de cada una de ellas.

2. Busque las normas de la Unión Europea por las que se aprueba la aplicación de las normas del IASB de forma obligatoria a determinadas empresas y para determinadas cuentas en el ámbito de la Unión y comente las obligaciones incluidas en las mismas.

\section{Caso 2. Cuadro de cuentas de una empresa}

1. Contacte con alguna empresa del entorno y solicite su cuadro de cuentas.

2. Compare el cuadro de cuentas con el incluido en el PGC.

3. Con las cuentas de dicho cuadro de cuentas prepare la estructura de un balance indicando las cuentas que incluiría en cada partida del mismo.

4. Con las cuentas de dicho cuadro de cuentas prepare la estructura de una cuenta de pérdidas y ganancias, indicando las cuentas que incluiría en cada partida del mismo.

\section{Caso 3. Diferencias entre normas contables en diferentes países}

Lea el siguiente trabajo y reflexione sobre la existencia de normas contables diferentes entre países y por qué sería útil una armonización entre ellas.

\footnotetext{
Hacia una convergencia internacional de las normas contables

Fernando García Martínez

Universidad Complutense de Madrid - Accésit (ex-aequo) del IX Premio AECA
}

La normativa contable utilizada por las empresas cuando elaboran su información financiera actualmente puede diferir de forma importante entre países. Al coexistir diferentes normativas contables con una interdependencia creciente en los mercados financieros mundiales se originan dos problemas importantes.

El primer problema afecta a los inversores debido a que estos, por un lado, se enfrentan con la incertidumbre cuando examinan la información financiera de empresas de países diferentes para evaluar posibles inversiones, al no resultar posible la comparación ya que las cifras responden a diferentes criterios de cómputo; por otro lado, las diferentes normas contables ocasionan que la información financiera que presenta una misma empresa varíe de forma importante según se apliquen unas u otras normas, confundiendo a los inversores. Resulta en este punto esclarecedor recordar la desconfianza creada en julio de 2002, en una época en que las irregularidades contables sacudían los mercados financieros estadounidenses, cuando la prensa publicó que Telefónica de acuerdo con las normas contables estadounidenses cerraba el año 2001 con unas pérdidas de 7.182 millones de euros, en lugar de los 2.106,8 millones de euros de beneficio que había obtenido con las normas contables españolas.

El segundo problema perjudica a las empresas interesadas en contar con fuentes financieras nacionales e internacionales, estando estas obligadas a soportar costes elevados al tener que elaborar estados contables basándose en las normas contables nacionales y estados contables apoyándose en las normas contables de los países donde desean cotizar. Así por ejemplo, si una empresa española quiere cotizar en la bolsa de Nueva York, tiene dos posibilidades para cumplir los requerimientos que le imponen: a) elaborar sus estados financieros de acuerdo con las normas contables de dicho país, es decir con los US GAAP (US Generally Accepted Accounting Principles), b) hacer un estado de adaptación o ajuste de las normas contables españolas a los us GAAP. En ambos casos, esta empresa española está teniendo un coste adicional al no ser posible preparar unos estados financieros que estén cumpliendo las normas contables españolas y las norteamericanas. Son precisamente las empresas que buscan financiación internacional, las que más están presionando para conseguir un conjunto de normas contables homogéneas para elaborar sus estados financieros, e incrementar así la comparabilidad de los estados contables. 


\begin{abstract}
[...]
En un mundo globalizado, parece tener sentido que una transacción económica sea contabilizada de forma similar, con independencia de donde se realice. De esta forma se promovería la inversión internacional, al contar los inversores con información más homogénea y las empresas reducir sus costes a la hora de elaborar la información financiera. La diversidad contable es uno de los grandes problemas que reducen la profundidad y liquidez de los mercados, si bien es cierto que para conseguir unos flujos de capital eficientes entre fronteras, no solo es necesario que la información financiera que presenten las empresas sea homogénea. Son en consecuencia muy numerosas las opiniones que podemos encontrar, defendiendo la conveniencia de armonizar las normas contables en los distintos países como consecuencia de la globalización. Sin embargo, la armonización contable no es tarea fácil, ya que cambiar las normas contables de un país puede implicar cambios en aspectos culturales, legales, etc.
\end{abstract}

En estos momentos no existen unas únicas normas reconocidas internacionalmente, pero sí dos emisores principales de normas con influencia internacional: el IASB (International Accounting Standards Board) y el FASB (US Financial Accounting Standards Board). La influencia del IASB viene originada en gran medida por el acuerdo alcanzado en 1995 con la ısco (International Organization of Securities and Exchange Commission), según el cual, el IASB desarrollaría un conjunto básico de normas contables que serían utilizadas por las empresas que deseasen cotizar, comprometiéndose la Iosco a recomendar a sus miembros que aceptasen las cuentas anuales de empresas extranjeras elaboradas con las normas referidas sin tener que adaptarlas a las normas del país donde desease cotizar. En diciembre de 1998 este proyecto fue completado, recomendando en mayo de 2000 la ısco este conjunto de normas.

A pesar de esta recomendación, la SEC (US Securities and Exchange Commission), organismo regulador de los mercados norteamericanos, sigue exigiendo que para cotizar en las bolsas norteamericanas, los estados financieros, tanto de las empresas nacionales como extranjeras, deben realizarse sobre la base de los us GAAP, es decir las normas del IASB no se aceptan en los mercados más importantes en el ámbito mundial. Los uS GAAP Son normas emitidas en la actualidad principalmente por el FASB, organismo que nunca ha prestado gran atención a la convergencia internacional de normas contables, ya que sus normas adquieren dimensión internacional en gran medida porque estas normas son las aceptadas por el mercado de valores norteamericano, que es el mercado al que pretenden acceder la mayoría de las multinacionales.

[...]

La no aceptación de las normas del IASB por parte de la SEC demuestra el gran camino que queda por recorrer para conseguir unas normas contables aceptadas en el ámbito internacional. El IASB ha continuado con el objetivo de desarrollar normas contables, para promover su aceptación y seguimiento en el ámbito internacional. Sin embargo la situación ha cambiado con la reunión del FASB e IASB en Norwalk (USA) el 18 de septiembre del 2002. En esta reunión ambos organismos acordaron desarrollar normas contables de alta calidad compatibles, que pudieran usarse tanto para los estados financieros a presentar por las empresas en su país como en otros países. En esta reunión el FASB e IASB se comprometieron, en primer lugar, a realizar un gran esfuerzo para hacer sus normas de registro financiero existentes totalmente compatibles tan pronto como fuese posible. En segundo lugar, coordinar sus programas de trabajo futuro para asegurar que una vez conseguida la compatibilidad, ésta se mantuviese. Estos acuerdos se materializaron el 29 de octubre de 2002 en un memorándum.

[...]

Por otro lado, este memorándum es un paso importante hacia un conjunto único de normas contables, pero ¿puede ayudar, en particular, a que la SEC acepte los estados financieros de empresas que desean cotizar en los mercados americanos, elaborados con las normas del IASB sin ajustes a los us GAAP?

La SEC ha defendido la adaptación o ajuste a los uS GAAP con el argumento de que pretende proteger los intereses de los inversores americanos, al requerir a todas las empresas que acceden a los mercados públicos americanos un registro financiero de alta calidad capaz de satisfacer las necesidades de información de los inversores. Igualmente ha señalado que la adaptación o ajuste exige a los emisores extranjeros complementar sus estados financieros del país de origen, pero a pesar de ello ha habido un incremento del número total de empresas extranjeras cotizando en USA. [...] 


\section{Bibliografía}

\section{A. Normativa contable}

\section{Básica}

- Plan General de Contabilidad, RD 1514/2007, de 16 de noviembre, BOE, 20 de noviembre de 2007. Puede obtenerse en: www.icac.meh.es

- Plan General de Contabilidad para PYMES, RD 1515/2007, de 16 de noviembre, BOE, 21 de noviembre de 2007. Puede obtenerse en: www.icac.meh.es

\section{Complementaria}

- Código de Comercio, con sus modificaciones posteriores.

- Ley 1564/1989, de 22 de diciembre, Texto refundido de la Ley de Sociedades Anónimas, y modificaciones posteriores.

- Ley 2/1995, de 23 de marzo, de Sociedades de Responsabilidad Limitada, y modificaciones posteriores.

- Ley 16/2007, de 4 de julio de 2007, de Reforma y Adaptación de la Legislación Mercantil en materia contable para su armonización internacional con base en la normativa de la Unión Europea, BOE, 5 de julio de 2007. Puede obtenerse de www.icac.meh.es

\section{B. Manuales y textos de contabilidad}

Debido al carácter básico de esta materia, pueden consultarse manuales u obras generales de introducción a la contabilidad financiera.

Cualquiera de las obras que a continuación se relacionan, que en su conjunto han servido como base para la elaboración de este texto, puede servir como complemento y ampliación del contenido de los distintos temas del mismo.

Andrés Gómez-JuÁrez y Martínez-PANTOJA (2009): Introducción a la contabilidad financiera: supuestos prácticos, Departamento de economía de la empresa, Universidad Carlos III, Madrid.

CAMAcho Miñano, Ma Del Mar (2010): Introducción a la contabilidad financiera, Pearson.

García SÁnchez, Isabel Ma (2009): Introducción a la Contabilidad, Universidad de Salamanca. www.eumed.net/libros/2009c/576. Puede descargarse gratuitamente en Internet.

Magda SolÀ, Inmaculada Vilardell (2009): Introducción a la contabilidad, Mc.Graw-Hill. 
Mallo Rodríguez, Carlos (coordinador) (2003): Introducción a la contabilidad financiera, Thomson.

Montesinos Julve, Vicente (coordinador) (2008): Introducción a la contabilidad financiera: un enfoque internacional, $5^{\text {a }}$ edición, Ariel.

MuÑoz Jiménez, José (coordinador) (2008): Contabilidad Financiera, PearsonPrentice Hall.

Omeñaca García, J. (2008): Contabilidad General, 11ª edición, Editorial Deusto. 